\title{
GLOBAL SUSTAINABLE DEVELOPMENT REPORT
}

\author{
2015 EDITION
}

ADVANCE UNEDITED VERSION

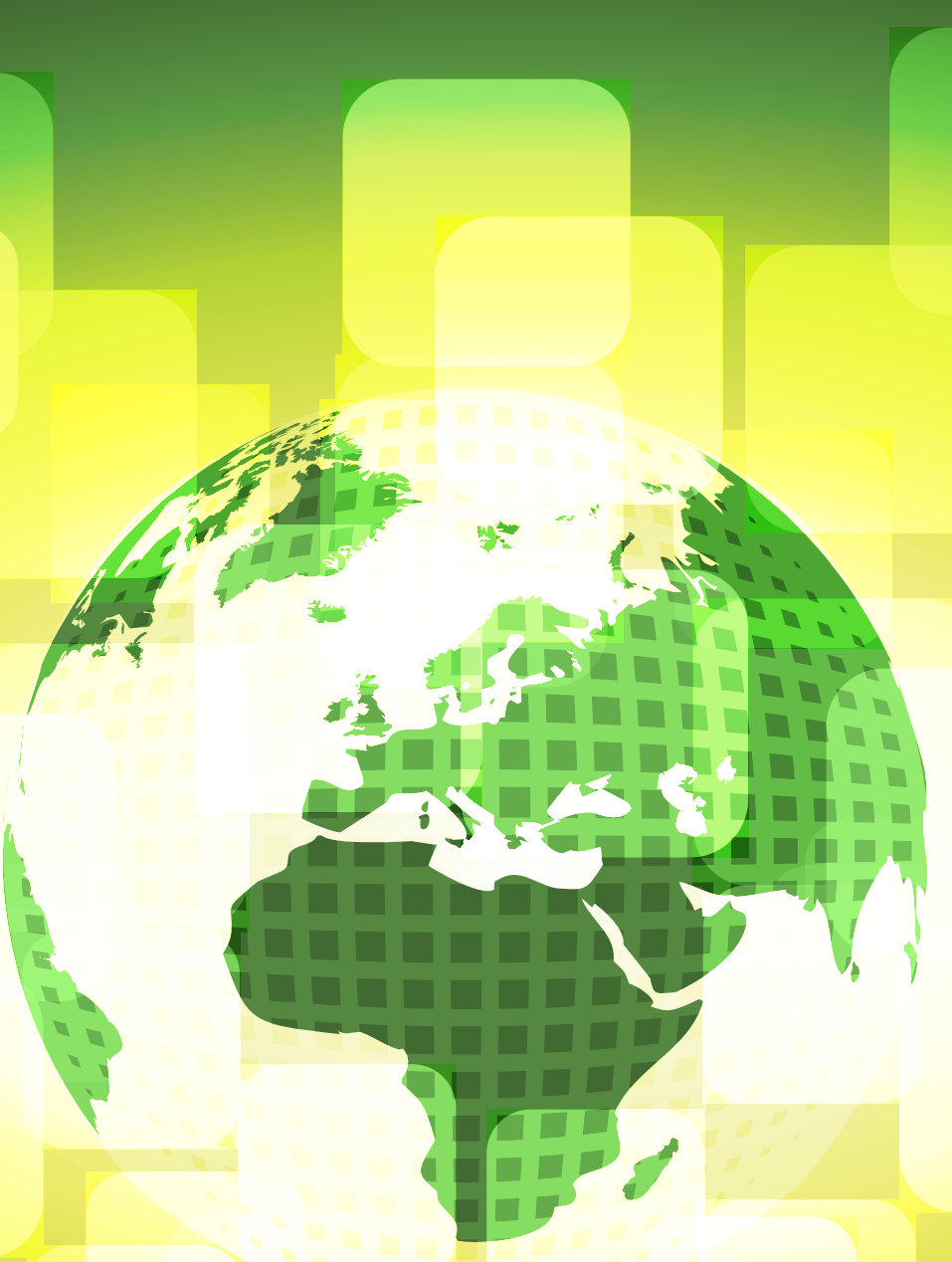




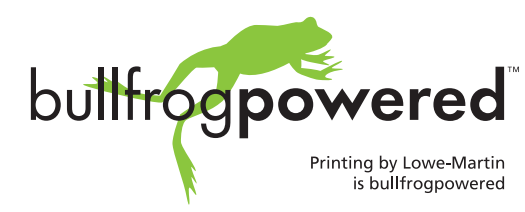

This publication was printed on recycled paper using renewable energy. 


\section{Foreword}

In September 2015, world leaders will meet to adopt a universal and transformative agenda for sustainable development, with a set of sustainable development goals (SDGs) at its core. The scientific community has provided valuable guidance in the formulation of the SDGs, and it will need to remain closely engaged as the world moves towards implementing the new agenda and reviewing our progress. The current report should help ensure that our efforts are underpinned by the latest and best scientific evidence and advice.

The GSDR is the only comprehensive, global report on sustainable development. It brings together a broad range of existing scientific assessments and reviews global progress and future sustainable development pathways in an integrated way, taking into account the perspectives of scientific communities across the globe.

Extensive inputs have been sought for the 2015 report from the UN system, scientists, government officials and stakeholders. More than 500 independent scientists and experts from many UN entities and affiliated organizations located in all regions of the globe have contributed to the report.

A crowdsourcing exercise carried out in the six UN languages invited scientists and researchers around the world to submit science briefs that highlight research findings or solutions relating to sustainable development, for the attention of policy-makers. Some 187 science briefs were submitted and, following a public review, a number have been featured in the report.

The report endeavours to present a range of scientific perspectives and to be policy-relevant but not policy-prescriptive. It offers suggestions on how to strengthen scientists' engagement with policy makers at national and international levels, in the latter case notably through the High Level Political Forum (HLPF). The report examines the SDGs as an interlinked system, analyzing how the goals are interrelated through their targets, and how progress towards one goal may depend on and contribute to progress towards others. Such an integrated assessment of the SDGs and the post2015 agenda will be a standard feature of future GSDRs.

2015 is a historic year. We are set to adopt an ambitious agenda that will move us towards a sustainable future for people and planet. But adopting the agenda is only the first step. Making it a reality will require work and dedication from all of us. The scientific community has a crucial role to play by sharing its advice and evidence in a compelling manner with policy-makers and conducting a dialogue with them, and the Global Sustainable Development Report serves as a tool to facilitate this exchange. Let us use it on our path towards the future we want.

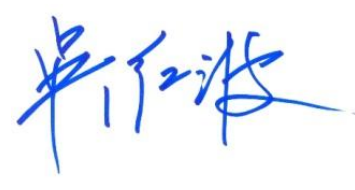

WU Hongbo

USG for Economic and Social Affairs United Nations 



\section{Contents}

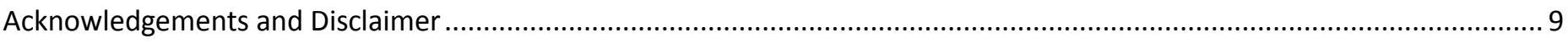

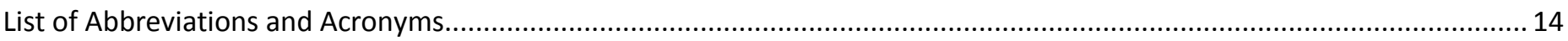

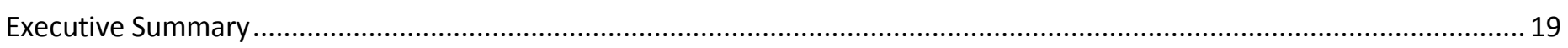

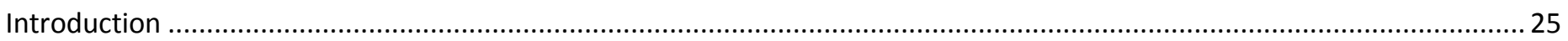

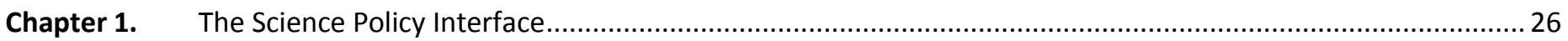

1.1. Introduction: the science-policy interface for sustainable development ...........................................................26

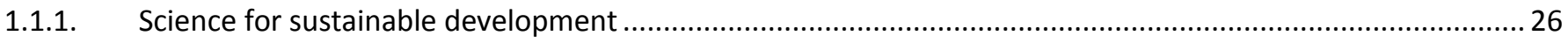

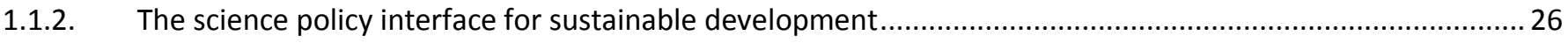

1.2. Possible roles of the HLPF for strengthening the science-policy interface: opinions from scientists and

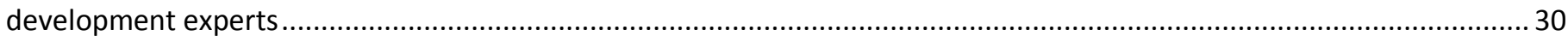

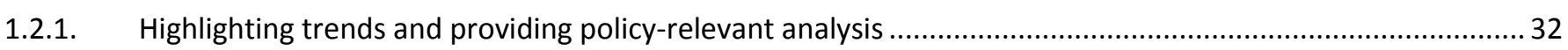

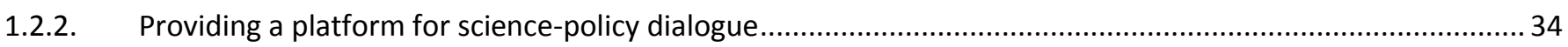

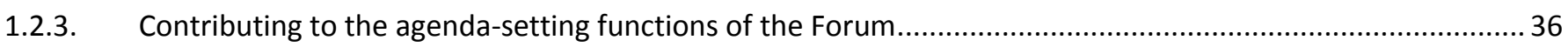

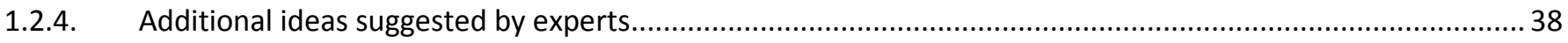

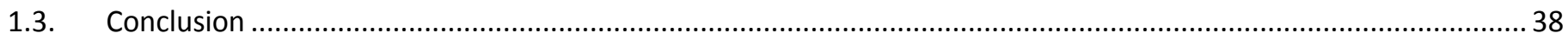

Chapter 2. Integrated Perspectives on the Sustainable Development Goals ..............................................................40

2.1. The Sustainable Development Goals and integrated perspectives suggested by the scientific community .............40

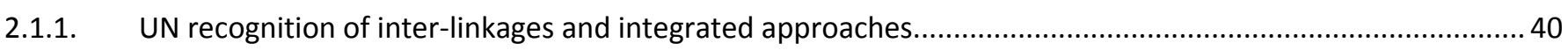

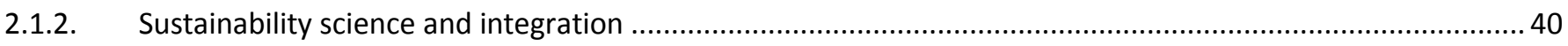

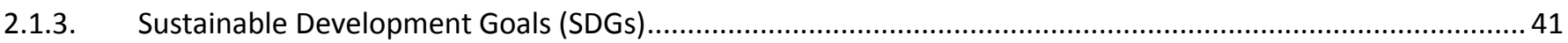

2.1.4. Recommendations by the International Council for Science (ICSU) and the International Social Science

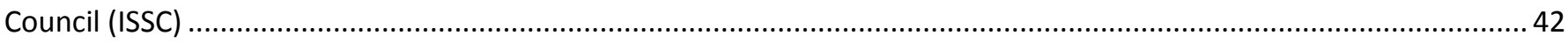

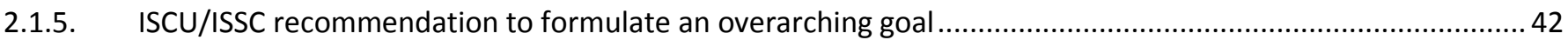

2.1.6. ISCU/ISSC recommendation to develop interlinking targets that are common to different goals....................42

2.1.7. ISCU/ISSC recommendation to formulate a compelling narrative of development....................................4 43

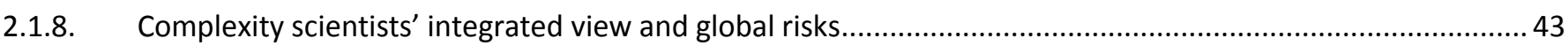

2.1.9. From a political to a scientific integrated view of the SDG network of inter-linked goals and targets ............. 44

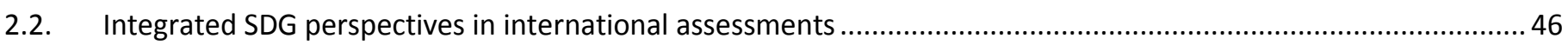

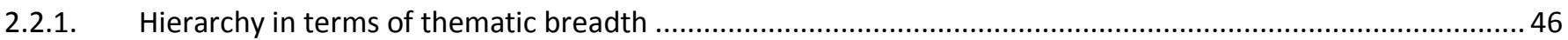

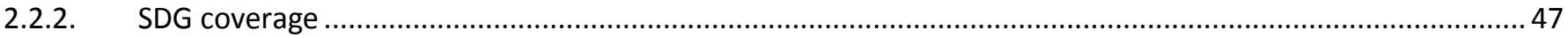

2.3. Global scenario models for integrated assessment of the SDGs......................................................................4

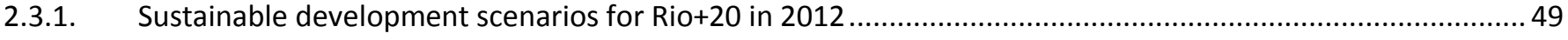

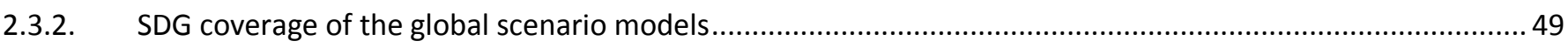

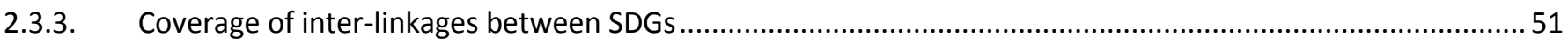

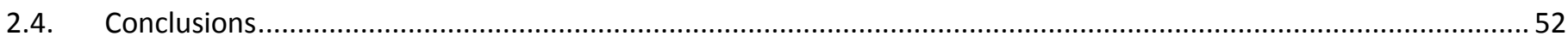

Chapter 3. The Oceans, Seas, Marine Resources and Human Well-being Nexus.........................................................53 
3.1. Interlinked issues: oceans, seas, marine resources and human well-being.....

3.2. Impact of important classes of threats on the oceans, seas, marine resources and human well-being nexus......... 58

3.3. Illustrative case studies - the need for an integrated approach when dealing with the nexus

3.4. Towards an integrated approach when dealing with the oceans, seas, marine resources and human well-being nexus 66

Annex 1 (Extended versions of Table 3-1, 3-3, 3-4) 68

Chapter 4. Disaster Risk Reduction: A Cross-cutting Necessity in the SDGs.....................................................69

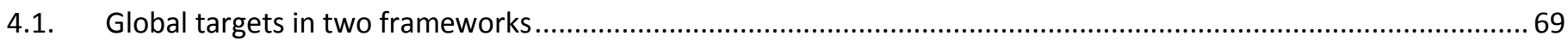

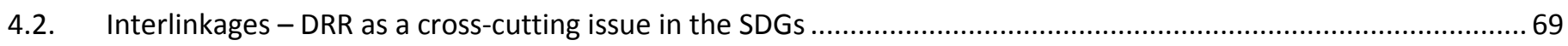

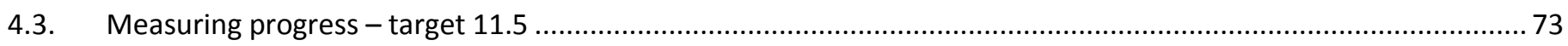

4.3.1. Global and national level target setting and differing risk profiles....................................................73

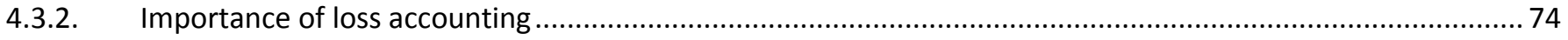

4.3.4. Baseline setting and assessing risk: strengths and challenges........................................................

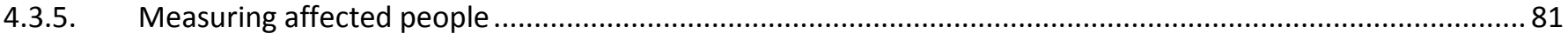

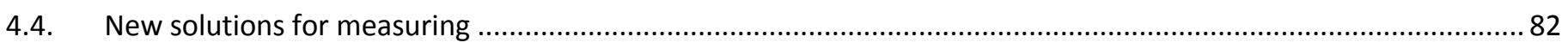

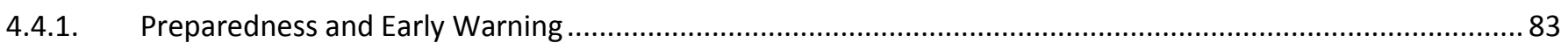

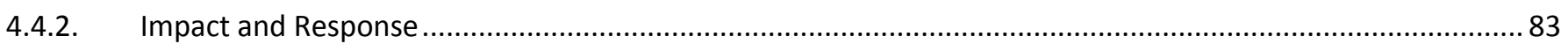

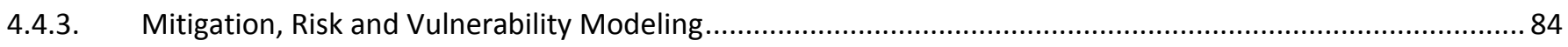

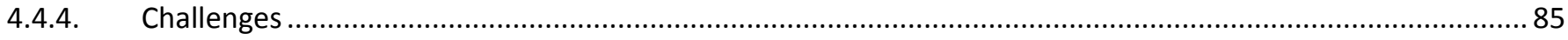

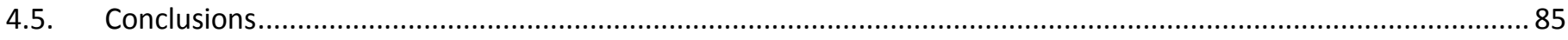

ANNEX 1. DRR related targets in the OWG proposal..................................................................................... 86

Chapter 5. Economic Growth, Inclusive and Sustainable Industrial Development and Sustainable Consumption and Production 87

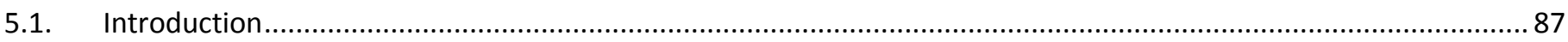

5.1.1. Overview of goals and development challenges in the post-2015 agenda .............................................87

5.1.2. Evolution of thinking on the role of Industrial Policy for development in past decades............................... 88

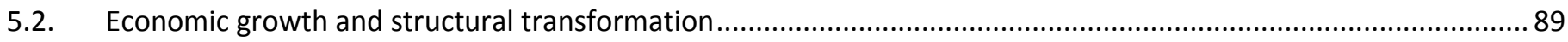

5.2.1. Developing manufacturing industries: economic growth, sustained technological change and world trade... 89

5.2.2. Transforming industrial systems - increasing value addition in resource, agriculture and service industries .. 91

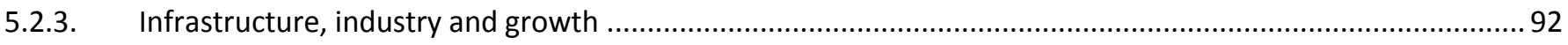

5.2.4. Industrial policies for structural transformation: rationales, scope and policy areas ..................................92

5.3. Industrialisation and social sustainability: inclusiveness, productive employment and education policies.............. 95

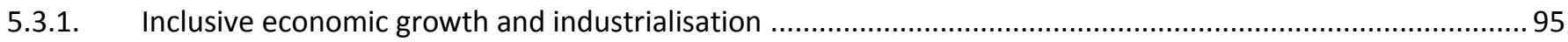

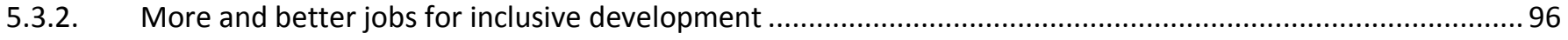

5.3.3. Education policies for industrial transformation and inclusive growth ..................................................96

5.4. Sustainable consumption and production in relation to industrialization ....................................................... 97

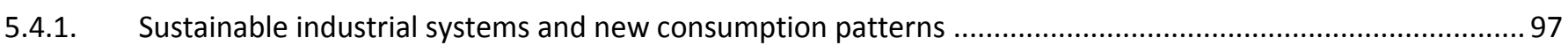

5.4.2. SCP in national governance - policies and programmes to drive structural transformation through SCP ....... 97 
5.5. New industrial policies for inclusive and sustainable development - policy alignment, trade-off management and

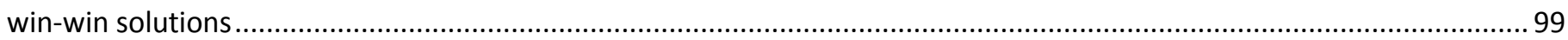

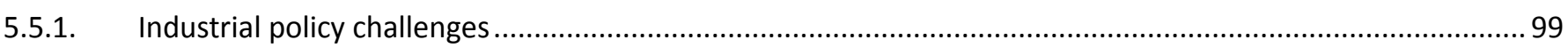

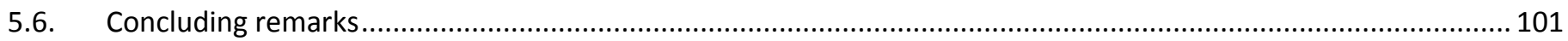

Technical notes

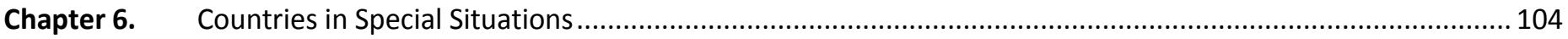

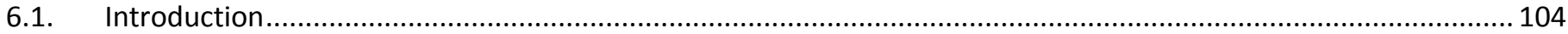

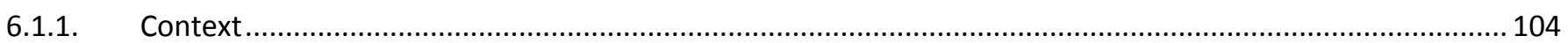

6.1.2. The three groups of countries and related international commitments in the area of sustainable development 104

6.1.3. Publications relevant to the sustainable development agenda in the three groups of countries ................. 106

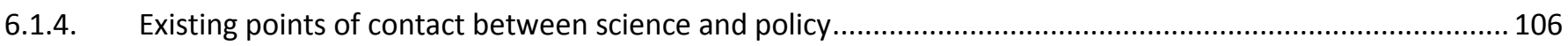

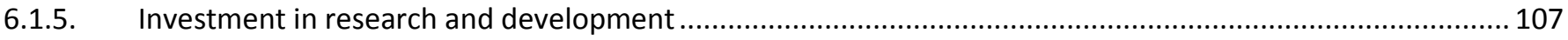

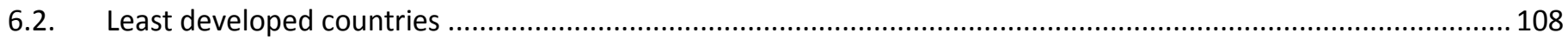

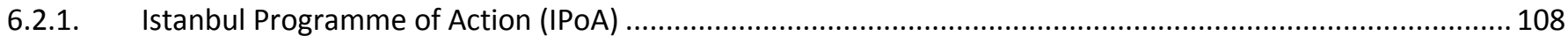

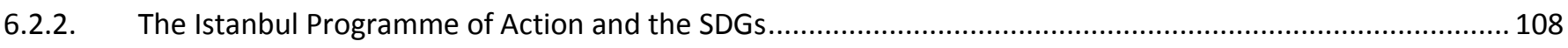

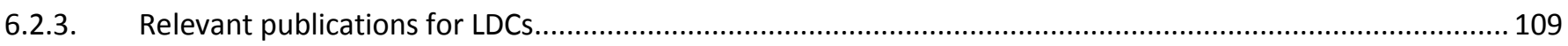

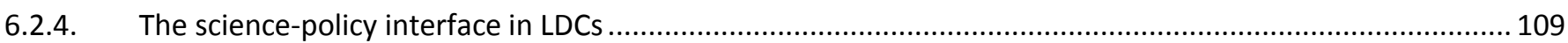

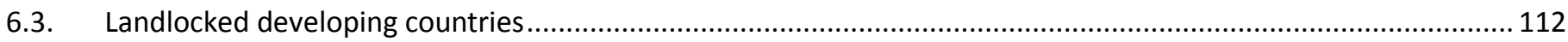

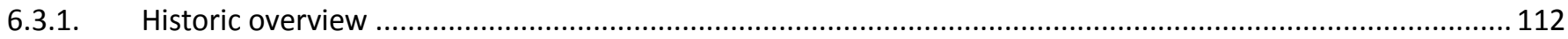

6.3.2. The Vienna Programme of Action and the proposed sustainable development goals (SDGs) and targets..... 113

6.3.3. Publications relevant for LLDCs....................................................................................................... 113

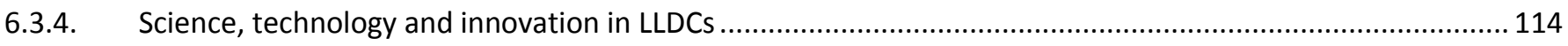

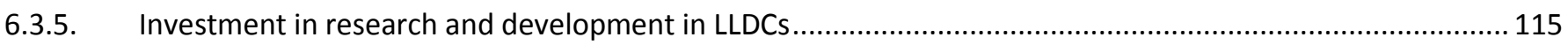

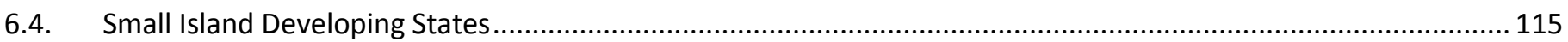

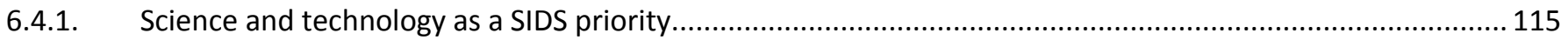

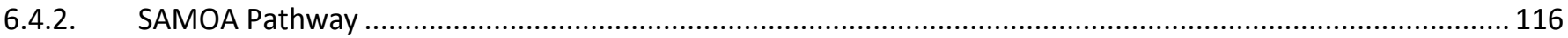

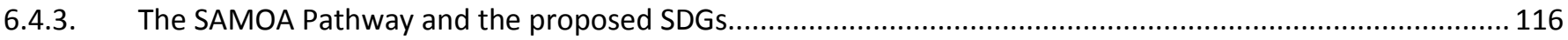

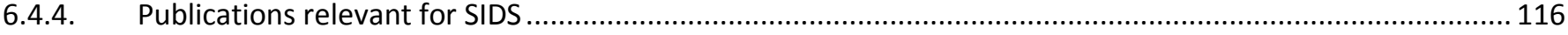

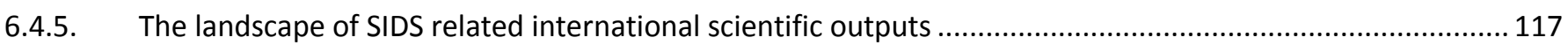

6.4.6. Research and data from the SIDS regional and national institutions ..................................................... 117

6.4.7. Existing points of contact between science and policy in SIDS .................................................................. 118

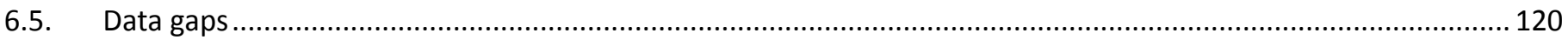

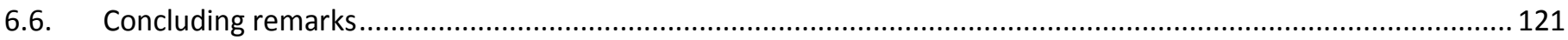

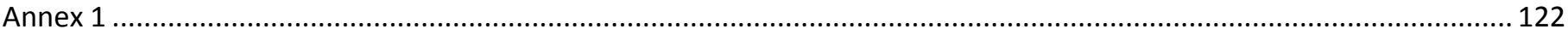

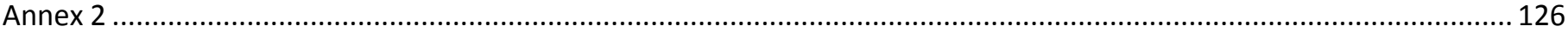

Chapter 7. Science Issues for the Attention of Policy Makers ......................................................................... 131

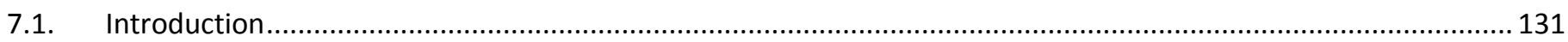

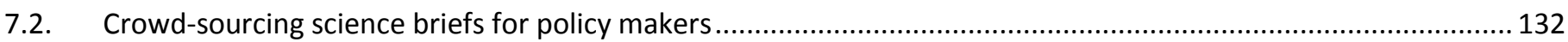


7.2.1. Open call for inputs to the present report.......................................................................................... 133

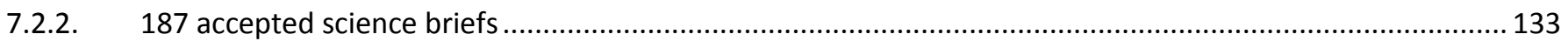

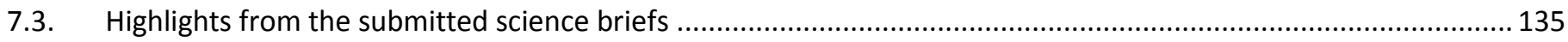

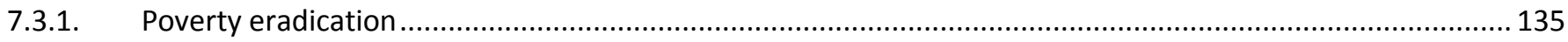

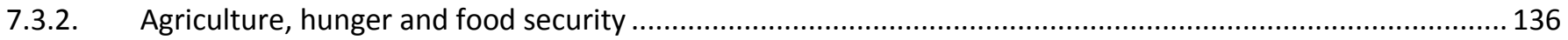

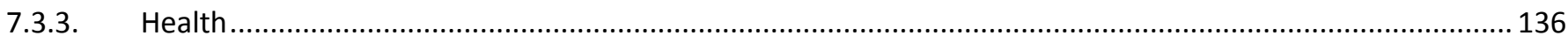

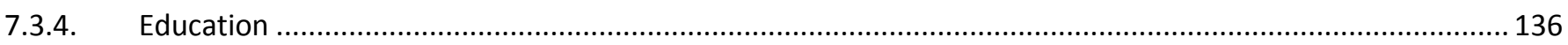

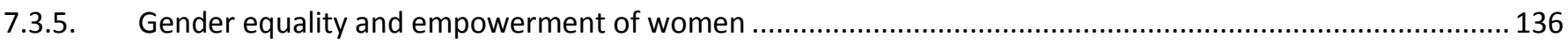

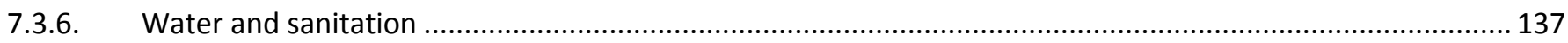

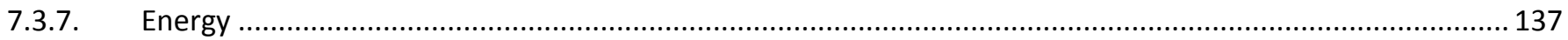

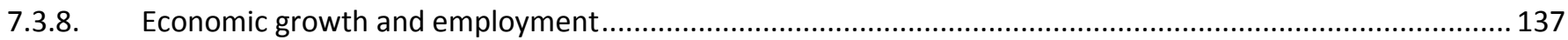

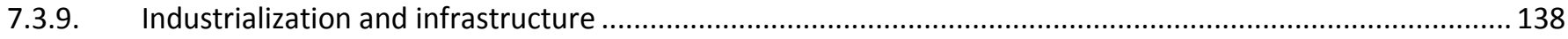

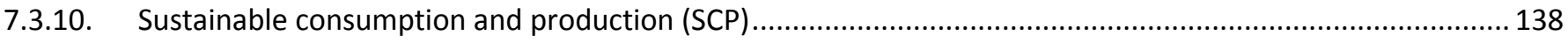

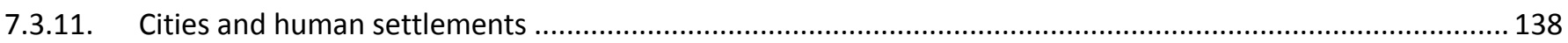

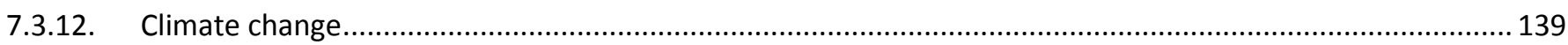

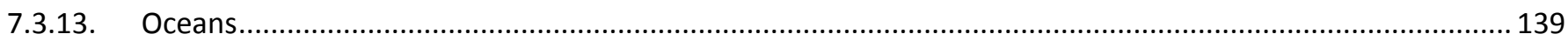

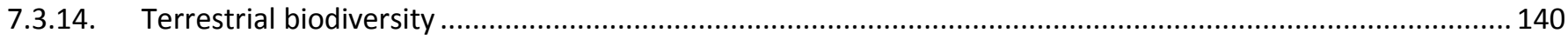

7.3.15. Peace, inclusive societies, justice and institutions ........................................................................... 140

7.3.16. Means of implementation, global partnership ....................................................................................... 140

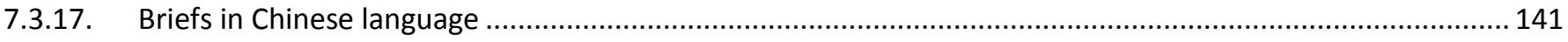

7.4. Selected sustainability science highlights from academic journals ............................................................ 141

7.5. Big data applications for sustainable development ..................................................................................... 144

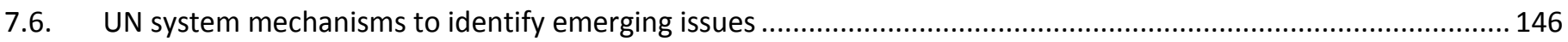

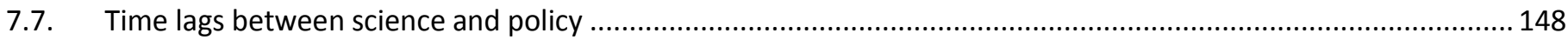

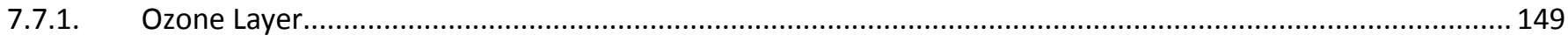

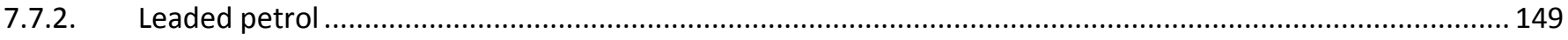

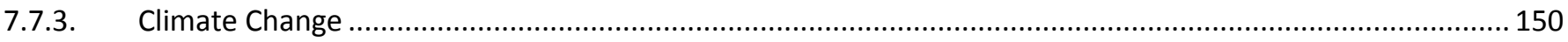

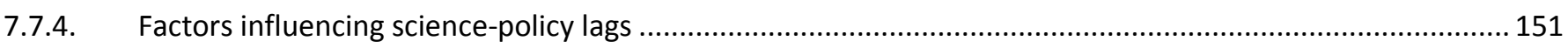

7.7.5. Research uptake in policy in the humanitarian sector in Africa ................................................................ 151

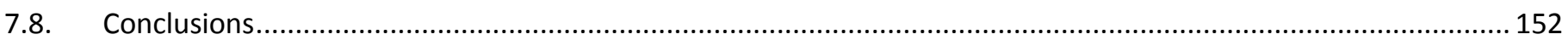

Chapter 8. New Data Approaches for Monitoring Sustainable Development Progress: The Case of Africa .................... 153

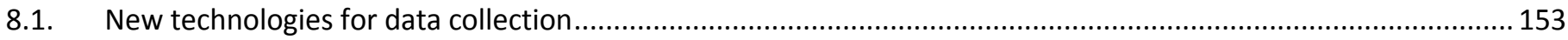

8.1.1. Face-to-face data collection with mobile devices.................................................................................... 153

8.1.2. Collecting data through cell phones, SMS and internet....................................................................... 154

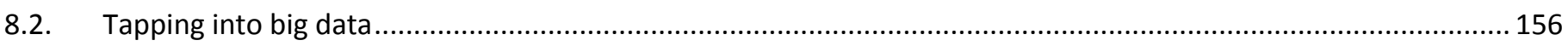

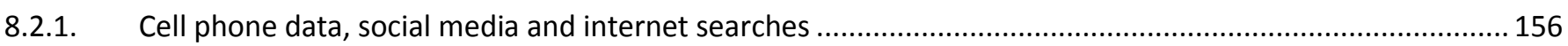

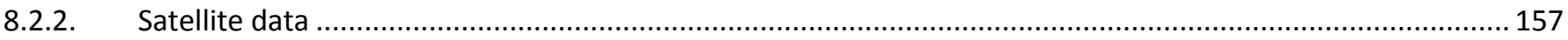

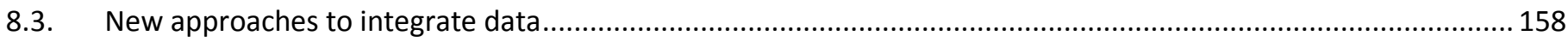




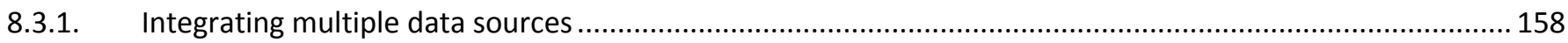

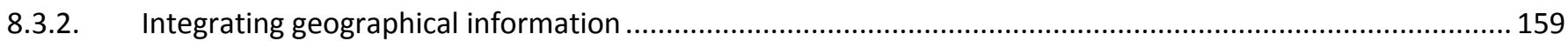

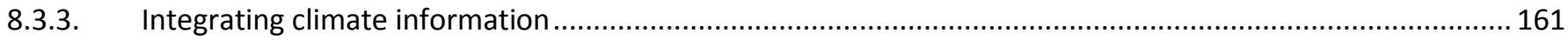

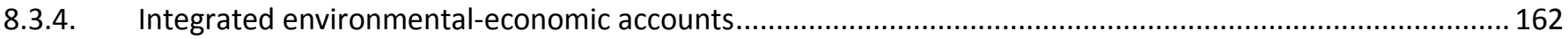

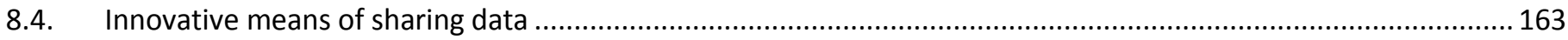

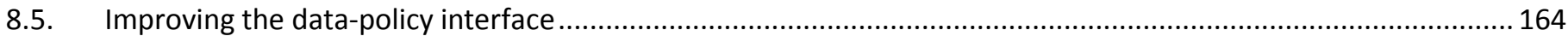

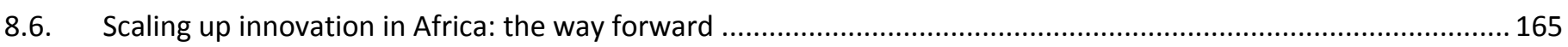

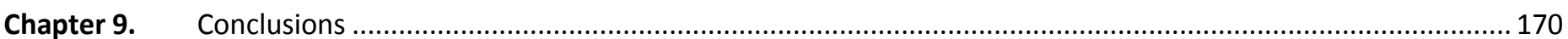

9.1. The science-policy interface and the High-level Political Forum on sustainable development............................170

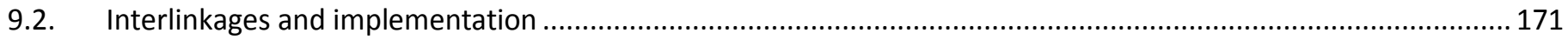

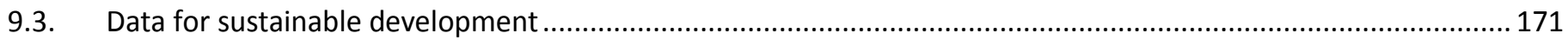

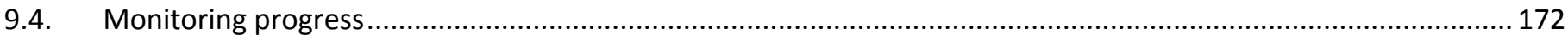

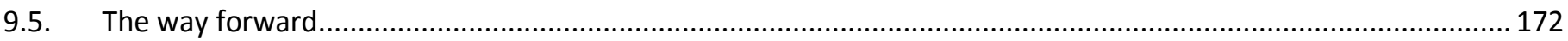

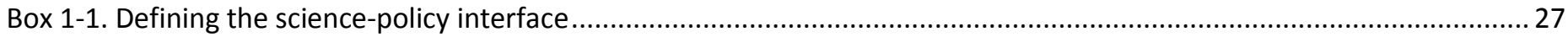

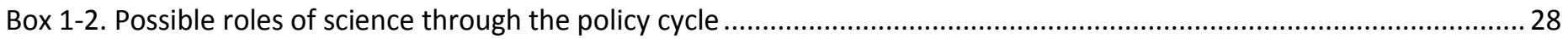

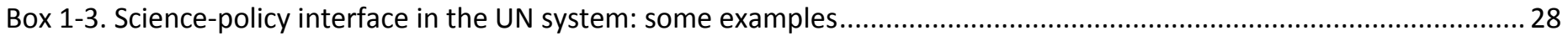

Box 1-4. Credibility, relevance and legitimacy: critical determinants of the effectiveness of SPI .......................................29

Box 1-5. An example of the science-policy interface in a private sector context: Finding appropriate metrics for voluntary

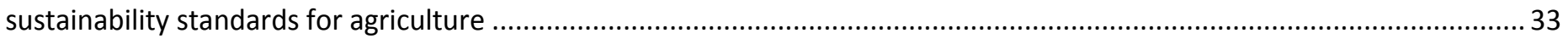

Box 1-6. Efforts to further integrate social sciences in the science-policy interface for sustainable development..................34

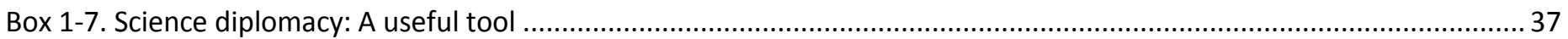

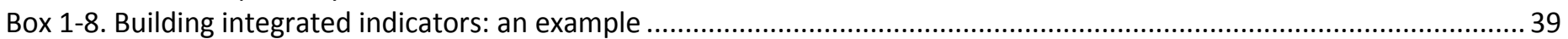

Box 2-1. Examples of "target-level" reports and "linkages-among-goals" reports...............................................................46

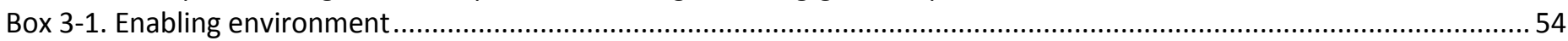

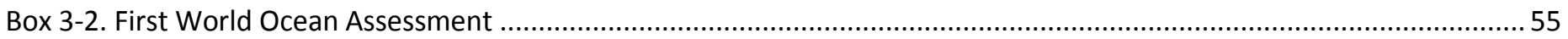

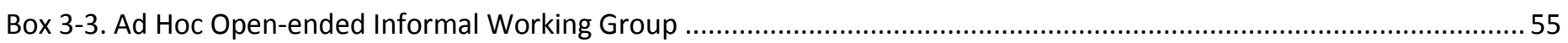

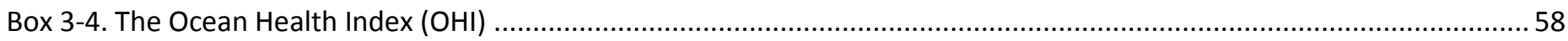

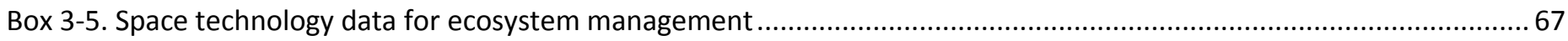

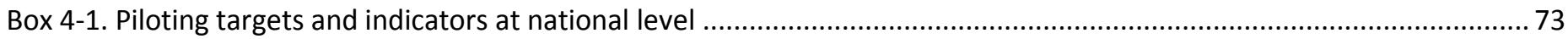

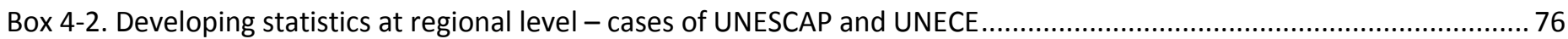

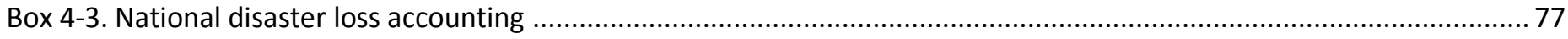

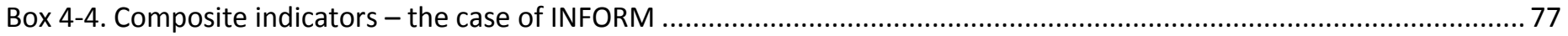

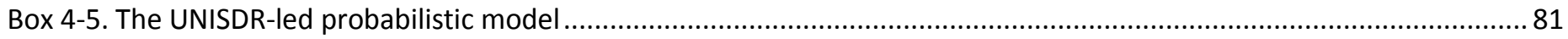

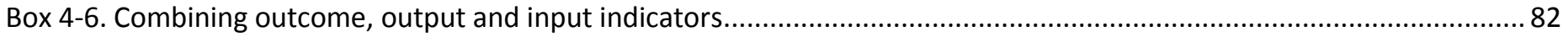

Box 5-1. Manufacturing transformation and economic development ….......................................................................... 90

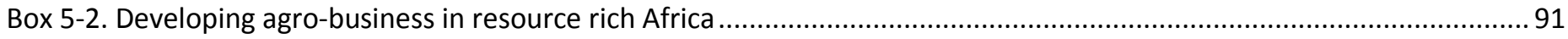

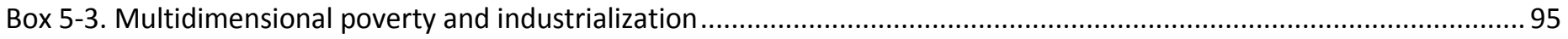

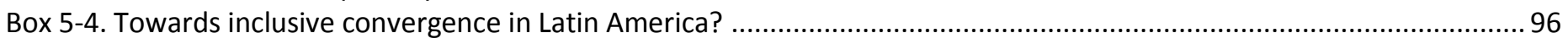

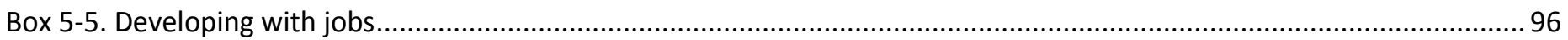

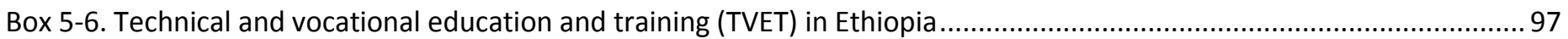

Box 5-7. State of the environment: current resource pressures and SCP as an imperative ................................................9. 97

Box 5-8. National cleaner production centres - catalysts to scale and institutionalise resource efficiency ............................99

Box 5-9. Production Transformation Policy Reviews - a shared tool for diagnostic and policy guidance .............................. 100 
Box 5-10. Operationalizing inclusive and sustainable industrial development - the Programme for Country Partnerships ... 100

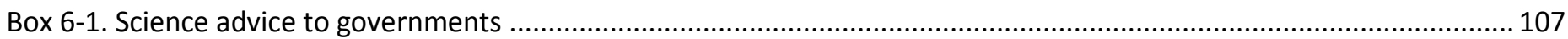

Box 6-2. Poverty reduction strategy papers (PRSPs) as an example of the STI system in LDC policymaking ......................... 110

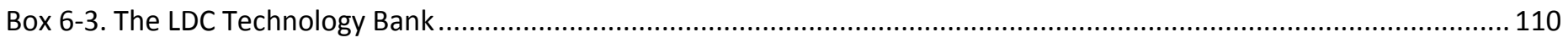

Box 6-4. Lesotho's 'Agriculture Trade Development Project for the Fresh Produce Sector' .............................................. 111

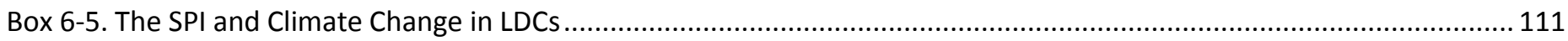

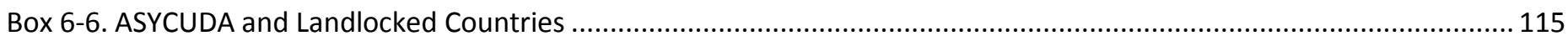

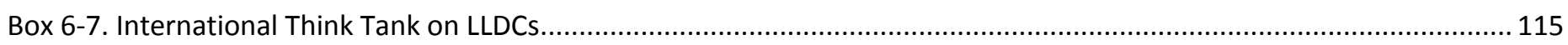

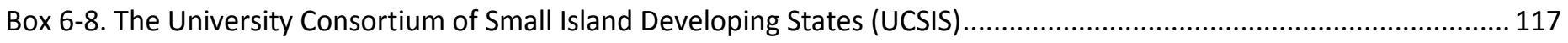

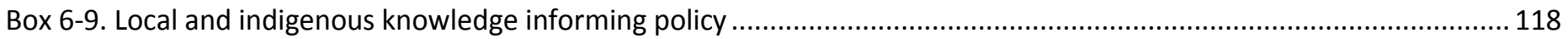

Box 6-10. Sustainable Sea Transport: Research to inform policy in the Pacific ............................................................ 119

Box 8-1. Innovative data collection, integration and dissemination in Nigeria ................................................................. 153

Box 8-2. Getting health and livelihood data through women informants equipped with smartphones .............................. 154

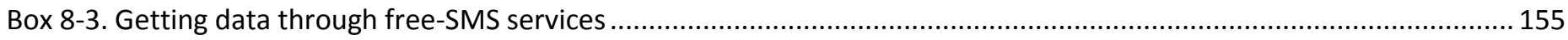

Box 8-4. Using cell phone records to estimate population flows and design targeted policies against Ebola........................ 155

Box 8-5. Using mobile phone data and airtime credit purchases to estimate food security and poverty ............................ 157

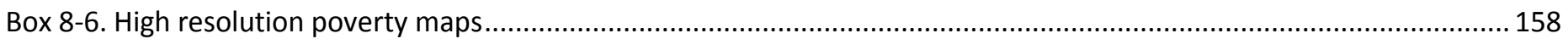

Box 8-7. Using satellite data in Sudan for flood prediction and detection ............................................................... 159

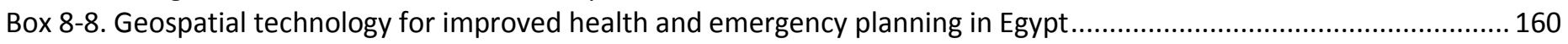

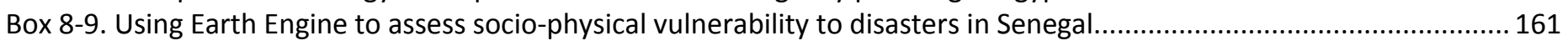

Box 8-10. Mixing different data sources to improve the availability of climate data in Africa........................................... 162

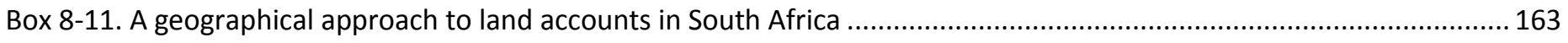

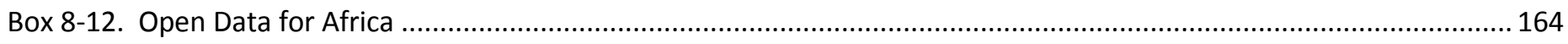

Box 8-13. Impact evaluation in Africa - four studies which made an impact on policy making .......................................... 165

\section{Tables}

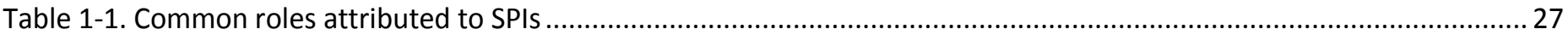

Table 2-1. The OWG Sustainable Development Goals allocated into six categories: people, economy, and society to be developed, and nature, life support and community to be sustained .................................................................................4 41

Table 2-2. SDG coverage of a sample of 36 international assessments and reports .......................................................... 48

Table 2-3. SDG-related targets considered in sustainable development scenarios for Rio+20 ..........................................5 50

Table 2-4. Number of models capturing "inter-linkages" between groups of SDGs ........................................................5 52

Table 3-1. Important inter-linkages between oceans, seas, marine resources and human well-being ...................................56

Table 3-2. Drivers and pressures of important classes of threats affecting the nexus.........................................................59

Table 3-3. Impact of important classes of threats on oceans, seas, marine resources and human well-being nexus ...............60

Table 3-4. Selected regional and local case studies of addressing threats affecting the nexus* ...........................................6. 64

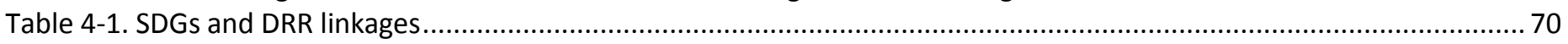

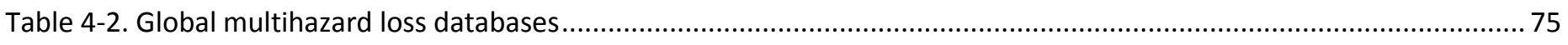

Table 4-3. Disaster management cycle and the use of different types of data sets............................................................ 83

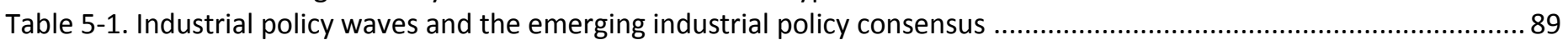

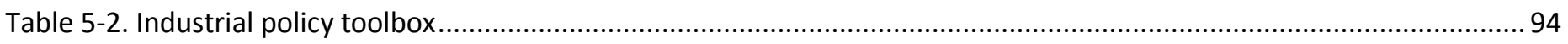

Table 5-3. UNEP's five key types of SCP action UNEP's five key types of SCP action ......................................................99

Table 6-1. Coverage of number of proposed SDGs in publications for the three groups of countries in special situations .... 106

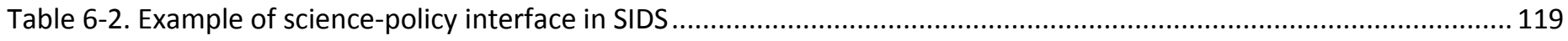

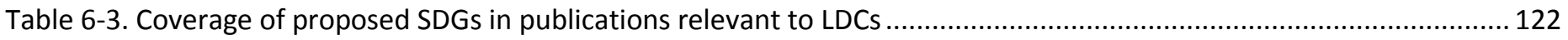

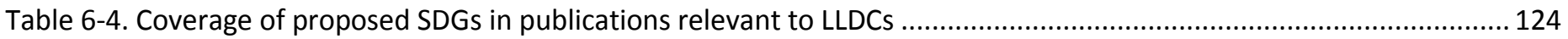

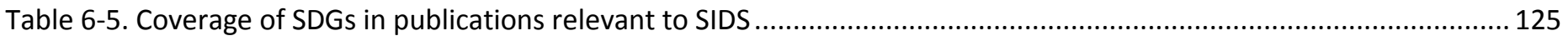

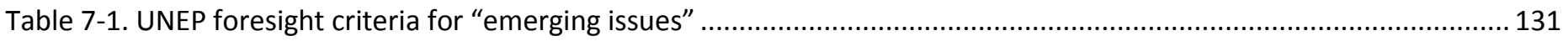

Table 7-2. Top sustainable development issues scientists worldwide would like decision-makers to consider for action ..... 132

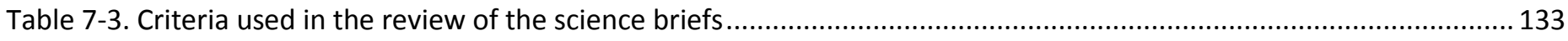

Table 7-4. Top-10 briefs that received most attention in open review ....................................................................... 134 
Table 7-5. Big data applications in areas covered by the SDGs and in topics relevant for sustainable development 144

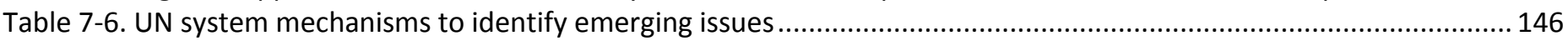

Table 7-7. Simple typology of emerging issues identification models within the UN system ...........................................148

Table 7-8. Factors that promoted or discouraged evidence-based policy action............................................................... 151

\section{Figures}

Figure ES-0-1. Possible roles for the HLPF in strengthening the science-policy interface: opinions of experts ........................20

Figure ES-0-2. Links among SDGs through their targets, based on scientists' assessment..................................................2 22

Figure 1-1. Possible roles for the HLPF for strengthening the science-policy interface: opinions of experts who contributed to the GSDR ....

Figure 2-1. A scientific view of the SDG system - links between SDGs as indicated by the ISCU/ISSC report (corrected for the

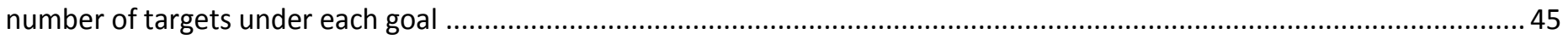

Figure 2-2. SDG coverage of the 72 selected global scenario models .......................................................................... 51

Figure 3-1. Oceans, seas, marine resources and human well-being nexus (Important inter-linkages and threats) ..................53

Figure 4-1. Economic losses relative to the size of the economy (GDP) by income group, 1990-2013................................. 74

Figure 4-2. Percentage of damage and loss from extensive and intensive disaster events (65 countries and 2 states), 1990-

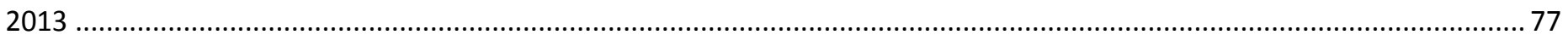

Figure 4-3. Internationally reported global disaster mortality (events with fewer than 100 deaths) ....................................79

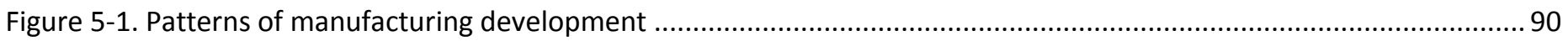

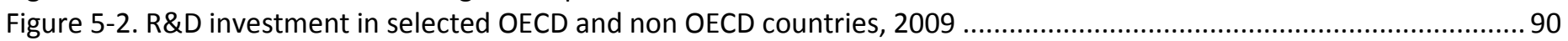

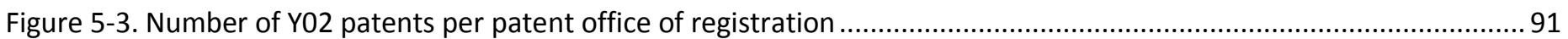

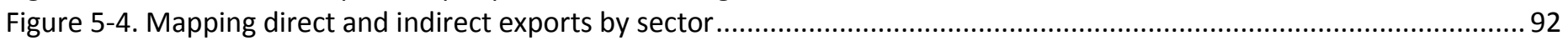

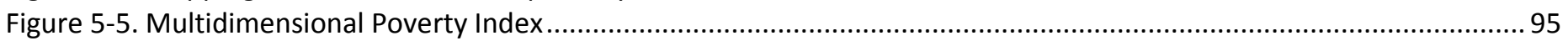

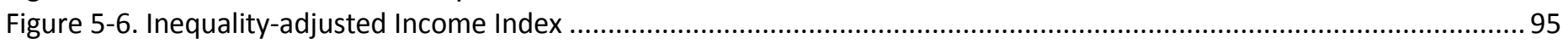

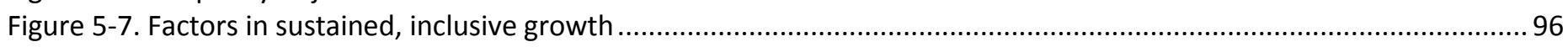

Figure 5-8. Production Transformation Policy Review Five-pillar Framework.............................................................. 100

Figure 6-1. Timeline of international commitments for countries in special situations .................................................... 104

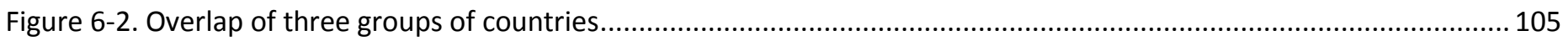

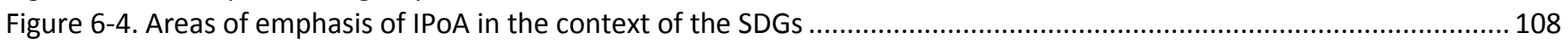

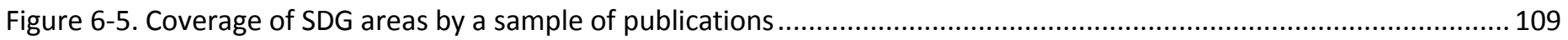

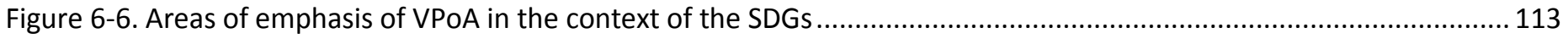

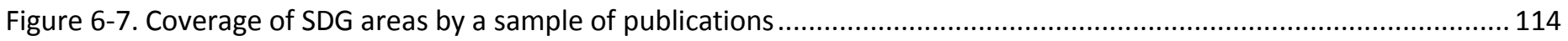

Figure 6-8. Areas of emphasis of the SAMOA Pathway in the context of the SDGs ..................................................... 116

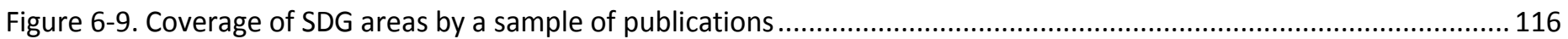

Figure 6-10. Data availability for illustrative indicators: percentage of LDC, LLDC and SIDS with one of or more data points

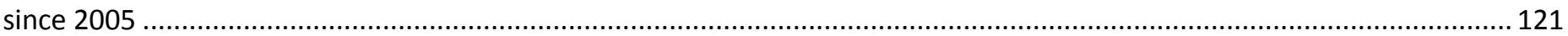

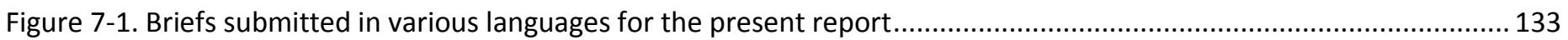

Figure 7-2. Number of authors of submitted briefs by country............................................................................. 134

Figure 7-3. Overview of 182 briefs provided by scientists and their coverage of the 17 SDGs ........................................ 135

Figure 7-4. Coverage of SDGs by all submitted briefs vs. those in Chinese language......................................................... 141

Figure 7-5. Concentrations of plastic debris in surface waters of the global ocean ....................................................... 143

Figure 7-6. Time lags (in years) between science and policy for selected environmental issues.......................................... 148

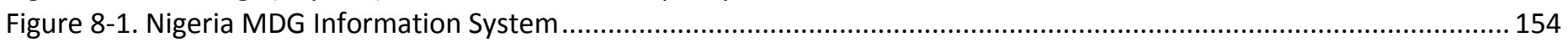

Figure 8-2. Mobility patterns in West-Africa according to cell phone records .............................................................. 156

Figure 8-3. Percentage of households with mobile phones, 2011-2014 ....................................................................... 157

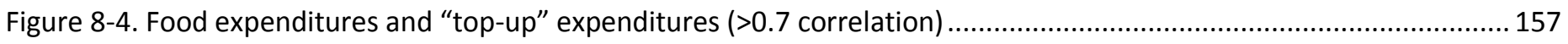

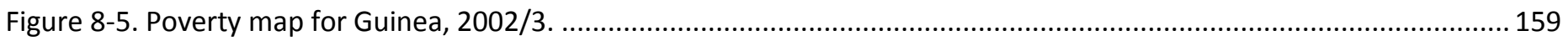

Figure 8-6. Flood zone levels and the related risk in Sudan: (1) high risk, mainly from the river Nile; (2) high risk, mainly from

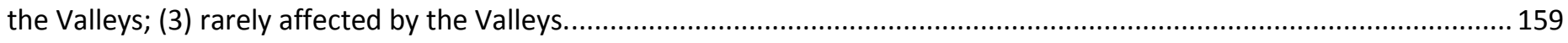

Figure 8-7. Lake Victoria Water Quality Assessment Visualization Tool .......................................................................... 160 
Figure 8-8. Location of ambulance units (triangles) and areas with population size greater than 100,000 inhabitants and more than $10 \mathrm{~km}$ away from the nearest ambulance unit (brown areas) .......................................................................... 160

Figure 8-9. Map of internet connectivity and Ebola treatment centres, Liberia .......................................................... 161

Figure 8-10. Combined socio-physical vulnerability to flooding in Senegal. ...................................................................161

Figure 8-11. Station observations (top left) are combined with satellite rainfall estimates (top right) to produce a more

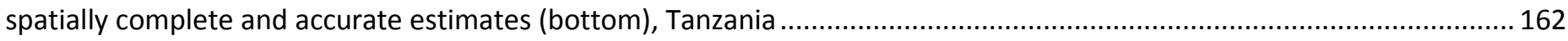

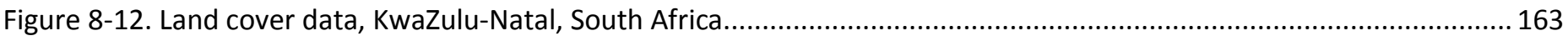

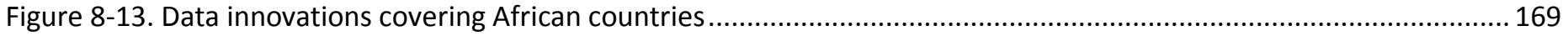




\section{Acknowledgements and Disclaimer}

The terms 'country' and 'economy' as used in this Report also refer, as appropriate, to territories or areas; the designations employed and the presentation of the material do not imply the expression of any opinion whatsoever on the part of the Secretariat of the United Nations concerning the legal status of any country, territory, city or area or of its authorities, or concerning the delimitation of its frontiers or boundaries. In addition, the designations of country groups are intended solely for statistical or analytical convenience and do not necessarily express a judgement about the stage of development reached by a particular country or area in the development process. Major country groupings referred to in this report are informed by the classification of the United Nations Statistical Division. Reference to companies and their activities should not be construed as an endorsement by the United Nations of those companies or their activities. The boundaries and names shown and designations used on the maps presented in this publication do not imply official endorsement or acceptance by the United Nations.

This Report was prepared by a team of UN staff based on inputs from expert contributors, including staff of the UN system. The views expressed in this publication are those of the authors and do not necessarily reflect those of the United Nations or its senior management, or of the experts whose contributions are acknowledged. The valuable comments provided by the UNDESA Editorial Board are gratefully acknowledged.

\section{Chapter Lead Authors}

Chapter 1: David Le Blanc (UNDESA); Chapter 2: Richard A. Roehrl (UNDESA); Chapter 3: Julie Ritz (UNDESA); Chapter 4: Riina Jussila (UNDESA); Chapter 5: Marina Plutakhina (UNIDO) and UNEP-DTIE (for section on SCP); Chapter 6: Irena Zubcevic (UNDESA); Chapter 7: Richard A. Roehrl and Friedrich Soltau (UNDESA); Chapter 8: Maria Martinho (UNDESA); Chapter 9: David O’Connor (UNDESA)

\section{Contributors}

\section{Organizations and Groups}

Austrian Academy of Science (Austria); Caribbean Natural Resources Institute; European Commission, Joint Research Centre (EC JRC); Executive Secretariat for Enhanced Integrated Framework (EIF); Food and Agriculture Organization (FAO); Global Environment Facility (GEF); Independent Partnership for the Monitoring of the Outcome of the Fourth United Nations Conference on the Least Developed Countries (LDC IV); Integrated Research on Disaster Risk (IRDR); International Council for Science (ICSU); International Labour Organisation (ILO); International Maritime Organization (IMO); International Telecommunication Union (ITU); LDC Independent Expert Group on the post-2015 development agenda, convened by the International Institute for Environment and Development; Office of the High Representative of the Least Developed Countries, Landlocked Developing Countries and Small Island Developing States (OHRLLS); Office of the Prime Minister's Science Advisor of New Zealand; Organization for Economic Cooperation and Development (OECD); Overseas Development Institute (ODI); Science and Technology Committee of Shijingshan District, Beijing, China; SDSN Thematic Group on Early Childhood Development, Education, and Transition to Work; SDSN Thematic Group on Sustainable Agriculture and Food System; SDSN/IDDRI Deep Decarbonization Pathways Project Team; SloCAT Partnership; United Nations Children's Fund (UNICEF); United Nations Conference on Trade and Development (UNCTAD); United Nations Department of Economic and Social Affairs (UNDESA); United Nations Development Programme (UNDP); United Nations Economic and Social Commission for Asia and the Pacific (UNESCAP); United Nations Economic and Social Commission for Western Asia (UNESCWA); United Nations Economic Commission for Africa (UNECA); United Nations Economic Commission for Europe (UNECE); United Nations Economic Commission for Latin America and Caribbean (UNECLAC); United Nations Educational, Scientific and Cultural Organization (UNESCO); United Nations Environment Programme (UNEP); United Nations Human Settlement Programme (UNHABITAT); United Nations Industrial Development Organization (UNIDO); United Nations Institute for Disarmament Research (UNIDIR); United Nations Office for Disaster Risk Reduction (UNISDR); United Nations Office for Outer Space Affairs (UNOOSA); United Nations Office for the Coordination of Humanitarian Affairs (UNOCHA); United Nations Research Institute for Social Development (UNRISD); World Bank; World Health Organization (WHO); World Trade Organization (WTO).

\section{$\underline{\text { Individuals }}$}

A J Tonolli (National Inter-University Council, Argentina); A M Baronio (National Inter-University Council, Argentina); A M Vianco (National InterUniversity Council, Argentina); A. Khaustov (Peoples' Friendship University of Russia, Russian Federation); A. Tamer Aker (Kocaeli University Medical School); Aakriti Grover (Department of Geography, Swami Shraddhanand College, University of Delhi, India); Aaron Vlasak (State University of New York College of Environmental Science and Forestry, USA); Ademola A.; Adenle (United Nations University and University of Oxford, UK); Adhemar Esquivel (Bolivia); Adriana Príncipe (Centre for Ecology, Evolution and Environmental Changes, Faculty of Sciences, University of Lisbon, Portugal); Alastair Norris (RMS); Alemayehu Wassie Eshete (Bahir Dar University, Ethiopia); Alessandra Alfieri (UNDESA); Alessandro Galli (Global Footprint Network, Switzerland); Alex Rutherford (UN Global Pulse); Alexandra Köves (Corvinus University of Budapest, Hungary); Alexandre Magnan (IDDRI, France); Alexandros Makarigakis (UNESCO); Alina Greslebin (CONICET-Universidad Nacional de la Patagonia $\mathrm{SJB}$, Argentina); Alison Newell (Pacific Centre for the Environment and Sustainable Development, The University of the South Pacific, Fiji); Allison K. Barner (Oregon State University, USA); Alpina Begossi (Fisheries and Food Institute (FIFO), Brazil; Amanda Driver (South African National Biodiversity Institute); Amina Aitsi-Selmi (Public Health England and University College London, UK); Andrew Allieu, Mathilde Closset (UNECA); Andrew Friedman (The Pew Charitable Trusts); Andrew Thomas (Aberystwyth University, UK); Angela Me (UNODC); Andy Hudson (UNDP); Angelika Planitz (UNDP); Anita Shankar (Johns Hopkins University, Bloomberg School of Public Health, USA); Anja Korenblik (UNODC); Anna 
Hentinnen (DFID); Annabelle Moatty (France); Annalisa Primi (OECD Development Centre); Anne H. Toomey (Lancaster Environment Centre, Lancaster University, UK); Anne-Sophie Stevance (ICSU); Annie Turek (The Pew Charitable Trusts); Anoush Tatevossian (UN Global Pulse); Anshul S. Bhamra (Development Alternatives, New Delhi, India); Anthony Capon (International Institute for Global Health, United Nations University UNU IIGH, Malaysia); Anton Santanen (UNOCHA); Antonia Rekman (KTH); Antonio Andreoni (University of Cambridge); Apulu O.A. (Peoples' Friendship University of Russia, Russian Federation); Arab Hoballah (UNEP); Ariane Goetz (IASS, Potsdam, Germany); Arjen Buijs (Forest and Nature Conservation Policy Group, Wageningen University, the Netherlands); Arvid de Rijck (Wageningen University and Research Centre, The Netherlands); Åse Johannessen (Stockholm Environment Institute, Sweden); Ashley Lin (State University of New York College of Environmental Science and Forestry, USA); Asif Khan (Department of Engineering, University of Cambridge, UK; Department of Engineering, KPK University of Engineering and Technology, Pakistan); Aster Denekew (ECA); Astrid Dispert (International Maritime Organization, UK); Ayako Kagawa (UN); BaiMass Taal (African Ministers' Council on Water AMCOW, Nigeria); Bálint Balázs (Environmental Social Science Research Group, Hungary); Bangwei Zhu (Zhongnan University of Economics and Law, China); Barbara Neumann (Kiel University, Germany); Barbara van Koppen (International Water Management Institute, Sri Lanka); Bassel Daher (Qatar Energy and Environment Research Institute, Qatar); Benjamin Mattondo Banda (UNECA); Bessie Schwarz (Yale Project on Climate Change Communication, Data-Pop Alliance); Beth Brockett (Lancaster Environment Centre, Lancaster University, UK); Beth Tellman (Arizona State University, Data-Pop Alliance); Biliana Cicin-Sain (Global Ocean Forum; University of Delaware, USA); Bin Wang (Beijing Institute of Technology, China); Birgit Elands (Forest and Nature Conservation Policy Group, Wageningen University, the Netherlands); Boaz Golany (Technion - Israel Institute of Technology, Israel); Bojana Bajželj (University of Cambridge, UK); Brian Hoskins (Reading University); Brian Jacobson (State University of New York College of Environmental Science and Forestry, USA); Byron Anangwe (RCMRD); Carl Abbott (University of Salford, School of the Built Environment, UK); Carl Mas (SDSN, France); Carmen Chan (The Fletcher School of Law and Diplomacy, Tufts University, USA); Carol Warren (Murdoch University, Australia); Carole-Anne Sénit (VU University Amsterdam, the Netherlands, and IDDRI, France); Caterina Negulescu (Department of Earth and Environmental Sciences, Munich University, Germany); Catherine Machalaba (EcoHealth Alliance, USA); Cecil Konijnendijk Van-den Bosch (Department of Geosciences and Natural Resource Management, University of Copenhagen, Copenhagen, Denmark); Cecilia Vidal (Bolivia); Celina N. Amato (Consejo Nacional de Investigaciones Científicas y Técnicas, Argentina); Changhua Lin (Fujian Academy of Social Sciences, China); Chantal Line Carpentier (UNCTAD); Charles Akol (UNECA); Charles Leyeka Lufumpa (African Development Bank); Cheikh Mbow (World Agroforestry Centre, Nairobi, Kenya); Chengrong Wang (Administrative Office of Dafeng State-level Sustainable Development Demo Zone, China); Chloe Carpentier (UNODC); Chong Zang (Steering Group for Yancheng State-level Sustainable Development Zone, China); Chris Ford (Stanford University Center for Design Research, USA); Christiaan Adams (Google Inc); Christian Rammel (Vienna University of Economics and Business, Austria); Christina Buczko (Sustainable Europe Research Institute (SERI), Vienna, Austria); Christina Corbane (EC JRC); Christophe Lefebvre (French Marine Protected Areas Agency, France); Chuanbin Zhou (Research Center for Eco-Environmental Sciences, Chinese Academy of Sciences, China); Claudia Sadoff (World Bank); Claudio Chiarolla (Institut du Développement Durable et des Relations Internationales IDDRI, and Paris School of International Affairs (PSIA) Sciences Po, France); Clemens Mader (Leuphana University of Lüneburg, Germany, and University of Zurich, Switzerland); Coli Ndzabandzaba (Institute for Water Research, Rhodes University, South Africa); Corbane Christina (EC JRC); Cristina Branquinho (Centre for Ecology, Evolution and Environmental Changes, Faculty of Sciences, University of Lisbon, Portugal); Cristina Romanelli (Secretariat for the Convention on Biological Diversity, Canada); Damien Demailly (IDDRI, France); Dan Chu (Tongji University, China); Danan Gu (UNDESA); Daniel Coviello (UNDESA); Daniele Ehrlich (EC JRC, Belgium); Daniele Giovannucci (Committee on Sustainability Assessment, COSA); Daphne van Dam (Wageningen University and Research Centre, The Netherlands); Darci Pauser (State University of New York College of Environmental Science and Forestry, USA); David Acuña Mora (Wageningen University and Research Centre, The Netherlands); David Black (ICSU); David Gee (Brunel University, UK); David Lin (Global Footprint Network, Switzerland); David Mbah (Cameroon Academy of Sciences); David Rinnert (DFID); David Rodriguez Rodriguez (Plymouth University, UK); Davide Poletto (UNESCO); De Grove Tom (EC JRC); Debarati Guha-Sapir (CRED, Université catholique de Louvain); Deborah Villarroel-Lamb (The University of the West Indies, Trinidad and Tobago); Dengcai Yan (Hohai University, China); Dengchang Wang (Rizhao Bureau of Science and Technology, Shandong, China); Dennis Konadu (University of Cambridge, UK); Derek Pieper (UNDP); Diana Suhardiman (International Water Management Institute, Lao PDR); Ding Ma (Tsinghua University, China); Dirk Steenbergen (Charles Darwin University, Australia); Dong Yang (Chinese Academy of Sciences, China); Dongjing Chen (Qingdao University, China); Doug Woodring (Ocean Recovery Alliance); Dusan Jasovsky (ReAct - Action on Antibiotic Resistance, Sweden); Edward Kleverlaan (International Maritime Organization, UK); Ehrlich Daniele (EC JRC); Eigo Tateishi (Lund University, Sweden); Ekaterina Yazhemsky (Hebrew University of Jerusalem, Israel); Elena Giotto (UNDESA); Elisa Tonda (UNEP); Elisabeth Holland (Pacific Centre for the Environment and Sustainable Development, The University of the South Pacific, Fiji); Elise Granek (Portland State University, USA); Elizabeth A. Peyton (The Fletcher School of Law and Diplomacy, Tufts University, USA); Elizabeth Curmi (University of Cambridge, UK); Emily Adams (Lancaster Environment Centre, Lancaster University, UK); Emma Kennedy (University of Exeter, UK); Emmanuel Guerin (SDSN, France); Emmanuel Letouzé (Data-Pop Alliance); Eric Gilman (Hawaii Pacific University, USA); Eric Wolff (University of Cambridge); Erik Olsen (Institute of Marine Research, Norway); Eve de la Mothe (SDSN, France); Everisto Mapedza (International Water Management Institute, South Africa); Fajun Jin (Administrative Bureau of Xinjiang Tianchi Bogda Natural Preservation Zone, China); Fareeha Y. Iqbal (GEF); Feifei Tan (Institute of Restoration Ecology, China University of Mining and Technology); Feng Li (Chongqing Environmental Impact Assessment Center, China); Feng Pan (Administrative Office of Dafeng State-level Sustainable Development Demo Zone, China); Fengting Li (Tongji University, China); Fengyu Li (Shandong Luxin Limited, Hunan, China); Fiona Napier (Development Initiatives Africa Hub); Floriane Clement (International Water Management Institute, Nepal); François Molle (International Water Management Institute, Egypt); Françoise Gaill (CNRS /INEE France); Frank R. Hall (Worcester State University, USA); Frank Thomalla (Stockholm Environment Institute, Sweden); Fraser Sugden (International Water Management Institute, Nepal); Fred Ellery (Rhodes University, South Africa); Fredrik Haag (International Maritime Organization, UK); Friedrich von Kirchbach (formerly with International Trade Centre, Switzerland); Fritz Hinterberger (Sustainable Europe Research Institute (SERI), Vienna, Austria); Fulai Sheng, Jose Pineda (UNEP); G. Wright (IDDRI, France); Gábor Király (Corvinus University of Budapest and Budapest Business School, Hungary); Gabriella Calvano (Center of Experience of Environmental Education, University of Bari, Italy); Geoff Carr (The Fletcher School of Law and Diplomacy, Tufts University, USA); Georgina Mace (University College London, UK); Giovanny Daza (Consejo Latinoamericano de Ciencias Sociales (CLACSO), Argentina); Giriraj Amarnath (International Water Management Institute, Sri Lanka); 
Gisbert Glaser (ICSU); Giulia Bongiorno (Wageningen University and Research Centre); Giuseppe De Simone (UNIDO); Glen Wright (IDDRI, France); Glenn Galloway (Center for Latin American Studies/Center for African Studies, University of Florida Gainesville, USA); Graham Eele (PARIS21); Greg Acciaioli (University of Western Australia, Australia); Greg Scott (UNDESA) ; Guangzhao Wang (School of Public Administration, Guizhou University, China); Guido Schmidt-Traub (SDSN, France); Gunda Zullich (The Millennium Institute, USA); Gunnar Köhlin (Gothenburg University); Guomin Li (School of Business, Hubei University, China); Gusti Ayu Fransiska Sri Rahajeng Kusuma Dewi (State University of New York College of Environmental Science and Forestry, USA); György Pataki (Corvinus University of Budapest and Environmental Social Science Research Group, Hungary); Hailan Hu (School of Public Administration, Guizhou University, China); Hans A. Baer (University of Melbourne, Australia); HansJoachim Schellnhuber (Postdam Institute); Hanyan Wu (Andesite Fiber Limited, China); Heide Hackmann (ICSU); Hein Gevers (Wageningen University and Research Centre, The Netherlands); Helen Adams (University of Exeter, UK); Henri Waisman (IDDRI, France); Heping An (School of Public Administration, Guizhou University, China); Hilary Nwokeabia (UNCTAD); Howard White (3ie); Hui Gao (Xinyang Normal University, China); Hui Liu (Chinese Academy of Fishery Sciences (CAFS), China); Hussein Farah (RCMRD); Hyosun Bae (The Fletcher School of Law and Diplomacy, Tufts University, USA); Ian Chubb (Chief Scientist, Australia); Ibariveni E. (Peoples' Friendship University of Russia, Russian Federation); Ibrahim Game (State University of New York College of Environmental Science and Forestry, USA); Ilaria Lenzi (FEEM, Italy); Ilaria Pais (FEEM, Italy); Ira Matuschke (IASS, Potsdam, Germany); Isatou Gaye (UNECA); Ivana Gadjanski (Belgrade Metropolitan University, Center for Bioengineering BiolRC and Fab Initiative NGO, Serbia); Ivonne Lobos Alva (IASS, Potsdam, Germany); J. Rochette (IDDRI, France); Jacopo Bonan (FEEM, Italy); Jade De Andrade (UNDESA); James Ehrlich (ReGen Villages, EIR, Stanford H-STAR Institute, and Opus Novum at NASA Ames, USA); James Terry (College of Sustainability Sciences and Humanities); Jan De Leeuw (World Agroforestry Center ICRAF, Kenya); Jane Lubchenco (Oregon State University, USA); Janne Kuhn (Wageningen University and Research Centre, The Netherlands); Jari Lyytimäki (Finnish Environment Institute, Finland); Jari Niemelä (Department of Environmental Sciences, University of Helsinki, Finland); Jasmijn Appels (Wageningen University and Research Centre); Jason Flower (University of Queensland, Australia); Javier Mateo-Sagasta (International Water Management Institute, Sri Lanka); Javier Teran (UNOCHA); Jayne Curnow (International Water Management Institute, Sri Lanka); Jean-Luc Dubois, UMI Résiliences (IRD-CIRES, France and Côte d'Ivoire); Jean-Marcel Koffi (UMI Résiliences, IRD-CIRES, France et Côte d'Ivoire, and Université de Bouaké, Côte d'Ivoire); Jeff Ardron (IASS, Germany); Jeffrey S. Crawford (UNDESA); Jérôme Ballet (University of Bordeaux, France); Jérôme Pelenc (Fund for Scientific Research and Free University of Brussels, Belgium); Jesse H. Ausubel (The Rockefeller University, USA); Jessica Espey (SDSN, France); Jessica N. Reimer (Oregon State University, USA); Jessie Mee (UNDP); Jesús Barreiro-Hurlé (EC JRC); Jesus Marcos Gamero Rus (Universidad Carlos III of Madrid, Spain); Jia Du (Beijing Institute of Technology, China); Jian Ma (Xinjiang Institute of ecology and geography, Chinese Academy of Sciences, China); Jianshe Liu (College of Environmental Science and Engineering, Donghua University, China); Jianxin Yang (College of Environmental Science and Engineering, Donghua University, and Research Center for Eco-Environmental Sciences, Chinese Academy of Sciences, China); Jie Chen (Hubei Academy of Agricultural Sciences, Research Institute of Agricultural Quality Standards and Testing Technology, China); Jilan Su (State Oceanic Administration (SOA), China); Jiliang Wu (Qingdao University, China); Jing Li (Zhongnan University of Economics and Law, China); Jing Ping (College of Environmental Science and Engineering, Donghua University, China); Jing Zhangv (Tongji University, China); Jing Zhu (Northeastern University at Qinhuangdao, China); Jingjing Liu (Information Center for the Ministry of Science and Technology, China); Jingru Liu (Research Center for EcoEnvironmental Sciences, Chinese Academy of Sciences, China); Jiutian Zhang (Administrative Center for China's Agenda 21, China); Jo Scheuer (UNDP); Joern Schmidt (Kiel University, Germany); Johannes Timaeus (Helmholtz-Zentrum für Umweltforschung); John Douglas (Department of Earth and Environmental Sciences, Munich University, Germany); John Douglas (French Geological Survey BRGM, Orléans, France); John Gunn (Australian Institute of marine Science); John McCarthy (Australian National University, Australia); Jonas Heirman (DFID); Jonathan Davies (IUCN, Kenya); Jonica D. Otarra (Center for Integrated Development and Social Marketing, Inc., Davao Del Sur, Philippines); José Siri (International Institute for Global Health, United Nations University UNU-IIGH, Malaysia); Juan Ding (Qingdao University, China); Juana Isabel Vera López (EI Colegio de Tamaulipas. México); Julia Hall (RMS); Julien Rochette (IDDRI, France); Junli Li (Qufu Normal University, China); Kaarin Taipale (Aalto University); Kaira Fuente (State University of New York College of Environmental Science and Forestry, USA); Kamran Niaz (UNODC); Karen E. McNamara (University of Queensland, Australia); Karen Sack (The Pew Charitable Trusts);; Karen Villhoth (International Water Management Institute, Sri Lanka) Kari Ravio (Finnish Academy of Sciences); Karine Payet-Lebourges (Mediterranean Institute of marine and terrestrial biodiversity and ecology (IMBE)) France); Karl Aiginger (Austrian Institute of Economic Research, Austria); Karlee Johnson (Stockholm Environment Institute, Sweden); Karmen Poljansek (EC JRC); Karumuna Kaijage (Psychology of Science in Policy PsySiP, Tanzania); Katharina Davis (UNDP); Katharine Jacobs (University of Arizona); Katherine Houghton (IASS, Germany); Kati Vierikko (Department of Environmental Sciences, University of Helsinki, Finland); Katia Opalka (McGill School of Environment, Canada); Katja Kuivanen (Wageningen University and Research Centre); Katsia Paulavets (ICSU); Kaveh Dianati (The Millennium Institute, USA); Kazuki Kitaoka (UNIDO); Ke Lu (Wuhan University of Science and Technology, China); Kebebush Welkema (UNDESA); Keetie Roelen (Institute of Development Studies IDS, UK); Keith S Richards (University of Cambridge, UK); Kevin Lompo (Université de Ouagadougou , Burkina Faso); Kirsten Grorud-Colvert (Oregon State University, USA); Kirsten Isensee (IOC-UNESCO); Klaus; Ammann (University of Bern, Switzerland); Konrad Ott (Kiel University, Germany); Kristin Meyer (United Nations University Institute for Integrated Management of Material Fluxes and of Resources, Dresden, Germany); Larissa Koch (Wageningen University and Research Centre, The Netherlands); Larry Leifer (Stanford University Center for Design Research, USA); Lene Buhl-Mortensen (Institute of Marine Research, Norway); Li Shang (Tongji University, China); Li Yan (Chinese Academy for Environmental Planning, Ministry of Environmental Protection, China); Liang Yao (School of Life Sciences, Anhui Normal University, China); Liette Vasseur (IUCN and Brock University, Canada); Liguang Liu (Central University of Finance and Economics, China); Hui Gao (Research Center for Eco-Environmental Sciences, Chinese Academy of Sciences, China); Lijuan Zhang (Shandong Normal University, China); Lilliam Alvarez (Cuban Academy of Science); Lin Yang (School of Management and Economics, Beijing Institute of Technology, China); Liu Hui (Yellow Sea Fisheries Research Institute, Chinese Academy of Fishery Sciences, China); Lizhi Zhu (Institute of Agricultural Economics and Development, Chinese Academy of Agricultural Sciences, China); Ljubomir Jeftic (Former Deputy Coordinator and Senior Marine Scientist of the Mediterranean Action Plan of UNEP, Croatia); Lorant Czaran (UNOOSA); Lorenzo Fioramonti (University of Pretoria, South Africa); Luca Vernaccini (EC JRC, Belgium); Lucas Chancel (IDDRI, France); Lucien Chabason (IDDRI, France); Ludgarde Coppens, (UNEP); Ludovico Alcorta (UNIDO); Luis Valdes (IOC-UNESCO); Lynne Zeitlin Hale (Nature Conservancy); Lynnette Brammer (Centers for Disease Control and Prevention, US); M A Mendoza (National Inter-University Council, Argentina); M. Niamir-Fuller (UNEP); M. Redina (Peoples' 
Friendship University of Russia, Russian Federation); M.B. Wehbe (Consejo Inter-Universitario Nacional, Argentina); Madar Samad (International Water Management Institute, Sri Lanka); Magdalena Muir (University of Calgary, USA); Mahua Mukherjee (IIT Roorkee, India); Mamadou Djerma (State University of New York College of Environmental Science and Forestry, USA); Manish Anand (The Energy and Resources Institute (TERI), New Delhi, India); Manuel Montes (The South Centre); Ephraim Nkonya (IFPRI); Margaret Kigozi (Business and Professional Women (BPW), Uganda); Margaret Lowman (California Academy of Sciences, USA); Margaret McKenzie (The Fletcher School of Law and Diplomacy, Tufts University, USA); Margarida Santos-Reis (Centre for Ecology, Evolution and Environmental Changes, Faculty of Sciences, University of Lisbon, Portugal); Maria Laura Vélez (CONICET-Centro de Investigación y Extensión Forestal Andino Patagónico CIEFAP, Argentina); Maria Martinho (UNDESA); Maria Rita Guercio (University of São Paulo, Brazil); Maria-Dolores Pitarch-Garrido (Local Development Research Institute, Department of Geography, University of Valencia, Spain); Marion Glaser (Leibniz Center for Tropical Marine Ecology (ZMT), Germany); Mark Eigenraam (UNDESA); Mark Howells (KTH); Mark Stafford-Smith (Future Earth); Markus Hametner (Vienna University of Economics and Business); Marleen Buizer (Land Use Planning Group, Wageningen University, the Netherlands); Martin Solan (University of Southampton, United Kingdom); Marvourneen Dolor (The Pew Charitable Trusts); Mathew Kurian (United Nations University Institute for Integrated Management of Material Fluxes and of Resources, Dresden, Germany); Mathis Wackernagel (Global Footprint Network, Switzerland); Matilda Richter (KTH); Matteo Garbelotto (University of California Berkeley, USA); Matteo Pedercini (The Millennium Institute, USA); Matthew Biggerstaff (Centers for Disease Control and Prevention, US); Matthew McCartney (International Water Management Institute, Lao PDR); Matthieu Meerpoël (Faculty of Law at Catholic University of Lille, and Technical Adviser on Disaster Risk Governance, France); Maurizio Azzaro (CNR - Institute for Coastal Marine Environment, Italy); Max Finlayson (Institute for Land, Water and Society, Charles Sturt University, Australia); Meili Han (Qufu Normal University, China); Melinda Alfano (UNDESA); Meng Li (UNDESA); Meredith Giordano (International Water Management Institute, Sri Lanka); Meryl Williams (AsiaPacific-FishWatch, Australia); Michael Böheim (Austrian Institute of Economic Research, Austria); Michael Clark (University of Minnesota, USA); Michael Grenfell (University of the Western Cape, South Africa); Michel Gressot (Global Footprint Network, Switzerland); Michele Biasutti (University of Padua, Italy); Mikes Jones (IUCN and Swedish Biodiversity Centre, Sweden); Milica Pešić (Department of Neurobiology, Institute for Biological Research Siniša Stanković, University of Belgrade, Belgrade, Serbia); Milica Vasijevic (University of Cambridge, UK); Mirle van Huet (Wageningen University and Research Centre, The Netherlands); Mirna Mariscal (Bolivia); Mohammed Yimer (College of Social Sciences and Humanities, Arba Minch University, Ethiopia); Moshe C. Kinn (University of Salford, School of the Built Environment, UK); Muhammad MehmoodUl-Hassan; Mukul Sanwal (formerly UN); Mustapha Mokrane (ICSU); Myra Foster (Oxfam); Nana Hu (Qufu Normal University, China); N. Hagelberg (UNEP); Nana Zhang (Research Center for Eco-Environmental Sciences, Chinese Academy of Sciences, China); Nathalie Risse (UNDESA); Ngone Diop (UNECA); Nicholas Zimmermann (Harvard GSD, USA); Nicole Adler (Hebrew University of Jerusalem, Israel); Nicoline de Haan (International Water Management Institute, Sri Lanka); Nils Markusson (Lancaster Environment Centre, Lancaster University, UK); Ning Ding (Research Center for Eco-Environmental Sciences, Chinese Academy of Sciences, China); Niranjan Sarangi (UNESCWA); Nobuya Haraguchi (UNIDO); Nobuyuki Yagi (The University of Tokyo, Japan); Nora Sticzay (Wageningen University and Research Centre, The Netherlands); Norman Warthmann (Research School of Biology, The Australian National University, Canberra, Australia); Olanike Adeyemo (University of Ibadan, Nigeria); Oscar Schmidt (IASS, Potsdam, Germany); Otto Cars (ReAct - Action on Antibiotic Resistance, Sweden); Pablo Pacheco (Center for International Forestry Research CIFOR, Bogor, Indonesia); Pamela Flattau (PsySiP Project, Washington DC, USA); Paolo Forti (International Union of Speleology UIS, France); Patricia Miloslavich (Universidad Simon Bolivar, Venezuela); Patricio Bernal (Facultad de Ciencias Biológicas, Chile); Patrick Paul Walsh (SDSN, USA); Patrizio Bianchi (UNIFE International, University of Ferrara); Emilia Romagna (Regional Government); Paul Durack (Lawrence Livermore National Laboratory, USA); Paul Pavelic (International Water Management Institute, Lao PDR); Pay Drechsel (International Water Management Institute, Sri Lanka); Pete Smith (University of Aberdeen, UK); Peter Daszak (EcoHealth Alliance, USA); Peter Howe (Utah State University); Peter Lanjouw (Free University of Amsterdam); Peter Liss (ICSU); Peter McCornick (International Water Management Institute, Sri Lanka); Peter Mumby (University of Queensland, Australia); Peter Nuttall (The University of the South Pacific, Fiji); Philipp Lepenies (Institute for Advanced Sustainability Studies); Philippe Hoyois (Université Catholique de Louvain); Phillippa Biggs (ITU) Pia Katila (Pia Katila Finnish Forest Research Institute, Finland); Priyanie Amerasinghe (International Water Management Institute, India); Qiang Zhang (Administrative Bureau of Xinjiang Tianchi Bogda Natural Preservation Zone, China); Qihong Sun (Chinese Research Acaemy of Environmental Sciences, China); Qing Su (Chinese Academy of Sciences, China); Qiushi Feng (National University of Singapore); R. A. Seiler (National InterUniversity Council, Argentina); R.B. Singh (University of Delhi, India); Rachel Emas (Florida International University, USA); Rahanna Juman (Institute of Marine Affairs; Rajeev Issar (UNDP); Rajiv Nair (Tufts University, USA); Raphaël Billé (IDDRI, France); Razingrim Ouedraogo (World Initiative for Sustainable Pastoralism WISP, Kenya); Rémi Quirion (Chief Scientist Officer, Québec); Rencai Dong (Chinese Academy of Sciences, China); Ricardo Porrúa Rodríguez (Universidad Iberoamericana, Campus Cd. de México, Mexico); Richaela Primus (State University of New York, USA); Richard Osaliya (UNECA); Robert Hamwey (UNCTAD); Robert Kirkpatrick (UN Global Pulse); Robert Muir-Wood (RMS); Robert Unteregger (Future Council Foundation, Switzerland); Roberto Carlos Sevillano Cordero (Bolivia); Robyn Johnston (International Water Management Institute, Sri Lanka); Roger Pulwarty (National Oceanic and Atmospheric Administration); Roger Sayre (US Geological Survey); Rogier "Justin" Reemer (Wageningen University and Research Centre); Roman Stöllinger (Vienna Institute for International Economic Studies); Romuald S. Kinda (UNECA); Ronglu Dou (Qufu Normal University, China); Rosanna Griffith-Mumby (University of Queensland, Australia); Roseanne Diab (Academy of Science of South Africa); Ru Guo (Tongji University, China); Rüdiger Haum and Carsten J. Loose (German Advisory Council on Global Change WBGU, Germany); Rui Xiao (Zhongnan University of Economics and Law, China); Ruqin Xiao (Qingdao University, China); Rusong Wang (Chinese Academy of Sciences, China); Ruth Butterfield (Stockholm Environment Institute, Sweden); Ruzanna Tarverdyan (the Geneva Consensus Foundation, Switzerland); Ryan Burns (University of Washington); Saahil Parekh (The Energy \& Resources Institute TERI, India); Sabrina Axster (UNDESA); Sabrina Juran (UNFPA); Saleh Ahmed (University of Arizona, USA); Salvatore Bushati (Academy of Sciences of Albania); Sam Teicher (Yale School of Forestry and Environmental Studies, USA); Samwar Hobohm (UNIDO); Sanjiv de Silva (International Water Management Institute, Sri Lanka); Sarah Freed (Portland State University, USA); Sarah Telford (UNOCHA); Sebastian Ferse (Leibniz Center for Tropical Marine Ecology (ZMT), Germany); Sebastian Unger (IASS, Germany); Sebastian Winkler (Global Footprint Network, Switzerland); Sébastien Treyer (IDDRI, France); Seleshi Bekele Awulachew (UNDESA); Serge Michel Garcia (IUCN/CEM/FEG); Shailly Kedia (The Energy and Resources Institute, India); Shaoli Chen (Wulong Bureau of Environmental Protection, Chongqing, China); Sheng Yu (Zhongnan University of Economics and Law, China); Shengming Niu 
(Fukang National Forests Administrative Bureau, Xinjiang, China); Sheryl Hendriks (University of Pretoria); Siddharth Singh (The Energy \& Resources Institute TERI, India); Sigrid Kusch (ScEnSers Independent Expert, Germany); Sijie Zhang (Capital University of Economics and Business, China); Siyuan Li (Chinese Academy of Sciences, China); Solene Ledoze (UNDP); Sonali Senaratna Sellamuttu (International Water Management Institute, Lao PDR); Souknilanh Keola (Institute of Developing Economies-JETRO, Japan); Stan Willems (Wageningen University and Research Centre); Stefan Rahmstorf (Potsdam Institute for Climate Impact Research, Germany); Sten Thore (IC2 Institute, University of Texas at Austin, USA); Stephan Sicars (UNIDO); Stephanie Rambler (UNDESA); Stephen Tooth (Aberystwyth University, UK); Steve Arquitta (The Millennium Institute, USA); Steve Kayizzi-Mugerwa (African Development Bank); Steve Sparks (Bristol University); Steven A. Moore (University of Texas, USA); Steven Lutz (GRID-Arendal, Norway); SU Jilan (Second Institute of Oceanography, State Oceanic Administration, China); Sukaina Bharwani (Stockholm Environment Institute, Sweden); Sulan Chen (UNDP); Susana Lizárraga (Bolivia); Taizo Nishikawa (UNIDO); Tara Garnett (University of Oxford, UK); Tara Richards (UNDESA); Tarik Kupusović (Hydro Engineering Institute, Bosnia and Herzegovina); Theresa M Marteau (University of Cambridge, UK); Thilo Klein (PARIS21); Thomas Reuter (University of Melbourne, Australia); Thomas Ulrich (Department of Earth and Environmental Sciences, Munich University, Germany); Tianqi Jiang (Research Center for Eco-Environmental Sciences, Chinese Academy of Sciences, China); Till Zbiranski (PARIS21); Tim Beringer (IASS, Potsdam, Germany); Tim G Benton (University of Leeds, UK); Tim Scott (UNDP); Timothy O. Williams (International Water Management Institute, Ghana); Timothy O'Riordan (University of East Anglia); Tizezew Shimekach Sisay (University of Maine, USA); Tom De Groeve (EC JRC, Belgium); Tom Dedeurwaerdere (Fund for Scientific Research (FRS-FNRS) and Catholic University of Louvain (UCL), Belgium); Tom Hetlage (Nethope); Tongde Li (Tsinghua Tongheng Urban Planning and Design Institute, Beijing, China); Tony Peacock (Cooperative Research Centres Association, Australia); Tonya Vaturi (UNDESA); Travis Reynolds (Colby College, USA); Trevor Fletcher (PARIS21); Tufa Dinku (Columbia University); Tushar Shah (International Water Management Institute, India); Ulrike Kronfeld-Goharani (Kiel University, Germany); V.G. Moya (Peoples' Friendship University of Russia, Russian Federation); V.N. Attri (University of Mauritius and Indian Ocean Rim Association, Republic of Mauritius); Vania Aparecida dos Santos (Geological Institute of Sao Paolo, Brazil); Venugopalan Ittekkot (University of Bremen, Germany); Verónica Argelis Gonzaléz (State University of New York College of Environmental Science and Forestry, USA); Virginia Murray (Public Health England and University College London, UK); Vladimir Smakhtin (International Water Management Institute, Sri Lanka); Wehbe M. B. (National Inter-University Council, Argentina); Wei Liu (UNDESA); Wei Lu (Steering Group for Yancheng State-level Sustainable Development Zone, China); Wei Meng (Chinese Research Academy of Environmental Sciences, China); Wei Tian (Chinese Academy of Sciences, China); Weina Yang (Administrative Bureau of Xinjiang Tianchi Bogda Natural Preservation Zone, China); Wenyan Zhao (Research Center for Eco-Environmental Sciences, Chinese Academy of Sciences, China); Wenying Chen (Tsinghua University, China); Wil de Jong (Center for Integrated Area Studies, Kyoto University, Japan); Wilfried Rickels (Kiel Institute for the World Economy, Germany); William B. Karesh (EcoHealth Alliance, USA); William Daley (The Fletcher School of Law and Diplomacy, Tufts University, USA); William S. Clarke (Independent Researcher, Australia); Winnie Lau (The Pew Charitable Trusts); Xian Zhang (Administrative Center for China's Agenda 21, China); Xiangjiang Yin (Administrative Bureau of Xinjiang Tianchi Bogda Natural Preservation Zone, China); Xiaodang Guo (Beijing Institute of Technology, China); Xiaojing Cao (Tongji University, China); Xiaoqing Shi (Chinese Academy of Sciences, China); Xiaoqing Zhang (Shandong Normal University, China); Xiaowei Ma (Beijing Institute of Technology, China); Xinmin Zhang (Chinese Research Acaemy of Environmental Sciences, China); Xuemin Liu (Beijing Normal University, China); Xueping Hu (Zhongnan University of Economics and Law, China); Yacouba Gnègnè (UNECA); Yali Wang (Shandong Normal University, China); Yaxin Xiao (College of Environmental Science and Engineering, Donghua University, China); Yi Du and Hanqing Guo (Shanxi Agricultural University, China); Yi Zeng (Center for Healthy Aging and Development Studies, Peking University); Yiming Zuo (Steering Group for Yancheng State-level Sustainable Development Zone, China); Ying Chang (Administrative Center for China's Agenda 21, China); Ying Qin (University of Cambridge, UK); Yong Zhang (Shanxi Institute of Soil and Water Conservation, China); Yuanjian Deng (Zhongnan University of Economics and Law, China); Yuanxiu Yu (Chongqing Environmental Impact Assessment Center, China); Yuejun Zhang (Hunan University, China); Yunfei Yao (SINOPEC Research Institute of Petroleum Engineering, China); Yutang Dai (Rizhao Bureau of Science and Technology, Shandong, China); Zdenka Myslikova (Tufts University, USA); Zeenat Niazi (Development Alternatives, India); Zenaida Mourao (University of Cambridge, UK); Zenan Wang (Shandong Normal University, China); Zhaohua Lu (Binzhou University, China); Zhaoxing Sun (Chinese Academy of Sciences, China); Zhenbin Gu (Chinese Academy of Agricultural Sciences, China); Zhenglian Wang (Duke University); Zhigang Xue (Chinese Research Academy of Environmental Sciences, China); Zhiguo Zhang (Shanxi Institute of Soil and Water Conservation, China); Zhiying Gao (School of Business, Hubei University, China); Zinta Zommers (UNEP); Zoraida Velasco (Tufts University, USA).

\section{Peer Reviewers}

Amparo Ballivian (World Bank); Andalib Elias (Permanent Mission of Bangladesh to the UN); Anne-Sophie Stevance (International Council on Science); Arevik Khnkoyan (Ministry of Education and Science, Armenia); Bob Kates (University of Maine, USA); Constantinos Taliotis (Royal Institute of Technology, Sweden); Bobir Tukhtabayev (UNESCO); Daniele Giovannucci (COSA); Debapriya Bhattacharya (LDC IV Monitor Centre for Policy Dialogue, Bangladesh); Dimitri Sanga (UNECA); Enrique J. M. Carrillo Gomez (Permanent Mission of Paraguay to the UN); Ephraim Nkonya (IFPRI) University of Cambridge; Erick Jean-Marie Zinsou (Permanent Mission of Benin to the UN); Jake Rice, (Fisheries and Oceans Canada (DFO); Johannes G. Hoogeveen (World Bank); Jonathan Reeves (IIED); Lichia Yiu-Saner (Center for Socio-economic Development, Switzerland); Limia Abdelgafar Khalaflla Ahmed (National Population Council, Sudan); Lindani B. Ndlovu (Independent Consultant); Lucien Chabason (Institut du Développement Durable et des Relations Internationales); Lucilla Spini (ICSU); Ludgarde Coppens (UNEP); Måns Nilsson (SEI, Sweden); Manuel Montes (The South Centre); Maria Ivanova (University of Massachusetts, Boston); Mark Howells (Royal Institute of Technology, Sweden); Mark Stafford-Smith (Future Earth); Martin Visbeck (GEOMAR/Helmholtz Centre for Ocean Research Kiel); Michael Lim (UNCTAD); Nathalie Risse (IISD); Raymond Saner (CSEND); Richard Glover (ICSU); Robert Costanza (Crawford School of Public Policy, Australia); Rolf Traeger (UNCTAD); Seydou Yaye, (Ministry of Planning and Development, Niger); Simon Hess (WTO); Shuaib Lwasa (Makerere University); Souknilanh Keola (Institute of Developing Economies-JETRO, Japan); Tesfachew Taffere (UNCTAD); Youba Sokona (South Center, Geneva). 


\section{List of Abbreviations and Acronyms}

\begin{tabular}{|c|c|}
\hline AAAS & American Association for the Advancement of Science \\
\hline$A A L$ & Annual Average Loss \\
\hline ABS & Access and Benefit Sharing \\
\hline ACPC & African Climate Policy Centre \\
\hline ADB & Asian Development Bank \\
\hline AlH & African Information Highway \\
\hline AIMS & Africa, Indian Ocean, Mediterranean and South China Sea \\
\hline Akvo FLOW & Field Level Operations Watch mobile application \\
\hline ALDFG & Abandoned, lost and otherwise discarded fishing gear \\
\hline AMOC & Atlantic Meridional Overturning Circulation \\
\hline ARMC & African Resource Management Constellation \\
\hline $\mathrm{BCD}$ & Bio-cultural Diversity \\
\hline BRICS & Brazil Russia India China South Africa \\
\hline CANARI & Caribbean Natural Resources Institute \\
\hline CAPRA & Comprehensive Approach to Probabilistic Risk Assessment \\
\hline CARICOM & Caribbean Community \\
\hline CARPHA & Caribbean Public Health Agency \\
\hline CBD & Convention on Biological Diversity \\
\hline $\mathrm{CCCCC}$ & Caribbean Community Climate Change Centre \\
\hline $\mathrm{CDB}$ & Caribbean Development Bank \\
\hline CDP & Committee for Development Policy of the United Nations \\
\hline CDRs & Call Detail Records \\
\hline CEO & Chief Executive Officer \\
\hline CEPAL & Spanish for ECLAC - Economic Commission for Latin America and the Caribbean \\
\hline CES & Conference of European Statisticians \\
\hline CFCs & Chlorofluorocarbons \\
\hline CGE & Computable General Equilibrium (model) \\
\hline $\mathrm{CHAl}$ & Clinton Health Access Initiative \\
\hline $\mathrm{CIMH}$ & Caribbean Institute for Meteorology and Hydrology \\
\hline CIP & Competitive Industrial Performance \\
\hline COP & Committee of Parties \\
\hline COSA & Committee on Sustainability Assessment \\
\hline CPDC & Caribbean Policy Development Centre \\
\hline CRED & Centre for Research on the Epidemiology of Disasters \\
\hline CRIM & Integrated Catastrophe Risk Management Model \\
\hline DALYs & Disability-Adjusted Life Years \\
\hline DBCP & Dibromochloropropane \\
\hline DDT & Dichlorodiphenyltrichloroethane \\
\hline DECA & Demographic Explorer for Climate Adaptation \\
\hline DES & Synthetic Estrogen Diethylstilboestrol \\
\hline DEWS & Drought Early Warning Program \\
\hline DFID & Department for International Development \\
\hline DMC & Disaster Monitoring Constellation \\
\hline DPSIR & Drivers-Pressures-State-Impacts-Responses \\
\hline DRR & Disaster Risk Reduction \\
\hline DSD & Division for Sustainable Development \\
\hline ECESA & Executive Committee on Economic and Social Affairs \\
\hline ECLAC & Economic Commission for Latin America and the Caribbean \\
\hline EEA & European Economic Area \\
\hline EIF & Enhanced Integrated Framework \\
\hline
\end{tabular}




\begin{tabular}{|c|c|}
\hline ENACTS & Enhancing National Climate Time Series \\
\hline EPD & Environmental product Declarations \\
\hline ESCAP & Economic and Social Commission for Asia and the Pacific \\
\hline ESCWA & Economic and Social Commission for Western Asia \\
\hline EST & Environmentally sound technologies \\
\hline EU & European Union \\
\hline EVI & Economic Vulnerability to External Shocks Index \\
\hline FAO & Food and Agriculture Organization \\
\hline FDI & Foreign Direct Investment \\
\hline FEEM & Fondazione Eni Enrico Mattei \\
\hline FTE & Full Time Equivalent \\
\hline GBO & Global Biodiversity Outlook \\
\hline GCM & Global Circulation Model \\
\hline GDP & Gross Domestic Product \\
\hline GEF & Global Environment Facility \\
\hline GEM & Global Earthquake Model \\
\hline GEO & Global Environment Outlook \\
\hline GESAMP & Group of Experts on the Scientific Aspects of Marine Environmental Protection \\
\hline GFW & Global Forest Watch \\
\hline GHG & Greenhouse gas \\
\hline GIS & Geographic Information Systems \\
\hline GM & General Motors \\
\hline GMOs & Genetically-modified Organisms \\
\hline GNI & Gross National Income \\
\hline GNSS & Global Navigation Satellite Systems \\
\hline GOOS & Global Ocean Observing System \\
\hline GPI & Global Genuine Progress Indicator \\
\hline GPS & Global Positioning System \\
\hline GRAMED & Global and Regional Assessments of the Marine Environment Database \\
\hline GSDR & Global Sustainable Development Report \\
\hline GSG & Global Scenario Group \\
\hline GVC & Global Value Chain \\
\hline HAI & Human Assets Index \\
\hline HFA & Hyogo Framework for Action \\
\hline HIV & Human Immunodeficiency Virus \\
\hline HLPF & High-Level Political Forum \\
\hline IAEA & International Atomic Energy Agency \\
\hline ICSU & International Council for Science \\
\hline ICT & Information and Communications Technology \\
\hline ICZM & Integrated Coastal Zone Management \\
\hline IIASA & International Institute for Applied Systems Analysis \\
\hline IIASA-GEA & International Institute for Applied Systems Analysis - Global Energy Assessment \\
\hline IISD & International Institute for Sustainable Development \\
\hline ILO & International Labor Organization \\
\hline IMF & International Monetary Fund \\
\hline IMO & International Maritime Organization \\
\hline IMPASEM & Integrated Marine Protected Areas Socio-Economic Monitoring \\
\hline INFORM & Index for Risk Management \\
\hline IOC & Indian Ocean Commission \\
\hline IOM & Institute of Medicine \\
\hline IPBES & Intergovernmental Platform on Biodiversity and Ecosystem Services \\
\hline IPCC & Intergovernmental Panel on Climate Change \\
\hline IPoA & Istanbul Programme of Action \\
\hline
\end{tabular}




\begin{tabular}{|c|c|}
\hline IRENA & International Renewable Energy Agency \\
\hline IRI & International Research Institute for Climate and Society, Columbia University \\
\hline ISEAL & International Social and Environmental Accreditation and Labelling Alliance \\
\hline ISSC & International Social Science Council \\
\hline ITC & International Trade Centre \\
\hline ITU-T & International Telecommunication Union - Telecommunication Standardization Sector \\
\hline IUCN & International Union for Conservation of Nature \\
\hline IUU & Illegal, Unreported and Unregulated \\
\hline IWMI & International Water Management Institute \\
\hline J-PAL & Jamel Lateef Poverty Action Lab \\
\hline LCA & Life Cycle Assessments \\
\hline LDCs & Least Development Countries \\
\hline LLDC & Land Locked Developing Countries \\
\hline MDG & Millennium Development Goal \\
\hline MedPAN & Network of Marine Protected Area Managers in the Mediterranean \\
\hline MODIS & Moderate Resolution Imaging Spectroradiometer \\
\hline MPA & Marine Protected Area \\
\hline MPI & Multidimensional Poverty Index \\
\hline MSI & Mauritius Strategy of Implementation \\
\hline MSP & Marine Spatial Planning \\
\hline MTBE & Methyl tertiary-butyl ether \\
\hline MTRAC & Monitoring Essential Medicine Supply mobile application \\
\hline MVA & Manufacturing value added \\
\hline NASA & National Aeronautics and Space Administration \\
\hline NCDs & Non-communicable Diseases \\
\hline NCPC & National Cleaner Production Centre \\
\hline NGOs & Non-Governmental Organizations \\
\hline NMS & National Meteorological Services \\
\hline NSDC & National Council for Sustainable Development \\
\hline NSDI & National Spatial Data Infrastructure \\
\hline NTL & Night-time Lights \\
\hline OBIS & Ocean Biogeographic Information System \\
\hline ODA & Official Development Assistance \\
\hline ODI & Overseas Development Institute \\
\hline OECD & Organization for Economic Cooperation and Development \\
\hline OECS & Organization of Eastern Caribbean States \\
\hline $\mathrm{OHI}$ & Ocean Health Index \\
\hline OWG & Open Working Group \\
\hline PANACHE & Protected Area Network Across the Channel Ecosystem Pathway \\
\hline PBDEs & Polybrominated diphenyl ethers \\
\hline PBL & Netherlands Environmental Assessment Agency \\
\hline PCBs & Polychlorinated biphenyls \\
\hline PCP & Programme for Country Partnerships \\
\hline PICs & Pacific Island Countries \\
\hline PIFS & Pacific Island Forum Secretariat \\
\hline PML & Probable Maximum Loss \\
\hline PMOC & Pacific Meridional Overturning Circulation \\
\hline POPs & Persistent Organic Pollutants \\
\hline PPP & Public-Private Partnerships \\
\hline PRSPS & Poverty Reduction Strategy Papers \\
\hline$R \& D$ & Research and Development \\
\hline$R \& D \& M$ & Research and Development and Marketing \\
\hline RCMRD & Regional Centre for Mapping of Resources for Development \\
\hline
\end{tabular}


RECP

RECPNet

RITE-ALPS

SAMOA Pathway

SAP

SCP

SDGS

SEEA

SEI

SG

SGP

SIDS

SIT

SME

SMS

SOM

SPC

SPI

SPREP

STAP

STI

TBT

TEL

TFP

TRIPS

TVET

UCSIS

UN

UNCED

UNCLOS15

UNCTAD

UNDESA

UNDP

UNECA

UNECE

UNEP

UNESCAP

UNESCO

UNESCO-IOC

UNFCCC

UNFPA

UN-HABITAT

UNICEF

UNIDO

UNISDR

UNODC

UN-OHRLLS

UNU-FLORES

UNU-IAS

USA
Resource Efficiency and Cleaner Production Programme

Resource Efficiency and Cleaner Production Programme Network

Research Institute of Innovative Technology for the Earth - Alternative Pathways toward

Sustainable Development and Climate Stabilization

SIDS Accelerated Modalities of Action

Strategic Action Plan

Sustainable Consumption and Production

Sustainable Development Goals

System of Environmental-Economic Accounting

Stockholm Environment Institute

UN Secretary General

Salinity Gradient Power

Small Island Developing States

Science, Technology and Innovation

Small and Medium Enterprises

Short Message Service

Soil Organic Matter

Secretariat of the Pacific Community

Science-Policy Interface

Secretariat of the Pacific Regional Environment Program

Scientific and Technical Advisory Panel

Science-Technology Innovation

Tributyltin

Tetraethyl Lead

Total Factor Productivity

Agreement on Trade-Related Aspects of Intellectual Property Rights

Technical and Vocational Education and Training

University Consortium of Small Island Developing States

United Nations

United Nations Conference on Environment and Development

United National Convention on the Law of the Sea 2015

United Nations Conference on Trade and Development

United Nations Department of Social and Economic Affairs

UN Development Programme

United Nations Regional Commission for Africa

United Nations Economic Commission for Europe

United Nations Environment Programme

United Nations Economic and Social Commission for Asia and the Pacific

UN Education, Science and Culture Organization

United Nations Educational, Scientific and Cultural Organization's Intergovernmental

Oceanographic Commission

UN Framework Convention on Climate Change

United Nations Population Fund

United Nations Human Settlements Programme

United Nations International Children's Emergency Fund

United Nations Industrial Development Organization

United Nations International Strategy for Disaster Reduction

United Nations Office on Drugs and Crime

UN Office of the High Representative for LDCs, LLDCs and SIDS

United Nations University - Institute for Integrated Management of Material Fluxes and of

Resources

United Nations University - Institute for the Advanced Study of Sustainability

United States of America 


$\begin{array}{ll}\text { USAID } & \text { United States Agency for International Development } \\ \text { VPOA } & \text { Vienna Programme of Action } \\ \text { VSS } & \text { Voluntary Sustainability Standards } \\ \text { WBGU } & \text { German Advisory Council on Global Change } \\ \text { WCDRR } & 3^{\text {rd }} \text { UN World Conference on Disaster Risk Reduction } \\ \text { WEF } & \text { World Economic Forum } \\ \text { WFP } & \text { World Food Programme } \\ \text { WMO } & \text { World Meteorological Organization } \\ \text { WTO } & \text { World Trade Organization } \\ \text { WWF } & \text { World Wildlife Fund }\end{array}$




\section{Executive Summary}

2015 will be a watershed year for sustainable development. Major international conferences - on financing for development, the post-2015 development agenda, and climate change - will take momentous decisions that could, if effectively implemented, have profound implications for the future of our societies, our economies and of our planet.

This is the context in which this year's Global Sustainable Development Report (GSDR) appears. Building upon the 2014 Prototype report, ${ }^{1}$ the current Report responds to the Rio+20 mandate to contribute to strengthening the science-policy interface (SPI) for sustainable development, particularly in the context of the High-level political forum (HLPF) on sustainable development. ${ }^{2}$ Given the anticipated adoption in September of the post-2015 development agenda with its sustainable development goals, the report asks how well prepared the scientific community is to inform the sort of integrated and multidimensional problem solving and policy making that will be needed for implementing this agenda.

True to its mandate, the report is designed as an assessment of assessments rather than seeking to pioneer new knowledge. It endeavors to present a range of scientific perspectives and to be policy-relevant but not policy-prescriptive. One distinctive feature of the report is its illustration of different vantage points from which to examine the science-policy interface and to view integration and interlinkages across goals, sectors, and issues. Its preparation involved an inclusive, multistakeholder process drawing upon scientific and technical expertise from within and outside the United Nations System.

\section{Science-policy interface for sustainable development}

The science-policy interface (SPI) functions at many levels. This report considers its functioning at international and national levels, the latter in relation to countries in special situations, and also in relation to the nexus of oceans, seas, marine resources and human well-being and the crosscutting issue of disaster risk reduction (DRR).

At the international level, there are multiple examples of the SPI in relation to sustainable development: formal and large-scale assessment processes and platforms like the Intergovernmental Panel on Climate Change (IPCC) and the Intergovernmental Platform on Biodiversity and Ecosystem Services (IPBES); advisory bodies like the UN SecretaryGeneral's Scientific Advisory Board; ad hoc meetings bringing together scientists and policy makers to discuss specific priority issues; and academic journal articles addressing emerging issues, such as nanotechnology3.

The current Report focuses in the first instance, in Chapter 1 , on how the HLPF could add value to the current landscape of SPI configurations addressing sustainable development issues at the UN. The chapter considers the views on the SPI offered by UN Member States, UN organizations and other stakeholders as inputs to the 2014 UN Secretary-General's report on "Options for the scope and methodology for a global sustainable development report". ${ }^{4}$ Another source was a survey of scientists and development practitioners conducted for this GSDR. Taken together, these two sets of responses suggest a range of ways for the HLPF to enable constructive interactions between science and policy-making at the UN. These can be clustered into three groups (illustrated in Figure ES-0-1). A first group of actions relates to the provision of policyrelevant data, analysis and information; a second to actions that the HLPF could take to support enhanced dialogue between science and policy; and a third to the translation of the results of science-policy dialogue into policy-making.

Scientists suggested that priorities for consideration by the HLPF could be based on an overall assessment of progress towards sustainable development. This assessment could inform policy responses to accelerate progress and overcome obstacles. Experts expressed the broadest support for the following SPI functions: providing improved access to the findings of existing assessments, highlighting synergies, trade-offs and tools to address them, and helping transpose the outcomes of global science-policy debates into regionally and nationally relevant frameworks for action. These ideas reflect some of the core mandates of the HLPF as contained in the Rio+20 outcome document, and the fact that experts rank them as very important, attests to a shared sense of priorities between scientists and policy-makers. Most of the expert respondents also suggested that the HLPF could inform the scientific research agenda.

Other important ideas revolve around the identification of sustainable development trends and the identification of, and action on, emerging issues. Many of the practitioners who provided inputs for the report emphasized the importance for the HLPF to consider an array of actions rather than any single prescription, recognizing the need for policy flexibility and also the scope for exploiting synergies across policies. 

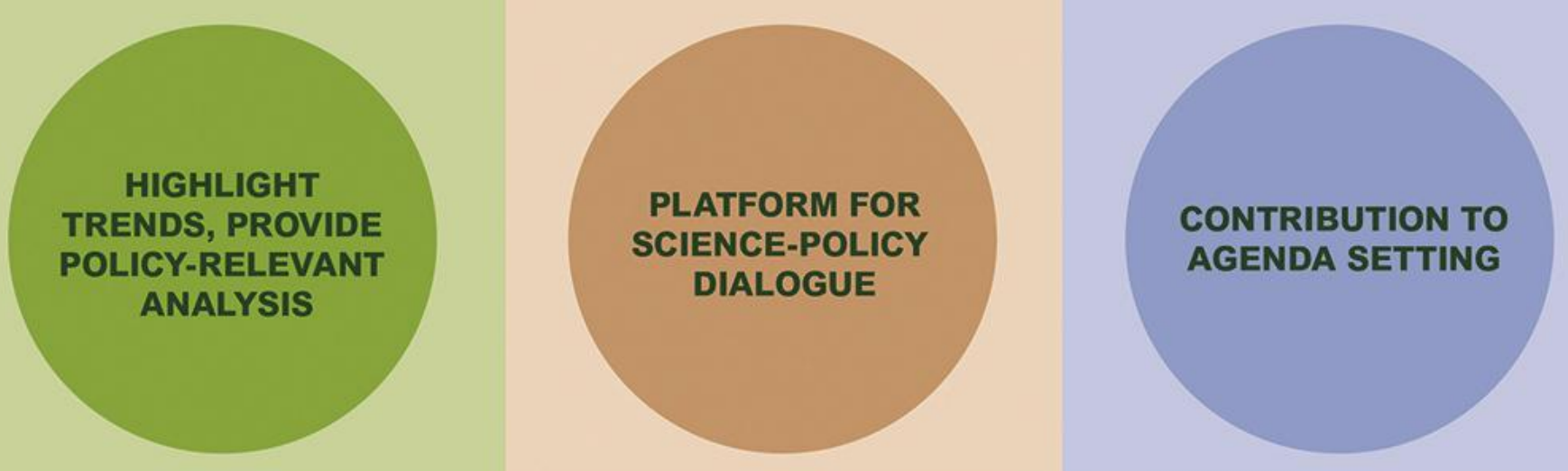

- Identify new and emerging issues through sound scientific evidence, assessments and forward-looking projections

- Capture past and future sustainable development trends, lessons learnt and scientific findings, indicating potential areas for policy action

- Provide a repository for recent assessments covering sustainable development goal areas

- Highlight interlinkages among sectors and tools to address them in an intergenerationally equitable way

- Assess the coverage, integration and coherence of international assessments in sustainable development goal areas

- Highlight lessons learnt and best practices from public-private research collaborations
- Provide a platform for two-way interactions between international assessments and regional and national policy-making

- Provide a forum for wide participation through multiple channels and feature a wide range of perspectives

- Provide improved access to the findings of existing assessments and highlight synergies and trade-offs

- Provide a platform for exchange of experience on how the science-policy interface at the national level has worked

- Bring the work of independent scientific advisory groups and assessment initiatives to the intergovernmental arena

- Involve scientists in specialized fields to engage in the broader science-policy interface through the production of science digests

- Promote in-depth cooperation on integrated sustianable development scenarios
- Identify areas where research, data and science-policy interface mechanisms would need increased resources for developing countries

- Agree on priority emerging issues that need addressing at the international level, based on national priorities

- Help transpose the outcomes of global science-policy debates into regionally and nationally relevant frameworks for action

- Provide political guidance on research needs of relevance to address sustainable development

- Request independent scientific bodies to carry out studies that address specific needs and questions raised by the forum

- Assess the effectiveness of the international science-policy interface mechanisms in sustainable development goal areas

- Commission reviews on how international law in specific sustainable development areas reflects changes in scientific consensus
As a measure of the effectiveness of the science-policy interface, the report presents an empirical review of timelags from scientific identification of sustainable development challenges, to policy action, through to policy impacts. This provides lessons-learnt with respect to the SPI, including the potential and limitations of any arrangements geared to shorten science-policy time-lags. Among the most important lessons are the complications posed by scientific uncertainty for policy makers, as well as by conflicting views within government and in the broader society over how scientists' warnings should be heeded.

Strengthening the SPI is a challenge for all countries, but those in special situations face particular challenges and difficulties in this regard. Science-based policymaking is not generally well institutionalized through formal mechanisms in these groups of countries, though there are important exceptions. Informed by scientific findings, Bangladesh has established two climate funds directly linked to new 
policies for mitigation and adaptation. In another example, the Caribbean Natural Resources Institute has carried out an initiative in "citizen science", enlisting local communities to map characteristics of island land areas based on their personal and familial knowledge, collecting valuable data which can inform policy makers when defining policies on climate change adaptation.

While science is a global enterprise, national capacity is critical to applying and adapting scientific knowledge and combining it with traditional knowledge for local needs. For the SPI to become more effective in countries in special situations and play more of its potential role in policymaking, domestic scientific institutions would need to be strengthened. As science and technology are instruments for improving human well-being, strong links are needed not only to policy but also to these countries' productive sectors, which generate the jobs and incomes that make rising living standards possible and sustainable.

Scientists of countries in special situations also need to be more systematically linked into global research initiatives and scientific communities. By virtue of these country groupings' sharing certain structural characteristics, they also share problems on which collaborative research and knowledge sharing can shed light. In the context of SIDS, for example, inter-regional collaboration on the sciencepolicy interface is an area that can be enhanced for the mutual benefit of countries facing similar challenges even if they are on opposite sides of the globe.

The chapter on the "oceans nexus" provides an illustration of how policy-relevant conclusions can be gleaned from major scientific assessments. It considers important classes of drivers of change and threats to the health and wellbeing of the oceans and their resources at the sub-national, national, regional and global levels. The chapter surveys the scientific understanding of interlinkages between the state of oceans and marine ecosystems on the one hand and human activities on the other.

In recent years, partnerships between scientific organisations, on one side, and practitioners and policy makers, on the other, have enhanced the uptake of evidence in DRR. For example, the Global Flood Partnership aims at bringing flood modelling and forecasting to the use of planners and practitioners. DRR planning and monitoring would benefit from greater uptake of scientific research, including risk assessments and models, as well as analysis of the underlying drivers of risk.

\section{SDGs as an interconnected system: integration and cross-cutting issues}

The framework for approaching sustainable development challenges in this Report is provided by the Open Working Group proposal for Sustainable Development Goals (SDGs). Due to their broad support thus far, the 17 goals and their 169 targets are likely to form the core of the post-2015 development agenda.

Thus, one can already begin to analyze how the SDGs fit together as a whole and what that means for policy and the science-policy interface. There are two interrelated aspects of the "fitting together" of the SDGs, both of which were anticipated by the Rio+20 outcome document when it called for developing SDGs that "address and incorporate in a balanced way all three dimensions of sustainable development and their interlinkages" (para 246, The Future We Want). Balance and interlinkage among the three dimensions of sustainable development is reflected not only at the level of the goals but also at the level of the targets. The goals themselves are linked through the proposed targets. Thus, action to achieve one goal and its targets clearly has a bearing on other goals' attainment. In this sense the SDGs function as an interconnected system, and the approach to their implementation therefore needs to be holistic, multi-sectoral and multidimensional.

The chapter on SDGs as a system illustrates, however, that some interconnections between goals are denser than others, as measured by the number of targets linking any particular goal to other goals (see Figure ES-0-2). By considering the patterns that emerge from such a network mapping, it may be possible to identify one or more nexuses of issues to be analyzed together for specific policy purposes.

\section{A nexus approach}

One such area examined in this Report is the nexus of oceans, seas, marine resources and human well-being. The analysis draws extensively upon multiple assessments and inputs from 47 contributing scientists and more than 40 United Nations experts, as well as a preliminary review of findings from the forthcoming World Ocean Assessment. 


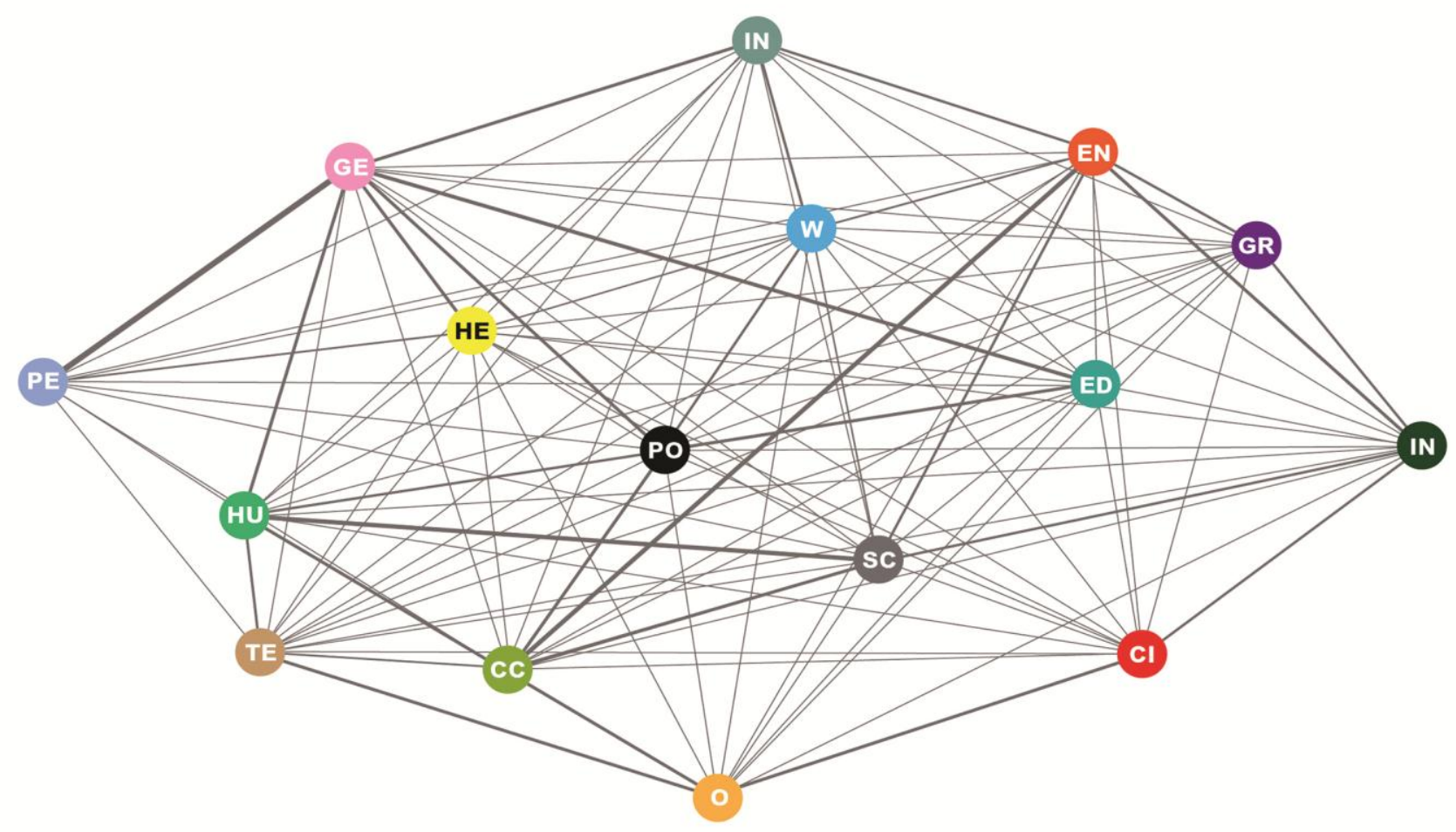

$\begin{array}{ll}\text { CI CITIES } & \text { IN INEQUALITY } \\ \text { CC CLIMATE CHANGE } & \text { IN INFRASTRUCTURE \& INDUSTRY } \\ \text { ED EDUCATION } & \text { O OCEANS } \\ \text { EN ENERGY } & \text { PE PEACEFUL \& INCLUSIVE SOCIETIES } \\ \text { GE GENDER } & \text { PO POVERTY } \\ \text { GR GROWTH \& EMPLOYMENT } & \text { SC SCP } \\ \text { HE HEALTH } & \text { TE TERRESTRIAL ECOSYSTEMS } \\ \text { HU HUNGER } & \text { W WATER }\end{array}$

Source: authors' elaboration, visualizing the interdependencies described in the ICSU/ISSC 2015 report on the SDGs ${ }^{5}$

Notes: The thickness of the lines is an adjusted measure of the strength of interlinkages between goals. It denotes the number of links between two goals divided by the sum of targets under the two goals. SDG17 on "means of implementation" (which links to all other goals) was excluded from the analysis.

Among the salient findings, the scientific coverage of the impact of ocean ecosystem integrity on human well-being is seen as being rather well developed with regard to the creation of jobs and sustainable livelihoods but weak with regard to the evaluation of benefits derived from marine resources and ecosystem services. Also, the scientific coverage of the impact of marine- and land-based human activities on oceans, seas and marine resources is better documented than the feedback effects to human well- being from resource degradation. Areas for further research include a better understanding of cumulative and interactive effects of different human activities as a basis for integrative management strategies, and evaluating properly the consequences of human activities on ocean ecosystems (e.g, geo-engineering and industrial development in extreme areas). 
Despite some evidence provided by projects and case studies, contributing experts also point to a lack of scientific information on the potential contribution of improvements in human well-being to reduced anthropogenic impacts on oceans, seas and marine resources. They suggest that further research needs to be undertaken on the effects of changes in lifestyle (e.g., production, consumption, and social organization) on the sustainability of marine resource use.

More integrated study of the oceans by teams of natural and social scientists is also needed, including fully integrated global and regional scientific assessments of interactions and interdependencies within and beyond this nexus.

\section{Cross-cutting issues in the SDGs}

DRR is an issue which cuts across the SDGs, being reflected in a number of goals and targets. They range from targets specifically referring to limiting the losses of life, output and infrastructure from disasters to targets calling for strengthened resilience to disasters among the poor and vulnerable as well as in cities and other human settlements.

DRR and resilience building are relevant concepts for all the goal areas in the SDGs. Examples range from the wellknown macroeconomic level impacts of disasters on growth and development, to the impact of disaster on infrastructure and basic services such as shelter, water and health, as well as food security, to less often scrutinized links between disaster and social stability, to the relationships between ecosystem and natural resource management and disaster risks. As a whole, these examples make a strong case for considering DRR aspects in all the SDG-related areas in disaster-prone countries.

\section{Data and monitoring}

It is widely recognized that, if the MDGs posed data and monitoring challenges for many developing countries, the SDGs will magnify those challenges. The discussion of data and monitoring in this Report focuses on the extent of SDG coverage of existing data and monitoring systems, particularly in countries in special situations, but also the ways in which data innovations are being used already in Africa (as a regional study in Chapter 8) to inform decision making in many of the SDG areas. Also, Chapter 4 takes a deep dive into the complex data, measurement and monitoring issues relating to the cross-cutting issue of DRR . Similar measurement challenges are likely to arise in many other issue areas.

There exists no easily accessible repository containing relevant documentation on various SDG areas for any of the three groups of countries featured in Chapter 6 of this Report - least developed countries (LDCS), landlocked developing countries (LLDCs) and small island developing states (SIDS). Most of the data-heavy international publications on the three groups of countries are done by the United Nations system or related entities such as the World Bank. They generally take a sectoral rather than an integrated, cross-sectoral approach. Many publications cover one or two SDG areas, and very few cover more than three or four. Coverage tends to be better of SDG areas that focus more on social issues (i.e. those that were covered by the MDGs) than of the goals focusing on economic and environmental dimensions.

Chapter 6 highlights lack of accurate and adequate data and statistics as a major challenge in these groups of countries. Crucial data needed to inform development strategies is often missing in countries in special situations. Although most of these countries are able to conduct censuses, data from those are typically available only every ten years. In many countries, reliable administrative records do not exist and surveys are scarce. For instance, since 2005 , only $46 \%$ of LDCs, $75 \%$ of LLDCs and $53 \%$ of SIDS have conducted a labour force survey - one of the main sources of data on employment. Very few SIDS have data on poverty or on inequality measures. Other data e.g. for water and electricity access - are more widely available because international agencies often produce estimates to fill data gaps. Administrative data systems that require substantial resources - such as lists of enrolled students and their gender, or registered births - are not so widely available.

In the case of Africa, Chapter 8 provides a snapshot of innovative uses of data for improving decision making relating, inter alia, to poverty eradication, education, water resources, terrestrial ecosystems, natural disasters, climate, and food security. The applications include early warning and planning tools for flood and natural disaster management, localized poverty maps, health and basic infrastructure mapping, and detailed land cover and land use data. For several topics covered by the SDGs, there are new data approaches in Africa, using new technologies, new methods and new data sources. There is an increasing tendency to make use of multiple data sources: official statistics, geographic and satellite data, big data (e.g., from mobile phone call records), scientific data, data produced by NGOs and research foundations, and data from the media, the public and the business sector.

Rapid development of new data approaches in Africa has been spurred by trends such as the rapid penetration of mobile phones. In African countries with very high penetration rates, cell phone records can be explored to 
increase either the availability or the frequency of data. In many countries of the region, access to the internet remains a challenge due to low internet connectivity, and data collection using internet platforms and data produced through internet use - e.g., social media, online searches, online transactions, etc. - is rare. Geospatial information is also increasingly being used in Africa.

Many African countries actively engage in piloting and implementing innovative approaches for improved data processes. As in other regions, many data innovations are developed by research institutes and universities and have not yet made it into channels influencing national policymaking. Where innovations, for example new software tools, are developed and disseminated by international agencies, countries may find it difficult to evaluate and assess their suitability and therefore could benefit from access to independent advice on new technologies and tools and their relative strengths and drawbacks. Further, most of the big-data applications need to be calibrated against official, "traditional" data. Therefore, strengthening national statistical agencies as the providers of such data remains a priority, particularly in countries where these agencies are under-resourced.

Developing disaster statistics and risk metrics will not only support evidence-based policy and decision making, but also improve reporting of progress towards internationally agreed goals and targets. Chapter 4 explains how the inclusion of targets related to DRR not only in the SDGs but also in the Sendai Framework for Disaster Risk Reduction 2015-2030 brings to the fore a range of practical issues that relate to all the stages of disaster risk reduction and management, from knowledge of past events to early warning to risk mitigation to disaster management plans. Issues include the need for definitions, accounting methods, baselines, methodologies for assessing risk, exposure and vulnerability, and data collection efforts.

The chapter illustrates ongoing efforts to mobilize conventional and more innovative data sources to inform decision-making (e.g. use of drones for vulnerability and loss assessments, crowd-sourcing information for mapping post-disaster needs).

Addressing these measurement issues in the context of the SDGs provides an opportunity to align the treatment of DRR in the post-2015 agenda and the post-Sendai DRR monitoring framework in order to avoid duplication and to ensure that progress in disaster risk reduction can be reported as an integral part of progress on sustainable development.
Identifying emerging issues: a critical role for science in informing policy

The identification of new and emerging issues warranting policy makers' attention is a critical function of the sciencepolicy interface. The process typically draws on scientific evidence, assessments, and projections. A common approach involves canvassing expert opinion to collect an initial list of issues, which is then whittled down in the course of discussions among experts.

Another, complementary approach is to crowd-source briefs from interested scientific communities around the world, asking scientists to motivate why they think a particular issue needs policy makers' attention. This provides a bottom-up, largely unfiltered science perspective. In response to an open call for contribution to the GSDR, 367 natural and social scientists from 24 developing and 22 developed countries submitted 187 science briefs for the consideration of policy makers in the HLPF. Many inputs were received from younger scientists and scientists from developing countries who previously were not involved in United Nations related activities and debates. While this process lacks the expert pedigree of formal assessment exercises, judgments about quality can be made based, e.g., on the degree to which findings are grounded in the peer-reviewed literature and are consistent with the scientific method.

The submitted briefs differed greatly in terms of their nature and focus; taken together they provide a mosaic of interdependent challenges. Many briefs focused on clusters of SDG-related issues, such as SCP-growth-employmentinfrastructure-industrialization, energy-water-climate, health-hunger-oceans, ecosystems-inequality. Few took a system-wide approach covering multiple SDG areas such as is commonly found in integrated global assessments. Many of the briefs followed a transdisciplinary approach characteristic of sustainability science.

Looking to possible future crowdsourcing efforts, there is a need to expand outreach efforts, in order to garner more inputs on emerging issues related to the economy, social systems, and technological change, as well as to expand outreach to science communities utilizing other languages. A systematic approach to identify science issues for the deliberations of the HLPF could be built on various input channels, including crowdsourcing combined with an expert review and vetting process based on clear criteria for selecting, filtering and prioritizing issues, as well as taking advantage of the diverse landscape of existing United Nations system mechanisms for identifying "emerging issues" in specific focus areas. 


\section{Introduction}

The present Report was prepared to inform the deliberations of Member States at the High-level Political Forum on sustainable development (HLPF) in July 2015, including with respect to the scope and methodology of a Global Sustainable Development Report (GSDR). ${ }^{6}$ It is a complement to the Prototype GSDR published in 2014 for the second session of the High-level Political Forum. ${ }^{7}$

The content of the report is based on the knowledge and expertise of more than 500 contributing scientists and many experts from more than 20 United Nations agencies. The chapters are examples of different analytical approaches that future editions of the GSDR could take to informing discussions on sustainable development at the HLPF with the latest science. Conforming to the mandate given in Rio+20, the chapters do not seek to produce new knowledge but to reflect existing documentation and assessments and turn them into simple, coherent "digests" that can inform decision-making.

The collection of chapters in this year's report can also be seen as a template for annual reports, which in the future would constitute the building blocks for a GSDR produced every four years for the meetings of the HLPF under the auspices of the United Nations General Assembly.

The Report is built around two structuring dimensions: the science-policy interface - and the various ways in which it could be strengthened - and the post-2015 development agenda, in particular the Sustainable Development Goals (SDGs). To this end, the Report outlines ways in which existing knowledge produced both inside and outside the UN system can be assembled to provide policy relevant data, analysis and information and support an enhanced dialogue between science and policy.

Integration is the thread that ties together the chapters covering aspects of the SDGs. Thus the Report contains a global, integrated perspective on the SDGs, informed by science. Selected issues - oceans and disaster risk reduction - illustrate approaches to integration: the socalled "nexus" approach, which groups a cluster of interrelated issues, and the analysis of a cross-cutting issue relevant to multiple goals. The Report also highlights the challenges facing groups of countries in special situations to devise strategies and policies to put in place an effective science-policy interface to support implementation of the new agenda. Overall, the aim is to support an informed discussion on what science-based products, in years to come, would be most helpful to United Nations decisionmaking on the sustainable development agenda.

Chapter 1 and Chapter 2 each illustrate one of the structuring dimensions of the report and serve as an introduction to the other chapters. Chapter 1 examines what the HLPF could do to add value to the current landscape of the science-policy interface for sustainable development. The chapter takes as a point of departure the ideas expressed by UN Member States, UN organizations and others for the preparation of the 2014 UN SecretaryGeneral's report on "Options for the scope and methodology for a global sustainable development report". ${ }^{8}$ Taken together with views from scientists and development practitioners, these ideas suggest a range of ways for the HLPF to enable constructive interactions between science and policy-making at the United Nations. Chapter 2 provides an integrated perspective on the SDGs. It surveys the landscape of major global assessments in terms of their coverage of the SDGs and their interlinkages. It also emphasizes the need for understanding such interlinkages across a wide range of scales.

These two dimensions - a prominent role for science and an integrated approach to implementing the SDGs and the post-2015 development agenda - critically shape the policy space for sustainable development.

Chapter 3 examines the nexus of oceans, seas, marine resources and human well-being. Chapter 4 looks at the theme of disaster risk reduction (DRR) as a critical crosscutting dimension in the sustainable development agenda. Chapter 5 examines debates on promoting industrialization as a strategy for advancing inclusive economic development, and how the industrialization challenge and opportunities are being recast in light of challenges like widening inequalities, climate change and unsustainable patterns of consumption and production. Chapter 6 examines selected aspects of the science-policy interface in the context of countries in special situations: least developed countries (LDCs), landlocked developing countries (LLDCS) and small island developing States (SIDS). Chapter 7 explores existing ways that have been used by United Nations processes and other institutions to identify issues of relevance for the consideration of policy-makers, and presents results of another approach involving an open call for crowd-sourced science briefs. Chapter 8 provides a snapshot of innovative uses of data for improving the SPI for sustainable development in Africa. The main conclusions from the report are gathered in Chapter 9. 


\section{Chapter 1. The Science Policy Interface}

\subsection{Introduction: the science-policy interface for sustainable development}

More than 20 years ago, the United Nations Conference on Environment and Development (Earth Summit) led to the adoption of a broad sustainable development agenda in the form of Agenda 21, which included an entire chapter on science for sustainable development (chapter 35). Since then, there has been a significant increase of scientific research and publications on sustainable development and more scientific evidence presented to policy-makers on this topic ${ }^{9}$. Science has also become more integrated into policy efforts to promote sustainable development. ${ }^{10}$

The United Nations Conference on Sustainable Development (Rio+20 Conference) held in June 2012, recognized that while some progress had been made in the implementation of sustainable development since the Earth Summit in 1992, implementation was still a challenge for many countries. Reasons for this lack of implementation lie, inter alia, in insufficient progress and setbacks in the integration of the various dimensions of sustainable development (economic, social and environmental). The establishment of the United Nations high-level political forum on sustainable development (HLPF) was part of the response of the international community to this problem.

Among other functions, the HLPF was given the task to "strengthen the science-policy interface through review of documentation bringing together dispersed information and assessments, including in the form of a global sustainable development report, building on existing assessments" (The Future We Want, §85k). ${ }^{11}$ This mandate foresees a space for discussions on the science-policy interface in an intergovernmental UN forum dedicated to sustainable development. UN Member States will have to determine how to structure this discussion, including which topics and issues should be covered and in what format.

This chapter aims to inform this reflection by bringing together insights from the literature and practical knowledge and expertise of scientific communities, development practitioners and experts of the sciencepolicy interface. The chapter provides a menu of concrete roles and actions that the HLPF could consider in order to strengthen the science-policy interface for sustainable development.

\subsubsection{Science for sustainable development}

Last year's GSDR documented the emergence of sustainability science over recent decades. ${ }^{12}$ Sustainability science has been described as "a field of research dealing with the interactions between natural and social systems, and with how those interactions affect the challenge of sustainability". Sustainability science is primarily useinspired, as are agricultural and health sciences, with significant fundamental and applied knowledge components, and with commitment to moving such knowledge into societal action. Sustainability science is carried out in all parts of the world and brings together many scientific disciplines. ${ }^{13}$

An integrated understanding of sustainable development is one of the prerequisites of science for sustainable development. Such integration calls for interdisciplinary research, which entails integrating disciplines of the natural sciences and the social sciences, and bringing together people and ideas from those disciplines to jointly frame problems, devise methodological approaches and analyze data. ${ }^{14}$ Many sustainable development research questions also require integrating the humanities and the engineering sciences, with their very different methods and traditions. ${ }^{15}$

The currently accepted paradigm for sustainable development science is that it also requires involving nonscientists - what is called transdisciplinarity. Transdisciplinarity combines interdisciplinarity and participatory approaches and requires reaching out to various communities and considering non-scientific knowledge (e.g. from local and indigenous communities, user groups, the general public, non-governmental organizations) in the research process. ${ }^{16}$ Other necessary conditions for science for sustainable development have been defined, inter alia, by the Scientific Advisory Board of the Secretary-General of the United Nations and include the need to consider the social responsibility of science (e.g. being oriented towards societal goals and values), and to ensure ethically acceptable, sustainable and socially desirable innovation processes. ${ }^{17}$

\subsubsection{The science policy interface for sustainable development \\ Defining the science-policy interface}

The science-policy interface (also referred to as SPI) is a broad concept for which various definitions and typologies exist. SPIs cover a very wide range of structures, communication forums, situations and methods. ${ }^{18}$ For example, they can be formal structures, designed for a specific purpose (e.g. scientific advisory bodies of international conventions, intergovernmental panels, scientific advisory boards, chief science advisors, national 
academies of science) or informal (e.g. policy workshops aiming to bring together scientists and policy-makers for discussing research results or issues). They can be longterm and/or recurring (recurring global assessments such as the IPCC assessment reports) or one-off events (e.g. Millennium Ecosystem Assessment). Their common feature is the potential for exchange of information, joint knowledge production and learning.

Roles of the science-policy interface

SPI mechanisms are established for a variety of purposes and fulfill many different functions. Table 1-1 outlines functions or roles commonly attributed to them. In practice, the range of roles of SPIs is even broader than this table suggests. Examples are detailed in boxes throughout the chapter.

\section{Box 1-1. Defining the science-policy interface}

SPIs are the many ways in which scientists, policy-makers and others link up to communicate, exchange ideas, and jointly develop knowledge to enrich policy and decisionmaking processes and/or research. SPIs involve exchange of information and knowledge leading to learning, and ultimately influencing decisions and changing behavior i.e. doing something differently as a result of the learning. These changes may be made by policy-makers, local-level decision-makers, scientists, other stakeholders or citizens. As such SPIs can lead to many - sometimes surprising practical impacts.

Source: Young et al. (2013)

Table 1-1. Common roles attributed to SPIs

\begin{tabular}{|c|c|}
\hline $\begin{array}{l}\text { Scientific } \\
\text { warning and } \\
\text { awareness } \\
\text { raising }\end{array}$ & $\begin{array}{l}\text { In the absence of public concern, before an issue enters the policy cycle, scientific expertise can be used to } \\
\text { bring an issue to the attention of policy-makers. Scientific warnings can steer public attention to issues that } \\
\text { form threats to human well-being and that imply policy intervention. Many environmental and health } \\
\text { problems (e.g. climate change, malaria, HIV/AIDS) were brought to the forefront of political attention through } \\
\text { a process of awareness creation through scientific expertise. }\end{array}$ \\
\hline $\begin{array}{l}\text { Def } \\
\text { def } \\
\text { pro }\end{array}$ & $\begin{array}{l}\text { Sustainable development problems are usually "wicked problems", as opposed to well-defined scientific } \\
\text { questions. In this context, it is not only the "solution" that is important, but as importantly the problem } \\
\text { definition and the definition of goals, and the identification of the range of options and possible approaches } \\
\text { that should be considered to address it. In addition, a problem can be re-opened and redefined several times } \\
\text { during the policy cycle so as to take into account dimensions or issues not adequately considered up front. } \\
\text { Science and SPIs have a critical role to play in this regard. }\end{array}$ \\
\hline $\begin{array}{l}\text { Assessing } \\
\text { policy choices } \\
\text { or the impacts } \\
\text { of different } \\
\text { policy options }\end{array}$ & $\begin{array}{l}\text { When defining a policy problem, it is usual to be faced with various policy options. Various scientific tools or } \\
\text { approaches are available to support choice among options including, inter alia, integrated impact assessments } \\
\text { and scenario modelling. In addition, scientific expertise can play a role in validating or questioning existing } \\
\text { policy choices by critically documenting their beneficial or harmful effects, their comparative advantage or } \\
\text { disadvantages, and their capacity or failure to achieve their stated goals. SPI can also play the role of } \\
\text { identifying and assessing the potential and limits of collective action among parties participating in sustainable } \\
\text { development, for example in relation to multilateral agreements. }\end{array}$ \\
\hline $\begin{array}{l}\text { Inforn } \\
\text { judici } \\
\text { legal }\end{array}$ & $\begin{array}{l}\text { nd international levels. In addition, the judicial } \\
\text { complex issues of science and technology, and } \\
\text { nce is therefore to provide evidence on issues }\end{array}$ \\
\hline $\begin{array}{l}\text { Monitoring } \\
\text { and } \\
\text { implementati } \\
\mathrm{n}\end{array}$ & $\begin{array}{l}\text { Many policies cannot be properly implemented or do not yield the intended outcome unless they are } \\
\text { scientifically monitored on a regular basis. This type of scientific expertise usually involves creating routine } \\
\text { procedures and methodologies. Once methodologies are established, the task ceases posing a scientific } \\
\text { challenge and the process of monitoring often falls to other parts of society. However, especially if the policy } \\
\text { issue is still contested during implementation and if the success of the regulation depends on cooperation of } \\
\text { stakeholders with divergent interests, an independent scientific source may be crucial for a credible monitoring } \\
\text { process. }\end{array}$ \\
\hline
\end{tabular}

Source: Authors' elaboration, based on Cash et al. (2003), Engels (2005), Treyer et al. (2012), White et al. (2001). 


\section{Complex relationship between science and policy}

As highlighted by the variety of roles that SPIs can play, the relationship between science and policy is not linear, but is better seen as a circular or nexus relationship. Science has different roles to play at the different stages of the policy process, from issues identification, to agenda setting and identification of goals and objectives, to the identification of tools, to monitoring and evaluation and subsequent changes in policies. However, science is only one of the elements in the policy process, and various actors play different roles at different points in the cycle. ${ }^{19}$ For example, engaged individuals, civil society organizations and the media have often played a critical role in raising public awareness of important societal issues. ${ }^{20}$ In addition, the role that science plays in the policy process is likely to be defined by actors who use scientific knowledge to prove or promote a specific course of action. Thus, it might be better to define science as an instrument rather than an actor. ${ }^{21}$

Box 1-2. Possible roles of science through the policy cycle Problem formulation is often led by societal actors, who can draw on researchers to help make the formulation rigorous. Science usually can play a role in the identification of solution options. The choice of options for action is led by the societal players, but can draw on research to provide analyses of the consequence of different options. Implementation is mainly led societally, but there is plenty of opportunity for research to contribute. Monitoring can be led by the research side and operational side, with the feedback and learning a joint activity between scientists and other actors.

Source: Stafford-Smith, M., contribution to the GSDR 2015.

\section{Expert quotes (1)}

"Many objectives and tools of sustainable development face implementation challenges of political, economic or technical nature. There is often doubt among policymakers on the relevance of the solutions proposed by proponents of sustainable development, especially when it comes to transitioning from small-scale, local experience to generalizations in terms of public policy. This should be of direct concern to science-policy interfaces, if they intend to be relevant from the perspective of public policy. The sciencepolicy interface should be able to study the modalities of implementation of public policy, and the use of different instruments: regulatory, economic or societal, and their respective effectiveness. The mandate of science-policy interfaces should include the scientific review of public policies to identify success stories, failures, and possible adverse effects."
Box 1-3. Science-policy interface in the UN system: some examples

The science-policy interface is a feature of the daily work of many organizations in the UN system. Organizations such as UNESCO and UNEP have strong mandates to promote the science-policy interface, and do so in different ways. UNESCO's intergovernmental and international scientific programmes (International Hydrological Programme; Man and the Biosphere Programme; International Geosciences Programme; International Basic Sciences Programme; Management of Social Transformations Programme) bring together scientists and government representatives on a range of sustainability issues, including water, biodiversity and sustainable development, social transformations and others. Its Intergovernmental Oceanographic Commission provides the UN Member States with an essential mechanism for global co-operation in the study of the ocean. In addition, UNESCO also co-sponsors global assessments that identify policy responses in different areas and contributes to the global intergovernmental mechanisms to strengthen the science-policy interface, such as the Intergovernmental Platform on Biodiversity and Ecosystem Services (IPBES).

Apart from various thematic assessments, UNEP uses the Year Book series and the Global Environmental Outlook series as the two main vehicles to address the sciencepolicy interface. Over the past 15 years, the GEO reports and their consultative and collaborative processes, have worked to bridge the gap between science and policy by turning available scientific knowledge into information relevant for decision makers. GEO uses the DPSIR framework to identify and evaluate the complex and multidimensional cause-and-effect relationships between society and the environment. The upcoming GEO-6, expected to be launched in mid-2017, will build upon regional assessment processes and create a comprehensive picture of the environmental factors contributing to human well-being, accompanied by an analysis of policies leading to greater attainment of global environmental objectives and goals.

Eleven years ago UNEP published the first edition of the UNEP Year Book series alerting the world to the development of dead zones in coastal waters resulting from excess nitrogen seeping into the water. In the intervening period many more emerging issues have been identified. The eleventh edition of the UNEP Year Book looks at ten issues flagged as emerging by previous reports over the past decade, including plastic waste in the ocean, the environmental impacts of excess nitrogen and marine aquaculture, air pollution's deadly toll, and the potential of citizen science. 
The Committee on the Peaceful Uses of Outer Space, the primary United Nations body dealing with space, has promoted the use of space-based data for development (for example, remote sensing data can provide information needed to monitor trends and changes in, as well as to formulate relevant public policies related to: climate change, sea level, ozone layer, glacier coverage, global health, impact of human activities on the environment, agriculture and food security, deforestation, droughts and floods, etc.). The Committee has pointed to the need for establishing sustainable national spatial data infrastructure; enhancing autonomous national capabilities in the area of space-derived geospatial data; engaging in or expanding international cooperation in the area of space-derived geospatial data and increasing awareness of existing initiatives and data sources; and supporting the United Nations in its efforts to access and use geospatial information in its mandated programmes.

As a specialized agency of the United Nations, IMO is the global standard-setting authority for the safety, security and environmental performance of international shipping. For parts of its scientific needs, IMO relies on the Joint Group of Experts on the Scientific Aspects of Marine Environmental Protection (GESAMP), an advisory body established in 1969 that advises the UN system on the scientific aspects of marine environmental protection. GESAMP is jointly sponsored by nine UN organizations with responsibilities relating to the marine environment (IAEA, IMO, FAO, UN, UNDP, UNESCO-IOC, UNEP, UNIDO, WMO), and they utilize GESAMP as a mechanism for coordination and collaboration among them. Through a well-established system of internal and external peer review, GESAMP ensures scientific credibility, transparency and independence of the advice it gives to the sponsoring organizations.

The Secretary-General's Scientific Advisory Board, created by the UN Secretary-General in September 2013 and convened by the Director-General of UNESCO, is an ad hoc group of 26 eminent scientists representing all regions and many scientific disciplines. The central function of the Board is to provide advice on science, technology and innovations (STI) for sustainable development to the UN Secretary-General and to executive heads of UN organizations.

Source: UNEP, UNESCO, IMO, OOSA, UNDP contributions to the GSDR 2015.

\section{Criteria for effectiveness of SPI mechanisms}

Commonly accepted criteria for assessing the effectiveness, influence and impact of science-policy interfaces are credibility, relevance and legitimacy. ${ }^{22}$ Other criteria mentioned in the literature have included accessibility (of scientific findings) and iteration and evolution over time: ${ }^{23}$ The literature on SPI also provides numerous analyses of "factors of success" for SPI and suggestions on how to strengthen the science-policy interface. ${ }^{24}$

\section{Box 1-4. Credibility, relevance and legitimacy: critical} determinants of the effectiveness of SPI

Credibility: refers to the perceived quality, validity and scientific adequacy of the information generated by the SPI such as the perceived scientific and technical soundness of an assessment. Credibility can be linked, for example, to the respect of the scientific method (hypotheses that are original and, where appropriate, predictive and testable; experiments repeated by colleagues in order to verify the results; presentation of uncertainties in results and in predictions presented; publication of results through a quality control mechanism such as a rigorous peer-review process).

Relevance (or salience): refers to the alignment of an assessment to the needs and priorities of decision-makers (e.g. its results need to be applicable and practical for decision-makers to make informed decisions). It is also linked to the perception of the usefulness of the knowledge, and how closely it relates to the needs of policy and society (e.g. do the assessment and its findings address the particular concerns of a user?). For example, an assessment can be considered relevant if users are aware of it and if it informs policy, behavioral change or other decisions.

Legitimacy: reflects the perception that the assessment or the production of information has been respectful of stakeholders' divergent values and beliefs, has been unbiased, and fair in its treatment of opposing views and interests. Issues of lack of legitimacy can arise, for instance, when one group questions the product or process of an assessment because it feels that its input was not considered, or when it is believed that data sources or modeling approaches used were dominated by experts from select backgrounds, disciplines or origin.

Source: Authors' elaboration, based on Cash et al. (2003); Young et al., (2013); Scientific Advisory Board of the Secretary-General of the United Nations (2014b); UNEP (2009b) 
Communication between scientists and policy-makers is one of the critical factors impacting the effectiveness of SPIs. Scientific information is more likely to be used if it is delivered in appropriate formats, at the right time and through the appropriate channels. SPI effectiveness is likely to suffer when communication is largely one-way, infrequent or occurs only at certain stages of the policy process. Gaps in effective communication have been identified in the literature: i) between knowledge holders inside science, across regions, scales, disciplines and assessments; ii) between science and traditional and practical knowledge holders; iii) between science and policy; and iv) between science and society. Improving communication and managing boundaries between scientists and decision-makers is therefore a critical issue. ${ }^{25}$ These gaps have to be assessed in the broader context of the interaction between science and the political process, as decisions by policy-makers on whether and when to use scientific knowledge may often be based on strategic calculations, based on their specific priorities and interests.

\subsection{Possible roles of the HLPF for strengthening the science-policy interface: opinions from scientists and development experts}

Decades of practice have resulted in a rich body of knowledge on the science-policy interface, going from the analysis of the roles it plays at various levels in society, to the way it impacts decision-making, to the design of effective science-policy interface mechanisms. The range of challenges that have been identified is vast, and concerns a range of actors operating across all geographical levels. Among the important issues identified in the literature, not all are equally relevant to intergovernmental discussions on sustainable development.

The GSDR team undertook a review of the literature on science-policy interface at the international level. The review considered academic articles and policy-oriented documents, in particular extensive reviews produced by UNEP $^{26}$ and background papers prepared for the first meeting of the UN Secretary-General's Scientific Advisory Board. ${ }^{27}$ Fifteen broad issues were highlighted as challenges for the science-policy interface in this field. The selection of issues was made based on the potential relevance of the HLPF to address them. ${ }^{28}$ The GSDR team also considered ideas that had been expressed by UN Member States, UN organizations and other stakeholders for the preparation of the UN Secretary-General's report on "Options for the scope and methodology for a global sustainable development report" in 2014. ${ }^{29}$ The submissions received for that report included a number of suggestions on how the global sustainable development report could support policy discussion at the high-level political forum in the future. ${ }^{30}$ The main themes that ran across the suggestions made were: the need to allow for a wide range of participation and feature a wide range of perspectives; capturing past and future trends; addressing interlinkages, synergies and trade-offs among sustainable development areas; examining emerging issues; presenting good practices in terms of integrated policies. Many of these themes suggest concrete ways in which the HLPF could contribute to strengthening the science-policy interface. $^{31}$

Based on this review, an initial list of 20 ideas regarding concrete ways for the HLPF to strengthen the science-policy interface for development was constituted. A questionnaire was sent to a sample of scientists, development practitioners and experts of the science-policy interface, asking them to classify the ideas identified in the first stage in terms of importance in the context of the mandate of the HLPF. Experts were also asked to provide additional ideas and provide more qualitative views, briefs or other relevant material. ${ }^{32}$ Inputs were received from 19 individual experts representing a broad range of professional backgrounds and expertise and several UN agencies. The GSDR team, in collaboration with the International Council for Science (ICSU), also requested inputs from national level scientists and science advisors, based on a short questionnaire addressing various aspects of the linkages between the international and national levels of sciencepolicy interface for sustainable development. ${ }^{33}$ Inputs were received from 15 national level advisors. Insights from such a small sample are not necessarily representative of the views of all science or development practitioners' communities. Rather, they provide a range of concrete suggestions for the HLPF going forward, while also shedding light on the diversity of views that exists.

\section{Expert quotes (2)}

"There is a lot of work going on, however, it is not coherent or systematic and there is no guidance or distillation process to make sense of it or to form the direction of priority."

"The focus ought to be not just advice from the UN but also looking at what the global community (UN) has a comparative advantage in offering. I believe it is, first and foremost, two things: 1. the identification and inclusion of broader perspectives so as to avoid the sustainability discussion getting clogged in solely "northern" points of view; and 2. the ability to generate and sustain a consistent level of interface between international science and "local" national needs and policy. The latter is an oft-lost opportunity, even though it is in the mandate of many agencies."

In their contributions, experts brought forth important nuances and suggestions regarding possible roles for the 
HLPF to strengthen the science-policy interface. One expert summarized his vision for the role of the HLPF as to "provide scientific and empirical evidence to help international and national policy makers and donors formulate policies and strategies for achieving sustainable development."

Possible roles that the HLPF could play in strengthening the science-policy interface can be clustered into three clusters that span the space between science and policy. A first group of actions relates to the provision of policy-relevant data, analysis and information. A second cluster relates to actions that the HLPF could take to support enhanced dialogue between science and policy. A third cluster of roles relates to the translation of the science-policy dialogue into policy. Figure 1-1 shows the various actions in the three clusters. All the ideas included in Figure 1-1 were ranked as important by the majority of experts who contributed to the chapter.

Figure 1-1. Possible roles for the HLPF for strengthening the science-policy interface: opinions of experts who contributed to the GSDR

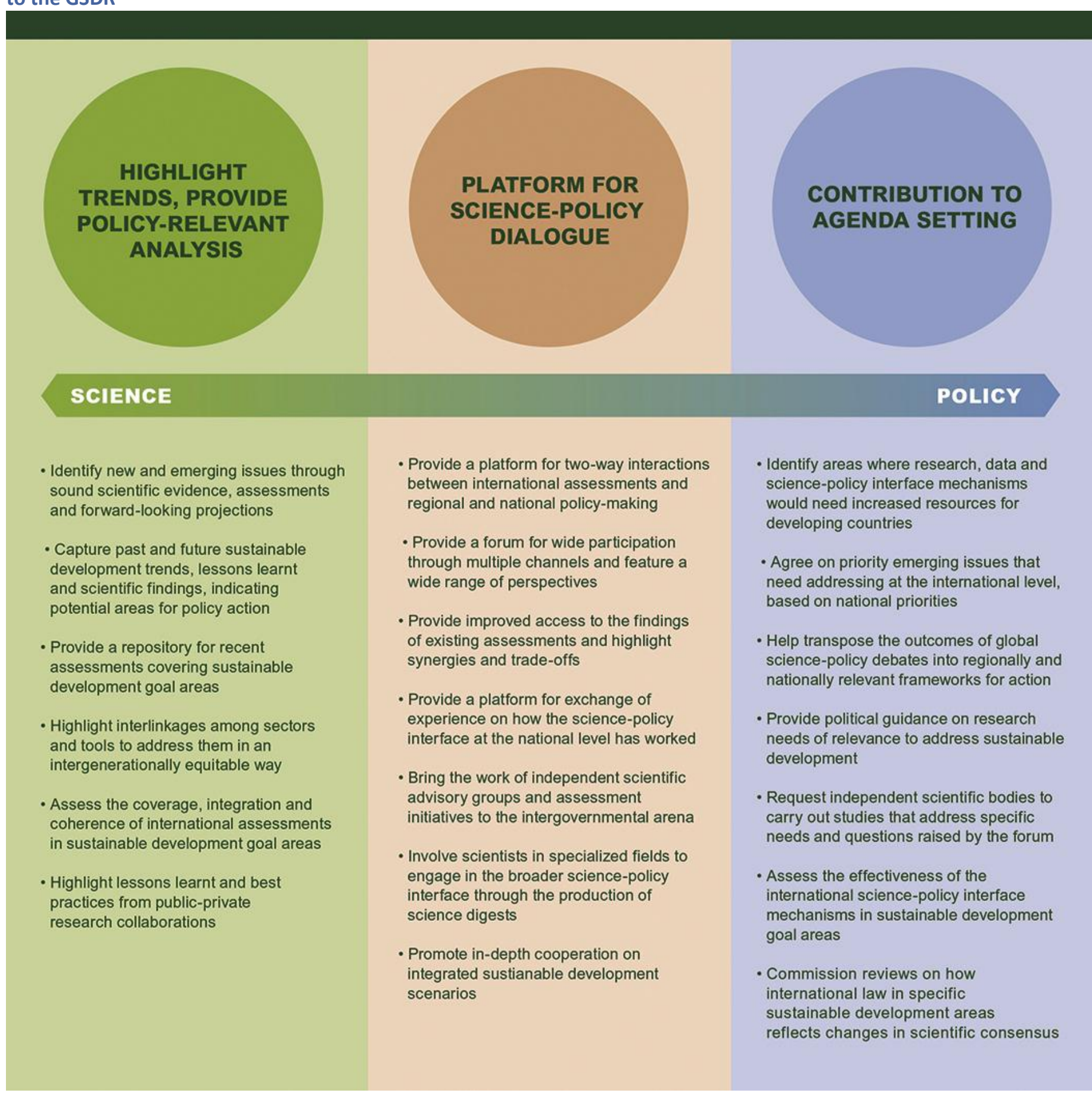


1.2.1. Highlighting trends and providing policyrelevant analysis

Possible roles for the HLPF in this category are directly linked to the HLPF mandates on monitoring the implementation of the sustainable development agenda. Experts pointed out that a key to the role of the HLPF is the capability to assess the significance of progress globally, i.e. the synthesis and interpretation across all goals and targets towards the overall outcome of global sustainability and human development. For many of the roles identified below, the Global Sustainable Development Report could play a key role in making information available to the HLPF.

Capture past and future sustainable development trends, lessons learnt and scientific findings, indicating potential areas for policy action. This function was included in the mandate of the UN Commission on Sustainable Development from its inception, and the high priority that experts grant it is a reflection of its continued relevance. It was also emphasized in the inputs from UN Member States on options for the scope and methodology of the GSDR. The GSDR is expected to feature scientific findings indicating potential areas for policy action in order to enable evidence-based decision-making within the highlevel political forum. Many also suggested reporting on trends and experiences at the national and local levels, based on countries' own national sustainable development reports.

Highlight interlinkages among sectors and tools to address them in an intergenerationally equitable way. Policy research in various clusters of issues has highlighted the need for integrated policies that consider interdependencies among sectors. In their inputs to the UN Secretary-General's report on options for the scope and methodology of the GSDR, Member States emphasized that the GSDR should indicate how interlinkages can be addressed and what the leverage points and gaps are for implementation. They suggested that the analytical focus should be on the interaction among economic, social and environmental dimensions, on key drivers of change, and on clusters of closely interlinked issues. This might include, in particular, a cross-sectoral analysis of progress made, obstacles encountered and potential integrated policy options. Many would like the report to present good practices of integrated policies. The GSDR 2014 documented interlinkages among sustainable development issues, both across the range of sustainable development themes and for the climate, land, energy, water and development nexus. ${ }^{34}$ Chapter 3 reviews the status of scientific knowledge on the interlinkages in the oceans, seas, marine resources and human well-being nexus. Similar approaches could be taken by future editions of the
GSDR, focusing on new clusters that are relevant to the agenda of the forum.

Expert quotes (3)

"Highlighting interlinkages among sectors and tools to address them needs to be done in a nuanced manner. I suggest adding 'disciplines' to 'sectors' and 'tools'. Risk analysis in financial modelling is quite different from CGE modelling (and theory), yet we merrily mix the two. We have no alternative, but little effort seems to be made to really understand the consistency of the information that we use to motivate decisions."

Provide improved access to the findings of existing assessments and highlight synergies and trade-offs. The review of sustainable development progress undertaken in the GSDR 2014 provided evidence that in recent decades, impressive gains in some areas have come at the expense of worsening trends in others. A synthesis report such as the GSDR is expected to add value and provide improved access to the findings of a large number of existing assessments and to highlight synergies and trade-offs between actions taken in various settings. ${ }^{35}$ In addition, as already suggested by the GSDR 2014, the Global Sustainable Development Report might help decisionmaking by bringing together sectoral outlooks in a coherent way and highlighting issues where interactions should be taken into account (see Chapter 2).

Identify new and emerging issues through sound scientific evidence, assessments and forward-looking projections. The importance of this role was highlighted by UN Member States in their inputs on the scope and methodology of the GSDR. The identification of emerging issues is one of the functions of the HLPF and was one of the functions of its predecessor, the Commission on Sustainable Development. Over the years, discussions at the Commissions played an important role in transferring some of the emerging issues identified in the review process to the political process, in areas such as forests, oceans, energy, hazardous chemicals and persistent organic pollutants. ${ }^{36}$ Finding adequate ways to identify emerging issues over the whole spectrum of sustainable development areas (including social and economic areas) and bring them to the attention of the political process is therefore important. Chapter 7 of the GSDR 2014 and Chapter 7 of this report are devoted to emerging issues and include practical suggestions in this regard.

Provide a repository for recent assessments covering sustainable development goal areas. As documented by the GSDR 2014, there are hundreds of assessments covering the thematic areas relevant to sustainable development. Based on the work done for this report (see 
Chapter 2), it appears that there is no publicly available database of assessments and flagship reports covering the 17 SDG areas and documenting, even succinctly, the content of the assessments. In some cases, work carried out by UNEP, IPBES, IPCC, as well as in the preparation of the World Oceans Assessments has produced extensive or quasi-exhaustive lists of reports. But the equivalent does not seem to exist in a readily available form for all of the SDG areas. A database of assessments, covering the 17 SDGs and listing landmark assessments and reports and the most recent flagship publications of international organizations, could therefore be useful for the purpose of informing the deliberations of intergovernmental processes, including the HLPF. Such a tool would also provide an entry point for practitioners working in different areas of sustainable development. Experts who contributed to the report mentioned the importance of considering relevant reports coming from outside the UN system and major international assessment efforts and produced by non-governmental organizations, think tanks, academia, global research programmes and the private sector. ${ }^{37}$

Assess the coverage, integration and coherence of international assessments in sustainable development goal areas. With the adoption of a new development agenda covering a much broader range of issues, it becomes important to consider how existing assessments cover the various areas as well as the interlinkages among them. In particular, it is important to identify key interactions among areas that are insufficiently addressed by the sum of existing assessments. Chapter 2 of this report addresses these issues in more detail. Experts who contributed to this chapter saw this as an important issue for research over the coming years, hopefully informing the follow-up of the SDGs. ${ }^{38}$ Going down to the policy level, all of the SDG areas are covered by a large number of international reports and assessments, many of which do not have this specific area as main focus. For example, the Millennium Ecosystem Assessment produced a synthesis report on health and ecosystems. ${ }^{39}$ As underscored in the GSDR 2014, reports produced by different scientific and expert communities tend to adopt different assumptions and perspectives. For the purpose of strengthening the science-policy interface, when looking at an SDG area, it would be important to examine the main conclusions and policy recommendations of the reports that cover that area, identify commonalities and differences in recommendations, and present in simple ways the main reasons for the differences - from availability of base data to interpretation of the data and trends to modelling assumptions to emphasis on alternative strategic options. Unfortunately, this is not frequently done. ${ }^{40}$ This is something that future editions of the GSDR could aim to feature, focusing on topics that are on the agenda of the HLPF. ${ }^{41}$

Highlight lessons learnt and best practices from publicprivate research collaborations. Lack of integration of the private sector into knowledge systems, both as user and source of relevant knowledge, has been identified as a recurrent issue. A substantial part of research and development in areas that are directly relevant to the SDGs (e.g. agriculture, energy) is undertaken by the private sector. Yet private research efforts are not always factored in public strategies for science and the science-policy interface. In order to avoid divergent outcomes, it is important to achieve a certain level of coordination in the direction of research in the public and private sectors. This has to be done in a context where the freedom of scientific research is a central policy tenet in many countries, even though research is regulated. ${ }^{42}$ The HLPF could help feature national experiences and practices in this regard, in relation to specific sectors and cluster of issues debated at the forum each year. ${ }^{43}$

Box 1-5. An example of the science-policy interface in a private sector context: Finding appropriate metrics for voluntary sustainability standards for agriculture

In agriculture, Voluntary Sustainability Standards (VSS) have emerged and they offer an explicit articulation of specific objectives - such as production practices, environmental benefits, or labor conditions - for farmers and value chains as well as the mechanisms to certify or audit those. As the only codified and readily verifiable market mechanisms that ensure and communicate key aspects of sustainability, VSS serve consumer needs and simultaneously support the role of the state by providing a valuable public good. However, the research literature is clear that the lack of comparability and narrow research designs makes it very difficult to determine the usefulness or the effectiveness of the VSS and their certification or verification systems. As these VSS approaches have grown in size and influence, the extent to which they actually fulfil sustainability objectives, and at what cost, needs to be understood better. Answering this question requires reliable and comparable metrics.

Already a number of efforts are under way. Common indicators, capable local institutions, and performance monitoring already exist, along with emerging best practices. The Sustainable Food Lab, an organization with more than 80 members that include leading companies, is collaborating on these approaches with the Committee on Sustainability Assessment (COSA). ISEAL, the umbrella organization for leading VSS including Fairtrade 
International, Marine Stewardship Council, Rainforest Alliance, Forest Stewardship Council and the Sustainable Agriculture Network is also collaborating with COSA on a very similar set of indicators and methods and integrating other leaders including MIT's J-PAL and 3le. Leading development agencies and donors are piloting programs that incorporate indicators and approaches fostered by the COSA Consortium. They have also been adopted by prominent producer organizations such as the National Federation of Coffee Growers of Colombia with more than 500,000 members. As more organizations take on such common approaches and help to improve and evolve them, more institutions are being trained to work with them in developing countries. The collective impact could be considerable, especially as both public agencies and companies with extensive global supply chains adopt such methods.

Source: D. Giovannucci and F. von Kirchbach, 2015, How New Metrics for Sustainable Agriculture Can Align the roles of government and business, Brief submitted for the GSDR 2015

\subsubsection{Providing a platform for science-policy dialogue}

Roles and actions identified in this cluster are directly linked to usual roles of science-policy interfaces, using the setting of the HLPF as a forum where international policymakers meet with scientific communities and development experts.

\section{Provide improved access to the findings of existing} assessments and highlight synergies and trade-offs. This is a direct extension of roles related to assessments described above. What seems to be a most pressing issue is the need for translation of the findings of international assessments into usable, policy-relevant material, at both international and national levels. Many contributors to this chapter, from developed and developing countries alike, mentioned the fact that, due to their complexity, assessments are not effectively used by policy makers. ${ }^{44}$ Material produced for the GSDR could be useful in this regard and could be disseminated at the HLPF, for example, thematic briefs highlighting the main messages from assessments covering specific clusters of issues.

\section{Provide a forum for wide participation through multiple} channels and feature a wide range of perspectives. While there is a growing awareness regarding the need to draw more systematically on a broad range of knowledge types (e.g. across sectors and disciplines, across scales, nonformal knowledge), their effective incorporation in SPI processes is still a challenge. In particular, incorporation of social science approaches in international assessment processes has often been identified as insufficient.
Consideration of a broader range of knowledge and in particular indigenous knowledge is critical to the credibility and legitimacy of science-policy interface mechanisms. ${ }^{45}$ The HLPF can provide a forum for broad participation, in which communities that do not usually have access to science-policy debates in the UN can have a voice.

\section{Box 1-6. Efforts to further integrate social sciences in the science-policy interface for sustainable development}

Efforts to bring together the natural sciences and the sciences of man and society started more than 40 years ago. An early example was the Man and the Biosphere Programme of UNESCO, established in 1971 to promote interdisciplinary approaches to management, research and education in ecosystem conservation and sustainable use of natural resources. Yet, it is widely recognized that these efforts have not fully succeeded. Only economic science has been able to gradually percolate into the assessments (IPCC, IPBES, World Oceans Assessments), but social sciences remain relatively absent. Yet, to the extent that sustainable development policy primarily seeks to change attitudes and behaviours, further integration of natural and social sciences is necessary in order to make the sciencepolicy interface fully relevant.

Many international research programmes currently promote integration of scientific disciplines from natural to social sciences, engineering and humanities and encourage research co-design in partnership with various stakeholders to address complex sustainability challenges. They include: Future Earth (http://www.futureearth.org/); ICSU's Programme on Ecosystem Change and Society (PECS) (http://www.icsu.org/what-we-do/interdisciplinarybodies/pecs/pdf/pecs-summary.pdf); the International Human Dimensions Programme on Global Environmental Change (IHDP, http://www.ihdp.unu.edu/pages/?p=about); the Integrated Research on Disaster Risk (IRDR, http://www.irdrinternational.org//); and others that address issues of relevance to both science and society such as climate change, oceans, urban health and well-being.

Source: Chabason, L., and ICSU, contributions to the GSDR 2015.

Bring the work of independent scientific advisory groups and assessment initiatives to the intergovernmental arena. As described above, many assessments and other scientific initiatives exist, both inside and outside the UN, and the forum could help bring their work to the policy arena. ${ }^{46}$ Getting away from a model where some actors have privileged access to policy circles, the Forum could be 
used to feature the work of these groups in a collaborative setting, in order to allow for comparisons and gap analysis.

Involve scientists in specialized fields to engage in the broader science-policy interface through the production of science digests. Selected science digests might be a useful way to involve scientists in highly specialized fields to engage in the broader science-policy interface in the context of the high-level political forum. ${ }^{47}$ This is one of the ways by which the science-policy debate at the forum can reflect a wider than usual range of views and perspectives. There is great interest from scientific communities worldwide for such an opportunity, as demonstrated by the large number of submissions to the GSDR 2015 in response to a public call for briefs. ${ }^{48}$

\section{Provide a platform for two-way interactions between} international assessments and regional and national policy-making. The scale at which scientific information is produced and the scale at which governance operates do not necessarily match the scale of concrete issues for which scientific knowledge is needed. For example, there are differences among regional and sub-regional priorities for sustainable development, and those do not necessarily reflect global priorities as addressed in international assessments. SPIs need to take into account these differences as well as the inter-linkages between the different levels of decisions (from international to national). ${ }^{49}$

\section{Expert quotes (4)}

"It would be good to consider reports produced on geographic areas that share common problems, interests or characteristics but belong to different UN regions, as these have something to contribute to the sharing of strategies and policy experiences. For example, countries of the Mediterranean basin succeeded in delivering the Mediterranean Strategy for Sustainable Development and they do produce important reports within the framework of the Barcelona Convention".

Effective links between SPI processes at the international and national levels are critical to the implementation of sustainable development, which to a significant degree is national and local in nature. In particular, in order to assess the effectiveness and relevance of the SPI at the international level, it is important to assess the extent to which the national and international levels of SPI communicate, in both directions. Such links vary widely across countries, due to a range of factors that include differing levels of development, varying importance given to science in national contexts, differing institutional structures to enable communication between science and policy, and others. Some issues have long been identified in the literature on science-policy interface, for example the need for improved communication and "translation" of the findings of international assessments, the critical importance of buy-in by politicians, and the unequal relevance of international assessment processes and findings to national realities.

International assessments can be important and useful in advising policy makers at the national level, in particular to increase the scientific awareness of those in leadership positions and to inform civil society on science topics of national importance; to provide international comparisons for national benchmarking; and to provide evidence-based information and scientific data that may not be available at the national level. However, the different assessments do not always have discernible impact on the elaboration of national policies. While there is a great variety of mechanisms and institutions at the national level which should allow international assessment to inform national and regional science priorities, ${ }^{50}$ in practice there is often low awareness of international assessment reports among policy makers and a lack of formal feedback processes for their dissemination. Conversely, national priorities should inform scientific research; however, the degree to which international assessments reflect national priorities for sustainable development seems to be highly variable across countries and across policy areas within countries. ${ }^{51}$

The HLPF could facilitate dialogue between international assessment processes, organizations specialized in sciencepolicy interface and national-level policy makers, with a view to relaying the needs of national decision-makers with respect to international assessments and reducing the gap between the existence of formal structures and the reality of communication between science and policy. ${ }^{52}$ Focusing on the UN system, the HLPF could provide a space for very high level interaction between elected officials and leaders of international organizations to address these issues.

Provide a platform for exchange of experience on how the science-policy interface at the national level has worked. In many countries, in particular developing countries, there are weak connections between science and policy and interfaces between science and policy are often perceived as marginal activities that are not prioritised for resources and time. Experts who contributed to this chapter mentioned a frequent lack of specific administrative mechanisms that would allow experts to inform national policy processes. The real impact of existing institutions and mechanisms on policy making is often unclear and unassessed. More broadly, in some countries there is lack of trust among academia, governments and the private sector, making the interaction quite complex. ${ }^{53}$ In many countries, capacity for undertaking scientific assessments is 
limited. There is a relative dearth of research that systematically examines the SPI in developing countries, and that provides recommendations for strengthening linkages between scientific processes and the policy process. $^{54}$ Strengthening capacity for building effective science-policy interfaces for sustainable development is a recognized need in many developing countries. ${ }^{55}$

The HLPF could provide a platform for discussion on national experiences with the science-policy interface, in relation to clusters of issues on its agenda, featuring existing initiatives in this area. ${ }^{56}$ Experts who contributed to the report pointed to the important role that National Councils for Sustainable Developments (NSDCs), in addition to playing a role in coordinating implementation of sustainable development at the national level, can play in facilitating dialogue between science and policy in an integrated, cross-sectoral way. ${ }^{57}$

\section{Expert quotes (5)}

"Inclusive discussions (scientists and policy makers) are important, but do not necessarily always reach intended goals, as both circles speak different languages. In order to support such necessary discussions to take place, my comments here are for academia and science: train a new generation of professionals with the skills needed to manage interactions between scientific experts and those with other kinds of specialized knowledge; revise current reward systems; promote effective science communication; deploy tools for managing and planning resources and risk management strategies; build institutional capacity required to implement collective decision making and reaching out to scientific circles; develop local capacity for R\&D in sustainability; consider nonstationarity in policy decisions; consider back casting and road mapping as opposed to projecting/forecasting."

Promote in-depth cooperation on integrated sustainable development scenarios. Scenarios have long been recognized as one of the tools that can inform choices on future pathways, at various geographical levels. Going forward, they can contribute to the important task of developing ways of looking more comprehensively at interactions across the whole set of SDGs (see Chapter 2). Efforts to synthesize key messages and lessons learned from sustainable development scenarios have long been seen as important, and the prototype GSDR included a chapter on this. ${ }^{58}$ The HLPF could help further efforts to promote in-depth cooperation on sustainable development scenarios, for example by providing space for meetings of scenario modelling communities with policy-makers, a platform for an exchange of best practices and lessons learned, or a forum for the development of new scenarios.
1.2.3. Contributing to the agenda-setting functions of the Forum

Possible roles for the HLPF in this category are directly linked to roles described in the other two clusters; they aim at translating the result of assessment work and sciencepolicy dialogue into agenda-setting in an intergovernmental context.

Help transpose the outcomes of global science-policy debates into regionally and nationally relevant frameworks for action. A critical aspect of the HLPF's work going forward will be to improve the links between global, regional and national policy processes for sustainable development. This was a weakness of the Commission on Sustainable Development, which was never satisfactorily addressed. ${ }^{59}$ The importance given by experts to this role echoes its prominence in the submissions of Member States regarding the scope and methodology of the GSDR. Priorities and needs differ across countries and across groups of countries, and this has a bearing on how international science-policy debates can be transposed into national and regional policy frameworks. The reverse relationship was also underscored by experts contributing to this chapter who noted "the importance for global assessments and dialogues to be informed by the sum of national frameworks". The HLPF could contribute to capacity building in this regard, including by highlighting the needs and gaps in terms of science-policy interface tools (assessments, scenarios, national reports, and others) in groups of countries in special situations. Chapter 6 in this report offers an initial example of efforts in this direction. ${ }^{60}$

Provide political guidance on research needs of relevance to address sustainable development problems. Insufficient feedbacks exist between policy needs and scientific research, especially in relation to research funding. A common challenge encountered in SPIs is the difficulty to influence the research agenda so as to better meet specific policy needs. Science agendas are to a considerable extent shaped by funding agencies. In some cases, current priorities for research funding may not be those that contribute most directly to helping decision-making. ${ }^{61}$ By conveying the priorities for sustainable development put forward by the political process to the science community in a clear fashion, the HLPF could suggest areas where additional research is needed to address sustainable development challenges, thus helping the international community to build a strategic vision of research needs and inform capacity-building efforts. ${ }^{62}$

Identify areas where research, data and science-policy interface mechanisms would need increased resources for developing countries. Scientists in developing countries rarely have the possibility to participate in decisions about 
global science agendas. In addition, bilateral donors and institutions often exert a strong influence on policy choices of developing countries, including those regarding science, technology and innovation systems. ${ }^{63}$ Assessments of existing documentation and tools (assessments, scenarios, national reports, and others) on sustainable development thematic areas undertaken for the HLPF could inform initiatives in other fora to support developing countries to develop science and science-policy interfaces for sustainable development. ${ }^{64}$ They could also inform international development agencies and donors about capacity needs for scientific research in developing countries.

\section{Box 1-7. Science diplomacy: A useful tool}

Science diplomacy is the use of scientific collaborations among nations to address common problems and to build constructive international partnerships. Science diplomacy has become an umbrella term to describe a number of formal or informal technical, research-based, academic or engineering exchanges. In January 2010, the Royal Society and the American. Association for the Advancement of. Science (AAAS) noted that "science diplomacy" refers to three main types of activities: informing foreign policy objectives with scientific advice (science in diplomacy); facilitating international science cooperation (diplomacy for science); using science cooperation to improve international relations between countries (science for diplomacy) As an example of the second type of science diplomacy, the Swiss federal government has created eighteen science counselors and six swissnex (a publicprivate partnership to promote cooperation in science, technology, and innovation) and thus created an extensive Swiss science diplomacy network consisting of representation offices in Boston, San Francisco, Singapore, Shanghai, Bangalore and Rio de Janeiro.

Science diplomacy should be considered as a means to reduce global imbalances and as a vehicle to lift humanity up towards sustainable growth and development.

Source: Saner. R. (2015), Policy Brief submitted for the GSDR 2015.

Request independent scientific bodies to carry out studies that address specific needs and questions raised by the forum. In some cases, review of existing assessments and reports (for example, as undertaken by UN agencies and for the GSDR) may reveal gaps, or the lack of clear syntheses aimed at informing decision-makers at the international level. In order to discharge its agenda-setting functions, the HLPF may need to encourage or request appropriate organizations to prepare such reports and syntheses. Regarding this, an expert noted that care needed to be taken in order not to accidently "herd research into a wrongly directed stampede", and called for a plurality of scientific advice to be maintained. Another noted that "studies may be available, and this might be more a matter of tailoring the existing assessments to cover the specific areas of the SDGs".

\section{Agree on priority emerging issues that need addressing at} the international level. Many experts saw the importance of going beyond mere identification of emerging issues, towards pointing out ways to address them. How this could be done should be further discussed. 0 in this report presents several existing models.

\section{Assess the effectiveness of the international science-policy} interface mechanisms in sustainable development goal areas. Assessing the effectiveness of international SPIs is important, as SPIs often mobilize large resources and are relied upon to advance the strategic connection between science and policy on sustainable development issues. ${ }^{65}$ While sustainable development problems require integrated responses, SPI mechanisms are often fragmented and working in isolation. This is partly due to the fragmentation of the international governance system, with multiple overlaps and poorly defined boundaries among institutions and mandates, and has the potential to lead to contradictory recommendations or actions. Many science-policy interfaces have modest budgets for the size of the task that they are expected to perform, potentially limiting their ability to ensure effectiveness in assessing knowledge comprehensively and ensuring the best scientific inputs into policy processes. ${ }^{66}$ The HLPF could be the place where a strategic view of the SPI for the whole sustainable development agenda is discussed by the international community, around such questions as: where are the needs? Are the existing bodies and assessment processes performing in a satisfactory way? How to efficiently combine science-policy interface mechanisms and assessments from different work streams?

Commission reviews on how international law in specific sustainable development areas reflects changes in scientific consensus. Scientific knowledge on issues relating to, inter alia, the management of natural resources and the risks posed by natural and socio-economic systems can evolve over time. In addition, the availability of new data can enable new ways of addressing sustainable development issues. Legal and regulatory frameworks and policies may be slow to adjust to such shifts and may keep reflecting superseded scientific paradigms for long periods, which can hinder efforts to achieve societal goals. Welldesigned science-policy interface mechanisms could help 
reduce the time lag between science and policy, even though the relationship between science and decisionmaking is too complex to allow for simple prescriptions in this regard ${ }^{67}$ (see Chapter 7 for an elaboration on this). The HLPF could commission reviews of how international legislation in areas relevant to its work reflects the current status of science in relation to sustainable development objectives.

\subsubsection{Additional ideas suggested by experts}

A number of suggestions put forward by scientists and experts concerned monitoring and evaluation of progress on sustainable development, reflecting the importance of these issues in the current debates on the SDGs and the post-2015 development agenda and that, for this, a set of metrics and scientifically sound and practically applicable and reliable measurements should be elaborated.

Specific suggestions made by contributors included: ensuring the integration of "non-numeric" findings in the assessment of progress towards the SDGs in order to facilitate quality judgments on the achievements of sustainable development; providing a mechanism for greater coherence and compatibility of the various international processes (e.g. SDGs, climate agreement, Hyogo Framework 2) in terms of reporting and data requirements; holding regional forums on methods for establishing baseline conditions and indicators of vulnerability and impact assessments and for evaluating progress towards sustainable development goals; improving consistency of data collection related to sustainable development goals; developing an open access database of timely spatial data related to sustainability to help authorities and scientists in less developed countries monitor progress; and developing an open access platform where scientists can share data and research outcomes on sustainability.

\subsection{Conclusion}

This chapter, informed by the perspective of scientists, development practitioners and science advisers, explored ways in which the HLPF, following its mandate, could contribute to strengthening the science-policy interface. Even focusing only on issues relevant to sustainable development at the international level, the domain of interactions between science and decision-making is vast; and many shortcomings and avenues for improvements have been identified in the literature on the science-policy interface. Consequently, the forum could contribute in many possible ways.

Among ideas considered by experts, providing improved access to the findings of existing assessments, highlighting synergies and trade-offs and tools to address them, and helping transpose the outcomes of global science-policy debates into regionally and nationally relevant frameworks for action were the most consensual. These ideas reflect some of the core mandates of the HLPF and the fact that experts rank them as very important attests to a shared sense of priorities among scientists and policy-makers. Most of the experts who contributed to the GSDR also considered important that the HLPF could inform orientations for science, as well as conveying to the political debate the work of scientific advisory groups and assessment initiatives. Other important ideas revolve around the identification of sustainable development trends, the identification of and action on emerging issues, and improving the link between international assessments and national policy-making. Many of the practitioners who provided inputs for this chapter emphasized the importance of considering an array of actions, rather than a single action, recognizing potential synergies among them.

UN Member States will have to decide on the actions they wish the HLPF to implement in the future, and prioritize. Scientists suggested that priorities for the forum should be based on the capacity for the forum to assess the significance of progress globally, based on a synthesis and analysis across all goals and targets towards the overall outcome of achieving global sustainability and human development, as an ingredient of an adaptive learning process that informs governance of sustainable development. $^{68}$

This suggests that a criterion for prioritization could be how well specific actions and roles of the forum would support other mandates of the HLPF, and especially: providing political leadership, guidance and recommendations; enhancing integration of the three dimensions of sustainable development at all levels; following up and reviewing progress in the implementation of sustainable development commitments, including means of implementation; promoting the sharing of best practices and experiences and enhancing evidence-based decisionmaking; and contributing to strengthening ongoing capacity-building for data collection and analysis in developing countries.

Other possible criteria for prioritization of HLPF roles include the comparative advantage of the UN with respect to other communities, and the comparative advantage of the HLPF within the UN architecture. Possible roles could be classified into those where the HLPF would take the lead, as opposed to those where it may provide guidance to and promote collaboration among others processes and institutions. 
Lastly, expert answers received for this chapter suggest that the level of awareness of national level science experts on the HLPF and its functions relating to the science-policy interface is low. This might point to a lack of awareness of the mandate and nature of the HLPF, or to a perceived lack of relevance of the HLPF to national policy reality. If the forum is to provide meaningful links between agendasetting for sustainable development at the international level and national implementation processes including science-policy interface mechanisms, solutions should be found to fill this information gap.

\section{Box 1-8. Building integrated indicators: an example}

There are numerous inter-linkages and relationships between the various SDG goals and targets and across the environmental, social and economic domains. To arrive at a common understanding of what specific indicators are actually measuring requires a clear analysis of terms, roles, classes and processes as well as a clear description of data flows and statistics. An ontology attempts systematically to identify, in simple and precise terms, what the component entities in some domain of interest are and how they relate to one another. The design of integrated indicators based on causal linkages captured through the use of ontologies and the semantic web avoids the risk of extensive redundancy in data gathering and ensures that different data and statistics standards can be combined across varying time and spatial scales. Air quality, especially in cities, is important to the achievement of all 17 SDGs; and in particular to four SDGs (see the diagram below). The overarching SDG objective for air quality can best be achieved through up-to-date assessments of urban emissions, including the estimation of exposures in urban populations and vulnerable groups, and assessments of the shortand long-term health impacts. Existing direct and indirect indicators, plus a new design for a global indicator based on ontology for urban air quality health has been developed. The integrated indicator is based on new global data sources derived from satellites and sensor-web enablement to provide air pollution exposure maps for vulnerable groups in cities.

\section{Urban air quality health indicator}

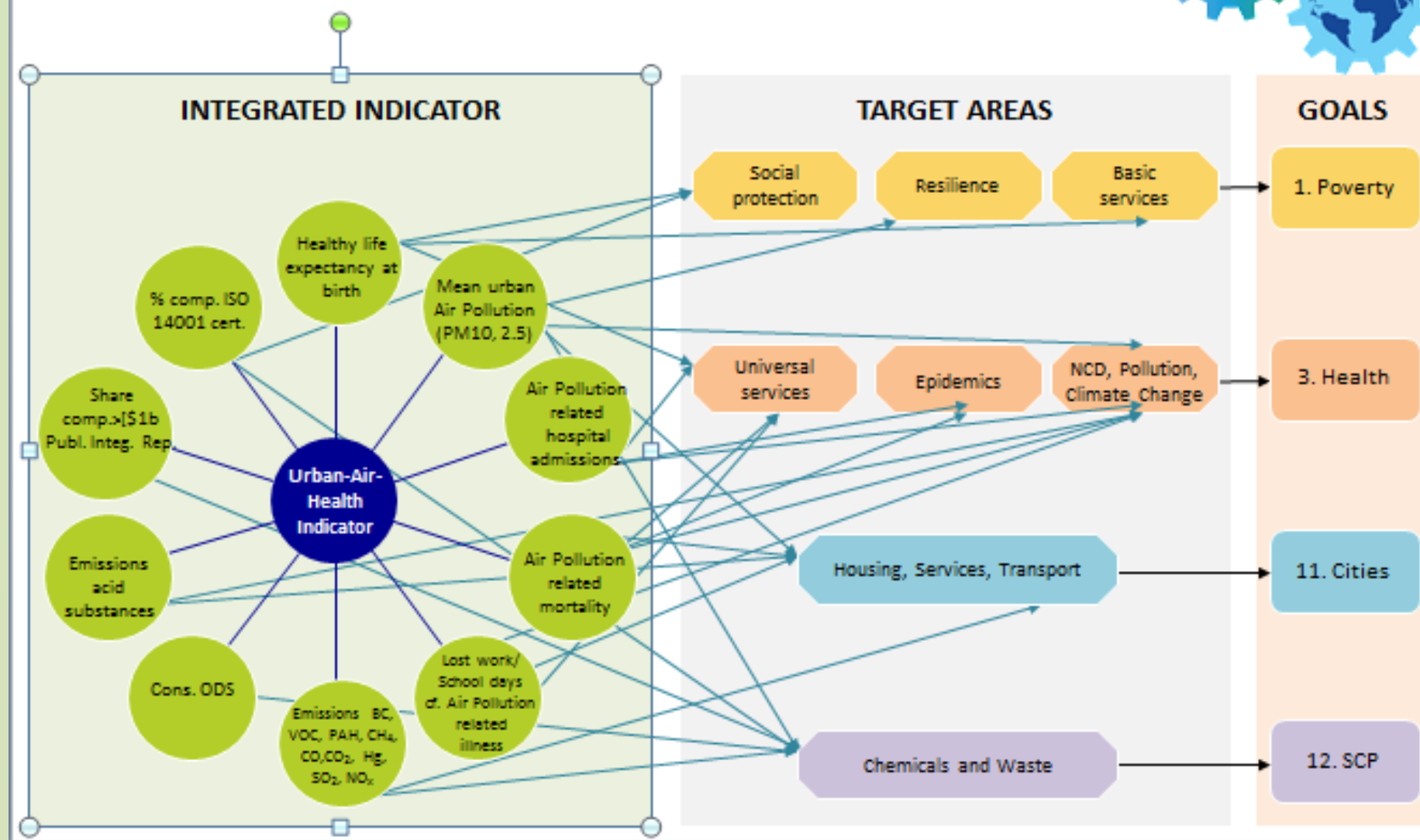

Source: UNEP, contribution to the GSDR 2015. 


\section{Chapter 2. Integrated Perspectives on the Sustainable Development Goals}

This chapter explores global, integrated perspectives on the Sustainable Development Goals (SDGs) viewed as a system as suggested by some scientists. It explores the SDG coverage of international assessments conducted within and beyond the UN system and the extent to which they apply integrated perspectives. In particular, the landscape of existing international assessment scenario models is briefly described, in terms of their ability to support an integrated analysis of progress and transition pathways toward achievement of the SDGs. This chapter complements and builds on the Prototype Global Sustainable Development Report 2014 which summarized various integrated concepts, progress measures, trends, and integrated future scenarios toward sustainable development. $^{69}$

The chapter distinguishes: (a) integration across the three dimensions of sustainable development for any substantive issue; (b) integration across substantive areas of what is to be developed or sustained; and/or (c) integration across a wide range of geographic and time scales.

2.1. The Sustainable Development Goals and integrated perspectives suggested by the scientific community

\subsubsection{UN recognition of inter-linkages and integrated approaches}

Since the creation of the United Nations, the world's peoples have aspired to making progress on the great global issues of peace and security, freedom, development, and environment. These issues remain prominent aspirations today. Political leaders and scientists alike have long acknowledged that these issues are closely inter-linked and require integrated approaches. ${ }^{70}$ High-level panels and commissions, major documents, and United Nations global conferences and summits have made a case for such integrated perspectives.

Already in 1972 at the UN Conference on Environment and Development, the "Stockholm Conference", Indira Gandhi emphasized the need for integrated action: "The population explosion; poverty; ignorance and disease, the pollution of our surroundings, the stockpiling of nuclear weapons and biological and chemical agents of destruction are all parts of a vicious circle. Each is important and urgent but dealing with them one by one would be wasted effort." Her insight remains as relevant today as then. Similarly, the Brundtland report ${ }^{71}$ of 1987 highlighted the need for an integrated approach to peace, development and environment, while the interlinkages with freedom had been highlighted in the earlier Palme and Brandt reports.

Such an integrated view was the basis for the agreement on Agenda $21^{72}$ and the 27 Rio Principles ${ }^{73}$ at the "Earth Summit" in 1992, which were reconfirmed at the UN Conference on Sustainable Development (known as "Rio+20") in Rio de Janeiro in 2012. ${ }^{74}$ The Rio+20 outcome document entitled "The future we want" did not only agree to devise Sustainable Development Goals, but has numerous references to integrated approaches.

\subsubsection{Sustainability science and integration}

The Prototype Global Sustainable Development Report 2014 described the evolution of the sustainable development debate from a primarily political concept to the emergence of "sustainability science" as a new interdisciplinary, unified scientific endeavour around the turn of the century, through to scientists becoming one of the most prominent groups at the side-events of Rio +20 in 2012. In 2014 alone, several tens of thousands of academics authored at least 165,000 academic papers that refer to sustainable development, according to Google scholar.

The Brundtland report has been hugely influential in defining "sustainable development" as development that meets the needs of the present without compromising the ability of future generations to meet their own needs. ${ }^{75}$ Underlying this definition is an integrated perspective - it refers to needs in general (all issues, all regions) and equity within and across generations.

Inspired by the Brundtland definition, scientists have shaped a wide range of views and definitions of sustainable development over the years. These definitions were reviewed and categorised by the US National Research Council in $1999^{76}$ and described further by Kates et al. in 2005. ${ }^{77}$ According to this review, scientists have emphasized different elements "to be developed" or "to be sustained". The review suggested six categories: people, economy, and society to be developed, and nature, life support and community to be sustained. Integrated perspectives have been used for various combinations of issues under these six areas, operating at a wide range of geographical and time scales.

Scientists' choices of "systems" have had great influence on the political debates, too. For example, the debate on the 
MDGs focused primarily on issues in the "people" cluster. The green economy debate aimed to combine developing the "economy" with preserving environmental "lifesupport" mechanisms. The "planetary boundaries" proponents suggested global targets related to the Earth's "life-support" and "nature" mechanisms. Proponents of "strong sustainability" emphasized the "nature" cluster, as they argue that nature cannot be substituted with other capital. It is important to note that each one of the six areas to be developed or sustained does exhibit social, economic and environmental aspects to varying degrees.

\subsubsection{Sustainable Development Goals (SDGs)}

In September 2014, the Open Working Group (OWG) on Sustainable Development Goals ${ }^{78}$ - a United Nations intergovernmental group - proposed 17 Sustainable Development Goals (SDGs) and 169 associated targets to be achieved by the year $2030 .^{79,80}$ The SDGs build upon the MDGs yet are more comprehensive and as broad in scope as the goals contained in Agenda 21. They are also intended as universal goals of political aspiration, applying to all countries, both developing and developed. Most of the associated with specific stakeholders and scientific communities. While no overarching sustainable development goal was included, many statements in the OWG emphasized the importance of integrated perspectives and approaches, and a number of proposals were made in the OWG with a view to integrating the three pillars of sustainable development within and across goals. As a result, issues such as the multiple functions of forests (particularly its water supply) received significant attention, consistent with the integrated approach to forests by the UN Forum on Forests.

Table 2-1 places the SDGs as proposed by the Open Working Group into the six areas captured by scientists in their definitions and usage of sustainable development. The SDGs capture major elements of the whole range of sustainable development issues. ${ }^{81}$ It should also be noted that scientists highlight additional action points that are not explicitly referred to in the SDGs. This is also evident from the scenario-based models used to assess pathways towards the SDGs (see Section 2.3)

SDGs focus on specific issues or themes which are

Table 2-1. The OWG Sustainable Development Goals allocated into six categories: people, economy, and society to be developed, and nature, life support and community to be sustained

\begin{tabular}{|c|c|}
\hline What is to be sustained? & What is to be developed? \\
\hline $\begin{array}{l}\text { Nature } \\
\text { Goal 13. Take urgent action to combat } \\
\text { climate change and its impacts. } \\
\text { Goal 14a. Conserve the oceans and marine } \\
\text { resources for sustainable development. } \\
\text { Goal 15a. Protect and restore terrestrial } \\
\text { ecosystems. } \\
\text { Goal 15d: Combat desertification. } \\
\text { Goal 15e. Halt and reverse land degradation } \\
\text { and halt biodiversity loss. }\end{array}$ & $\begin{array}{l}\text { People } \\
\text { Goal 1. End poverty in all its forms everywhere. } \\
\text { Goal 2: End hunger, achieve food security and improved nutrition, and promote sustainable } \\
\text { agriculture } \\
\text { Goal 3: Ensure healthy lives and promote well-being for all at all ages. } \\
\text { Goal 4: Ensure inclusive and equitable quality education and promote life-long learning } \\
\text { opportunities for all. } \\
\text { Goal 6. Ensure availability and sustainable management of water and sanitation for all. } \\
\text { Goal 7. Ensure access to affordable, reliable, sustainable, and modern energy for all. } \\
\text { Goal 16b. Provide access to justice for all. } \\
\text { Goal 8b. Promote decent work for all. }\end{array}$ \\
\hline $\begin{array}{l}\text { Life support } \\
\text { Goal 12. Ensure sustainable consumption } \\
\text { and production patterns. } \\
\text { Goal } 14 \text { b. Sustainably use the oceans and } \\
\text { marine resources for sustainable } \\
\text { development. } \\
\text { Goal 15b. Promote sustainable use of } \\
\text { terrestrial ecosystems. } \\
\text { Goal 15c. Sustainably manage forests. }\end{array}$ & $\begin{array}{l}\text { Economy } \\
\text { Goal 8a. Promote sustained, inclusive and sustainable economic growth, and full and productive } \\
\text { employment. } \\
\text { Goal 9. Build resilient infrastructure, promote inclusive and sustainable industrialization and } \\
\text { foster innovation. } \\
\text { Goal 10. Reduce inequality within and among countries. } \\
\text { Goal 11. Make cities and human settlements inclusive, safe, resilient and sustainable. } \\
\text { Goal 17a. Strengthen the means of implementation (finance; technology; capacity building; } \\
\text { systemic issues policy and institutional coherence; data, monitoring and accountability) }\end{array}$ \\
\hline $\begin{array}{l}\text { Community } \\
\text { Goal 16a. Promote peaceful ...societies }\end{array}$ & $\begin{array}{l}\text { Society } \\
\text { Goal 5. Achieve gender equality and empower all women and girls. } \\
\text { Goal 16a. Promote peaceful and inclusive societies for sustainable development. } \\
\text { Goal 16c. Build effective and accountable and inclusive institutions at all levels. } \\
\text { Goal 17b. Revitalize the global partnership for sustainable development. }\end{array}$ \\
\hline
\end{tabular}

Note: Adapted from NRC (1999) ${ }^{76}$; Kates et al. $(2005)^{82}$; and United Nations (2012) ${ }^{74}$. The listed issues are indicative of areas typically covered in sustainable development definitions. Source: Authors' compilation. 
2.1.4. Recommendations by the International Council for Science (ICSU) and the International Social Science Council (ISSC)

In early 2015, the two major non-governmental groups representing science at the UN - the International Council for Science (ICSU) and the International Social Science Council (ISSC) - presented a report entitled "Review of Targets for the Sustainable Development Goals - The Science Perspective". ${ }^{83}$

In addition to a review of the 169 SDG targets, the report also made a number of recommendations regarding the overall framework for the SDGs ${ }^{84}$ which also built on work by Future Earth ${ }^{85}$, the UNU-IAS Post-2015 project ${ }^{86}$, and the Independent Research Forum ${ }^{87}$. It noted that from a science perspective the SDGs offered "major improvements on the Millennium Development Goals..." and welcomed the universal framework and process that created a collective and shared commitment for SDG implementation. However, it also pointed out the absence of a systematic means-end separation, of scenario-based pathways towards the SDGs, and noted that "the level of integration is far lower than justified from a science perspective". While the SDGs are presented as 17 separate elements, "it is clear from systems science that goal areas overlap, that many targets might contribute to several goals, and that some goals may conflict.... It is possible that the framework as a whole might not be internally consistent - and as a result not be sustainable". Interestingly, the report highlighted the importance of what Sen called "key freedoms" ${ }^{88}$, including economic opportunities and political liberty. It was suggested to build on the values highlighted in the Millennium Declaration: "freedom, equality, solidarity, tolerance, respect for nature and shared responsibility".

In addition to specific suggestions on improved specification of the SDG targets and potential aggregation or "packaging" of goals, the ICSU/ISSC report made three recommendations which promote an integrated perspective on the SDGs. They are described next and could be carried out in partnership among scientific communities, the UN system and Member States, and could complement and support the SDG proposal of the Open Working Group.

\subsubsection{ISCU/ISSC recommendation to formulate an overarching goal}

Formulating an overarching goal can help communicating the SDGs to a wider public and tracking overall progress. The aforementioned ISCU/ISSC report provides an example of an overarching goal - "a prosperous, high quality life that is equitably shared and sustainable" 89 - and highlights the need for new integrated economic metrics of progress beyond GDP, beyond the Human Development Index and other established aggregate indices which were already reviewed in the Prototype Global Sustainable Development Report 2014. The latter also provided information on selected proposals by scientists that remain outside the official statistical systems. Aggregate measures, such as the Global Genuine Progress Indicator $(\mathrm{GPI})^{90}$, respond to Kuznets' request voiced already in 1934 that "Goals for more growth should specify more growth of what and for what." $^{\text {91 }}$

\subsubsection{ISCU/ISSC recommendation to develop interlinking targets that are common to different goals}

While acknowledging that the proposed OWG formulation of the SDGs reflects important political and institutional realities and thus creates ownership indispensable for their implementation, the ICSU/ISSC report also proposes a composite framework to link interdependent targets that span different goals ${ }^{92}$. For example, efficiency, pollution intensity and access targets can be linked to most goals (e.g., water and energy efficiency targets can be linked to food security goals, energy access to industrial development, carbon intensity to most goals, etc.). Some targets must be realized in order for another one to be viable, some targets impose constraints, some targets reinforce each other, and trade-offs may also occur. The Prototype Global Sustainable Development Report 2014 provided an overview of the inter-linkages between trends and sustainable development issues as they actually played out from $1950-2013^{93}$. It shows a complex picture where trade-offs and synergies also depend on trends in multiple areas and their direction can change over time. For example, economic growth can increase or decrease pollution loads depending on the type of growth and the presence of many other factors. The ICSU-ISSC report concludes: "Ultimately, there is a need to incorporate a wider systems perspective that can articulate how the goals and targets would interact over time, in both positive and negative ways, and how they would contribute to the overarching goal." ${ }^{84}$ Eventually, "integrated indicators" based on causal linkages could support monitoring progress against such interlinking targets (see Box 1-8) 


\subsubsection{ISCU/ISSC recommendation to formulate a compelling narrative of development}

The ICSU/ISSC report proposes the development of scenario-based stories (or "narratives") of alternative pathways toward the SDGs. These stories would explicitly link means to the goals and describe how the trade-offs will have been overcome and synergies built on. These stories are expected to support the public discussion of the type of future we actually want and how to get there. ${ }^{94}$ Scenariobased models could help assess the internal consistency and feasibility of the stories. The Prototype Global Sustainable Development Report 2014 already included elements of a global pathway toward the SDGs and compared them with a dynamics-as-usual future pathway. However, a much more in-depth and quantitative understanding will need to be developed from national to regional and global levels. Most actions will need to be taken at the national level and it is far from clear which types of national actions will add up to the achievement of global SDGs. In fact, policy actions in one country often have a bearing on other countries and sometimes limit their policy space. Hence, a regular conversation between decision-makers and scenario analysts would be useful. In this context, a UN SDG modellers forum could be considered either at or in conjunction with the High-level Political Forum for Sustainable Development. Such a forum could promote exchange of experiences among all interested SDG modellers and with decision-makers, from national to global scale. Such forum could also cooperatively map the status and dynamics of the overall system that underlies the Sustainable Development Goals.

\subsubsection{Complexity scientists' integrated view and global risks}

Complexity scientists can provide another integrated perspective on the SDGs. The world we live in is what scientists call a "complex system". Economic opportunities in one country are linked through the trading, investment, transport and communication systems to what goes on in other parts of the world. Many of the environmental issues are of regional (e.g., many types of air pollution) or even of global nature (e.g., climate change). Furthermore, many of the means at humanity's disposal to deal with the challenges have a strong global element, e.g., science, technology, innovation, finance, and education. And most human aspirations are shared by humanity across the globe. The responses from around the world to the online MyWorld survey ${ }^{95}$ suggest that what respondents value most are: a good education, better healthcare, better job opportunities, an honest and responsive government, and affordable and nutritious food.

It is an intrinsic feature of complex systems that sometimes small perturbations can lead to big impacts. And this can happen, even if all the information and skills are available. Systems consisting of networks of networks can appear very stable and then collapse, seemingly with little forewarning. The emerging disciplines of complexity science and network science provide an increasing body of knowledge which, however, has typically not been considered by policy makers to date, in large part because it is not readily accessible knowledge. Yet, this knowledge has become increasingly important, in view of the global scale that man-made networking has reached: today there are interlinked global networks comprising infrastructure networks (transport, energy, communications); investment, financing and trade networks; technology, innovation and education networks; social and value-based networks (e.g., driven by NGOs); and networks of intergovernmental agreements and international organizations. ${ }^{96}$ Networking is beneficial as it supports the global exchange of people, money, goods, information, ideas, but it can give rise under certain circumstances to cascading effects with global impacts. Network infrastructures can create the modern pathways for disasters spread. ${ }^{97}$

Risk inherent to specific activities or events is typically quantified through measures such as the probability of an event and its impacts given that the risk materializes. Systemic risk arises from interdependent, cascading failures in a network of interconnected system components, and the potential damage is largely determined by the size of the system. An example of systemic risk is the risk of outage in an electric grid. Hyper-risks arise from networks of networks, as different subsystems are interconnected, and potential damage also depends much on the system structure. Examples of hyper-risk are the risks of collapse of the global supply chain or of the energy-food-water system. While these risks typically increase with increasing networking density and size, so too do network benefits. For example, integration of transport, communications and trading networks in the form of modern logistics and supply chain management has enabled the global production and distribution systems which have literally lifted billions of people from poverty around the world. Yet, it has also added significant risks to the stability of the system.

Adaptive decoupling strategies can be developed to deal with the resulting interconnected, global risks. ${ }^{98}$ The 
ultimate idea is systems design - to change the system to make it inherently more resilient, resource efficient, equitable, etc. Lessons learnt from the emerging new science could be applied to SDG implementation in the future.

The system underlying the SDGs is highly complex and, therefore, is not well geared to planning approaches. The complexity of Earth Systems dynamics has been popularized for policy makers in the form of "planetary boundaries" where scientists have quantified safe levels below expected thresholds beyond which irreversible damage might be unavoidable. ${ }^{99,100}$ There are obvious limits to what humanity can do to control or engineer the earth-system. There are also limits to re-designing the manmade subsystems. While there are significant possibilities to change physical infrastructures and institutions, there are biological limits to shaping human behaviour and ultimately society. Yet, adaptive decoupling strategies can be developed for man-made subsystems, provided enough information is available about the system. However, as will be illustrated later in this chapter, to date scientists do not have a comprehensive "map" of the system underlying the SDGs, nor do they understand its dynamics well.

Resilience, metrics to measure risk, and approaches to minimize risks, do not feature highly in the SDGs. Yet, a risk management approach could be considered for SDG implementation at various levels. Chapter 4 illustrates how disaster risk reduction can be analysed as a cross-cutting issue across a range of SDGs. It should also be noted that political country groupings at the UN, such as the Small Island Developing States and the Least Developed Countries, are characterized and even identified by their low levels of resilience to natural and man-made shocks. As various actions to achieve the SDGs will be discussed in the coming years, a better understanding of the complex dynamics of the SDGs as a system will be important.

2.1.9. From a political to a scientific integrated view of the SDG network of inter-linked goals and targets

In view of the above, it is important to take an integrated perspective of the SDGs and it appears very important for SDG implementation to have a good understanding of the SDGs as a system.

The proposal of the intergovernmental Open Working Group (OWG) on SDGs is a political document, but one grounded in an extended reflection by Member States on the technical specificities of the 17 goal areas and their related targets. In the end, how integrated a perspective does the proposal provide? The OWG explicitly highlighted cross-linkages between goals - some of the 169 targets explicitly refer not only to the goal under which they are listed, but also to other areas. In fact, SDG17 on "means of implementation" (finance, trade, technology transfer and capacity building) has a special role in this regard. There are targets under almost all the other goals that link to at least one of these means under SDG17. However, other goals are less closely inter-linked. Some goals, however, have multiple linkages to others through the targets. For instance, SDG15 on terrestrial ecosystems is closely connected to, among others, SDG2 on food security, SDG6 on water and sanitation, as well as SDG8 on economic growth and employment, including through forest, land and other ecosystem-related targets. Besides SDG17, the goals with most connections to other goals are SDG12 on SCP and SDG10 on inequality. Most strongly indicated are the linkages between poverty and inequality, as well as between gender and education. On the other hand, SDG7 on energy appears to have few links with other goals based on the language of targets, even though energy is a "master resource" required to sustain any kind of life and for any kind of transformation or production.

It is interesting to compare this perspective with a scientific view as reflected in the aforementioned ICSU/ISSC report $^{101}$. There, scientists highlighted the complex nature of the SDG system, identifying many more inter-linkages among the 17 goals and 169 targets. In the view of scientists, the network of SDG goals and targets is a much denser network than suggested by an analysis of the language in the OWG outcome itself. Actions on almost any goal/target have multiple synergies and trade-offs with other goal/targets. Hence, in the view of scientists, it is clearly insufficient to pursue SDG implementation on a goal-by-goal basis, a view that would likely be widely shared by policy makers who helped craft the SDG proposal as well as those charged with implementation.

Figure 2-1 shows a scientific view - a network of goals as implied by the ISCU/ISSC report. Links between two goals indicate the number of links through SDG targets as suggested by the scientific literature. As the number of targets under each goal varies greatly, links between two goals are weighted by the total number of targets under the two goals. When SDG17 on "means of implementation" (which is linked to all other goals) is excluded from the 
analysis, SDG1 on poverty is most central node for the system. In other words, in the view of scientists, it is not only essential to mobilize the required "means of implementation", but progress on poverty eradication is also central to all other goals. As a word of caution, however, it should be noted that the ICSU/ISSC did not define the precise nature of inter-linkages, e.g., in terms of being strong/weak, direct or indirect, or their dynamic and scope.

A DESA background paper produced for the present chapter describes and maps the political and scientific views of the SDG network in more detail. ${ }^{102}$

Figure 2-1. A scientific view of the SDG system - links between SDGs as indicated by the ISCU/ISSC report (corrected for the number of targets under each goal

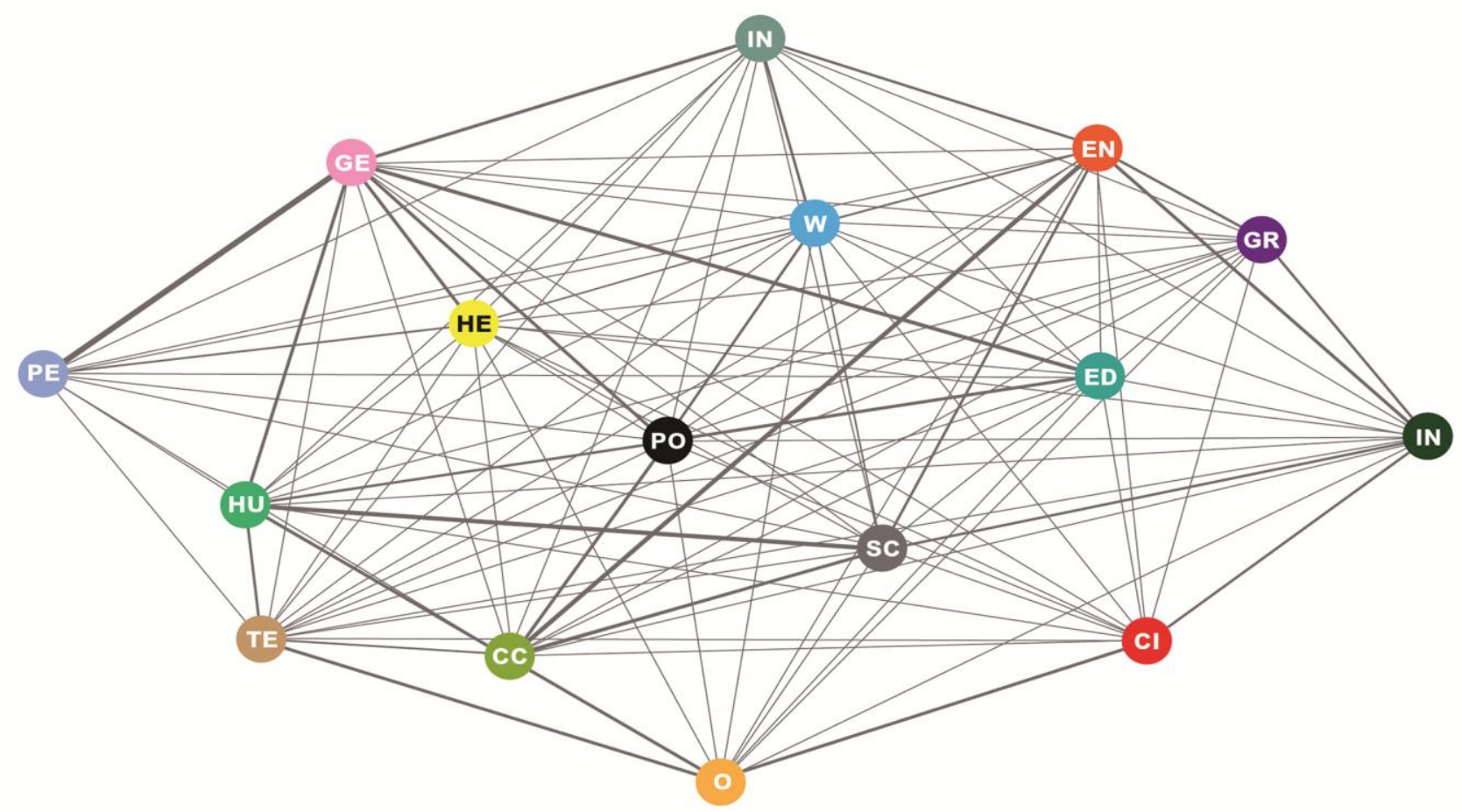

$\begin{array}{ll}\text { CI CITIES } & \text { IN INEQUALITY } \\ \text { CC CLIMATE CHANGE } & \text { IN INFRASTRUCTURE \& INDUSTRY } \\ \text { ED EDUCATION } & \text { O OCEANS } \\ \text { EN ENERGY } & \text { PE PEACEFUL \& INCLUSIVE SOCIETIES } \\ \text { GE GENDER } & \text { PO POVERTY } \\ \text { GR GROWTH \& EMPLOYMENT } & \text { SC SCP } \\ \text { HE HEALTH } & \text { TE TERRESTRIAL ECOSYSTEMS } \\ \text { HU HUNGER } & \text { W WATER }\end{array}$

Source: authors' elaboration

Notes: The numbers on the links indicate the percentage of targets linking the two goals (number of links between two goals divided by the sum of targets under the two goals). SDG17 on "means of implementation" (which links to all other goals) was excluded from the analysis. 


\subsection{Integrated SDG perspectives in international assessments}

A large number of international assessments are carried out in the UN system and beyond. Many of them take an integrated perspective to a subset of the SDGs. The SDG coverage of these assessments is summarized next.

The Prototype Global Sustainable Development Report 2014 introduced some of the most important recent international assessments, proposed a typology of these assessments, and discussed the strengths and weaknesses of various assessment models. It also compiled a list of more than one hundred assessments, outlook reports and other flagship publications of the UN system.

Here we build on and extend that work. In a first step, a database of international assessments was created, which included the assessments and flagship reports considered in the Prototype GSDR $2014^{69}$; a background paper of the SG's Scientific Advisory Board $^{103}$; various UNEP and IPBES reports $^{104}{ }^{105}$; the Assessment of Assessments ${ }^{106}$; and reports provided by UN entities. In a second step, the list was narrowed down by excluding assessments that are not strictly international assessments (e.g. policy briefs or regional reports) and including only a selection of recurring reports. In a third stage, a subsample of 36 international assessments was selected, in order to keep about 3 reports for each SDG and preferentially keep reports that cover a range of SDGs (Table 2-2) As a result, the selection of 36 assessments is not a representative sample, but can provide insights on how the assessments actually cover combinations of SDG areas.

\subsubsection{Hierarchy in terms of thematic breadth}

In general, international assessments show a hierarchy of assessments in terms of their thematic breadth.

Target-level reports focus on well-defined themes many of which can be associated with specific SDG targets, but many are even more specific than SDG targets. This includes many UN system reports, which provide detailed data in areas covered by organizational mandates.

Goal-level reports have a broader focus, and many can be associated with a specific SDG goal. They seldom explore links with other areas.

Integrated reports consider several of the SDGs areas in depth, even though their main focus may be on one specific area.

Linkages-among-goals reports investigate the linkages between at least two SDG areas (targets or goals).

\section{Box 2-1. Examples of "target-level" reports and "linkages-among-goals" reports}

Target-level reports:

- Global Wage Report 2012-13 (ILO)

- Global Employment Trends 2013: Recovering from a second jobs dip (ILO)

- Food Wastage Footprint. Impact on Natural Resources. Summary report (FAO)

- Food Outlook. Biannual report on global food markets (FAO)

- World Drug Report 2013 (UNODC)

- Scientific Synthesis on the Impacts of Underwater Noise on Marine and Coastal Biodiversity and Habitats (CBD)

- Review of Maritime Transport 2012 (UNCTAD)

- Global Mountain Biodiversity Assessment (CBD)

- Urban World: Cities and Land Rights (UN-HABITAT)

- Nuclear Safety Review for the Year 2012 (IAEA)

- World Trade Report (WTO)

- World Investment Report 2013 - Global Value Chains: Investment and Trade for Development (UNCTAD)

- Technology and Innovation Report 2012 - Innovation, Technology and South-South Collaboration (UNCTAD)

- Global Mercury Assessment 2013: Sources, emissions, releases, and environmental transport (UNEP)

- State of World Population 2012: By Choice, Not By Chance: Family Planning, Human Rights and Development (UNFPA)

Links among goals reports:

- Forests and climate change (FAO)

- Forests and water (FAO)

- Climate Change Adaptation and Disaster Risk Management in Agriculture (FAO)

- The State of the World's Children 2013: Children with Disabilities (UNICEF)

Climate Change and Nuclear Power 2013 (IAEA)

- Climate Change Adaptation and Disaster Risk Management in Agriculture (FAO)

- Scientific Synthesis of the Impacts of Ocean Fertilization on Marine Biodiversity (CBD)

Scientific Synthesis of the Impacts of Ocean Acidification on Marine Biodiversity (CBD) 


\subsubsection{SDG coverage}

Jointly, the selected 36 international assessments published by 19 organizations in the ten year period from 2004 to 2014 capture the full range of 17 SDGs (Table 2-2). The selected 36 assessments tend to cover multiple SDG areas, either as stand-alone chapters of these assessments or as consistent cross-cutting dimension of the analysis therein (Table 2-2). They typically capture three to five SDG areas in depth. However, this does not mean that all thematic areas receive similar attention. Means of implementation, poverty, and growth and employment tend to be central concerns of assessments, whatever their main area of focus is. In the sample, the urban dimension (SDG 11) and sustainable consumption and production (SDG 12) are rarely considered in depth compared to the other SDGs. ${ }^{107}$ This illustrates the challenge for the Global Sustainable Development Report, which is expected to be more integrated and to cover wider scope compared to these established flagship reports.

Large-scale international assessments in the sample (e.g., Global Energy Assessment, Global Environment Outlook, IPCC Assessment Report on Impacts, Adaptation and Vulnerability) covered the largest number of thematic areas. Assessments which focused on the themes of SDGs 1 to 9 (poverty, hunger and agriculture, health, education, gender, water, energy, growth and employment, infrastructure and industrialization) tended not to consider much the themes of SDGs 11 to 16 (urban development, SCP, climate change, oceans, terrestrial ecosystems and peaceful and inclusive societies). In contrast, assessments which focused on the themes of SDGs 11 to 16 tended to look at thematic areas under goals 1 to 10 more consistently and in more depth, even though both coverage and depth of treatment of these areas varies. Areas that were typically considered together include: energy and climate change; poverty and health; poverty and inequality; inequality and peaceful and inclusive societies; inequality and health; education and gender; and water and terrestrial ecosystems. Reports with a strong focus on energy showed greater diversity in terms of SDG coverage.

While these findings are based on a limited sample of assessments, they do suggest that there is scope for targeting assessments on currently under-investigated SDG linkages. As illustrated in the Prototype GSDR, the importance of such linkages depends on location and scale. Some linkages may be critical for groups of countries sharing similar characteristics, for example, Small Island Developing States or Land-locked Countries. Hence, the geographic scope for such studies needs to be adapted.
The selected reports follow a variety of formats, structures, and approaches. Some are truly integrated in the sense that their content in different areas results from an integrated analysis, where inter-sectoral linkages are considered from the start, whereas others comprised a collection of independently developed chapters. Still others are based on a collection of specific, individual expert views which were assembled to provide a broad picture of the topic and reflect a diversity of views.

In line with the HLPF's function to strengthen the sciencepolicy interface, the UN system could consider creating and maintaining an online and open database of international assessments on sustainable development. It would build on and integrate more specific collections of such assessments, preferably based on a common data standard.

In view of the fact that international assessments conducted by different scientific communities tended to adopt diverse assumptions and perspectives, policy makers could learn much from a regular synthesis of the diverse views on policy options in particular SDG areas. This would include identifying commonalities and differences in policy recommendations, in scopes, data and interpretation of trends. The UN's study entitled "Sustainable Development in the $21^{\text {st }}$ Century" (SD21) aimed to do that for agriculture $^{108}$ and energy ${ }^{109}$, respectively.

The Global Sustainable Development Report could aim systematically to bring together sectoral and thematic outlooks in a coherent way and highlight issues where interactions should be taken into account.

\subsection{Global scenario models for integrated assessment of the SDGs}

In taking an integrated perspective of the SDGs as a system, quantitative models and related tools can provide useful support. In view of the complexity of the interdependencies and the fact that many assumptions have to be made about the future, these models are typically used to create "scenarios", or internally consistent, plausible future pathways. 


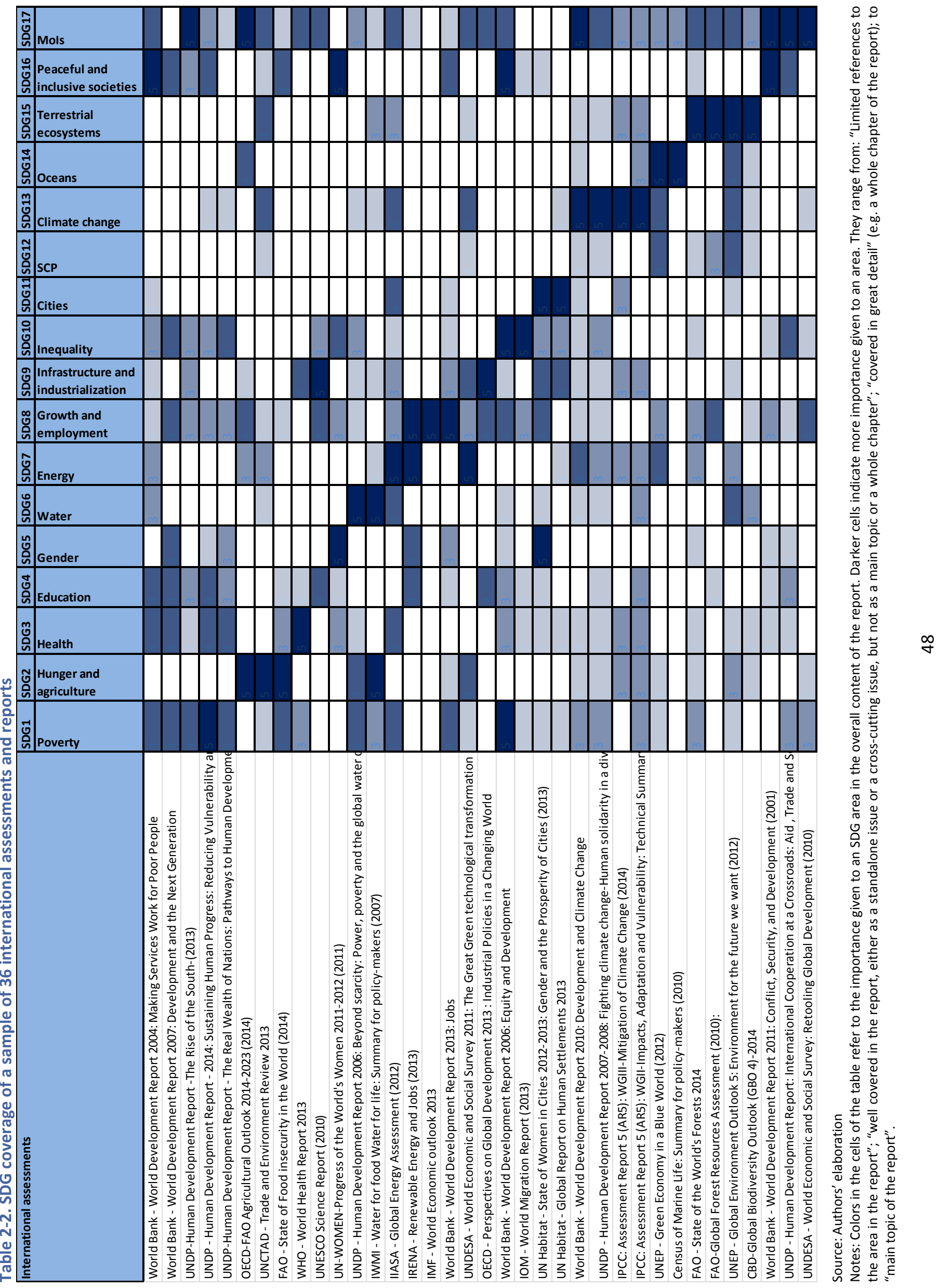


Since the early 1970s, scientists have used computer-based quantitative scenario models of the world. For example, the World3 model (a systems dynamics model) was used to create the 12 scenarios of the "Limits to Growth" study in $1972 .{ }^{110}$ The model focused on capturing the inter-linkages and feedbacks among key variables of interest: population, natural resources consumption, food availability, production and standard of living. The technology optimists' response to this study was "Energy in a Finite World" published in 1981 which provided a scientifictechnocratic picture of how a sustainable world energy system could be achieved from 1980 to $2030 .{ }^{111}$ It was supported by the MESSAGE model which focused on a detailed presentation of the technology system rather than the inter-linkages with other sectors, even though the study looked at a very wide range of sustainable development issues. The World3 and MESSAGE model frameworks have greatly influenced global scenario model development since. One group of models focuses on capturing inter-linkages (e.g., energy - water) at the expense of a detailed presentation of subsystems (e.g., the energy technology system), whereas the other group focuses on a detailed modelling of the subsystems themselves which are only "soft-linked". The two approaches highlight the two kinds of fundamental choices that scientists have in building global scenario models that can support the full range of SDGs - either soft-linking existing thematic models for the various SDGs, or building comprehensive models with a focus on capturing all important inter-linkages and feedbacks but with less sectoral/thematic detail. Pragmatically, this means that we will always need various types of models to make sense of our future policy choices to achieve the SDGs by 2030. Most likely there will not be one "best model" or modelling approach.

Generally speaking, global scenario models aim to provide the simplest representation of the highly complex SDG system that can replicate the essential dynamic elements of the system, in order to support decision-making for specific questions. Different questions require different models. Many such models exist and aim to answer key questions related to various parts of sustainable development. A review of prominent sustainable development scenarios and the associated model frameworks was prepared in preparation for the Rio+20 conference. ${ }^{116}$ Lesson learnt from these sustainable development scenarios were also summarized in the form of brief stories or narratives in the Prototype Global Sustainable Development Report $2014 .{ }^{69}$ One important finding was that the scenario model community remains fragmented into different schools of thought and with little to no integration between efforts at the national and global levels. Hence, the prototype report proposed a UN SDG scenario modellers forum to bring these communities together.

\subsubsection{Sustainable development scenarios for Rio+20 in 2012}

Table 2-3 provides an overview of the SDG-related targets considered in sustainable development scenarios for Rio+20 in 2012. ${ }^{69}$ The broad picture shows a selective, yet fairly good coverage of most of the SDGs. While none of the scenario models captures the full range of the SDGs, when put together they provide a glimpse of SDG scenarios. It should also be noted that these global scenarios are optimistic views that do not consider important constraints at the local and national levels.

According to Table 2-3, the coverage of SDG areas is neither complete nor uniform. Energy and water-related targets were considered most often, highlighting the core areas around which the models considered here tend to be built. Scenario targets related to energy are often expressed in absolute value, which differs from those in the SDGs, which are expressed as relative values or in reference to a baseline. Health is weakly covered. No scenario incorporated explicit gender targets. No explicit industrialization-related targets (or employment-related targets) were considered. While two models considered targets related to inequality between countries, withincountry inequality does not appear in the targets considered by any scenario. The urban dimension was considered only in relation to air pollution. While some of the targets in Table 2-3 can be related to the area of sustainable consumption and production, none refers explicitly to it or to targets included under SDG12; this may reflect the fact that SCP-related actions and targets are considered by modellers more as a means to achieve the other goals, than as a goal in themselves (industrialization perhaps falls in this category as well, as a strategy not an explicit goal). There are no targets related to SDG16 on peaceful and inclusive societies. Lastly, means of implementation, which are considered under SDG17 as well as under other SDGs, do not figure as explicit targets in these scenarios, as tends to be the practice.

\subsubsection{SDG coverage of the global scenario models}

Rio+20 in 2012 and the adoption of the SDGs by the intergovernmental OWG in 2014 have spurred the interest in many new scenario and model developments, with the objective to cover a significant portion of the SDGs and ultimately even the whole range. This includes new partnerships of established global change modelling groups, such as the "The World in 2050 Project", extensions of macro-economic MDG models, plans by the Balaton Group, plans for new broader scenarios for UNEP's GEO report and the International Resource Panel, as well as 
separate undertakings of research initiatives in various areas of the SDGs that had not earlier engaged in sustainability science work.

As the field is emerging, the present section aims to take stock of the extent to which the existing global scenario models cover the full range of 17 SDGs and to what extent they can account for the linkages among them. For this Table 2-3. SDG-related targets considered in sustainable development scenarios for Rio+20

\begin{tabular}{|c|c|c|c|c|c|c|c|c|}
\hline SDG & Types of goals, targets, and outcomes & 崖出 & $\overrightarrow{\underline{a}}$ & $\bar{山}$ & Ö & 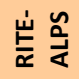 & $\sum_{\text {出 }}$ & Чֶ \\
\hline 1 & Eliminate poverty by 2050 & & & $\mathrm{x}$ & & & & \\
\hline 2 & Eradicate hunger by 2050 & & $\mathrm{X}$ & & & & & $\mathrm{X}$ \\
\hline 2* & $\begin{array}{l}\text { From } 2010 \text { to } 2050 \text {, limit increase in cropland area for food production to }+15 \% \text {, and reduce } \\
\text { the irrigated area for food production by } 5 \% \text {. }\end{array}$ & & & & & $\mathrm{x}$ & & \\
\hline 2* & $\begin{array}{l}\text { Reduce nitrogen and phosphorus use where possible, but without harming the ability of the } \\
\text { agricultural system to meet the hunger target }\end{array}$ & & $\mathrm{X}$ & & & & & \\
\hline 3 & Decreased impact of environmental factors on DALY & & $\mathrm{X}$ & & & & & \\
\hline $3^{*}$ & Reduce premature deaths due to air pollution by $50 \%$ by 2030 & $\mathrm{X}$ & & & & & & \\
\hline 4 & Achieve universal primary education by 2015 & & & & & & $\mathrm{X}$ & \\
\hline 6* & Water demand increases from $3,560 \mathrm{~km}^{3}$ in 2000 to only $4,140 \mathrm{~km}^{3}$ in 2050 & & & & $\mathrm{X}$ & & & \\
\hline 6 & Universal access to improved water source and basic sanitation by 2050 & & $\mathrm{X}$ & & $\mathrm{X}$ & & & \\
\hline 6 & $\begin{array}{l}\text { Limit the increase in the number of people under severe water stress to an additional }+2 \text { bln } \\
\{\text { or }+1.4 \text { bln }\} \text { from } 2000 \text {, reaching } 3.7 \mathrm{bln}\{\text { or } 3.1 \mathrm{bln}\} \text { in } 2050 \text {. }\end{array}$ & & & & $\mathrm{x}$ & $\{X\}$ & & \\
\hline 6 & People under severe water stress $<2$ bln until 2050 for 2.9 billion in 2100$\}$ & & & & & $\{\mathrm{X}\}$ & & $\mathrm{x}$ \\
\hline 6 & Reduce number of people living in water scarce areas vs. trend scenario & & $\mathrm{X}$ & & & & & \\
\hline $6^{*}$ & $\begin{array}{l}\text { Phosphorus removal in wastewater treatment increases from } 0.7 \mathrm{Mt} \text { in 2000, } 1.7 \mathrm{Mt} \text { in } \\
2030 \text {, to } 3.3 \mathrm{Mt} \text { in } 2050\end{array}$ & & & & $\mathrm{X}$ & & & \\
\hline 7* & Primary energy use less than 70GJ per capita by 2050 & & & & & & $\mathrm{X}$ & \\
\hline 7* & $\begin{array}{l}\text { Primary energy use per capita is only } 13 \% \text { higher in } 2050 \text { than in 2010, and } 48 \% \text { higher in } \\
2100 .\end{array}$ & & & & & $\mathrm{x}$ & & \\
\hline 7 & Use of renewables increase by 3.1 times from 2010 to 2050. & & & & & $\mathrm{x}$ & & \\
\hline 7 & Universal access to electricity and modern cooking fuels by 2030 or 2050$\}$ & $\mathrm{x}$ & $\mathrm{X}$ & $\{X)$ & & & & \\
\hline $7^{*}$ & Limit energy trade, increase diversity and resilience of energy supply by 2050 & $\mathrm{X}$ & & & & & & \\
\hline 7* & Population weighted average of energy security index increases only by 2.3 . & & & & & $\mathrm{x}$ & & \\
\hline 7* & Cumulative fossil fuel use limited to $<520$ Gtoe from 2010 to 2050 & & & & & $\mathrm{x}$ & & \\
\hline 7* & Reduce the area for energy crop production to almost zero by 2020. & & & & & $\mathrm{x}$ & & \\
\hline $8^{*}$ and 10 & GDP per capita > US\$10,000 PPP in all regions by 2050 & & & $\mathrm{X}$ & & & & \\
\hline $8 *$ and 10 & Income convergence between regions; catch-up of Africa by 2050 & & & & & & $\mathrm{X}$ & \\
\hline $11^{*}$ & Keep PM2.5 concentration below $35 \mu \mathrm{g} \mathrm{m}^{3}$ by 2030 & & $\mathrm{X}$ & & & & & \\
\hline $11^{*}$ & Reduce $\mathrm{NO}_{x}, \mathrm{SO}_{2}$ and black carbon emission by $25 \%$ vs. baseline by 2050 & & & & $\mathrm{X}$ & & & \\
\hline $11^{*}$ & Reduce $\mathrm{SO}_{2}$ by $42 \%$ and black carbon by $21 \%$ by 2050 vs. 2010 & & & & & $\mathrm{x}$ & & \\
\hline $13^{*}$ & $\begin{array}{l}\text { Limit global average temperature change to } 2^{\circ} \mathrm{C} \text { [or } 2.8^{\circ} \mathrm{C} \text { ] above pre-industrial levels with a } \\
\text { likelihood of }>50 \% \text { or } 60 \% \text { by } 2100 \text {. }\end{array}$ & $\mathrm{x}$ & $\mathrm{X}$ & $\{\mathrm{X}\}$ & $\mathrm{x}$ & {$[\mathrm{X}]$} & & $\mathrm{x}$ \\
\hline $13^{*}$ & $\begin{array}{l}\text { Atmospheric GHG concentration stabilization below } 450 \mathrm{ppm} \text { [or } 350 \mathrm{ppmv} \text { ] \{or } 550 \mathrm{ppmv}\} \\
\mathrm{CO}_{2} \text {-eq. by } 2100 \text {. }\end{array}$ & & $\mathrm{X}$ & & & & $\{\mathrm{X}\}$ & {$[\mathrm{X}]$} \\
\hline 14 & Limit ocean acidification to keep aragonite stable, with $\mathrm{pH}=8.0$ in 2150 & & & & & $\mathrm{x}$ & & \\
\hline 14 & Slow overfishing and later restore fish stocks & & & & & & & $\mathrm{X}$ \\
\hline 14 & CBD Aichi target of protecting $10 \%$ of coastal and marine areas by 2020 . & & $\mathrm{X}$ & & $\mathrm{x}$ & & & \\
\hline 15 & $\begin{array}{l}\text { By 2020: Prevent extinction of known threatened species and improve situation of those in } \\
\text { most decline; halve the rate of biodiversity loss; halve the rate of loss of natural habitats } \\
\text { and reduce degradation and fragmentation by 2020; by 2050: stabilize biodiversity at the } \\
2020 / 2030 \text { level. }\end{array}$ & & $\mathrm{x}$ & & & & & \\
\hline 15 & CBD Aichi targets of protecting $17 \%$ of terrestrial areas and inland water areas by 2020 . & & $\mathrm{X}$ & & $\mathrm{X}$ & & & \\
\hline 15 & Slow and later reverse deforestation and land degradation & & & & & & & $\mathrm{x}$ \\
\hline
\end{tabular}

Sources: IIASA-GEA (Riahi et al., 2012); PBL (van Vuuren et al., 2012) ; SEI (Nilsson et al., 2012), OECD (2012) ; RITE-ALPS (Akimoto et al., 2012) ; FEEM (2011) ; GSG (Raskin et al., 2010).

Note : Green shading indicate targets in scenarios that match proposed SDG targets, even if the target dates and/or quantitative target differs. Asterisks (and blue shading) indicate targets considered by scenarios that have no direct counterparts in the SDG targets. \{X\} refers to the alternative target values provided in \{\} parentheses. purpose, we assessed 72 models ${ }^{112}$, methods and tools, which are described in the online Annex to this chapter ${ }^{113}$. These models were chosen based on expert judgement and de Vries $(2010)^{115}$, and the UN's SD21 project ${ }^{116}$. It is important to note that the selection is non-exhaustive, as the field is evolving rapidly since Rio+20. recent literature reviews by the European Commission ${ }^{114}$, 
Figure 2-2 provides an overview of the number of global scenario models that are covering each of the 17 SDGs. Many of the 72 models covered SDG13 on climate change (45 models), SDG8 on economic growth and employment (42 models), SDG7 on energy (35 models), SDG15 on terrestrial ecosystems and biodiversity (26 models), and SDG17 on means of implementation (25 models). The models of means of implementation typically focus on international taxation, fuel subsidies, trade, and technology change and transfer. ${ }^{117}$ In contrast, only 5 models considered governance aspects of SDG16 in one way or another, only a few explored SDG10 on inequality and no model considered SDG5 on gender equality. We only identified five scenarios that explicitly addressed the SDGs on ending poverty, sustainable consumption and production, water, oceans, education, health, and reducing inequality. This pattern is consistent with the findings of a related scoping study commissioned by the European Commission. $^{114}$

Figure 2-2. SDG coverage of the 72 selected global scenario models

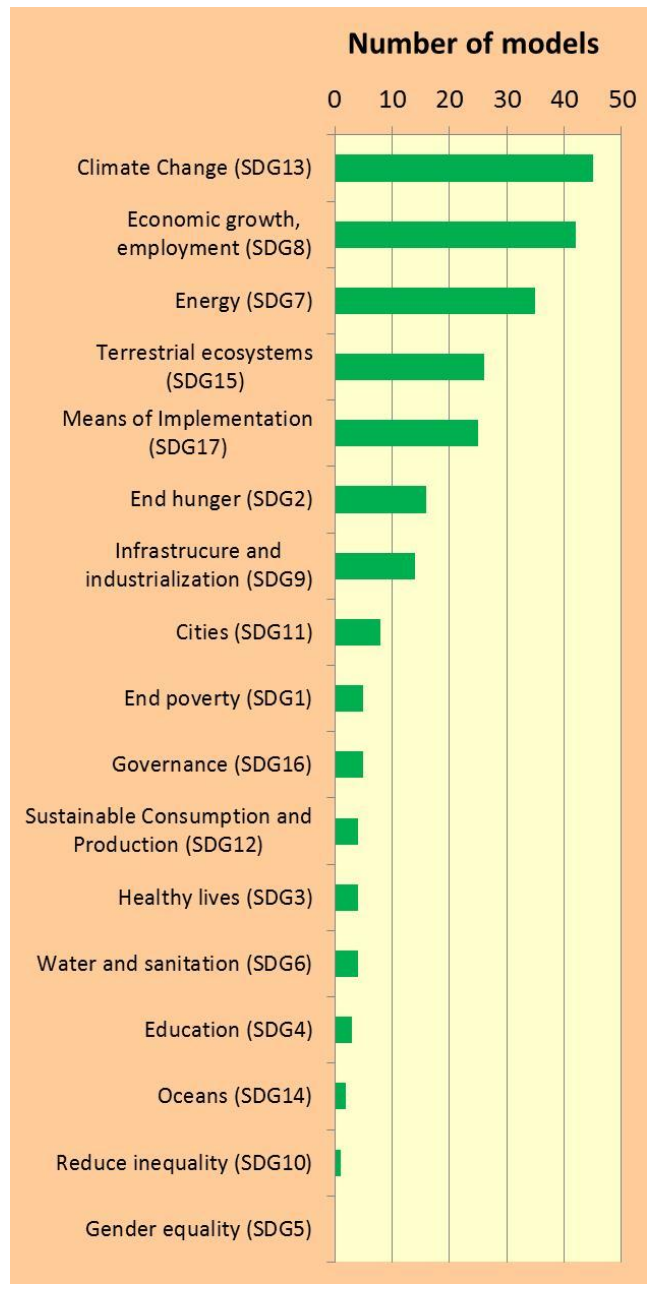

Source: author's elaboration
It should also be noted that the model coverage of most SDGs was only partial. For example, with regard to SDG15 on terrestrial ecosystems, food production aspects were captured by many models, but other ecosystem services and biodiversity aspects of SDG15 were only captured by a few models.

Many models were concerned with economic development and means of implementation through macroeconomic analysis, with many of them tying into poverty issues, and environment-related themes such as energy and climate change policies. A number of economic growth models have been used to estimate the costs of internationally agreed goals and investment requirements for infrastructure. For example, the World Bank used an economic growth model to estimate the additional resource needs for achieving the MDGs. ${ }^{118}$ Some socioeconomic models specifically focused on international trade. ${ }^{119}$ Most of the macroeconomic analyses were based on neoclassical theory and ultimately oriented towards maximizing economic and trade growth. Ecological economics models explicitly included the environment and its services and sometimes considered planetary boundaries. ${ }^{120}$ These models tended to explore alternative development avenues, address issues of equity, allocation, and scale. ${ }^{121} 114$

Only a few models have explicitly addressed sustainable consumption and production (SCP) in a way in which they could support SCP policy ${ }^{122}$ - in order to do so, they would need to be technology-explicit, link policies to technology acquisition cost and consumer behaviour, have macroeconomic feedbacks to energy supply and demand, and include trade and financial feedbacks between countries in the case of global environmental challenges. ${ }^{122}$

\subsubsection{Coverage of inter-linkages between SDGs}

How well do the global scenario models capture interlinkages between SDGs? ${ }^{123} 124$ Table 2-4 provides an overview of the number of models that capture the interlinkages between 8 groups of the 17 SDGs. Most of the models that quantify SDG inter-linkages focus on assessing synergies and trade-offs between economic and environmental domains, such as energy and climate change.125 Inter-linkages to social issues focus primarily on employment. 
Table 2-4. Number of models capturing "inter-linkages" between groups of SDGs

\begin{tabular}{|c|c|c|c|c|c|c|c|c|}
\hline Policy themes & $\begin{array}{c}\text { Economic } \\
\text { development } \\
\text { (SDG1, 2, 8, } \\
9,11)\end{array}$ & $\begin{array}{c}\text { Sustainable } \\
\text { consumption } \\
\text { and } \\
\text { production } \\
\text { (SDG12) }\end{array}$ & $\begin{array}{l}\text { Energy } \\
\text { (SDG7) }\end{array}$ & $\begin{array}{l}\text { Climate } \\
\text { change } \\
\text { (SDG13) }\end{array}$ & $\begin{array}{c}\text { Natural } \\
\text { resources } \\
\text { and } \\
\text { ecosystems } \\
\text { (SDG6, 14, } \\
15 \\
\end{array}$ & $\begin{array}{c}\text { Social } \\
\text { inclusion } \\
\text { (SDG3, 4, 5, } \\
10)\end{array}$ & $\begin{array}{c}\text { Means of } \\
\text { implementation } \\
\text { (SDG17) }\end{array}$ & $\begin{array}{l}\text { Governance } \\
\text { (SDG16) }\end{array}$ \\
\hline \multicolumn{9}{|l|}{$\begin{array}{l}\text { Economic } \\
\text { development }\end{array}$} \\
\hline $\begin{array}{l}\text { Sustainable } \\
\text { consumption and } \\
\text { production }\end{array}$ & 3 & & & & & & & \\
\hline Energy & 34 & 3 & & & & & & \\
\hline Climate change & 43 & 4 & 22 & & & & & \\
\hline $\begin{array}{l}\text { Natural resources and } \\
\text { ecosystems }\end{array}$ & 5 & 2 & 5 & 7 & & & & \\
\hline Social inclusion & 8 & 0 & 1 & 0 & 0 & & & \\
\hline $\begin{array}{l}\text { Means of } \\
\text { implementation }\end{array}$ & 21 & 2 & 14 & 12 & 3 & 0 & & \\
\hline Governance & 5 & 0 & 2 & 0 & 0 & 0 & 0 & \\
\hline
\end{tabular}

Source: adapted from European Commission ${ }^{114}$ and author's elaboration...

\subsection{Conclusions}

A number of issues arise from the present chapter which may warrant consideration.

Firstly, policy makers could learn much from a systematic synthesis of diverse perspectives arising from assessments for particular SDGs and from fully integrated perspectives on the SDGs. Integration is needed across the three dimensions of sustainable development, for any thematic issue, across substantive areas of what is to be developed or sustained, and across a wide range of geographic and time scales. In this context, the three recent ICSU/ISSC recommendations on integrated SDG perspectives, contained in their "Review of targets for the sustainable development goals: the science perspective", could be carried out jointly by scientific communities and the UN system.

Secondly, an annual SDG scenario modellers forum could be instituted in support of the HLPF. Such a forum might assist in exchanging experiences and building capacity, so that purpose-built SDG models will be developed and national planners, policy-makers, and delegates can access all relevant scenario information. Some of the gaps identified through the analysis here in the coverage of existing models could also be addressed. The forum could also help bringing together sectoral outlooks prepared by UN entities and other international organizations. The SDG scenario modellers forum might also want to support a joint research effort to create a quantitative map of the entire system underlying the SDGs - an effort that could be supported by UN-DESA.

Thirdly, an online and open database of international assessments on sustainable development should be created. It would build on and integrate more specific collections of such assessments, preferably based on a common data standard. 


\section{Chapter 3. The Oceans, Seas, Marine Resources and Human Well-being Nexus}

The present chapter aims to demonstrate the necessity of using an integrated approach when dealing with the "oceans, seas, marine resources ${ }^{126}$ and human well-being" nexus at the global, regional, national and local levels. It identifies important inter-linkages between nexus areas (Section 3.1) and elaborates on important classes of threats (Section 3.2) (Figure 3-1). It examines the scientific coverage of interlinkages and threats, lists illustrative scientific reports and indicates areas for further research. Furthermore, it documents selected case studies illustrating inter-linkages and the benefits of integrated approaches for implementation (Section 3.3). of the scientific literature. It is written with the full understanding that the First Global Integrated Marine Assessment (the World Ocean Assessment) ${ }^{127}$ (see Box 3-2) will provide a much more detailed analysis of the topics at hand. Annex 1 (Extended versions of Table 3-1, 3-3, 3-4) (available online ${ }^{128}$ ) contains extended versions of the tables with supplementary illustrative scientific reports, case studies and contributions submitted by experts to give readers the ability to gain a deeper insight into specific topics. The scientific reports listed in this chapter and Annex 1 (Extended versions of Table 3-1, 3-3, 3-4) are of illustrative nature and are not meant to be exhaustive.

The chapter is based on the knowledge and expertise of contributing scientists and UN staff and based on a review

Figure 3-1. Oceans, seas, marine resources and human well-being nexus (Important inter-linkages and threats) ${ }^{129}$

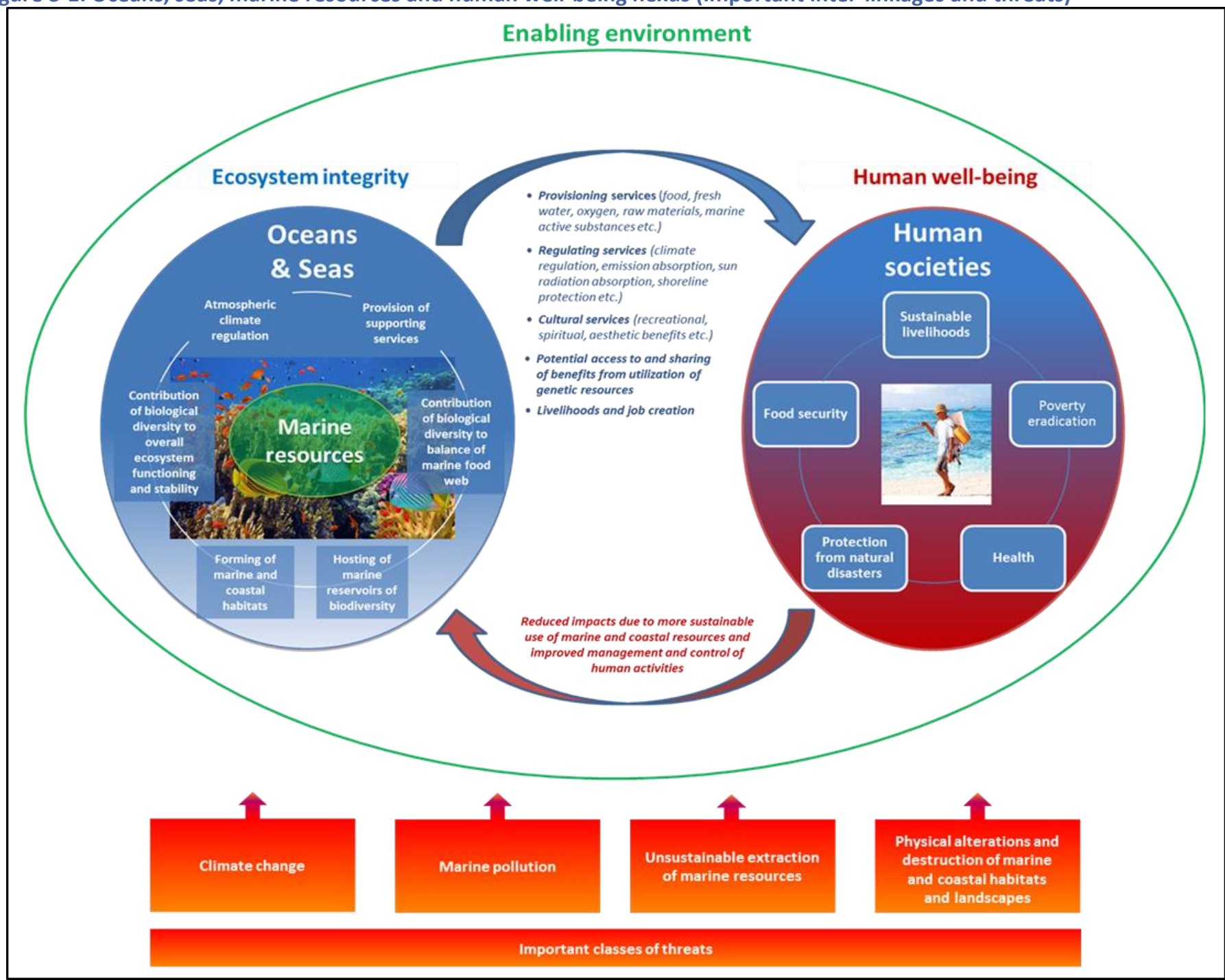


In order for oceans, seas and marine resources to successfully contribute to human well-being, ecosystem integrity ${ }^{130}$, with properly functioning biogeochemical and physical processes, is required. This does not require unperturbed systems, but systems that have not suffered serious or irreversible harm. Ecosystem integrity allows for the provision of supporting ecosystem services which, in turn, are the bases of important regulating, provisioning and cultural ecosystem services that are of crucial importance for humans. Whereas the benefits provided by oceans, seas and marine resources are important to all people, vulnerable groups, including the poor and indigenous peoples, with a high dependency on natural resources and ecosystem services may have their wellbeing especially tied to these benefits.

The following illustrative examples underline the importance of oceans, seas and marine resources for human well-being:

- Over 3 billion people depend on marine and coastal resources for their livelihoods. ${ }^{131}$

- Fish provide 4.3 billion people with at least $15 \%$ of their intake of animal protein. ${ }^{132}$

- At least $90 \%$ of the volume of global trade is seaborne. ${ }^{133}$

- Approximately $50 \%$ of all international tourists travel to coastal areas. In some developing countries, notably Small Island Developing States (SIDS), tourism can account for over $25 \%$ of GDP. ${ }^{134}$

- The global oceans-based economy is estimated at between USD 3-6 trillion/year. ${ }^{135}$

- Oceans capture and store about $30 \%$ of carbon dioxide produced by humans. ${ }^{136}$

- Mangroves and coral reefs offer shoreline protection. Global coral reefs protect around 150,000 km of shoreline in more than 100 countries and territories. ${ }^{137}$

- Marine phytoplankton produces $50 \%$ of oxygen on Earth. ${ }^{138}$

The link between oceans, seas and marine resources and human well-being is not one-sided. While an increase in human well-being is frequently generated at the cost of ecosystem integrity, it can also potentially reduce the negative anthropogenic impacts on the marine environment, for example due to a more sustainable use of resources, changes in production and consumption patterns and improved management and control of human activities, for which good governance and an enabling environment are required (see Box 3-1).

\section{Box 3-1. Enabling environment ${ }^{13}$}

An enabling environment comprises a multitude of elements, including political will; effective legal and policy frameworks, institutions and cooperation mechanisms; compliance with, and enforcement of, UNCLOS ${ }^{140}$ and its implementing agreements, as well as other relevant instruments; national, regional, global action plans, strategies and policies aimed at sustainable development; social and economic security and opportunities; stakeholder involvement and empowerment; increased cross-sectoral cooperation and coordination at all levels; decent work conditions; capacity development; scientific capacity; technology transfer and advancement; education and training; knowledge sharing and awareness raising; and changes in (consumer and producer) behaviour.

The importance of oceans for sustainable development is widely recognized by the international community and embodied in chapter 17 of Agenda 21, the Johannesburg Plan of Implementation and various decisions taken by the Commission on Sustainable Development. The Millennium Ecosystem Assessment emphasizes that all humans depend on the Earth's ecosystems and the services they provide. ${ }^{141}$ In the Rio+20 outcome document, The Future We Want, Member States called for "holistic and integrated approaches to sustainable development that will guide humanity to live in harmony with nature and lead to efforts to restore the health and integrity of the Earth's ecosystem". In this context, they stressed, among others, the importance of "the conservation and sustainable use of the oceans and seas and of their resources for sustainable development, including through their contributions to poverty eradication, sustained economic growth, food security and creation of sustainable livelihoods and decent work...". Accordingly, the proposal of the Open Working Group on sustainable development goals submitted to the United Nations General Assembly in August 2014 contains sustainable development goal (SDG) 14 which aims to "Conserve and sustainably use the oceans, seas and marine resources for sustainable development". ${ }^{142}$ The idea of a stand-alone ocean SDG was previously supported by various organizations and academic institutions. ${ }^{143} \mathrm{~A}$ recent report released by the International Council for Science and the International Social Science Council confirmed that SDG 14 is directly or indirectly connected to all other SDGs which underlines the concept of a network of SDGs presented in Chapter 2 of the present report. ${ }^{144}$ 


\section{Box 3-2. First World Ocean Assessment}

The Regular Process for Global Reporting and Assessment of the State of the Marine Environment, including Socioeconomic Aspects was established by the United Nations General Assembly to strengthen the regular scientific assessment of the state of the marine environment in order to enhance the scientific basis for policymaking. The startup phase to the Regular Process, called the "assessment of assessments", was concluded in 2009. ${ }^{145}$ A census of existing ocean assessments was conducted and consolidated in the Gramed database. ${ }^{146}$ The output of the first cycle of the Regular Process, the First Global Integrated Marine Assessment ("World Ocean Assessment") ${ }^{147}$, is under preparation and will be considered by the Ad Hoc Working Group of the Whole in September 2015 and a summary thereof will be considered by the United Nations General Assembly at its seventieth session. It is expected to provide an overall assessment of the scale of human impact on the oceans and the overall value of the oceans to humans; the main threats to the marine environment and human economic and social well-being; the needs for capacity-building and effective approaches to meeting such needs; and the most serious gaps in knowledge and possible ways of filling them.

Apart from supporting the World Ocean Assessment, ocean scientists are informing other intergovernmental processes and meetings, including the United Nations Open-ended Informal Consultative Process on Oceans and the Law of the Sea and the Ad Hoc Open-ended Informal Working Group to study issues relating to the conservation and sustainable use of marine biological diversity beyond areas of national jurisdiction (see Box 3-3).

\section{Box 3-3. Ad Hoc Open-ended Informal Working Group}

In recent years, the international community has become increasingly aware of the range of services provided by marine ecosystems and of the rich biodiversity of pelagic and benthic ecosystems beyond the limits of national jurisdiction, namely in the high seas ${ }^{148}$ and the Area ${ }^{149}$. The Ad Hoc Open-ended Informal Working Group to study issues relating to the conservation and sustainable use of marine biological diversity beyond areas of national jurisdiction has been meeting regularly since 2006. The last meeting of the Working Group, held in January 2015, stressed the need for a comprehensive global regime to better address the conservation and sustainable use of marine biodiversity beyond areas of national jurisdiction and resulted in the recommendation to develop an international legally-binding instrument under the United Nations Convention on the Law of the Sea. ${ }^{150}$
3.1. Interlinked issues: oceans, seas, marine resources and human well-being

Regarding the overall scientific coverage of the nexus and its threats (Section 3.2), contributing experts note that the number and quality of assessments are very variable in terms of the geographic range or areas they cover. Some research areas and regions are more poorly covered than others due to a lack of or uneven distribution of financial support, technological and human resources and capacities and/or logistical limitations due to habitat inaccessibility (remote areas or deep sea). Research tends to be very results-driven, so that areas where clearly definable results can be demonstrated in a short amount of time tend to be more pursued and financed. There is a need for more integrated study of the oceans by teams of natural and social scientist to propose and assess different sustainable development scenarios. However, natural and social scientists seldom work together due to their use of different research methods, different geographical scales of research and the fact that funding is often only targeted at one type of research. Some areas are at the forefront of new science and need more time for research to mature. Another problem identified by experts is the lack of free and openly available data. Quite few data remain unpublished or are not available through open access databases. While the experts' priorities for future research vary according to their expertise, important research areas mentioned by several experts were: (1) understanding the direct, cumulative and interacting effects of anthropogenic threats on biodiversity, ecosystem functioning and stability and human well-being; (2) qualitative and quantitative evaluation of ecosystem services and their connection to human well-being; (3) importance of biodiversity (at all levels of food web) for ecosystem functioning and stability; (4) impact of different policy and management options on sustainable ocean management; (5) adaptive capacity of ocean-dependent communities and livelihoods vis-à-vis threats.

Table 3-1 summarizes some important inter-linkages among nexus areas and lists illustrative scientific reports, as well as areas for further research suggested by contributing experts. Contributing experts estimate the scientific coverage of oceans, seas and marine resources as being rather developed, notwithstanding the fact that large areas of the oceans are unexplored and unknown forms of marine life and their habitat remain to be discovered. The scientific coverage of the impact of ecosystem integrity on human well-being is seen as being rather developed with regard to the creation of jobs and sustainable livelihoods, but weak with regard to the evaluation of benefits derived from marine resources and ecosystem services. This illustrates a need for more systematic global and regional 
fully integrated scientific assessments addressing the nexus. The contribution of oceans, seas and marine resources to human well-being should be properly acknowledged and operationalized for policy recommendation and design. The integration of mapping efforts of ecosystem services that are undertaken by separate entities $^{151}$ could be a potentially beneficial assessment tool, which is currently being undertaken by the World Ocean Assessment.

Table 3-1. Important inter-linkages between oceans, seas, marine resources and human well-being

Oceans, seas marine resources (ECOSYSTEM INTEGRITY)

\section{Biogeochemical and} physical processes

Hosting of marine reservoirs of biodiversity

Forming of coastal and marine habitats, including nursery grounds

Provision of supporting services (nutrient cycling, carbon cycling/ sequestration, oxygen provision, soil formation, primary production etc.)

Contribution of biological diversity to balance and maintenance of marine food web

Contribution of biological diversity to overall ecosystem functioning and stability

Atmospheric climate regulation

Illustrative scientific reports*

- UN World Ocean Assessment $(2015)^{152}$

- Census of Marine Life ${ }^{153}$

- Ocean Biogeographic Information System (OBIS) ${ }^{154}$

- WWF Living Planet Index ${ }^{155}$

- National Research Council of the National Academies (2015). Sea Change: 2015-2025 Decadal Survey of Ocean Sciences.

- Gamfeldt et al. (2014). Marine biodiversity and ecosystem functioning: what's known and what's next?

- IPCC (2014). Climate Change 2014: Impacts, Adaptation, and Vulnerability. Chapter 6. Ocean Systems.

- Secretariat of CBD (2014). Global Biodiversity Outlook 4.

- Global marine biodiversity assessment and outlook (2010).

- UNEP, UNESCO-IOC (2009). An Assessment of Assessments. Findings of the Group of Experts.

- Kondoh, M. (2003). Foraging Adaptation and the Relationship between FoodWeb Complexity and Stability.

Further research areas suggested by contributing experts:

- Assessing actual direct, indirect and cumulative impacts of human activities on marine and coastal ecosystems, including deep sea ecosystems; assess resilience of marine and coastal ecosystems

- Sustainable approaches to marine aquaculture

- Indirect and cumulative effects of biodiversity loss on ecosystem functioning and stability and role of keystone species

- Modeling of production functions for multiple ecosystem services of critical marine habitats, especially coral and bivalve reefs, seagrass beds, mangroves and marshes

- Valuing carbon storage capacity of marine ecosystems and potential to increase sequestration through habitat protection and restoration

- Ecological effects of emerging activities, such as ocean energy development, ocean geo-engineering (e.g. $\mathrm{CO}_{2}$ injection, ocean fertilization) and open ocean aquaculture

- Goods and services provided by deep sea ecosystems and their real values

- Biodiversity role in ecosystem functioning, stability and resilience, including the roles of genetic diversity and functional redundancy

- Diversity of marine bacteria, microbes, and viruses and their role in ecosystem functioning

- Influence of habitat-forming species on biodiversity throughout their range; their response to climate change and consequences for associated biodiversity; resilience of various habitat types and communities to perturbation and capacity to recover from it

- Analyze how global changes interact currently and in the future with changing patterns in biodiversity and ecosystem functioning

- Accelerate discovery as much biodiversity can be lost before it has been discovered

- Baselines for monitoring and evaluation of biomass and/or distribution of stocks (benthic and pelagic species)

- Reproduction of important marine species

- Marine species lifecycle and habitats of commercially important species

- Development of methodologies for assessment of marine ecosystems and open ocean

- Functional links between terrestrial, coastal and marine ecosystems, and consequences of degradation on neighbouring systems

Oceans, Seas and marine resources (Ecosystem Integrity) $\rightarrow$ HUMAN WELL-BEING

Creation of livelihoods and jobs

[e.g. in fisheries and aquaculture, maritime transportation, shipbuilding, ports and related services, coastal developments, tourism, oil, gas, mining industries and emerging sectors (e.g., offshore renewable energy $\left.^{156}\right)$ ]

Illustrative scientific reports*

- UN World Ocean Assessment $(2015)^{157}$

- Mapping Ocean Wealth ${ }^{158}$

- UNCTAD (2014). Review of Maritime Transport.

- Begossi (2013). Small-scale Fisheries and Biodiversity: Alleviating Poverty and Conserving Natural Resources.

- UNEP et al. (2012). Green Economy in a Blue World.

- Secretariat of CBD (2009). Biodiversity, Development and Poverty Alleviation.
Further research areas suggested by contributing experts:

- Census of small-scale fisheries; better document impact of small-scale fisheries and small and medium-scale aquaculture enterprises; improve availability and quality of disaggregated data

- Census of people depending on coastal resources for consumption/sale

- Mapping and qualitative and quantitative evaluation of ecosystem services

- Quantification of distribution of wealth generated by newer industries (e.g. eco-tourism) among communities, gender etc.

- Role of women in fisheries

- Impact of increasingly connected markets and consumption on local livelihoods, food security and resource management

- Economic consequences of ecosystem responses to changing biodiversity

- Economic and environmental viability of regional wave and other renewable energy devices

- Green economy approach in ocean sectors; Contribution of blue natural capital to macroeconomics 


\begin{tabular}{|c|c|c|}
\hline & $\begin{array}{l}\text { Recognizing the role of } \\
\text { Biodiversity for Human Well- } \\
\text { being. } \\
\text { - Charles (2001). Sustainable } \\
\text { fishery systems. }\end{array}$ & $\begin{array}{l}\text { - Distribution of power among participants in marine sectors/industries and } \\
\text { ways to address inequities where they occur } \\
\text { - Measurement of socio-economic value of marine and coastal tourism } \\
\text { - Adaptive capacity of communities and livelihoods vis-a-vis threats } \\
\text { - Undertake risk assessments and identify hazardous activities in specific } \\
\text { fish value chains that pose risks to young people /support child labour }\end{array}$ \\
\hline $\begin{array}{l}\text { Provisioning services } \\
\text { (food, fresh water, raw } \\
\text { materials, pharmaceutical } \\
\text { compounds) } \\
\text { Regulating services } \\
\text { (climate regulation, } \\
\text { emission absorption and } \\
\text { storage, shoreline } \\
\text { protection) } \\
\text { Cultural services } \\
\text { (recreation, spiritual and } \\
\text { religious sites, aesthetics) }\end{array}$ & $\begin{array}{l}\text { - UN World Ocean Assessment } \\
(2015)^{159} \\
\text { - Ocean Health Index } 160 \\
\text { - High-level Panel of Experts on } \\
\text { Food Security and Nutrition } \\
\text { (2014). Sustainable fisheries } \\
\text { and aquaculture for food } \\
\text { security and nutrition. } \\
\text { - IUCN (2014). The Significance } \\
\text { and Management of Natural } \\
\text { Carbon Stores in the Open } \\
\text { Ocean - A Summary. } \\
\text { - UNEP, UNESCO-IOC (2009). } \\
\text { An Assessment of } \\
\text { Assessments. Findings of the } \\
\text { Group of Experts. } \\
\text { - Millennium Ecosystem } \\
\text { Assessment (2005). } \\
\text { Ecosystems and Human Well- } \\
\text { being: Synthesis. }\end{array}$ & $\begin{array}{l}\text { - Map and inventory of ecosystem services; role for human well-being - } \\
\text { - Minks and interdependencies } \\
\text { - More comprehensive valuation of regulatory services provided by coastal } \\
\text { - Systematic qualitative and quantitative evaluation of ecosystem services, } \\
\text { including aboriginal usage, views and values } \\
\text { - Better quantification of the role of seafood in food security } \\
\text { - Connection between high seas and ecosystem services in coastal areas } \\
\text { - Extended research into cultural ecosystem services } \\
\text { - Impact of global threats on provision of ecosystem services }\end{array}$ \\
\hline $\begin{array}{l}\text { Potential access to and } \\
\text { fair and equitable sharing } \\
\text { of benefits arising from } \\
\text { the utilization of genetic } \\
\text { resources and associated } \\
\text { traditional knowledge, as } \\
\text { internationally agreed }^{161}\end{array}$ & $\begin{array}{l}\text { - ABS Capacity Development } \\
\text { Initiative (2014). Relevance of } \\
\text { marine bioprospecting for } \\
\text { access and benefit sharing } \\
\text { frameworks. } \\
\text { - German Advisory Group on } \\
\text { Global Change (WBGU) (2004). } \\
\text { World in Transition. Fighting } \\
\text { Poverty through } \\
\text { Environmental Policy. } \\
\text { - IUCN (2004a). Access to } \\
\text { genetic resources and benefit } \\
\text { sharing: Key questions for } \\
\text { decision makers. }\end{array}$ & $\begin{array}{l}\text { - Evaluation of marine genetic resources with focus on commercially viable } \\
\text { - Recies (e.g. algae and extremophiles) } \\
\text { - Dole and impacts of bioprospecting } \\
\text { - } \text { - Development of low-tech methods for screening for product potential } \\
\text { resources } \\
\text { - Examine access and benefit-sharing systems for their consistency, } \\
\text { effectiveness and feasibility }\end{array}$ \\
\hline \multicolumn{3}{|c|}{ HUMAN WELL-BEING $\rightarrow$ Oceans, Seas and marine resources (Ecosystem Integrity) } \\
\hline Inter-linkages & Illustrative assessments* & Further research areas suggested by contributing experts: \\
\hline $\begin{array}{l}\text { Within an enabling } \\
\text { environment (Box } 3 \text { ), } \\
\text { reduced negative impacts } \\
\text { on marine and coastal } \\
\text { ecosystems due to more } \\
\text { sustainable use of marine } \\
\text { and coastal resources and } \\
\text { improved management of } \\
\text { human activities }\end{array}$ & $\begin{array}{l}\text { - UN World Ocean Assessment } \\
(2015)^{162} \\
\text { - Secretariat of CBD (2010). } \\
\text { Linking biodiversity } \\
\text { conservation and poverty } \\
\text { alleviation: A State of } \\
\text { Knowledge Review. } \\
\text { - Langmead et al. (2007). } \\
\text { European Lifestyles and } \\
\text { Marine Ecosystems: Exploring } \\
\text { challenges for managing } \\
\text { Europe's seas. } \\
\text { - FAO (2005). Reducing } \\
\text { fisherfolk's vulnerability leads } \\
\text { to responsible fisheries. }\end{array}$ & $\begin{array}{l}\text { - Effects of changes in lifestyle (e.g., production, consumption, social } \\
\text { - Incentives for changing behaviour such as payment for ecosystem services } \\
\text { and participatory management schemes } \\
\text { - Data availability and resolution at different levels and geographic spread } \\
\text { - Synthesis of lessons from (successful) projects } \\
\text { - Cost - benefit analysis of effects of coastal tourism } \\
\text { - Impacts of human sectoral activities on marine and coastal resources and } \\
\text { - ecosystem integrity } \\
\text { - Effects of improved management of human activities on marine and } \\
\text { - Reaction of communities to imposition of management measures on their } \\
\text { livelihoods, and ways to increase compliance and cooperation between } \\
\text { regulators and those being regulated } \\
\text { - Comparison of ports to ascertain their performances in terms of corporate } \\
\text { social responsibility and sustainability goals }\end{array}$ \\
\hline
\end{tabular}


While some efforts are undertaken to account for ecosystem services $^{164}$, the quantitative evaluation or monetization of ecosystem services represents a challenge, especially with respect to cultural services. Given such limitations, qualitative ways of investigating the meaning, relevance and significance of ecosystem services should be promoted. The ocean health index $(\mathrm{OHI})^{165}$ is one example of a possible translation of the provision of ecosystem services into traceable and quantifiable indicators (see Box 3-4).

\section{Box 3-4. The Ocean Health Index (OHI) ${ }^{166}$}

The Ocean Health Index (OHI), developed by 65 scientists/ocean experts and partners ${ }^{167}$, is a measure of ocean health that includes people as part of the ocean ecosystem. It compares and combines all dimensions of ocean health -biological, physical, economic and social- in order to generate a snapshot of the health of the oceans. The $\mathrm{OHI}$ evaluates the condition of marine ecosystems according to 10 goals, which represent important ecological, social, and economic benefits that a healthy ocean can provide: (1) Food Provision, (2) Artisanal Fishing Opportunities, (3) Natural Products, (4) Carbon Storage, (5) Coastal Protection, (6) Sense of Place, (7) Coastal Livelihoods \& Economies, (8) Tourism \& Recreation, (9) Clean Waters and (10) Biodiversity. The Index score is the average of the 10 goal indices.

Despite some evidence provided by projects and case studies $^{168}$, contributing experts point to a lack of scientific information on the potential contribution of improvements in human well-being to reduced anthropogenic impacts on oceans, seas and marine resources. They suggest that further research needs to be undertaken on the effects of changes in lifestyle (e.g., production, consumption, social organization) on the sustainability of marine resource use. A more systematic analysis of lessons-learned from projects and initiatives could provide information and support the sharing of best practices.

\subsection{Impact of important classes of threats on the oceans, seas, marine resources and human well-} being nexus

Oceans, seas and marine resources are increasingly threatened, degraded or destroyed by human activities, reducing their ability to provide crucial ecosystem services. $^{169}$ Important classes of threats identified by contributing experts were climate change, marine pollution, unsustainable extraction of marine resources and physical alterations and destruction of marine and coastal habitats and landscapes.
One estimate found that at least $40 \%$ of the global oceans are heavily affected by human activities. ${ }^{170}$ A recent global analysis of threats to marine biodiversity warns against a possible future marine mass extinction event driven by increased human uses of the oceans. ${ }^{171}$ Already today, 30\% of the world's fish stocks are over-exploited, while more than $50 \%$ are fully exploited. ${ }^{172}$ Coastal habitats are under pressure, with approximately $20 \%$ of the world's coral reefs lost and another 20\% degraded. Mangroves have been reduced to between 30 to $50 \%$ of their historical cover, impacting biodiversity, habitat for fisheries, coastal protection from severe weather and tide events and carbon sequestration potential. Some $30 \%$ of seagrass habitats are estimated to have disappeared since the late $1800 .^{173}$ Over $80 \%$ of the world's 232 marine eco-regions report the presence of invasive species, which is considered the second most significant cause of biodiversity loss on a global scale. $^{174}$

The deterioration of coastal and marine ecosystems and habitats is negatively affecting human well-being worldwide, with more severe and immediate impacts on the vulnerable groups, including the poor, women, children, and indigenous peoples, due to their often high dependency on natural resources, lack of alternative options, and inability to protect themselves from natural disasters and other threats. Coastal regions and SIDS are particularly vulnerable to these challenges as oceans, seas and marine resources play a central role in their culture, while at the same time being tightly linked to their economies.

Given the Earth's limited natural resource base as suggested by the concept of "planetary boundaries"175, the foreseen global population growth to 9.6 billion people by $2050^{176}$, the persistence of unsustainable consumption and production patterns in high-income countries, and the increased economic "catching up" of developing countries with related increases in resource demands, are anticipated to aggravate the situation if no adequate counter measures are taken.

Coastal regions are more densely populated and experience higher rates of population growth and urbanization than the hinterland. This trend is expected to continue. ${ }^{177}$ Poorly planned and managed developments of coastal areas can have detrimental impacts on local marine ecosystems and the services they provide.

Negative impacts of climate change and other threats are already felt in coastal areas around the world and are expected to increase. ${ }^{178}$ More than 600 million people (around $10 \%$ of the current global population) live in coastal areas that are less than 10 meters above sea level. With regard to sea level rise, almost two-thirds of the 
world's cities with populations of over five million are located in at-risk areas. ${ }^{179}$ With sea level projected to rise further, large numbers of people might have to relocate and several small island developing States (SIDS) are at risk of being submerged. It is even possible that areas - and countries - might become uninhabitable long before they are submerged (e.g. due to intrusion of saltwater into coastal aquifers). ${ }^{180}$
Important classes of threats identified by contributing experts and their drivers and pressures are illustrated in Table 3-2, an adaptation of the Drivers-Pressures-StateImpacts-Responses (DPSIR) framework which intends to organize information about the state of the environment and reflects the complex chain of cause-and-effect in the interactions between society and the environment. ${ }^{181}$

Table 3-2. Drivers and pressures of important classes of threats affecting the nexus

\begin{tabular}{|c|c|c|c|c|}
\hline & Climate change & Marine pollution & $\begin{array}{l}\text { Unsustainable extraction of } \\
\text { marine resources }\end{array}$ & $\begin{array}{c}\text { Physical alterations and } \\
\text { destruction of marine and } \\
\text { coastal habitats and landscapes }\end{array}$ \\
\hline 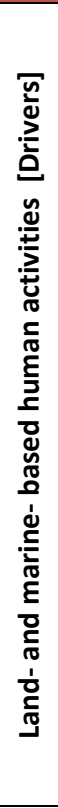 & $\begin{array}{l}\text { - Any activities leading to } \\
\text { release of greenhouse } \\
\text { gas into atmosphere } \\
\text { (e.g., combustion of } \\
\text { fossil fuels, animal } \\
\text { rearing, land-use change) } \\
\text { - Potential impacts of } \\
\text { emerging activities, such } \\
\text { as ocean geo-engineering } \\
\text { (e.g. } \mathrm{CO}_{2} \text { injection, ocean } \\
\text { fertilization) }\end{array}$ & $\begin{array}{l}\text { - Agriculture } \\
\text { - Aquaculture } \\
\text { - Industrial activities } \\
\text { - Maritime transport } \\
\text { - Fishing operations } \\
\text { - Dumping at sea } \\
\text { - Abandoned, lost and otherwise } \\
\text { - discarded fishing gear (ALDFG) } \\
\text { - Solid waste disposal } \\
\text { - Industrial and municipal sewage } \\
\text { discharge } \\
\text { - Damming of rivers and lakes, } \\
\text { - dredging } \\
\text { Offshore infrastructure; oil and } \\
\text { gas production; seabed mining }\end{array}$ & $\begin{array}{l}\text { - Overfishing } \\
\text { - IUU fishing, including } \\
\text { harmful subsidies that } \\
\text { contribute to IUU fishing } \\
\text { and overcapacity; abusive } \\
\text { and unsafe labour practices } \\
\text { and exploitation of poor } \\
\text { migrant workers } \\
\text { - Destructive fishing } \\
\text { practices, including harmful } \\
\text { bottom trawling, use of } \\
\text { explosives and poisons } \\
\text { - Inappropriate } \\
\text { deployment/deployment in } \\
\text { wrong areas of fishing gear } \\
\text { - Ballast water (shipping) } \\
\text { - Deep sea mining, offshore } \\
\text { oil and gas drilling }\end{array}$ & $\begin{array}{l}\text { - Unsustainable coastal } \\
\text { - Sevelopment } \\
\text { - Submarine infrastructure (e.g. } \\
\text { - Unsus) } \\
\text { recreational activities } \\
\text { - Shipping/Fishing operations in } \\
\text { fragile or vulnerable marine } \\
\text { areas } \\
\text { - Harvesting by local } \\
\text { communities for building } \\
\text { materials and energy } \\
\text { - Unsustainable aquaculture } \\
\text { - Dredging / marine sediment } \\
\text { extraction (e.g. sand removal) } \\
\text { - Potential impacts of emerging } \\
\text { activities, such as ocean geo- } \\
\text { engineering (e.g. CO }{ }_{2} \text { injection, } \\
\text { ocean fertilization) } \\
\text { - Land reclamation } \\
\text { - Beach nourishment }\end{array}$ \\
\hline 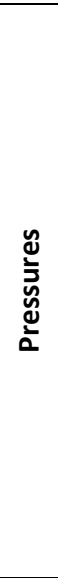 & $\begin{array}{l}\text { - Ocean warming } \\
\text { - Ocean acidification } \\
\text { - Sea level rise } \\
\text { - Changes in circulation } \\
\text { patterns (ocean currents) } \\
\text { - Increased frequency and } \\
\text { intensity of weather and } \\
\text { climate extremes } \\
\text { - Changes in hydrological } \\
\text { cycles (e.g. freshwater } \\
\text { flow, water storage, } \\
\text { evaporation) }\end{array}$ & $\begin{array}{l}\text { - Introduction of: } \\
\text { - Heavy metals } \\
\text { - Persistent organic pollutants } \\
\text { (POPs) } \\
\text { - Pesticides } \\
\text { - Nutrients (nitrogen and } \\
\text { phosphorus) } \\
\text { - Oil } \\
\text { - Plastics } \\
\text { - Munitions } \\
\text { - Hazardous substances } \\
\text { - Radioactive material } \\
\text { - Anthropogenic underwater noise } \\
\text { - Other particulate matter } \\
\text { - Alien invasive species }\end{array}$ & $\begin{array}{l}\text { - Seabed disturbances or } \\
\text { damage } \\
\text { - Removal of aggregates }\end{array}$ & $\begin{array}{l}\text { - Seabed disturbances or } \\
\text { damage } \\
\text { - Changes in sediment fluxes }\end{array}$ \\
\hline
\end{tabular}

Table 3-3 summarizes the impact of important classes of threats on the nexus, enumerates some illustrative scientific reports and contains areas for further research suggested by contributing experts. 
Table 3-3. Impact of important classes of threats on oceans, seas, marine resources and human well-being nexus Climate change (caused by anthropogenic greenhouse gas emissions) (I) Impact on Oceans, Seas and Marine Resources $\quad$ Illustrative scientific reports*

- Change in ocean temperature

- McCauley et al. (2015). Marine defaunation: Animal loss in the global ocean.

- Change in ocean salinity

- Changes in stratification

- Reduction of oxygen level

- IPCC (2014). Climate Change 2014: Impacts, Adaptation,

- Increasing acidification of ocean water

- Increased flooding and inundation, coastal erosion and coastal squeezing, saltwater intrusion in coastal aquifers

- Melting of permafrost contributing to release of methane (enhancing greenhouse gas effect)

- Decreased capacity to absorb and store greenhouse gas emissions

- Decline and loss of marine species

- Change in species range and survivorship due to changes in habitat and living conditions

- Change in resilience and adaptation capacity

- Changes in migratory patterns of fish stocks (increasingly poleward distribution of many marine species)

- Degradation or destruction of marine and coastal wildlife habitats, including nesting and spawning areas and nursery grounds and Vulnerability.

- Secretariat of CBD (2014). An Updated Synthesis of the Acidification on Marine Biodiversity.

- Doney et al. (2012). Climate Change Impacts on Marine Ecosystems.

- Scientific and Technical Advisory Panel (STAP) (2011). Hypoxia and Nutrient Reduction in the Coastal Zone. Advice for Prevention, Remediation and Research.

- Halpern et al. (2007). Evaluating and ranking the vulnerability of global marine ecosystems to anthropogenic threats. Impacts of Ocean

Further research areas suggested by contributing experts:

- Polar, Antarctic and Greenland ice sheet dynamics

- Downscaling of global climate model to regions

- Modelling of population change and resulting impacts on natural environment/resources

- Role of ecosystems in adaptation to climate change

- Ocean/climate dynamics (AMOC, PMOC, El Nino, etc.)

- Increase model resolution of boundary currents, shelf circulations and mesoscale dynamics in climate projections

- Establish observation programs for time series of volume and heat transport of ocean currents; Expand ocean climate observations to validate other datasets, ground truth satellite observations, verify models and improve understanding of ocean processes and heat fluxes; Monitoring of sea level rise at national/regional level (for model validation)

- Long term measuring and monitoring of ocean acidification [e.g., projections of spatial and temporal variability in its progress; impacts on marine biodiversity, incl. marine food web; indirect effects (e.g. on behaviour of marine species)]

- Impact on biodiversity and consequence for ecosystem functioning and stability; multispecies and food web models of climate change impacts on sustainable (re)production of marine resource; study place-based changes in species composition

- Study (shifts in) distribution and abundance of indicator species and experimental transplants to recover depleted habitats

- Improved economic evaluation of costs and benefits of climate change impacts on marine systems, and on their distribution

- Study scope for adaptation of marine biota to climate change; identification of resilience enhancing measures

- Ecological effects of emerging activities, such as ocean geo-engineering (e.g. $\mathrm{CO}_{2}$ injection, ocean fertilization) and open ocean aquaculture

- Storage and sequestration of carbon in coastal and marine ecosystems

Climate change (caused by anthropogenic greenhouse gas emissions) (II) Implications for Human Well-being Illustrative scientific reports*

- Increased vulnerability of local communities due to undermined natural protection barriers and damage or destruction of human settlements and infrastructure, including coastal transport infrastructure, services and operations (ports and other assets); loss of coastal investments; displacement of local communities

- Decreased availability of freshwater

- Reduced wild food fish availability - increased food insecurity and reduced sources of livelihood and employment (small-scale
- FAO (2014). Climate Change Adaptation in Fisheries and Aquaculture.

- High-level Panel of Experts on Food Security and Nutrition (2014). Sustainable fisheries and aquaculture for food security and nutrition.

- IPCC (2014). Climate Change 2014: Impacts, Adaptation, and Vulnerability.

- Ruckelshaus et al. (2013).
Further research areas suggested by contributing experts:

- Long-term monitoring and related integrative research (e.g. climate change and conflict)

- Coastal vulnerability assessments

- Develop realistic projections of impacts on communities, including climate-induced migration

- Identify ways to enhance resilience of communities; (cost benefit) analysis of adaptation measures/strategies, including specific strategies for vulnerable groups

- Research on how ecosystem based adaptation, and adoption of low cost good practices can reduce risks (and costs) of climate change impacts 
fisheries particularly affected)

- Loss of low-lying agricultural land or homeland; decreased availability of useable/arable land

- Decreased seed and feed availability for aquaculture as alternative livelihood decreased productivity undermining food security

- Reduced attractiveness of destination and quality of tourist experience -reduced sources of employment and revenue

- Increase of vector-borne (e.g. through mosquitoes and marine invertebrates) and water borne diseases (contact with contaminated water/food) in coastal areas
Securing ocean benefits for society in the face of climate change.

- WMO (2013): The Global Climate 2001-2010: A Decade of Climate Extremes.

- World Bank (2013). Turn Down the Heat: Climate Extremes, Regional Impacts, and the Case for Resilience.

- FAO/OECD (2012). Building resilience for adaptation to climate change in the agriculture sector.

Proceedings of a Joint FAO/OECD Workshop.
- Equity effects of climate change

- Identification of high priority coastal ecosystems for protection and restoration to reduce coastal community vulnerability

- Effect of on tourism sector in coastal areas

- Assess vulnerability of coastal transport infrastructure, services and operations (ports and other assets) at local level

- Conduct research on gender-specific impacts of climate change

Marine pollution from marine and land-based sources (I) Impact on Oceans, Seas and Marine Resources

- Creation of low oxygen "hypoxic" conditions, harmful algal blooms and dead zones and changes of ecosystems due to eutrophication

- Decreased sea water quality

- Accumulation of toxins in food web

- Contamination with toxic chemicals causing illnesses or death of marine species

- Spilled oils affecting animals and plants both from internal exposure (ingestion or inhalation) and from external exposure (skin and eye irritation) (e.g. reducing ability to maintain body temperatures)

- Decline and loss of marine species

- Degradation or destruction of marine and coastal wildlife habitats, including nesting and spawning areas and nursery grounds

- Potential effects on growth, reproduction and trophic interactions, including effect of hormones and pharmaceuticals in watersheds on estuaries and coastal animal populations

- Alien invasive species may outcompete local marine species and threaten marine food web

Illustrative scientific reports*

- UN World Ocean Assessment $(2015)^{182}$

- UNEP (2014). Plastic Debris in the Ocean.

- Wright et al. (2013).The physical impacts of microplastics on marine organisms: a review.

- Secretariat of CBD (2012). Scientific Synthesis of the Impacts of Underwater Noise on Marine and Coastal Biodiversity and Habitats.

- IUCN (2010). Marine Menace: Alien invasive species in the marine environment.

- UNEP (2009). Marine Litter: A Global Challenge.

- GESAMP (2009). Pollution in the open oceans: a review of assessments and related studies.
Further research areas suggested by contributing experts:

- Census of heavily populated areas with important industrial activities and fisheries; mapping of risk areas where industries that discharge materials are located

- Better understanding of ecology of pollution impacts and quantification of impacts, especially extrapolating from individual impacts to population and ecosystem impacts

- Cumulative and/or simultaneous impact of multi-stress factors on marine and coastal ecosystems

- Link between marine coastal ecosystem change and occurrence of harmful algae blooms and dead zones/hypoxia

- Impact of contaminants of emerging concern (e.g. from micro-plastics, pharmaceuticals, personal care products, ethylene dichloride)

- Impact of nanomaterials on biota

- Linking terrestrial and coastal/marine policies to address pollution from land-based sources

- Impacts of underwater noise

- Depollution techniques and pollution preventive measures

- Pathways and fate of contaminants (especially, POPS, heavy metals and microplastics) into marine environments

- Ecological threshold of contaminants or water quality standards for ecosystem functioning and stability

- Understanding the extent and effects of alien invasive species (lags behind that for terrestrial invasive species)

- Economic assessment of impact of alien invasive species on coastal and marine environment, including deep and open oceans

- Effectiveness of eradication programs for alien invasive species

- Cascading effects of alien invasive species on marine food web and ecosystem functioning and stability 
Implications for Human Well-being

- (Increase of) health hazards such as:

- freshwater pollution;

- human intoxication/poisoning (e.g. toxins in fish and shellfish):

- accumulation of plastic nanoparticles in food web

- degradation of bathing water quality;

- skin diseases from exposure;

- Displacement of local communities (by cases of pollution which make economic activities inviable for years or decades)

- Decrease in attractiveness of destination for tourists - decrease in related job opportunities and revenues

- Decreased wild food fish availability significant loss of food supply and income

- Decrease in coastal real estate value (e.g. due to unhealthy water quality and/or degraded landscape/seascapes)

- Decreased seed and feed availability for aquaculture as alternative livelihood decreased productivity undermining food security

- Introduction of alien invasive species reduces or potentially causes disappearance of commercial or food-important marine resources

- Increased spread of diseases as a result of harmful algae blooms worsened by alien invasive species

- Direct and indirect impacts on coastal transport infrastructure, services and operations (ports and other assets), including fouling of marine infrastructure caused by alien invasive species

- Threat to navigation and safety at sea through abandoned, lost and otherwise discarded fishing gear (ALDFG)
Illustrative scientific reports*

- UN World Ocean Assessment $(2015)^{183}$

- UNEP (2013). Regional Plan on Management of Marine Litter in the Mediterranean.

- Ngah et al. (2012). Marine pollution trend analysis of tourism beach in Peninsular Malaysia.

- Hester and Harrison (2011). Marine Pollution and Human Health.

- Corcoran et al. (2010). Sick Water? The central role of wastewater management in sustainable development.

- Mouat et al. (2010). Economic Impacts of Marine Litter.
Further research areas suggested by contributing experts:

- More marine ecosystem evaluation studies

- Quantification of socioeconomic impacts

- Economic evaluation of waste water treatment plants

- Aggregate effects of marine pollution on food quality and health

- Health implications of microplastic ingestion

- More studies about successful participatory coastal rehabilitation projects and on ways to replicate them

- Effects of visual marine pollution on destination choice made by the tourists

- Agricultural development and pollution from landbased sources and activities (LBS)

- Impact of contaminants on human health

- Impacts of harmful algal blooms on human health

- Externalities resulting from port activities (air pollution, noise, land use, dredging costs and impact on environment, etc.)

- Socio-economic impact of specific alien invasive species invasions

- Potential use of alien invasive species for livelihoods (e.g. lionfish)

Unsustainable extraction of marine resources (I)

\begin{tabular}{|c|c|c|}
\hline Impact on Oceans, Seas and Marine Resources & Illustrative scientific reports* & Further research areas suggested by contributing experts: \\
\hline $\begin{array}{l}\text { - Decline and loss of marine species - } \\
\text { threatening marine food web and overall } \\
\text { ecosystem functioning and stability } \\
\text { - Changes in ecological interactions between } \\
\text { species with unpredictable consequences for } \\
\text { food web and ecosystem functioning and } \\
\text { stability } \\
\text { - Capturing and mortality of non-target species } \\
\text { (by-catch), including endangered, threatened } \\
\text { and protected } \\
\text { - Damage and/or destruction of critical and } \\
\text { vulnerable fishing grounds and marine and } \\
\text { coastal habitats } \\
\text { - Degradation of water quality }\end{array}$ & $\begin{array}{l}\text { - UN World Ocean Assessment } \\
(2015)^{184} \\
\text { - FAO (2014). The State of } \\
\text { World Fisheries and } \\
\text { Aquaculture - Opportunities } \\
\text { and Challenges. } \\
\text { - Agnew et al. (2009). } \\
\text { Estimating the Worldwide } \\
\text { Extent of Illegal Fishing. }\end{array}$ & $\begin{array}{l}\text { - Environmental impacts of deep sea mining and } \\
\text { adequacy of environmental management approaches } \\
\text { and regulatory regimes } \\
\text { - Better quantification of spatial extent of bottom } \\
\text { trawling (and uses of other gears such as gill nets) } \\
\text { - Rehabilitation of depleted invertebrate wild stock } \\
\text { - Research on properties that make marine ecosystems } \\
\text { resilient (or lose resilience) }\end{array}$ \\
\hline
\end{tabular}




\begin{tabular}{|c|c|}
\hline Implications for Human Well-being & Illustrative scientific reports* \\
\hline $\begin{array}{l}\text { - Decreased wild food fish availability - } \\
\text { significant loss of food supply and income } \\
\text { - Decrease in attractiveness of destination for } \\
\text { tourists - decrease in related job } \\
\text { opportunities and revenues } \\
\text { - Possible displacement of local communities by } \\
\text { abusive or unregulated extraction of } \\
\text { resources (e.g. reduced fishing opportunities } \\
\text { generating internal or external migration } \\
\text { flows) } \\
\text { - Unacceptable working conditions affecting } \\
\text { fishers and fish workers; child labor } \\
\text { - Decreased seed and feed availability for } \\
\text { aquaculture as alternative livelihood - } \\
\text { decreased productivity undermining food } \\
\text { security }\end{array}$ & $\begin{array}{l}\text { - UN World Ocean Assessment } \\
(2015)^{185} \\
\text { - High-level Panel of Experts on } \\
\text { Food Security and Nutrition } \\
\text { (2014). Sustainable fisheries } \\
\text { and aquaculture for food } \\
\text { security and nutrition. } \\
\text { - UNCTAD (2014). The Oceans } \\
\text { Economy: Opportunities and } \\
\text { Challenges for Small Island } \\
\text { Developing States. } \\
\text { - Srinivasan et al. (2012). } \\
\text { Global fisheries losses at the } \\
\text { exclusive economic zone } \\
\text { level, } 1950 \text { to present. }\end{array}$ \\
\hline
\end{tabular}

Further research areas suggested by contributing experts:

Physical alterations and destruction of marine and coastal habitats and landscapes (I)

Impact on Oceans, Seas and Marine Resources

- Decline and loss of marine species

- Destruction, displacement or alteration of marine and coastal wildlife habitats, including nesting and spawning areas and nursery grounds

- Impact on ecosystem functioning and stability

- Impact on shorelines and coastal stability; coastal erosion

- Alteration of microbial structure and biogeochemistry, including greenhouse gas cycles
- Systematic assessment of poverty dimensions associated with livelihoods in fisheries and aquaculture

- Estimated value of fisheries beyond value of fish resources or harvest sector

- Impact of IUU fishing on local communities (e.g. significant loss of income); link between IUU fishing and unacceptable working conditions

- Identification of most suitable options for sustainable fish farming, especially in developing countries

- Social (employment) versus economic (profit) trade-offs in uses of living marine resources

- Costs and benefits of shift to more sustainable practices
- United Nations World Ocean Assessment $(2015)^{186}$

- Liu and Su (2015).

Vulnerability of Nearshore Ecosystems from Rapid Intensive Coastal Development.

- Halpern et al. (2008). A global map of human impact on marine ecosystems.
Further research areas suggested by contributing experts:

- Evaluation and mapping (in multiple terms) of coastal ecosystems

- Impact of underwater noise

- Systematic assessment of deep-sea ecosystems

- Specific impacts of physical alterations on marine and coastal ecosystems and resilience of affected ecosystems

- Ecological effects of emerging activities, such as ocean geo-engineering (e.g. CO2 injection, ocean fertilization), renewable energy and open ocean aquaculture

- Study tourism operators and land developers' level of involvement and concern in nature conservation

- Release of carbon from coastal ecosystems by physical alteration and land use change

- Impacts of eroded sand from beach nourishment on benthic communities

Physical alterations and destruction of marine and coastal habitats and landscapes (II)

Implications for Human Well-being

- Decreased wild food fish availability threatening food security

- Increased vulnerability of local communities due to undermined natural protection barriers and degradation and destruction of coastal settlements

- Reduced attractiveness of destination and quality of tourist experience -reduced sources of employment and revenue

- Loss of access to marine and coastal resources for livelihoods and recreation (e.g. hotel resorts not allowing passage to beach) affecting food security and income (smallscale fisheries)

- Decreased seed and feed availability for aquaculture as alternative livelihood

- Displacement of communities
Further research areas suggested by contributing experts:

- Evaluation of impacts of physical alterations on marine and coastal ecosystems and subsequent effects on communities

- Adaptive capacity of coastal communities

- Development of ecosystem-based solutions for coastal defence and "hybrid-engineering"

- Cost benefit analysis of coastal development

${ }^{*}$ Further illustrative scientific reports are available in Annex I. ${ }^{18}$ 
While the scientific coverage of the different threats and their impacts varies, contributing experts strongly believe that oceans, seas and marine resources are severely affected, with negative implications for human well-being. They found that the scientific coverage of the impact of marine- and land-based human activities on oceans, seas and marine resources is often better documented than the implications of the deterioration of oceans, seas and marine resources for human well-being. There is a therefore a need to improve further the scientific coverage of socio-economic impacts of threats affecting the nexus.

Different human activities and natural processes affect marine and coastal ecosystems simultaneously, interacting and leading to cumulative effects. Contributing experts point out that a better understanding of cumulative and interactive effects of different human activities is needed to develop more effective integrated management and is vital to properly evaluate the consequences of human activities, especially of emerging activities like geo-engineering or industrial development in extreme areas (e.g. Arctic and deep-water). According to the Assessment of Assessments, science has however limited ability to detect both indirect and cumulative effects as they can be non-linear and manifest only after long time delays, which makes them very difficult to predict. ${ }^{188}$
3.3. Illustrative case studies - the need for an integrated approach when dealing with the nexus

Table 3-4 contains a number of case studies illustrating how regions and countries have been addressing threats affecting the nexus, with benefits for both human communities and the environment (see also Annex I). They underline the connection between ecosystem integrity and societal well-being, and the need for integrated approaches. The majority of case studies reviewed focuses on conservation and protection measures targeted at a particular threat. Few aim to address several threats simultaneously. Apart from the creation of marine protected areas and other conservation measures, the creation of sustainable livelihoods, the use of policy regulations as well as capacity-building, education and awareness-raising measures are some of the forms of interventions used. The quantitative evaluation of the impacts of respective projects, in particular as they relate to human well-being, is often not existent. Some of the lessons learned and best practices of existing case studies could possibly be useful for and adapted to other countries and regions of the world.

Table 3-4. Selected regional and local case studies of addressing threats affecting the nexus*

\begin{tabular}{|c|c|c|c|c|}
\hline Case study & Challenges faced & Measures undertaken & $\begin{array}{l}\text { Impact on Oceans, Seas } \\
\text { and Marine Resources }\end{array}$ & $\begin{array}{l}\text { Implications for } \\
\text { Human well-being } \\
\end{array}$ \\
\hline \multicolumn{5}{|l|}{ Regional level } \\
\hline $\begin{array}{l}\text { Marine litter, } \\
\text { regional seas in } \\
\text { Europe }\end{array}$ & $\begin{array}{l}\text { Mortality of marine } \\
\text { species (e.g., through } \\
\text { entanglement and } \\
\text { ingestion); } \\
\text { loss of ecosystem } \\
\text { functioning and services; } \\
\text { marine habitat } \\
\text { alteration, degradation, } \\
\text { or destruction }\end{array}$ & $\begin{array}{l}\text { Prevention through } \\
\text { awareness-raising/market- } \\
\text { based instruments (e.g. } \\
\text { plastic bag reduction by } \\
\text { banning or taxing); Regional } \\
\text { Action Plan for the } \\
\text { Management of Marine } \\
\text { Litter, including adequate } \\
\text { waste reducing/reusing/ } \\
\text { recycling measures; } \\
\text { extended producer } \\
\text { responsibility; establishment } \\
\text { of voluntary agreements with } \\
\text { retailers and supermarkets; } \\
\text { clean-up of litter }\end{array}$ & $\begin{array}{l}\text { - Reduced risk of } \\
\text { environmental impacts } \\
\text { due to reduced marine } \\
\text { litter such as plastic } \\
\text { items (e.g. significant } \\
\text { reduction of plastic bag } \\
\text { usage) }\end{array}$ & $\begin{array}{l}\text { - Maintenance of fish catch } \\
\text { and tourism revenue } \\
\text { - Revenue through levies } \\
\text { and taxes } \\
\text { - Reduced marine litter } \\
\text { removal activities and } \\
\text { damage to nautical } \\
\text { equipment }\end{array}$ \\
\hline $\begin{array}{l}\text { Marine ecosystem } \\
\text { conservation: } \\
\text { preserving the } \\
\text { wealth of natural } \\
\text { capital, } \\
\text { Mediterranean } \\
\text { region }\end{array}$ & $\begin{array}{l}\text { Biodiversity in region } \\
\text { severely at risk: } 19 \% \text { of } \\
\text { all species threatened } \\
\text { with extinction and } 1 \% \\
\text { already extinct at } \\
\text { regional level }\end{array}$ & $\begin{array}{l}\text { Network of Marine Protected } \\
\text { Areas (170 MPAs; } 2 \text { UNESCO } \\
\text { World Heritage Sites and } 5 \\
\text { Biosphere Reserves); MedPan } \\
\text { as coordination framework } \\
\text { for conservation activities; } \\
\text { changes of unsustainable } \\
\text { fisheries practices (catch } \\
\text { monitoring etc.) }\end{array}$ & $\begin{array}{l}\text { - Increase in diversity, } \\
\text { abundance, and average } \\
\text { size of exploited species } \\
\text { - Ecosystems rebuilt } \\
\text { - Preservation of } \\
\text { ecological processes and } \\
\text { coastal and marine } \\
\text { habitat }\end{array}$ & $\begin{array}{l}\text { - Support of economically } \\
\text { valuable activities (e.g., } \\
\text { tourism, small scale } \\
\text { sustainable fisheries) } \\
\text { - Maintenance of } \\
\text { associated cultural values }\end{array}$ \\
\hline $\begin{array}{l}\text { Economic, social and } \\
\text { environmental } \\
\text { benefits from } \\
\text { sustainable }\end{array}$ & $\begin{array}{l}\text { Over-exploitation of the } \\
\text { region's oceanic fishery } \\
\text { resources }\end{array}$ & $\begin{array}{l}\text { Regional Strategic Action } \\
\text { Programme (SAP) for } \\
\text { International Waters of } \\
\text { Pacific Islands to integrate }\end{array}$ & $\begin{array}{l}\text { Catches of bigeye, } \\
\text { albacore, and yellow fin } \\
\text { tuna at or below } \\
\text { maximum sustainable }\end{array}$ & $\begin{array}{l}\text { - Increase in fish catches } \\
\text { by a factor of } 2 \\
\text { - Number of people } \\
\text { employed by local }\end{array}$ \\
\hline
\end{tabular}




\begin{tabular}{|c|c|c|c|c|}
\hline $\begin{array}{l}\text { management of tuna } \\
\text { fisheries: The } \\
\text { GEF/UNDP Pacific } \\
\text { Islands Oceanic } \\
\text { Fisheries } \\
\text { Management } \\
\text { Project, Western } \\
\text { Pacific }{ }^{191}\end{array}$ & & $\begin{array}{l}\text { national and regional } \\
\text { sustainable development } \\
\text { priorities; Sustainable } \\
\text { management of regional/ } \\
\text { transboundary fish stocks }\end{array}$ & $\begin{array}{l}\text { yield (stocks at lower } \\
\text { risk of being overfished) } \\
\text { - Decreased discarding of } \\
\text { non-target species - } \\
\text { rates for longliners } \\
\text { targeting albacore, } \\
\text { bigeye, and yellowfin } \\
\text { tuna have decreased } \\
\text { from an average of } 12.4 \text {, } \\
3.5 \text { and } 3.85 \% \\
\text { respectively to nearly } \\
\text { 0\% for all species. } \\
\text { Similar decreases were } \\
\text { seen for purse seine } \\
\text { fishery. }\end{array}$ & $\begin{array}{l}\text { inshore tuna processing } \\
\text { facilities doubled } \\
\text { - Increase in fishery } \\
\text { exports by US\$ } 134 \\
\text { million, representing a } \\
\text { third of the region's } \\
\text { overall exports } \\
\text { - Increase in foreign fishing } \\
\text { access fees by } 24 \%\end{array}$ \\
\hline $\begin{array}{l}\text { Nutrient pollution } \\
\text { reduction, } \\
\text { Danube/Black Sea } \\
\text { Basin }\end{array}$ & $\begin{array}{l}\text { Fertilisers used in } \\
\text { agriculture leading to } \\
\text { nutrient pollution } \\
\text { (nitrogen, phosphorus) } \\
\text { from farm run-off plus } \\
\text { increase in "point } \\
\text { sources" of pollution } \\
\text { from poorly or untreated } \\
\text { wastewater and large } \\
\text { scale livestock farms } \\
\text { (manure) - creation of } \\
\text { hypoxic/low oxygen } \\
\text { conditions, a number of } \\
\text { species and benthic } \\
\text { ecosystems disappeared, } \\
\text { economic losses }\end{array}$ & $\begin{array}{l}\text { Danube and Black Sea } \\
\text { Strategic Action Programmes- } \\
\text { reform of policies, legislation } \\
\text { and institutions related to } \\
\text { reducing nutrient pollution in } \\
\text { the basin, including adoption } \\
\text { of best agricultural practices } \\
\text { for manure management and } \\
\text { fertiliser application, phase } \\
\text { out of phosphorus-containing } \\
\text { detergents, promotion of } \\
\text { industrial cleaner production } \\
\text { etc.; capacity-building and } \\
\text { partnerships }\end{array}$ & $\begin{array}{l}\text { - Substantial reduction in } \\
\text { nutrient pollution } \\
\text { - Restoration of good } \\
\text { water quality } \\
\text { - Decrease of biomass of } \\
\text { phytoplankton } \\
\text { - Return of key benthic } \\
\text { "phylophora" habitat } \\
\text { - Return of many species } \\
\text { considered locally } \\
\text { extinct }\end{array}$ & $\begin{array}{l}\text { Restoration and } \\
\text { maintenance of } \\
\text { environmental and } \\
\text { socioeconomic benefits } \\
\text { for nearly } 160 \text { million } \\
\text { residents of the basin }\end{array}$ \\
\hline \multicolumn{5}{|l|}{ Local level } \\
\hline $\begin{array}{l}\text { Development of } \\
\text { mariculture activities } \\
\text { as an alternative } \\
\text { livelihood option for } \\
\text { coastal communities: } \\
\text { Milkfish farming in } \\
\text { Kilwa and Mtwara } \\
\text { districts, Republic of } \\
\text { Tanzania }\end{array}$ & $\begin{array}{l}\text { Increased overfishing } \\
\text { and use of destructive } \\
\text { fishing practices (e.g. } \\
\text { dynamite fishing) } \\
\text { resulting in decline of } \\
\text { fish quality and quantity }\end{array}$ & $\begin{array}{l}\text { Conservation measures, } \\
\text { including marine parks, } \\
\text { reserves and protected areas; } \\
\text { development of mariculture } \\
\text { activities as alternative } \\
\text { livelihood }\end{array}$ & $\begin{array}{l}\text { - Protection of oceans } \\
\text { and marine and coastal } \\
\text { biodiversity } \\
\text { - Restoration and } \\
\text { conservation of wild } \\
\text { fishery }\end{array}$ & $\begin{array}{l}\text { - Welfare gains (e.g. } \\
\text { improved dietary intake, } \\
\text { better capacity to meet } \\
\text { household food needs, } \\
\text { ability to purchase new } \\
\text { assets, ability to meet } \\
\text { student requirements for } \\
\text { school) } \\
\text { - Improved food security } \\
\text { (from two to three meals } \\
\text { a day) } \\
\text { - Enhancement of } \\
\text { investments and savings }\end{array}$ \\
\hline $\begin{array}{l}\text { Community-based } \\
\text { green sea turtle } \\
\text { conservation, The } \\
\text { Comoros }^{194}\end{array}$ & $\begin{array}{l}\text { Turtle poaching leading } \\
\text { to conflicts between } \\
\text { turtle poachers and } \\
\text { community of Itsamia } \\
\text { (willing to address issue } \\
\text { of poaching) }\end{array}$ & $\begin{array}{l}\text { Education of entire } \\
\text { community and awareness } \\
\text { raising; Beach patrols, } \\
\text { monitoring of nesting sites, } \\
\text { involvement of police, } \\
\text { confiscation of poachers' } \\
\text { boats; Additional } \\
\text { conservation efforts, incl. } \\
\text { implementing and enforcing } \\
\text { fishing regulations, cleaning } \\
\text { of beaches and collection of } \\
\text { household waste }\end{array}$ & $\begin{array}{l}\text { - Significant reduction of } \\
\text { turtle poaching } \\
\text { - Maintenance of large } \\
\text { fish populations } \\
\text { - Increase in fish biomass } \\
\text { from } 16 \text { to } 32 \mathrm{~kg} / 100 \mathrm{~m} 2\end{array}$ & $\begin{array}{l}\text { - Creation of successful } \\
\text { eco-tourism generating } \\
\text { income and jobs } \\
\text { - Poverty eradication } \\
\text { benefits (e.g. health } \\
\text { initiatives and acquisition } \\
\text { of aid to subsidize local } \\
\text { doctor and hospital visits) } \\
\text { - Sustainability of fishing } \\
\text { opportunities allows } \\
\text { fishers to earn livelihood } \\
\text { to meet their needs }\end{array}$ \\
\hline $\begin{array}{l}\text { Ban of queen conch } \\
\text { harvesting by } \\
\text { fisheries: A recent } \\
\text { conservation co- }\end{array}$ & $\begin{array}{l}\text { Conch fishery decline to } \\
\text { unsustainable levels due } \\
\text { to unsustainable and } \\
\text { illegal fishing }\end{array}$ & $\begin{array}{l}\text { Conservation and } \\
\text { management measures, } \\
\text { including designation of } \\
\text { biosphere reserve (in }\end{array}$ & $\begin{array}{l}\text { - Increased health and } \\
\text { quality of marine flora } \\
\text { and fauna } \\
\text { - Restoration and }\end{array}$ & $\begin{array}{l}\text { - Lobster and deep-sea } \\
\text { snapper harvests provide } \\
\text { a new source of income } \\
\text { and seafood for local }\end{array}$ \\
\hline
\end{tabular}




\begin{tabular}{|c|c|c|c|c|}
\hline $\begin{array}{l}\text { management } \\
\text { initiative in Banco } \\
\text { Chinchoro, Quintana } \\
\text { Roo, Mexico }\end{array}$ & & $\begin{array}{l}\text { consultation with local } \\
\text { communities), no-take zones } \\
\text { and conch harvesting bans; } \\
\text { establishment of alternative } \\
\text { livelihoods }\end{array}$ & $\begin{array}{l}\text { conservation of conch } \\
\text { fishery }\end{array}$ & $\begin{array}{l}\text { communities } \\
\text { - Increased emphasis on } \\
\text { eco- tourism leading to } \\
\text { significant improvements } \\
\text { in community livelihoods }\end{array}$ \\
\hline $\begin{array}{l}\text { Ecosystem Health } \\
\text { Report Card for } \\
\text { Managing Chilika } \\
\text { Lake of Odisha State: } \\
\text { a collaborative } \\
\text { approach, India }\end{array}$ & $\begin{array}{l}\text { Deterioration of the } \\
\text { lake's ecosystem due to } \\
\text { natural processes and } \\
\text { human activities }\end{array}$ & $\begin{array}{l}\text { Restoration strategy based on } \\
\text { ecosystem approach; } \\
\text { development of "Ecosystem } \\
\text { Health Report Card" to } \\
\text { diagnose problems and } \\
\text { identify intervention } \\
\text { priorities; messages used in } \\
\text { communication strategy to } \\
\text { engage stakeholders for } \\
\text { sustainable management of } \\
\text { ecosystem }\end{array}$ & $\begin{array}{l}\text { - Eight-fold increase in } \\
\text { annual fish and prawn } \\
\text { landings } \\
\text { - Decrease of alien } \\
\text { invasive species } \\
\text { - Protection of marine } \\
\text { environment from land- } \\
\text { based activities }\end{array}$ & $\begin{array}{l}\text { - Increase in fish catch } \\
\text { - Increase of monthly } \\
\text { family income of } \\
\text { fishermen } \\
\text { - Development of } \\
\text { community-based } \\
\text { ecotourism as alternative } \\
\text { livelihood }\end{array}$ \\
\hline $\begin{array}{l}\text { Linking Conservation } \\
\text { and Livelihoods in } \\
\text { the Oracabessa Bay } \\
\text { Fish Sanctuary, } \\
\text { Jamaica }{ }^{197}\end{array}$ & $\begin{array}{l}\text { Severe degradation of } \\
\text { marine ecosystems and } \\
\text { high loss of biodiversity - } \\
\text { declining fish catch and } \\
\text { challenges for local } \\
\text { tourism industry }\end{array}$ & $\begin{array}{l}\text { 2-phase project to preserve } \\
\text { the marine ecosystem and } \\
\text { increase biodiversity and } \\
\text { species population; creation } \\
\text { of a no-fishing zone } \\
\text { protecting critical breeding } \\
\text { areas and fish habitat; } \\
\text { improve surveillance and } \\
\text { monitoring of fish, turtle, and } \\
\text { coral populations within } \\
\text { sanctuary; strengthen } \\
\text { community capacity to } \\
\text { manage its marine resources; } \\
\text { removal of debris from } \\
\text { beaches }\end{array}$ & $\begin{array}{l}\text { - Increase in coral reefs } \\
\text { by } 153 \% \text {, fish density by } \\
272 \% \text {, fish size by } 16 \% \text {, } \\
\text { fish biomass by } 564 \% \\
\text { - Reduction of algae by } \\
43 \% \\
\text { - Several species made a } \\
\text { comeback or recovered } \\
\text { - Improved sea turtle } \\
\text { nesting conditions and } \\
\text { hatching rates }\end{array}$ & $\begin{array}{l}\text { - Generation of alternative } \\
\text { income opportunities } \\
\text { through the project } \\
\text { (fishermen re-employed } \\
\text { as coral gardeners and } \\
\text { tour guides) } \\
\text { - Income from ecotourism } \\
\text { and collection/sale of } \\
\text { nutrient-rich debris } \\
\text { - Involvement of youth in } \\
\text { project elaboration to } \\
\text { ensure future marine } \\
\text { conservation }\end{array}$ \\
\hline
\end{tabular}

*Further illustrative case studies are available in Annex I.

A number of methods can be used to assess the socioeconomic impacts of oceans-related conservation measures and policies and should ideally be applied before implementation: (1) project appraisal and evaluation methods, including some mainstream methods such as cost-benefit analysis, and other less frequently used but promising methods such as social return on investment or multi-criteria analysis; (2) bio-economic models; (3) indicator systems; and (4) social surveys. As an example, the Marine Institute of Plymouth University recently developed the Integrated Marine Protected Areas SocioEconomic Monitoring (IMPASEM) framework to monitor and assess the socioeconomic effects of marine protected areas within the PANACHE project. ${ }^{199}$

Asked whether overall the sum of existing projects and programmes at various geographical levels "added up" to a more sustainable management of oceans, seas and marine resources and an increase in human well-being, contributing experts note that, despite a multitude of different programs and initiatives, there seems to be a lack of common vision and integration among them, which can lead to duplications, overlaps, gaps and possibly conflicting actions by different actors. The quantitative and qualitative level of projects and programmes across various geographical regions varies. Some programs and projects are not necessarily commensurate with the needs on the ground. Contributing experts find that that projects and programmes are often able to result in more sustainable oceans management at the local and community scales, but need to be scaled up to the national and regional level. A challenge perceived is the lack of sufficient resources human, financial, and knowledge-coupled with a lack of political will to tackle issues at the scale that is required. The implementation of national action plans, strategies and policies aimed at sustainable development is seen as being important to support ongoing efforts.

3.4. Towards an integrated approach when dealing with the oceans, seas, marine resources and human well-being nexus

Oceans, seas and marine resources support the human well-being of all people by contributing to poverty eradication, food security, the creation of sustainable livelihoods and jobs, human health and protection from natural disasters. They are the primary regulator of the global climate and an important sink for greenhouse gases, while also providing humans with water and oxygen. However, marine- and land-based human activities often threaten ecosystem integrity and hamper the provision of ecosystem services crucial to humans and sustainable development. 
Good governance, an enabling environment, sustainable land- and marine-based human activities, and adequate measures will be required to reduce the negative anthropogenic impacts on the marine environment. Projects and measures should ideally be designed and implemented in an integrated, cross-sectoral and crossscale manner, in line with the ecosystem approach and involving all stakeholders. Terrestrial and marine/coastal governance should be linked, specifically addressing the impact of land-based activities on marine and coastal environments (e.g. marine pollution).

An ecosystem approach to ocean management is required, which considers the entire ecosystem, including humans, in an integrated manner and takes into account the cumulative impacts of different sectors and human activities. The United Nations General Assembly noted that such approaches should be "focused on managing human activities in order to maintain and, where needed, restore ecosystem health to sustain goods and environmental services, provide social and economic benefits for food security, sustain livelihoods in support of international development goals" ... "and conserve marine biodiversity". ${ }^{200}$ Marine spatial planning (MSP) and integrated coastal zone management (ICZM) are some of the management tools that play an important role, particularly in relation to managing conflicts of use. A multitude of measures can be implemented to restore, conserve and protect oceans, seas and marine resources such as the creation of marine protected areas and reserves. In this regard, it should be kept in mind that sustainable alternative livelihood opportunities might have to be created simultaneously so as not to undermine the livelihoods of local populations. Policy regulations and/or incentives might be necessary to change the behaviour of stakeholders and encourage their engagement in conservation and protection measures.

High-quality data can support effective ecosystem management (see as an example Box 3-5). In support of the World Ocean Assessment, the Gramed database ${ }^{201}$ is expected to be updated to ensure that a single portal will enable those interested to identify the information on which the first World Ocean Assessment is based and help them to access it. ${ }^{202}$ In the past, scientific assessments contributed solid foundations in terms of information systems, for example the Census of Marine Life ${ }^{203}$ with the Ocean Biogeographic Information System (OBIS) ${ }^{204}$. According to contributing experts, comprehensive databases, first at the country and then at the regional level, are required. Research institutions within each region should seek to work collaboratively to ensure that research efforts are not duplicated, and that limited resources are efficiently utilized. The observation and monitoring of marine and coastal ecosystems are important to identify changes over time, assess the effectiveness of implemented measures and policies and allow decisionmakers to develop appropriate and timely responses. The Global Ocean Observing System (GOOS) is a good example of a system for observations, modelling and analysis of marine and ocean variables to support marine science, assessment of change and operational ocean services worldwide. Its three advisory bodies ${ }^{205}$ supply scientific studies and expertise. One of them, the newly created Biology and Ecosystems Panel, will, among others, identify major scientific and societal challenges that require sustained ocean biology and ecosystem variable observations. $^{206}$

\section{Box 3-5. Space technology data for ecosystem} management

Space technology and other spatial applications can supplement in-situ observations and provide valuable nearreal time observations of physical, chemical and some biological parameters at the sea surface and help overcome some of the issues caused by the trans-boundary nature of the oceans. Several key ocean parameters can be obtained in this manner (e.g. ocean bottom character, contaminants, heat flux, ice distribution, ocean colour, salinity, sea level, stream flow, surface currents, surface waves, temperature, wind speed and direction, and upper layer zooplankton abundance). Space technology can also support the management of biodiversity and wildlife, for example by tracking tagged animals. Other ways of using satellite data are being explored, including for tracking illegal, unregulated and unreported fishing. ${ }^{207}$

The illustrative case studies presented in Section 3.3 confirm the close inter-linkages between oceans, seas, marine resources and human well-being and demonstrate that actions impacting one area of the nexus may also have an effect on the other areas. This aligns with the concept of a network of SDGs with a multitude of interactions and synergies (see chapter 2 ). In this context, future scientific research needs to be integrative and cross-sectoral and further "system or cluster thinking" approaches.

Scientific information combined with relevant knowledge from experiences in implementing concrete projects can guide policy-making and activities. A collection of relevant scientific reports organized by topics, as presented in Annex II of this chapter, could be useful. In this context, the continuation and update of the Gramed database ${ }^{208}$ could be considered. The scientific coverage of socio-economic aspects of the nexus and threats affecting it needs to be improved. Enhanced trans-/multidisciplinary research is 
required, with natural and social scientists working together with holders of relevant traditional and experiential knowledge, to better understand the nature of the complex interactions between humans and marine and coastal ecosystems. More research towards valuing ecosystem services, which might in turn encourage the protection, conservation and more sustainable use of oceans, seas and marine resources, is required.

Contributing experts indicate a need to strengthen the communication between scientists, practitioners, decisionmakers and the wider public. All stakeholders need to be engaged in a more effective and systematic manner. Institutional barriers to an effective science-policy interface should be eliminated, in order to enable closer collaboration among researchers, practitioners and government officials. Research could sometimes be more demand-driven and focused on policy-relevant information rather than on knowledge and research gaps. Research findings could be disseminated to the wider public for the purpose of education and increased awareness. The effectiveness of environmental education and engagement programmes with respect to changing the behaviours of resource users and decision makers could be analysed.

Human well-being cannot be achieved without the protection and conservation of the Earth's ecosystem. To maintain the quality of life that the oceans have provided to humankind, a change will be required in how humans view, manage and use oceans, seas and marine resources. Science can play an important supporting role in this regard.

Annex 1 (Extended versions of Table 3-1, 3-3, 3-4)

Given its large size, Annex 1, containing extended versions of Tables 3-1, 3-3, 3-4 is available on the DESA-administered Sustainable Development Knowledge Platform under: https://sustainabledevelopment.un.org/globalsdreport/201 $\underline{5}$. 


\section{Chapter 4. Disaster Risk Reduction: A Cross-cutting Necessity in the SDGs}

\subsection{Global targets in two frameworks}

Since the year 2000, natural disasters have caused the loss of life of over 1.1 million and affected another 2.7 billion people ${ }^{209,210}$. Using another metric more known in the health sector, around 42 million human life years are lost in internationally reported disasters each year, a setback to development comparable to diseases such as tuberculosis ${ }^{211}$. While improvements in disaster risk management have led to dramatic reductions in mortality in some countries in the last decade, economic losses are now reaching an average of US\$250 billion to US\$300 billion each year ${ }^{212,213}$.

The ways that disasters undermine sustainable development have been much discussed in two significant United Nations processes.

During the intergovernmental negotiations of the General Assembly Open Working Group on Sustainable Development Goals (SDGs), many Member States stressed the need to weave disaster risk reduction (DRR) as a strong cross-cutting issue in several SDGs. As a result, the proposal of the Open Working Group on SDGs that was presented in July $2014^{214}$ includes several targets (see Annex 1 ) directly related to resilience and disaster risk reduction.

The third UN World Conference on Disaster Risk Reduction (WCDRR) organized on 14-18 March in Sendai, Japan, agreed on the Sendai Framework for Disaster Risk Reduction 2015-2030215, a successor to the Hyogo Framework for Action (HFA). To support the assessment of global progress in achieving the outcome and goals of the Sendai Framework, Member States also agreed on seven targets that will be measured at the global level. The first four targets aim at reduction of disaster mortality, number of affected people, economic losses and disaster damage to critical infrastructure. The remaining three aim at increasing the number of countries with national and local disaster risk reduction strategies, enhancing international cooperation in support of DRR in developing countries, and increasing availability and access to early warning systems and disaster risk information. This chapter takes the proposal of the Open Working Group as its reference point and focuses on DRR in the context of the SDGs. It will first look at the interlinkages between DRR and several SDGs, giving illustrative examples of links in order to position DRR in the framework. Second, it will consider what setting DRR targets will mean for monitoring progress, highlighting issues related to data collection, methodologies and baseline setting. The last part of the chapter showcases new solutions for data collection and measurement in the context of DRR. The chapter aims at serving as one example of how the GSDR can help in capturing past and future sustainable development trends, lessons learnt and scientific findings, indicating potential areas for policy action, as set out in Chapter 1 of the report.

\subsection{Interlinkages - DRR as a cross-cutting issue in the SDGs}

Due to its cross-cutting nature DRR is interlinked with various SDGs beyond the explicit DRR targets set out in the OWG proposal. With most of the issues the linkage is twofold; if DRR is not given prominent focus, achieving several of the SDG targets, such as ones related to poverty eradication, water, education, slums, and health, will be extremely challenging for many, particularly developing, countries. Also, falling behind the set ambition level on many of the existing SDG targets that have a direct bearing on disaster risk, such as the ones related to poverty eradication, sustainable cities, food security, health, natural resources management, or climate change, will mean additional challenges in achieving the DRR targets. For instance, case studies indicate that the impacts of drought can only be partly attributed to deficient or erratic rainfall, as drought risk appears to be constructed over time by a range of drivers. These include for example poverty and rural vulnerability; increasing water demand due to urbanization, industrialization and the growth of agribusiness; inappropriate soil and water management; weak or limited governance; and climate variability and change ${ }^{216}$. Reducing drought losses will be challenging without addressing also these underlying drivers.

In Table 4-1 some of the SDG goals have been combined under joint headings merely for brevity's sake. 


\begin{tabular}{|c|c|c|}
\hline SDGs & Main DRR linkages & Examples \\
\hline $\begin{array}{l}\text { Poverty } \\
\text { eradication and } \\
\text { economic growth }\end{array}$ & $\begin{array}{l}\text { Disasters tend to have the greatest long-term } \\
\text { impacts on those people in the poorest income } \\
\text { quartile or quintile, although lack of data and } \\
\text { research on long-term effects of disasters at } \\
\text { house-hold level makes analysis of the } \\
\text { complicated linkages between disasters and } \\
\text { impoverishment difficult }{ }^{217} \\
\text { - Impoverishment is linked to lack of access to } \\
\text { markets, capital, assets, and social security and } \\
\text { insurance mechanisms that can help people to } \\
\text { cope and to rebuild } \\
\text { Disasters affect disproportionally the poor at } \\
\text { global level; high-income countries account for } \\
39 \% \text { of the exposure to tropical cyclones but } \\
\text { only } 1 \% \text { of the mortality. Low-income countries } \\
\text { represent } 13 \% \text { of the exposure but no less than } \\
\text { 81\% of the mortality } \\
\text { Taking on risks and proactively managing them } \\
\text { is a natural element of development and } \\
\text { economic growth, and risk assessments and DRR } \\
\text { planning should be integrated in investment } \\
\text { planning at all levels }\end{array}$ & $\begin{array}{l}\text { - According to one assessment, without concerted action, } \\
\text { there could still be up to } 325 \text { million extremely poor people } \\
\text { living in the } 49 \text { most hazard-prone countries in } 2030^{219} \\
\text { - } \quad \text { Following an exceptionally strong typhoon in the Philippines, } \\
\text { both high- and low-income households experienced similar } \\
\text { levels of loss in the year after. However, the consumption } \\
\text { and income of low-income households did not recover over } \\
\text { the next few years, in contrast with that of the wealthier } \\
\text { households } \\
\text { Myanmar's annual average loss }{ }^{221} \text { represents } 30 \text { per cent of } \\
\text { its annual capital investment and in the Philippines and } \\
\text { Cambodia } 14 \text { per cent and } 10 \text { per cent respectively. In Latin } \\
\text { America, for Honduras and Guatemala the AAL represents } \\
\text { almost } 18 \text { per cent and around } 10 \text { per cent of new capital } \\
\text { investment, respectively. }{ }^{222}\end{array}$ \\
\hline $\begin{array}{l}\text { Food security, } \\
\text { sustainable } \\
\text { agriculture }\end{array}$ & $\begin{array}{l}\text { Disasters destroy critical agricultural } \\
\text { infrastructure and assets, and they cause losses } \\
\text { in the production of crops, livestock and } \\
\text { fisheries, causing serious damage to livelihoods } \\
\text { and food security of millions of small farmers, } \\
\text { pastoralists, fishers and forest-dependent } \\
\text { communities in developing countries } \\
\text { Increasing demand for farm land can increase } \\
\text { the risk of hazards through environmental } \\
\text { degradation. For example, landslides can } \\
\text { increase when vegetation is cleared for } \\
\text { agriculture on steep slopes } \\
\text { The agriculture-food-nutrition sector is } \\
\text { challenged to move towards resilient sector } \\
\text { specific DRR measures, technologies and } \\
\text { practices which raise yields and increase } \\
\text { resilience against production failure, as well as } \\
\text { towards a more sustainable use and } \\
\text { management of vital resources }\end{array}$ & $\begin{array}{l}\text { - According to a study on recurrently hazard exposed } \\
\text { developing countries, } 22 \% \text { of all damages and losses caused } \\
\text { by medium to large-scale disasters occurring between } 2003 \\
\text { and } 2013 \text { were in the agriculture sector } \\
\text { In southwestern China the Grain for Green Program bans } \\
\text { logging and agriculture on steep slopes and prohibits forest } \\
\text { clearing and, in exchange, the local communities receive grain } \\
\text { and cash subsidies as well as protection against flooding } \\
\text { events } \\
\text { Drought alone has caused more deaths during the last } \\
\text { century than any other physical hazard }{ }^{226} \text {, and according to } \\
\text { FAO estimates, there has been a total of USD } 4.9 \text { billion in } \\
\text { crop and livestock production losses caused by droughts in } \\
\text { the Horn of Africa between } 2003 \text { and } 2013 \\
\text { A severe drought in } 2000 \text { and } 2001 \text { in Tajikistan and } \\
\text { Uzbekistan cut the availability of drinking and irrigation water } \\
\text { and led to slow, chronic forms of malnutrition as households } \\
\text { eliminated meat and dairy products from their diet }{ }^{227} \\
\text { The agriculture sector - including crops, livestock, fisheries } \\
\text { and forestry - absorbs approximately } 22 \% \text { of the economic } \\
\text { impact caused by medium and large scale natural hazards and } \\
\text { disasters in developing countries }\end{array}$ \\
\hline $\begin{array}{l}\text { Health and } \\
\text { education }\end{array}$ & $\begin{array}{l}\text { - } 42 \text { million human life years lost in } \\
\text { internationally reported disasters each year, } \\
\text { and tens of thousands people injured }{ }^{229} \text {, } \\
\text { burdening health care systems worldwide and } \\
\text { causing long term physical and mental health } \\
\text { problems } \\
\text { - } \quad \text { Disasters destroy and disrupt service in health } \\
\text { and education facilities } \\
\text { Outbreaks of communicable diseases are often } \\
\text { linked to the displacement of people in post- } \\
\text { disaster situations }{ }^{230} \text {, and can further hamper } \\
\text { disaster relief } \\
\text { Disasters hamper countries' ability to invest in } \\
\text { social development }\end{array}$ & $\begin{array}{l}\text { In Niger children aged two or under who were born during, } \\
\text { and affected by, a drought year are } 72 \% \text { more likely to be } \\
\text { stunted. In Ethiopia, children aged five or less are } 36 \% \text { more } \\
\text { likely to be malnourished and } 41 \text { per cent more likely to be } \\
\text { stunted if they are born during a drought; that translates into } \\
\text { some } 2 \text { million additional malnourished children in } 2005^{232} \text {, } \\
\text { with possible long term effects on their education and future } \\
\text { economic opportunities } \\
\text { In } 2005 \text { in the Gulf states of the United States of America, } \\
\text { Hurricane Katrina and subsequent flooding destroyed } 56 \\
\text { schools and } 1,162 \text { were damaged. } 700 \text { schools were closed } \\
\text { and } 372,000 \text { children displaced } \\
\text { While annual social expenditure is about } 400 \text { times greater in } \\
\text { high-income countries than in low-income countries, the AAL }\end{array}$ \\
\hline
\end{tabular}




\begin{tabular}{|c|c|c|}
\hline & $\begin{array}{l}\text { Education can also greatly contribute to } \\
\text { preparing communities and building inclusive, } \\
\text { disaster resilient societies, as was acknowledged } \\
\text { in the HFA }\end{array}$ & $\begin{array}{l}\text { in low income countries is equivalent to about } 22 \text { per cent of } \\
\text { social expenditure, compared to only } 1.45 \text { per cent in high- } \\
\text { income countries }\end{array}$ \\
\hline $\begin{array}{l}\text { Water and } \\
\text { sanitation }\end{array}$ & $\begin{array}{l}\text { - Floods, droughts and windstorms are the most } \\
\text { frequently occurring natural disaster events and } \\
\text { account for almost } 90 \% \text { of the } 1,000 \text { most } \\
\text { disastrous events since } 1990^{235} \\
\text { - Lack of basic services and sanitation combined } \\
\text { with disasters can also create new risks, for } \\
\text { example by turning a heavy rain into a } \\
\text { disastrous flood with the spread of disease } \\
\text { Disasters, particularly localised, small-scale } \\
\text { events, hinder progress in achieving universal } \\
\text { access to water and sanitation by damaging } \\
\text { sewerage and water supply infrastructure }\end{array}$ & 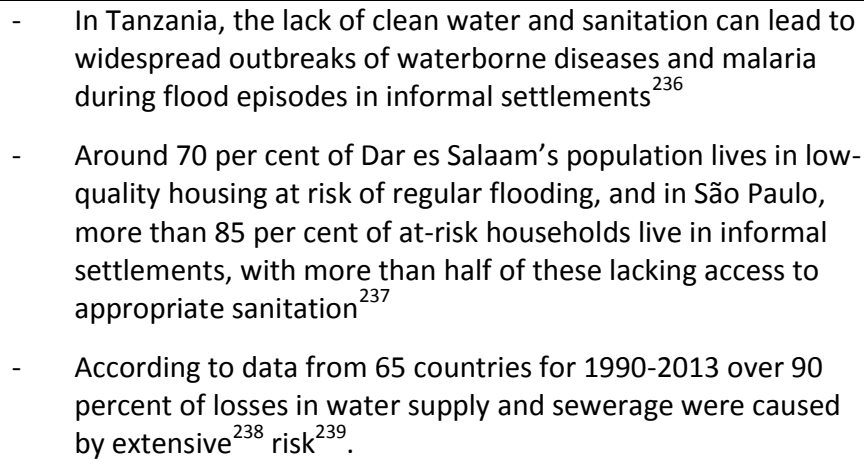 \\
\hline $\begin{array}{l}\text { Gender equality } \\
\text { and women's } \\
\text { empower-ment }\end{array}$ & $\begin{array}{l}\text { Due to existing socio-economic conditions, } \\
\text { cultural beliefs and traditional practices, women } \\
\text { and men are affected differently by disasters } \\
\text { - Productive resources tend to be owned by men, } \\
\text { and losses in the informal sector and } \\
\text { subsistence farming, dominated by women, are } \\
\text { not often recorded at all } \\
\text { Desp } \\
\text { Docial and cultural factors, women can serve as } \\
\text { agents of change and their role in disaster } \\
\text { preparedness and relief both at family and } \\
\text { community level is well documented }\end{array}$ & $\begin{array}{l}\text { - Women represented an estimated } 61 \% \text { of fatalities in } \\
\text { Myanmar after Cyclone Nargis in } 2008 \text {, and } 70 \% \text { after the } \\
2004 \text { Indian Ocean Tsunami in Banda Aceh }{ }^{242} \text {. } \\
\text { The } 1991 \text { cyclone Gorky in Bangladesh killed } 140,000 \text { people. } \\
\text { Within the age group } 20-44 \text {, the female death rate was } 71 \text { per } \\
\text { 1000, compared to } 15 \text { per } 1000 \text { for men }{ }^{243}\end{array}$ \\
\hline Inequality & $\begin{array}{l}\text { - } \quad \text { Low-income households suffer a } \\
\text { disproportionate share of disaster impacts and } \\
\text { people living in multidimensional poverty are } \\
\text { likely to live in hazard-exposed areas and are } \\
\text { less able to invest in risk-reduction measures } \\
\text { - } \quad \text { Disasters hit hardest the most marginalized, } \\
\text { notably children, older persons and persons } \\
\text { with disabilities } \\
\text { Extensive risk particularly affects areas already } \\
\text { characterized by social inequality and exclusion, } \\
\text { where a deficit of infrastructure is an underlying } \\
\text { source of vulnerability and loss of this further } \\
\text { aggravates the situation }\end{array}$ & $\begin{array}{l}\text { - In villages affected by the } 2004 \text { Indian Ocean tsunami the } \\
\text { death rate was highest for young children and older persons, } \\
\text { and was } 40 \% \text { higher for women than for men }{ }^{245} \text {. } \\
\text { Following the Great Tohoku earthquake in Japan in 2011, the } \\
\text { death rate in Miyagi region amongst the total population of } \\
\text { the coastal area was } 0.8 \% \text {, while it reached } 3.5 \% \text { amongst } \\
\text { persons with disabilities }{ }^{246} \text {. }\end{array}$ \\
\hline $\begin{array}{l}\text { Sustainable cities } \\
\text { and resilient } \\
\text { infra-structure }\end{array}$ & $\begin{array}{l}\text { - More than } 60 \text { percent of the area projected to } \\
\text { be urban in } 2030 \text { has yet to be built }{ }^{247} \text {; this } \\
\text { poses significant challenges but also } \\
\text { opportunities to properly integrate DRR in long- } \\
\text { term planning } \\
\text { Hazards provide opportunities for major } \\
\text { advancements in DRR with focus on building } \\
\text { back better; it should not be limited to } \\
\text { structural improvements in buildings or to } \\
\text { specific elements of infrastructure without } \\
\text { adequate focus on underlying drivers } \\
\text { - Those living in informal settlements are most } \\
\text { vulnerable to disasters, and many have migrated } \\
\text { to slums due to disasters in their original } \\
\text { settlements } \\
\text { Extensive risk is characteristic of informal urban } \\
\text { settlements and low-income rural areas, where }\end{array}$ & $\begin{array}{l}\text { - Jakarta's plan for } 2010-2030 \text { calls for incorporating risk } \\
\text { reduction activities into long-term spatial planning for the } \\
\text { city; including restoration of mangrove forests, improvement } \\
\text { in public facilities and mass transit, refinement of building and } \\
\text { environmental regulations that consider hazard risk, redesign } \\
\text { of technology and engineering in disaster areas, and } \\
\text { improvements of provision of open space for anticipated } \\
\text { increases in intense rainfall } \\
\text { Slum populations and their increase in metropolises such as } \\
\text { Dhaka or Manila are significantly augmented by flood, storms } \\
\text { and drought related migration } 251252 \\
\text { Case studies carried out in Dar es Salaam, Jakarta, Mexico City } \\
\text { and Sao Paolo found that, in all four cities, those living in } \\
\text { informal settlements were most vulnerable to climate related } \\
\text { and disaster risk } \\
\text { Case studies in Colombia } \\
\text { - } 254 \text { and Turkey }{ }^{255} \text { found that } \\
\text { structural (i.e. retrofitting) and functional investments (i.e. } \\
\text { protection of people and assets so that they remain }\end{array}$ \\
\hline
\end{tabular}




\begin{tabular}{|c|c|c|}
\hline & $\begin{array}{l}\text { poverty forces low-income households to } \\
\text { occupy areas of low land value that may be } \\
\text { exposed to floods, landslides and other } \\
\text { hazards }\end{array}$ & $\begin{array}{l}\text { functional during and after an emergency) not only provide } \\
\text { for reduction in property losses, but may also save lives and } \\
\text { reduce the number of injuries }\end{array}$ \\
\hline Climate change & $\begin{array}{l}\text { - Many parts of the world are witnessing an } \\
\text { increase in extremes of climate, such as greater } \\
\text { extremes of temperature, heavier rainfall, or } \\
\text { higher maximum wind speed of storms }{ }^{256} \text {. This } \\
\text { can result in an increase in natural hazards such } \\
\text { as flash flooding, drought, landslide, and storm } \\
\text { surge } \\
\text { In most countries, the predicted annual average } \\
\text { loss increases under climate change scenarios. } \\
\text { But affects will differ country by country } \\
\text { Drought and flood hazards are among the most } \\
\text { potent causes for long-term impoverishment, } \\
\text { particularly in rural areas }\end{array}$ & 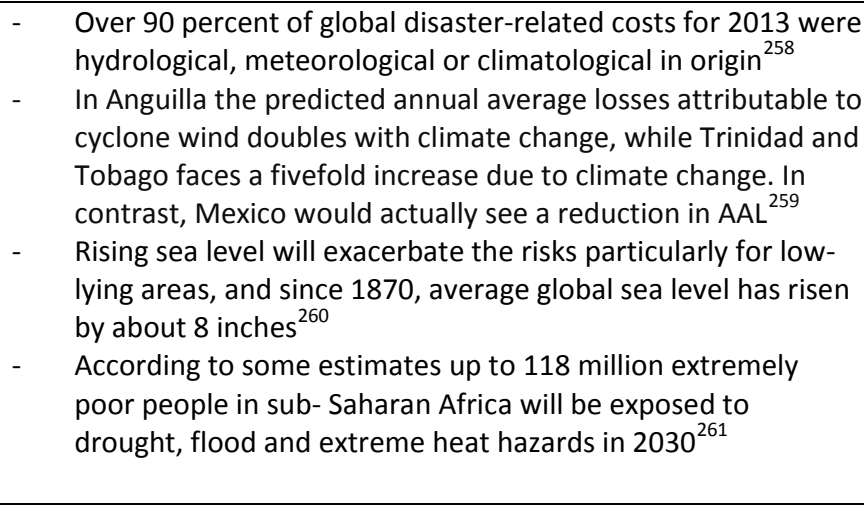 \\
\hline Ecosystems & $\begin{array}{l}\text { - } \quad \text { Environmental degradation is one of the main } \\
\text { drivers of disaster risk } \\
\text { - } \\
\text { Natural ecosystems can reduce vulnerability to } \\
\text { natural hazards and extreme climatic events } \\
\text { and complement, or substitute for, more } \\
\text { expensive infrastructure investments } \\
\text { Communities dependent on fragile or degraded } \\
\text { landscapes - such as overgrazed, heavily } \\
\text { deforested or severely eroded lands - are often } \\
\text { the most vulnerable to losses from natural } \\
\text { hazards }{ }^{264} \\
\text { The effects of land degradation are often } \\
\text { irreversible }\end{array}$ & $\begin{array}{l}\text { - Modeling for the Seychelles suggests wave energy has } \\
\text { doubled partially as a result of changes in the structure (due } \\
\text { to bleaching) and species composition of coral reefs. In the } \\
\text { Caribbean, more than } 15,000 \text { kilometers of shoreline could } \\
\text { experience a } 10-20 \text { percent reduction in protection from } \\
\text { waves and storms by } 2050 \text { as a result of reef degradation }{ }^{265} \\
\text { - Dense vegetation protects riverbanks and adjacent land and } \\
\text { structures from erosion by floodwaters. In Mantadia National } \\
\text { Park, Madagascar, conversion from primary forest to swidden } \\
\text { can increase downstream storm flow by as much as } 4.5 \\
\text { times }{ }^{266} \\
\text { - In Africa, } 52 \text { per cent of land is considered degraded to some } \\
\text { degree }\end{array}$ \\
\hline $\begin{array}{l}\text { Governance and } \\
\text { peaceful } \\
\text { societies }\end{array}$ & $\begin{array}{l}\text { - Governance arrangements adopted by many } \\
\text { countries, relying heavily on specialized } \\
\text { emergency management organizations, are not } \\
\text { always appropriate to address disaster risk } \\
\text { - } \quad \text { Disaster risk governance often mirrors the } \\
\text { challenges, restrictions, blockages and obstacles } \\
\text { that exist within the overall governance } \\
\text { arrangements }{ }^{269} \text {, but DRG can also support good } \\
\text { governance } \\
\text { Conflict and fragility can increase the impact of } \\
\text { disasters, and disasters can exacerbate } \\
\text { conflicts }\end{array}$ & $\begin{array}{l}\text { - In India, following the earthquakes in Maharashtra (1993) and } \\
\text { Gujarat (2001), housing records were digitized and land titles } \\
\text { that were traditionally only recorded under the name of the } \\
\text { male head of household for the first time also included the } \\
\text { female head of household. This practice was institutionalized } \\
\text { and transformed the general practice of social housing in } \\
\text { these states } \\
\text { According to one assessment the } 2007-2010 \text { drought } \\
\text { contributed to the conflict in Syria, causing widespread crop } \\
\text { failure and a mass migration of farming families to urban } \\
\text { centers }\end{array}$ \\
\hline $\begin{array}{c}\text { Means of } \\
\text { implemen-tation, } \\
\text { Renewed Global } \\
\text { Partnership }\end{array}$ & $\begin{array}{l}\text { - International cooperation has heavily } \\
\text { concentrated on emergency-relief and } \\
\text { reconstruction instead of preventive DRR } \\
\text { - Funding for DRR is strongly concentrated in just } \\
\text { a few recipient countries, with all but one } \\
\text { (Bangladesh) of the top } 10 \text { recipients of } \\
\text { financing being middle-income countries } \\
\text { - Capacity building will be crucial, and there exists } \\
\text { a need for closer coordination between DRR and } \\
\text { climate change adaptation; lack of coordination } \\
\text { on technology transfer has led to fragmented } \\
\text { implementation }\end{array}$ & 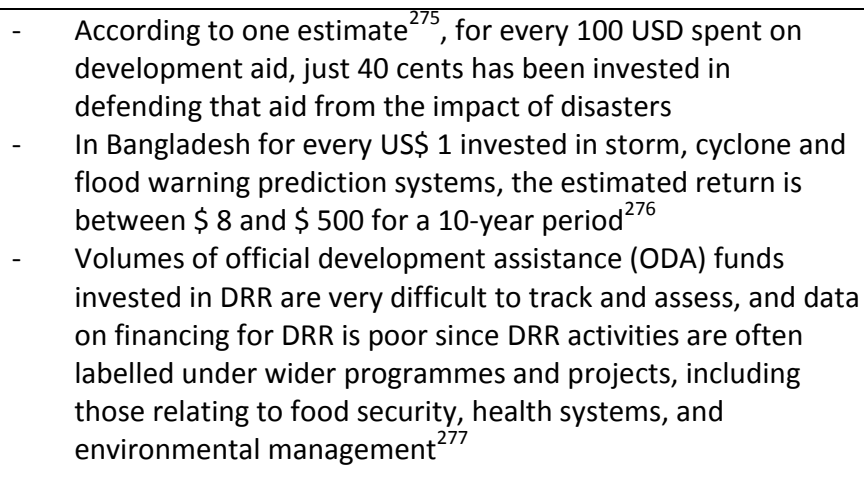 \\
\hline
\end{tabular}




\subsection{Measuring progress - target $\mathbf{1 1 . 5}$}

One of the disaster-related targets proposed by the OWG is the outcome target 11.5 that aims to "By 2030, significantly reduce the number of deaths and the number of people affected and decrease by $[\mathrm{x}]$ per cent the economic losses relative to gross domestic product caused by disasters, including water-related disasters, with a focus on protecting the poor and people in vulnerable situations".

This section of the chapter aims at advancing the discussion, showcasing several issues that will need to be taken into consideration both when considering appropriate target levels and when planning the monitoring of progress towards the target. There are several DRR related targets in the SDG proposal, but 11.5 is used here as an illustrative example to showcase issues related to monitoring. At the same time, the section aims at highlighting monitoring issues that are relevant also for the implementation and planning of DRR measures, such as the importance of loss accounting, risk assessments and probabilistic modelling.

\subsubsection{Global and national level target setting and differing risk profiles}

During the negotiations of the OWG the Member States discussed options for filling the so called " $x$ 's and $y$ 's", the target levels of numerous targets that were not specified by the OWG proposal. Member States discussed the issue further in the WCDRR negotiations, and the UNISDR provided a Secretariat note ${ }^{278}$ proposing potential target levels depending on the desired ambition level, but in the end the Sendai Framework for Disaster Risk Reduction did not include percentages.

One option proposed in the SDG negotiations was to fill the gaps later with suitable global target percentages. Another option proposed was for the Member States each to set suitable, ambitious target levels at national level which could then be brought together and aggregated to a global target for 2030.

Due to very differing country risk profiles, differentiation at the national level is inevitable with DRR. For countries with extremely low risks, DRR measures will not play a significant role in implementing the SDGs, while for others, it will be a prerequisite for achieving not only the DRR targets, but also many other goals. Also, for some countries significant reductions in mortality and economic losses will be easier to achieve than for others, depending on the hazards they face.
Since 1990, almost 90 per cent of the mortality recorded in internationally reported disasters has occurred in low and middle-income countries. Improved health and education systems and infrastructure enhance emergency preparedness, evacuations and care of the affected and help to bring down disaster mortality ${ }^{279}$.

Box 4-1. Piloting targets and indicators at national level Since early 2014, UNISDR developed a set of proposed DRR indicators and subsequently tested their feasibility jointly with UNDP in country contexts. Taking into consideration existing data availability and capacity, measuring systems and information needs for national planning purposes, a proposed indicator framework was tested in five pilot countries (Mozambique, Japan, Armenia, Paraguay and Japan). The pilots were organized in close collaboration with UN country teams and involved a broad range of development, disaster risk management and climate change adaptation practitioners.

Pilot countries responded positively to the exercise and the possibility to both take ownership of the indicator and target proposals, and align the ones relevant to their country context to existing national measuring mechanisms. Findings from the pilots reconfirmed the proposed targets and indicators as generally applicable yet with the need to simplify and adapt to different capacity contexts. The results from these and further pilots to be conducted in $\mathbf{2 0 1 5}$ will contribute to refining the indicators for measuring progress against the seven targets outlined in the 'Sendai Framework for Disaster Risk Reduction 20152030 '.

Absolute economic loss is rising, but in relative terms taking into account economic growth, the global increase in economic loss from disasters is not statistically significant. However, in some regions, losses have outstripped GDP growth. While absolute economic loss is concentrated in higher-income countries, in relative terms it remains a far greater problem for low income countries Table $4-1^{280}$. Most high-income countries have made investments to significantly reduce the more extensive layers of disaster risk associated with high-frequency, low-severity losses, such as urban flooding, landslides and storms. However, although investments in risk reduction and regulation have enabled a reduction of extensive risks, the value of assets in hazard-prone areas has grown, generating an increase in intensive risks. For example, investing in risk reduction measures to protect a floodplain against a 1-in-20-year flood may encourage additional development on the floodplain in a way that in the end increases the risks associated with a 1-in-200-year flood ${ }^{281}$. 
Figure 4-1. Economic losses relative to the size of the economy (GDP) by income group, 1990-2013

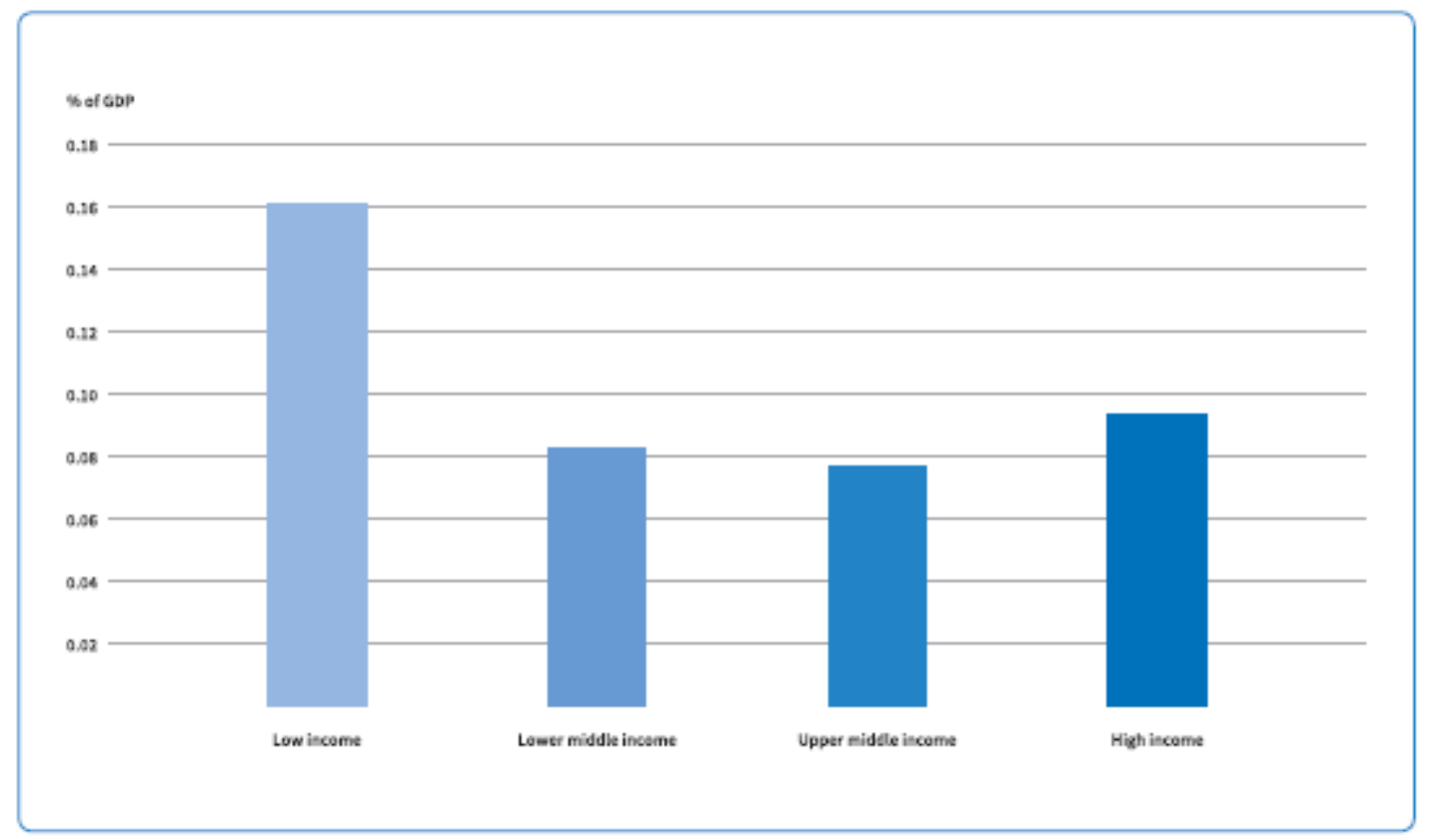

(Source: UNISOR with doto from EM-DAT and the Worid Bank.)

Losses, however, only explain the past and therefore do not act as a good guide to future risk. Probabilistic risk estimates can provide guidance on future risks and target levels. Currently, the global expected annual loss, or average annual loss ( $A A L)$, in the built environment alone, associated with earthquakes, cyclones, tsunamis and floods, is estimated at US\$314 billion $^{283}$. In absolute terms, global AAL is concentrated in large, higher-income, hazardexposed economies. However, in relation to annual capital investment or social expenditure, many low and middleincome countries, and in particular small island developing states (SIDS), have the highest concentrations of risk.

\subsubsection{Importance of loss accounting}

The OWG target does not specify how mortality and economic losses should be accounted for and some basic questions need to be clarified when setting up the monitoring framework.

Even though mortality can be perceived as a fairly clear cut indicator, some questions arise especially related to the inclusion of missing persons and the causality of deaths. While attributing victims of an earthquake to a certain disaster can be fairly easily done, distinguishing whether deaths in the hazard-affected region are caused by a drought or a heatwave or merely due to non-disaster related health issues can be challenging and depends on the methodology used. For example the global database EM-DAT's review in 2007 of its drought data resulted in a reduction of $56 \%$ from the original number of drought event entries, a $20 \%$ increase in the number of deaths and a $35 \%$ increase in economic losses from droughts ${ }^{284}$. It should be noted though that drought accounting poses particular challenges for monitoring. The impacts for slow onset events such as drought can be largely non-structural and spread over a larger geographical area than damages from other natural hazards. The non-structural characteristic of drought impacts has hindered the development of accurate, reliable, and timely estimates of severity and, ultimately, the formulation of drought preparedness plans by most countries ${ }^{285}$. One option that has been proposed ${ }^{286}$ for mortality accounting is to assess whether the disaster affected community is presenting higher death rates than expected in the period (e.g. 6 months following the disaster) - that is 'excess deaths' that may be attributable to the disaster shock. In this case, the baseline would be the 'normal death rate' in that region. This approach would aim at resolving the debate on distinguishing direct and indirect deaths from disasters as it would capture all deaths.

Economic losses are often categorized in three main categories: direct losses; losses due to business interruption; and indirect losses ${ }^{287}$. Direct losses usually include costs due to physical destruction of buildings and other assets while indirect losses include the costs of knock-on impacts such as failure of production by businesses relying on directly impacted companies and foregone consumption. One comprehensive review of different approaches and challenges for costing frameworks was done by the CONHAZ project ${ }^{288}$. In the OWG the question of direct or indirect economic losses was not much discussed. During the WCDRR negotiations, however, countries debated whether indirect losses should 
be included ${ }^{289}$ in the accounted losses. In the end countries decided to focus on direct losses that are more easily measured, even though the importance of accounting for indirect losses at the national level was noted.

Monitoring of progress towards proposed goals and targets will require high quality loss data with a good temporal and spatial resolution, which is also important for DRR planning. Disaster loss accounting is considered a backbone for setting baselines and for measuring progress towards set targets. However, compiling, maintaining and updating disaster data is challenging, and lack of clear standards and definitions has led to inconsistency and poor interoperability of different data initiatives. While disaster loss data quality and coverage has significantly improved in recent years, data gaps are common in many databases at all levels. There are gaps regarding: a) temporal coverage with missing years and/or months; b) spatial coverage with missing reports from some regions, communities, etc.; c) loss estimation with no losses reported for some events, particularly low impact/high frequency events; and d) loss indicators with inconsistent completeness across events ${ }^{290}$.
At present there are three well-established global multihazard loss databases, Centre for Research on the Epidemiology of Disasters's (CRED) EM-DAT, MunichRe's NatCatSERVICE, and SwissRe's Sigma (Table 4-2). While EMDAT is an open database, the latter two are owned by insurance companies and have limited public accessibility. The databases include reports provided by national governments, United Nations entities and other international organisations or specialised national agencies and NGOs, as well as newspaper sources. It has been noted, that information sources are fairly homogenous across databases and that reliability of the information rests with the organisation in charge of publishing official figures ${ }^{291}$. This highlights the significance of data validation for monitoring purposes. Other databases with global or regional coverage do exist but they concentrate on one or a handful of hazards, such as the United States Geologic Survey's database and Global Earthquake Model (GEM) ${ }^{292}$ for earthquakes ${ }^{293}$, and European PERILS ${ }^{294}$ database mainly for insured losses from windstorms.

Table 4-2. Global multihazard loss databases ${ }^{295}$

\begin{tabular}{|l|l|l|l|}
\hline Database & Events covered since & Threshold levels & Variables covered \\
\hline $\begin{array}{l}\text { EM-DAT International } \\
\text { Disaster Dataset }\end{array}$ & $\begin{array}{l}1900 \text { (about 21 } 000 \\
\text { disasters) }\end{array}$ & $\begin{array}{l}\text { casualties }>10 ; \text { number } \\
\text { affected }>100 ; \text { declaration } \\
\text { of state of emergency; call } \\
\text { for international assistance }\end{array}$ & $\begin{array}{l}\text { Casualties, affected (injured, homeless, } \\
\text { affected), estimated damage }\end{array}$ \\
\hline $\begin{array}{l}\text { Natcat-SERVICE } \\
\text { (MunichRe) }\end{array}$ & $\begin{array}{l}1980 \text { (about } 28000 \\
\text { disasters) }\end{array}$ & $\begin{array}{l}\text { Some socioeconomic } \\
\text { impact; small-scale property } \\
\text { damage or 1-9 fatalities }\end{array}$ & $\begin{array}{l}\text { Insured losses; total losses; injured; } \\
\text { infrastructure areas and industries affected }\end{array}$ \\
\hline Sigma (SwissRe) & 1970 (about 9 000 disasters) & $\begin{array}{l}\text { casualties > 20; injured > } \\
50 ; \text { homeless > 2000; total } \\
\text { losses > USD 91.1 million }\end{array}$ & $\begin{array}{l}\text { Casualties; missing; injured; homeless; insured } \\
\text { losses (claims); total losses }\end{array}$ \\
\hline
\end{tabular}

National loss databases do exist but to date these have not usually followed a common methodology in their data collection, limiting their usability for monitoring and particularly research and planning. However, a UN-led effort to standardise methods and criteria for disaster loss accounting, originally set up by an academic network in 1994 in Latin America, has developed into a promising basis for the future. Based on the DesInventar ${ }^{296}$ methodology, 85 countries and territories have now published national loss data and many more are in the process of establishing linking databases. The European Commission recently included the common methodology used for these databases in its guidelines for disaster loss accounting in Europe and beyond ${ }^{297298}$. While not all countries currently have national disaster loss databases, the adoption of both the SDGs and the Sendai Framework targets for DRR will represent a strong incentive for systematically recording loss data.

\section{Role of jointly used methodologies and definitions}

Significant efforts have been undertaken to improve the interoperability of disaster loss data from national and global databases through the development of common data standards and methodologies, but much work remains to be done. An overview of the current practices in EU countries at national level showed that the methodologies for loss data recording are appropriate for national purposes, but to make the databases compatible within Europe and with international organisations they all would require adjustments ${ }^{299}$. Another analysis ${ }^{300}$ noted that national loss databases are not consistently available across 
OECD countries and, if they are available, they differ significantly in the way information is collected.

To begin with, to improve the comparability of existing loss databases, event classifications should be standardised. If event and hazard type or peril categories diverge from each other, any subsequent efforts to standardise indicators will be useless. A consistent peril classification will allow data users to compare losses from, for example, landslides in database A with losses from landslides in database B, thereby illustrating that differences are due to estimations of loss, not different definitions of landslides or how they were categorised $^{301}$.

\section{Box 4-2. Developing statistics at regional level - cases of UNESCAP and UNECE}

Work on standardized methodologies for disaster impact data has also been undertaken at the regional level. Member States of the United Nations Economic and Social Commission for Asia and the Pacific (UN-ESCAP) have established an expert group ${ }^{302}$ that consists of government nominated technical advisors and regional and international experts in the field of statistics and disaster risk management, to work on developing a basic range of disaster-related statistics. The Expert Group will be reporting to and obtains the guidance from ESCAP Committee on Disaster Risk Reduction and Committee on Statistics. The final version of the basic range of disasterrelated statistics, i.e. a framework and an implementing guide, will be presented to the ESCAP 72nd Commission in 2016 for endorsement.

In October 2014, the Bureau of the United Nations Economic Commission for Europe (UNECE) Conference of European Statisticians (CES) undertook an in-depth review of international work on measuring extreme events and disasters. The review emphasized several priority action areas, including: institutional cooperation with mapping agencies to integrate statistical data with geographical information; and the need for common classifications and definitions for extreme events and disasters for statistical purposes. As a follow-up, the CES Bureau set up a Task Force on measuring extreme events and disasters, which is planning to prepare recommendations for national statistical systems by 2017, and will coordinate its work with the related ESCAP initiative and other international organizations working in this area.

Several initiatives have been launched to tackle the issue, including the IRDR Disaster Loss Data (DATA) Project Working Group's peril classification ${ }^{303}$, OECD work on a accounting framework for national risk management expenditures and losses ${ }^{304}$, and the ESCAP $^{305}$ and ECE initiatives on regional standards (See Box 4-3)
In the Sendai Framework for Disaster Risk Reduction, the Conference recommended the establishment of an openended intergovernmental expert working group supported by UNISDR for the development of a set of possible indicators to measure global progress in the implementation. The working group, set up in May in New York, is expected also to consider the recommendations on the update of the 2009 UNISDR Terminology on Disaster Risk Reduction ${ }^{306}$ by December $2016^{307}$.

\section{Extensive risk}

Extensive risk refers to the risk layer of high-frequency, low-scale losses, and is mainly associated with flash floods, landslides, urban flooding, storms, fires and other localized events. Extensive disaster risk is magnified by drivers such as badly planned and managed urban development, environmental degradation, poverty and inequality, vulnerable rural livelihoods and weak governance ${ }^{308}$.

At the time when the HFA was adopted, losses from extensive risk had not been accounted for in official national or international reports, except in a number of Latin American countries. As a result, this risk layer remained largely invisible and has not been captured by global risk modelling. However, since 2007, a sustained effort to assist countries in systematically recording local disaster losses has generated systematic and comparable evidence regarding the scale of extensive risk from over 80 countries (Box 4-2).

Reports show that the majority of damage and losses since 1990 have been associated with extensive disasters in those countries with consistent data sets (Figure 4-2). In 2012, EM-DAT database reported economic losses of US\$ 157 billion, an estimate that is lower than those published by Swiss Re (US\$186 billion) and Munich Re (US\$ 160 billion). As an indicative example, if the economic cost of assets lost in extensive disasters across 85 countries and territories featured in the Global Assessment Report on Disaster Risk Reduction 2015 (GAR15) is extrapolated globally, direct economic losses would be around 60 per cent higher than those internationally reported by EM DAT, implying a total of around US\$250 billion for 2012. This total loss represents 0.33 per cent of global GDP, 1.4 per cent of global capital investment and an annual loss of more than US\$35 per capita ${ }^{309}$.

In particular, such losses represent a serious erosion of public investment in some of those countries with the least capacity to invest. For example, the average historical annual losses from disasters in Madagascar since 2001 are equivalent to around 75 per cent of annual average public investment; in El Salvador, they amount to almost 60 per cent, and in Vanuatu they exceed 40 per cent ${ }^{310}$. 
Figure 4-2. Percentage of damage and loss from extensive and intensive disaster events (65 countries and 2 states), 1990$2013^{311}$

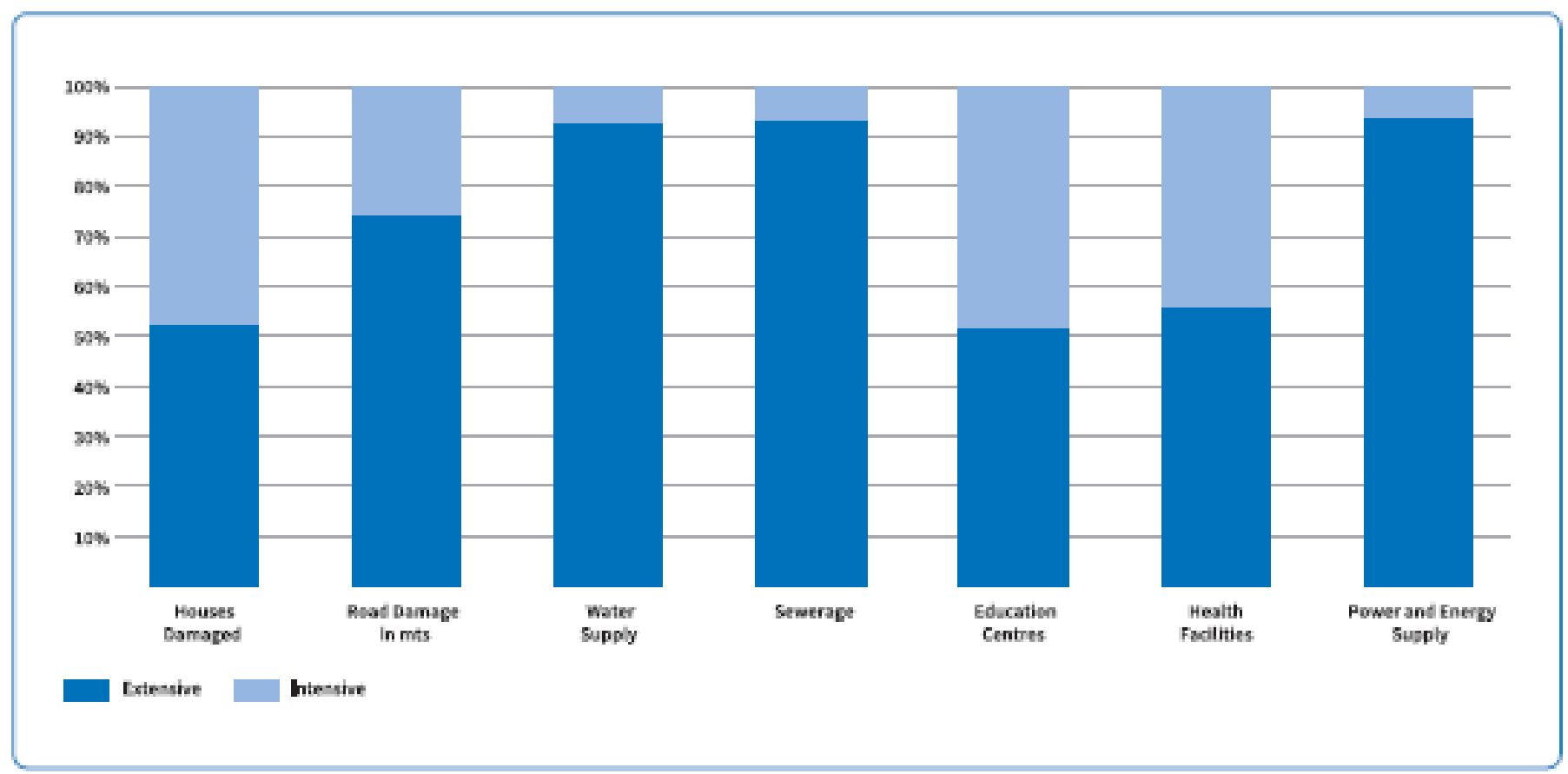

(Source: UNISOR with doto from national loss databases.)

\section{Box 4-3. National disaster loss accounting}

To uncover extensive risks, an increasing number of countries around the world are adopting a simple methodology to report, analyse and display disaster occurrence and losses at the local level through a standard definition of hazards, impacts and other indicators. Because the loss data is captured at the level of local administrative units, this makes it possible to record losses associated with huge numbers of small extensive disasters that are not internationally reported and thus do not appear in other disaster databases. The number of countries systematically collecting disaster loss data has roughly doubled every two years since these efforts began in Latin America in the 1990s, with the DesInventar database initiative.

The United Nations' GAR15 report features data collected using the same methodology and parameters in 82 countries and 3 states $^{312}$. The variables used to define the threshold between intensive and extensive disaster losses are mortality and housing destruction. Statistically, the threshold is fixed at:

Mortality: less than 30 people killed (extensive); 30 or more killed (intensive); or

Housing destruction: less than 600 houses destroyed (extensive); 600 or more houses destroyed (intensive).

This threshold has proved robust even as the universe of national disaster databases continues to grow. Given that 95 per cent of these databases have been built using a comparable approach and methodology, it is possible to analyse these local records at a global level of observation.

\section{Box 4-4. Composite indicators - the case of INFORM ${ }^{313}$}

There is a need to create multi-hazard risk metrics, particularly for the use of international organizations, based on scientific evidence to inform disaster risk reduction policy. One such tool is a composite indicator. One example is the recently developed Index for Risk Management - INFORM. INFORM is a way to measure the risk of humanitarian crises and disasters and how the conditions that lead to them affect sustainable development. INFORM simplifies information about risk and uses 50 different indicators to measure three dimensions: hazards and people's exposure, vulnerability, and coping capacity. INFORM is a collaboration of the InterAgency Standing Committee ${ }^{314}$ Task Team for Preparedness and Resilience and the European Commission.

The experience of INFORM can be used in the effort to develop metrics for DRR and its coping capacity component is often used as a proxy for efficient disaster risk management. It also allows organisations to develop INFORM-based indexes for specific purposes, with a methodological overview and technical support provided. Current projects include national and regional pilots in Sahel and East Africa, national pilots in Lebanon, thematic pilots on Ebola, Old Age and Disaster Risk Reduction (DRR). INFORM is only one composite index aiming at capturing risk levels and risk reduction, and other examples include the Disaster Risk Index ${ }^{315}$ and the World Risk Index ${ }^{316}$. 


\subsubsection{Baseline setting and assessing risk: strengths and challenges}

Robust monitoring of the SDG targets will also require the use of sound baselines, numbers used as a starting point against which progress would be measured against. The baseline-setting methodology should be the same as the method used to measure progress towards a target.

As a very simplified categorization, three different options for baseline setting could be envisaged, as put forward by the scientific community. These include the use of average losses derived from observed historical data over a certain period of time; measuring progress using simplified hazard, exposure and vulnerability to measure levels of risk and compare points in time; and measuring progress from expected losses from catastrophe models, to compare points in time. The two latter options compare the estimated risk at single points in time, such as 2015 to 2030 , and the baseline numbers of risk would be based on the exposure and vulnerability in those particular years.

The question of the method is also linked to the issue of target level setting, since enhanced data and use of risk assessments and probabilistic scenario models will directly contribute to countries' understanding of their risk profile and possible progress in the upcoming 15 years. Taking into account current coverage of data sets and the state of risk assessments, the use of baselines based on observed historical losses might prove to be the most feasible option for the moment. However, risk assessments and models based on scientific information also provide countries immensely useful tools in other spheres of DRR planning and are hence showcased here. A detailed assessment could be carried out for each of the options of the suitability of methods and what can be achieved in a certain timeframe.

\section{Observed historical data}

Using observed disaster loss data as the baseline is the simplest of the three options. However, it is important to mention that during the WCDRR discussions some noted that even this would prove challenging at national level for some countries due to the lack of loss data. In the Sendai Framework the Member States decided to use a 10-year average as a measure for global targeted reduction of mortality, and built this in the target: "Substantially reduce global disaster mortality by 2030 , aiming to lower average per 100,000 global mortality between 2020-2030 compared to 2005-2015". For economic losses a baseline was not specified, as is the case with the SDG targets.

Questions arise with respect to the 15-year timeframe proposed for the SDGs and whether the target will be only addressed at the global level or also with countries setting appropriate national target levels. First, for natural disasters loss distributions are often dominated by the impact of high-severity and low-frequency events (e.g. earthquakes, volcanic eruptions and earthquake-related tsunamis and landslides). This means that particularly at national level there is unlikely to be a sufficient number of events occurring in a particular country to make statistically significant comparisons between two 15-year periods of observation. While mortality might appear to be on the rise, this trend might not be statistically significant and can change depending on the time period chosen and the intensive disasters occurring in that period. One good example of this is Haiti, where from 1900 to 2009 earthquakes killed fewer than 10 people, but then in the 2010 earthquake an estimated 222,570 people were killed $^{317}$.

Second, past experience shows that 15 years will allow countries with some types of risk profiles, such as recurring floods, to make significant progress in reducing mortality by building effective defences and evacuation planning, while for others experiencing significant earthquakes, reducing the existing risk exposure by re-building or retrofitting the building stock, will prove much more challenging. These issues need to be taken into consideration when proposing appropriate target levels at national level.

However, when assessing losses for smaller and localised, more frequent events, i.e. losses associated with extensive disaster events, a significant upward trend can be observed, both in national and in global loss data sets. There is a statistically significant trend towards increasing mortality in events with fewer than 100 deaths (Figure 4-3), and extensive disaster mortality is also increasing relative to population size ${ }^{318}$. Hence, during the negotiations for the WCDRR, the UNISDR Secretariat proposed to monitor the mortality target from national disaster databases using a baseline of 2005-2015 and adopting an appropriate procedure to filter out low-frequency high-impact losses. For economic losses the Secretariat proposed combining modelled economic losses for smaller disasters from national disaster databases with assessed losses from large disasters captured from international disaster databases ${ }^{319}$. 
Figure 4-3. Internationally reported global disaster mortality (events with fewer than 100 deaths) ${ }^{320}$

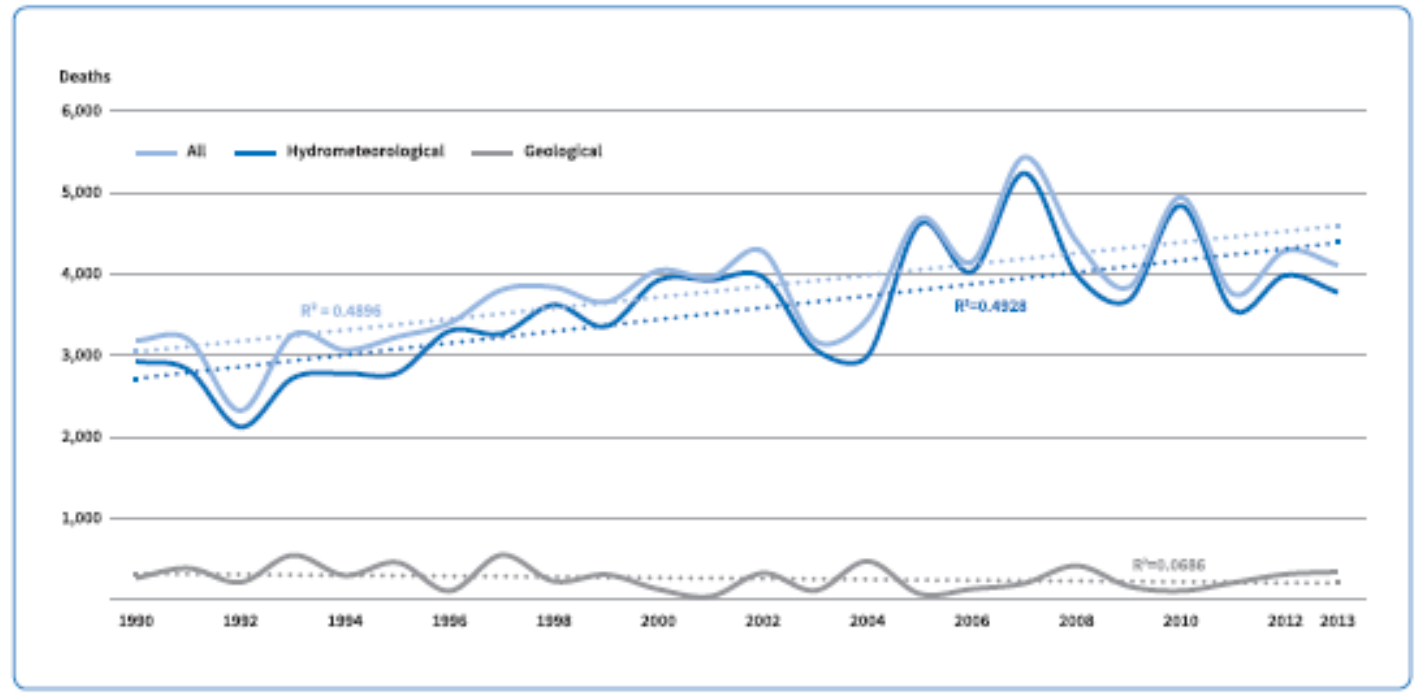

(Source: UNISDR with data from EM-DMT.)

\section{Assessed level of risk; hazard, exposure, vulnerability and capacity}

Another option for baseline setting would be to use the assessed level of risk (for mortality and economic losses) for the year 2015 as the baseline. In this option, the countries could aim at bringing down their estimated risk by reducing their exposure or vulnerability to hazards and increasing their capacities to deal with them. This would help to take better into consideration the existing situations in different countries and the specific risk types they face, but would require a considerable amount of additional research to build countries' risk, exposure, vulnerability and capacity profiles. In this case the countries could monitor their progress by updating the risk assessments based on their actions.

Risk assessment usually encompasses the systematic use of available information to determine the likelihood of certain events occurring and the magnitude of their possible consequences. As a process, it is generally agreed that it includes: identifying the nature, location, intensity and probability of a hazard; determining the existence and degree of vulnerabilities and exposure to those hazards; identifying the capacities and resources available to address or manage hazards; and determining acceptable levels of risk $^{321}$. The first is often determined by establishment of probabilistic hazard maps that serve as the basis for assessment. These represent the hazard parameter (e.g. strength of ground shaking, flood depth etc.) expected at each location at a given annual probability of a hazard, and form the basis also for probabilistic models. For assessing vulnerability and capacity, several different methods exist.
For SDG monitoring ODI for example has proposed ${ }^{322}$ a differentiated approach depending on the hazards faced, using three categories of hazard, based on the appropriate type of responses: Category 1 . would include hazards such as floods and storms, where, for mortality reduction, evacuation of people is key. Category 2. would include hazards such as earthquakes where reduction of building vulnerability is key to reduce expected mortality rates. Category 3. would consist of slow-onset hazards, such as drought, where appropriate action plans regarding for example distribution of water and food are needed to reduce expected mortality rates. Simply summarized, for category 1 for example, probabilistic hazard would be combined with the exposure (number of people in a defined hazard area combined with the people covered by an evacuation plan, multiplied by an effectiveness factor of these plans) and vulnerability (the percentage of people expected to die who do not evacuate). For category 2, hazard would be combined with exposure (number of people and the buildings they are in) and vulnerability (fatality rates for certain types in buildings at certain levels of ground shaking.

For assessing economic losses, it would be necessary to combine the hazard with estimated values of buildings/infrastructure/agricultural production in the affected area. With categories 1 and 2 the vulnerability of buildings affected would need to be taken into consideration, while with drought the effectiveness of mitigation efforts, such as coverage of irrigation systems, should be factored in. These calculations however would only capture a portion of economic losses and, if so wished, costs of business and livelihood disruption would need to be accounted for. 
Using assessed levels of risk as baselines would allow the countries to assess the specific hazards they face and to take into account existing DRR measures in place. However, it is to be noted that such an approach would require substantial investments in methodology, data and analysis. While sources for hazard maps include national surveys (e.g. European flood zones), commercial catastrophe modelling companies, international agency initiatives (such as the Global Earthquake Model (GEM), the Global Risk Assessment, CAPRA) re/insurance companies, independent scientific research and government studies, their coverage is not yet adequate for monitoring purposes particularly in low- and middle-income countries. Also, the method uses as a variable the effectiveness of a country's DRR plans, an issue that should be first independently assessed.

Proponents of this approach have argued that, where methodological gaps exist, the exposure data could still be collected and the 2015 baseline could be then calculated retrospectively in a few years, when a method would have been agreed upon.

\section{Probabilistic scenario models}

A third option for baseline setting would be to use a full multi-hazard probabilistic scenario model estimate for 2015 as a basis for monitoring at both global and national level. Probabilistic risk modelling simulates those future disasters which, based on scientific evidence, are likely to occur. As a result, these risk assessments could resolve the problem posed by the limits of historical data. Probabilistic models aim at "completing" historical records by reproducing the physics of the phenomena and recreating the intensity of a large number of simulated events.

While the scientific data and knowledge used is still incomplete, provided that their inherent uncertainty is recognized, these models can provide guidance on the likely "order of magnitude" of risks. The results of probabilistic risk models are usually presented in terms of metrics such as average annual loss (AAL), and probable maximum losses (PML) for various periods. The AAL is the annualized average expected loss annualized over a long time frame. It represents the amount that countries would have to set aside each year to cover the cost of future disasters in the absence of insurance or other disaster risk financing mechanisms. PML represents the maximum loss that could be expected within a given period of time. Typically, PML is relevant to determine the size of reserves that, for example, insurance companies or a government should have available to buffer losses. In simplified terms, as with the option of assessed risk, the countries could use the calculated AAL in 2015 as their baseline and aim at bringing the numbers down by reducing their exposure and vulnerability to hazards and increasing their capacities to deal with them.

The catastrophe modelling paradigm has principally been used to help insurance entities quantify financial risk and hence the large majority of catastrophe models have been developed in high- and upper-middle-income countries with an active insurance industry. While today a number of programmes aim at expanding the coverage of models, data availability remains a challenge. In addition, a majority of the models provide information on economic losses but not for mortality, although examples of national or regional mortality models can be found for example for Japan and California ${ }^{323}$.

Examples of modelling platforms for disasters include CAPRA and CRIM. The Comprehensive Approach to Probabilistic Risk Assessment ${ }^{324}$ (CAPRA) initiative started in January 2008, as a partnership between the Center for Coordination of Natural Disaster Prevention in Central America, UNISDR, the Inter-American Development Bank, and the World Bank. It has been used for example to design risk transfer instruments, and for probabilistic cost-benefit ratios of risk mitigation strategies, such as building retrofitting. The International Institute for Applied Systems Analysis (IIASA) developed the Integrated Catastrophe Risk Management model $\left(\right.$ CRIM) ${ }^{325}$. Among the first case studies, the model was used for designing earthquake insurance policies in Russia and Italy by integrating an earthquake hazard module and geographic information system-based maps of seismic intensities and vulnerabilities. The approach has been extended to other types of natural and anthropogenic hazards, such as urban flash floods, windstorms, livestock epidemics, and security management. The use of assessment models for sustainable development is addressed more in-depth in Chapter 2.

While an increasing number of risk models are now being produced for specific hazards and portfolios of exposed assets, up to now it has been difficult to estimate global disaster risk due to major geographical gaps and the fact that global assessments for single hazards use different data sets and methodologies. The global AAL for economic losses has been calculated as part of the new Global Risk Assessment coordinated by UNISDR, the first of its kind to provide worldwide coverage for multiple hazards. In the built environment alone, global economic losses associated with earthquakes, cyclones, tsunamis and floods are estimated at US\$ 314 billion $^{326}$. The new global assessment (see Box 4-5) uses the CAPRA modelling platform and enables comparisons of risk levels between countries and regions and across hazard types. 
The models also raise the question of how far can countries take into consideration the expected changes in risk drivers such as climate change, demographic changes and urbanization. For example, given the specific disaster risks posed by ageing populations, countries and regions with ageing and declining populations are likely to see increases in vulnerability ${ }^{327}$. Exposure increases with the size of the population and its activities in a certain area. The greater the number of people settled in an at-risk area, coupled with high vulnerability, the higher the exposure exposure. Increased production, investments, infrastructure and economic assets can mean increased value at risk, while increased consumption can contribute to risk factors either by removing natural barriers that act as protection against the risks and causing environmental degradation or, for example, blocking drainage or other events that exacerbate the impact of natural phenomena ${ }^{328}$. While climate change is now being taken into consideration to an increasing degree, for example with updates to hurricane intensities in models, most models still do not take into consideration other underlying drivers of risk.

\section{Box 4-5. The UNISDR-led probabilistic model}

Since 2011, UNISDR has spearheaded a multi-hazard Global Risk Assessment in partnership with leading scientific and technical organizations. The objective is to provide comparable open-access disaster risk metrics across countries and hazard categories with a relatively coarse resolution as a means of raising risk awareness. Probabilistic hazard models have been developed for earthquake, tropical cyclone wind and storm surge, tsunami and river flooding worldwide, for volcanic ash in the Asia-Pacific region and for drought in parts of Africa. The principal metrics from the global assessment are average annual loss (AAL), also known as the pure risk premium (when normalized by exposed value or capital stock), and probable maximum loss (PML). The global assessment aims at enabling a better mapping and understanding of the global risk landscape, an estimate of the order of magnitude of losses in each country, and a calculation of the risk contributions from different hazards. In the development of risk models, many different data sets are used as input components, and the level of epistemic uncertainty is directly linked to the quality of the input data. On many occasions during model development, expert judgment and proxies are used in the absence of empirical data, and the results can be very sensitive to these assumptions and variations in input data. Nevertheless, the results of this global effort give an indication of orders of magnitude of probabilistic risk and provide global coverage that countries can use as starting points for assessing risk and appropriate risk management strategies.

\subsubsection{Measuring affected people}

During the discussions of the OWG and in the WCDRR preparations, countries highlighted their wish to include in the targets people affected by disasters. This is understandable when looking at the trends. Housing damage and injuries have increased approximately fourfold since 1990, the number of people evacuated ten-fold and the number of relocated six-fold in nationally reported disasters ${ }^{329}$. While OWG target 11.5 aims at reducing the number of people affected by disasters, the definition of "affected" in this context remains unclear. During the WCDRR negotiations the ISDR Secretariat proposed using a compound indicator combining people injured, evacuated and relocated and housing damaged and destroyed ${ }^{330}$. However, in the final outcome the Member States decided that the categories of affected people would be elaborated after the Conference.

A challenge for this type of reporting has been that data on affected people has not been collected systematically and the definitions of "affected" vary considerably depending on the source. Debate revolves mostly around the question of how to address people who are affected directly or indirectly and where to draw the line. Also there remains the question of whether including the number evacuated in measure could have perverse effects by discouraging evacuation.

Some data sources report strictly only those who are affected by the disaster and are receiving humanitarian assistance. Others report the population of the entire district or province where the disaster (typically floods) has occurred, either including or excluding the impact on communities that host displaced persons. EMDAT ${ }^{331}$ for example defines affected as follows: "People requiring immediate assistance during a period of emergency, i.e. requiring basic survival needs such as food, water, shelter, sanitation and immediate medical assistance. This may include displaced or evacuated people ${ }^{332 "}$, while the IASC Operational Guidelines on the Protection of Persons in Situations of Natural Disasters ${ }^{333}$ defines affected people as "those who suffer the negative consequences of a particular disaster, whether they are displaced or not, for instance if they have sustained injuries, loss of property and livelihoods and other damages due to disasters".

The criteria for homeless or displaced is uncertain - some consider a few nights away from home as displaced and others only those who have permanently lost their homes and have to rebuild or relocate ${ }^{334}$. The Guiding Principles on Internal Displacement define displaced as: "internally displaced persons are persons or groups of persons who have been forced or obliged to flee or to leave their homes or places of habitual residence, in particular as a result of or in order to avoid the effects of armed conflict, situations of 
generalized violence, violations of human rights or natural or human-made disasters, and who have not crossed an internationally recognized State border ${ }^{335}$." Forms of displacement vary and might change over time, with associated monitoring challenges; although evacuation is meant as a temporary measure, it might lead to longerterm displacement and permanent relocation. The collection of data on displacement, in particular registration of displaced persons and its accuracy, involves particular challenges in urban and semi-urban locations that differ from those in traditional camp settings ${ }^{336}$.

Box 4-6. Combining outcome, output and input indicators During the OWG negotiations, Member States often emphasized the need to set outcome or impact-oriented targets, although the 15-year timeframe of the SDGs poses challenges for properly tracking progress in some countries as stated above. In order to make sure that the countries which will experience lesser exposure to hazards than usual during the SDG monitoring timeframe, can track their progress in DRR, it will be necessary to assess also the degree to which protection against risks is being provided.

The 22 indicators of the HFA Monitor were input indicators, and it was noted that, due to the absence of consistent output indicators, it has been more difficult to measure how much of the progress at the policy level has translated into improved outcomes on the ground ${ }^{337}$. For the post2015 DRR agenda UNISDR has proposed the use of outcome indicators at global level combined with national level input and output indicators ${ }^{338}$. In the SDG framework, one such example is target 11.b that aims at increasing the percentage of cities and human settlements adopting and implementing integrated policies and plans towards resilience to disasters. Several different types of indicators have been proposed ${ }^{339}{ }^{340}$ for DRR such as the percentage of population with access to livelihood asset protection measures, such as insurance and social safety nets, and the percentage of buildings complying with hazard-resistant building codes. Such indicators can be seen as proxies for countries' abilities to manage the underlying risk. A balance among suitable input, output and outcome indicators should be taken into consideration in the selection of post2015 agenda indicators at national level, to ensure that indicators complement each other and contribute towards facilitating achievement of the proposed targets.
The other question related to monitoring affected people is which methodology to use for data gathering. While persuasive evidence to assess disaster-affected population can be obtained through sample surveys, particularly using representative sampling, this is not always the most timeefficient or resource effective method. New technologies and ways to gather data, elaborated below, could suggest ways to adjust the scope and definition of the target for number of affected people in the future.

\subsection{New solutions for measuring}

As new technologies for data collection have become increasingly available and user-friendly, the disaster risk reduction community has been exploring these channels to complement and even by-pass often arduous and expensive traditional data collection methods. In particular, traditional and new data sources, including big data, could be brought together for better and faster data collection at several phases of the disaster cycle (for a detailed discussion on big data see Chapter 8). Big data and other new ways of data collection can be used in the full disaster management cycle to guide preparedness and early warning, impact and response as well as mitigation, risk and vulnerability monitoring.

Although all these new types of data have the potential to fulfil current data gaps, socio-economic, infrastructural, data management, and educational, barriers remain to be addressed in many developing countries before big data can be applied on a large scale to disaster monitoring. 
Table 4-3. Disaster management cycle and the use of different types of data sets ${ }^{341}$

\begin{tabular}{|c|c|c|}
\hline Phase & Data Type & Example Data Sets \\
\hline \multirow{2}{*}{$\begin{array}{l}\text { Preparedness } \\
\text { and Early } \\
\text { Warning }\end{array}$} & User-generated & Twitter (food crisis, earthquake), web traffic (flu) \\
\hline & Sensor & $\begin{array}{l}\text { Precipitation (PERSIAN, TRMM, planned GPM), evapotranspiration, soil moisture, temperature, } \\
\text { vegetation density and water content (MODIS, LANDSAT, Sentinels), groundwater levels (GRACE) }\end{array}$ \\
\hline \multirow{2}{*}{$\begin{array}{l}\text { Impact and } \\
\text { Response }\end{array}$} & User-generated & CDR, Flickr, Twitter, SMS traffic \\
\hline & Sensor & $\begin{array}{l}\text { Optical imagery (LANDSAT, MODIS, DigitalGlobe, SPOT, Pleiades, RapidEye SkyBox, PlanetLabs } \\
\text { etc.), thermal (LANDSAT, MODIS), radar (RADARSAT-1, TerraSAR, Alos, Sentinels, CARTOSAT), } \\
\text { georeferenced video }\end{array}$ \\
\hline \multirow{3}{*}{$\begin{array}{l}\text { Mitigation, Risk } \\
\text { and Vulnerability } \\
\text { Modeling }\end{array}$} & User-generated & CDR, emergency call content, Facebook \\
\hline & Sensor & $\begin{array}{l}\text { Nighttime Lights (NTL), Imagery, thermal, Radar, spatial video, Temporal Flood Inundation Mapping } \\
\text { (GIEMS, DFO, etc.) }\end{array}$ \\
\hline & institutional, public & $\begin{array}{l}\text { GCM (Global Climate Model), Transportation data (subway, bike share), census, Landscan, } \\
\text { Worldpop, Open Cities }\end{array}$ \\
\hline
\end{tabular}

\subsubsection{Preparedness and Early Warning}

Big data both from individuals and from various sensors (space-based, aerial or ground-based) can contribute to enhancement of early warning systems and disaster preparedness.

Using sensors to detect weather patterns has a wellestablished history, and meteorological data collections dates back over a hundred years. For instance, it has been useful in predicting floods ${ }^{342}$, droughts ${ }^{343}$, fires ${ }^{344}$, and ENSO (El Nino Southern Oscillation) driven drought ${ }^{345}$. Satellite imagery can also be used as a source for early warning for epidemics, by using spatial modeling to correlate disease cases with land use characteristics and creating risk prediction maps to inform health agencies, as has been done with malaria, Rift Valley fever ${ }^{346}$, and schistosomiasis $^{347}$.

By using "citizens as sensors" 348349 , often referred to as crowdsourcing, many crises can be predicted before they occur, allowing for lead-time for evacuation and other crucial preparations. For example, the UN Global Pulse Program was able to predict three separate food crises in Indonesia in 2012 by filtering tweets by using key words about price and inflation ${ }^{350}$. Public health professionals have also used online searches as an early warning to flu outbreaks, as disease outbreaks correlate with queries of disease for early detection ${ }^{351}$. Earth observation derived imagery has also been combined with precisely geo-located field users' generated information in FLOODIS ${ }^{352}$, a collaborative European Community project. It aims at producing alerts and management information on incoming and occurring floods events with high- accuracy, providing a centralised platform for emergency responders and citizens.

\subsubsection{Impact and Response}

Both individual data and sensor data can play a key role in the immediate aftermath of a disaster in support of humanitarian aid allocation, in rapid damage assessment and in the response phase in monitoring progress.

Over the last decade, efforts from the major space data and space-based information providers have focused mainly on the response phase of disasters, including the establishment of successful operational support services such as the International Charter on Space and Major Disasters $^{353}$ and the Sentinel Asia ${ }^{354}$ that aim at providing a unified system of space data acquisition and derived mapping products delivery to those affected by natural or man-made disasters. Traditional satellite imagery data can be used for disaster impact assessment by surveying the spatial extent of impact for floods ${ }^{355}$, fires ${ }^{356}$, landslides ${ }^{357}$, drought $^{358}$, and more, when the right data and techniques are employed. Satellite Earth observation offers unique 
scope and coverage, and in some cases, because in-situ observations can be difficult to obtain or access of disaster assessment and assistance teams to the affected areas is delayed or restricted, remote sensing data may be the only reliable information source, especially in the immediate aftermath of disasters. In addition, user-generated data valuably serves the ground validation and calibration of space-based data, and increases understanding of social implications of disasters.

New individual datasets that help understand disaster impacts include phone call detail records (CDR) and airtime expense records. The former are anonymized records of caller and receiver phone IDs and cell towers, and call date and time. Airtime expense records detail the amount and nearest tower location of cell minute purchases ${ }^{359}$. This data has been used by researchers to understand broad human mobility and population response across many contexts such as measurements in post-earthquake Haiti in $2010^{360}$, and in 2009 floods in Tabasco, Mexico ${ }^{361}$.

Recent innovations have also increased the utility of spatially-referenced video obtained with GPS-enabled cameras, since these can be much quicker for damage assessments than deploying staff to the field ${ }^{362}$. Such georeferenced videos involve attaching a camera to a vehicle or small aircraft and recording a damage-affected area, possibly later isolating individual frames to use as static images. This technique has been used to track damage after tornadoes in Tuscaloosa, Oklahoma ${ }^{363}$, and to track recovery of New Orleans neighbourhoods after Hurricane Katrina $^{364}$.

Crowdsourcing can support efforts to filter the signal from noise in Big Data. Networks of volunteers often dubbed "digital humanitarians" ${ }^{365}$ have been solicited to geotag and categorize images of damaged buildings in postdisaster assessments for earthquakes in Haiti, China, and Christchurch, as well as for Typhoon Haiyan in the Philippines $^{366}$. Tools and groups such as TomNod and the Humanitarian OpenStreetMap Team have also aided disaster relief logistics by digitizing features like roads and buildings from satellite imagery ${ }^{367}$. Similarly, volunteers within the Google MapMaker community have also made significant contributions to rapid post-disaster mapping in the past, while contributing to improving base mapping of regions or areas at risk as well.

Use of social networks and mobile phone technology are also being explored to crowdsource information from disasters where access to victims is difficult. A good example is the application of the Ushahidi ${ }^{368}$ open-source crisis-mapping software in Haiti which gathered Information through social media (e.g. Twitter and
Facebook) and text messages sent via mobile phones. Here efforts to harness crowdsourced information on who is disaster-affected, where and how resulted in vast quantities of information available to anyone with an Internet connection. Although the exercise was aimed at providing immediate information for relief response to the disaster-affected, this data once it is verified, could also contribute to assessing the final numbers of disasteraffected $^{369}$, in combination with other geographic and space-based data and population density modeling. At the same time it is important to remember that often in the immediate aftermath of disasters those in need have lost their access to Internet. Another example where new data sources can help in assessing the affected population was Typhoon Ketsan in the Philippines ${ }^{370}$. GIS-based environmental vulnerability models derived from cyclone advisory data and the Shuttle Radar Topographic Mission (SRTM) global data set, coupled with pre-disaster population data from the Global Rural Urban Mapping Project was overlaid on vulnerability models to produce total affected population numbers.

New technologies also benefit from improvements in wellestablished methods to make monitoring processes more efficient. In the last decade the use has increased of spatial, geographic information system (GIS), remote sensed and Global Navigation Satellite Systems (GNSS) techniques has increased to identify a sampling frame for surveys in postdisaster and post-conflict settings ${ }^{371}$. Furthermore, satellite telecommunications better enable response activities and monitoring, especially in situations where permanent infrastructure is damaged.

\subsubsection{Mitigation, Risk and Vulnerability Modeling}

Many analyses now include reframing future risk in terms of climate change from GCM (global circulation model) and reanalysis or downscaling of this data through products such as Climate Wizard ${ }^{372}$, where users can choose a variety of emissions scenarios to download maps on predicted changes in temperature and precipitation at various special scales. Combining climate model outputs and disaster risk models with satellite imagery such as night-time lights (NTL), to estimate human settlement and economic exposure to risk is common ${ }^{373,374}$.A major advantage of satellite data is its collection in the same place over time (in days, weeks, or months depending on the source), allowing for automated validation and updating of risk models with each new satellite pass. This allows for analysis of change over time or summary of long-term trends, resulting in data sets such as Global Inundation Extent from Multi-Satellites $(\text { GIEMS })^{375}$, that maps average annual and historic flooding for each month at a global scale. 
New sensor data also includes unmanned aerial vehicles ("drones") and spatially referenced (georeferenced) video. Georeferenced video has been used quickly to identify sites of standing sewage and water to aid in cholera risk mapping in $\mathrm{Haiti}^{376}$ and vulnerability of homes in Los Angeles, California to wildfire ${ }^{377}$. Drones can provide very high-resolution 2-D and 3-D imagery, which can be useful in mapping complex urban riverine topography, which has been used in Haiti for flood modeling assessments ${ }^{378}$.

New data sets can help in understanding vulnerability and mobility, and data to estimate mobility patterns can be gleaned for example from geolocated tweets. One piece of research found that by analyzing New York City tweeters before, during, and after Superstorm Sandy, pre-disaster mobility patterns can indicate the potential range of mobility during a disaster ${ }^{379}$. Other indicators of mobility include transit data by bikes ${ }^{380}$, buses and subways being made available by hundreds of municipalities ${ }^{381}$. Transit data can monitor population flux at different times of day, and is just one example of open Big Data cities are releasing that could be valuable for risk assessment.

\subsubsection{Challenges}

When highlighting several new advances in the use of new data collection methods for DRR it is also important to remember that challenges remain. For example the Twitter algorithm used to detect food crises in Indonesia mentioned earlier in this chapter also had one misfire, predicting a food crisis where there was none. Sometimes questions arise from the representativeness of the data as in the case of the Superstorm Sandy, where in the wake of the storm the social media data were more highly concentrated in less-impacted areas of New York City, rather than in neighbourhoods in south Queens which bore the brunt of its impact ${ }^{382}$. In the example of crowd-sourced information in Haiti, of the more than 3,500 messages published on the Ushahidi-Haiti crisis map, only 202 messages were tagged as "verified" by the Ushahidi team, mostly from early web submissions that had been based on media reports ${ }^{383}$. The challenges related to the use of big data will be addressed in more depth in Chapter 7 and Chapter 8 of the report.

\subsection{Conclusions}

Effective disaster risk reduction measures will need to play a key role for disaster-prone countries in implementation of the post-2015 development agenda in order to prevent hard won development gains from being eroded by disasters.

- Disaster loss accounting and risk assessments will play a pivotal role in monitoring progress, and concerted efforts are required to improve the coverage and quality of data, including establishment and support to national loss databases using common methodologies. Developing disaster statistics and risk metrics will not only improve reporting of progress towards internationally agreed goals and targets but also support evidence-based planning and decision making.

- Countries will need to address the issue of baseline setting for monitoring of progress and, despite some of the weaknesses of the method, use of the 10-year average of observed historical data as decided in the Sendai Framework for Action on global mortality might be the simplest option for the moment. Nevertheless, data availability is increasing rapidly and scientific assessment and modelling capacity follows suit, and new options could be considered for future use.

- In recent years, partnerships between scientific organisations and practitioners and policy makers have enhanced the uptake of evidence in DRR. Use of scientific research, including risk assessments and models, from both the academic and business community, and analysis of the underlying drivers of risk, should be further promoted in planning and monitoring.

- The regional dimension can provide valuable support to the implementation of both the SDGs and the Sendai Framework. Countries from the same region face similar problems and benefit from sharing experiences, and it can be easier to assess the transferability of their experiences at the regional than the global level. The region can also serve as the suitable level to provide support to countries, through capacity building activities, and appropriate harmonisation and validation initiatives.

- New methods and technological solutions for data gathering are being developed with increasing speed. In order to harness these as efficiently as possible, capacity development as well as more open access to data will be required to support developing countries in making full use of the opportunities.

- Several questions related to definitions of terms and the target scope, accounting methods, baselines and data sources will need to be answered when setting up the monitoring framework for SDGs. Therein lies a golden opportunity to align the work being done for the post-2015 agenda with the post-Sendai DRR monitoring framework in order to avoid duplication, and to ensure that progress in disaster risk reduction can be reported as an integral part of progress on sustainable development. This will spare precious resources and allow countries to focus on implementation in order to make development sustainable and resilient. 
ANNEX 1. DRR related targets in the OWG proposal

Goal 1. End poverty in all its forms everywhere

1.5 by 2030 build the resilience of the poor and those in vulnerable situations, and reduce their exposure and vulnerability to climate-related extreme events and other economic, social and environmental shocks and disasters

Goal 2. End hunger, achieve food security and improved nutrition, and promote sustainable agriculture

2.4 by 2030 ensure sustainable food production systems and implement resilient agricultural practices that increase productivity and production, that help maintain ecosystems, that strengthen capacity for adaptation to climate change, extreme weather, drought, flooding and other disasters, and that progressively improve land and soil quality

Goal 9. Build resilient infrastructure, promote inclusive and sustainable industrialization and foster innovation

9.1 develop quality, reliable, sustainable and resilient infrastructure, including regional and trans-border infrastructure, to support economic development and human well-being, with a focus on affordable and equitable access for all
Goal 11. Make cities and human settlements inclusive, safe, resilient and sustainable

11.5 by 2030 significantly reduce the number of deaths and the number of affected people and decrease by $y \%$ the economic losses relative to GDP caused by disasters, including water-related disasters, with the focus on protecting the poor and people in vulnerable situations

$11 . b$ by 2020 , increase by $x \%$ the number of cities and human settlements adopting and implementing integrated policies and plans towards inclusion, resource efficiency, mitigation and adaptation to climate change, resilience to disasters, develop and implement in line with the forthcoming Hyogo Framework holistic disaster risk management at all levels

Goal 13. Take urgent action to combat climate change and its impacts *

13.1 strengthen resilience and adaptive capacity to climate related hazards and natural disasters in all countries

13.3 improve education, awareness raising and human and institutional capacity on climate change mitigation, adaptation, impact reduction, and early warning 


\section{Chapter 5. Economic Growth, Inclusive and Sustainable Industrial Development and Sustainable Consumption and Production}

\subsection{Introduction}

\subsubsection{Overview of goals and development challenges in the post-2015 agenda}

As the international community debates the post-2015 development agenda, it is timely to reflect on what constitutes inclusive and sustained economic growth and sustainable development, and what are the policy tools that could support societies' aspirations for sustainable and shared prosperity.

The 17 SDGs and 169 targets, as submitted to the UN General Assembly by the Open Working Group on SDGs ${ }^{384}$, will serve as the world's roadmap for completing the work of MDGs and implementing a transformative and universal development agenda. The SDGs are highly interdependent and offer a "three-dimensional" view of the challenges faced by different countries on the road to sustainable development.

The universality of the agenda implies that there is work to be done by all countries, including developed countries, in putting the world economy on a sustainable development path and ensuring that the outcome benefits all countries and people. The globalization process of the past several decades has made countries' economies ever more interdependent through channels of world trade, technology and investment and globally distributed supply chains. Thus, consumption patterns are closely linked to production patterns across the globe, and a shift towards sustainable patterns of consumption must proceed in parallel with a shift towards sustainable production, including sustainable industrialization. Closer international cooperation will be needed to make this possible.

A key feature of the new goals and new agenda is recognition of the need for countries to secure strong economic foundations for shared and sustainable prosperity, including productive production systems and strong technological capabilities ${ }^{385}$. Another important feature is the treatment of sustainable consumption and production (SCP), both as a stand-alone goal and as a cross cutting contributor to the attainment of other goals. A shift towards SCP will result in reduced environmental impacts due to more efficient energy and resource consumption, reduced waste and increased materials recycling and reuse.
China stands out as the clearest example in recent decades - but not the only one - of how industrial transformation of an economy can help raise people out of poverty and sustain improvements in living standards over time. Following in the footsteps of an earlier generation of rapid industrializers like the Republic of Korea, China has become the "archetypal test case for understanding the effects of contemporary industrialization on social transformation". ${ }^{386}$

Rapid industrialization also often entails sizeable environmental health costs with which countries have had to cope.

Today's would-be industrialising economies face a number of challenges. Studies of economic growth and productivity advance point to the unique contribution of the manufacturing sector to productivity catch-up in the process of development ${ }^{387}$. Yet, some research ${ }^{388389}$ suggests that in the recent past developing countries have been reaching lower peak shares of manufacturing in total employment and GDP and at lower levels of per capita income than historically experienced by early industrializers. Given manufacturing's role as driver of productivity growth and productive employer of surplus labour from agriculture, this finding raises concerns for today's would-be late industrializers, including African countries that have put this high in their development agenda. Coupled with this, manufacturing growth is no longer automatically synonymous with decent job growth.

A better understanding is needed of what explains these results: whether they reflect structural shifts in the global economy and/or fundamental technological shifts that are unlikely to be reversed. For example, how far is information technology-enabled automation dimming the future prospects for strong manufacturing employment growth, especially of relatively low-skilled labor?

Perhaps the most important new challenge facing today's industrializers is the growing global urgency of climate change and the need to devise less energy-intensive and low-carbon industrial development paths, which few countries have managed to do historically. Thus there are few good models to follow and more innovative solutions are needed. 
Inspired in part by the work of international organizations on green growth/green economy and on low-carbon, climate-resilient development, a number of developing countries at varying levels of development have begun to pursue development strategies aimed at leapfrogging the "grow now, clean up later" approach associated with the traditional industrialization model. An important line of work has focused on the potential health and productivity benefits from reducing severe levels of air pollution in human settlements, while at the same time limiting greenhouse gas emissions.

Industrialization strategies of most developing countries still rely heavily on export expansion to support large-scale production. Thus, the capacity to adapt to changes in consumer preferences, labelling requirements and government regulations in overseas markets has an important bearing on export prospects. As developed country consumers become more discriminating in their purchase decisions, more frequently evaluating environmental and social benefits as well as cost, quality and reliability criteria, producers will need to adapt. This is becoming a more familiar feature of the landscape for doing business, not just for manufacturers but also for exporters of primary commodities of various kinds. For developing countries this is both a challenge and an opportunity to leap-frog if they can meet the technological benchmarks for success.

This chapter reviews the current landscape of industrialization and the challenges ahead for today's late industrializers, in light of the changes just highlighted. It considers what sorts of policy and institutional support may be needed to enable late industrialization today, particularly along a low-carbon, sustainable path. It considers how a shift towards sustainable consumption and production globally is likely to alter the options for late industrializers.

\subsubsection{Evolution of thinking on the role of Industrial Policy for development in past decades}

In the period since World War II, academic thinking on policies to promote industrial development has gone through several phases (enumerated in Table 5-1). This evolution has in turn shaped policy practice in both developed and developing economies.
A stylized laissez faire economic view confines the role of the state to providing an enabling environment for businesses by securing property rights, enforcing contracts, streamlining procedures for starting new enterprises, putting in place effective legal processes for dispute resolution and, under certain circumstances, providing reliable infrastructure. In this view governments should intervene in cases of market failures, due to information asymmetries, existence of public goods, externalities and/or imperfect competition.

In practice, few governments have adhered to this stylized model. Most have been activist to some degree in promoting industrial development. This is partly because the notion that countries should be content to specialize in accordance with static comparative advantage is seen as resigning countries to remaining "hewers of wood and drawers of water" of the international economy.

An alternative perspective ascribes to government an active role in promoting the structural and technological transformation of the economy ${ }^{390}$. Within this framework, governments operate alongside market forces and partner with productive enterprises and households to foster structural transformation. They can create the conditions for the development of new industries and reduce the dislocations caused by shifts in investment and profits from old to new industries. Governments can provide incentives that accelerate a process of discovering and developing successful sectors $^{391}$ and even fill the gaps where the private sector is reluctant to enter into risky ventures with potentially high social returns such as infrastructure.

New thinking on industrial policy's role focuses on promoting individual and collective forms of learning and innovation dynamics within manufacturing and broader production systems. A more sophisticated understanding is emerging of industrial eco-systems that encompasses interlinkages among producers at different stages of the supply chain, technology infrastructure and other service providers, and sophisticated users. 
Table 5-1. Industrial policy waves and the emerging industrial policy consensus

\begin{tabular}{|c|c|c|c|c|}
\hline Main features & $\begin{array}{l}\text { First wave } \\
40 \text { s to mid- } 70 \mathrm{~s}\end{array}$ & $\begin{array}{l}\text { Second wave } \\
\text { Mid-70s to } 90 \text { s }\end{array}$ & $\begin{array}{l}\text { Third wave } \\
2000 \mathrm{~s}\end{array}$ & $\begin{array}{l}\text { Emerging themes } \\
2010 \mathrm{~s}\end{array}$ \\
\hline Development as/through & $\begin{array}{l}\text { Indu strialisation } \\
\text { and structura I change }\end{array}$ & $\begin{array}{c}\text { Stabilisation, liberalisation, and } \\
\text { poverty reduction }\end{array}$ & Global knowledge economy & $\begin{array}{l}\text { Learning economy and } \\
\text { Innovation in production }\end{array}$ \\
\hline Policy target/s & $\begin{array}{l}\text { Creating markets } \\
\text { Structural change and } \\
\text { diversification }\end{array}$ & $\begin{array}{c}\text { Specialisation and } \\
\text { modernisation (Market-led) }\end{array}$ & $\begin{array}{c}\text { Innovation } \\
\text { Increasing productivity } \\
\text { Diversification and specialisation }\end{array}$ & Industrial ecosystem developm ent \\
\hline Policy framework & $\begin{array}{l}\text { Import Substitution/Export } \\
\text { oriented } \\
\text { Selective industrial policies } \\
\text { Sectors development } \\
\text { Gradual open ing to competition }\end{array}$ & $\begin{array}{l}\text { The best industrial policy is "no } \\
\text { industrial policy". } \\
\text { Horizontal policies } \\
\text { Exposure to competition } \\
\text { FDI attraction }\end{array}$ & $\begin{array}{l}\text { Targeted strategies in open economies } \\
\text { Increasing national competitiveness } \\
\text { Enab ling business environment } \\
\text { Strategic manage ment of FDI }\end{array}$ & $\begin{array}{l}\text { Smart (new sele ctive) policies } \\
\text { Value creation in glocal systems } \\
\text { Value capture in production netwo riks } \\
\text { Competence s/capabilities }\end{array}$ \\
\hline Policy model & $\begin{array}{l}\text { Top-down } \\
\text { Centra lised system } \\
\text { National agencies/councils } \\
\text { Developmental institutions }\end{array}$ & $\begin{array}{l}\text { Minimal state } \\
\text { (We akening and/or dismanting } \\
\text { of national institutions) }\end{array}$ & $\begin{array}{c}\text { Multi-layered } \\
\text { (Top-down/Bottom-up) } \\
\text { Pub lic-private identification of priorities. } \\
\text { Science institutions }\end{array}$ & $\begin{array}{l}\text { Multi-layered } \\
\text { Institutions for public-private } \\
\text { coordination } \\
\text { Multi-level implementation } \\
\text { RegionaVcities clusters development }\end{array}$ \\
\hline Policy package/s & $\begin{array}{l}\text { Capital movement management } \\
\text { Production-oriented finance } \\
\text { National champions } \\
\text { development } \\
\text { Infant industry protection } \\
\text { Hard infrastructure development } \\
\text { Public funded research } \\
\text { Compensation policies for } \\
\text { lagging areas. }\end{array}$ & $\begin{array}{c}\text { Innovation policies } \\
\text { ICT diffusion } \\
\text { Competitiveness programmes } \\
\text { Human capital } \\
\text { SM Es support (regional level) }\end{array}$ & $\begin{array}{l}\text { Credits and grants for production } \\
\text { development and innovation } \\
\text { Public procurement } \\
\text { Promotion of entrepreneurship (venture } \\
\text { capital, angel investors and support to } \\
\text { business capabilities) } \\
\text { Hard and soft infrastructure } \\
\text { Technical competences and skills } \\
\text { development }\end{array}$ & $\begin{array}{l}\text { Technology infrastructure \& } \\
\text { intermediate R\&D\&M in stitutions } \\
\text { Manufacturing re search } \\
\text { Scaling up } \\
\text { Strategic public procurement } \\
\text { General purpose technologies } \\
\text { Key enabling technologies } \\
\text { Risk reduction } \\
\text { Manufactura bility challenges }\end{array}$ \\
\hline Policy rationales & $\begin{array}{l}\text { Market failures } \\
\text { Structural coordination }\end{array}$ & $\begin{array}{l}\text { Government failures }>\text { Market } \\
\text { failures }\end{array}$ & $\begin{array}{l}\text { Market failures } \\
\text { System failures }\end{array}$ & Learning and System failures \\
\hline Policy space & $\begin{array}{l}\text { High room of manoeuvre and } \\
\text { high political legitimacy of } \\
\text { national de velopment strategies }\end{array}$ & $\begin{array}{l}\text { Reduction in the room of } \\
\text { manoeuvre (WTO, TRIPS } \\
\text { commitments, etc.) and low } \\
\text { political legitim acy of nation al } \\
\text { development strategies. }\end{array}$ & $\begin{array}{l}\text { Moderate room of manoeuvre in } \\
\text { traditional fields; regain of legitim acy of } \\
\text { national development strate gies }\end{array}$ & $\begin{array}{l}\text { High room of manoeuvre in emerging } \\
\text { fields }\end{array}$ \\
\hline
\end{tabular}

Source: Andreoni (2015)

With the resurgence of interest in the development of manufacturing industries and production systems, developed and developing countries are now experimenting with a broad array of industrial policies. They are no longer exclusively focused on sector-specific interventions or general enabling policies. In line with changes in the global production landscape and dramatic technological changes, new industrial policies have been increasingly targeting production systems and sectoral interfaces, as well as their underpinning technology platforms and business organisation models. ${ }^{392}$ The systemic and cross-sectoral nature of some of these policy interventions poses challenges to policymaking, but also opens new opportunities.

New thinking on industrial policy's role also focuses on promoting innovation to switch manufacturing towards sustainable production processes, such as with the emergence of "re-manufacturing" and "closed-loop" production systems ${ }^{393}$.

\subsection{Economic growth and structural transformation}

5.2.1. Developing manufacturing industries: economic growth, sustained technological change and world trade

Research suggesting that the narrowing of productivity gaps across countries happens more predictably in the manufacturing sector than in other sectors of the economy is one reason why developing countries justifiably view industrialization as an important policy objective. ${ }^{394}$

A fundamental feature of development is structural transformation ${ }^{395}$, that is, a process of sectoral recomposition of the economy involving the development of new production and technology systems and changes in employment composition. Manufacturing industries have always been central to this process because of the direct and indirect role they play in the transformation of the overall economy via production and productivity, the development of technological and organisational capabilities, the promotion of sustained innovation, and the creation of decent jobs. Sustaining economic growth requires the ability of an economy to "constantly generate 
new fast growing activities characterized by higher value added and productivity". 396,397,398,399

Manufacturing represents a hub for technical progress in both developed and developing countries ${ }^{400}$. Empirical evidence shows that manufacturing is, by far, the sector in which most R\&D investment is undertaken. ${ }^{401}$ Investment in the development of manufacturing technologies and infrastructure contributes significantly to productivity growth across sectors and the overall transformation of industrial systems.

According to the 2008 report by the Commission on Growth and Development, all countries that have enjoyed decades of high growth rates have exhibited structural change. On the other hand, "all countries that remain poor have failed to achieve structural change". In a 2013 study by UNIDO, evidence from 50 developing countries in the period 19702007 shows that a strong correlation exists between per capita growth in the economy and the average change in share of manufacturing sector value added (MVA) in GDP.

Box 5-1. Manufacturing transformation and economic development $^{402}$

The manufacturing sector plays a key role in economic development due to its scale economies, strong backward linkages with other sectors, and high potential for productivity catch-up and innovation. Throughout different stages of development, the structure of the manufacturing sector changes continuously, to catapult an agrarian economy onto an industrialization path, deepen the industrialization process through capital accumulation, and sustain growth based on technological development and innovation.

Figure 5-1 from UNIDO's on-going structural change research shows the patterns of manufacturing development. See technical notes for elaboration.

Figure 5-1. Patterns of manufacturing development

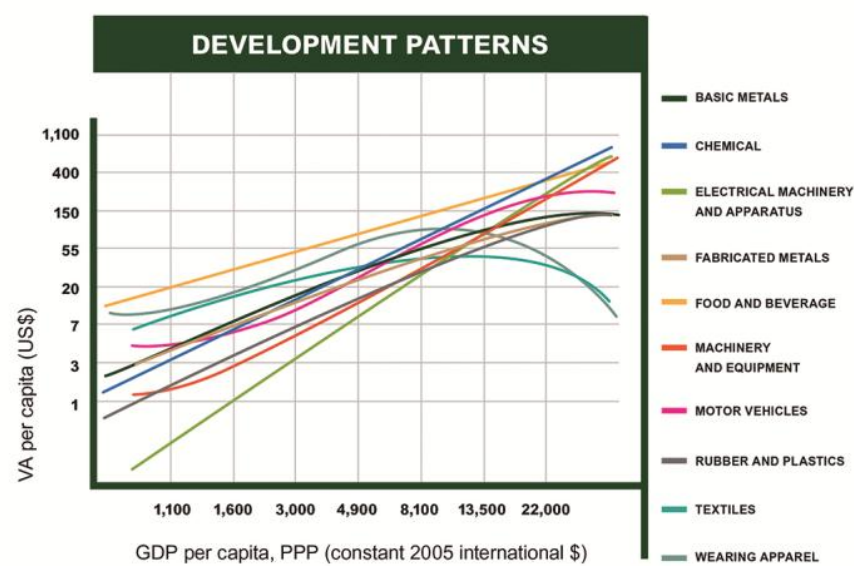

Economic literature and development experience of the past several decades demonstrate the important role of innovation and technology in growth dynamics. ${ }^{403}$ Developing countries have accorded a higher priority to science and technology, and some large emerging economies are becoming sizeable locations of R\&D activities, including through foreign investment ${ }^{404}$.

Figure 5-2. R\&D investment in selected OECD and non OECD countries, $2009^{405}$

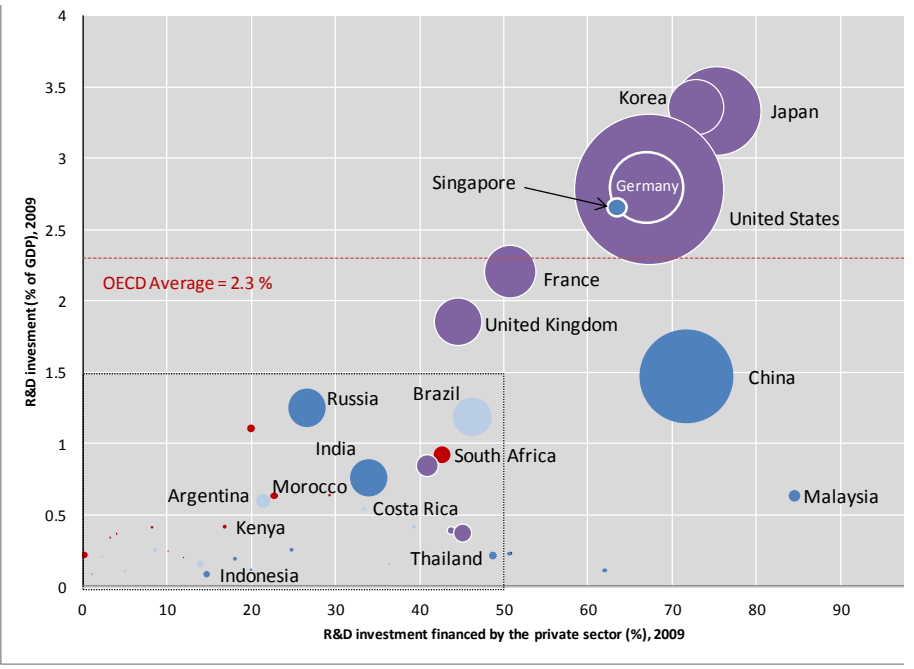

Note: 2009 or latest available year. Large, medium and small bubbles refers to gross domestic expenditure on R\&D of US\$100, 10 and 1 billion, respectively (US\$ PPP, constant 2005 prices).

The transition process towards low-carbon development and SCP has stimulated interest in green technologies. Innovative activity in this domain can be assessed through patent registrations for the novel meta-class Y02, which is a patent category proposed by the European Patent Office for climate change prevention and mitigation technologies (see Figure 5-3). ${ }^{406}$ There is a rising interest in clean energy and environmental impact mitigation technologies among traditional innovation-leaders, such as Japan and the USA, but also among rising innovators, particularly China. ${ }^{407}$ The last has developed significant cleaner production technologies $^{408}$. 
Figure 5-3. Number of Y02 patents per patent office of registration ${ }^{409}$

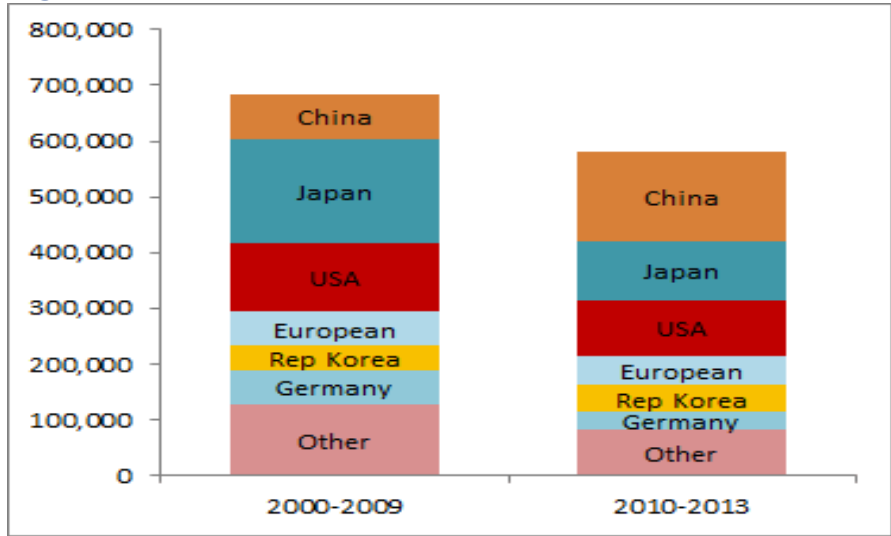

Another significant factor affecting structural transformation is globalization. The rapid globalization process of the past several decades has reshaped global economic geography. Domestic economies are increasingly interwoven with the global economic system, and centres of innovation and growth are more dispersed.

Production patterns have been driven primarily by the emergence of transnational corporations and global value chains $(\mathrm{GVCs})^{410}$ linked through trade and investment flows. ${ }^{411}$ Many countries have benefited from this process, while others remain marginalized. ${ }^{412}$ According to UNIDO study, "the 30 developing countries that successfully integrated in GVCs and showed the highest participation rates grew almost five times faster than the 30 bottom countries". ${ }^{413}$ A large part of China's rapid structural transformation is attributed to the ability of its producers to link to global value chains. ${ }^{414}$ Over the years, China has successfully diversified its production to cover entire value chains through backward and forward integration.

Patterns of international trade are changing towards increasing trade activity between developing countries. Two trends are clear. First, Africa is emerging as a point of interest for trade, especially for China, India and Brazil. Secondly, the expanding middle class in developing countries represents a major consumer market for which an intense race has already started. All developing countries stand to benefit from strengthening regional trade as an important channel for trade in consumer goods and infrastructure services, and the development of regional value chains ${ }^{415}$.

\subsubsection{Transforming industrial systems - increasing value addition in resource, agriculture and service industries}

Due to its multiple linkages, manufacturing has important pull effect on the rest of the economy. ${ }^{416}$ An expanding manufacturing industry fuels the demand for more and better primary goods (agriculture, forestry, fishing and mining) and services (banking, insurance, communications, trade and transport). ${ }^{417}$

Value addition in agro-industry can play a crucial role in employment generation and income improvement in rural areas, where $75 \%$ of the world's poor live. Rising middle classes with changing food consumption patterns create growing global demand for processed food. The sector is a leading employer, accounting for $12-13 \%$ of global employment in manufacturing and generating around 25 million jobs in 2009. ${ }^{418}$ Rural non-farm earnings account for $30-45 \%$ of rural household income in developing countries and have the potential to increase substantially. ${ }^{419}$

\section{Box 5-2. Developing agro-business in resource rich Africa} Africa's abundant natural resource endowment (e.g. $60 \%$ of the world's arable land) has contributed to the continent's rapid growth since $2000 .{ }^{420}$ Much of the growth is attributable to raw material-based commodity exports. ${ }^{421} \mathrm{~A}$ comprehensive analysis by UNECA of African agriculture value chain linkages concludes that promoting agriculture and agro-industry based agri-business and manufacturing industry value chain development can greatly enhance job creation, allow for investments innovation and industrial upgrading, and facilitate broad-based growth on the continent including addressing poverty and hunger effectively. ${ }^{422}$ Studies by UNECA covering Africa's most resource rich countries show that countries are making modest progress in developing local manufacturing value added in the hard, soft and energy commodity sectors. ${ }^{423}$

In developed countries, but increasingly also in rapidly industrialising economies, manufacturing industries also support the development of production related and knowledge intensive services. Modern manufacturing systems consist of complex interdependencies, often across a range of industries, which contribute a variety of components, materials, production systems and subsystems, producer services and product-related service systems. For countries with advanced manufacturing systems, sophisticated manufactured products are becoming important vectors for exporting production related and knowledge intensive services and for increasing value addition opportunities (see Figure 5-4). 
Figure 5-4. Mapping direct and indirect exports by sector

Global Exports in a Gross and Value Added Perspective, broad sectors, 2011

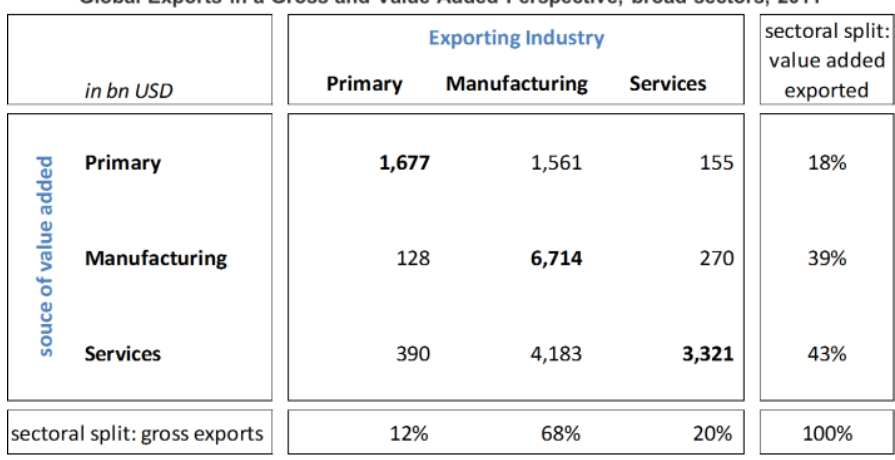

Source: WIOD, wilw-calculations.

\subsubsection{Infrastructure, industry and growth}

Infrastructure supports growth and, in particular, industrial development. Adequate, resource-efficient economic infrastructure improves productivity and reduces the costs of existing and new productive activity. Also, the availability of infrastructure may help to attract investment and to generate agglomeration economies through attracting productive capacity to a specific location. ${ }^{424}$ If introduced to places where disadvantaged groups are located, such physical infrastructure as energy, water, roads and communication facilities can have a major direct impact on the 'inclusiveness' of growth. ${ }^{425}$ Hence, ensuring inclusive and sustained growth through structural transformation will require investments in complementary economic and social infrastructure. ${ }^{426}$

In the context of the post-2015 development agenda, countries face the challenge of planning long-term infrastructure investments in ways that do not lock them into unsustainable patterns of development. This applies with particular force to transport and energy infrastructure, where the choice of modal mix and the energy mix respectively have longstanding consequences for the environmental impacts of development.

\subsubsection{Industrial policies for structural transformation: rationales, scope and policy areas}

\section{Industrial policy rationales}

Over the past two decades the global industrial landscape has been reshaped by profound structural transformations. These dynamics have been mainly driven by changes within and increasing interdependencies across national manufacturing systems, as well as alterations to their underlying technologies. De-industrialisation (the loss of manufacturing industries), increasing trade imbalances and decreasing technological dynamism have all been major concerns in advanced industrial economies. Meanwhile, many middle-income countries have faced difficulty maintaining global competitiveness in manufacturing industries and have sought with varying degrees of success to upgrade technologically to higher value-added segments of those industries.

In order to govern these structural transformations and respond to the social and environmental sustainability challenges they pose, a variety of industrial policies have been designed and implemented by governments in the recent past. ${ }^{427}$

\section{Industrial policy scope}

Industrial policies include all policy interventions affecting industries - their productivity growth, employment intensity and technological dynamism. Therefore, industrial policies encompass a broad set of policies.

Industrial policy carries a broad definition nowadays, targeting not only manufacturing industries but also high value-added activities in the agro-processing and other resource-based sectors, as well as a number of knowledgeintensive and production related services. There are two reasons why the 'sectoral' scope of industrial policies has been broadening over the years.

First, sectoral boundaries are blurring and interdependencies between sectors are becoming more critical as a result of increasing technological linkages. For example, productivity in agriculture industries depends on production and process technologies developed in manufacturing industries as well as on information technologies, while certain manufactured products increasingly embed new services. Depending on the production development and structural composition of various countries' economies, these sectoral interfaces are becoming new targets of system level industrial policy. ${ }^{428}$

Second, with the changing geography of production and the increasing division of labour within global production networks, countries have been exposed to new production opportunities and markets as well as new competitive challenges. Some countries have managed to scale up their firms' production capacity to a global market and have captured learning opportunities for enhancing the technological content of their products. Others have been less successful. ${ }^{429}$

Industrial policy interventions present different 'degrees of selectivity' according to the way in which they are designed and implemented. Even those policy interventions that are considered 'general' like education and health (also called 'horizontal' policies) involve some element of selectivity ${ }^{430}$. Beyond primary education, skills development becomes 
increasingly production specific and tends to favour certain industries more than others. Another broadly defined horizontal policy - infrastructure development - is in fact location specific and different types of infrastructure might be more or less cost-reducing depending on the products, energy intensity or destination market of the industries concerned.

Given this, some degree of targeting is inevitable, although there is no consensus on how much targeting is desirable. $^{431}$

The question remains what 'rule of thumb' countries should follow when choosing which industries to target? ${ }^{432}$ For developing countries, the debate is divided between whether they ought to be pushing the frontier through diversification towards more knowledge-intensive industries, or if they should rather be changing the production structure towards higher productivity in sectors of comparative advantage. ${ }^{433}$

UNCTAD suggests a dual strategy: "The first is to exploit more effectively those sectors, which are in line with current comparative advantage, while progressively upgrading technologies in those sectors. The second is to encourage the development of sectors and activities, which are somewhat ahead of the country's current comparative advantage, while accelerating the evolution of comparative advantage towards sectors and activities more conducive to development." ${ }^{434}$ The latter entails the strategic development of production, technological and organizational capabilities. The question remains of what, for a particular country, constitutes a feasible migration path towards an economy of increasing complexity and technological sophistication ${ }^{435}$.

Industrial policies have also been increasingly addressing the social and environmental sustainability of industry-led structural transformation. The need for industrial policy to meet the social and environmental challenges of sustainable development and capture the opportunities associated with these challenges is widely recognized.

\section{Industrial policy areas}

Governments can address the challenges characterizing the industrial development process by focusing on five main areas of policy intervention. For each of them it is possible to think of a plurality of measures and tools, affecting both supply side and demand side dynamics. Table 5-2 provides a snapshot of selected commonly adopted policy measures.
Supply side policy areas

(a) Production, technological and organizational capabilities development and production capacity expansion

Technology and innovation policies vary significantly depending on the level of development and technological capabilities of different countries, with more advanced countries being involved in advanced research and new product development and less advanced countries focusing on generating absorption capacity, product adaptation and process technologies. Government backing includes supporting and financing R\&D investments, including industrial $R \& D$ expenditures, which account for more than $70 \%$ of total business R\&D; tax support for technological investments and for businesses developing new products and processes; promoting eco-innovation and so-called "green" technologies; investing in professional and technical education in the fields of computer science and mathematics, engineering, life and physical sciences, and managerial sciences; labour market regulation; intellectual property protection; and promoting technology transfer between research institutions and businesses and across countries. ${ }^{436} 437438$ Some of these interventions, especially those linked to skills development and labour market regulation, are key for enhancing the social sustainability of the industrialization process (see Section 5.3).

\section{(b) Development finance and access to financial resources}

The availability of a wide array of financial services and of long-term predictable funding for productive investments is a fundamental catalyst for economic growth and structural transformation. Developmental finance focuses on three areas: supply of long-term funding, intermediation; and credit for SMEs. In terms of supply of funding, the main task is to increase the availability of investment financing through encouragement of savings as well as through the reduction of costs and risks, and increasing the efficiency of the financial system. This may involve expanding the role of development and investment banks as well as establishing new mechanisms of long-term finance, including investment funds. In terms of improving intermediation, it is necessary to enhance transparency and information efficiency and improve investor protection. 
Regarding SMEs, the challenge is to increase access to credit through dedicated and diversified funding mechanisms, which include for example small business loans, impact investment, venture capital, and standards for credit assessments of SMEs. ${ }^{439,440}$ Fiscal incentives and financial support schemes that promote increasing productivity, reallocating resources towards higher value added products and industries, and enhancing sustainability are also widely used.

\section{Demand side policy areas}

\section{(a) Sustainable public procurement}

Public procurement is a powerful transversal tool for promoting domestic market development and steering the market towards production and consumption transformation in pursuit of specific social and environmental goals. For example, precommercial public procurement is used by governments to support socially and environmentally valuable technology endeavours characterised by a high level of uncertainty. Various forms of public procurement are used to stimulate the development of more sustainable production and products. At initial stages of development, public procurement can be instrumental for the creation of domestic markets and the growth of private companies as government is often a major consumer in developing countries.

\section{(b) Trade development and regulation}

Developing countries have much to gain from a strategic development of their export capacity. Trade development introduces competitive forces in the domestic economy and offers multiple opportunities for technological learning. Alongside "traditional" trade policies, countries have historically relied on other instruments aimed at increasing the export-orientation and integration in the international market of domestic companies. These measures include both hard and soft measures, from subsidies, conditionality, export zones and inward investment agencies, to various bilateral cooperative partnerships, country-brand building and market foresight analysis and investment advice.

There is often an element of serendipity in how particular industries come to gain a foothold in a particular country. Once established, agglomeration economies and dense supplier networks may attract other enterprises in the same or related businesses to the same location ${ }^{441}$.

Table 5-2. Industrial policy toolbox

\begin{tabular}{|c|c|c|c|c|c|}
\hline & \multicolumn{3}{|c|}{ SUPPLY SIDE } & \multicolumn{2}{|c|}{ DEMAND SIDE } \\
\hline & $\begin{array}{l}\text { Production, } \\
\text { technological and } \\
\text { organizational } \\
\text { capabilities } \\
\text { development and } \\
\text { production capacity } \\
\text { expansion }\end{array}$ & $\begin{array}{l}\text { Developmental finance } \\
\text { and access to financial } \\
\text { resources }\end{array}$ & $\begin{array}{l}\text { Infrastructures } \\
\text { development and } \\
\text { natural resource } \\
\text { management }\end{array}$ & $\begin{array}{l}\text { Strategic public } \\
\text { procurement }\end{array}$ & $\begin{array}{l}\text { Trade development and } \\
\text { regulation }\end{array}$ \\
\hline \multirow{9}{*}{ 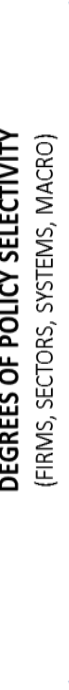 } & Education policies & Loan guarantees & Infrastructure regulation & $\begin{array}{l}\text { Pre-commercial public } \\
\text { procurement }\end{array}$ & Exchange rate policies \\
\hline & Science research funding & Capital allowances & $\begin{array}{l}\text { Physical infrastructures } \\
\text { development }\end{array}$ & $\begin{array}{l}\text { Green public } \\
\text { procurement }\end{array}$ & $\begin{array}{l}\text { Country-brand } \\
\text { development }\end{array}$ \\
\hline & $\begin{array}{l}\text { Labour market } \\
\text { regulation }\end{array}$ & $\begin{array}{l}\text { Financial market } \\
\text { regulation }\end{array}$ & $\begin{array}{l}\text { Land use planning and } \\
\text { regulation }\end{array}$ & $\begin{array}{l}\text { Public procurement for } \\
\text { betterment of job } \\
\text { standards }\end{array}$ & $\begin{array}{l}\text { Market niches scouting, } \\
\text { investment advice and } \\
\text { foresight }\end{array}$ \\
\hline & $\begin{array}{l}\text { Intellectual property } \\
\text { rights regulation }\end{array}$ & $\begin{array}{l}\text { Development banks long } \\
\text { term financial schemes }\end{array}$ & $\begin{array}{l}\text { Special economic and } \\
\text { enterprises zones }\end{array}$ & $\begin{array}{l}\text { Public procurement for } \\
\text { domestic market } \\
\text { support }\end{array}$ & Export promotion zones \\
\hline & $R \& D$ tax credit & SMEs finance & $\begin{array}{l}\text { Industrial clusters and } \\
\text { parks development }\end{array}$ & $\begin{array}{l}\text { Public procurement for } \\
\text { domestic market } \\
\text { creation }\end{array}$ & $\begin{array}{l}\text { Inward investments } \\
\text { agencies }\end{array}$ \\
\hline & $\begin{array}{l}\text { In-job training subsidies } \\
\text { and }\end{array}$ & Matching grants & Smart grids & & $\begin{array}{l}\text { Bilateral agreements and } \\
\text { partnerships }\end{array}$ \\
\hline & $\begin{array}{l}\text { Technical and vocational } \\
\text { skills development }\end{array}$ & $\begin{array}{l}\text { Public strategic } \\
\text { investment funds }\end{array}$ & & & $\begin{array}{l}\text { Trade policies for specific } \\
\text { sectors }\end{array}$ \\
\hline & $\begin{array}{l}\text { Intermediate institutions } \\
\text { for industrial research } \\
\text { and extension services }\end{array}$ & & & & $\begin{array}{l}\text { Export subsidies and } \\
\text { conditionality }\end{array}$ \\
\hline & $\begin{array}{l}\text { Mission-oriented } \\
\text { technology policy }\end{array}$ & & & & \\
\hline
\end{tabular}


5.3. Industrialisation and social sustainability:

inclusiveness, productive employment and education policies

5.3.1. Inclusive economic growth and industrialisation Over the past decades, although global poverty has been reduced, income inequality is rising, which is a source of concern in terms, among other things, of social tensions and exclusion. Only about $10 \%$ of the total wealth in most countries is in the hands of the poorest half of the population. ${ }^{442}$

The available evidence suggests that wage income from industrial employment has helped greatly in pulling large sections of the population out of poverty. ${ }^{443}$ UNIDO offers evidence from successful developing countries suggesting that economic growth and transformation triggered by industrialization, international trade and related services have contributed to poverty eradication and inequality reduction. ${ }^{444,445}$ (see Box 5-3).

\section{Box 5-3. Multidimensional poverty and industrialization}

The Multidimensional Poverty Index $(\mathrm{MPI})^{446}$ depicted in Figure 5-5 reflects the prevalence of multidimensional deprivation at the household and individual level in health, education and standard of living. A person is considered "multi-dimensionally poor" if he or she suffers deprivations in a third of the weighted indicators of the index. According to UNDP, more than $30 \%$ of the populations in the countries covered (corresponding to $75 \%$ of the world total) experienced such a multitude of deprivations between 2005 and 2012. The strong negative correlation between the MPI and the Competitive Industrial Performance Index (CIP) indicates that in countries with very competitive industries, multidimensional poverty is low.

Figure 5-6 depicts the relationship between inequalityadjusted income levels and industrial development. No country with a CIP value over 0.1 in 2012 had an inequality adjusted income index value of less than 0.4 and only two countries with a CIP below 0.01 surpassed this index value. Countries with the highest index value (i.e. the Netherlands, Switzerland, Belgium, and Germany,) are also ranked in the top 10 on the CIP index. A high rank correlation is particularly visible in the bottom 10 ranked countries in both indexes, which include Madagascar, the Central African Republic, Nepal, Malawi, Niger, Rwanda, and Uganda.
Figure 5-5. Multidimensional Poverty Index

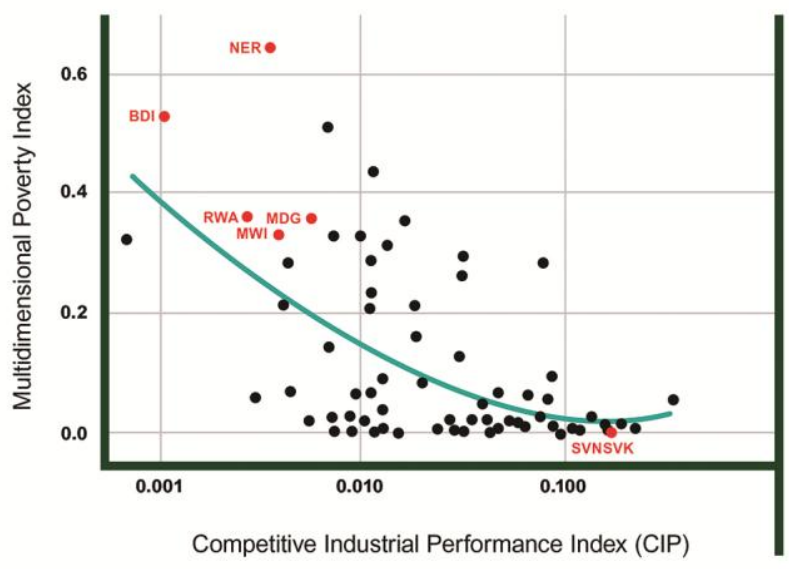

Figure 5-6. Inequality-adjusted Income Index

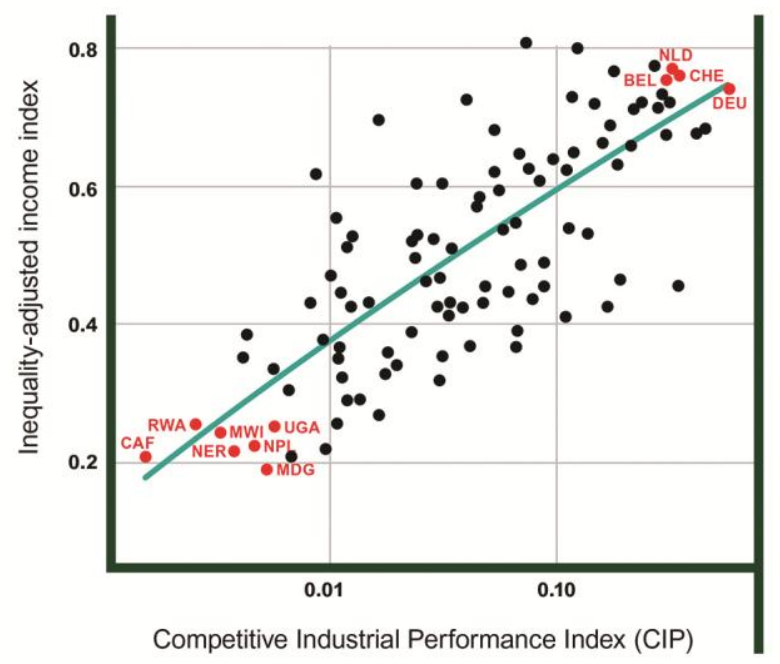

Source: Upadhyaya, Shyam and David Kepplinger (2014). ${ }^{447}$

However, the process of structural change associated with industrialization can also cause job dislocations in some sectors. Thus, industrial policy and social policy should be closely aligned to ensure the social protection of disadvantaged workers while economies undergo industrial transformation. ${ }^{448}$

Box 5-4 describes how social policies were an important element in the inclusive convergence that took place in Latin America in the early 2000s. Moreover, educational policies supporting industrial transformation and inclusive growth through training and capacity building (see Section 5.3.3) are critical to accommodating the rising demand for skilled labour. ${ }^{449}$ 
Figure 5-7. Factors in sustained, inclusive growth ${ }^{450}$

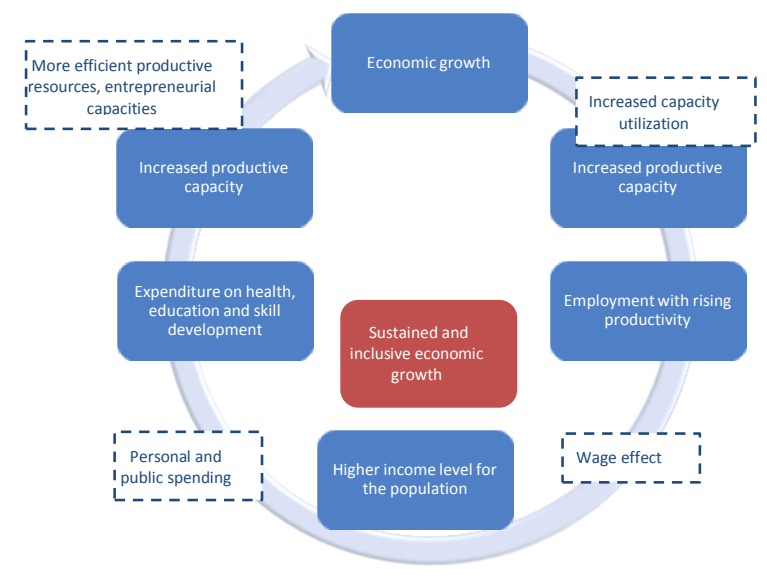

An important element in structural transformation is the increased opportunity for female employment through a greater availability of stable wage jobs. This has been an important accompaniment of industrialization in all countries. Female labour however is often concentrated in low-productivity, low-paid jobs with limited opportunities for skills development. Moving female workers to higher productivity jobs will require policy action on multiple fronts, including better coherence among industrial policies, social policies, and education and training policies $^{451}$.

\section{Box 5-4. Towards inclusive convergence in Latin America?}

Covering a 20-year period, ECLAC has traced patterns of growth in Latin America. With a few exceptions, the period 1990-2002 was characterised by "exclusive growth", i.e. economic growth accompanied by a deterioration in the income distribution. Fuelled by rising commodity prices, improved credit accessibility etc., between 2003-2007 income convergence with growth rates approaching those of Asian economies took place. Social policies together with increases in formal employment and minimum wages across the region made this development possible. However, the progress may not be sustainable, as the boom remains vulnerable to a reversal of commodity prices and economic diversification remains limited ${ }^{452}$.

The empirical literature clearly supports a positive relationship between gender equality and development. Empowering women and securing formal work and fair wages for them have tremendous implications for poverty alleviation in any country. Increasing female employment offers large gains to the community, as women are more prone to invest in education, health and nutrition for their families. In Uganda, women with traditional female jobs earn three times less than women working in maledominated sectors. ${ }^{453}$ World Bank estimates suggest that 100-150 million people could be lifted out of poverty if women on a global level had equal access to productive resources (e.g. seeds, fertilizer, and extension services) ${ }^{454}$.

However, progress towards eliminating gender-based disadvantages has been slow and uneven. In general, gender inequality is highest in LDCs and lowest in industrialized countries. China stands out for its significant progress in reducing both gender discrimination and extreme poverty. ${ }^{455}$

\subsubsection{More and better jobs for inclusive development} As industrialization evolves, the quality of jobs tends to improves. Besides having higher wages, manufacturing jobs typically provide better benefits (e.g., retirement plans, paid holidays, etc.) and security (e.g., life and health insurance, etc.) than jobs in other sectors, and tend to develop higher levels of skills than equivalent jobs in the rest of the economy. ${ }^{456}$

Globally, manufacturing accounts directly for $15-20 \%$ of total employment, with the manufacturing sector's potential for direct employment generation being inversely related to the level of income per capita. ${ }^{457}$ The employment impact of industrialization is multiplied through the productive linkages that manufacturing has with other sectors. Job-centred or labour-intensive growth has been advocated as an effective poverty reduction strategy (see Box 5-5). ${ }^{458}$

\section{Box 5-5. Developing with jobs ${ }^{45}$}

An ILO study covering 145 developing countries from 19802013 finds fundamental empirical regularities characterising their structural development trajectories: What sets different income categories of developing countries apart is job quality. These qualitative changes seem to move together, with job quality being better in manufacturing and weaker in informal sectors. See technical notes for more information.

From a policy perspective, the study suggests that registration and formalization can be a driver of improved job quality. Enhanced security in employment, and therefore enhanced duration of employment, increases capabilities through learning by doing effects and therefore productivity. Registration of workers is seen as a policy instrument enabling them potentially to access social protection, minimum wages and benefit from national legislation on improved conditions and rights.

\subsubsection{Education policies for industrial transformation and inclusive growth}

The education necessary to build productive human capabilities for industrial development tends to be underprovided without active labour market policies. In particular, the difficulty of assessing private returns of 
education will either make it hard for people to self-finance or discourage them to invest on their own even though their chances for a higher-paid job may increase.

Beyond government investment in education, policy instruments have been used to encourage firms and individuals to invest in education or training. These include scholarships or long-term loans for undergraduate and graduate university studies; vocational or engineering scholarships to carry out in-house training of prospective workers by firms; wage subsidies as an incentive for firms to hire and train more employees; demand-driven courses to train workers in the technical standards in certain industries; and business training for owners and managers of SMEs in issues like management, finance, accounting and investment analysis." 460 To ensure a shift towards resource efficiency, this training could include knowledge on how resource efficient production processes and sustainable products can improve a company's bottom line.

University curricula in both developed and developing countries often do not meet the skills set required by industry; partly because the industrial system is constantly changing. ${ }^{461}$ Technical and vocational education and training (TVET) has been increasingly acknowledged as a means to meet the demand for industrial skills as the private sector has an active role in designing and executing such programmes (see Box 5-6)

\section{Box 5-6. Technical and vocational education and training (TVET) in Ethiopia}

Ethiopia is an example of a developing country with an active policy to address the development of productive capabilities and skilled labour for its growing manufacturing sector. Its TVET system, introduced as part of the national strategy for sustainable development and poverty reduction, offers innovative approaches to face this challenge, taking into account the socio-economic context and priorities of domestic manufacturing industries. It includes the integration of school- and apprenticeshipbased elements of vocational training.

Having developed the second highest number of training institutions on the continent, $30 \%$ of them sponsored by private actors, Ethiopia's TVET system is one of the most successful in Africa. Between 2009/2010 and 2011/2012, the share of TVET graduates identified as competent by a professional certification system increased from $17.4 \%$ to $40.2 \%{ }^{462 .}$

At the same time, the importance of tertiary enrolment in subjects for advanced industry, such as engineering and mathematics, cannot be understated. "The shift from simple assembly and processing to technology-intensive industries calls for a skilled workforce capable of operating state-of-the-art technologies ${ }^{\prime 463}$.

\subsection{Sustainable consumption and production in relation to industrialization}

\subsubsection{Sustainable industrial systems and new consumption patterns}

Even as the concept of sustainable development has gained ground in recent decades, global consumption and production trends are unsustainable, as measured by such indicators as total material consumption, material footprints, and environmental impacts of various types (see Box 5-7). The global increase in consumer demand has closely followed global economic growth and thus far dematerialization and reduction in energy intensity of economic activity (or relative decoupling) have not been enough to offset what has been a huge increase in absolute volumes. Absolute decoupling of economic growth from resource use and environmental degradation has yet to occur globally.

Shifting to more sustainable patterns of consumption and production is an established commitment of the international community since the Earth Summit in 1992. Currently, member states are also considering the topic of sustainable consumption and production (SCP) for the post2015 agenda including a stand-alone Goal - Sustainable Development Goal 12 - and a range of targets that clearly embody the importance of a shift to SCP patterns.

Box 5-7. State of the environment: current resource pressures and SCP as an imperative

The science of industrial ecology shows that improvements in resource efficiency of up to $80 \%$ are possible in many sectors of the economy. ${ }^{464}$ Such improvements can occur in the material intensive sectors of the economy such as the iron and steel and cement industry, they can occur in housing and transport as well as in the food provision sector, and can include more efficient use of energy and water. A 2011 report by McKinsey Global Institute has identified that three-quarters of resource efficiency improvements would come from a small number of activities including improving the energy efficiency of buildings, promoting a modal split in transport favouring public transport, renewable energy, and greater ecoefficiency of heavy industries including iron and steel and cement. ${ }^{465}$

\subsubsection{SCP in national governance - policies and} programmes to drive structural transformation through SCP

SCP has the potential not only to change aggregate consumer demand, but also to transform production 
practices across economic sectors in both developed and developing countries. For this, there is a need to identify and ensure the enabling conditions that will allow: i) consumers to choose to consume more sustainably, and ii) producers to increase the supply of sustainable products that are aligned with the preferences of consumers.

Within the overall umbrella of SCP policies, there are different sets of policy instruments that are broadly classified as follows ${ }^{466}$.

Regulatory instruments: These include elements such as product and substance bans, emissions limits, production process standards, minimum product standards and building codes aimed at determining which products, services, substances and production methods are allowed.

Economic instruments: These include instruments such as fees and charges, taxes and subsidies, cap and trade schemes, tradable permits, feed-in tariffs, deposit-refund systems, etc. Examples include energy taxes, water user fees, subsidies for clean technology adoption, and feed-in tariffs for renewable energy installations. The use of economic instruments can greatly influence the market conditions for businesses, including SMEs, by influencing supply and/or demand for specific products and services.

Information-based instruments: These include instruments such as eco-labelling, consumer guidelines, consumer campaigns, websites and portals, education on SCP and training seminars for authorities and/or the private sector, all aimed at raising awareness about SCP. Most of these instruments influence the demand side and thus play an important role in stimulating the market for more sustainable solutions to which the supply side would respond.

There are also educational and learning instruments that facilitate corporate learning:

- Corporate Sustainability Reporting aims at public disclosure of information about the 'non-financial performance' of a company and is an important mechanism to improve corporate transparency.
- Product sustainability information such as ecolabels or Environmental Product Declarations (EPD) aim to provide relevant, verified and comparable information about the environmental and/or social impact of goods and services. Normally these are life cycle based, thus stimulating companies to address impacts beyond their corporate boundaries, along their global supply chains. Combined with sustainable supply chain or procurement policies, they can provide the necessary information and criteria for purchasing decisions.

Behavioural instruments: A behavioural approach represents a non-regulatory means to influence human behaviour towards more sustainable choices. It is an essentially demand-side instrument. A policy innovation in itself, it contains elements from cognitive psychology, behavioural economics, and cultural studies. Behavioural instruments aim to understand fundamental drivers for behaviour and use those to encourage consumers to change consumption behaviours, which can also create a stronger market demand for sustainable and innovative solutions. In a broader context, this approach is sometimes referred to as "nudging".

Technical support to enterprises, notably SMEs, to introduce more sustainable production methods, is an important complement to such policy instruments to enable an effective supply-side response to changing market and government procurement demands (see Box 58).

Delivering the required improvements on the supply and demand sides for structural transformation and SCP will require a set of changes in the public policy agenda. Governments will need to set the rules of the game to foster private investment in more sustainable products through complementary policies and incentives. It will also require enhanced capacity of government agencies to identify policy tools and implementation pathways in line with structural transformation as presented in this chapter. 
Table 5-3. UNEP's five key types of SCP action UNEP's five key types of SCP action

\section{Supply-side key actions}

Reducing material/energy intensity of current economic activities and reducing emissions and waste from extraction, production, consumption and disposal.

Applying life cycle thinking, which considers the impacts from all life-cycle stages of the production and consumption process.

\section{Demand-side key actions}

Promoting a shift of consumption patterns towards groups of goods and services with lower energy and material intensity and recyclable waste streams without compromising quality of life.

Incentivizing sustainable consumption: sharing best practices, most efficient approaches that could be scaled up to reach targeted consumer groups.

Guarding against the rebound effect, where efficiency gains are cancelled out by resulting increases in consumption.

\section{Box 5-8. National cleaner production centres - catalysts to scale and institutionalise resource efficiency}

Beginning in the 1990s, UNEP and UNIDO have promoted sustainable industrial production in developing and transition economies through the Resource Efficiency and Cleaner Production (RECP) Programme and an associate network (RECPNet).

The promotion of SCP practices within small- and medium-sized enterprises (SMEs) has been one of the main targets of this programme and network. They have facilitated the establishment and strengthening of technical partners in developing countries and emerging economies, notably the National Cleaner Production Centres (NCPCs), which offer such services as: i) Provision of technical assistance to enterprises, with a specific focus on SMEs, for the adoption of more resource efficient and cleaner production practices; ii) Provision of policy advice to government counterparts with the aim of strengthening the enabling conditions for uptake of SCP; iii) Identification, development and transfer of environmentally sound technologies (ESTs); and iv) Awareness-raising among different stakeholders of the opportunities and benefits associated with resource efficient, sustainable consumption and production practices. At present, there are more than 50 developing countries and emerging economies with established NCPCs. These NCPCs have diversified their offer of services, with the objective of strengthening the sustainability of the entire value chain in which SMEs operate. Over 20 years of operation, the programme and network have fostered, among supported enterprises, a reduction in energy consumption by $25 \%$, a reduction in water consumption by $40 \%$, and a reduction in waste generation by $25 \%$.

5.5. New industrial policies for inclusive and sustainable development - policy alignment, trade-off management and win-win solutions

\subsubsection{Industrial policy challenges}

The breadth and depth of structural transformations that countries will require for meeting the SDGs pose new challenges to industrial policy making ${ }^{467}$. Inclusive and sustainable development necessitates stronger integration of economic, social and environmental objectives.

Production and consumption patterns are an important connective point among these dimensions. Through fundamental changes to production systems, employment patterns and technologies, as well as accompanying behavioural changes influencing consumption, ${ }^{468}$ countries have the opportunity to chart new paths to industrial and economic development that are more resource and energy efficient and less environmentally damaging.

To capture opportunities offered by structural change ${ }^{469}$ and to manage the potential trade-offs, new packages of industrial policy measures will have to be experimented with and supported over time.

Industrial policymaking is a complex process as it entails the management of packages of measures. The design, implementation and enforcement of these measures also require the involvement of different government levels, from the local to the regional to the national and, in certain circumstances, supranational level ${ }^{470}$. Policies must also be consistent with international trade and other obligations.

Industrial policy areas can be used by governments in more or less selective ways to enable or steer changes in: firms their capabilities, innovation activities and production 
opportunities; industrial sectors; industrial systems and, thus, linkages across sectors; and institutions and regulations at the macroeconomic level. According to the specific challenges that countries face at different development stages, different industrial policy packages will be needed.

Countries will need to coordinate different policy instruments either to have a combined effect on the same goal or to manage potential trade-offs among different goals. For example, education policies can be aligned to labour market reforms to improve workers' employment opportunities. Technology policies can also be aligned to trade policies or public procurement measures supporting domestic industrial sectors' development. Potential tradeoffs arising between economic growth and increasing pressure on natural resources can be addressed by aligning sectoral policies and technology policy, in particular green technology development and deployment over time. Achieving integration of policy goals, instruments and governance will be difficult, but there are great benefits from even partial successes.

Integration does not equal a single integrated policy or a single integrated governance system. There remains a need for specialized policies and specialized governmental bodies." Rather, "effective integration for practical decision making centres on acceptance of common overall objectives, coordinated elaboration and selection of policy options, and cooperative implementation designed for reasonable consistency and, where possible, positive feedbacks" ${ }^{472}$ (see Box 5-9 for one policy diagnostic tool).

Box 5-9. Production Transformation Policy Reviews - a shared tool for diagnostic and policy guidance

In a global economy, industrial policies go beyond national borders and their design and implementation can benefit from a structured policy dialogue between countries. The OECD Initiative on Global Value Chains, Production Transformation and Development is a platform for knowledge sharing and creation, which gathers together countries to discuss on an equal footing the challenges and policy options for production transformation. A new policy tool under the Initiative, the Production Transformation Policy Review, aims at providing a guiding framework to identify options and actionable policy responses to promote structural transformation and upgrading based on comparative assessment of countries' assets, upgrading potential and priorities. It operates on a five-pillar framework (see Figure 5-8.), which takes into account features of success of production transformation strategies as a basis for assessing countries' potential. ${ }^{473}$
Figure 5-8. Production Transformation Policy Review Fivepillar Framework

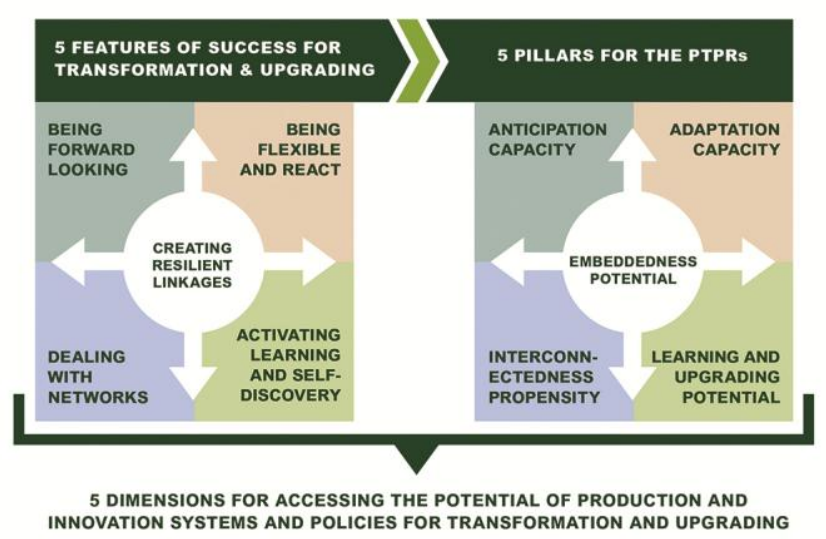

The increasing role that new developmental partnerships play in sustainable structural transformation at the country and international level is widely recognised. Many multilateral organisations consider cooperative partnerships at the core of their mandate (Box 5-10).

Box 5-10. Operationalizing inclusive and sustainable industrial development - the Programme for Country Partnerships

UNIDO has developed a new approach to partnerships for inclusive and sustainable industrial development by partnering with development finance institutions to develop a new type of technical assistance package for its Member States known as the Programme for Country Partnerships (PCP). The development of a PCP includes 1) an analysis of existing strategies and policies for industrialization; 2) an analysis of all national programmes that are relevant for industry; 3 ) the development of appropriate technical assistance programmes; 4) the mobilization of partnerships; and 5) the establishment of a national coordination mechanism for funds mobilization and results monitoring.

Not only can these collaborations make industrial policies more effective in addressing existing challenges, they may also be used to identify future economic, social and environmental challenges via road-mapping and forecasting exercises. Technological road-mapping tools, manufacturing foresight analysis and public-private policy platforms involving industry associations, research centres and other actors of the innovation system, are widely used by advanced industrialized economies. For countries planning medium-to-long-term industrial policy strategies, developmental partnerships offer the potential to identify current strengths and future production and market opportunities. 


\subsection{Concluding remarks}

The preceding discussion points to the key role that structural transformation towards higher value-added activities and sectors will continue to play in achieving sustainable prosperity for all in the post-2015 world. It points to integrated policy frameworks that link policies to build fundamental production capabilities with those that support education and social development as well as those geared to advancing environmental sustainability.

An inclusive and sustainable industrial development strategy that targets simultaneously the development of domestic production and innovation capabilities and longterm sustainable development objectives can be a cornerstone of a transformative post-2015 development agenda.
SCP provides a systemic approach to the pursuit of inclusive and sustainable growth and to managing the related tradeoffs. The ultimate objective of SCP promotion is to make possible a "decoupling" of economic growth and social progress on the one hand from environmental degradation on the other, including through the de-carbonization of economic activities over the coming decades.

As developing countries pursue industrialization on the path to economic development, finding new, low-carbon, resource- and energy-efficient development paths will be essential, and international cooperation - involving both the private and public sectors - to facilitate the freer flow of finance, knowledge and technologies will be crucial to success. 
Technical notes

\section{Developmental stages}

At a relatively low-income stage, labour-intensive industries prevail. The key input to make such industries competitive is cheap, trainable labour, which is relatively abundant in low-income countries. Success in labour-intensive industries drives up labour costs higher and makes countries less competitive in those industries. Thus, in a middle-income stage, normally the growth of labourintensive industries slows down. At this income level, sustained manufacturing and economic growth requires the development of more capital-intensive industries, starting with relatively simple products and production processes. These industries usually have higher labour productivity than labour-intensive industries and pay commensurately higher wages, indicating that better qualities of labour and infrastructure are the necessary conditions to develop competitive capital-intensive industries. Transition from a middle income to a high income status is associated with further changes in manufacturing structure but also with the evolution of services. Labour intensive industries usually start declining, and differences in growth rates even among capital intensive industries become increasingly noticeable. Industries largely driven by capital investment and the employment of semi-skilled labour tend to experience a slowdown as less developed middle income countries move into such industries and start producing similar products at lower costs. Therefore, entry to a high income stage and sustained economic growth thereafter usually go along with the development and expansion of industries that employ highly-skilled labour whose success depends on a country's ability to continuously upgrade technologies and innovate.

\section{Market failure rationales}

Market failure rationales for industrial policy build on the idea of information gaps, namely insufficient information and lack of price signals, leading to underinvestment. ${ }^{474}$ Investment in new non-traditional industrial sectors might be limited by capital market failures, lack of effective equity markets or sufficient financing resources internal to the firm. The price mechanism does "not provide clear enough indication of the profitability of resources that do not actually exist (e.g. new skills and technology)". ${ }^{475}$ Moreover, information externalities and problems of 'appropriability' in the innovation process will also drastically affect investment in new activities. Specifically, in the so-called process of 'self-discovery,' 476 firms invest heavily in the discovery of new combinations of factors and procedures. If one firm cannot fully internalize the value of its discovery (because of imitation by other firms and informational externalities), there will be no incentive to undertake the initial investment. Some of these marketfailure arguments become particularly strong in the context of green technologies. ${ }^{477}$

\section{Structural coordination problems}

Structural coordination problems tend to arise as dynamic market failures. $^{478}$ The first problem of coordination is related to the existence of demand complementarities and increasing returns to scale in manufacturing industries. Many sectors and industries require a series of complementary investments in interconnected activities in the early phases of their development. This is because their returns, and sometimes even existence, depend on the existence of a web of forward, backward and horizontal linkages. ${ }^{479}$

\section{Systemic failures and challenges}

Systemic failures and challenges refer in particular to issues affecting the technological change and innovation process in regional, sectoral and national systems of innovation. ${ }^{480}$ These challenges include infrastructural and institutional problems, technological lock-in, path dependency, quality of linkages, and issues related to learning dynamics at the firm, local network, sectoral and system levels. These problems apply not only to developing economies but also to countries at the technological and production frontiers, which might also require complementary investments in sets of interrelated new key enabling technologies or production activities. ${ }^{481}$

Fundamental empirical regularities characterising the structural transformation trajectories of developing countries $^{482}$

Growth: The first empirical regularity concerns growth in developing countries. The evidence suggests that it is not so much the quantum of GDP growth that sets developing countries apart in terms of their per capita incomes. It is the composition of their GDP growth, i.e., the degree and direction of productive transformation of their economy.

Employment: The second empirical regularity is related to jobs and the labour market in developing countries. Employment growth does not set developing countries apart, in terms of their per capita incomes. What does set different income categories of developing countries apart are changes in job quality. Further, these qualitative changes seem to move together, with job quality being generally better in manufacturing than in primary production and in the informal services economy. This 
occurs despite the lower share of employment in manufacturing, a larger employment outflow from agriculture to services, and apparent limits to the employment absorption capacity of manufacturing. In developing countries, lack of social protection compels the poor and low income portion of the labour force to work, which causes employment growth to be largely determined by labour force growth.

Macro drivers: A third empirical regularity is observed in the classical drivers of growth and jobs, accumulation and exports. Accumulation of physical capital and savings are observed to explain in part the differences in income across developing countries. However, investment in workers' education and skills - human capital - is an even more powerful explanatory variable. Further, this investment in human capital is seen to operate at both ends of the skills scale; at the upper end, per capita incomes also show a significant impact from intangible knowledge based capital. 


\section{Chapter 6. Countries in Special Situations}

\subsection{Introduction}

\subsubsection{Context}

The science-policy interface (SPI) is a complex process, as elaborated in Chapter 1 of this report. In the relationship of science and policy, influence and causality go in both directions, with scientific evidence guiding policymaking, and national priorities informing scientific and technological research. Evidence based on scientific research is ideally combined with other forms of information to enable policymakers to design, implement and evaluate evidence-based policies. Policymakers in turn directly influence the generation of further scientific knowledge through budget allocations, science, technology and innovation policy, educational policy, industrial policy and other means.

This chapter focuses on selected aspects of the interface between science and policy in three groups of countries that the UN recognizes as being in special situations - least developed countries (LDCs), landlocked developing countries (LLDCS) and small island developing States (SIDS). The chapter analyzes the scope of a sample of UN and nonUN publications on these groups of countries that may be relevant for decision making at the national level, and also examines the issue of availability of information and data for these groups of countries. It also analyses whether and how publications and existing international commitments specific to these groups (Istanbul Programme of Action for LDCs; Vienna Programme for Action for LLDCs; and SAMOA Pathway for SIDS) address the proposed 17 sustainable development goals $(\mathrm{SDGs})^{483}$. In addition, the chapter examines existing points of contact between science and policy making and potential approaches for scaling up and sharing good practices. Information used for this chapter was gathered through research of existing publications, a questionnaire circulated to the representatives of the countries in special situations to the UN, as well as inputs from the United Nations system and the scientific community. ${ }^{484}$ The chapter was also informed by expert group meetings ${ }^{485}$.

\subsubsection{The three groups of countries and related international commitments in the area of sustainable development}

The three categories of countries in special situations are determined by United Nations criteria and are treated as such in the United Nations as well as by donors, regarding eligibility for various forms of development assistance in particular, and sometimes in other areas of international law. These categories have given rise to specific UN processes with outcome documents and plans of action that serve as their respective development frameworks (see Figure 6-1). This chapter takes as context the most recent international commitments from each of the three processes.

The identification of LDCs is currently based on three criteria: per capita gross national income (GNI), human assets index (HAl) and economic vulnerability to external shocks index (EVI). To be included in the list of LDCs, a country must satisfy all three criteria. In addition, since the fundamental meaning of the LDC category (i.e. the recognition of structural handicaps) excludes large economies, the population must not exceed 75 million. Many of LDCs are also SIDS or LLDCs. The Committee for Development Policy (CDP) of the United Nations is mandated to review the category of the least developed countries (LDCs) every 3 years and monitor their progress after graduation from the category.

Figure 6-1. Timeline of international commitments for countries in special situations

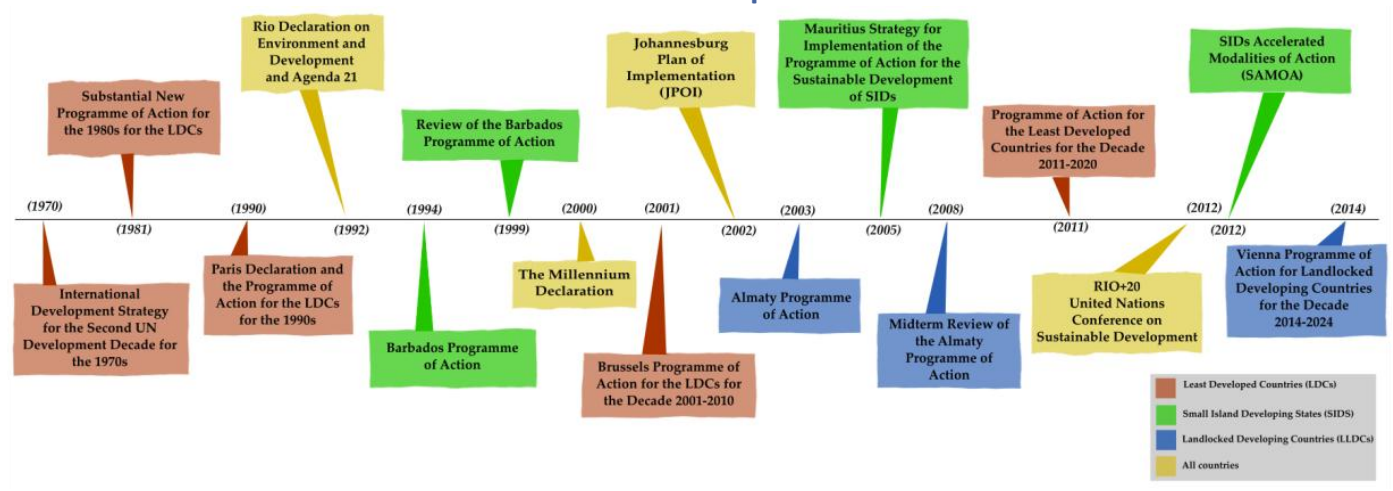


LLDCs face several development challenges linked to landlockedness including long distances to the nearest sea ports, remoteness from markets, additional border crossings, inadequate physical infrastructure, and logistical and institutional bottlenecks. These challenges substantially increase the transport and transit costs for LLDCs, eroding their competitive edge and trade volumes. Furthermore, LLDCs' trade unavoidably relies on their transit neighbours, many of which are themselves developing countries, often of broadly similar economic structure and beset by similar scarcities of resources and limited capacities.

A 2013 UN-OHRLLS study (Development Economics of Landlockedness), looking at around 150 countries, including LLDCs and coastal countries over the period 1980-2010, revealed that LLDCs' trade was just $61 \%$ of the trade volume of coastal countries. Transport costs for LLDCs were $45 \%$ higher than the representative coastal economy. As a result, LLDCs continue to be marginalized in world trade, as their exports account for just $1.2 \%$ of global exports. Overall, the level of development in LLDCs is about $20 \%$ lower than what it would be had they not been landlocked, other things being equal. Their lack of territorial access to the sea and their remoteness and isolation from world markets, high transit costs and dependence on transit Figure 6-2. Overlap of three groups of countries countries impose serious constraints on their socioeconomic development.

LLDCs typically have low economic growth rates and are often heavily dependent on a very limited number of commodities for their export earnings. However, LLDCs are a heterogeneous group. Even though they face similar challenges linked to landlockedness, the 16 LLDCs out of 32 that are also classified as LDCs (see Figure 6-2) face even greater challenges. Small island developing States (SIDS) were recognized as a distinct group of developing countries facing specific social, economic and environmental vulnerabilities at the United Nations Conference on Environment and Development (UNCED) in 1992, and there has been a global consensus on this ever since. This recognition was made specifically in the context of Agenda 21, which found that their small size, limited resources, geographic dispersion and isolation from international markets place them at a disadvantage economically and limit economies of scale ${ }^{486}$. Their challenges were also recognized at the first Global Conference on SIDS in Barbados in 1994, the second in Mauritius in 2005, and the Third International Conference on SIDS in Samoa in 2014. Out of 38 SIDS, 9 are also LDCs (see Figure 6-2).

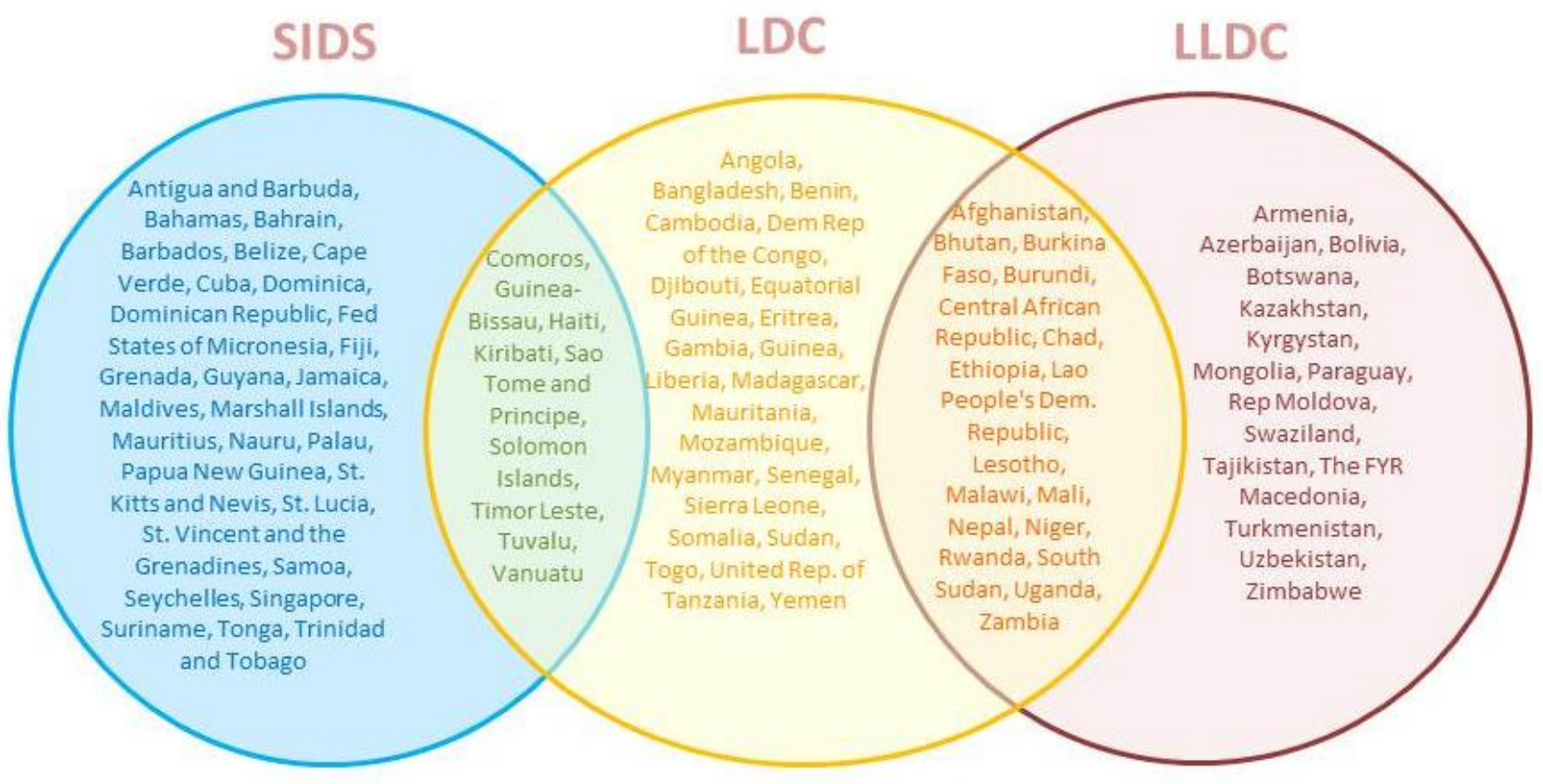

Source: Author's elaboration on the basis of UN OHRLLS list of countries 
There is general consensus among the international community that all three groups of countries should be accorded special attention in the post-2015 development agenda in order to build their resilience and achieve sustainable development ${ }^{487}$. Rio Principle 6 articulated that the special situation and needs of the LDCs shall be given special priority, while Chapter 17 (G) of Agenda 21 underlined the special needs of $\operatorname{SIDS}^{488}$. Paragraphs 178180, 181, 182 of the Rio+20 outcome document, "The Future We Want ${ }^{489}$, focused on special challenges of LDCs, LLDCs and SIDS. Special emphasis on these groups of countries has also been given in the report of the Open Working Group on Sustainable Development Goals, both in the introduction and in targets accompanying the proposed $\mathrm{SDGs}^{490}$.

\subsubsection{Publications relevant to the sustainable development agenda in the three groups of countries}

International publications considered in this chapter, including UN flagship publications, cover the period from 2004-2014. Despite the limited time period, the magnitude of publications is on the order of thousands and no exhaustive lists exist. Therefore, the chapter considers a sample of publications that have been deemed relevant for these groups of countries. ${ }^{491}$ The criterion used was that they are larger international publications, especially recurring ones, and that they are relevant by treating issues of priority for the whole group or groups of countries and not specific to only one country. Many national, subregional and regional publications exist which were not considered in the Chapter this year, but would merit analysis in future editions of the GSDR.

One of the challenges encountered during this analysis was an imprecision in the use of the terms LDCs, LLDCs and SIDS in non-UN publications and in the way studies are conducted about them.

Most of the data-heavy international publications are done by the United Nations system or related entities like the World Bank. Their findings are often referenced in publications done by the scientific community. Likewise, United Nations flagship reports across the board engage scientific sources outside the United Nations for their research and reports. Based on the samples of publications analysed for this report, there are more United Nations publications that cover LDCS and LLDCs than SIDS; on the other hand, SIDS seem to stimulate significant academic research and publications. Both types of publications often take a sectoral rather than an integrated, cross-sectoral approach. Analysis found that most publications cover one or two proposed SDGs and very few cover more than three or four (see Table 6-1). Generally, the publications analysed here tend to cover better SDG areas that were already included in the scope of the MDGs, with a focus on social issues (see Annex 1).

Table 6-1. Coverage of number of proposed SDGs in publications for the three groups of countries in special situations

\begin{tabular}{|c|c|c|c|c|c|c|c|c|c|c|c|c|c|c|c|c|c|c|}
\hline \multicolumn{19}{|c|}{ Number of Publications Addressing Goals } \\
\hline $\begin{array}{l}\# \quad \text { of } \\
\text { Covered }\end{array}$ & Goals & 1 & 2 & 3 & 4 & 5 & 6 & 7 & 8 & 9 & 10 & 11 & 12 & 13 & 14 & 15 & 16 & 17 \\
\hline \multirow{3}{*}{ 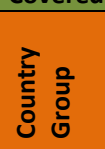 } & LDCs & 3 & 7 & 8 & 4 & 3 & 1 & 1 & 3 & 2 & & & 1 & & 2 & & & \\
\hline & LLDCS & 1 & 5 & 5 & 5 & 2 & & 1 & 2 & & 1 & 1 & & & & & & \\
\hline & SIDS & 20 & 6 & 3 & 1 & & 1 & & & 1 & & & & & & & & \\
\hline
\end{tabular}

Source: Author's elaboration

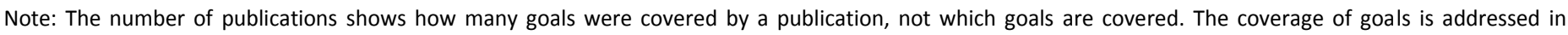
subsequent sections

\subsubsection{Existing points of contact between science and policy}

Evidence-based policymaking is not generally well institutionalised in the countries in special situations, though there are exceptions to this rule. There is an overall lack of formal mechanisms for the integration of scientific knowledge into policy. ${ }^{492}$

Policy-makers in developing countries would like to have scientific findings complemented by policy-relevant recommendations, presenting a range of possible policy options for their consideration ${ }^{493}$.
Consultation with policy makers in the formulation of scientific research agendas is key to ensuring science's ultimate policy relevance. Those agendas, in the end, are influenced strongly by funding, and in many of these countries there is a large foreign component thereof. The question then is how far external funders' research priorities are aligned with the needs of national policymakers.

According to some perspectives, over the past 15 years, the emphasis on poverty reduction strategy papers (PRSPs) and on the MDGs has meant that research on social areas of policymaking was boosted, especially in areas such as health, education, water and sanitation. Agriculture, industrial policy, long-term planning, and science- 
technology-innovation (STI) policies generally received relatively less policy attention and resources. ${ }^{494}$

With the transition from the MDGs to SDGs, policy-relevant research agendas may need to broaden and shift focus somewhat.

It has been noted that, for these three groups of countries, not only science but applied science, research and development, technology and innovation play a very important role.

\section{Box 6-1. Science advice to governments}

The emerging International Network for Science Advice to Governments was created in 2014. It operates under the aegis of ICSU. A first conference of this network, entitled "Science advice to Governments: An emerging network for leading practitioners", was held Auckland on 28-29 August 2014.

The network brings together leading practitioners of high-level science to give advice to governments. It is dedicated to an examination of the current and future state of the science for policy practice. Participants share the best practices in operationalising science advice, including in relation to some of the most challenging policy contexts such as science advice in situations of crisis.

Issues highlighted are:

- Complex relationship between the culture of science and the culture of policy;

- Interactions between science and policy;

- Different roles of science advice;

- Capacity building - critical role of science advice to government;

- Incorporating evidence into the science advice system.

This project has already generated a lot of information and has a dedicated website: www.globalscienceadvice.org.

Source: International Council for Science (ICSU)

Responses to a questionnaire sent to government representatives of countries in special situations support this conclusion, although with 15 responses the sample is merely illustrative. The respondents were asked to (i) assess the extent to which national, regional and international assessments and other relevant outputs are used to inform policymakers; (ii) identify data gaps that may exist within these countries, to better understand how they can be bridged, and; (iii) analyse how the sciencepolicy interface can be improved at the international, regional and national levels to benefit countries in special situations.

Responses showed consistency with the analysis of publications presented above. Most research and information exist in areas covered by the MDGs, especially in education, health, water and sanitation, while there is little to no data available on inequality, which was very rarely mentioned as an area of priority in the questionnaire. Availability of data on trade, technology, and urbanization was also reported as low in the questionnaire.

When asked how data collection could be improved and what could enable a stronger SPI in general, public-private partnerships, financial support and technical resources were ranked highest among the respondents, while national research and development capacity and scientific and technological infrastructure were deemed most important for strengthening SPI at the national level.

\subsubsection{Investment in research and development} It is also important to look at the investment in research and development (R\&D) as well as the number of researchers as indicators of the state of development of the scientific community in the countries in special situations. However, there are methodological issues, such as partial coverage, no information on full-time equivalents, incomplete time series, etc. The most widely used R\&D indicator is the amount of R\&D expenditure, expressed as a percentage of GDP. The global expenditure on research and development averages $1.8 \%$, but this hides a wide variation between developing and developed countries. For the developed countries, the average is $2.3 \%$, while for developing countries (excluding the least developed countries - LDCs) this number drops to $1.1 \%$ and for the LDCs it stands at only $0.2 \%$. Data points to a similar situation for the LLDCs which average below 1 per cent and for SIDS which, with the exception of Singapore, average 0.5 per cent of GDP ${ }^{495}$. In the case of R\&D personnel, the 
number of researchers is relative to the population of each country. Data used for full-time equivalent (FTE) researchers suggest a global average of somewhat more than 1000 researchers per million inhabitants. In developed countries, the number stands at more than 3600 , while in developing countries (excluding LDCs), the number stands at just over 500 and in the LDCs, this indicator does not reach $50^{496}$. However, it will be seen below that the amount of investment in R\&D does not correlate closely with the number of researchers.

\subsection{Least developed countries}

\subsubsection{Istanbul Programme of Action (IPoA)}

LDCs represent the poorest and most vulnerable group of countries, and as a group they have made the least progress of all developing countries in achieving the MDGs $^{497}$. They are characterized by weak, fragile and vulnerable economies. Their trade and development challenges and difficulties are further exacerbated by their exposure to disruptive environmental shocks, climate change and natural disasters. Expected climatic changes will have adverse impacts on and ramifications for these countries' water resources, agricultural production, biodiversity, living conditions in human settlements, as well as trade and transport infrastructure.

The international community has been paying special attention to LDCs through dedicated 10-year programmes of action to provide differential treatment to this specific group of countries since the early 1980s. These are exclusively targeted to LDCs, with a view to fostering sustained economic growth and structural transformation and thereby reducing inequality between LDCs and the rest of the world.

For the last one and a half decades, the MDGs served as the key guiding principles for international development cooperation in LDCs. Since the MDGs are highly focused on the social sectors, global attention was naturally tailored to these areas. Science and technology and their relationship with the productive sector often remained at the periphery of the development strategy

The Istanbul Programme of Action (IPoA), adopted at the Fourth United Nations Conference on LDCs in 2011, is an ambitious document that sets a target of enabling half the number of LDCs to meet the criteria for graduation by 2020. It includes eight priority areas for action: (1) productive capacity, (2) agriculture, food security and rural development, (3) trade, (4) commodities, (5) human and social development, (6) multiple crises and other emerging challenges, (7) mobilizing financial resources for development and capacity building, and (8) good governance at all levels.

\subsubsection{The Istanbul Programme of Action and the SDGs} Comparing the SDGs and the IPoA, it can be seen that IPoA priorities are covered in full and share a number of targets in common with the SDGs. The objectives, priorities, goals and targets of the IPOA are more targeted and specific as well as comprehensive in the areas of special focus to LDCs (hunger, with special emphasis on agriculture; gender equality; energy; infrastructure; industrialization; innovation and trade; climate change; and means of implementation) (see Figure 6-3).

In addition to the quantitative indicators proposed for the eight priority areas and for the first objective of the Programme of Action, qualitative information is also used to monitor the rate of progress in achieving the goals and targets. ${ }^{498}$ It is important that existing indicators and data are taken into consideration and incorporated into the SDGs and the Post-2015 Development Agenda, to enable coordination of monitoring and implementation.

Figure 6-3. Areas of emphasis of IPoA in the context of the SDGs

\section{Sustainable Development Goals}

\begin{tabular}{|c|c|c|c|c|c|c|c|c|c|c|c|c|c|c|c|c|c|}
\hline $\begin{array}{l}\text { Level of comprehensiveness } \\
\text { between IPoA and SDGs }\end{array}$ & $\begin{array}{c}\text { GOAL } \\
1\end{array}$ & $\begin{array}{c}\text { GOAL } \\
2\end{array}$ & $\begin{array}{c}\text { GOAL } \\
3\end{array}$ & \begin{tabular}{|c|} 
GOAL \\
4 \\
\end{tabular} & $\begin{array}{c}\text { GOAL } \\
5\end{array}$ & $\begin{array}{c}\text { GOAL } \\
6 \\
\end{array}$ & $\begin{array}{c}\text { GOAL } \\
7\end{array}$ & $\begin{array}{c}\text { GOAL } \\
8\end{array}$ & $\begin{array}{c}\text { GOAL } \\
9\end{array}$ & $\begin{array}{c}\text { GOAL } \\
10 \\
\end{array}$ & $\begin{array}{c}\text { GOAL } \\
11 \\
\end{array}$ & \begin{tabular}{c|} 
GOAL \\
12 \\
\end{tabular} & \begin{tabular}{c|} 
GOAL \\
13 \\
\end{tabular} & $\begin{array}{c}\text { GOAL } \\
14 \\
\end{array}$ & $\begin{array}{c}\text { GOAL } \\
15\end{array}$ & $\begin{array}{c}\text { GOAL } \\
16\end{array}$ & $\begin{array}{c}\text { GOAL } \\
17\end{array}$ \\
\hline IPOA more comprehensive tha SDGs & & $X$ & & & $X$ & & $X$ & & $X$ & & & & $X$ & & & & \\
\hline IPOA less comprehensive than SDGs & $X$ & & $X$ & $X$ & & $X$ & & $X$ & & $X$ & $X$ & $X$ & & $X$ & $X$ & $X$ & \\
\hline IPoA as comprehensive as the SDGs & & & & & & & & & & & & & & & & & $X$ \\
\hline
\end{tabular}

Source: Author's elaboration 


\subsubsection{Relevant publications for LDCs}

Analysis of a sample of publications focusing on LDCs undertaken for this report shows ample coverage of the first nine proposed SDGs. By contrast, the other SDG areas are sporadically covered and SDG 14 was not covered in any of the reports analysed (see Table 6-3 in Annex 1). Among publications addressing SDG areas, most are concentrated on social issues, with the exception of SCP and climate change, reflecting the emphasis of the existing MDG framework. Few publications cover the science-policy interface per se, its organisation and effectiveness.

Figure 6-4. Coverage of SDG areas by a sample of publications

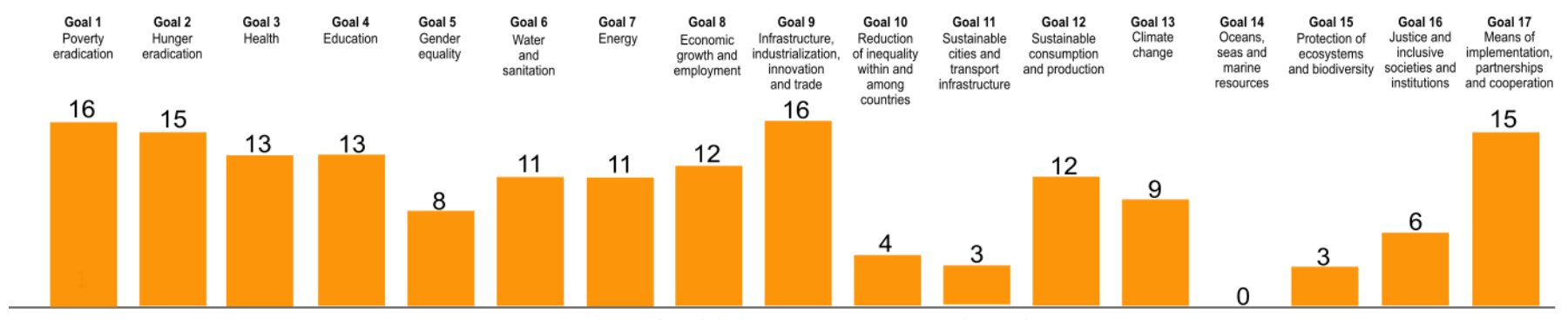

Number of publications covering each goal

Source: Author's elaboration

Note: Coverage of SDG areas by a sample of 35 publications on LDCS

\subsubsection{The science-policy interface in LDCs}

It is widely recognized that there is a dearth of studies on the SPI in developing countries, and this is especially true for the LDCs ${ }^{499}$. Nevertheless, research on LDCs' science, technology and innovation (STI) systems supports the conclusion that, in these countries, SPI is beset by structural and institutional deficiencies on both sides of the interface (i.e. both the science and the policymaking). Indeed, SPI cannot be assessed without examining the state of STI in LDCs.

According to UNCTAD, the STI system of the LDCs has suffered from a long-term neglect since the inception of structural adjustment programmes starting in the late 1980s, which aimed inter alia to reduce the economic role of the state to that of market regulation. ${ }^{500}$ In this context, STI fell back in the order of priorities of $\mathrm{LDCs}^{501}$. This led to the weakening of STI institutions, including universities, research centres, laboratories, and extension services ${ }^{502}$.

Nevertheless, some science and technology-related areas have been addressed in Poverty Reduction Strategy Papers (PRSPs), notably initiatives aimed at agricultural research and agricultural extension; expanding technical and vocational education; and extending and upgrading electricity networks. Many PRSPs acknowledge the importance of improving telecommunications networks and access to ICT.

STI programmes and activities are the responsibility of ministries of science and technology, who often focus more on technology than science, specifically where the expansion of telecommunications is a priority. In many countries, there tends to be very little interaction among academia, government and industry. ${ }^{503}$

The volume of expenditure in the area of $R \& D$ has a great impact on the level of scientific capacity of a country. Yet investment in research in LDCs is persistently low, especially in Africa, as is the number of researchers and technicians. Many African LDCs are struggling to meet the African Union goal of spending $1 \%$ of GDP on R\&D. Research and development expenditure as a percentage of GDP has stagnated at nearly zero in most LDCs. Thus, even those who spent the most on R\&D, such as Mali $(0.66 \%)$, Ethiopia $(0.61 \%)$ and Uganda $(0.56 \%)$ have not reached 1 per cent ${ }^{504}$.

It is interesting to note that the amount of investment in $R \& D$ does not correlate with the number of researchers in these countries. Thus, Senegal who has the highest proportion of full-time researchers in LDCs (361 per million of inhabitants) is only fourth in R\&D investment $(0.54 \%$ of GDP), while Mali, with the highest investment in R\&D per unit of GDP, is only $13^{\text {th }}$ with only 13 researchers per million of inhabitants. ${ }^{505}$ This merits further research.

Many of the concerned countries have decided to concentrate their S\&T policies on education initiatives; however, the problem of brain drain persists and, given local conditions, researchers from the diaspora may or may not return home, but circular migration is increasing ${ }^{506}$. 
Box 6-2. Poverty reduction strategy papers (PRSPs) as an example of the STI system in LDC policymaking

PRSPs are a mid-term policy planning and execution framework. They show the policy priorities of national governments and thus reflect the prioritization of STI issues in these countries. An analysis of a sample of the latest generation of PRSPs of 37 LDCs from Africa, Asia and the Americas undertaken by UNCTAD yielded the following findings:

- Only 14 of the 37 LDCs include science and/or technology as priority policy areas for poverty reduction;

- Only nine countries (Bangladesh, Ethiopia, Lesotho, Malawi, Mozambique, Rwanda, United Republic of Tanzania, Uganda and Zambia) include a specific section or paragraph on science and technology issues;

- Only 16 of the 37 LDCs include explicit and specific science and technology initiatives to enhance technology transfer and acquisition through either international trade or foreign direct investment (FDI);

- Only 13 of the 37 countries include specific initiatives to support basic research;

- Only eight countries (Bangladesh, Madagascar, Malawi, Mozambique, Sudan, the United Republic of Tanzania, Uganda and Zambia) include specific science and technology initiatives at all three levels of education - primary, secondary and higher;

- Only 18 of the 37 LDCs make explicit reference to the need to expand business development services that support technological upgrading efforts by local firms;

- The same number (18) of countries include policies to promote best practices and quality standards by local firms, typically through the creation and capacitation of local standards and metrology institutions;

- Only 18 of the 37 countries include specific initiatives for applied research outside agriculture.

Source: UNCTAD, contribution to GSDR 2015

In many LDCs, the SPI is also hampered by the fact that the STI system has very weak linkages with national productive systems. This means that the results of scientific research are not effectively translated to productivity or product improvements in enterprises, farms, or health systems. Such disconnect between scientific activity and the production of goods and services may also downgrade the importance of science and technology in the priorities of policy-makers.

Beyond the features already mentioned, the SPI in LDCs tends to have some of the following characteristics:

- The degree and quality of science-policy interaction depends on the subjects in question and the nature of the institutions responsible for policy design and implementation in different areas.

- The uptake of scientific evidence is relatively stronger in some ministries (agriculture, environment) in the policy design and formulation stage, while for the other ministries it is stronger at the implementation and evaluation stages ${ }^{507}$.
- Priorities in funding are not always aligned to government objectives, and research can often be driven by external objectives and based on the influence of donors.

- Synergies between modern scientific paradigms and traditional knowledge should be noted, for example in medicine, with both sides adapting to new ways of thinking.

Overall, LDCs continue to suffer from weak state capacity for policymaking. In an effort to overcome structural handicaps to growth and sustainable development and bridge the technology gap, the IPoA called for the establishment of an LDC Technology Bank. The proposal of the establishment of a Technology Bank and associated Science, Technology and Innovation Supporting Mechanism for LDCs under the auspices of the United Nations is an important way of boosting their STI capacity, which could eventually make substantive contributions to their economic prospects as well as to science and evidencebased policy making (see Box 6-3).

\section{Box 6-3. The LDC Technology Bank}

IPoA has recognized the importance of STI and has called for analysis of gaps in STI with the aim of establishing a Technology Bank. The report of the Open Working Group on SDGs also proposes in target 17.8. "to fully operationalize the technology bank and science, technology and innovation capacity-building mechanism for least developed countries by 2017 (...)" The LDC Technology Bank will have an integrated structure, reflecting the following interrelated functions:

- A science, technology and innovation mechanism would build capacity in target countries by building LDCs' human and institutional capacity in the area of STI, assisting the establishment of technology incubators and ICT connectivity, supporting the marketing of the LDCs' research results and improving IPR management capability, and leveraging LDCs' diaspora knowledge networks. 
- A patent bank would help LDCs secure relevant IP at negotiated or concessionary rates; provide technical assistance to identify appropriate technologies; and help protect IP rights derived by LDC inventors.

- A research depository facility could provide LDC researchers with better access to scientific literature, create and support networking and research through collaborative partnerships among LDC research communities, and build capacity for publication of LDCs' scientific work.

The General Assembly has requested the Secretary-General to establish a High-level Panel of experts to undertake a feasibility study that will be concluded prior to the launch of the post-2015 Development Agenda, providing expert views on the possibility of operationalizing the Technology Bank during the 70th session of the General Assembly ${ }^{509}$.

The operationalization of the LDC Technology Bank will require a combination of national policies to build STI capabilities and international support, including robust international cooperation; and effective involvement of the private sector, STI communities, the United Nations system and other relevant organizations.

Source: OHRLLS 2015

Building scientific and technological capacity and technical know-how requires dedicated national policies. Thus, it has been proposed by LDCs that at least 0.1 per cent of the ODA to LDCs should be provided for science, technology and innovation activities through the Technology Bank, and that regional STI centres should be established. ${ }^{510}$

Strengthening of innovative capacities in the productive sectors can benefit LDCs' economic development by enhancing trade opportunities. For instance, the Enhanced Integrated Framework (EIF) (see Box 6-4), an "Aid for Trade" programme that aims to enable LDCs to mainstream trade into national development strategies, enhances trade-related technical assistance, builds capacity and strengthens trade institutions.

\section{Box 6-4. Lesotho's 'Agriculture Trade Development Project for the Fresh Produce Sector'}

The project supports the introduction of new technologies to enhance productive capacity, primarily through the introduction of greenhouses for fresh vegetable production and mushroom spawning systems. The project aims to benefit over 1,000 farmers of which an estimated $30 \%$ are women and contributes to the enhancement of Lesotho's sustainable economic growth, employment, food security, nutrition and poverty alleviation through building and strengthening the capacity of smallholder producers to commercialize, diversify and promote production of fresh fruits and vegetables for domestic and export markets.

The introduction of greenhouse technology prolongs the growing season providing additional income and mitigates the impacts of increasingly volatile climatic patterns. The project is implemented through the Government of Lesotho with the support of the International Trade Centre (ITC), and financed through the Enhanced Integrated Framework (EIF), a development initiative focused on LDCs and enabled through a multi-donor trust fund.

Source: EIF contribution to GSDR 2015

\section{Box 6-5. The SPI and Climate Change in LDCs}

Working Group II of the Intergovernmental Panel on Climate Change (IPCC) released its Fifth Assessment Report in 2014, highlighting LDCs as particularly vulnerable to climate change due to economic and capacity barriers. In follow-up, a recent study undertook an examination of the report to assess each LDC country in detail, noting how various climatic impacts, vulnerabilities and adaptation are portrayed. The study produced the following conclusions:

- While LDCs are very vulnerable, they are also addressing this vulnerability through various multi-scale processes.

- Coping capacity is exemplified within affected communities, and national-level efforts to support such capacity are increasing.

- It is essential that such actions are monitored and assessed, and that lessons are highlighted and shared-both with other LDCs who may be seeking similar responses, and with other national and external bodies that have the ability to support LDCs.

- South-South learning is crucial but not in isolation from global support, both financially and politically, and through increasing efforts to curb climate change through mitigation. 
- IPCC report data must be translated into a format that is easy to digest by all stakeholders, to ensure that current knowledge is acted upon in effective ways by policymakers and decision makers within wide-ranging institutions and at multiple scales.

- There is a need for a greater focus on the LDCs by the IPCC and for further research concentrated on the LDCs in general, in order to enhance the state of knowledge on LDCs and appropriately guide related policy.

- The production, availability and uptake of quality research from LDCs needs to be encouraged and enhanced, to ensure that adequate knowledge about each country is available in internationally recognised spaces and formats.

Source: Clare Stott, 2014. An Examination of the Least Developed Countries in the IPCC AR5 WGII. IIED Issue Paper. IIED, London

\subsection{Landlocked developing countries}

\subsubsection{Historic overview}

In 1957, the UN General Assembly Resolution 1028 (XI) recognized the special case of landlocked developing countries and their need for adequate transit facilities in promoting international trade. Since then, LLDCs as a group of countries have been on the agenda of the United Nations, including the General Assembly and other UN bodies. The special needs and concerns of the LLDCs were also recognized in the Millennium Declaration where both bilateral and multilateral donors were urged "to increase financial and technical assistance to this group of countries to meet their special development needs and to help them overcome the impediments of geography by improving their transit transport systems" ${ }^{\prime 511}$. In recognition of these specificities, the International Ministerial Conference of Landlocked and Transit Developing Countries, Donor Countries, International Financial and Development Institutions on Transit Transport Cooperation was held in Almaty, Kazakhstan, in August 2003. It adopted the Almaty Programme of Action: Addressing the Special Needs of Landlocked Developing Countries within a New Global Framework for Transit Transport Cooperation for Landlocked and Transit Developing Countries ${ }^{512}$, and the Almaty Ministerial Declaration.

The second Conference on LLDCs was held in November 2014 in Vienna, and the Vienna Declaration and the Vienna Programme of Action for Landlocked Developing Countries for the Decade 2014-2024 (VPoA) were adopted, succeeding the Almaty Programme of Action.

The overarching goal of the VPoA is to address the special development needs and challenges of the LLDCs in a coherent manner and contribute to sustainable and inclusive growth and eradication of poverty.

It defines six objectives: (a) to promote unfettered, efficient and cost-effective access to and from the sea by all means of transport, on the basis of the freedom of transit, and other related measures, in accordance with applicable rules of international law; (b) to reduce trade transaction costs and transport costs and improve international trade services through simplification and standardization of rules and regulations; (c) to develop adequate transit transport infrastructure networks and complete missing links connecting landlocked developing countries; (d) to effectively implement bilateral, regional and international legal instruments and strengthen regional integration; (e) to promote growth and increased participation in global trade; and ( $f$ ) to enhance and strengthen international support for landlocked developing countries to address the needs and challenges arising from landlockedness in order to eradicate poverty and promote sustainable development.

The VPoA also identifies six priority areas as follows: Priority 1: Fundamental transit policy issues; Priority 2: Infrastructure development and maintenance: (a) Transport infrastructure; (b) Energy and information and communications technology infrastructure; Priority 3: International trade and trade facilitation: (a) International trade; (b) Trade facilitation; Priority 4: Regional integration and cooperation; Priority 5: Structural economic transformation; and Priority 6: Means of implementation.

In addition to these specific objectives and the priorities, it is important to note the action-oriented nature of the VPoA. Overall, within its 6 priorities, it includes 21 specific objectives and 87 actions by LLDCs, transit developing countries and development partners through which the objectives of the VPoA are to be achieved.

In terms of thematic areas covered, the VPoA is more encompassing than the preceding Almaty Programme of Action, whose focus was on transit transport cooperation and establishment of efficient transit systems. In contrast, the Vienna Programme takes a more comprehensive approach and calls for not only enhancing trade performance, trade facilitation and infrastructure, but also building of productive capacities, economic diversification and value addition, regional integration and increased connectivity to regional and global value chains, as well as increased partnerships with the private sector. 
In comparison to the Almaty Programme of Action, there are three new priorities, namely, structural economic transformation, regional integration and means of implementation. In addition, priorities included in the Almaty Programme of Action have been further strengthened and enhanced to reflect the developing situation in LLDCs.

Another important aspect of the VPoA is the focus on strengthened and renewed partnerships among LLDCS, transit developing countries and development partners. Partnerships between LLDCs and transit developing countries are important for the improvement of infrastructural connectivity, efficient transit transport systems and regional policy coherence. Partnerships with and support of UN system and other international organizations, as well as South-South and triangular cooperation and partnerships with the private sector are also highlighted.

\subsubsection{The Vienna Programme of Action and the proposed sustainable development goals (SDGs) and targets \\ Analysing VPoA and the proposed SDGs and their targets, it} can be seen that the proposed SDGs also cover areas highlighted in the VPoA (see Figure 6-5). LLDCs are also underlined as a special group in the proposed SDGs, namely in the Introduction as well as in proposed Goal 9 (Build resilient infrastructure, promote inclusive and sustainable industrialization and foster innovation) and proposed Goal 10 (Reduce inequality within and among countries). The VPoA has a higher level of comprehensiveness than proposed SDGs (see Figure 4) in its focus areas as enumerated above, which overlap with SDGs 7, 9, 11 and 17 in particular.

On the other hand, VPoA does not cover all areas of SDGs (see Figure 6-5). It would be important, therefore, going forward to review and monitor both SDGs and VPoA jointly in order to assess LLDC progress on both agendas. This argument can be supported by an example in relation to the human development of LLDCs and MDGs. Those LLDCs who were able to achieve MDGs as well as LLDC priorities at least to some extent did much better on UNDP's human development index than those LLDCs who were seriously lagging behind in achieving MDGs and/or LLDC priorities. It can be noted that, out of 32 LLDCs for which data exists, only four were listed in the "high human development" and seven in the "medium human development" categories, while the rest were in the "low human development" category in the 2014 human development index. ${ }^{513}$

Figure 6-5. Areas of emphasis of VPoA in the context of the SDGs

Sustainable Development Goals

\begin{tabular}{|c|c|c|c|c|c|c|c|c|c|c|c|c|c|c|c|c|c|}
\hline $\begin{array}{c}\text { Level of comprehensiveness } \\
\text { between VPOA and SDGs }\end{array}$ & $\begin{array}{c}\text { GOAL } \\
1 \\
\end{array}$ & $\begin{array}{c}\text { GOAL } \\
2\end{array}$ & $\begin{array}{c}\text { GOAL } \\
3\end{array}$ & $\begin{array}{c}\text { GOAL } \\
4\end{array}$ & $\begin{array}{c}\text { GOAL } \\
5\end{array}$ & $\begin{array}{c}\text { GOAL } \\
6\end{array}$ & $\begin{array}{c}\text { GOAL } \\
7\end{array}$ & $\begin{array}{c}\text { GOAL } \\
8\end{array}$ & $\begin{array}{c}\text { GOAL } \\
9\end{array}$ & $\begin{array}{c}\text { GOAL } \\
10\end{array}$ & $\begin{array}{c}\text { GOAL } \\
11\end{array}$ & $\begin{array}{c}\text { GOAL } \\
12 \\
\end{array}$ & \begin{tabular}{|c|} 
GOAL \\
13
\end{tabular} & \begin{tabular}{|c|} 
GOAL \\
14
\end{tabular} & \begin{tabular}{|l|} 
GOAL \\
15
\end{tabular} & $\begin{array}{c}\text { GOAL } \\
16\end{array}$ & $\begin{array}{c}\text { GOAL } \\
17\end{array}$ \\
\hline VPOA more comprehensive than SDGs & & & & & & & X & & X & & $X$ & & & & & & $X$ \\
\hline VPoA less comprehensive than SDGs & $X$ & X & & X & & X & & X & & X & & $X$ & $X$ & $X$ & $X$ & $X$ & \\
\hline SDG not covered in VPoA & & & $X$ & & X & & & & & & & & & & & & \\
\hline
\end{tabular}

\subsubsection{Publications relevant for LLDCs}

A sample of publications relevant for LLDCs shows the coverage of proposed SDGs (see Table 6-4 in Annex 1). Most of the publications analysed come from the UN system and the World Bank. Figure 6-6 shows how many publications cover each of the proposed SDG areas. It can be seen that SDG areas that coincide with VPoA priority areas are covered by a higher number of publications, while very few or none exist in the areas that are not considered by VPoA. Also, Figure 11 shows that publications cover only one or two SDG areas, pointing to a possible lack of exploration of linkages among proposed SDGs.

Most of the publications analysed were written during the period of the Almaty Programme of Action, which focused more exclusively on development of transit transport systems and integration into global trade. It can be seen that the best coverage is in the LLDC priorities in proposed goals 9 (build resilient infrastructure, promote inclusive and sustainable industrialization and foster innovation) and 11 (make cities and human settlements inclusive, safe, 
resilient and sustainable; this goal includes references to transport infrastructure).

In the future, it would also be important that publications also take a more integrated approach and make more linkages across the proposed SDGs and their priority areas.

Given the broader scope of the VPoA, it can be expected that publications focusing on LLDCs in coming years will focus more on new elements of the VPoA such as regional integration and structural economic transformation, as well as the overall linkages among LLDC-specific challenges. It would thus be interesting for future editions of the GSDR to continue looking at the possible new trends in publications relevant to LLDCs.

Figure 6-6. Coverage of SDG areas by a sample of publications

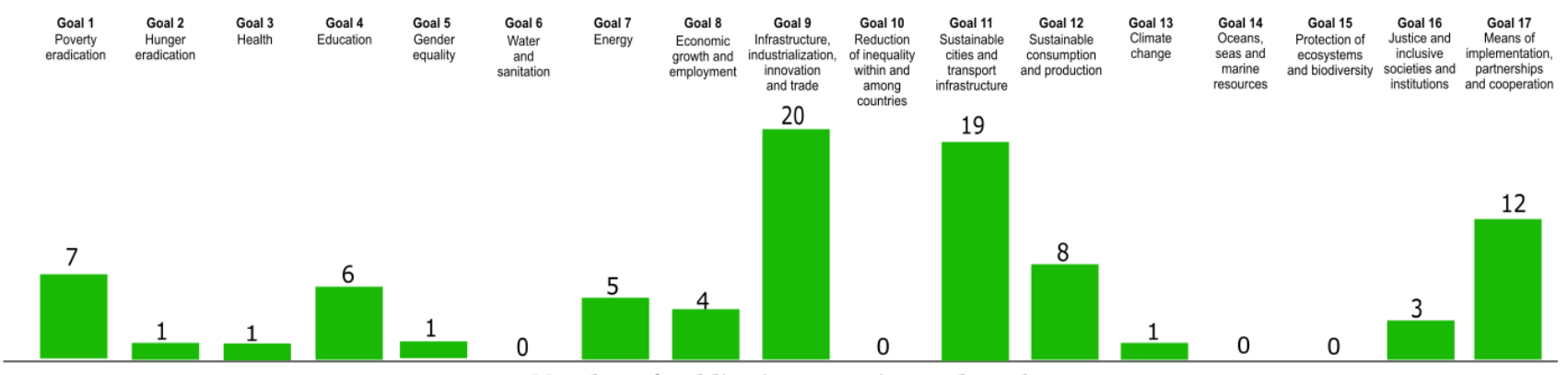

Number of publications covering each goal

Source: Author's elaboration

Note: Coverage of SDG areas by a sample of 22 publications on LLDCs

6.3.4. Science, technology and innovation in LLDCs

The importance of science, technology and information for all countries including LLDCs has received increased attention in UN processes, and this is reflected in both the processes that led to the new development agendas and in their content.

In terms of process, both the SDG process and VPoA were informed by science. The SDG process relied heavily for scientific and technical input on the UN technical support team (TST) ${ }^{514}$, which gathered about forty different entities across the United Nations system as well as a number of eminent scientists both from the north and the south 515.

The VPoA always mentions the source of evidence used, which comes from studies done by the Office of the High Representative for the Least Developed Countries, Landlocked Developing Countries and Small Island Developing States of the United Nations, the Statistic Division of the UN Department of Economic and Social Affairs, the World Bank, UN Conference on Trade and Development and UNEP's Global Environment Outlook.

In terms of content, the VPoA underlines that "Science, technology and innovation play a critical role in achieving structural economic transformation, productive capacity development and value addition (...) ${ }^{\prime 516}$. Among the actions that LLDCs need to undertake, the VPoA stresses that LLDCs need "to develop a structural transformation strategy aimed at improving science, technology and innovation $(\ldots)^{1517}$.

When looking at a sample of publications related to LLDCs at the international level, it becomes clear that scientific inputs have focused on the priority areas highlighted in VPoA. Most of the articles and papers analysed focus on trade, transport, energy, means of implementation and partnerships.

The authors of this report could not find sufficient evidence of how science might have influenced policies regarding LLDCs at the international level and more research needs to be done in this area.

Improvements in technology and infrastructure based on scientific studies and experiments could assist governments in the implementation of policies benefiting LLDCs (see the example of ASYCUDA in Box 6-6. 


\section{Box 6-6. ASYCUDA and Landlocked Countries ${ }^{518}$}

ASYCUDA consists of a computerised customs management system developed by UNCTAD and covers a wide range of foreign trade procedures, including manifests, customs declarations, accounting, transit and suspense procedures. The system also generates trade data that can be used for statistical economic analysis. ASYCUDA is an example of how policy and science can interconnect to promote sustainable development. In this case, science plays a crucial role in implementing policy and assuring that related international commitments are carried out effectively. Considering the special situation of the LLDCs, trade is placed as one of the priority areas for this group of countries. Border clearance facilitation is crucial in order to foster commerce, exports and exchange of goods. Many landlocked countries have adopted or are in the process of adopting the system. Zambia, for example, recently embarked on a strategic modernization of ASYCUDA, known as "ASYCUDA World", which is expected to bring positive results for an electronic commerce-based tax administration. Similar improvements adopted in Burundi allowed a reduction in the number of customs statements filed and the establishment of an application relating management and monitoring of exemptions ${ }^{519}$.

Source: UNCTAD/Division on Technology and Logistics. ASYCUDA Newsletter - June 2014.

\section{Box 6-7. International Think Tank on LLDCs}

The international Think Tank for LLDCs was established in Ulaanbaatar, Mongolia in 2009 to enhance analytical capability within LLDCs and to promote the exchange of experiences and best practices. The goal of the International Think Tank is "to use top-quality research and advocacy to improve the ability of landlocked developing countries to build capacity with a view to benefiting from the international trade including WTO negotiations, with the ultimate aim of raising human development and reducing poverty." The aim of the Think Tank is to produce and disseminate research and studies on issues of importance to LLDCs, promote cooperation among LLDCs with a view to strengthening their analytical capacity in key areas such as transit transport, infrastructure investment, aid and trade facilitation, trade negotiations, poverty reduction and economic growth; facilitate better understanding of challenges facing LLDCs and foster convergent views and approaches among LLDCs with respect to global issues. The Think Tank provides a platform for sharing of knowledge, experience and best practices and exchanging views. Through evidence-based analytical studies and research on key issues, the Think Tank can assist in formulation of strategies and policies in LLDCs aimed at the effective implementation of the Vienna Programme of Action and the Sustainable Development Goals.

One of the specific actions of the VPOA is for LLDCs to utilize the International Think Tank for "sharing experiences, knowhow, research and other resources on issues related to trade, transit, transport and capacity-building among LLDCs". The VPoA also calls on LLDCs that have not yet ratified the Multilateral Agreement for the Establishment of the Think Tank, to do so in order to fully operationalize it.

Source: UN-OHRLLS; more information at http://land-locked.org

\subsubsection{Investment in research and development in LLDCs}

The volume of expenditure in the area of R\&D has a great impact on the level of scientific capacity of a country. Yet investment in research and development for LLDCs is closer to the level of LDCs than to the $1.1 \%$ of GDP average for developing countries. The highest investments into R\&D in proportion to GDP in LLDCs are by countries that are both LDCs and LLDCs, namely Mali, Ethiopia and Uganda ${ }^{520}$. Similarly to the case of LDCs, the proportion of researchers in the population does not necessarily correspond to the level of investment in R\&D. The highest number of researchers per million inhabitants is in Kazakhstan (763) and Moldova (752) and yet these countries invest only $0.18 \%$ and $0.36 \%$ of GDP respectively. ${ }^{521}$

\subsection{Small Island Developing States}

\subsubsection{Science and technology as a SIDS priority}

SIDS have prioritized science and technology in international commitments since the Barbados Programme of Action, which called for national environment and sustainable development strategies to be strongly linked to science. The commitment included enhancing the role of women in science. Regional actions were prescribed to strengthen ocean science networks especially related to data collection and sharing, and the importance of marine science and establishing infrastructure to share data was highlighted for international attention. In 2005 the Mauritius Strategy of Implementation (MSI) recognized that science and technology were cross-cutting issues for all sectors and emphasized targeting investments in science and technology capacity in a way that is appropriate for small island developing States. 


\subsubsection{SAMOA Pathway}

The Samoa Pathway, adopted in September 2014 at the Third International Conference on Small Island Developing States in Samoa, recognised that access by Small Island Developing States to appropriate reliable, affordable, modern and environmentally sound technologies is critical to achieving their sustainable development objectives and called for fostering an environment that provides incentives for innovation and entrepreneurship. The SAMOA Pathway also identified science, technology and innovation as essential enablers and drivers for sustainable development.
6.4.3. The SAMOA Pathway and the proposed SDGs Whether as a result of cross-pollination between the SDG process and the Samoa process, or because of an inherent alignment of SIDS priorities with global priorities, there is a correspondence between the SAMOA Pathway and the Open Working Group's proposal for the SDGs. There are areas where arguably the SAMOA Pathway attains a higher level of comprehensiveness as they are priority areas for SIDS and others where the SDGs aim higher. However, with their significant degree of correspondence and coverage of all areas in both documents, implementation of the two documents will of necessity proceed simultaneously (see Figure 6-7).

Figure 6-7. Areas of emphasis of the SAMOA Pathway in the context of the SDGs

\section{Sustainable Development Goals}

\begin{tabular}{l|c|c|c|c|c|c|c|c|c|c|c|c|c|c|c|c|c|c}
\hline $\begin{array}{c}\text { Level of comprehensiveness } \\
\text { between SAMOA Pathway and SDGs }\end{array}$ & $\begin{array}{c}\text { GOAL } \\
1\end{array}$ & $\begin{array}{c}\text { GOAL } \\
2\end{array}$ & $\begin{array}{c}\text { GOAL } \\
3\end{array}$ & $\begin{array}{c}\text { GOAL } \\
4\end{array}$ & $\begin{array}{c}\text { GOAL } \\
5\end{array}$ & $\begin{array}{c}\text { GOAL } \\
6\end{array}$ & $\begin{array}{c}\text { GOAL } \\
7\end{array}$ & $\begin{array}{c}\text { GOAL } \\
8\end{array}$ & $\begin{array}{c}\text { GOAL } \\
9\end{array}$ & $\begin{array}{c}\text { GOAL } \\
10\end{array}$ & $\begin{array}{c}\text { GOAL } \\
11\end{array}$ & $\begin{array}{c}\text { GOAL } \\
12\end{array}$ & $\begin{array}{c}\text { GOAL } \\
13\end{array}$ & $\begin{array}{c}\text { GOAL } \\
14\end{array}$ & $\begin{array}{c}\text { GOAL } \\
15\end{array}$ & $\begin{array}{c}\text { GOAL } \\
16\end{array}$ & $\begin{array}{c}\text { GOAL } \\
17\end{array}$ \\
\hline SAMOA Pathway more comprehensive than SDGs & & & & & & & $X$ & $X$ & $X$ & & & & $X$ & $X$ & $X$ & & $X$ \\
\hline SAMOA Pathway less comprehensive than SDGs & $\mathrm{X}$ & $\mathrm{X}$ & & & & $\mathrm{X}$ & & & & $\mathrm{X}$ & & & & & & & \\
\hline SAMOA Pathway as comprehensive as SDGs & & & $\mathrm{X}$ & $\mathrm{X}$ & $\mathrm{X}$ & & & & & & $\mathrm{X}$ & $\mathrm{X}$ & & & & $X$ &
\end{tabular}

Source: Author's elaboration

\subsubsection{Publications relevant for SIDS}

It can also be seen that the number of publications that deal with SDGs is highest in the SIDS priority areas such as water and sanitation (6); economic growth and employment (11); climate change (11); and oceans, seas and marine resources (8). This emphasis on environmental challenges in SIDS contrasts with the LDCs and LLDCs, where publications in the social areas are most prevalent, the exception being SDG 8 (Promote sustained, inclusive and sustainable economic growth, full and productive employment and decent work for all), which is fairly well covered by publications relevant to SIDS (Table 6-5).

Figure 6-8. Coverage of SDG areas by a sample of publications

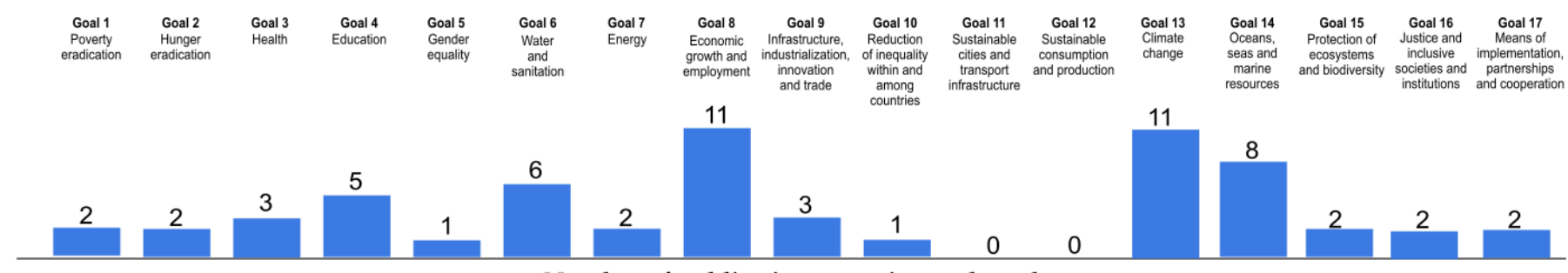

Number of publications covering each goal

Source: Author's elaboration

Note: Coverage of SDG areas by a sample of 32 publications on SIDS 


\subsubsection{The landscape of SIDS related international scientific outputs}

Both the SAMOA Pathway and the proposed SDGs are very broad-based and inclusive of the full range of thematic areas fundamental to sustainable development in general. As noted in Chapter 2, many international assessments address the thematic areas covered by the SDGs. And as illustrated in Figure 6-7 above, the issues underpinning each of the SDGs are also included in the SAMOA Pathway.

Less straightforward is the degree to which the SIDS perspective on these issues is currently being addressed in the international scientific literature. Of the sample of 36 international assessments analyzed in Chapter 2, for instance, 14 include reference either to SIDS as a group of countries recognized by the United Nations, or more generally to the sustainable development challenges of islands. However, the level and nature of the coverage varies and is often limited by the data gap noted above.

The coverage of SIDS issues in international flagship publications does not tell the whole story, since SIDS have received significant targeted scientific attention from UN entities as well as regional and national institutions.

International organizations, both within and outside the UN system, such as the Intergovernmental Panel on Climate Change (IPCC), the International Council for Science (ICSU), the UN Education, Science and Culture Organization (UNESCO), the UN Environment Program (UNEP), the International Monetary Fund (IMF), the World Bank, the Food and Agriculture Organization (FAO) and many others have built island-focused research and analysis into their global work programs. The Fifth Assessment Report of the IPCC, for instance, Climate Change 2014: Impacts, Adaptation and Vulnerability, includes a regional chapter on Small Islands. UNISDR's 2013 Global Assessment Report on Disaster Risk Reduction includes extensive discussion of SIDS specific challenges, and the FAO 2014 State of the World Fisheries and Aquaculture mentions SIDS in a number of contexts including "blue growth" and small-scale fisheries. UNEP spun out its "Global Environment Outlook" ("GEO") series to include a "GEO SIDS" edition in 2014 on the occasion of the Samoa Conference.

UNEP and UN-DESA collaborated on a study ${ }^{522}$ of emerging issues in the social, economic and environmental dimensions of development. This exercise built on UNEP's "Foresight" initiative, which engaged more than 400 scientists to identify and rank emerging environmental issues, in anticipation of the Rio+20 Conference-in part to inform the decision makers taking part in negotiations at the Conference. UN-DESA also has published two SIDS editions of the Trends in Sustainable Development series. Trends collects existing data on SIDS priority areas (the 2014 edition addresses most of the SAMOA priorities) and provides distilled analysis intended for use by policy makers and other stakeholders.

In addition to publications, the United Nations system has made a number of tools available to SIDS policy makers and other constituencies. SIDSnet, a web platform, was established in the lead up to the Mauritius conference to serve as an information portal for SIDS stakeholders and to facilitate expert exchanges among the SIDS regions. It is designed to highlight SIDS data and best practices. In 2014, UNEP launched a comprehensive web platform, UNEP Live, with extensive SIDS data and analysis on a range of environmental topics.

International academic institutions, NGOs and non-SIDS governments are also undertaking a range of research and project work to support SIDS sustainable development.

\section{Box 6-8. The University Consortium of Small Island Developing States (UCSIS)}

UCSIS, a product of the 2005 Conference in Mauritius, has launched a joint Master's programme in Sustainable Development for Small Island States and is exploring joint research programs that take advantage of the complementary strengths of the partner universities, develop joint curricula and foster exchange among SIDS regions. Members are: University of Las Palmas de Gran Canaria, the University of West Indies, University of the South Pacific, University of Mauritius, University of Seychelles, University of the Virgin Islands and University of Malta. The Secretariat for UCSIS is housed at the UWI.

Source: UNDESA, Division for Sustainable Development, SIDS Unit

\subsubsection{Research and data from the SIDS regional and national institutions}

While UN and other international scientific reports and tools consider the SIDS and their priorities as one piece of a broad intellectual and policy agenda, some very rich and targeted work is coming out of the national and regional
SIDS universities, civil society and other public sector institutions. Within the UN system, the Economic Commission for Latin America and the Caribbean (ECLAC) and the Economic and Social Commission for Asia and the Pacific (ESCAP) both have sub-regional offices, in Trinidad and Tobago and Fiji respectively, that are carrying out region-specific research and analysis to advance 
development in their regions and to feed back into the global policy making processes supported at the UN headquarters. Other UN entities including UNESCO, FAO, UNICEF, UNEP and others also maintain subsidiary offices within the SIDS regions. And of course, the UNDP country offices forge links among operational activities in the SIDS, support to SIDS governments, and global processes.

The University of the West Indies in the Caribbean, and the University of the South Pacific in the Pacific both have extensive research programs relevant to regional sustainable development. While there is no comparable regional university system in the AIMS region, there are national universities including the University of Mauritius that are producing research and scientific literature with regional importance.

In addition to the universities, regional and sub-regional organizations such as the Pacific Island Forum Secretariat (PIFS), the Secretariat of the Pacific Community (SPC), the Secretariat of the Pacific Regional Environment Program (SPREP), the Caribbean Community (CARICOM) Secretariat, the Organization of Eastern Caribbean States (OECS), and the Indian Ocean Commission (IOC) are undertaking important scientific work. Within CARICOM, the Caribbean Development Bank (CDB), the Caribbean Public Health Agency (CARPHA), the Caribbean Institute for Meteorology and Hydrology (CIMH), and the Caribbean Community Climate Change Centre (CCCCC) are also producing important research and analysis, as are civil society institutes like the Caribbean Natural Resources Institute (CANARI) and the Caribbean Policy Development Centre
(CPDC). For some African AIMS countries there are also ties to academic and public sector institutions in mainland Africa, such as the Network of African Science Academies. And the Commonwealth Secretariat has announced in its current strategic plan an enhanced emphasis on the development of the "small states," in the Commonwealth, which includes 24 SIDS. The Commonwealth has recently conducted research on relevant subjects including resilience and the green economy.

An examination of the array of research and outputs coming from the SIDS regional universities and institutes reveals in many cases a close correlation with the sustainable development priorities outlined in the SAMOA Pathway (and, therefore, the SDGs). These institutions are pursuing significant research in fisheries, marine protection, climate change impacts, biodiversity protection and land management, strategies to promote economic growth in the face of the structural challenges of SIDS, youth crime and domestic violence, and non-communicable diseases and other health challenges, among others.

However, looking at the investment in R\&D in SIDS, the same trend can be seen as in the above two groups of countries, namely that with the exception of Singapore that invests $2.02 \%$ of GDP in R\&D and has 6,438 researchers per million of inhabitants ${ }^{523}$, all other SIDS for whom data is available spend no more than $0.5 \%$ of GDP on R\&D with highest spending of Cuba at $0.42 \%$ and the Seychelles at $0.30 \%$.

\section{Box 6-9. Local and indigenous knowledge informing policy}

Discussions of the science-policy interface must define science broadly, to include not only the physical and natural sciences but the social sciences as well. Local and indigenous knowledge offers another important perspective, particularly in the context of SIDS. The Caribbean Natural Resources Institute, for instance, noting that traditional knowledge is enriched by long term engagement with the natural environment and plant and animal life of a given local area, is working to harness this traditional knowledge for climate change adaptation policy in the Caribbean. The organization has carried out "participatory 3-D modelling," enlisting local communities to map the elevation, natural resources and other characteristics of island land areas based on their personal and familial knowledge, collecting valuable data that could otherwise have taken years to amass. In another example, the University of Guyana Amerindian Research Unit is analysing indigenous dietary patterns to develop policy recommendations for improving health and reducing incidence of non-communicable diseases in SIDS.

Source: CANARI Policy Brief No. 15 (2013) and "Science-policy interface in SIDS," expert meeting, St. Lucia, 16-18 March 2015.

\subsubsection{Existing points of contact between science and policy in SIDS}

The research undertaken for this chapter has identified a number of tools and mechanisms in place that facilitate the engagement between science and policy. Table 6-2 shows just a few illustrative examples of SPI in SIDS as many others exist. 


\begin{tabular}{|c|c|c|c|}
\hline \multirow[t]{3}{*}{$\begin{array}{l}\text { Tools/ } \\
\text { procedures/p } \\
\text { rojects/ } \\
\text { research }\end{array}$} & $\begin{array}{l}\text { Scientific and } \\
\text { compliance } \\
\text { committees of the } \\
\text { Indian Ocean Tuna } \\
\text { Commission }\end{array}$ & $\begin{array}{l}\text { CANARI's "action learning group" gathered policy } \\
\text { makers and other stakeholders to develop a Green } \\
\text { Economy research agenda }\end{array}$ & $\begin{array}{l}\text { Integration of local community councils to ensure } \\
\text { buy-in for sustainable development research in Gau } \\
\text { (Fiji) and for solar light use in Dominican Republic's } \\
\text { mountain community }\end{array}$ \\
\hline & $\begin{array}{l}\text { Jamaica's National } \\
\text { Ocean Zone Council } \\
\text { mandates a marine } \\
\text { geology seat and a } \\
\text { marine science seat }\end{array}$ & $\begin{array}{l}\text { Importance of fisheries to Eastern Caribbean } \\
\text { economies, society and environment led to } \\
\text { development of the Organisation of Eastern } \\
\text { Caribbean States' Marine Research Strategy, the } \\
\text { Eastern Caribbean Marine Research Platform, the } \\
\text { Code of Conduct for Marine Research and the } \\
\text { compendium of standards for marine data collection } \\
\text { to support sustainable ocean governance }\end{array}$ & $\begin{array}{l}\text { Multi-disciplinary teams formed to study fishing } \\
\text { communities in Pedro Bank }\end{array}$ \\
\hline & $\begin{array}{l}\text { Some UNFCCC SIDS } \\
\text { national COP } \\
\text { delegations include } \\
\text { local scientists }\end{array}$ & $\begin{array}{l}\text { UMass research on SIDS implementation of global } \\
\text { environmental conventions }\end{array}$ & $\begin{array}{l}\text { MoU signed between CARICOM Secretariat and } \\
\text { Secretariat of the Pacific Community for joint work } \\
\text { on health and culture. }\end{array}$ \\
\hline \multirow[t]{2}{*}{$\begin{array}{l}\text { Creating } \\
\text { opportunities } \\
\text { for } \\
\text { interaction }\end{array}$} & $\begin{array}{lr}\text { Mauritius "Research } \\
\text { Week" } & \text { sharing } \\
\text { university research } \\
\text { work with policy } \\
\text { makers }\end{array}$ & $\begin{array}{l}\text { UWI "Research Opportunity Lounge" for } \\
\text { governments and donors: leading to IDB funded } \\
\text { research on domestic violence and youth crime }\end{array}$ & $\begin{array}{l}\text { Joint meeting of Ministers of Health and of Finance } \\
\text { in the Pacific to address NCD crisis }\end{array}$ \\
\hline & $\begin{array}{l}\text { Sir Hilary Beckles, } \\
\text { economic historian } \\
\text { from Barbados, } \\
\text { serves on Scientific } \\
\text { Advisory Board of } \\
\text { the UN SG }\end{array}$ & $\begin{array}{l}\text { Training in Caribbean region led to lasting capacity in } \\
\text { data and statistics in Belize, Suriname and Jamaica. }\end{array}$ & $\begin{array}{l}\text { "Promoting Investment in Agrotourism," ECLAC } \\
\text { seminar with Health, Culture, Agriculture, Tourism } \\
\text { and Finance ministries from across Caribbean }\end{array}$ \\
\hline
\end{tabular}

Source: Author's elaboration

Ideally, the science-policy interface is a relationship that moves in two directions, so that scientific research informs policymakers' decisions and the policy needs and priorities of a country are one factor influencing the scientific community's decisions on the topics of research undertaken (though not on the methods or results).
A number of vivid examples of science-policy interface were gathered, either through formalized mechanisms or through exchanges among researchers, experts and policy makers (see Table 6-2). ${ }^{524}$ As noted above, some of the case studies illustrated the need for institutional change to address sustainable development imperatives.

\section{Box 6-10. Sustainable Sea Transport: Research to inform policy in the Pacific}

In recent years, the transport sector has been neglected in the search for reduced emissions in Pacific Islands Countries (PICs), in spite of the fact that transport accounts for at least 70 percent of fossil fuel use in the PICs. In 2013, USP and the International Union for the Conservation and Nature (IUCN) established the Oceania Centre for Sustainable Transport to research and develop alternative energy sea transport projects. The Centre is exploring the use of fleets of smaller sustainable ships-solar, wind, and biofuel powered-to replace aging large vessel operations. The Centre is making the research available to governments in the region.

Source: Policy brief based on Nuttall, P., Newell, A. Prasad, B. Veitayaki, J. and Holland, E. (2013) "A review of sustainable sea-transport for Oceania: Providing context for renewable energy shipping for the Pacific". Marine Policy Vol. 43 (Jan 2014) 283-287. 
In spite of the successful examples listed in Table 6-2 above, many challenges still remain in SPI in SIDS, including inadequate communication between researchers and policymakers and the related tendency of line ministries to work in isolation from one another and for research institutions to operate with a silo structure. A tendency to use the same group of experts again and again, for instance, or appointing scientists to advisory boards who act as only passive members have been noted as drawbacks. The outcome documents from different conferences on SIDS (see Figure 6-1 above) have emphasized the importance of regional institutions and inter-regional collaboration, which needs to be enhanced further.

\subsection{Data gaps}

The report of the UN Secretary-General's Expert Advisory Group on a Data Revolution for Sustainable Development, A World That Counts: Mobilising The Data Revolution for Sustainable Development ${ }^{525}$, recognized data as a basis for ensuring that no one is left behind. Reliable data, disaggregated in such a way that no one is invisible, is key to inform decision makers. Yet, crucial data is missing in countries in special situations. Although most of these countries are able to conduct a census - $83 \%$ of LDCs, $91 \%$ of LLDCs and all SIDS have conducted at least one census since $2005^{526}$ - these data are typically available only every ten years. Due to their low frequency, census data has to be complemented with reliable administrative records or surveys. But in many countries reliable administrative records do not exist and surveys are scarce. For instance, since 2005 , only $46 \%$ of LDCs, $75 \%$ of LLDCs and $53 \%$ of SIDS have conducted a labour force survey ${ }^{527}$ - one of the main sources of data on employment. An analysis of data available in official international databases on 17 indicators related to diverse topics pointed out some data gaps (see Figure 6-9).
Since 2005, very few SIDS have data on poverty or on inequality measures - all these indicators require living standards measurement surveys, which are costly for SIDS due to small populations. Since sampling errors do not change much with population size, the per capita cost of reaching similar levels of sampling errors tend to be higher for smaller countries compared with larger countries. ${ }^{528}$ Data on slum populations that relies on census or surveys is also not available for many countries. In this as in other areas, innovative approaches to data gathering may be able to fill gaps, for example by using information and communication technology (ICT) to support communitybased enumeration and mapping in human settlements ${ }^{529}$. Other data that relies primarily on surveys - like water and electricity access - are more widely available because international agencies apply models and produce estimates to fill data gaps. Although models can produce informative estimates to guide policymaking, it is unclear if countries in special situations have the capacity to develop their own models and use these estimates to inform their policy decisions. Data that relies on inventories or easy-tomaintain administrative records - like CO2 emissions and forest area - are more widely available. But administrative data systems that require more resources - such as lists of enrolled students and their gender, or registered births are not so widely available.

With cheap cell phones and increasingly cheaper satellite images, indicators based on big data may be explored to complement survey data gaps (see Chapter 7 , section on Big Data). In Senegal, cell phone detailed records have been used to estimate literacy rates at very fine geographical resolution $^{530}$ (see also Chapter 8 ). In Haiti, social and news media have been used to monitor cholera outbreaks. ${ }^{531}$ Some LDCs are also using mobile devices to collect data faster and with reduced costs (see e.g. Chapter 8 for use of mobile devices in data collection in Burkina Faso Mozambique and Senegal). 
Figure 6-9. Data availability for illustrative indicators: percentage of LDC, LLDC and SIDS with one of or more data points since 2005

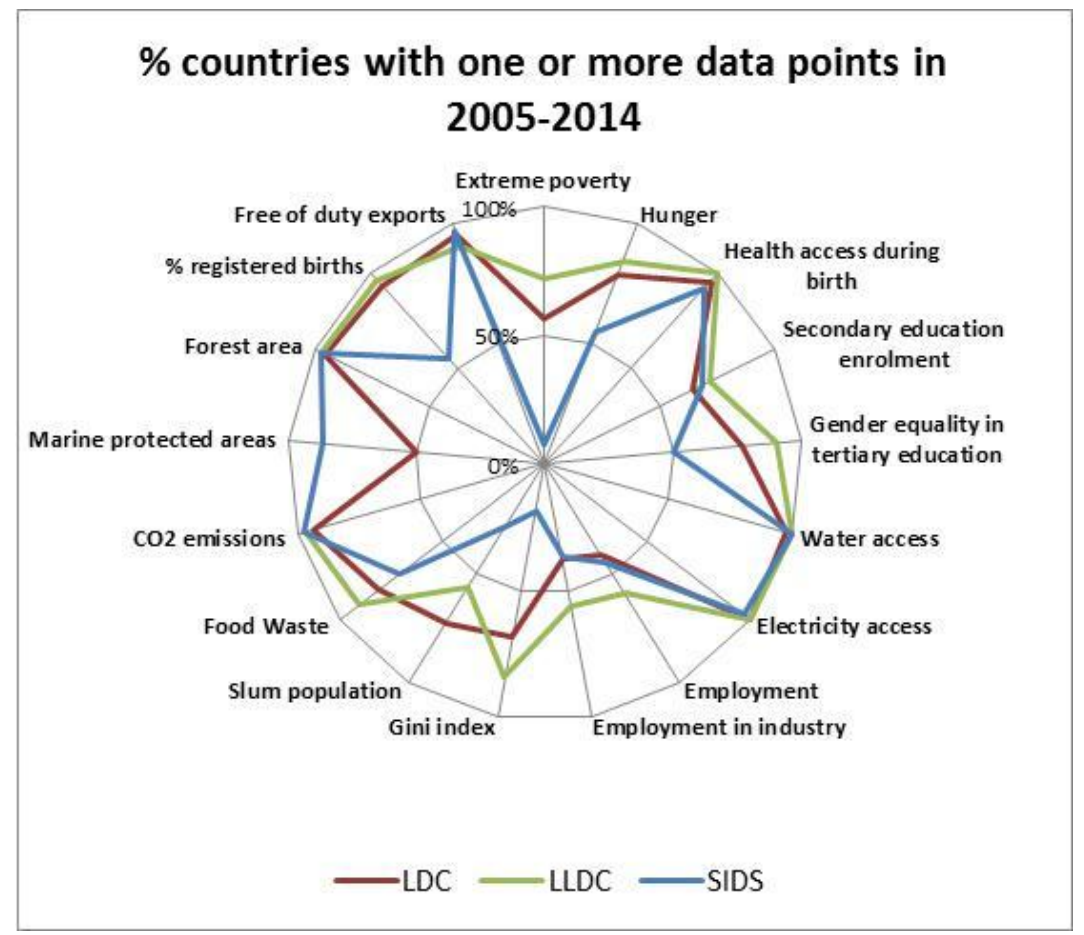

Source: MDG Official Database; ${ }^{532}$ FAO Statistics; ${ }^{533}$ World Bank Databank; ${ }^{534}$ UNICEF. ${ }^{535}$

Note: Indicators above ${ }^{536}$ were chosen because related to distinct areas covered by the SDGs and are part of existing frameworks such as MDG indicators, CSD indicators, SE4All indicators and IPOA indicators. ${ }^{537}$ Data availability according to data available in international databases. Details of the data sources, whether national or international, are indicated in brackets.

\subsection{Concluding remarks}

Despite awareness of the need to strengthen SPI in countries in special situations and a number of good examples, there are still many instances of gaps, including poor institutionalization of SPI. There is, therefore, a strong need to explore possible ways to improve SPI and encourage greater interaction, discussion and deliberation between researchers and policymakers.

Sustainable development is by definition an integrated approach to development, and the current existing international commitments of countries in special situations and the proposed SDGs signal an understanding of this with targets and benchmarks that are mutually reinforcing. ${ }^{538}$ It will be critical in the implementation of the existing international commitments for countries in special situations and the SDGs to strengthen and enhance these types of integrated approaches, including through strong engagement of the scientific community in transdisciplinary research.

Going forward, the monitoring and review of progress will need to take advantage of synergies between the IPoA, VPoA and SAMOA Pathway respectively, on the one hand, and the SDGs. However, the question of monitoring highlights a major challenge that has been recognized by these groups of countries: the lack of accurate and adequate national data and statistics. In addition, another challenge in some cases is that the data does exist, having been collected by national and regional entities, but is not used for international assessments and analysis.

Intra- and inter-regional scientific and policy research collaboration to examine shared sustainable development challenges could be further encouraged. In the context of SIDS, such collaboration is perhaps most advanced but still could be further developed.

Proactive engagement of a variety of stakeholders is another aspect of integrated and evidence-based policymaking and both scientists and policymakers need to engage effectively with stakeholders by communicating their aims and priorities clearly and persuasively. Scientists can be most effective if they communicate their research in an accessible way to policymakers and the general public. If communicated correctly, the concepts of sustainable development can also resonate deeply with traditional communities, who have in fact been practicing sustainable development for generations. Equally, communities and policy makers need to communicate their needs and priorities to the scientists. 
A three-way dialogue among scientists, civil society and policy-makers is a fruitful way of bringing different perspectives on the implications of emerging scientific findings for broader societal well-being, as a basis for a conversation on how those findings might shape policy.

Policymakers need a better understanding of scientific information, along with civil servants in a number of ministries in national and local government. This includes raising policymakers' awareness of STI issues and of STI culture and modus operandi. ${ }^{539}$ Similarly, scientists require a better understanding of policy processes in order to communicate research findings more effectively and to engage in a timely manner, An International Network for Science Advice to Governments, which was created in 2014 and operates under the aegis of International Council for Science is a good example of a mechanism for bringing the two communities together.

Strengthening the STI system may reinforce the development of productive capacities and hence accelerate the overall development of these countries, as well as contributing to more fruitful cooperation with policymakers.

The research for this chapter has shown specifically that it would be important for LDCs to strengthen their STI systems and carry out capacity-building activities for both scientists and policymakers.

A comprehensive, high-level midterm review of the IPOA taking place in June 2016 will assess progress and strengthen the global partnership for LDCs and would also represent a possibility to look at SPI.

The LLDCs need to institute new and strengthen existing channels and mechanisms for interaction and dialogue between policymakers and researchers on a long-term basis, while looking at their geographical specificities and putting emphasis on priorities like trade and infrastructure.

High quality data and statistics are not always readily available in SIDS. This makes scientific collaboration and shared learning especially important, especially because in many cases SIDS from all three regions share priorities and challenges.

The institutionalization of long-term planning can contribute to the convergence of the time horizons of policymakers and scientists, which are usually in conflict due to the former's short-term political cycle and the latter's longer-term work cycle.

Annex 1

Table 6-3. Coverage of proposed SDGs in publications relevant to LDCs

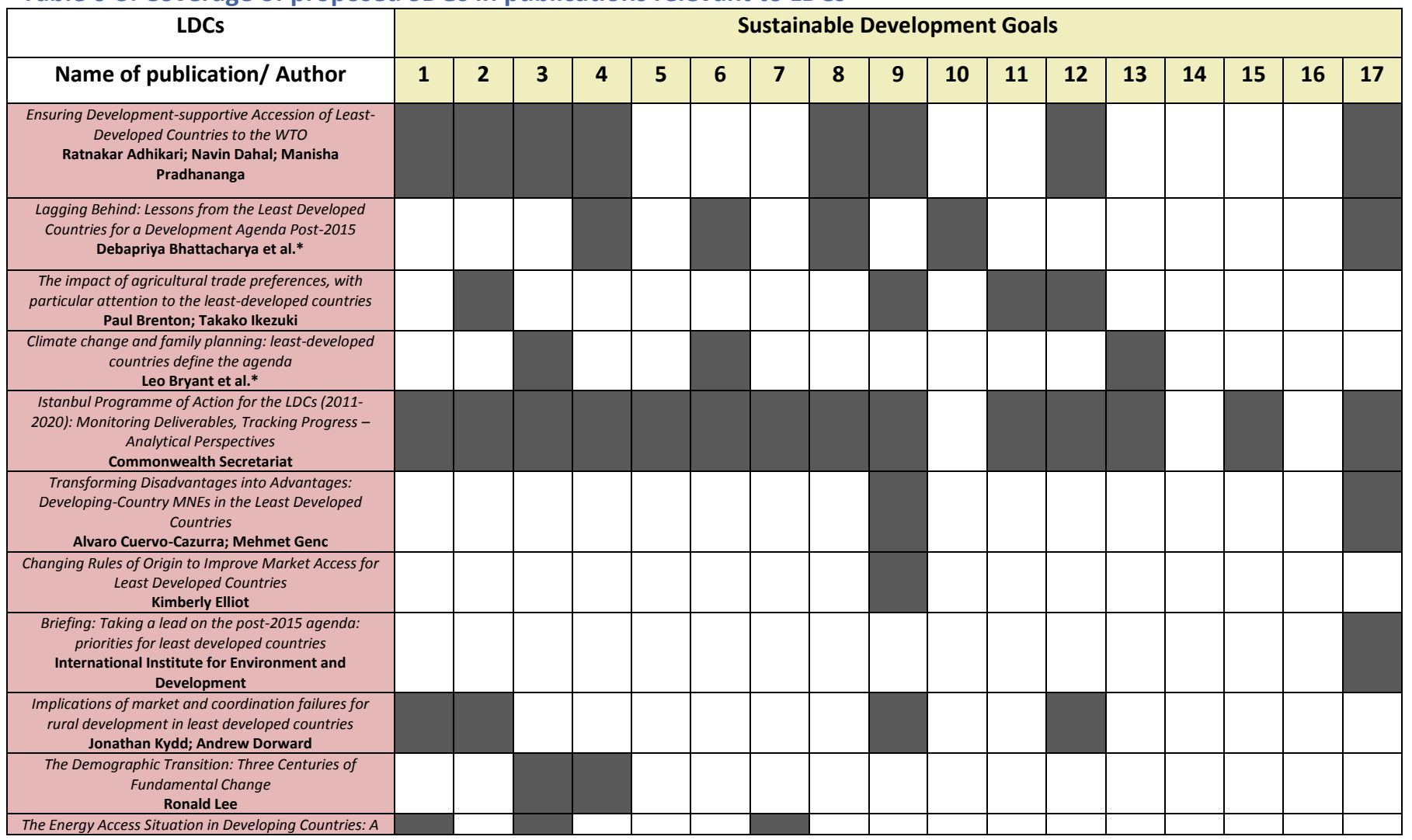




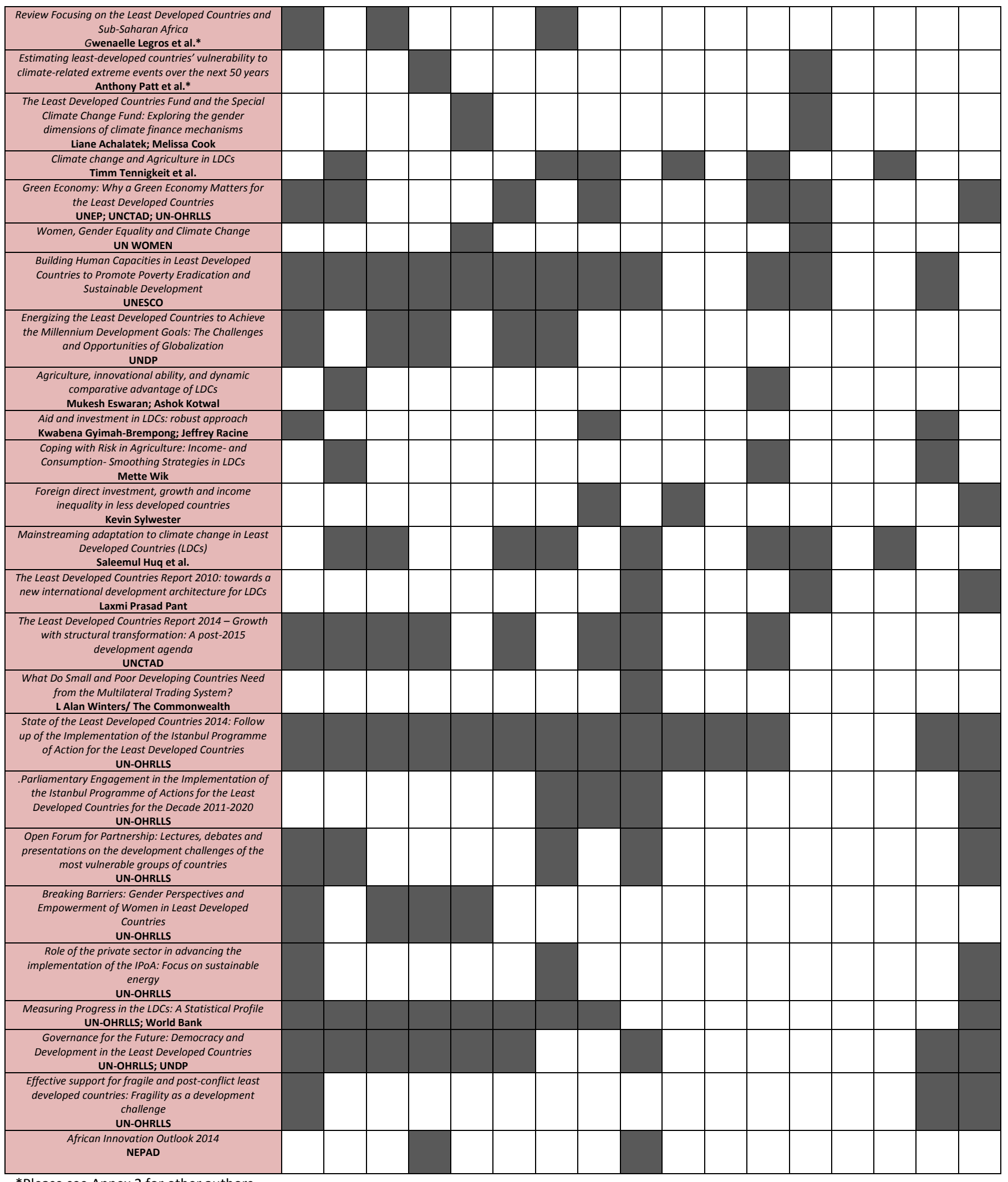

*Please see Annex 2 for other authors.

Source: Author's elaboration 
Table 6-4. Coverage of proposed SDGs in publications relevant to LLDCs

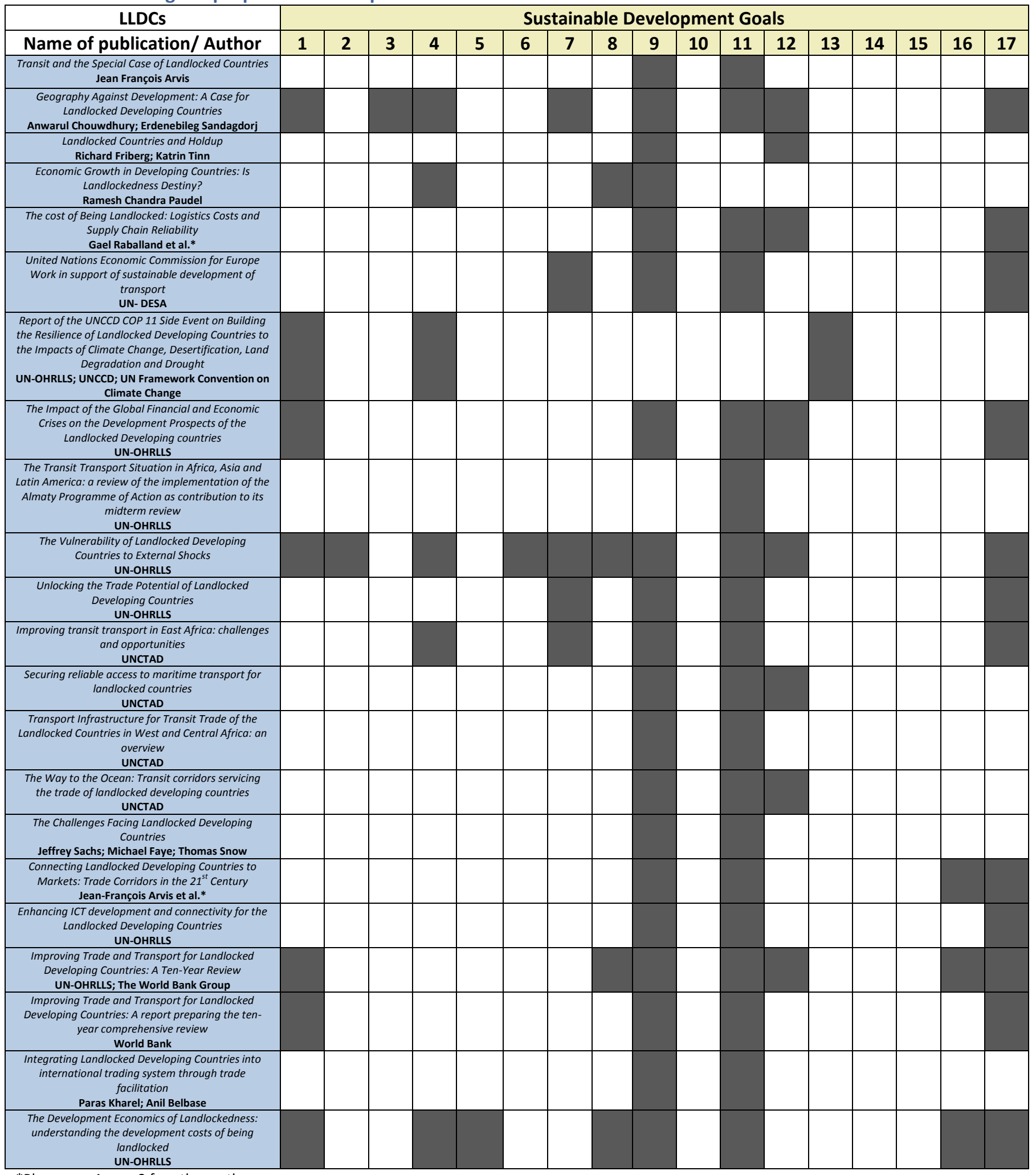

*Please see Annex 2 for other authors.

Source: Author's elaboration 
Table 6-5. Coverage of SDGs in publications relevant to SIDS

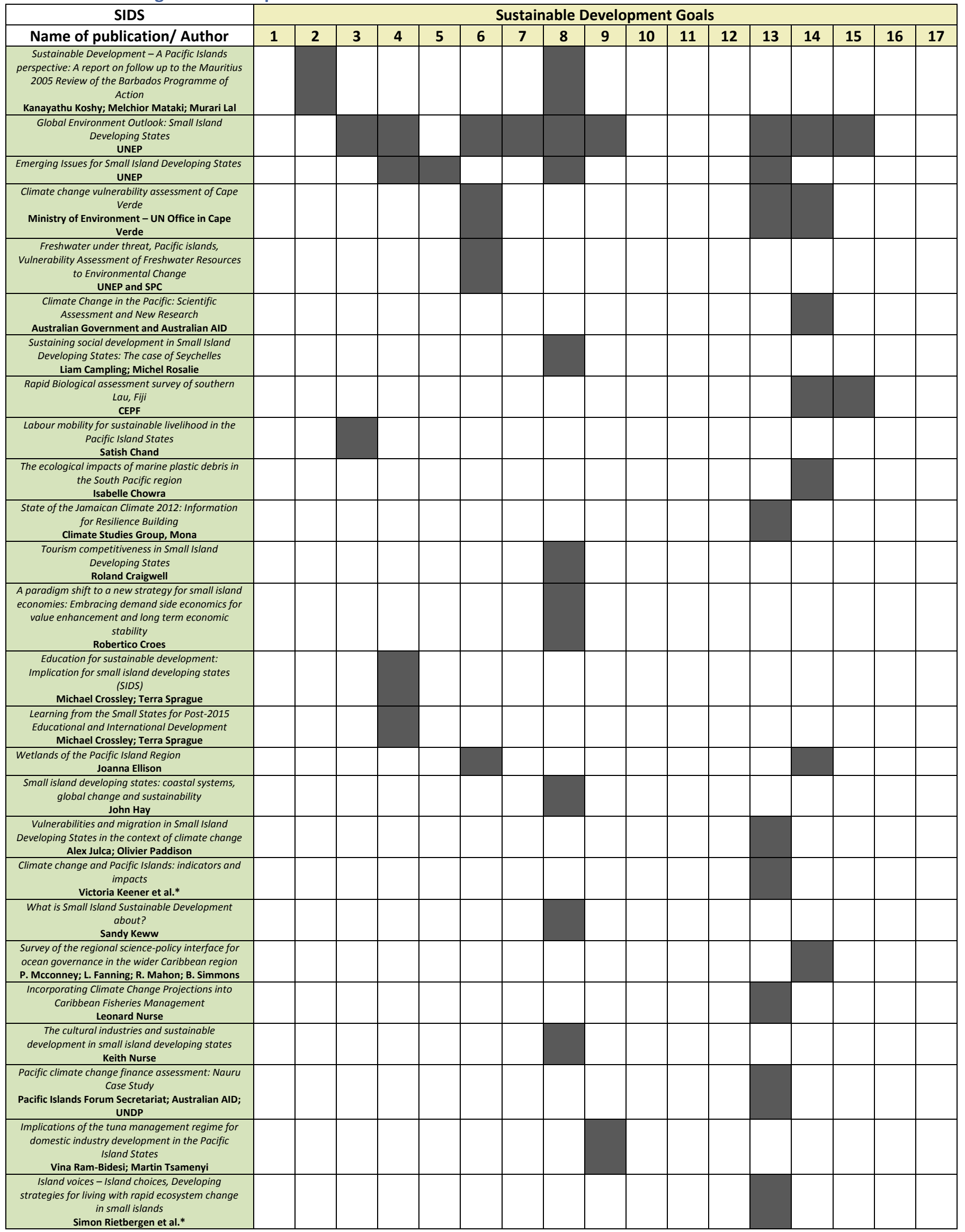




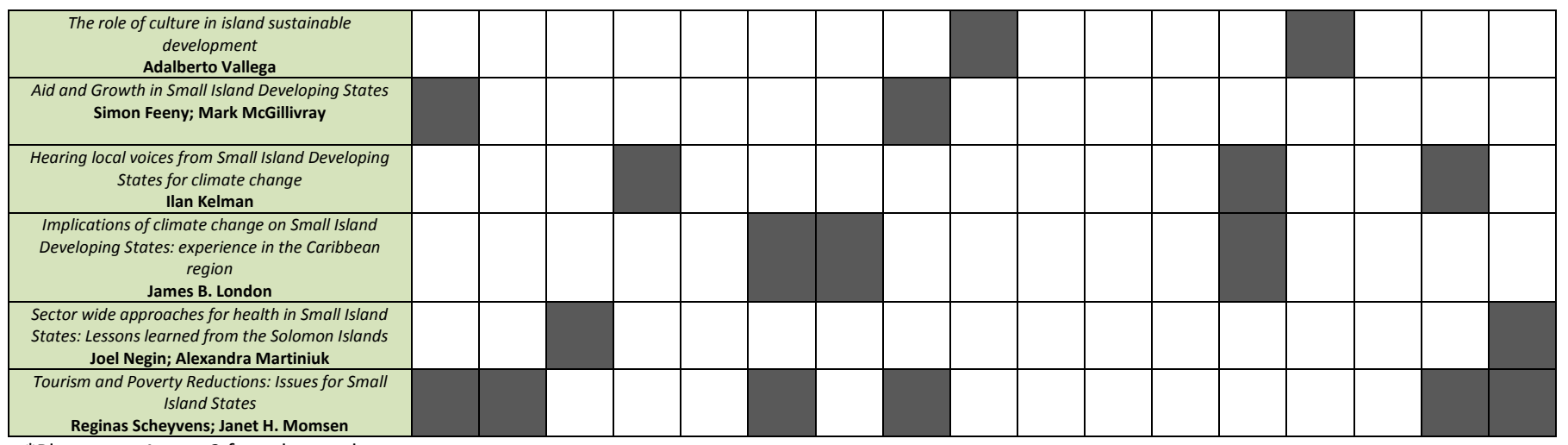

*Please see Annex 2 for other authors.

Source: Author's elaboration

Annex 2

List of Publications

LDCs:

\section{Academic and NGOs}

- $\quad$ ADHIKARI, Ratnakar; DAHAL, Navin; PRADHANANGA, Manisha. Ensuring Development-supportive Accession of LeastDeveloped Countries to the WTO. South Asia Watch on Trade, Economics \& Environment: June, 2008.

- BHATTACHARYA, Debapriya; ET AL. Lagging Behind: Lessons from the Least Developed Countries for a Development Agenda Post-2015. Friedrich Ebert Stiftung: November, 2013.

- $\quad$ BRYANT, Leo; CARVER, Louise; BUTLER, Collin; ANAGE, Ababu. Climate change and family planning: least-developed countries define the agenda. Bull World Organ, 2009.

- CUERVO-CAZURRA, Alvaro; GENC, Mehmet. Transforming Disadvantages into Advantages: Developing-Country MNEs in the Least Developed Countries. Journal of International Business Studies, Vol. 39, No. 6, pp. 957-979.

Palgrave Macmillan Journals, 2008.

- ELLIOTT, Kimberly. Changing Rules of Origin to Improve Market Access for Least Developed Countries. Center for Global Development: October, 2010.

- $\quad$ ESWARAN, Mukesh; KOTWAL, Ashok. Agriculture, innovational ability, and dynamic comparative advantage of LDCs. The Journal of International Trade \& Economic Development: An International and Comparative Review: 09 Dec 2010.

- GYIMAH-BREMPONG, Kwabena; RACINE, Jeffrey. Aid and investment in LDCs: robust approach. The Journal of International Trade \& Economic Development: An International and Comparative Review: 11 Jun 2010.

- $\quad$ HUQ, Saleemul; REID, Hannah; KONATE, Mama; RAHMAN, Atiq; SOKONA, Youba; CRICK, Florence. Mainstreaming adaptation to climate change in Least Developed Countries (LDCS). Climate Policy: 15 Jun 2011.

- KYDD, Jonathan; DORWARD, Andrew. Implications of market and coordination failures for rural development in least developed countries. Center for Development and Poverty Reduction, Imperial College London: September, 2003.

- LEE, Ronald. The Demographic Transition: Three Centuries of Fundamental Change. The Journal of Economic Perspectives, Vol. 17, No. 4. American Economic Association, 2003. Pp. 167-190.

- PANT, Laxmi P. The Least Developed Countries Report 2010: towards a new international development architecture for LDCs. Canadian Journal of Development Studies: 06 Mar 2013.

- PATT, Anthony; ET AL. Estimating least-developed countries' vulnerability to climate-related extreme events over the next 50 years. Proceedings of the National Academy of Sciences of the United States of America: January, 26, 2010. 
- SYLWESTER, Kevin. Foreign direct investment, growth and income inequality in less developed countries. International Review of Applied Economics: 19 Aug 2006

- $\quad$ TENNIGKEIT, Timm; WILKES, Andreas; PARKER, Charlie; KOSSAM, Fred. Climate change and Agriculture in LDCs. ECBI: November, 2013.

- $\quad$ WIK, Mette. Coping with Risk in Agriculture: Income- and Consumption-Smoothing Strategies in LDCs. Forum for Development Studies: 28 Jan 2011.

\section{UN, Government and International Organizations}

- $\quad$ BRENTON, Paul; IKEZUKI, Takako. The impact of agricultural trade preferences, with particular attention to the leastdeveloped countries. In: Global Agricultural Trade and Developing Countries. World Bank, 2005.

- COMMONWEALTH SECRETARIAT. Istanbul Programme of Action for the LDCs (2011- 2020): Monitoring Deliverables, Tracking Progress - Analytical Perspectives. Commonwealth Secretariat: UK, 2014.

- $\quad$ INTERNATIONAL INSTITUTE FOR ENVIRONMENT AND DEVELOPMENT (IIED). Briefing: Taking a lead on the post-2015 agenda: priorities for least developed countries. IIED: June, 2013.

- $\quad$ LEGROS, Gwenaelle; HAVET, Ines; NIGEL, Bruce; BONJOUR Sophie. The Energy Access Situation in Developing Countries: A Review Focusing on the Least Developed Countries and Sub-Saharan Africa. United Nations Development Program: November, 2009.

- $\quad$ NEPAD Planning and Coordinating Agency (NPCA). African Innovation Outlook 2014. NPCA: Pretoria, 2014.

- $\quad$ SCHALATEK, Liane; COOK, Melissa. The Least Developed Countries Fund and the Special Climate Change Fund: Exploring the gender dimensions of climate finance mechanisms. United Nations Development Programme: November, 2011.

- UN-OHRLLS. Breaking Barries: Gender Perspectivea and Empowerment of Women in Least Developed Countries. United Nations: New York, 2006.

- UN-OHRLLS. Effective support for fragile and post-conflict least developed countries: Fragility as a development challenge. United Nations, 2013.

- UN-OHRLLS. Open Forum for Partnership: Lectures, debates and presentations on the development challenges of the most vulnerable groups of countries. United Nations, 2012.

- UN-OHRLLS. Role of the private sector in advancing the implementation of the IPoA: Focus on sustainable energy. United Nations, 2014.

- UN-OHRLLS. State of the Least Developed Countries 2014: Follow up of the Implementation of the Istanbul Programme of Action for the Least Developed Countries. United Nations, 2014.

- UN-OHRLLS. Parliamentary Engagement in the Implementation of the Istanbul Programme of Actions for the Least Developed Countries for the Decade 2011-2020. United Nations, 2013.

- UN-OHRLLS; UNDP. Governance for the Future: Democracy and Development in the Least Developed Countries. United Nations, 2006.

- UN-OHRLLS; World Bank. Measuring Progress in the LDCs: A Statistical Profile. United Nations/ World Bank Development Data Group, 2006.

- $\quad$ UNEP; UNCTAD; UN-OHRLLS. Green Economy: Why a Green Economy Matters for the Least Developed Countries. United Nations Environmental Program, 2011.

- UN WOMEN. Women, Gender Equality and Climate Change. The UN Internet Gateway on Gender Equality and Empowerment of Women, 2009.

- $\quad$ UNESCO. Building Human Capacities in Least Developed Countries to Promote Poverty Eradication and Sustainable Development. France, 2011.

- UNCTAD. The Least Developed Countries Report 2014 - Growth with structural transformation: A post-2015 development agenda. United Nations: New York and Geneva, 2014. 
- UNDP. Energizing the Least Developed Countries to Achieve the Millennium Development Goals: The Challenges and Opportunities of Globalization. United Nations Ministerial Conference of the Least Developed Countries: Istanbul, 2007.

- WINTERS, L Alan. What Do Small and Poor Developing Countries Need from the Multilateral Trading System?. Commonwealth Trade Policy Discussion Papers: The Commonwealth, 2014.

LLDCs:

\section{Academic and NGOs}

- $\quad$ FRIBERG, Richard; TINN, Katrin. Landlocked Countries and Holdup. Stockholm School of Economics: April 15, 2009.

- $\quad$ KHAREL, Paras; BELBASE, Anil. Integrating Landlocked Developing Countries into international trading system through trade facilitation. Asia-Pacific Research and Training Network on Trade Working Paper Series, No. 84, September 2010.

- PAUDEL, Ramesh Chandra. Economic Growth in Developing Countries: Is Landlockedness Destiny?. Australian National University: January, 2014.

- $\quad$ SACHS, Jeffrey; FAYE, Michael; SNOW, Thomas. The Challenges Facing Landlocked Developing Countries. Journal of Human Development, vol. 5, No. 1: March, 2004.

\section{UN, Government and International Organizations}

- $\quad$ ARVIS, Jean François. Transit and the Special Case of Landlocked Countries. In: Customs Modernization Handbook. SOKOL, José; DE WULF, Luc. The World Bank: Washington D.C., 2005.

- $\quad$ ARVIS, Jean-François; CARRUTHERS, Robin; SMITH, Graham; WILLOUGHBY, Chrispopher. Connecting Landlocked Developing Countries to Markets: Trade Corridors in the $21^{\text {st }}$ Century. The World Bank: Washingtong, 2011.

- CHOUWDHURY, Anwarul; SANDAGDORJ, Erdenebileg. Geography Against Development: A Case for Landlocked Developing Countries. UN-OHRLLS: New York, 2006.

- $\quad$ RABALLAND, Gael; MARTEAU, Jean-François; ARVIS, Jean François. The cost of Being Landlocked: Logistics Costs and Supply Chain Reliability. The World Bank: Washington D.C., 2010.

- UN-DESA. United Nations Economic Commission for Europe Work in support of sustainable development of transport. Commission on Sustainable Development: Eighteenth Session,

- 3-14 May 2010

- UN-OHRLLS; UNCCD; UN Framework Convention on Climate Change. Report of the UNCCD COP 11 Side Event on Building the Resilience of Landlocked Developing Countries to the Impacts of Climate Change, Desertification, Land Degradation and Drought. Namibia, 2013.

- UN-OHRLLS. Enhancing ICT development and connectivity for the Landlocked Developing Countries. United Nations, 2013.

- UN-OHRLLS; World Bank Group. Improving Trade and Transport for Landlocked Developing Countries: A Ten-Year Review. United Nations: November, 2014.

- $\quad$ UN-OHRLLS. The Development Economics of Landlockedness: understanding the development costs of being landlocked. United Nations.

- UN-OHRLLS. The Impact of the Global Financial and Economic Crises on the Development Prospects of the Landlocked Developing countries. Report prepared by John Serieux. June, 2009.

- UN-OHRLLS. The Transit Transport Situation in Africa, Asia and Latin America: a review of the implementation of the Almaty Programme of Action as contribution to its midterm review. Report prepared by Ernest Vitta Mbuli. June, 2008.

- $\quad$ UN-OHRLLS. The Vulnerability of Landlocked Developing Countries to External Shocks. August, 2014.

- UN-OHRLLS. Unlocking the Trade Potential of Landlocked Developing Countries. Almaty, Kazakhstan: Semptember, 2012. 
- UNCTAD. Improving transit transport in East Africa: challenges and opportunities. Report by Ernest Vitta Mbuli, UNCTAD consultant as a part of the preparatory process for the Mid-term Review of the Almaty Programme of Action Ouagadougou, Burkina Faso, 18-20 June 200

- UNCTAD. Securing reliable access to maritime transport for landlocked countries. Review of Maritime Transport: New York and Geneva, 2013.

- UNCTAD. Transport Infrastructure for Transit Trade of the Landlocked Countries in West and Central Africa: an overview. United Nations Conference on Trade and Development Thematic Meeting on Transit Transport Infrastructure Development as a part of the preparatory process for the Mid-term Review of the Almaty Programme of Action: Ouagadougou, Burkina Faso, 18-20 June 2007

- UNCTAD. The Way to the Ocean: Transit corridors servicing the trade of landlocked developing countries. Transport and Trade Facilitation, Series No. 4. New York and Geneva, 2013.

- WORLD BANK. Improving Trade and Transport for Landlocked Developing Countries: A report preparing the ten-year comprehensive review. The World Bank: June, 2013.

SIDS:

\section{Academic and NGOs}

- $\quad$ CAMPLING, Liam; ROSALIE, Michel. Sustaining social development in small island developing state: The case of Seychelles. Islands of the World VIII International Conference: Taiwan, Province of China, 2004.

- CEPF. Rapid Biological assessment survey of southern Lau, Fiji. Conservation International: Samoa, 2013

- CHAND, Satish. Labour mobility for sustainable livelihood in the Pacific island states. The Australian National University, 2004.

- $\quad$ CHOWRA, Isabelle. The ecological impacts of marine plastic debris in the South Pacific region. Degree Project in Energy and Environment, First Level, 2013.

- Climate Studies Group, Mona (CSGM), 2012: State of the Jamaican Climate 2012: Information for Resilience Building (Summary for Policymakers). Planning Institute of Jamaica (PIOJ), Kingston, Jamaica.

- CRAIGWELL, Roland. Tourism competitiveness in small island developing states. United Nations University: Barbados, 2007.

- CROES, R. Robertico. A paradigm shift to a new strategy for small island economies: Embracing demand side economics for value enhancement and long term economic stability. Elsevier: Florida, 2004

- CROSSLEY, Michael; SPRAGUE, Terra. Education for sustainable development: Implication for small island developing states (SIDS), International Journal of Educational Development, 2014.

- $\quad$ CROSSLEY Michael, SPRAGUE Terra, Learning from the Small States for Post-2015 Educational and International Development. Current issues in comparative education, 2014.

- ELLISON, C. Joanna. Wetlands of the Pacific Island region. School of Geography and Environmental Studies, 2009.

- FEENY, Simon; MCGILLIVRAY, Mark. Aid and Growth in Small Island Developing States. The Journal of Development Studies: 21 May 2010.

- HAY, E. John. Small island developing states: coastal systems, global change and sustainability, Springer. Japan 2013.

- JULCA, Alex; PADDISON, Olivier. Vulnerabilities and migration in small island developing states in the context of climate change. Springer and Business Media B.V: New York, 2009.

- $\quad$ KEENER, W. Victoria; MARRA, J. John; FINUCANE, L. Melissa; SPOONER, Deanna; SMITH, H. Margaret. Climate change and pacific islands: indicators and impacts. Report for the 2012 PIRCA. Island Press: USA, 2012.

- $\quad$ KELMAN, Ilan. Hearing local voices from Small Island Developing States for climate change. Local Environment: The International Journal of Justice and Sustainability, 20 Aug 2010.

- $\quad$ KEWW A. Sandy, What is small island sustainable development about?, Elsevier, Scotland, 2005

- LONDON, James B. Implications of climate change on small island developing states: experience in the Caribbean region. Journal of Environmental Planning and Management, 22 Jan 2007. 
- $\quad$ MCCONNEY P., FANNING L., MAHON R., SIMMONS B. Survey of the regional science-policy interface for ocean governance in the wider Caribbean region. CERMES Technical Report N51: Barbados, 2012.

- NEGIN, Joel; MARTINIUK, Alexandra. Sector wide approaches for health in small island states: Lessons learned from the Solomon Islands. Global Public Health: An International Journal for Research, Policy and Practice, 13 Jun 2011.

- $\quad$ NURSE, A. Leonard. Incorporating Climate Change Projections into Caribbean Fisheries Management, Centre for Resource management and environmental studies. Barbados, 2009.

- NURSE, Keith. The cultural industries and sustainable development in small island developing states, Institute of International Relations. Trinidad and Tobago, 2007.

- $\quad$ RAM-BIDESI, Vina; TSAMENYI, Martin. Implications of the tuna management regime for domestic industry development in the Pacific Island States. Elsevier: Australia, 2003.

- $\quad$ RIETBERGEN, Simon; HAMMOND, Tom; SAYEGH, Chucri; HESSELINK, Frits; MOONEY, Kieran. Island voices - island choices, Developing strategies for living with rapid ecosystem change in small islands. IUCN, 2008.

- SCHEYVENS, Regina; MOMSEN, Janet. Tourism and Poverty Reduction: issues for Small Island States. Tourism Geographies: An International Journal of Tourism Space, Place and Environment, 12 Feb 2008.

- VALLEGA, Adalberto. The role of culture in island sustainable development. Elsevier: Genoa, 2007

\section{UN, Government and International Organizations}

- IPCC, Fifth Assessment Report Climate Change 2014: Impacts, Adaptation and Vulnerability, regional chapter on Small Islands.

- $\quad$ UN-DESA, Trends in Sustainable Development, Small Island Developing States, 2009.

- $\quad$ UN-DESA, Trends in Sustainable Development, Small Island Developing States, 2012.

- Australian Government; Australian AID. Climate Change in the Pacific. Scientific Assessment and New Research: Volume 1: Regional Overview. CSIRO: Australia, 2011.

- $\quad$ KOSHY, Kanayathu; MATAKI, Melchior; LAL, Murari. Sustainable Development - A pacific islands perspective: $A$ report on follow up to the Mauritius 2005 Review of the Barbados Programme of Action. UNESCO \& USP: Samoa, 2008.

- $\quad$ UNEP. Global Environment Outlook Small Island Developing States. Kenya, 2014.

- $\quad$ UNEP, Emerging Issues for Small Island Developing States, Results of the UNEP Foresight Process, Kenya, 2014

- $\quad$ Ministry of Environment, Housing and Territory Planning; UN Office in Cape Verde; UNEP; UNDA. Climate change vulnerability assessment of Cape Verde - Summary for policy makers, 2007.

- UNEP; SPC. Freshwater under threat, Pacific islands, Vulnerability Assessment of Freshwater Resources to Environmental Change. Thailand 2011.

- Pacific Islands Forum Secretariat; Australian AID; UNDP. Pacific Climate Change Finance Assessment, Nauru Case Study, Final Report. Fiji, 2013. 


\section{Chapter 7. Science Issues for the Attention of Policy Makers}

\subsection{Introduction}

The identification of new and emerging issues, drawing on scientific evidence, assessments and projections, is a function of the science-policy interface (see Chapter 1). In this context, this chapter reports on the process and results from an experiment to crowd-source briefs from interested scientific communities around the world. This initiative was undertaken in the context of identifying "emerging issues" from a science-based perspective.

The categorization of an issue as "emerging" involves a degree of subjective judgment, as emphasized, e.g., in the UNEP Foresight process $2012 .^{540}$ An issue can also be understood as emerging where the scientific community considers it important, but the policy community has not given it "adequate" attention. Others argue that an issue becomes "emerging" as soon as there scientific confidence in causality is established. ${ }^{541}$ It must be clear that these are broad generalizations; some issues have been squarely on the policy agenda - climate change for instance - for a long time, but with attention arguably failing to translate into action commensurate with the scale of the problem. The inherently subjective process of identifying "emerging issues" can be guided by criteria, e.g., those used in the UNEP Foresight exercise. In an inter-dependent world, what at first appear to be local and isolated problems may potentially be of global significance.

Table 7-1. UNEP foresight criteria for "emerging issues"

\begin{tabular}{|l|l|}
\hline Indicative criteria & Illustrative issue \\
\hline $\begin{array}{l}\text { Global significance - is critical to achieving } \\
\text { sustainable development in many parts of the world }\end{array}$ & Climate change \\
\hline $\begin{array}{l}\text { Affects one or more of the dimensions of } \\
\text { sustainable development }\end{array}$ & $\begin{array}{l}\text { Disaster risk } \\
\text { reduction }\end{array}$ \\
\hline $\begin{array}{l}\text { Evidence-based, including scientific and traditional } \\
\text { sources of knowledge }\end{array}$ & $\begin{array}{l}\text { Biotechnology, } \\
\text { GMOs }\end{array}$ \\
\hline Newness - the result of new knowledge & Ocean acidification \\
\hline
\end{tabular}

Source: Adapted from UNEP Foresight 2012. ${ }^{540}$

A range of approaches can be applied to identify a set of emerging issues; a common way is expert consensus, using criteria to collect an initial list of issues, which is then whittled down in the course of discussions among experts. The involvement of experts tends to enhance the credibility of the process. ${ }^{52}$ Criteria are explicit, and the process of selection and elimination of issues can be transparently recorded and justified. The overall exercise can be characterized as systematic. However, while observers can scrutinise the process, initial choices about the framing and articulation of criteria, as well as the selection of experts, may significantly affect what issues are identified as "emerging". Related to this, the perceived legitimacy of such exercises will depend on the extent to which the process is perceived as unbiased and fair in the treatment of views. These weaknesses may be overcome by combining the structured process with crowd-sourcing.

By contrast, the "crowd-sourced" approach adopted for the GSDR and described below lacks the systematic character of more formal exercises designed to identify emerging issues. Lacking the pedigree of formal assessment exercises, credibility is more difficult to assess, but can be judged from, e.g., the degree to which findings are grounded in the peer-reviewed literature. Because the open call contained only very minimal criteria, very few issues were foreclosed from the beginning. In a sense the approach can be compared to the first, scoping stage of an expert-led process, when the "raw" list of issues is compiled. But for the present report the process of scoping was decentralized with expert contributors from diverse disciplines and a range of countries. As a result, policymakers gain access to a bottom-up, largely unfiltered science perspective, with the freedom to judge the policyrelevance of the issues identified. Many inputs were received from younger scientists and scientists from developing countries who previously were not typically involved in UN-related activities and debates.

The result is a wealth of information that scientists would like policy makers to consider in their deliberations at the United Nations, in particular relation to the mandate of the High-level Political Forum on Sustainable Development (HLPF) to strengthen the science-policy interface. However, it must be emphasized that the crowd-sourcing exercise is presented as a complement to more formal assessment exercises in the context of the science-policy interface. This is in keeping with one of the overall objectives of the GSDR to feature a wide range of perspective from multiple channels.

The present chapter also presents selected highlights from scientific journals on sustainability science and on big data applications for sustainable development. It reviews existing mechanisms in the UN system to identify "emerging issues" and provides empirical data on the typical time-lags between environmental science and policy. It concludes with a number of issues for consideration by the HLPF. 


\subsection{Crowd-sourcing science briefs for policy makers}

The Prototype Global Sustainable Development Report published in 2014 already provided initial information on existing lists of "emerging issues" and how they were identified. The report also compared these lists of issues to an open process in which issues were "crowdsourced" from more than 1,000 participating scientists who identified issues they wanted to bring to the attention of policy makers. The differences in results between the open crowdsourcing for the prototype report and more "managed" established processes were significant (Table 72).

In the open crowdsourcing exercise for the Prototype GSDR last year, participants could simply propose an issue and did not have to "invest" time and resources in writing a brief with all the necessary analysis and information to carry the issue forward to the policy level.

The performance of scientists is often measured by the number of peer-reviewed publications in high-impact journals. Hence, when scientists have to invest significant time in preparing a brief, it suggests that they perceive the issue as very important. Against this background, for this year's Report, it was decided to issue an open call for science briefs, inviting researchers and scientists to submit short papers on issues relevant to sustainable development. Table 7-2 compares the top issues highlighted in the scientific briefs this year with those identified in last year's prototype report, the World Economic Forum's Global Risk report and the Worldwatch Institute's State of the World Report 2015.

Table 7-2. Top sustainable development issues scientists worldwide would like decision-makers to consider for action

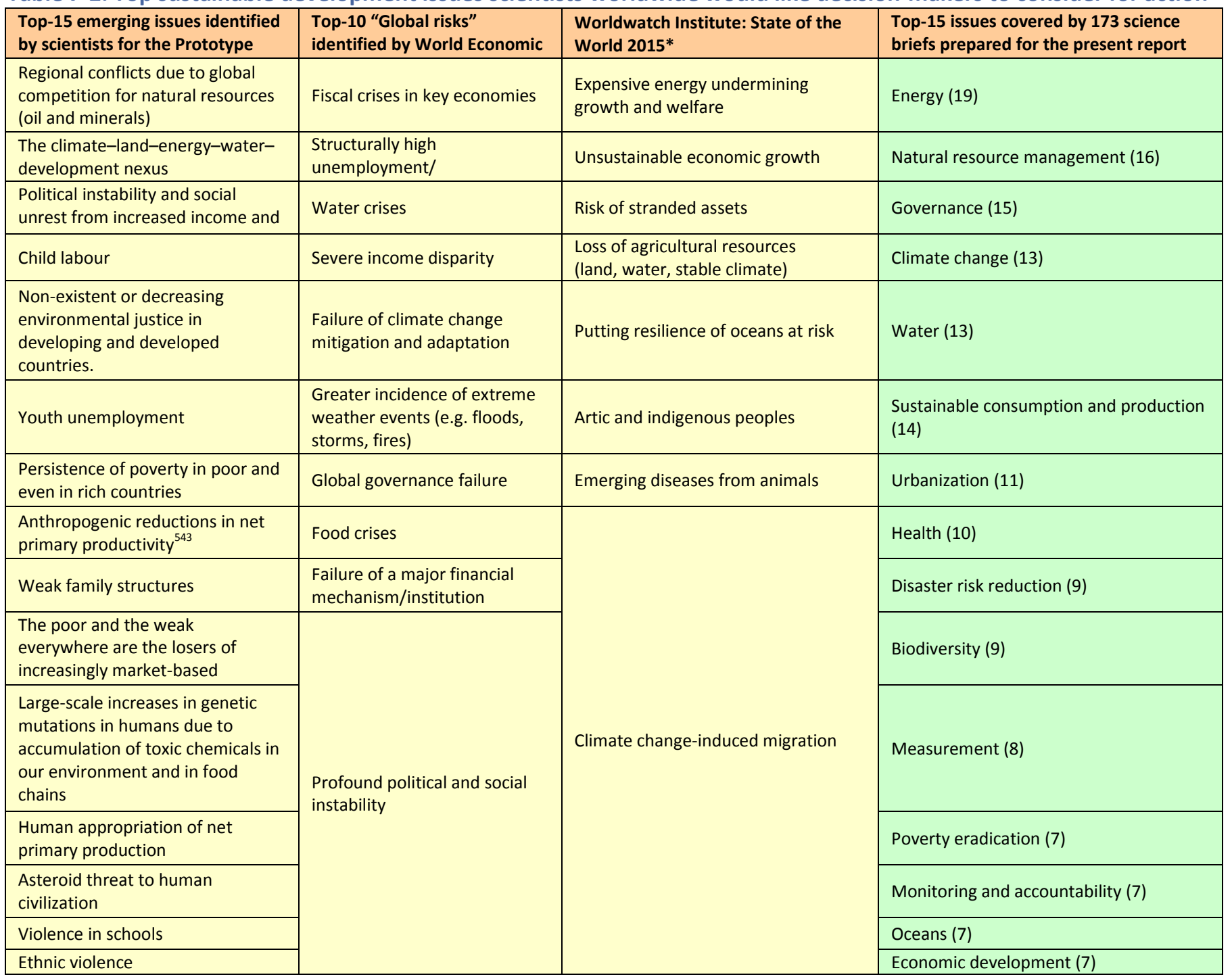

Sources: left column: Results of crowdsourcing issues from scientists, conducted by the United Nations for the Prototype Global Sustainable Development report 2014. Second from left: Global Risks Perception Survey 2013-2014, as reported in WEF's Global Risks Report 2014 ${ }^{544}$. Second from right: State of the World 2015: Confronting Hidden Threats to Sustainability, Worldwatch Institute. ${ }^{545}$ * Listing unranked. Right column: Briefs submitted by scientists in response to an open call for the present report. ${ }^{546,552}$ Note: In the WEF survey, from a list of 31 risks, survey respondents were asked to identify the 5 they are most concerned about. The right column covers the first 173 of 187 accepted science briefs only. 


\subsubsection{Open call for inputs to the present report}

By way of general guidance, the open call stated that the briefs should address an issue, finding, or research with a bearing on sustainable development in its three dimensions - economic, social, and environmental - or the interlinkages between them. It was suggested that prospective authors could review up-to-date findings relating to a particular issue, address a single issue of importance, or present solutions to a problem or challenge. Briefs could also present the "story" of a research finding with potentially great policy relevance but that hitherto had not been typically considered in the policy debate. Authors were reminded that the briefs had to be factual and based on peer-reviewed literature. The call specifically stated that contributions from both the natural and social science communities from all disciplines were highly valued and welcomed. Further guidance to potential authors called for concise briefs (less than 1,500 words) that are factual and based on peer-reviewed literature. It was also recommended to highlight key messages from the current scientific debate for the attention of policy-makers.

The call for briefs was posted in five of six United Nations languages on the website of the Division for Sustainable Development of the United Nations Department of Economic and Social Affairs. ${ }^{547}$ It welcomed submissions in all United Nations languages. The call was also shared with a number of organizations in the sustainable development community, such as the IUCN scientific community; ICSU and online networks; and the SDG listserve of IISD. The call was also disseminated via working-level contacts and networks of GSDR team members in various UN entities. A number of briefs were also sourced from young academics through close collaboration with universities. ${ }^{548}$ All briefs were reviewed by the GSDR team and were accepted, if they met basic quality requirements in terms of language, structure and, critically, grounding in the peer-reviewed literature or exposition of new research findings. Overall, the guiding principle adopted in reviewing the briefs was not the imposition of uniform standards of perceived quality, but rather facilitating the sharing of thinking on sustainable development issues from as wide a range of perspectives as possible.

\subsubsection{7 accepted science briefs}

The open call for science briefs resulted in 187 accepted contributions. ${ }^{549}$ They provide a bottom-up, "crowdsourced" sample of sustainable development issues from a diversity of perspectives around the world. The briefs cover topics ranging from antibiotic resistance, karst and caves, through to the health of the oceans.

Of the 187 accepted science briefs, 136 were in English, 41 in Chinese, 6 in Spanish, 3 in French, and one in Portuguese (Figure 7-1). No briefs were received in Russian or Arabic. Briefs were received from 367 natural and social scientists from 46 countries representing all continents and developed and developing countries alike (Figure 7-2). 24 of these countries - a slight majority - are developing countries, and China topped the list with the most contributions. Most of the contributing scientists had affiliations with universities and research centres, only a few with other NGOs or government institutions. Anecdotal evidence indicates that a sizable share of the participating scientists with affiliations to universities in developed countries are citizens of developing countries.

Figure 7-1. Briefs submitted in various languages for the present report

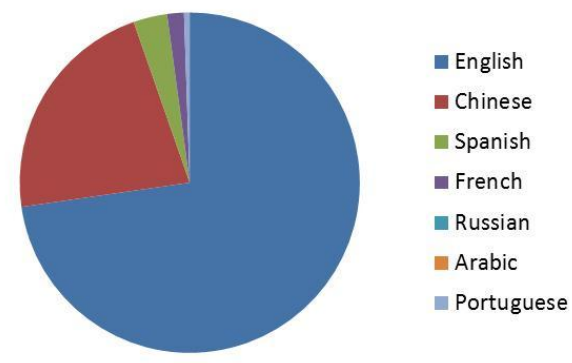

Source: https://gsdr2015.wordpress.com/

All the briefs accepted for publication were posted on the GSDR website. ${ }^{550,551}$ They were also made available for an open, public comment and review using an online platform. ${ }^{552}$ All the authors of the briefs were encouraged to provide feedback on each other's briefs, and notices of the open review were also disseminated via social media channels and the SDG list-serve. Four criteria were used in the review of the science briefs: scientific basis, balanced approach, novelty, and accessibility (Table 7-3).

Table 7-3. Criteria used in the review of the science briefs

\begin{tabular}{|l|l|}
\hline Criteria & Question \\
\hline Scientific basis & Is the brief factual and based on peer-reviewed literature? \\
\hline $\begin{array}{l}\text { Balanced } \\
\text { approach }\end{array}$ & $\begin{array}{l}\text { Does it consider a wider range of scientific perspectives? } \\
\text { Does it reflect economic, social and environmental aspects? }\end{array}$ \\
\hline Novelty & $\begin{array}{l}\text { Does it present an issue that is typically not adequately } \\
\text { considered in the global SD policy debate? }\end{array}$ \\
\hline Accessibility & Is the brief well-written and easily understandable? \\
\hline
\end{tabular}

Table 7-4 presents a list of briefs that had received most attention in the course of the open review (as of 24 March 2015). The wide range of topics that are not typically high 
on the agenda of UN deliberations should be noted, such as the open genome sequence data framework, anthropological perspectives, village designs, and Austrocedrus forests.

Figure 7-2. Number of authors of submitted briefs by country

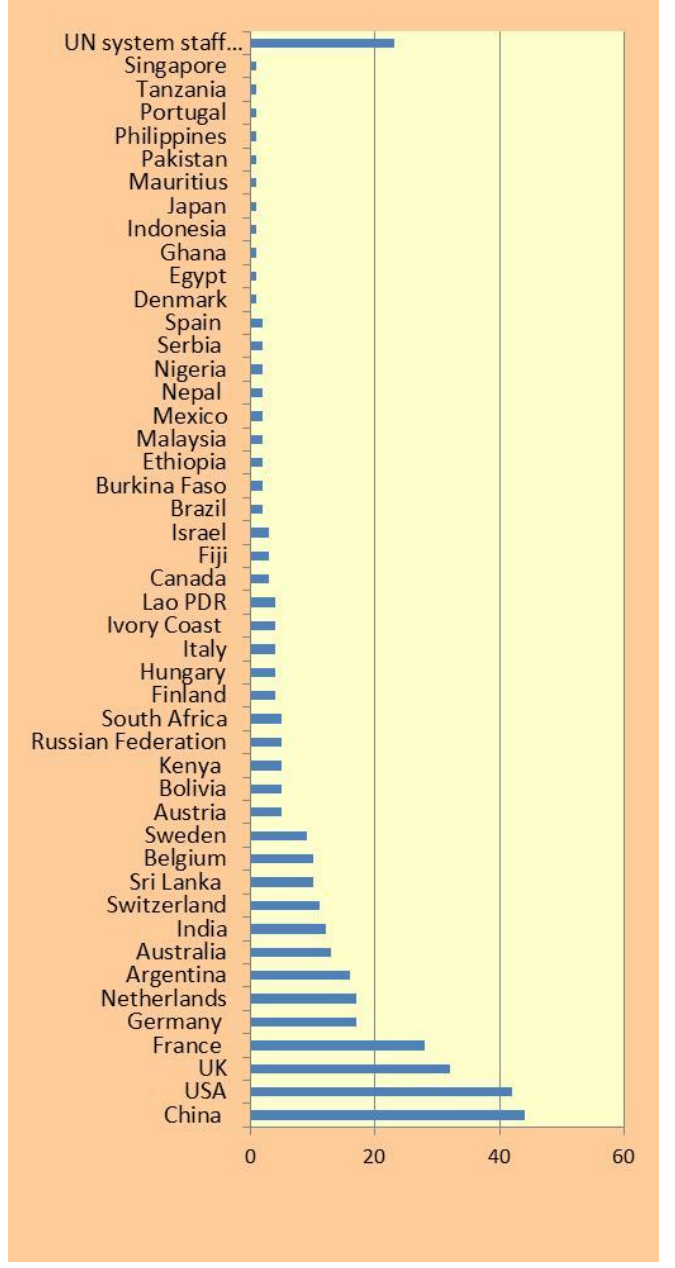

The submitted briefs differed greatly in terms of their nature and focus. Taken together they provide a mosaic glimpse of a system of inter-dependent challenges. Most briefs focussed on particular aspects or interlinkages and took a bottom-up perspective, in contrast to the top-down approach typically used by integrated global assessments. The geographic scope of the briefs ranged from local projects at the village level to the world as a whole. Important interlinkages between geographic scales were typically identified, too. Authors also made the case that some local concerns (e.g., exotic forest tree disease) can have regional and global impacts. A near and medium-term perspective was dominant in the briefs, while implications for the longer-term were typically pointed out.
Table 7-4. Top-10 briefs that received most attention in open review

\begin{tabular}{|c|c|}
\hline Author & Title of brief (hyperlink) \\
\hline $\begin{array}{l}\text { Norman Warthmann, } \\
\text { Claudio Chiarolla } \\
\text { (Australia, France) }\end{array}$ & $\begin{array}{l}\text { Thinking a Global Open Genome Sequence Data } \\
\text { Framework for Sustainable Development }\end{array}$ \\
\hline $\begin{array}{l}\text { Hans A. Baer, Thomas } \\
\text { Reuter (Australia) }\end{array}$ & $\begin{array}{l}\text { Anthropological perspectives on climate change } \\
\text { and sustainability: implications for policy and } \\
\text { action }\end{array}$ \\
\hline $\begin{array}{l}\text { Clemens Mader, } \\
\text { Christian Rammel } \\
\text { (Germany, Austria, } \\
\text { Switzerland) }\end{array}$ & $\begin{array}{l}\text { Transforming Higher Education for Sustainable } \\
\text { Development }\end{array}$ \\
\hline $\begin{array}{l}\text { Mathew Kurian, Kristin } \\
\text { Meyer (Germany) }\end{array}$ & $\begin{array}{l}\text { The UNU-FLORES Nexus Observatory and the } \\
\text { Post- } 2015 \text { Monitoring Agenda }\end{array}$ \\
\hline $\begin{array}{l}\text { Celina N. Amato } \\
\text { (Argentina) }\end{array}$ & $\begin{array}{l}\text { Relación entre Sustentabilidad, Responsabilidad } \\
\text { Social y Responsabilidad Extendida al Productor } \\
\end{array}$ \\
\hline $\begin{array}{l}\text { James Ehrlich, Larry } \\
\text { Leifer (USA) }\end{array}$ & $\begin{array}{l}\text { RegenVillages - Integrated village designs for } \\
\text { thriving regenerative communities }\end{array}$ \\
\hline $\begin{array}{l}\text { Saahil Parekh and } \\
\text { Siddharth Singh (India) }\end{array}$ & $\underline{\text { Towards an energy efficient oil and gas sector }}$ \\
\hline $\begin{array}{l}\text { Olanike Adeyemo } \\
\text { (Nigeria) }\end{array}$ & $\begin{array}{l}\text { Towards sustainable tackling of emerging and re- } \\
\text { emerging infectious diseases }\end{array}$ \\
\hline $\begin{array}{l}\text { Alina Greslebin, Maria } \\
\text { Laura Vélez, Matteo } \\
\text { Garbelotto (Argentina, } \\
\text { USA) }\end{array}$ & $\begin{array}{l}\text { Austrocedrus forests of South America are pivotal } \\
\text { ecosystems at risk due to the emergence of an } \\
\text { exotic tree disease: can a joint effort of research } \\
\text { and policy save them? }\end{array}$ \\
\hline $\begin{array}{l}\text { Helen Adams, Karen E. } \\
\text { McNamara (UK, } \\
\text { Australia) }\end{array}$ & $\begin{array}{l}\text { Climate Change Responses: Mitigation and } \\
\text { Adaptation for Whom? }\end{array}$ \\
\hline
\end{tabular}

Source: http://gsdr2015.wordpress.com

Many briefs emphasized knowledge production and the need to improve our understanding of various subsystems. They addressed various aspects of measurement (including indicators) - providing a scientist's rather than an official statistician's perspective on measuring sustainable development progress. Many of the briefs follow the spirit of transdisciplinary approaches and are firmly located within sustainability science.

Most of the briefs stayed primarily at the empirical and descriptive level, with only minimal normative elements, in great contrast to most briefs typically prepared by NGOs and UN entities in support of UN deliberations.

Figure 7-3 provides a network overview of all the briefs submitted by scientists and their coverage of the 17 SDGs. Submitted briefs (denoted as circles) are connected to those SDGs (denoted as squares) that they addressed. Larger circles represent briefs that cover many SDGs. Larger squares indicate SDGs that are addressed in many of the submitted briefs. The network is drawn so as to highlight in the middle the nodes that are most central to the "system". In other words, SDGs that were considered systemically most central by the whole group of scientific contributors are presented in the middle. ${ }^{553}$ Central themes of many briefs are growth and employment (SDG8), means of 
implementation (SDG17), peaceful and inclusive societies (SDG16), poverty (SDG1) and terrestrial ecosystems (SDG15). Education (SDG4) and gender (SDG5) are clear outliers on the periphery with only few connections. There were also few briefs that connect the topics of health (SDG3), water (SDG6), or oceans (SDG14) with other SDGs. Many briefs focused on clusters of SDGs, such as SCPgrowth-employment-infrastructure-industrialization, energy-water-climate, poverty-health-hunger-inequalityoceans.

Figure 7-3. Overview of 182 briefs provided by scientists and their coverage of the 17 SDGs

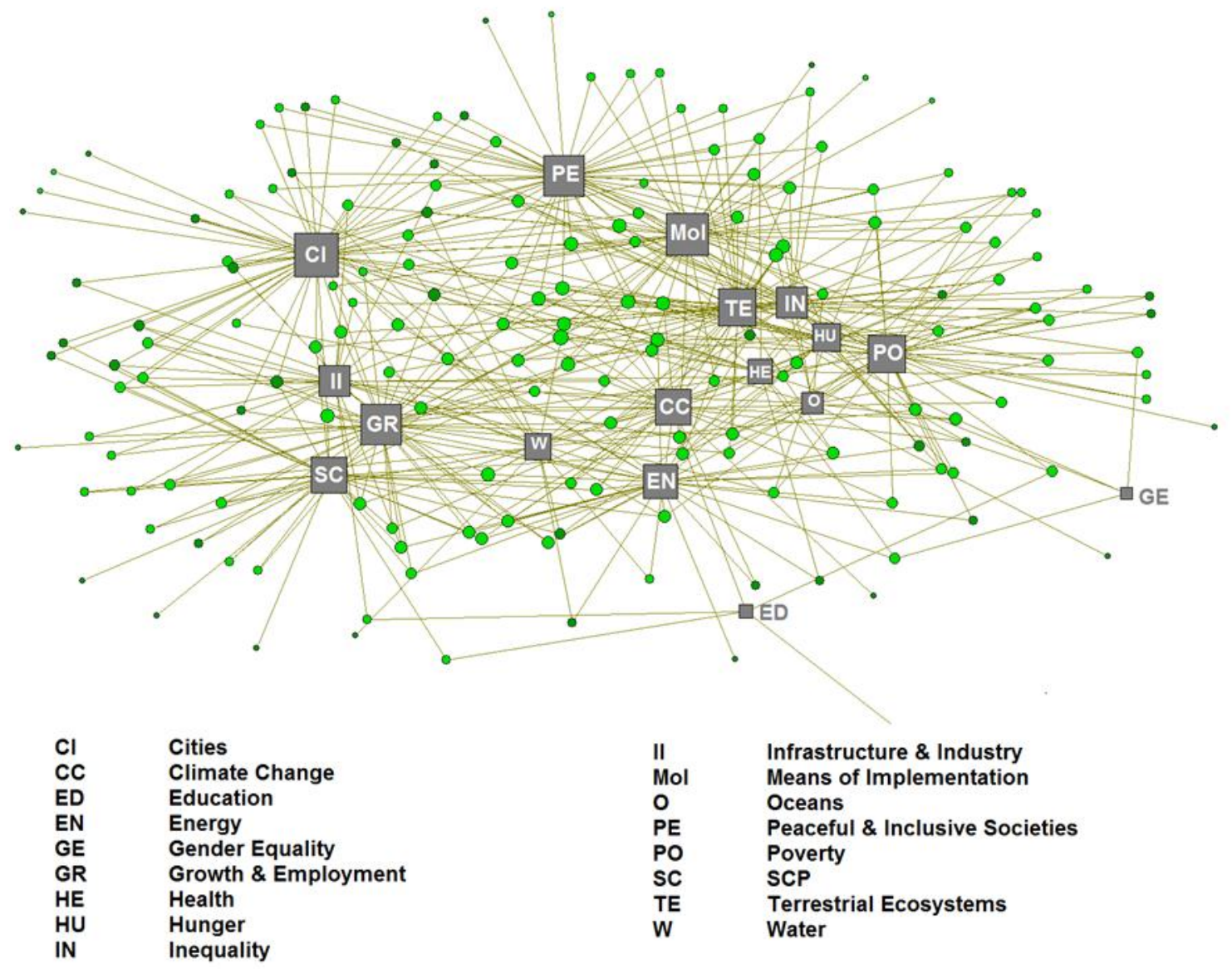

Note: Submitted briefs (denoted as circles) are connected to those SDGs (denoted as squares) that they addressed. The size of the nodes is proportional to the number of links connected to the node ("all degree"). Dark green circles indicate Chinese language briefs, whereas bright green ones indicate all other languages. The network of briefs and their coverage of SDGs is presented in a Kamada-Kawai projection. It allows identification of the central SDG nodes and of clusters of the SDGs that are typically covered in an integrated in manner in some of the briefs.

\subsection{Highlights from the submitted science briefs}

This section sets out some of the main contours of the science briefs, referring to selected brief for illustrative purposes and relating findings to the SDG framework. Accordingly, the views summarized below are attributable to the respective authors of the briefs.
Dark green circles in Figure 7-3 indicate briefs submitted in Chinese language, whereas bright green ones indicate all other languages. It is important to note that, if the briefs submitted in Chinese language are excluded, the set of briefs is much more in line with the issues presently on the UN agenda. In this case, most central are the "means of implementation" (including technology, finance, trade and capacity building) (SDG17) and cities (SDG11). Poverty (SDG1) and peaceful and inclusive societies (SDG16) are captured by many briefs, but few briefs treat them as part of a cluster of issues. 
of the poor and vulnerable, e.g. a brief that looks critically at whether community-based climate adaptation projects are prone to capture by elites and fail to benefit the poor. ${ }^{554}$ Tackling a specific manifestation of poverty, a brief on child poverty explains that, despite mounting evidence of its multiple facets, efforts to track progress towards the reduction of child poverty lack reflection of its complexities. ${ }^{555}$ With an estimated 569 million children below the age of 18 years in low- and middle-income countries living in extreme poverty, measurement and monitoring efforts still fall short, resulting in policy efforts being misdirected or providing an inadequate response. Arguing that pastoralism is a livelihood form uniquely suited to drylands, one brief argues that long-term marginalization of pastoralists has resulted in lack of access to productive assets and basic services, dependence on aid, food crises and conflict. ${ }^{556}$ While insightful, the briefs received arguably do not capture the breadth of research and thinking on poverty and development, possibly a result of a paucity of responses from the relevant research communities, primarily in the social sciences.

\subsubsection{Agriculture, hunger and food security}

Agriculture and food systems face enormous challenges feeding a world population of nine to ten billion, making more efficient use of water and fertilizers, and adapting to climate change. These issues are addressed in a range of briefs. For instance, a brief on agricultural transformation points out the need to leverage agriculture to meet health and nutrition goals, noting that more than 840 million people remain chronically undernourished and two billion people face micronutrient deficiencies that inhibit mental and physical development. ${ }^{557}$ Another brief outlining the conditions for sustainable intensification of agriculture calls, among other things, for large, sustained investments in agricultural research, which, it notes, has high rates of return in both developed and developing countries. ${ }^{558}$ Also against the backdrop of meeting increased food needs, another brief examines two alternate agricultural paradigms: industrial agriculture dependent on agrochemicals, fuel-based mechanization and irrigation, and sustainable, low external input agriculture centred on preservation of soil organic matter (SOM). ${ }^{559}$ Likening the heavy and routine use of fertilizer to an addiction, the brief contends that the continuous use of industrial practices destroys organic matter, with the effect of decreasing fertilizer efficiency, leading to the application of yet more fertilizer.

\subsubsection{Health}

In relation to health, several science briefs address issues relating to the emergence of infectious diseases and the risks arising from antibiotic resistance. Both issues are fairly "settled" in the scientific community in that they have serious implications for public health. For example, antibiotic resistant infections cause an estimated 700,000 deaths annually. ${ }^{560}$ And while the message from the scientific community is that the situation is set to worsen, the issue has not emerged fully on the policy agenda, with largely piecemeal action at the national level. By contrast, a policy concern that came strongly to the fore in the SDGs, around non-communicable diseases (NCDs), is not covered in the science briefs.

The recent Ebola pandemic has brought to the fore the need for improved surveillance, international coordination and response, as well as the consequences of poorlyresourced national health systems. The linkage between gender, health and energy access is reflected in briefs approximately 300,000 deaths, 88 per cent of which are women, are attributed to burns resulting from traditional cooking fires. ${ }^{561}$ The briefs explore interlinkages between energy and air pollution, but there was little coverage of health and hazardous chemicals and water and soil pollution.

\subsubsection{Education}

On the issue of education, one brief highlighted the impact of early childhood development, a policy priority reflected in SDG target 4.2. Thus a brief cites research findings that nutrition and parenting stimulation interventions for infants and toddlers resulted in impacts 20 years later, in the form of higher $\mathrm{IQ}$, reduced anxiety, depression and violence, and 50 per cent higher earnings. ${ }^{562}$

Other messages from the briefs are the need to mobilize institutions of learning more effectively as agents to promote trans-disciplinary research and build capacity on sustainable development. ${ }^{563}$

\subsubsection{Gender equality and empowerment of women} In relation to gender equality and empowerment of women, the briefs touched on the dimension of natural resource management, for instance highlighting the imperative of seeing the role of women in water management beyond domestic uses and training and building the capacity of women so that they can have more active leadership roles in water management systems. ${ }^{564}$ In the area of energy, there is a similar need to increase the 
percentage of women holding a leadership or management position in the sector. ${ }^{565}$

\subsubsection{Water and sanitation}

Several of the briefs underlined the tight inter-relationship between water issues and other issues covered in the SDGs. Water, energy and land resources are all interconnected. One brief pointed out that agriculture and industry (including energy) account for 70 per cent and 22 per cent of global water withdrawals, respectively, while 7 per cent of all energy is used for water supply and 4 per cent of energy is directly used in agriculture. ${ }^{566}$

The plight of smallholder farmers in sub-Saharan Africa highlights the linkage between agriculture, water access and poverty eradication. In this respect, one of the briefs notes that in sub-Saharan Africa the area equipped for irrigation is a small fraction - 3.2 per cent in 2006 - of the total cultivated area. ${ }^{567}$ The recommended policy options include increasing investment in sustainable water infrastructure (from small scale to large scale) and technologies to augment water supply, as well as guaranteeing water and land rights for poor smallholder farmers.

With SDG target 6.3 addressing water pollution and safe reuse of wastewater, one of the briefs states that at present 92 per cent of sewage generated in low-income countries and 72 per cent in lower middle-income countries is discharged in untreated form to water courses. ${ }^{568}$ While safe and regulated use of wastewater is the case in some regions, the brief notes that informal irrigation with raw or diluted wastewater all too often remains the norm, representing up to 90 per cent of all current wastewater use.

A number of briefs examine the nexus between energy (SDG7) and water resources (SDG6), using modeling frameworks, such as TIMES-Water model, to forecast the peak year of water demand and simulate the impact of water cost on energy structure. ${ }^{569}$ Applications of other approaches, such as Water Ecological Footprint Model, are also described in this context.

\subsubsection{Energy}

Many briefs make explicit reference to energy, identifying it as a key condition to guarantee access to clean water, sanitation, schooling and overall a key factor for growth and development. $^{570}$ In relation to the commitment to universal access, one brief notes that current financing falls far short of the estimated requirements - only $\$ 9$ billion of an estimated $\$ 45$ billion required annually - and that without ramped-up efforts very large numbers of persons will be left without access to electricity in $2030 .^{571}$

In relation to influencing household-level energy use, one brief outlined applicable strategies, including the design of user-centered energy monitoring tools to inform household decisions, for instance by making energy use "visible", as well as taking into account the social and cultural factors that influence household energy practices. ${ }^{572}$

Several briefs addressed questions related to the supply side. The authors of one brief - arguing that the continued dominance of hydrocarbons in the energy mix is the result of a lock-in of fossil fuel energy systems - point out that 6.9 per cent of the total energy produced by the oil and gas industry is consumed by the industry itself. ${ }^{573}$ They conclude that there exist a range of feasible short-term options to cut emissions from the extraction and transformation industry, such as curbing gas flaring and improving refining efficiency. Noting the continued trend towards drilling in deeper and more environmentally sensitive areas, one brief points out that there is no international convention on the safety of offshore drilling activities. $^{574}$ Moreover, the authors noted that there exist no global rules regulating liability and compensation for pollution damage resulting from offshore drilling activities.

In relation to new energy technologies, one brief explores a new and largely untested renewable technology, so-called 'Blue Energy' or 'Salinity Gradient Power' (SGP). ${ }^{575}$ This technology seeks to exploit energy obtained by the controlled mixing of a stream of saltwater (e.g. seas) and a stream of less saline water, treated wastewater, or fresh river water.

\subsubsection{Economic growth and employment}

The briefs relevant to economic growth and employment also cut across industrialization and infrastructure, as well as sustainable consumption and production.

In the context of renewed debate around innovation, an interesting perspective comes from exploring the role of community-based digital fabrication facilities that enable the development and production of custom-made things which are not accessible by conventional industrial scale technologies. $^{576}$ Such tools have the potential to democratize access to technology and permit communities to participate in creating their own technological tools. 
A number of briefs tackle the issue of transition, some within the prevailing paradigm, others exploring recognized but less mainstream approaches. For instance, the key messages of the brief on deep decarbonisation pathways for achieving the 2 degree climate change goal are outwardly reassuring, e.g. options can be achieved with existing technology, albeit only with international cooperation to ensure the deployment of low-carbon technology at scale. ${ }^{577}$ Structural change is mentioned, as is the need to alter consumer behaviour, but are not central to the analysis. Addressing the transition problem from a different, system-wide mode of analysis, the authors of another brief argue that absolute decoupling of economic growth from resource use will not be politically viable without at least stabilizing or increasing employment. ${ }^{578}$ In their analysis, the environmental constraints to continued growth in material and energy use are such that options such as the reduction of average labour time, structural changes to a service/recycling economy, new models of wealth, lifestyle changes and sufficiency policies have to be taken into account. Examining the conditions for a transition to a non-growth oriented economy, the authors of another brief highlight the most important entry points as diversity of employment forms, ecologically and socially responsible economic actors, community spirit, and conscience-based education. ${ }^{579}$

\subsubsection{Industrialization and infrastructure}

Drilling down to the firm level, a brief on industrial symbiosis - mutually beneficial relationships between two or more industrial firms, e.g. where the waste from one is a resource for another - provides an example of tools that can put decoupling into practice. ${ }^{580}$ Robust industrial systems show features of complex adaptive systems rather than centrally planned models, thus complicating policy interventions designed to promote industrial symbiosis.

In setting out the tenets of a "new" industrial policy, the authors of one brief argue, among other things, that it should downgrade or abandon the concept of price competitiveness, which emphasises low costs (or low unit labour costs). Instead, competitiveness should be defined as the "ability to achieve beyond-GDP goals". ${ }^{581}$ In a similar vein, another brief on industrial policy argues that investment support should be channelled to companies that fulfil not only criteria such as generating tax revenues and backward and forward linkages to existing business sectors, but also social and environmental norms. ${ }^{582}$
7.3.10. Sustainable consumption and production (SCP) The linkages between emissions from agriculture and livestock rearing, on one side, and food consumption patterns, on the other, are sketched out in a brief that touches on health and sustainable consumption and production. ${ }^{583}$ The authors point out that in many countries per capita caloric consumption is, on average, about 500 kcal per day (or 20 per cent) greater than needed - curbing this overconsumption would have obvious health benefits, but would also mean that the production of these calories and the attendant resources could be re-directed or avoided. With respect to food waste - an issue addressed in SDG target 12.3 - the brief states that 30 to 40 per cent of food is wasted due to losses in storage and transport, and lack of portion control. Finally, dietary choices also have an impact.

Emissions from plant-based foods for human consumption are on average smaller than for meat, because the efficiency of producing food calories or protein can be four to twenty times greater without the intermediate step of feeding livestock. A brief analysing voluntary sustainability standards in agriculture points out that they provide - in the absence of state intervention - a valuable public good, in the form of codified and verifiable market mechanisms that communicate key aspects of sustainability. Yet, the brief also acknowledges that there are questions about whether existing initiatives help the poorest. ${ }^{584}$

\subsubsection{Cities and human settlements}

A large number of briefs relate to human settlements, either addressing systemic issues, such as the provision of public housing ${ }^{585}$, or providing case studies on local development. ${ }^{586}$ Cities present in essence a microcosm of the whole agenda, especially in relation to issues such as poverty eradication, provision of basic services, disaster risk reduction, climate change, and governance. Several briefs make the case for alternative methods of analysis, which are less expert-led and more transdisciplinary. An example is the call to consider urban biodiversity not only in terms of ecosystem services, but also through the lens of biocultural diversity (BCD), which aims to examine the linkages between cultural diversity and biological diversity and what these mean for nature. ${ }^{587}$ Similarly, addressing the way forward for disaster risk reduction, a brief on the topic argues that building long-term resilience to environmental risks requires a fundamental shift away from current topdown and expert-driven governance approaches, too heavily influenced by vertical networks of power and influence and an excessive focus on technological quickfixes. $^{588}$ A brief on public housing for the poor - a quintessential issue in cities - makes the case for integrating social equity in the analysis of the built 
environment, in order to make stronger progress on climate goals. ${ }^{589}$ This entails broadening the perspective to consider not only technical efficiency of a design, but also what social and environmental goods were both consumed and produced.

\subsubsection{Climate change}

A brief on adaptation and resilience classifies climate change as a "super wicked problem" - resistant to the usual disciplinary approaches that have long been the basis for policy making because its causes are complex and subject to different interpretations according cultural values and beliefs. ${ }^{590}$ Challenging the predominance of top down policy, the brief makes the case for a resilience approach, characterized by organizations and institutions that can conceptualize, anticipate, and learn from change over time. Another brief contains a critical appraisal of community-based adaptation - popular with donors arguing that this approach ignores unequal access to livelihood resources and land tenure, inequitable participation in decision-making processes, and political disenfranchisement and elite capture. ${ }^{591}$ In this case the concerns raised also touch on other SDG targets, for instance target 10.2 on empowerment and target 16.7 on participatory decision-making. A brief calling for a greater peer review capacity in African climate change science addresses the science-policy interface and the production of knowledge. ${ }^{592}$ The brief notes that the dearth of peerreviewed scientific journals in Africa may have created the perception amongst African policymaking institutions that Western and Northern climate change science remains divorced from African realities and issues; the science may be credible, but it lacks salience and legitimacy, which are keys to its utilization by policy makers. Also addressing questions of knowledge, a brief on the contribution of anthropology (and social scientists more broadly) argues that efforts to examine and respond to the adverse impacts of human practice on nature and, conversely, of environmental degradation on humanity, have to be a multi-disciplinary. ${ }^{593}$ It concludes, among other things, that sustainable human development should take into account variation in cultural values and knowledge around the world, both as an asset and as a potential impediment to sustainability programmes.

According to one brief, in 2007, before the global economic downturn, international shipping is estimated to have emitted 885 million tonnes of $\mathrm{CO}_{2}$, which represented 2.8 per of the global emissions of $\mathrm{CO}_{2}$ for that year. ${ }^{594}$ At the same time, shipping is the principal carrier of world trade, carrying as much as 90 per cent by volume. The authors state that technical and operational measures could increase energy efficiency of ships by 25 to 75 per cent.

\subsubsection{Oceans}

A brief on oceans reviews the science behind an emerging marine ecosystem management approach - the implementation of paired secure-access fisheries and conservation areas. ${ }^{595}$ One of the findings in the brief is that, contrary to expectations, restrictions on fishing do not necessarily negatively affect the local economy. Instead, reforming fisheries in tandem with implementing no-take marine reserves can improve both ecosystem health and economic well-being of coastal communities, one reason being that fisheries output can improve due to the 'spilling over' of greater numbers of fish from inside marine reserves. A brief on coastal systems explores the impacts of aquaculture, which is on the rise due to sharply declining wild fisheries and increased consumption of fish products. $^{596}$ The brief states that it is estimated that emissions from aquaculture could account for 5.72 per cent of anthropogenic nitrous oxide emissions by 2030, if the industry continues to increase at the present annual growth rate. A brief on micro-plastics - small pieces of plastic found in the ocean, commonly defined as less than 5 $\mathrm{mm}$ in diameter - outlines the science around this form of marine pollution, which threatens a range of marine organisms. $^{597}$ According to the authors, one reason for concern is that due to their small size micro-plastics tend to accumulate persistent, bio-accumulating and toxic contaminants such as PCBs, DDT and PBDEs. Among the policy options suggested in the brief are improved understanding of sources of plastics and modelling of their distribution, as well as their inclusion in overall waste reduction strategies. Also addressing an emerging threat to ocean ecosystems, a brief on ocean acidification notes that, while the chemistry of ocean acidification is generally well understood from observations and models, its potential consequences on marine organisms are inherently more complicated. ${ }^{598}$ While curbing $\mathrm{CO}_{2}$ emissions is the only way to halt ocean acidification, the authors suggest that actions can be taken, especially at local levels, to increase ecosystem resilience, including sustainable fisheries management practices and control of localized sources of acidification from river runoff and pollutants such as fertilizers. Another brief outlines research that used satellite derived sea-surface temperatures to identify areas where coral reefs are likely to be best acclimated to stress and subjected to relatively mild acute bleaching events. ${ }^{599}$ 
The authors state that this mapping could help to locate marine protected areas (MPAs) in locations with a more benign physical environment. In addition to acidification and ocean warming, a third major stressor is decreased oxygen concentrations in the ocean, leading to so-called "dead zones". A brief examining this issue contends that oxygen levels can recover, even in severely depleted areas, but doing so will require dramatic increases in fertilizer-use efficiency. ${ }^{600}$

\subsubsection{Terrestrial biodiversity}

In the context of biodiversity, a brief urging the adoption of a strong sustainability position rejects the argument that natural capital can be readily substituted by manufactured capital. ${ }^{601}$ In the process, the brief analyses the case for designating certain elements of natural capital as "critical", due to their unique contribution to human well-being. In defining what is critical "objective" ecological criteria, e.g. maximum sustainable yield, are not conclusive; societal values and perceptions, ethics and attitude to risk also play important roles in the determination of what aspects of natural capital can be considered critical. Thus, the authors contend, it is necessary to move beyond solely technical and expert-based calculations of critical thresholds of natural capital to include public deliberation and stakeholder participation. Examining wetlands in drylands, a brief raises the question whether the findings of scientific studies focussed on the more-or-less permanentlysaturated tropical, temperate and arctic wetlands can be readily transferred to drylands. ${ }^{602}$ Gaps in understanding for instance whether wetlands in drylands are stores of carbon through incorporation of atmospheric $\mathrm{CO}_{2}$ - hamper the resolution of potential conflicts and maximization of ecosystem service provision for the widest possible benefit. A number of briefs address species survival, e.g. the potential of joint research and policy to save a South American tree species from an exotic tree disease. ${ }^{603}$ What may at first appear to be a local or regional problem is in fact directly connected to global scale processes: emerging plant diseases are on the rise, and they often appear to be linked to the commercial trade of plants and plant products. New technologies frequently give rise to discussion about benefits, risks and appropriate regulation - a process played out in particularly contentious terms in the case of biotechnology. While favouring greater adoption of genetically modified organisms (GMOs), a brief on the topic reminds us that developing countries, particularly in Africa, lack the requisite capacity to carry out adequate risk assessments and to establish and enforce regulatory frameworks that serve their interests. ${ }^{604}$ Addressing another aspect of biotechnology, a brief argues that the demand for sustainably intensifying yields, in the face of a changing climate, calls for the acceleration of plant breeding and the sharing of genomic information. ${ }^{605}$ The authors propose that genome sequence information and related data on genetic diversity from publicly funded repositories and other stakeholders be made freely available as a public good, through a licence for genomic information on germplasm. Assessing the potential of synthetic biology - the construction of customized biological systems to perform new and improved functions - another brief also calls for open source development models and platforms that direct research and resources to sustainable development challenges. ${ }^{606}$ Many of the briefs addressing biodiversity-related issues also have strong linkages with poverty eradication, agriculture, science and innovation, and institutions and governance.

\subsubsection{Peace, inclusive societies, justice and institutions}

Although a number of briefs touch on issues related to governance, institutions, peaceful societies, and the rule of law, the coverage is limited, despite this being an active area of research. It may be that the call for briefs did not reach the communities most implicated in this area of research. In relation to participatory decision-making, research highlighted in one of the briefs suggests that opportunities for community decision-making through enhanced participation entail transaction and opportunity costs that constitute a disincentive for involvement of the poor. ${ }^{607}$ Among the conclusions of the brief is that because empowerment interventions do not themselves facilitate sustainable outcomes - sustainability criteria ought to be built into community interventions. In examining the role and potential of global online consultations, another brief concludes that the use of this tool can best be deployed by: (i) systematically combining not only direct with representative participation, but also web-based with offline methods to bypass the digital divide; and (ii) by building civil society actors' capacities. ${ }^{608}$

\subsubsection{Means of implementation, global partnership} While a number of briefs address issues related to means of implementation and strengthening the global partnership, there is limited coverage of core concerns such as finance and trade. Technology crops up in a range of briefs, for instance in relation to the growth-SCP-energy cluster of issues, but there is little if any engagement with questions around the conditions and mechanisms for 
technology transfer. Respect for each country's policy space - for instance articulated in SDG target 17.15 - finds expression in a brief arguing that Latin America needs an alternative development model rooted in the continent's particular experience, one that represents a shift away from the unsustainable primary commodity export model. ${ }^{609}$ The issue of multi-stakeholder partnerships finds little if any coverage in the collection of briefs. By contrast, a number of briefs highlight issues of data, measurement and monitoring, including measures that complement gross domestic product. Thus a brief on monitoring the performance of food systems points out that metrics are frequently inadequate or contradictory, and that there are differences in methodologies and definitions for even basic measurements of crop yields, prevalence of poverty and hunger. ${ }^{610}$

\subsubsection{Briefs in Chinese language}

Almost one quarter of the crowdsourced briefs were submitted in the Chinese language (Figure 7-1), warranting a separate analysis. ${ }^{611}$

The Chinese briefs targeted many pertinent topics, mainly on environmental and economic domains within national and local context, and addressed a wide spectrum of issues within the SDG framework, including urbanization, SCP, energy and water sustainability (Figure 7-4) - many of which are major challenges in China's efforts to build an "ecological civilization". Topics range from carbon footprint analysis of radial car tires, to the wellbeing of migrants relocated due to hydropower plants, to issues in densely populated mega-cities, through to fine particle emissions from coal-fired power plants. Some briefs used entropy and similar measures from the natural sciences. Some highlighted the experience in sustainable development experimental zones somewhat following the earlier model of special economic zones.

Figure 7-4. Coverage of SDGs by all submitted briefs vs. those in Chinese language

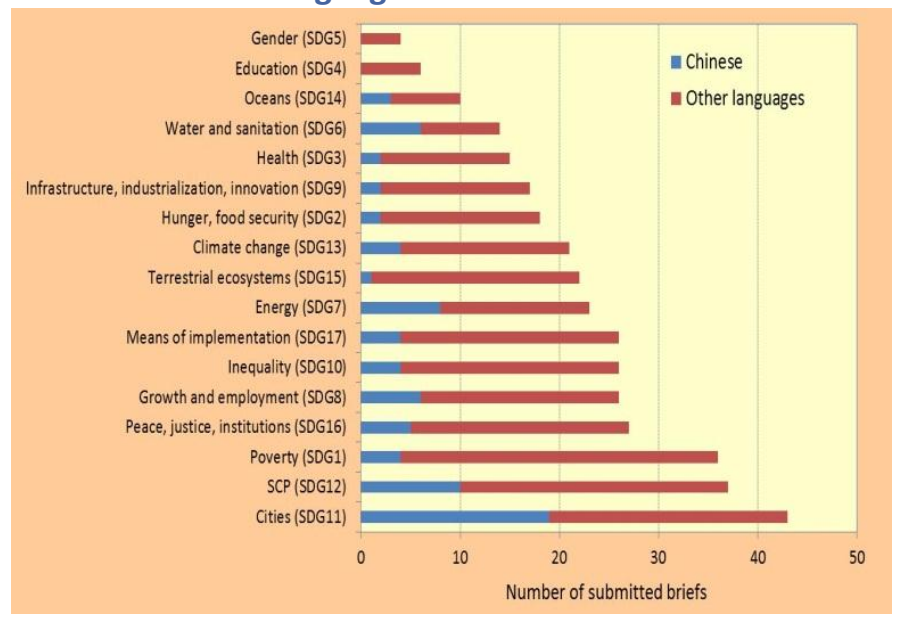

Exploring inter-linkages between poverty alleviation and ecological capital, on the basis of vulnerability analysis, some briefs focus on ecologically fragile areas and illustrate various pathways of poverty alleviation such as ecological capital management, establishing an ecological capital investment mechanism, as well as ecological compensation mechanisms for poverty alleviation. A number of briefs reported on the use of models of the nexus between energy and water resources. A Water Ecological Footprint Model was also presented. About half the briefs in Chinese discussed the application of sustainability principles in the urbanization process in various contexts ranging from small towns to megacities. Lessons learned from several national sustainable development experimental zones were shared, including on the local use of integrated environmental assessments and indicators which have become increasingly common. Many briefs proposed ways and means to reduce material and energy consumption. Some The briefs reported on the results of life cycle assessments (LCA) to assess products' carbon footprints and GHG reduction potentials. For example, they found that the use of car tires contributed $80 \%$ of the carbon footprint, compared to $20 \%$ related to their production. Some briefs discuss governance aspects, trade-offs, and their link to conflicts (SDG16), including in the context of accelerated urbanization. The authors suggested balanced approaches for land transfer and ecological and intergenerational compensation.. Using entropy measures and combining socio-economic and environmental data, authors showed the improving sustainable development of the Bohai Sea region.

In summary, the briefs submitted in Chinese provide a wealth of ideas, findings and approaches, many with specific applications to China.

\subsection{Selected sustainability science highlights from academic journals}

Besides an open call for contributions, various other expertbased methods exist to identify issues that scientists may want to bring to the attention of decision-makers. One of them is horizon scanning which refers to a "structured and continuous activity aimed to monitor, analyse and position 'frontier issues' that are relevant for policy, research and strategic agendas. The types of issues mapped include new/emerging trends, policies, practices, stakeholders, services/products, technologies, behaviours/attitudes, 'surprises' (i.e. wild cards) and 'seeds of change' (i.e. weak signals)". 612 
More than a thousand horizon scanning exercises have been undertaken worldwide in recent years - most of them by the European Union and its member States. Almost all of them focus on rather narrow areas and disciplines. ${ }^{612}$ In its simplest form, horizon scanning can be based on a fixed set of highly-authoritative peer-reviewed academic journals. For the purpose of the GSDR, criteria such as the following might be used for selection:

- Major breakthrough in knowledge or technology, or providing a completely new perspective on a well-known issue

- Potentially high impact on sustainable development (in positive or negative terms) and global significance (possibly with impacts across themes or dimensions)

- Greatly increased scientific interest in the issue (starting from a low base)

- Calling for or implying the need for policy action or for new sustainable business opportunities

- $\quad$ Long-term significance at least up to 2030.

Due to resource constraints, it was not possible to complete a comprehensive horizon scanning for the present report. However, it might be considered for future editions of the Report. Next we present selected results from a very limited horizon scanning exercise based on the most recent issues of Science, Nature, Science Advances, and the Sustainability Science Section of the Proceedings of the National Academy of Sciences of the United States of America. Interestingly, the issues identified differ in significant ways from those identified in the open process. $^{613}$

A rapid loss of lakes in the Mongolian plateau has been documented with a satellite-based survey, threatening the livelihood of local people in the region. The number of lakes with a water surface area greater than $1 \mathrm{~km}^{2}$ decreased from 785 in the late 1980s to 577 in 2010. The decrease has been most rapid since the late 1990s in Inner Mongolia and the number of lakes greater than $10 \mathrm{~km}^{2}$ has declined by 30 per cent. Changing precipitation was the main driver of change in Mongolia, whereas coal mining was the most important factor in Inner Mongolia in grassland areas and irrigation in cultivated areas. The deterioration of lakes is expected to continue in the following decades. The scientists call for "urgent action". ${ }^{614}$
A first global map of antimicrobial use in food animals has been created. Antimicrobials are used to sustain health and increase productivity, but can lead to drug-resistant pathogens in both livestock and humans. The global consumption of antimicrobials is expected to increase by 67 per cent, from 63,151 tons in 2010 to 105,596 tons in 2030. A third of the increase is due to shifting production practices in middle-income countries from extensive to intensive farming operations. Scientists "call for initiatives to preserve antibiotic effectiveness while simultaneously ensuring food security in low- and lower-middle-income countries."

Large-scale emotional contagion was demonstrated among a set of 689,003 Facebook users. It showed that emotional states can be transferred to others via emotional contagion, leading people to experience the same emotions without their awareness. Emotional contagion occurs without direct interaction between people (exposure to a friend expressing an emotion is sufficient), and in the complete absence of nonverbal cues. ${ }^{616}$ This has important implications on the effectiveness of policies that aim to change consumer behaviour.

Global map and a first order approximation of the magnitude of the plastic pollution in surface waters of the open ocean. The global load of plastic on the open ocean surface was estimated to be on the order of tens of thousands of tons, far less than previously expected (Figure 7-5). The size distribution of floating plastic debris points at important size-selective sinks removing millimeter-sized fragments of floating plastic from the surface on a large scale. As these plastics at various sizes have effects on organisms ranging from small invertebrates to whales, much more work is needed to understand the underlying dynamics and their ecosystem impacts. ${ }^{617}$

The first signs of the carbon sink of Amazon forests levelling off have been spotted. The carbon sink in the land biosphere has grown during the past 30 years, taking up much of the carbon dioxide produced by human activities. This was primarily due to higher $\mathrm{CO}_{2}$ concentrations in the atmosphere. However, this growth has now levelled off, indicating approaching saturation. ${ }^{618}$ It is an indication that atmospheric $\mathrm{CO}_{2}$ concentrations might increase faster in the future than previously expected. 
Figure 7-5. Concentrations of plastic debris in surface waters of the global ocean

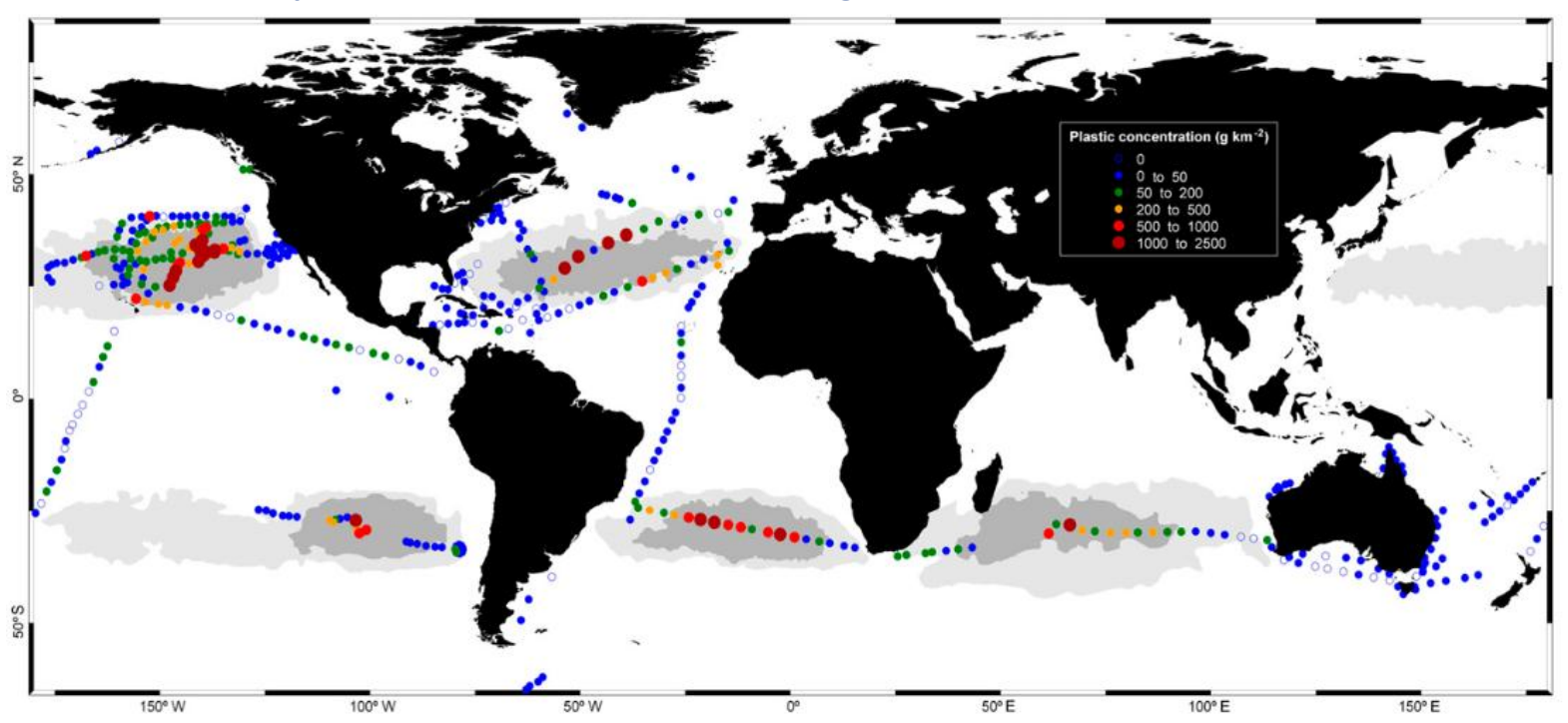

Source: PNAS (2015). ${ }^{617}$

Notes: The coloured dots indicate the level of plastic concentration where they were measured.

The first large-scale neuromorphic chips have been demonstrated. They are designed to process information in ways more akin to living brains. The brain's network of 100 billion cells linked by 100 trillion synapses still dwarfs anything neuromorphic chips can muster. But a new chip ${ }^{619}$ includes 5.4 billion transistors and 256 million "synapses," and there is work to tile multiple chips together to build more complex networks. In the future, brain-like processors could transform fields such as machine vision and environmental monitoring, integrating real-time data from sensors from around the globe. ${ }^{620} 621$

A global synthesis of habitat fragmentation over the past 35 years demonstrated that such fragmentation reduced biodiversity by 13 to $75 \%$ and impaired key ecosystem functions by decreasing biomass and altering nutrient cycles. Global forest cover analysis revealed that $70 \%$ of remaining forest was within $1 \mathrm{~km}$ of the forest's edge. Effects have magnified over time, indicating a need for conservation and restoration measures to improve landscape connectivity. ${ }^{622}$

Carbon dioxide emissions from the global energy sector remained flat in 2014, even though the world's economy grew by $3 \%{ }^{623}$ This is the first time in 40 years that global $\mathrm{CO}_{2}$ emissions have not increased in the absence of an economic downturn. Global efforts to reduce emissions, increased energy efficiencies, the oil and gas fracking expansion in North America, and the expansion of renewable energy in China may have had a sizable impact.

An efficient solar-to-fuels production from a hybrid microbial-water-splitting catalyst system has been demonstrated. The scalable bio-electrochemical system converts $\mathrm{CO}_{2}$, along with $\mathrm{H}_{2}$ and $\mathrm{O}_{2}$ produced by water splitting using solar energy, into biomass and fusel alcohols, using the bacterium Ralstonia eutropha. Water-splitting used catalysts made of earth-abundant metals. The achieved (equivalent) solar-to-biomass yields of up to $3.2 \%$ of the thermodynamic maximum exceed that of most terrestrial plants. Engineered Ralstonia eutropha produced fusel alcohol isopropanol at up to $216 \mathrm{mg} /$ litre which is the more than three times the highest previously reported bioelectrochemical fuel yield. This may lead to solar to fuel systems for transportation that actually reduce $\mathrm{CO}_{2}$ in the atmosphere. $^{624}$

Wheat yields in India in 2010 were on average 36\% lower than they would have been in the absence of climate and pollutant emissions trends, with some densely populated states experiencing relative yield losses of $50 \%$. Short-lived climate pollutants, especially tropospheric ozone and black carbon, have direct effects on crop yields beyond their indirect effects through climate. This direct effect was found to account for $90 \%$ of the relative wheat yield losses. ${ }^{625}$

Another approach to identifying trends is based on analysis of citations of scientific publications on key issues or "research fronts". A publication by a news and database service has prepared a report with a total of 144 research fronts, classified into 10 broad research areas in the sciences and social sciences, of which four (agricultural, plant and animal sciences; ecology and environmental sciences; geosciences; and economics, psychology and other social sciences) are of greatest relevance to sustainable development. ${ }^{626}$ Among the most cited papers were ones covering: foodborne diseases and economic 
losses; predicting species distribution using a modelling tool; application of regional climate models in the prediction of surface temperature and precipitation; model analysis of non- $\mathrm{CO}_{2}$ greenhouse gases; bio-diesel performance and emissions; mobile health technology; and African schistosomiasis control and drug research.

\subsection{Big data applications for sustainable development}

So-called "big data" is another area in which scientists have applied new tools to provide information and analysis on aspects of sustainable development. Much of this emerging work lies outside the official statistics systems and employs approaches from the natural sciences to analyse social, economic and environmental questions. While chapter 8 of the present report provides a more in-depth account of applications of big data in the specific case of Africa, here we provide a glimpse of the emerging broad picture of big data applications for sustainable development.

"Big data" have been defined along divergent lines. According to one definition, big data are: high in volume, velocity, and variety; exhaustive in scope; fine-grained in temporal or spatial resolution, and inherently relational. ${ }^{627}$ Data might be user-generated (e.g. call records data, Twitter, Flickr), gathered by sensors (e.g., satellites, videos), or draw on data repositories made public by governments or corporations (e.g. real estate prices, subway records). Table 7-5 provides an overview of the wide range of emerging big data applications and how they can support the whole range of SDGs at various geographical and time scales. At present, big data applications tend to be used in sectors that are either correlated with big data production of some kind, or that are currently monitored through traditional means. Some uses, such as for environmental or land-use monitoring through satellite data analysis have become commonplace. ${ }^{634}$ Others like monitoring illegal fishing with satellites or literacy with cell phone records have just started.
"Big" may refer to gigabytes, terabytes or even to petabytes. $^{628}$ It is important to note that natural scientists have long used these methods for production and analysis of scientific data. However, their diffusion into corporations and the social sciences has attracted great attention by the wider public and earned the new label "big data". Recently big data has been described as a complex ecosystem of data crumbs, capacity (tools and methods, the hardware and software requirements) and community (producers and users of the data crumbs and capacities). ${ }^{629}$

The geographies of user-generated information are very uneven between and within countries, and informational poverty has increased in some places. ${ }^{630}$ In contrast, many data gathered via sensors show a geographic coverage that does not stop at national borders. For example, satellite data is often global in scope - leaving no country "data poor", even though socio-economic, infrastructural, and educational barriers to using these data remain.

In the context of the SDGs, recent deliberations at the UN have focussed on the question of whether big data could contribute to the monitoring of progress and the effectiveness of policies, programmes and activities. $^{631,632,633}$ They are envisaged to complement official statistics. This is in contrast to the monitoring of MDGs which focussed exclusively on official statistics.

A number of big data sources may be representative only of particular segments of society. ${ }^{635}$ Data analysis methods are being developed that aim to correct for sample bias and various types of data gaps, and to separate the sought-after signals from noise. For example, a Twitter-mining algorithm used to detect changes in food prices in Indonesia predicted a food crisis where there was none. ${ }^{636}$ In the 2010 Haiti earthquake aftermath, social media data production was only weakly (and inversely) correlated with damage. 637638

Table 7-5. Big data applications in areas covered by the SDGs and in topics relevant for sustainable development

\begin{tabular}{|c|c|c|c|}
\hline SDGs & What is measured? & Data source & Geographic scope of application \\
\hline \multirow{4}{*}{ Poverty (SDG1) } & \multirow{2}{*}{ Poverty } & Satellite images (night-lights) ${ }^{639}$ & Global map \\
\hline & & Cell phone records ${ }^{640}$ & Côte d'Ivoire \\
\hline & Price indexes ${ }^{641}$ & Online prices at retailers websites & Argentina \\
\hline & Socio-economic levels & Cell phone records & City in Latin America ${ }^{642} ; \mathrm{UK}^{643}$ \\
\hline \multirow{4}{*}{$\begin{array}{l}\text { Hunger and food } \\
\text { security (SDG2) }\end{array}$} & Food price crises $^{644}$ & Tweets & Indonesia \\
\hline & Money spent on food ${ }^{645,646}$ & Cell phone data and airtime credit purchases & A country in East-Central Africa \\
\hline & Crop productivity $^{647}$ & Satellite images & Africa \\
\hline & Drought & Remote sensing & $\begin{array}{l}\text { Australia }^{648} \text {; Afghanistan, India, Pakistan } \\
\text { China }{ }^{640}\end{array}$ \\
\hline \multirow{5}{*}{ Health (SDG3) } & \multirow{3}{*}{ Influenza } & Online searches & US $^{651} ;$ China $^{652}$ \\
\hline & & Twitter & $\operatorname{Japan}^{653} ;$ US $^{654}$ \\
\hline & & Voluntary reporting through the internet ${ }^{655,656}$ & $\begin{array}{l}\text { Belgium, Italy, Netherlands, Portugal, United } \\
\text { Kingdom, United States }\end{array}$ \\
\hline & Malaria $^{657}$ & Cell-phone records & Kenya \\
\hline & $\begin{array}{l}\text { Population movements } \\
\text { during an epidemic }\end{array}$ & Cell-phone records & West Africa \\
\hline
\end{tabular}




\begin{tabular}{|c|c|c|c|}
\hline \multirow[t]{12}{*}{ SDGs } & What is measured? & Data source & Geographic scope of application \\
\hline & Cholera $^{659}$ & Social and news media & Haiti \\
\hline & Dengue ${ }^{660,661}$ & Web search queries & $\begin{array}{l}\text { Argentina, Bolivia, Brazil, India, Indonesia, Mexico, } \\
\text { Philippines, Singapore, Thailand, Venezuela }\end{array}$ \\
\hline & $\begin{array}{l}\text { Flu, gastroenteritis and } \\
\text { chickenpox }^{62}\end{array}$ & Online searches & France \\
\hline & Vaccine concerns ${ }^{663}$ & $\begin{array}{l}\text { Media reports (e.g., online articles, blogs, } \\
\text { government reports) }\end{array}$ & 144 countries \\
\hline & Illnesses & Twitter 664 & US \\
\hline & Vaccine concerns & Twitter & US $^{665} ;$ Indonesia ${ }^{666}$ \\
\hline & $\mathrm{HIV}^{667}$ & Twitter & US \\
\hline & & Twitter $^{668}$ & US \\
\hline & & Wastewater analysis ${ }^{669}$ & Europe \\
\hline & Drug use & $\begin{array}{l}\text { social media and web platform scans; emergency } \\
\text { room and poison centre calls; arrestee drug testing; } \\
\text { listservs }\end{array}$ & US \\
\hline & $\begin{array}{l}\text { Perceptions towards } \\
\text { contraception methods }^{671}\end{array}$ & Facebook and U-report & Uganda \\
\hline Education (SDG4) & Literacy $^{672}$ & Cell phone call and SMS records & Senegal \\
\hline \multirow{2}{*}{ Women (SDG5) } & Women's well being $^{673}$ & Twitter & Mexico \\
\hline & Discrimination of women ${ }^{674}$ & Twitter & Indonesia \\
\hline \multirow[t]{2}{*}{$\begin{array}{l}\text { Water and sanitation } \\
\text { (SDG6) }\end{array}$} & $\begin{array}{l}\text { Water flows, quality of } \\
\text { drinking water }\end{array}$ & $\begin{array}{l}\text { Precipitation measurements, water level and water } \\
\text { quality monitors, levee sensors, radar data, model } \\
\text { predictions as well current and historic } \\
\text { maintenance data from sluices, pumping stations, } \\
\text { locks and dams. }\end{array}$ & Netherlands \\
\hline & $\begin{array}{l}\text { Leaks, clogs and water } \\
\text { quality issues }\end{array}$ & Sensors & Singapore \\
\hline \multirow[t]{2}{*}{ Energy (SDG7) } & $\begin{array}{l}\text { Electric power } \\
\text { consumption }^{677}\end{array}$ & Satellite images & 21 countries \\
\hline & Energy use ${ }^{678}$ & Smart meters & Canada \\
\hline \multirow{6}{*}{$\begin{array}{l}\text { Economic growth } \\
\text { and employment } \\
\text { (SDG8) }\end{array}$} & GDP growth $^{679}$ & Satellite images & 30 countries; \\
\hline & GDP at sub-national levels ${ }^{680}$ & Satellite images & China, India, Turkey, US \\
\hline & Inflation $^{641}$ & Prices from online retailers & Argentina, Brazil, Chile, Colombia, Venezuela \\
\hline & \multirow{2}{*}{ Unemployment } & Blogs, forums and news ${ }^{61}$ & Ireland, US \\
\hline & & Online searches ${ }^{682,683}$ & US \\
\hline & Tourism $^{684}$ & Mobile phone records & Finland-Sweden \\
\hline $\begin{array}{l}\text { Infrastructure, } \\
\text { industrialization and } \\
\text { innovation (SDG9) }\end{array}$ & $\begin{array}{l}\text { Map with internet devices } \\
\text { by location }\end{array}$ & $\begin{array}{l}\text { Internet tools to scan all addresses of the fourth } \\
\text { version of the internet protocol }\end{array}$ & World \\
\hline \multirow{2}{*}{ Inequality (SDG10) } & Wealth and inequality ${ }^{686}$ & Airtime credit purchases & Cote d'Ivoire \\
\hline & Migration & Social media ${ }^{687}$, online searches ${ }^{688}$ & Several countries \\
\hline \multirow{7}{*}{ Cities (SDG11) } & $\begin{array}{l}\text { Urban extent and } \\
\text { population }^{689,690}\end{array}$ & Satellite images & Global \\
\hline & $\begin{array}{l}\text { Transport use and } \\
\text { journeys }{ }^{691} \text {; Subway } \\
\text { flows }^{692,693}\end{array}$ & Transport cards data & London, UK \\
\hline & Travel patterns ${ }^{694}$ & Cell phone records & Cote d'Ivoire \\
\hline & \multirow{2}{*}{ Commuting time ${ }^{695,696}$} & Traffic sensors & Finland \\
\hline & & Cell phone records ${ }^{697}$ & Cote d'Ivoire, Portugal, Saudi Arabia, USA (Boston) \\
\hline & Flood hazard and risk & Satellite images & $\begin{array}{l}\text { Namibia }^{698} \text {; Global } \\
\text { River }^{609} ; \text {; Nigeria, Niger-Benue } \\
\text { Chamoli district, Uttarakhand, India }\end{array}$ \\
\hline & Flood impact & Cell phone records & Mexico ${ }^{702}$ \\
\hline \multirow{2}{*}{ SCP (SDG12) } & $\begin{array}{l}\text { Perceptions of fuel subsidy } \\
\text { reform }^{703}\end{array}$ & Twitter & El Salvador \\
\hline & $\begin{array}{l}\text { Net primary } \\
\text { production }^{704,705}\end{array}$ & Satellite images & Greater Mekong sub-region \\
\hline \multirow{4}{*}{$\begin{array}{l}\text { Climate change } \\
\text { (SDG13) }\end{array}$} & $\begin{array}{l}\text { Population and energy } \\
\text { related GHG emissions }\end{array}$ & Satellite images & Worldwide \\
\hline & Methane $^{707,708}$ & Satellite measurements & US \\
\hline & $\begin{array}{l}\text { Perceptions on climate } \\
\text { change }^{709}\end{array}$ & Twitter & Worldwide \\
\hline & $\begin{array}{l}\text { Perceptions on climate } \\
\text { change }^{710}\end{array}$ & Twitter & Worldwide \\
\hline \multirow{2}{*}{ Oceans (SDG14) } & $\begin{array}{l}\text { Vessels conducting illegal } \\
\text { fishing }\end{array}$ & \multirow{2}{*}{ Satellite data } & Worldwide ${ }^{711}$; covers $75 \%$ of the globe ${ }^{712}$; \\
\hline & Ocean measurements ${ }^{713}$ & & Worldwide \\
\hline
\end{tabular}




\begin{tabular}{|c|c|c|c|}
\hline SDGs & What is measured? & Data source & Geographic scope of application \\
\hline $\begin{array}{l}\text { Terrestrial } \\
\text { ecosystems (SDG15) }\end{array}$ & Forest cover & Satellite images & Costa Rica ${ }^{714}$, Mexico ${ }^{715}$ \\
\hline \multirow{2}{*}{$\begin{array}{l}\text { Peace, justice, } \\
\text { institutions (SDG16) }\end{array}$} & Crime $^{716}$ & Mobile phone and demographic data & London, UK \\
\hline & Violent events $^{717}$ & News stories database & Syria \\
\hline $\begin{array}{l}\text { Means of im- } \\
\text { plementation } \\
\text { (SDG17) }\end{array}$ & $\begin{array}{l}\text { Feedback from communities } \\
\text { in assessing aid flows }\end{array}$ & $\begin{array}{l}\text { U-Report } \\
\text { (online monitoring tool) }\end{array}$ & Uganda \\
\hline \multirow{3}{*}{ Other } & Population & Mobile phone records ${ }^{720}$ & France, Portugal \\
\hline & & $\begin{array}{l}\text { Satellite images combined with population count } \\
\text { data }^{721}\end{array}$ & Africa \\
\hline & Well-being & Twitter $^{722}$ & US \\
\hline
\end{tabular}

Open access to data remains a challenge. Much of these data is owned or in the possession of private sector companies. Data provided to outside organizations and individuals is often aggregated and "anonymized" (true anonymization is difficult to achieve, which has raised privacy concerns), and even such access is often only obtained through personal connections. High cost is another barrier. For example, while Facebook has an open API to access their data, access to Twitter's data can be expensive. Accessing call data record (CDR) data requires an agreement with each provider. Some business data is free to view but not to download ${ }^{723}$, and other data can be purchased. ${ }^{724}$ Some satellite data is free ${ }^{725}$, and others for sale. ${ }^{726}$ Access to computing power to analyse data continues to be an issue, even though cloud computing and open source software has removed some of those barriers. In short, the current practice of big data sharing is ad hoc and unreliable including in terms of predictable future data access. The question of the rights to data remains open in the debate on the future legal architecture of the global big data system, even though there is increased recognition that people should have greater control of the rights to their data-the data they produce. Greater control by people over their data would hopefully contribute to more accountable use. Much of the benefit of big data may be in spurring non-policy actions, by people using insights from the data that are largely unrelated to policies. For example, big data can be used to change people's behaviour. Access to real time traffic data can lead to changes in driving behaviours and hopefully reduced congestion.

To date, the dialogue between official statistics and big data has been limited - a UN Statistics Division/UNECE survey conducted in 2014 revealed that only a few countries national statistical offices had developed a longterm vision for the use of big data. ${ }^{727}$

\subsection{UN system mechanisms to identify emerging issues} For the present report, a survey was conducted among all ECESA Plus members - all 53 UN entities working on economic, social or environmental issues. Table 7-6 summarizes the survey results. The questions asked in the survey were:

- Is emerging issues identification a regular exercise in the work programme?

- Is it internal or does it involve any external partners?

- What is the output and how is it being used?

- Are there dedicated staff-time assigned to this task?

- Is it conducted based on peer-reviewed literature, or other publications, or is it mainly relying on multi-stakeholder inputs?

Table 7-6. UN system mechanisms to identify emerging issues

\begin{tabular}{|c|c|c|c|c|c|}
\hline $\begin{array}{l}\text { UN System } \\
\text { entity }\end{array}$ & Drafting process & Type of knowledge assessed & Staff-time & Frequency & Output \\
\hline $\begin{array}{l}\text { World Food } \\
\text { Programme } \\
\text { (WFP) }\end{array}$ & $\begin{array}{l}\text { Drafted and reviewed } \\
\text { internally }\end{array}$ & $\begin{array}{l}\text { Academic, } \quad \text { peer-reviewed } \\
\text { journals, United Nations } \\
\text { publications, Civil society / } \\
\text { multi-stakeholder inputs }\end{array}$ & $\sim 3$ months & Regular & $\begin{array}{l}\text { Incorporated into strategic plans and } \\
\text { operational activities }\end{array}$ \\
\hline WMO & $\begin{array}{l}\text { Drafted by external } \\
\text { experts but coordinated } \\
\text { by internal managers }\end{array}$ & $\begin{array}{l}\text { Academic, peer-reviewed } \\
\text { journals, United Nations } \\
\text { publications, Civil society/multi- } \\
\text { stakeholder inputs, Media, } \\
\text { Feedback from members } \\
\end{array}$ & $\begin{array}{l}\text { More than } 24 \\
\text { months }\end{array}$ & Regular & $\begin{array}{l}\text { Submission of reports to National } \\
\text { Governments, } \\
\text { Information to the Committee of Parties } \\
\text { (COP) Meetings of permanent } \\
\text { representatives of intergovernmental Board }\end{array}$ \\
\hline ITU-T & $\begin{array}{l}\text { Drafted and reviewed } \\
\text { internally, primarily } \\
\text { based on external } \\
\text { inputs, or drafted by } \\
\text { external experts }\end{array}$ & $\begin{array}{l}\text { Academic, peer-reviewed } \\
\text { journals, United Nations } \\
\text { publications, Civil society/multi- } \\
\text { stakeholder inputs, Media, input } \\
\text { (documents) by ITU } \\
\text { membership }\end{array}$ & $\begin{array}{l}\sim 0.5 \text { to } 1 \text { staff } \\
\text { year }\end{array}$ & Regular & $\begin{array}{l}\text { Either on ITU webpage - publicly available } \\
\text { for free, or submitted to ITU membership } \\
\text { which includes governments, policy-making } \\
\text { bodies, companies }\end{array}$ \\
\hline
\end{tabular}




\begin{tabular}{|c|c|c|c|c|c|}
\hline $\begin{array}{l}\text { UN System } \\
\text { entity }\end{array}$ & Drafting process & Type of knowledge assessed & Staff-time & Frequency & Output \\
\hline ECLAC & $\begin{array}{l}\text { Drafted and reviewed } \\
\text { internally, primarily } \\
\text { based on external } \\
\text { inputs, or drafted by } \\
\text { external experts }\end{array}$ & $\begin{array}{l}\text { Academic, peer-reviewed } \\
\text { journals, Civil society/multi- } \\
\text { stakeholder inputs }\end{array}$ & - & Ongoing & $\begin{array}{l}\text { Publications, including a peer-reviewed } \\
\text { magazine where emerging issues are } \\
\text { discussed (Revista CEPAL). }\end{array}$ \\
\hline ESCWA & $\begin{array}{l}\text { Drafted internally } \\
\text { primarily based on } \\
\text { external inputs }\end{array}$ & $\begin{array}{l}\text { Academic, peer-reviewed } \\
\text { journals, United Nations } \\
\text { publications, Civil society/multi- } \\
\text { stakeholder inputs, Media, } \\
\text { Official data from government } \\
\text { sources }\end{array}$ & - & Ongoing & $\begin{array}{l}\text { Reports, publications, working papers, } \\
\text { technical material, databases. }\end{array}$ \\
\hline ESCAP & $\begin{array}{l}\text { Drafted in combination } \\
\text { of contributions from } \\
\text { internal and external } \\
\text { authors, including } \\
\text { partner agencies: } \\
\text { reviewed internally and } \\
\text { co-publishers }\end{array}$ & $\begin{array}{l}\text { Academic, } \quad \text { peer-reviewed } \\
\text { journals, United Nations } \\
\text { publications, Civil society/multi- } \\
\text { stakeholder inputs, media }\end{array}$ & $\begin{array}{l}\text { \%3 to } 6 \text { months } \\
\text { per report on } \\
\text { emerging and } \\
\text { persistent issues } \\
\text { for parliamentary } \\
\text { discussions } \\
\text { (Commission, } \\
\text { Committee) }\end{array}$ & Regular & $\begin{array}{l}\text { Reports and publications, including regional } \\
\text { reports on emerging and persistent issues } \\
\text { are prepared for the annual Commission } \\
\text { session and subsidiary thematic Committees. }\end{array}$ \\
\hline UNEP & $\begin{array}{l}\text { Drafted internally } \\
\text { primarily based on } \\
\text { external inputs, relies } \\
\text { on collaboration with } \\
\text { partners such as ICSU, } \\
\text { SCOPE, Future Earth, } \\
\text { EcoResearch }\end{array}$ & 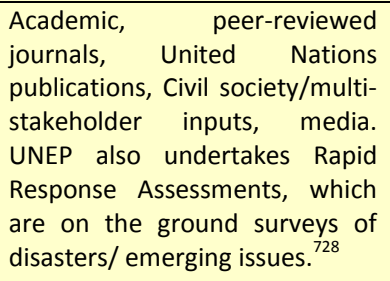 & $\begin{array}{l}22 \text { staff listed on } \\
\text { the project } \\
\text { document, but } \\
\text { actual share of } \\
\text { staff time varies } \\
\text { and is currently at } \\
50 \% \text { of } 2 \text { staff. }\end{array}$ & Regular & $\begin{array}{l}\text { "UNEP Year Book: Emerging issues in our } \\
\text { global environment"; Global Environment } \\
\text { Alert Service (GEAS); Global Foresight } \\
\text { Process, UNEP Live; engaging stakeholders } \\
\text { through newsletters, social media outlets, } \\
\text { eBooks/Apps, etc. }\end{array}$ \\
\hline IMO & $\begin{array}{l}\text { Drafted internally } \\
\text { primarily based on } \\
\text { external inputs, or } \\
\text { drafted externally by } \\
\text { experts. }\end{array}$ & $\begin{array}{l}\text { Academic, peer-reviewed } \\
\text { journals, UN publications, Civil } \\
\text { society/multi-stakeholder } \\
\text { inputs, Member States }\end{array}$ & - & Regular & $\begin{array}{l}\text { Information on emerging issues would be } \\
\text { brought to the attention of the various } \\
\text { bodies of IMO (committees, subcommittees, } \\
\text { etc.), as appropriate. }\end{array}$ \\
\hline
\end{tabular}

Source: Survey among 53 ECESA Plus members, conducted for the present report.

Among the UN offices and agencies that reported existing emerging issues identification mechanisms, the top-ranked knowledge sources included: academia and peer-reviewed journals; civil society and multi-stakeholder inputs; as well as media. Other sources mentioned included expert group meetings, UN publications, online consultation, and interdepartmental discussions. Some argued that the combination of structured identification through experts with continuous dialogues with all stakeholders tended to generate the best results. It was also mentioned that crossdiscipline, cross-region and cross-institution collaboration was important for the effectiveness of emerging issues identification. Regular and institutionalized processes were said to be attracting more attention of the policy-making community.

Three broad types of mechanisms to identify emerging issues emerged from the survey: the strategic planner model, the knowledge broker model, and the political adviser model. In conclusion, a future mechanism to identify science issues for the deliberations of the HLPF can be built on various inputs channels, including the diverse landscape of existing UN system mechanisms to identify "emerging issues" in various clearly defined areas (Table
7-7). The strategic planner model is oriented internally and feeds into the organization's strategic planning process. The knowledge broker model entails a more open process and engages the largest number of people in order to aggregate knowledge that can benefit the organization and beyond. The political adviser model is typically more expert-oriented and potentially has more impact on the political decision-making process. This typology is, of course, an over-simplification, and most United Nations entities follow a model that combines elements of all three. For example, UNEP's various product lines such as the global environmental alerts, the yearbook and foresight process, and UNEP Live, primarily play a knowledge broker role but are also connected to the UNEP Governing Council (United Nations Environment Assembly since 2014) and the Global Ministerial Environment Forum.

In conclusion, a future mechanism to identify science issues for the deliberations of the HLPF can be built on various inputs channels, including the diverse landscape of existing UN system mechanisms to identify "emerging issues" in various clearly defined areas. 
Table 7-7. Simple typology of emerging issues identification models within the UN system

\begin{tabular}{|l|l|l|}
\hline Type & Description & Example \\
\hline $\begin{array}{l}\text { Strategic } \\
\text { Planner } \\
\text { model }\end{array}$ & $\begin{array}{l}\text { Emerging issues identification takes place } \\
\text { according to the organization's strategic } \\
\text { planning cycles, or in conjunction with internal } \\
\text { planning meetings. }\end{array}$ & $\begin{array}{l}\text { WFP } \\
\text { strategic } \\
\text { planning } \\
\text { cycles }\end{array}$ \\
\hline $\begin{array}{l}\text { Knowledge } \\
\text { Broker }\end{array}$ & $\begin{array}{l}\text { Emerging issues identification feeds into an } \\
\text { Modganization's knowledge management } \\
\text { process, mostly aggregating from various } \\
\text { sources in a comprehensive manner, for public } \\
\text { consumption and awareness-raising. }\end{array}$ & $\begin{array}{l}\text { UNEP } \\
\text { "Year in } \\
\text { Review" }\end{array}$ \\
\hline $\begin{array}{l}\text { Political } \\
\text { Advisor } \\
\text { Model }\end{array}$ & $\begin{array}{l}\text { Closely linked to an intergovernmental process } \\
\text { and the political decision-making process, } \\
\text { selectively highlighting emerging issues with } \\
\text { significant relevance for political decision- }\end{array}$ & IPCC \\
& making. & \\
\hline
\end{tabular}

7.7. Time lags between science and policy

At the heart of strengthening the science-policy interface is the idea of providing timely scientific and empirical information in an accessible manner to policy makers, in order to support their informed decision-making. In the past, there have been long time lags from the identification of issues and causes by scientists ("confidence in causality" ${ }^{729}$ ), to effective policy actions, through to impacts (e.g., reduction of harm). This section provides empirical data regarding such time lags for a number of environmental issues and discusses the range of factors that were responsible for these time lags.
Implicit in the view of time lags from scientific identification to harm reduction is, of course, a belief that evidencebased single-issue policy achieves the intended reduction of risk/harms associated with the identified issue. Reality is not always that straightforward. For example, single-issue policies can have unintended effects in other areas due to synergies/trade-offs, substitution effects and generally complex systems dynamics which are not always wellunderstood. Nevertheless, the selected environmental examples provide an empirical background to the potentials and limitations of any HLPF or other initiative aimed at shortening the science-policy-impact time-lags. The examples clearly support a cautionary approach. Figure 7-6 provides an overview of science-policy time lags for nine selected environmental and health issues: ozone layer, lead, PCBs, climate change, DDT, tobacco, acid rain, asbestos, and mercury. For each issue, three types of timelags are shown:

- Science: From early warning by scientists to scientific confidence in causality.

- Policy: From effective policy action in one country, to a region and to global action.

- Impact: From the first policy impact to effective impacts (such as reducing risks related to harm to very low levels).

Figure 7-6. Time lags (in years) between science and policy for selected environmental issues

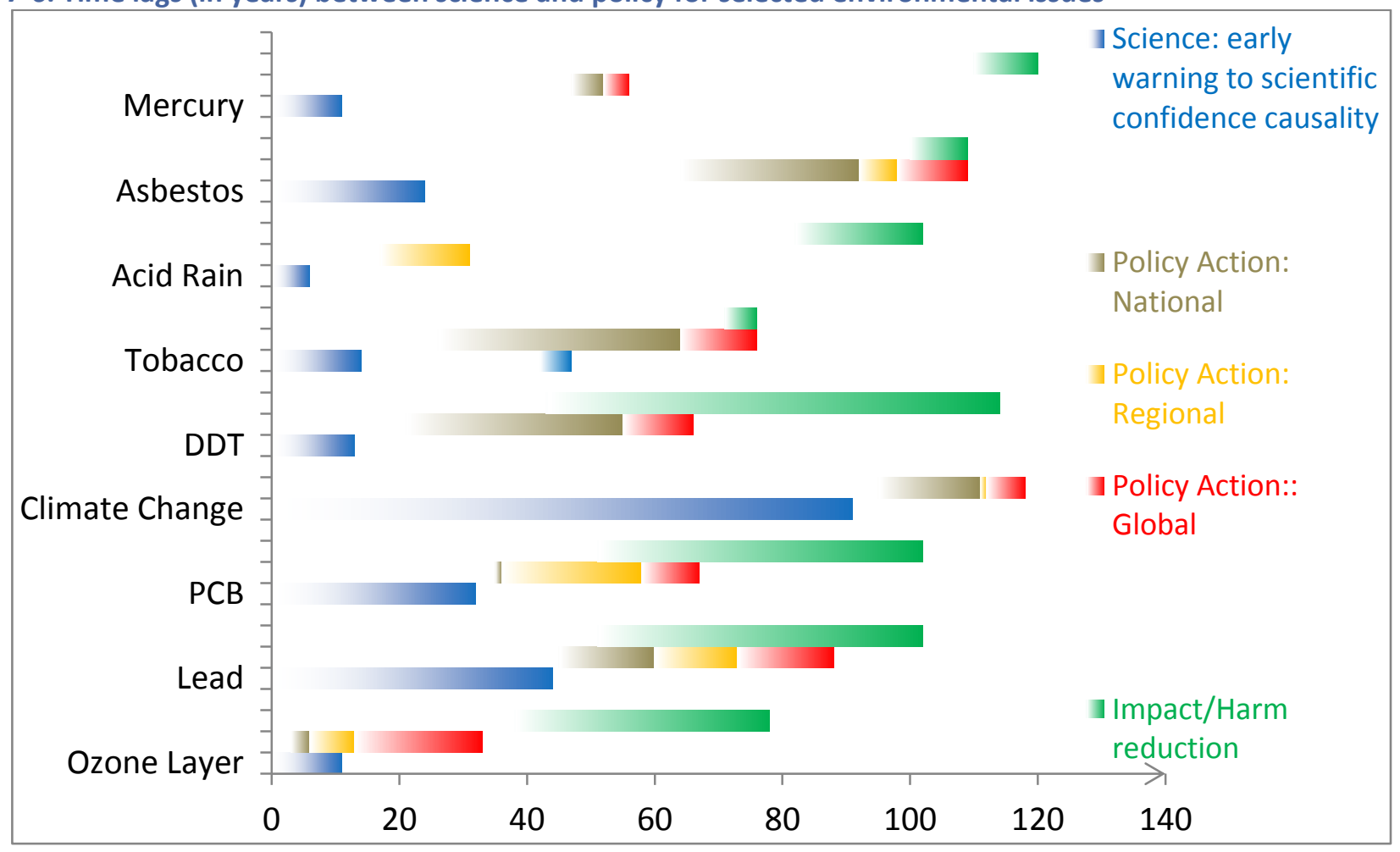

Source: Produced by UNEP colleagues and David Gee based on EEA reports ${ }^{730}$ and various sources cited in the text of this section.

Notes: The timeline for ozone layer and lead are provided in the text, those for $\mathrm{PCB}^{731}$, climate change ${ }^{732}, \mathrm{DDT}^{733}$, tobacco ${ }^{734}$, acid rain ${ }^{735}$, asbestos ${ }^{736}$, mercury ${ }^{737}$ can $^{2}$ be found in the footnotes. 
Figure 7-6 shows very wide ranges for science, policy and impact time lags - spanning two orders of magnitude from a few years to more than a century. Many reasons have been suggested for these wide ranges, including factors that case specific and others that are more general. They are described in Table 7-8. Three cases - ozone layer, lead in gasoline, and climate change - are described below, in order to illustrate the interplay between multiple factors.

It is important to note that the determinations of "scientific confidence in the causal hypothesis under scrutiny" and of "the strength of evidence deemed sufficient to justify policy action" are based on case-specific judgments that include a consideration of the consequences of being wrong with either action or inaction. ${ }^{738}$ The term is often used to justify action based on the "precautionary principle". For this report, we base our approach on that used by the Intergovernmental Panel on Climate Change (IPCC) in its "Guidance for lead authors of the IPCC $5^{\text {th }}$ assessment report on the consistent treatment of uncertainties". ${ }^{739}$ It should be noted also that the IPCC's approach to assessing uncertainty has significantly evolved over the years. ${ }^{740}$ Some commonly used standards of confidence include "beyond all reasonable doubt" (as used in criminal courts) or "scientific suspicion of risk" (as in the Swedish Chemicals Law 1973). Often, precautionary actions are justified on the basis of lower standards of scientific evidence than the higher standard required for scientific 'proof'. Examples include the "reasonable grounds of concern" of the European Union's Communication on the Precautionary Principle; ${ }^{741}$ the "balance of evidence" that humans are changing the climate of the 1995 report of the Intergovernmental Panel on Climate Change; and "no conclusive proof ...but a reasonable expectation of harmful effects" used by the Environmental Protection Agency of the USA in 1987.

\subsubsection{Ozone Layer}

In 1974, Rowland and Molina (and independently Cicerone) suggested that long-lived organic halogen compounds, such as CFCs, might deplete the ozone layer. ${ }^{742,743}$ This hypothesis was strongly disputed by representatives of the aerosol and halocarbon industries. For example, the Chair of the Board of DuPont called it "a science fiction tale ... a load of rubbish ... utter nonsense". ${ }^{74}$ Following lab and open air tests, in 1976 the US National Academy of Sciences concluded that the ozone depletion hypothesis was strongly supported by the scientific evidence.

In response, in 1978 the United States of America, Canada and Norway banned the use of CFCs in aerosol sprays - in the case of the US based on "reasonable expectation" of damage. Similarly at the regional level, in 1980 there was a European decision to restrict the use of CFCs in aerosols. In
1985, large-scale ozone depletion over Antarctica was reported by Farman et al in Nature and confirmed by NASA. ${ }^{745}$ At the global level, the Montreal Protocol on the protection of the ozone layer was signed soon thereafter, in 1987.

The Montreal Protocol is a showcase of a functioning scientific early warning followed by global coordinated action merely 13 years after the original hypothesis. Policy action has proven effective. By 2012, combined chlorine and bromine levels had declined by 10 to $15 \%$ from their peak values. By 2005, the global amount of ozone in the atmosphere had stabilized. ${ }^{746}$ Ozone concentrations in the lower stratosphere over Antarctica are expected to return to pre-1980 levels by about $2060-2075 .^{747}$

\subsubsection{Leaded petrol}

The toxicity of lead has been known to man for a long time. The Romans were already aware of the toxicity of lead (Pliny, ca AD 77-79). ${ }^{748}$

Leaded petrol was a global commodity between the 1930s and the 1990s. The new generation of high compression engines that emerged in the 1920 required gasoline with fuel additives for which two additives were available at the time - tetraethyl lead (TEL) and alcohol. ${ }^{749}$ Although both were technically effective, TEL was chosen by DuPont, GM, and Standard Oil, because of its lower cost and because of complications arising from alcohol prohibition in the USA at the time. ${ }^{750}$ The potential health dangers of TEL were anticipated by many health professionals. In 1924, a public controversy erupted over the "loony gas" which had killed its production workers in the first US TEL factories. The US Public Health Service conducted a conference in 1925 at which many public health scientists warned that putting lead into petrol would cause "insidious" health effects which would take many years for the public and governments to recognize. TEL sales were then voluntarily suspended for one year to conduct a hazard assessment. ${ }^{751}$ The Public Health Service created an expert committee that suggested not to ban TEL, but to closely monitor, study, and regulate its introduction. ${ }^{752}$ TEL was widely marketed without such controls until the 1980s. By 1969, the first clinical studies were published which proved the toxicity of TEL in humans. ${ }^{753}$ Commercial production of the alternative fuel additive methyl tertiary-butyl ether (MTBE) to replace TEL/lead as octane enhancer in gasoline started in Europe in 1973 and in the United States in 1979. ${ }^{754}$

By 1970, the annual incidence of symptomatic and asymptomatic lead poisoning in the U.S. was as high as 250,000 cases. $^{755}$ Lead poisoning in the industrializing world called for preventive action, and a number of legislative and other preventive measures were introduced in many 
countries. $^{756}$ Policy measures included reductions in the lead content of petrol; provision of unleaded petrol; a ban on leaded petrol; and taxes that favoured unleaded petrol. Policy action milestones included: GM's announcement of the phase-out of leaded petrol in 1970; the 1985 European Commission directive; and the 1998 Aarhus Protocol. By 2013, almost all countries in the world had phased-out leaded petrol.

The long-term cost associated with health effects on children has been significant. The economic costs were estimated to be as high as 4 to 6 per cent of GDP in EU countries during the leaded petrol decades. ${ }^{757}$ Although exposure is on the decline due to targeted policy actions, particularly the widespread phase-out of leaded gasoline, exposure to lead (from old paint mines and factories and electronic waste) remains an important cause of disease. In 2004, 0.6 per cent of the global burden of disease (in DALYs) was attributable to exposure to lead. The highest lead-associated rates of disease occurred in the Eastern Mediterranean and South-East Asian regions, where exposures also remain the highest. ${ }^{758}$

The lead petrol case is the case of a man-made disaster which was predictable and avoidable, as the necessary scientific information was available, and alcohol was available as a better substitute. However, industry special interests and prohibition of alcohol at the time led to "lockin" of tetraethyl lead. It is important to note that ultimately the key motive for removing lead was that it interfered with catalytic converters which were deployed for the removal of air pollutants, such as $\mathrm{SO}_{2}$ and $\mathrm{NO}_{\mathrm{x}}$, as demanded by environmental legislation (e.g., the US Clean Air Act of 1970). Hence, both the introduction of TEL and its eventual removal were closely linked to other seemingly unrelated policy actions - alcohol prohibition and local air pollution regulation.

\subsubsection{Climate Change}

In 1897, Swedish physicist Arhennius estimated that doubling the $\mathrm{CO}_{2}$ in the atmosphere would raise the average global temperature by about $5^{\circ} \mathrm{C}$. It can be considered the first scientifically credible early warning about the possible dangers of climate change due to fossil fuel-related carbon dioxide $\left(\mathrm{CO}_{2}\right)$ emissions. Arhennius' estimates compare with latest estimates of between 2.5 to $4.0{ }^{\circ} \mathrm{C}$ today. While the basic physical principles of global warming are simple, the more detailed science of climate change is exceedingly complicated. For example, the absence of atmospheric warming from the late 1940s until the 1970s despite the increase in greenhouse gases, revealed yet another facet of the anthropogenic climate change 'puzzle': that surface cooling could occur as a result of increased atmospheric turbidity, both in clear and cloudy atmospheres. Even today, many details of climate change remain highly uncertain (e.g., the net effects of clouds). However, by 1990 the IPCC's first assessment report concluded: "The potentially serious consequences of climate change give sufficient reasons to begin adopting response strategies that can be justified immediately even in the face of significant uncertainties."759 In other words, climate change scientists deemed the scientific confidence in the evidence of anthropogenic climate change as sufficient to justify policy action.

During the 1980s, the climate change issue had become a matter of concern for environmental policymakers. The science-policy knowledge was formalised with the establishment of the IPCC in 1988, and most policymakers have since acknowledged IPCC findings as authoritative. In this context, it should be noted that the IPCC is intergovernmental and sponsored by the United Nations (UNEP and WMO). Scientists and Governments select the IPCC reports' authors. The reports are reviewed by scientific communities and adopted by governmentnominated experts. The first IPCC reports supported the establishment of the UN Framework Convention on Climate Change (UNFCC) 760 and its Kyoto Protocol (signed in 1997) which came into force in 2005.

Global climate change differs from other environmental problems in various ways. It is mainly caused by widespread fossil fuel burning and agriculture. The impacts of climate change and of climate change policies are potentially large and widespread. The distribution of 'winners' and 'losers' raises questions about equity across countries and generations. In view of the complexity of the science and economics of climate change, there are no "one-size-fits-all" optimal solutions available. International political action on climate change has been slowly moving forward in the 2000s, in the context of increasingly strong calls from scientific communities. Environmental NGOs and business organisations have influenced Governments' climate change-related policies, inter alia, by providing information (e.g., newsletters, scientific briefs) and through awareness campaigns and lobbying. 
Table 7-8. Factors that promoted or discouraged evidencebased policy action

\begin{tabular}{|c|c|}
\hline Area & Factors \\
\hline Economy & 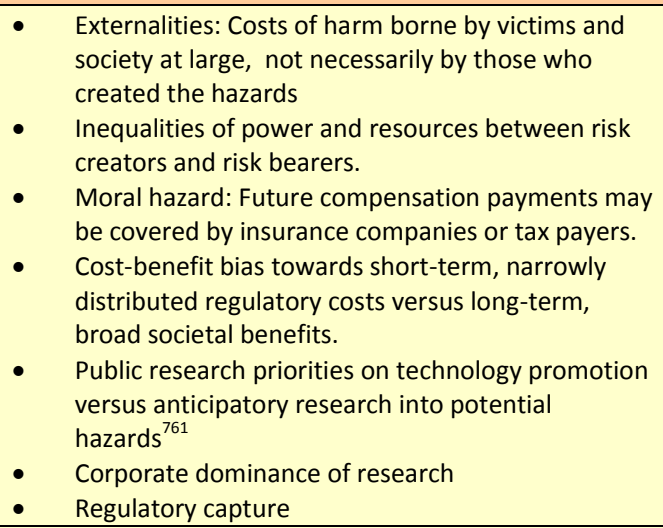 \\
\hline $\begin{array}{l}\text { Society \& institu- } \\
\text { tions }\end{array}$ & $\begin{array}{l}\text { - Low quality media reporting and opposition to } \\
\text { "inconvenient truths" } \\
\text { - Scientific uncertainty and the "manufacture of } \\
\text { doubt". } \\
\text { - Speedy innovation versus slow science. } \\
\text { Conservative science with methodological, } \\
\text { intellectual, funding, reporting biases towards } \\
\text { caution } \\
\text { - Short-term view of politics. } \\
\text { - Conflicts of interest in research and politics } \\
\text { Conflicts of interest within and between } \\
\text { government departments }{ }^{762} \text {. Asymmetry of power } \\
\text { between health/environment and business/finance } \\
\text { ministries } \\
\text { Asymmetry of power between NGOs protecting } \\
\text { health and environments, and corporations or } \\
\text { governments which create or enable risks } \\
\text { Inertia and 'willful blindness' in science and politics } \\
\text { "Silos" in science and governance which inhibit } \\
\text { trans-disciplinary research and understanding }\end{array}$ \\
\hline Corporate Law & $\begin{array}{l}\text { - Corporations' legal duty is to maximize profits and } \\
\text { growth for shareholders } \\
\text { Criminal liability for CEOs etc. is very difficult to } \\
\text { achieve even in the US where there is vicarious } \\
\text { liability for actions of employees } \\
\text { Mismatch between responsibility for harm at } \\
\text { corporate level and responsibility for reducing } \\
\text { harm at global, national, regional, and local levels }\end{array}$ \\
\hline
\end{tabular}

Source: Assembled by UNEP colleagues and David Gee based on EEA reports. $^{763}$

\subsubsection{Factors influencing science-policy lags}

Why are there usually decades between scientific early warnings and effective prevention of harm? A multitude of factors has promoted and/or discouraged evidence-based policy action. ${ }^{764}$ Table 7-8 presents such economic, cultural, political and legal factors. Timely scientific information and its trusted communication to decision-makers is important, but only one of many factors which determine whether policy action is taken.

The risks related to the cases above were typically underestimated by regulatory authorities. The safe exposure limits determined by science decreased over time. Long-latent-period hazards lead to long delays in preventative action. For example, in the case of asbestos exposure studies, the 20-25 years before lung cancer appeared meant it was not possible to say what the risks were until many years after first exposure. ${ }^{765}$ Disregarding scientific evidence of risks appeared to be a deliberate strategy by some industry groups and think tanks to undermine precautionary or preventive decision-making in some cases. ${ }^{766}$ For example, from the 1920 s to the 1960 s, the main source of information on the health impact of lead in petrol in the USA was industry and industrysponsored researchers. Challenges also arose from split responsibilities among government entities with different views and competing interests. ${ }^{767} \mathrm{NGOs} \mathrm{(e.g.,} \mathrm{in} \mathrm{the} \mathrm{lead}$ case), victim support groups and compensation campaigns (e.g., in the Minamata and asbestos cases) played a role in spurring action. Insurance companies also played a role, for example, when they declined insurance cover for asbestos workers in $1918{ }^{768}$ Immediate, economic damage spurred quick action. For example, when oyster beds collapsed in France in 1982, legislation prohibiting the application of TBT paints to small boats was quickly implemented even though the evidence on causation was far from certain. ${ }^{769}$ And where the harm to humans is severe and rare, speedy action is more likely to follow. For example, it took only 4 cases of human cancer, 7 cases of vaginal cancer, and 7 cases of male infertility in small groups to generate action on VCM, synthetic oestrogen diethylstilboestrol (DES) ${ }^{770}$ and DBCP respectively. ${ }^{771}$

Even when policy action was slow, some stakeholders took voluntary action which in turn informed policy-making. For example, in the 1970s Johnson \& Johnson took early action to remove CFCs from their aerosols, and, in 1971, Monsanto limited the types of PCB mixtures (Aroclor) to those containing less than $60 \%$ chlorine substitution. ${ }^{772}$ Similarly, benzene was voluntarily withdrawn from consumer products in the USA after it was shown that the use of paint strippers in homes generate atmospheric levels up to $200 \mathrm{ppm}$ in a short period of time. ${ }^{773}$

\subsubsection{Research uptake in policy in the humanitarian sector in Africa}

Internationally, whilst there has been a stronger focus on evidence over the past few years, there is room for improvement in the quality and use of research in the humanitarian sector ${ }^{774}$. A current DFID study identified the key determinants of the humanitarian research and evaluation operating environment in East Africa. A key factor limiting research uptake is the minimal involvement of local actors, such as local government, researchers and communities, in the design and planning stage. It undermines a sense of ownership and accountability for response, at both local and national levels, and so is likely 
to result in the research having less impact than it could. There is no regional repository of learning or 'clearing house' for assessing and coordinating humanitarian research and evaluation.

\subsection{Conclusions}

Based on the experience with crowd-sourced science briefs, there are a number of preliminary conclusions that could be considered for future editions of the GSDR.

- The "open" character of the exercise meant that the process did not create incentives for consensus or "seeking the middle ground", either with respect to prevailing modes of analysis or the scales (local, national, regional, global) at which issues ought to be discussed.

- The open call for science briefs for the present report, combined with minimal quality control and broad open review, has proven to provide science issues for the attention of policy makers in the HLPF that also differ considerably from the issues covered in peer-reviewed academic journals.

- There is a need to expand outreach efforts, in order to garner more inputs on emerging issues related to the economy, social systems, and technological change.

- Future editions of the GSDR might use open crowdsourcing and open calls for briefs as a starting point for selective, systematic research and analysis.

- In view of the great differences of inputs provided by different language communities, it appears essential to promote multi-lingual input channels. Sustainability science research in Chinese and Russian languages, in particular, remain rather inaccessible to the rest of the world.

Additionally, a number of issues arise from the present chapter which might be considered by the HLPF.

Tapping into multiple input channels for all relevant scientific communities across the world could make available to policy-makers a broader spectrum of emerging issues, as well as presenting sustainable development challenges from a range of different perspectives. To this end, open crowdsourcing can complement traditional expert group models and existing UN system mechanisms for identifying "emerging issues", in the process strengthening the science-policy interface.

A future mechanism to identify science issues for the deliberations of the HLPF could be built on various input channels, including the diverse landscape of existing United Nations system mechanisms, to identify "emerging issues" in various clearly defined areas, as well as to scope innovative big data applications for sustainable development. In this context, the empirical review of timelags from scientific identification of environmental and health issues, to policy action, through to policy impacts, provides lessons-learnt and a cautionary note as to the potential and limitations of any arrangements geared to shorten the science-policy time-lags. 


\section{Chapter 8. New Data Approaches for Monitoring Sustainable Development Progress: The Case of Africa}

This chapter covers new data approaches for monitoring sustainable development progress, by focusing on Africa, a continent that has been continuously challenged in the production and use of data in support of its development efforts. An analysis of MDG data availability in Africa provides a clear snapshot of the issues that the data revolution should address. Only three African countries have data on all MDG indicators. ${ }^{775}$ Even when data is available, its frequency is low for some indicators. Although about three-quarters of African countries have some data on extreme poverty since 1990, these data is available on average only every ten years in the period 1990-2012. ${ }^{776}$ This is clearly insufficient to address the data needs of policy makers. For sustainable development indicators, there have been calls to have data available annually. ${ }^{777}$ To address crisis and rapidly evolving situations, higher frequency data may be needed.

Innovations can assist in many ways. They can automate tedious tasks and thus free up human resources for more challenging work. Innovations can make data more relevant by increasing its timeliness, its quality and its availability while cutting costs. The focus of the chapter is on innovative approaches in generating, collecting, analysing and using data which can be useful to monitor sustainable development progress and that can provide benefits compared to traditional data approaches. Here, an approach is considered innovative if it is recent or still only used by a small number of countries.

\subsection{New technologies for data collection}

8.1.1. Face-to-face data collection with mobile devices One of the major issues for large scale and complex data collection operations, such as censuses and surveys, is the time lag between data collection and the release of the results. The use of handheld mobile devices in data collection has reduced that time lag. In Africa, they were used initially by researchers and NGOs, in countries like Mozambique, ${ }^{778}$ Tanzania and Burkina Faso, but mobile handheld devices have started to be used in official data collections in recent years. Mozambique used mobile devices in its agricultural census as far back as 2009. ${ }^{779}$ Cape Verde was the first country in Africa to use mobile devices with geo-positioning for data collection in a population census in $2010,{ }^{780}$ but since then the technology has expanded to official surveys and censuses in other countries, including Botswana, ${ }^{781}$ Côte d'Ivoire,
Senegal ${ }^{782}$ and S. Tomé and Principe. Non-governmental organizations are also investing in this technology. Oxfam has been conducting surveys using Android smartphones on people's knowledge of symptoms of Ebola and how to prevent the disease in Gambia, Guinea Bissau and Senegal. These surveys use the Mobenzi app, ${ }^{783}$ which has been developed by a South African company.

By using mobile devices, preliminary results of the 2013 census in Senegal were available in just three months as opposed to one year in previous censuses. For an HIV survey conducted in Botswana in $2013,{ }^{784}$ the time to release the results was reduced by six months. Apart from reducing time, the use of mobile devices is paper smart and reduces costs by eliminating printing, transportation and storage of questionnaires. It also eliminates the cost of entering the data recorded on paper into a digital form, since with mobile devices the data is directly transmitted to central servers. For instance, for a large sample survey of about 13,000 households the resulting cost saving has been estimated at about US\$200,000. ${ }^{785}$ Two other beneficial features of using mobile devices for census/survey data collection is the less propensity of data entry errors (because there is one less step in data transcription, a lot of errors come from data entry from paper to digital formats); and the possibility of doing quick data validations -both in the field and in headquarters- that allow enumerators to re-visit the household before leaving the area to correct any inconsistencies.

Box 8-1. Innovative data collection, integration and dissemination in Nigeria

The Nigerian Senior Special Advisor to the President on the MDGs, with support from the Earth Institute's Sustainable Engineering Laboratory, developed the Nigeria MDG Information System, an online interactive data platform which gives the location and status of health, water and education facilities. These data were collected by trained enumerators using Android-based smartphones to collect location information using GPS and combined with data available through surveys. Using this system, all government health and education facilities as well as water access points were mapped across Nigeria within a mere two months. The data are freely available online. 
Figure 8-1. Nigeria MDG Information System

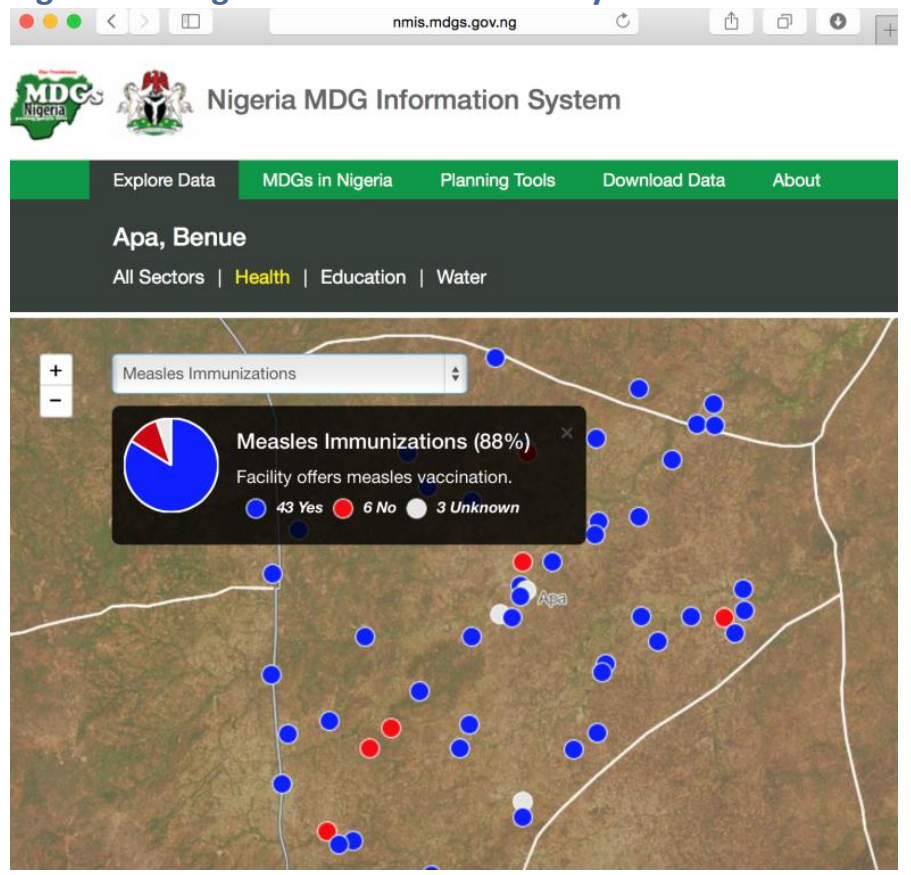

Source: Nigeria MDG Information System,

http://nmis.mdgs.gov.ng/explore\#benue apa/map health

Another advantage of using this technology is that georeferenced data can be collected on the spot to provide location-specific information. The 2009/10 agricultural census in Mozambique and the 2010 population census in Cape Verde used GPS with mobile devices. Mobile devices with GPS information have also been used in Nigeria to map water points as well as education and health facilities (see Box 8-1 and Figure 8-1).

However, the initial investment in acquiring mobile devices can be costly. In order to make such initiatives sustainable, some countries are sharing the hardware and adapting the software to their needs and languages. For instance, Côte d'Ivoire, Senegal and another country outside of Africa, Haiti, have shared the same mobile devices in recent data collections.

Lack of reliable electrical power and internet in some parts of Africa still poses challenges to this technology, but there are adaptations in which data is collected offline in the mobile devices and then transmitted to the servers when an internet connection is available. In emergency situations, small provisional satellite terminals have been deployed to provide internet connectivity. ${ }^{786,787}$ Solar charged devices have also been used when electrical power is not available. When mobile phones are not equipped with solar chargers, enumerators can carry small selfstanding solar chargers to charge them. ${ }^{788,} 789,790$

\subsubsection{Collecting data through cell phones, SMS and internet}

Due to the absence of high-quality, comprehensive administrative records, most data in Africa are typically collected through face-to-face surveys. Since those surveys are expensive and time consuming, they tend not to be carried out very frequently. In an attempt to reduce the cost and increase the frequency of data collection, international agencies, commercial, academic and nongovernmental institutions have been exploring the use of mobile-phone surveys, SMS surveys and online surveys to collect the data remotely. ${ }^{791,792,793,794}$

Box 8-2. Getting health and livelihood data through
women informants equipped with smartphones
The Drought Early Warning Program (DEWS) in southern
Ethiopia is run by women data informants and women and
men health extension workers employed by the Ministry of
Health. The women informants use Android smartphones
and tablets to collect data on water, health, food security,
and livelihoods indicators every month from their
communities with the KoBo app (developed by Harvard
Humanitarian Initiative). The app is able to capture audio
and photo data and GPS, to support a range of question
types, such as multiple choice and free response and to
enable quick analysis and geographical mapping of the
data. Moving from pen and paper surveys to digital
platforms speeds the data collection. Anecdotal evidence
derived from focus groups and interviews indicates digital
collection methods saved data collectors $30-90$ minutes out
of the two hours it once took to conduct a pen and paper
survey.

There are two types of approaches: the first selects a representative sample from lists of cell phone subscribers $^{791}$ or of household/populations ${ }^{795}$; the second relies on registered participants who provide data through SMS/cell phone services. At times, these registered participants are pre-selected and act as data providers for their community, like the health and livelihood data collected by women informants in Ethiopia (Box 8-2) and the Ebola surveys conducted by Nethope in Liberia. In other cases, the overall population is invited to participate and whoever registers can respond to the surveys (Box 8-3). SMS surveys in particular are being increasingly used due to their low cost. Due to the constraints of the medium, SMS surveys tend to be short (5-10 questions). ${ }^{796}$ Several platforms for SMS-based surveys are currently being used in Africa such as U-Report in Uganda (Box 8-3) ${ }^{797}$ FrontlineSMS $^{798}$ in Malawi and Burundi; Ushahidi ${ }^{799}$ in Kenya, Uganda, Malawi, and Zambia; and RapidSMS ${ }^{800}$ in Senegal, Mauritania, Uganda, Somalia, Zambia, Kenya, Nigeria, Malawi, and Ethiopia. 
These novel Internet- and SMS-based collaborative systems can have an important role in gathering information quickly and improving coverage and accessibility. They represent a departure from the careful control, verification, and datainformed actions of traditional structures, but can provide advantages in scalability, coverage, timeliness, and transparency. These data do not satisfy the golden standard of statistics (i.e. random, representative sample), but its usefulness is undeniable, particularly managing and monitoring for disease outbreaks, agricultural challenges and natural disasters. ${ }^{801}$ For instance, data compiled through U-Report has successfully assisted to combat a disease affecting banana trees. ${ }^{802}$ Promising mobile/smartphone applications for health monitoring and information sharing have also been put in place, which enable the general public to report infectious disease events. $^{803}$

\section{Box 8-3. Getting data through free-SMS services}

The U-Report is a free SMS-based system that allows young Ugandans to speak out on what's happening in communities across the country. Participants can enrol in U-report by SMS. Polls are conducted also through a free SMS service and can attract large numbers of participants. For instance, a poll posted in Jan-2015 asking "During the Polio house to house immunisation campaign, did Polio vaccinators come to your home to immunise all the children under 5? Yes/No" received more than 25,000 responses. The results are also available geographically.

SMS surveys require literate respondents and literacy rates in some African countries are under $50 \%{ }^{804,805}$ But many other African countries already have literacy rates well above $80 \%$. Some SMS data reporting services like Ushahidi have developed the possibility for illiterate users to leave voice messages instead, but analysis of the "voice data" is time consuming and costly.

Cell-phone ownership tends to be biased towards the wealthy, and this can introduce serious bias. ${ }^{806}$ But as these services become increasingly popular, and statistical tools are being developed to correct for biases in the sample, the data will become more and more reliable. To address a similar problem, replies to surveys conducted online elsewhere in the world - also not a random, representative sample - are calibrated to match the population structure. These surveys are reporting results as reliable as other more institutionalized surveys. ${ }^{807}$ More research will be needed to adapt this correction to cell phone and SMS surveys. Also, cell phone/SMS surveys are being combined with face-to-face interviews for non-connected populations - there are reports that this would still be a lower cost option compared to a full face-to-face interview. ${ }^{808}$
SMS services are being particularly useful for monitoring administrative and institutional data. This includes for instance real-time stock management of essential medicines in health facilities (mTRAC ${ }^{809}$ ) in Uganda. Birth registrations through mobile phones and SMS are already taking place in Nigeria ${ }^{810}$ and Uganda. ${ }^{811}$ RapidSMS is also being used to collect data on facilities and attendance from schools. $^{812}$ For monitoring water and sanitation, mobile applications like Akvo FLOW (Field Level Operations Watch $)^{813}$ permit collecting and reporting data on any device running a modern web browser. The system has been used in 17 countries in Africa since 2010. In 2011, the Liberian government, assisted by the World Bank, used Akvo FLOW to map 10,000 water points in Liberia. The mWater service ${ }^{814}$ - used by 240 small public-private piped water schemes in Senegal, Mali, Benin and Niger - is a mobile-to-web platform allowing water-service operators to share information with national authorities and financial institutions via mobile phone. Text messages provide data about water production levels, account balances and service disruptions.

\section{Box 8-4. Using cell phone records to estimate population} flows and design targeted policies against Ebola

The benefits of cell phone detailed records (CDRs) in the context of the current Ebola outbreak are clear. The rapid spread of the virus has been driven by local and regional travel.815 Epidemiological models of the spatial spread of Ebola rely on estimates of the volumes and flows of traffic between populations. This allows modellers to assess the likely routes of infected individuals between populations, with imported cases sparking new outbreaks or augmenting local transmission. Since mobility is not only a major driver of the epidemic, but is also likely to shift dramatically in response to the outbreak and be directly targeted by control policies, these estimates are critical. Figure 8-2 shows population flows in West-Africa estimated by CDRs. Although CDRs cannot currently capture cross-border movements, understanding the potential routes of spread of the virus within a country are critical to national containment policies. 
Figure 8-2. Mobility patterns in West-Africa according to cell phone records

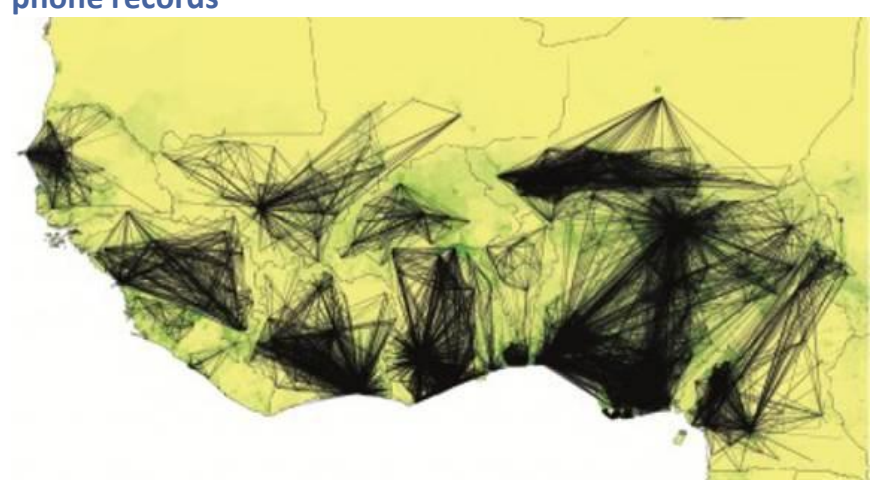

Source: Wesolowski et al. (2014).

Another setting where data collection and sharing with SMS and cell phones has proved useful is in monitoring disease outbreaks, such as the Ebola epidemics in West Africa. Smart phones have been deployed in Ebola affected countries to monitor Ebola cases - this approach is time saving, as the information on cases can be pulled together in a quicker way than the traditional routes of reporting. ${ }^{816,817}$ Maps showing Ebola cases and the location of Ebola Assistance Centres have been used to assist Ministries of Health in deciding where to build new centres and allocate health resources. ${ }^{818}$

\subsection{Tapping into big data}

Big data has been described by its volume, due to the massive data sets coming out from satellite images, social media, online commercial transactions and cell phone records, among others. But its real power comes from the fact that these data are continuously generated and contain information that can trace many aspects of human life. Big data has also been called the "data breadcrumbs", i.e. the data people leave behind as they go about their daily lives (for a more detailed discussion on big data, see Chapter 7). It is thus not surprising that these data are being explored to fill data gaps in Africa. In a region struggling for resources to implement functional statistical systems, and with numerous data gaps, big data can complement other data sources. In particular, it can provide fine granular data in space and time to uncover so far hidden local heterogeneity, as long as privacy of the individual is protected (see section 7.5 on big data in Chapter 7 for more details on privacy).

\subsubsection{Cell phone data, social media and internet searches}

Cell phone service providers maintain data sets with Call Detail Records (CDRs), which contain the time of every voice call or SMS exchange and the duration of the call along with the approximate location of the cell phones involved. Because they are routinely recorded for resource planning and billing, these records provide a comprehensive, inexpensive and continuing source of information. The information is often available quickly, within minutes after a cell phone or SMS communication occurred. Phone companies typically have records of call patterns among their customers extending over multiple years. This allows not only access to real time data but also to historical data. CDR location information is imprecise as it is determined by the towers that captured the signal, but remains practical for many data applications (see section 7.5 on big data in Chapter 7). The spatial granularity of the data depends on the range of a cell tower which tends to be, in sub-Saharan Africa, from 5 to 10 kilometres. ${ }^{819}$

Compared to other regions, the number of applications using CDR analysis for topics related to sustainable development has been low in Africa (see Table 7-5) on big data in Chapter 7). The few existing applications show however promising results. They tend to be from countries which have already achieved a relatively high mobile phone usage, like Senegal and Côte d'Ivoire. The release of the data by the cell phone service providers in these two countries has also encouraged a lot of research in exploring applications of these data (see section 8.4).

Cell phone records have been used to produce estimates of poverty in Côte d'Ivoire, ${ }^{820}$ literacy rates in Senegal ${ }^{821}$ and food expenses in a country in East Africa (Box 8-5); ${ }^{822}$ as well as to determine travelling patterns to better manage public transportation in Côte d'Ivoire, ${ }^{823}$ among others. ${ }^{824}$ CDRs are also being used for malaria prevention in Kenya ${ }^{825}$ and for estimating population flows to inform the Ebola response in West Africa (Box 8-4). ${ }^{826}$ Despite concerns on the lack of representativeness of these data - which leaves those without cell phones out - studies have succeeded in obtaining reliable estimates (see e.g. Box 8-4).

This is not surprising as cell phone access in Africa is increasing dramatically and thus expanding the coverage of CDR data. In 2013, about $65 \%$ of the population in subSaharan Africa was in areas with sufficient signal to connect to a mobile network. In several African countries, more than $60 \%$ of households have at least one mobile phone (Figure 8-3). In some African countries, the percentage is more than $80 \%$. 
Figure 8-3. Percentage of households with mobile phones, 2011-2014

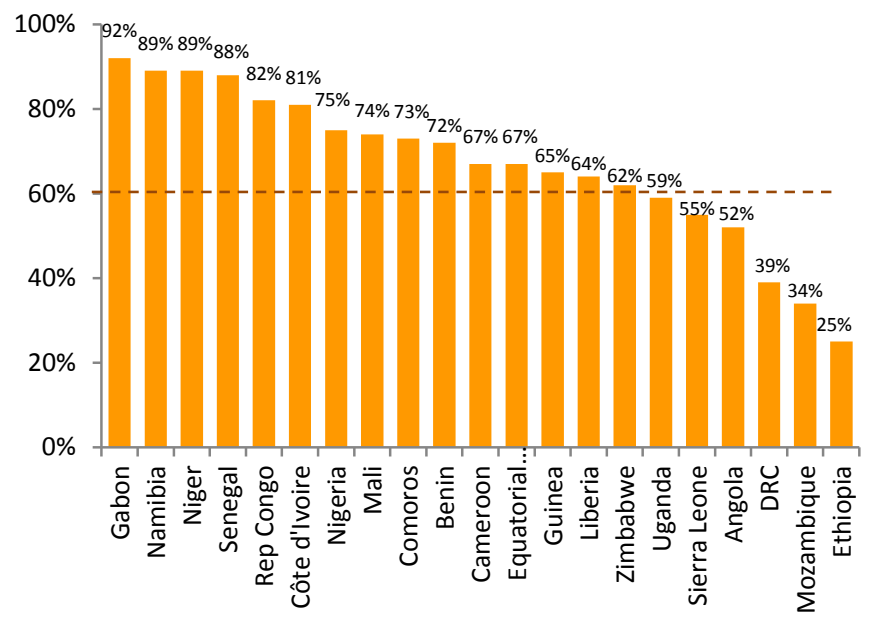

Source: DHS surveys. ${ }^{827}$

Box 8-5. Using mobile phone data and airtime credit purchases to estimate food security and poverty

As mobile phone handsets have become more ubiquitous across Africa, the data generated by the use of mobiles presents a unique new opportunity for policy makers to understand vulnerable populations. UN Global Pulse and the UN World Food Programme, together with Université Catholique de Louvain in Belgium and Real Impact Analytics, conducted a study to assess the potential use of mobile phone data as a proxy for food security and poverty indicators. Data extracted from airtime credit purchases (or "top-ups") and mobile phone activity in an East African country was compared to a nationwide household survey. Results showed high correlations between top-up expenditures and consumption of several food items, such as vitamin-rich vegetables or meat. These findings demonstrated that spending on top-ups could serve as a proxy indicator for food spending in market-dependent households. In addition, models based on both anonymised mobile phone calling patterns and top-ups were shown to accurately estimate multidimensional poverty indicators. This preliminary research suggested that proxies derived from mobile phone data could provide real-time, granular information on the level of several food security and poverty indicators. This framework could be integrated into early warning and monitoring systems, filling data gaps between survey intervals, and in situations where timely data is not possible or accessible.

Another known source of big data is social media - a set of internet-based applications and websites that allow users to communicate directly with friends and strangers alike. Social media have been increasingly used worldwide to monitor human behaviour and opinions as well as to estimate larger phenomena using people's reaction as a proxy. For instance, increased social media conversations about work-related anxiety and confusion provided a threemonth early warning indicator of an unemployment spike. $^{828}$

Figure 8-4. Food expenditures and "top-up" expenditures (>0.7 correlation)

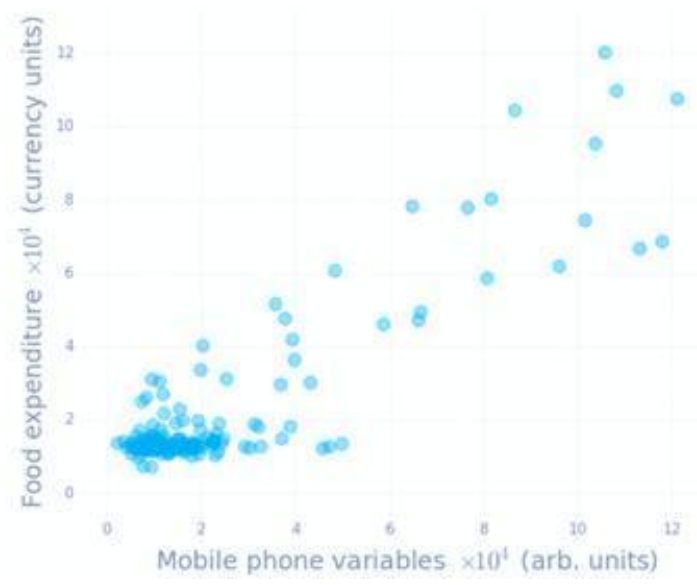

Source: UN Global Pulse.

Social media analysis "for development" is not common in Africa, but there are already a few examples: attitude analysis using Facebook data towards contraception in Uganda $^{829}$ or accessibility of finance for small businesses using twitter data in Kenya. ${ }^{830}$ One of the challenges of using social media, data online searches and online transactions for monitoring sustainable development in Africa is the low internet penetration rate: only 38 internet users per 100 people in Northern Africa and, even fewer, 15 internet users per 100 people in sub-Saharan Africa as of 2012. ${ }^{831}$ No country in Africa has internet penetration rates above 50 internet users per 100 inhabitants. However, social media data, often of limited use due to group selection biases, can still be of value when targeted at specific sub-populations which more commonly use social media, like the youth or businessmen.

\subsubsection{Satellite data}

Satellite imagery has been around for a few decades but, in the early 21st century, became widely available when affordable, easy to use satellite imagery databases were offered by several companies and organizations. ${ }^{832}$ Because the images are routinely taken by satellites in orbit, satellite images are a vast, comprehensive and continuing source of information.

This prompted an explosion of innovative applications using satellite imagery, some covering African countries, from estimating $\mathrm{GDP}^{833,834}$ to crop productivity. ${ }^{835}$ Satellite 
images are also permitting to monitor changes to ecosystems and natural resources in Africa, like lake Chad. $^{836}$

Satellite images have become one of the key resources to assess vulnerability to natural disasters, including droughts and floods. In Africa, satellite images have been used to identify flood risk areas in Namibia, ${ }^{837}$ Senegal (Box 8-9) and Sudan (Box 8-7); and data from satellite imagery has been combined with GIS and precipitation data to produce a flood risk map along the Niger-Benue river. ${ }^{838}$ Nigeria is participating with UK, Spain and China, in the Disaster Monitoring Constellation (DMC), ${ }^{839}$ the first Earth observation constellation of low cost small satellites providing daily images for applications including global disaster monitoring. The Disaster Monitoring Constellation aims at providing both commercial and free satellite imagery for humanitarian use in the event of major international disasters.

Satellite big data applications are likely to continue to emerge in the years to come. Given the importance of these data, a few countries in Africa - Algeria, Egypt, Nigeria, and South Africa - have launched their own satellites. ${ }^{840}$ These countries negotiated multilateral partnerships to establish the African Resource Management constellation (ARMC), ${ }^{841}$ to pool imagery and other remote sensing data from all their micro-satellites. This joint project is meant to form the cornerstone of the African Satellite Constellation dedicated to the monitoring and management of African resources and environment.

\subsection{New approaches to integrate data}

\subsubsection{Integrating multiple data sources}

Methods to integrate diverse data sources, such as census and surveys, satellite and ground information, have been in existence for some years but their usage is not yet widely spread. These methods attempt to fill data gaps and/or improve the timeliness and geographical resolution of data, by pulling together information from various sources.

A case in point is the production of poverty maps by combining census and survey estimations (Box 8-6). This approach has not been used widely in African countries because, for some of them, the census and the surveys either don't even exist or are too old. As innovative big data approaches attempt to fill the poverty data gaps, more research will be needed to further integrate big data with census and survey data.

Some examples integrating "big" and "small" data are already out there. Worldpop ${ }^{842}$ combines satellite, census and cell phone data to create detailed and freely available datasets and maps with high resolution on poverty, population, births, pregnancies, urban change and age structures. Using this small and big data approach, population maps have been produced for most African countries, even those for which census data is very old and official population figures are inexistent or unreliable.

\section{Box 8-6. High resolution poverty maps}

An understanding of poverty and inequality levels at detailed spatial scales is a prerequisite for fine geographic targeting of interventions aimed at improving welfare levels. Similarly, decentralization in many countries has meant that decision making for poverty alleviation programs is shifting from central government to regional or local levels. Such decisions should ideally be based on reliable, locally-relevant information on living standards and the distribution of wealth. In most countries such information is not readily available. Data on material living standards generally come from household surveys. Nationally representative household sample surveys rarely permit a fine disaggregation of the population by place of residence.

In recent years there has been an accumulation of experience with methods to estimate poverty drawing on household survey data alongside population census data, based on statistical techniques. One approach, explored by the World Bank in collaboration with researchers in academia, combines household and census data using statistical procedures aimed at taking advantage of the detailed information available in household sample surveys and the comprehensive coverage of a census. An important feature of the small area estimation approach is that it produces confidence intervals for its estimated welfare measures. These can be examined to gauge the reliability of the estimates. Successful applications of combining census and survey data to obtain poverty estimates ${ }^{843,844}$ at the level of small communities with perhaps only 5,000 households have been produced for several African countries. $^{845,846}$

Another audacious example, the Global Forest Watch (GFW) ${ }^{847}$ combines satellite technology, open data, and crowdsourcing to produce timely and reliable information about forests worldwide. The platform is used to detect deforestation - particularly illegal deforestation -, classify land cover, estimate forest biomass and carbon, and map the world's roadless areas. It functions as a monitoring and alert system that empowers people everywhere to better manage forests, including people in Africa. 
Figure 8-5. Poverty map for Guinea, 2002/3.

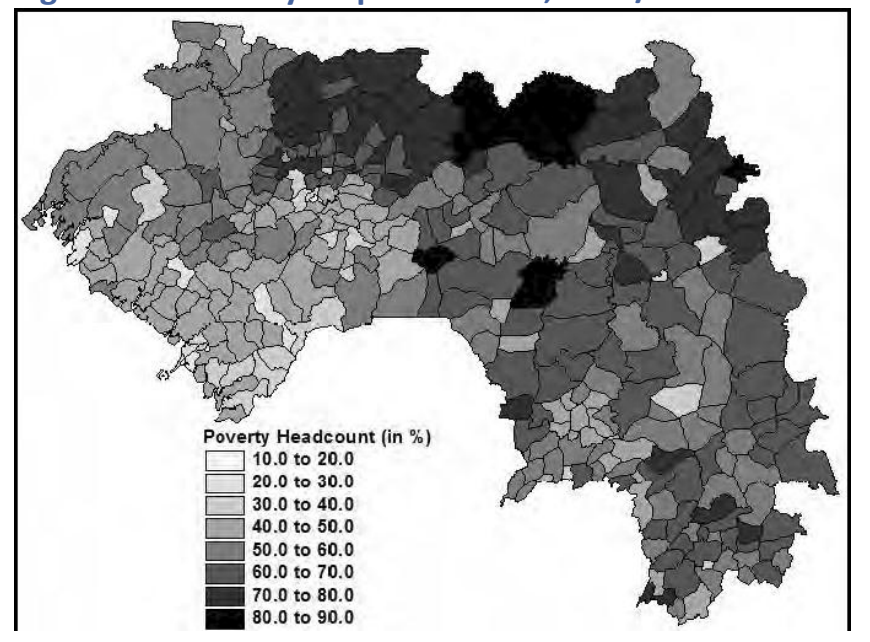

Source: H. Coulombe (2008), ${ }^{848}$ @ World Bank.

By integrating as many sources of data as possible, maps of terrestrial ecosystems in Africa were recently produced at a $90 \mathrm{~m}$ resolution. These maps represent the finest spatial resolution data of its kind ever produced for the entire continent. Several layers of data on climate regions, landforms, geology, and land cover were combined to produce these maps. Some of those layers were originally developed using satellite imagery. ${ }^{849}$ These maps are useful for biodiversity conservation, for assessments of the value of ecosystem goods and services and to better understand how and which ecosystems are being impacted by climate change and other disturbances.

Box 8-7. Using satellite data in Sudan for flood prediction and detection

Hundreds of villages line the banks of the river Nile, and because of their proximity to the river banks are adversely affected in years of above average floods. In recent years, the Sudan Survey Authority has been using geospatial technologies to monitor the flow of the River Nile using satellite imagery data (MODIS provided by NASA) on a daily basis to ensure the flooding risk to their citizens is minimised. Sudan has developed hazard and risk maps as a basis to run multiple flood scenarios, depending on the specific water levels of the River Nile. The scenarios are able to approximate the level of impact to citizens and their economic resource base such as agricultural land. It is difficult for governments to impose restrictive access policies to sources of livelihood such as water, even if those same sources create risks to the population residing nearby. Therefore, it is important for countries such as Sudan to have continuous monitoring capabilities to be able to warn their citizens when natural hazards such as flooding may take place, and to ensure that there is an effective and efficient emergency response.
Figure 8-6. Flood zone levels and the related risk in Sudan: (1) high risk, mainly from the river Nile; (2) high risk, mainly from the Valleys; (3) rarely affected by the Valleys.

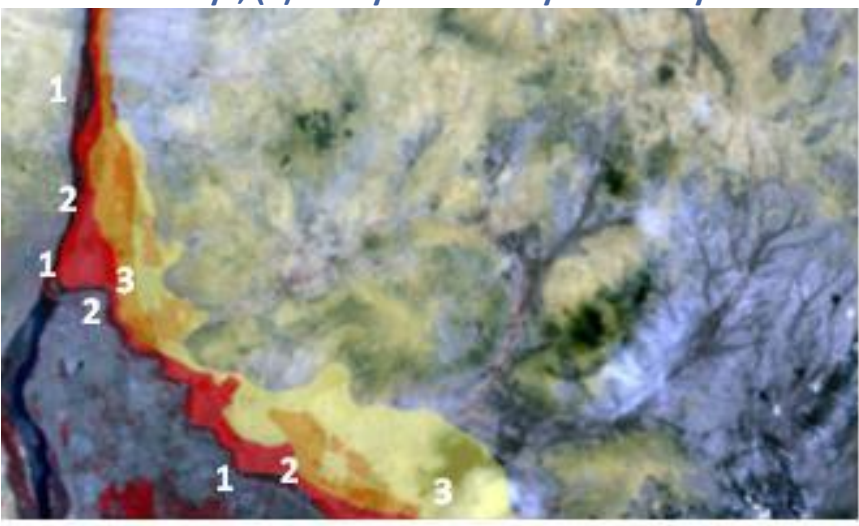

Source: Alhussein (2014). ${ }^{850}$

\subsubsection{Integrating geographical information}

Governments now rely on comprehensive and accurate, location-based information to support strategic priorities, making decisions, and to measure and monitor outcomes. Overall, the use of geospatial information and technology by African countries is increasing, with many innovations in numerous areas (see Box 8-7 to Box -8-9). This expansion of geospatial initiatives has been grounded on the spread of mobile devices for data collection with geo-positioning (see section 8.1) and an enhanced accuracy of GPS data in Africa. The improved accuracy of the GPS data in Africa is due to a rise in the number of GPS based stations, as part of the African Geodetic Reference Frame (AFREF) project. ${ }^{851}$. Recent survey results indicate that there are 116 GPS base stations and a total of 43 stations broadcasting data to be used for computing position data. All African countries have started utilizing Global Navigation Satellite Systems (GNSS), in particular GPS, in various geospatial applications. ${ }^{852}$ With the recent UN General Assembly's adoption of a resolution on the Global Geodetic Reference Frame for Sustainable Development, the region can benefit further by having a global framework to improve the positional accuracy of data in Africa. ${ }^{853}$ 
Figure 8-7. Lake Victoria Water Quality Assessment Visualization Tool

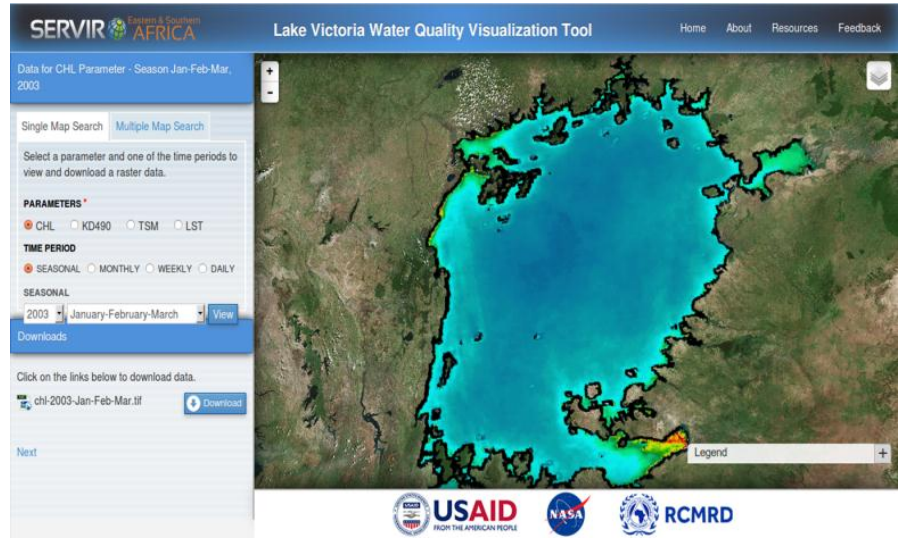

Source: Regional Centre for Mapping of Resources for Development (RCMRD), www.rcmrd.org

National and regional initiatives are also expanding the use of geospatial data. The Regional Centre for Mapping of Resources for Development (RCMRD) in Kenya is not new it was established in 1975 - but the work it develops in generating and applying geospatial information to natural resource and environmental management problems is at the forefront of geospatial innovations in the African continent. $^{854}$ By providing services on demand to 20 countries in South and East Africa, it ensures a demanddriven approach. By centralizing resources to address the needs of 20 countries, it optimizes resources and facilitates knowledge sharing across countries. Developed applications include geographical assessments of soil erosion, lake Victoria water quality assessment (Figure 8-7), flood forecasting, GHG inventories and urban mapping. RCMRD has also developed a smartphone application which takes as inputs land and soils characteristics and provides in return a graph illustrating production potential and erosion susceptibility for the site.

Countries in Africa are increasingly using geospatial information to inform policy, for instance for better allocating health care resources (e.g.Box 8-8), for vulnerability assessments for climate change and disaster mitigation, ${ }^{855}$ for mapping risk of soil loss, among others. ${ }^{856}$ Several official data collection processes are already recording geographical information using GIS (see section 8.1). For instance, the Ghana Statistical Service digitised the geospatial information using GIS in the 2010 Population and Housing Census and Living Standard Survey. The ability to build the collected statistical information on a geospatial platform allowed Ghana to produce products such as population density and poverty incidence maps at subnational scales.
Box 8-8. Geospatial technology for improved health and emergency planning in Egypt

Egypt's Health Sector Reform Program, in the Ministry of Health and Population, improved emergency response using geospatial technology and location-based analysis. The Ministry collected geospatial information within Egypt's standard administration regions (Governorates) identifying all ambulance station locations and resources; road and highway networks; and then linked them to geographic population density data to identify areas of ambulance service. Spatial and statistical analysis then quickly enabled the Ministry to identify those areas of population which were better served by ambulances, and also determine those areas which lacked the appropriate services. This same use of geospatial information also allowed decision makers to determine ambulance response times, based on road and traffic situations, and to determine new ambulance station locations based on the population growth and demands.

Figure 8-8. Location of ambulance units (triangles) and areas with population size greater than 100,000 inhabitants and more than $10 \mathrm{~km}$ away from the nearest ambulance unit (brown areas)

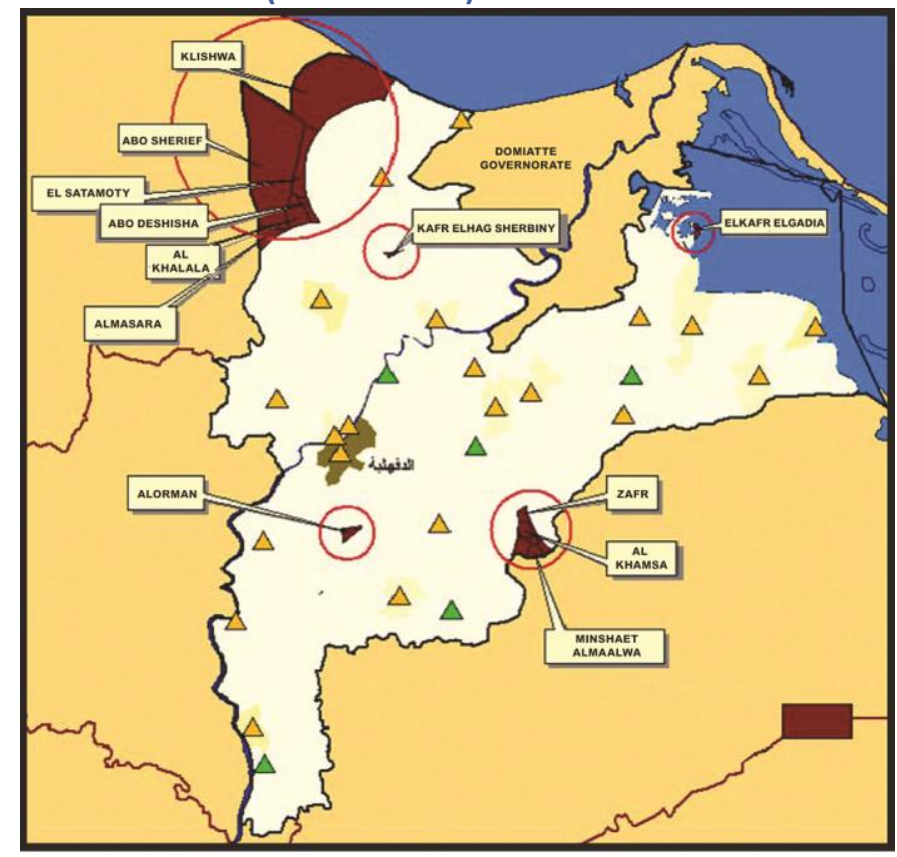

Source: Adapted from Central Agency for Public Mobilization and Statistics (CAPMAS), ww.capmas.gov.eg

A few African countries, like Kenya and Rwanda, have developed their own National Spatial Data Infrastructure (NSDI), which defines the technologies, policies and institutional arrangements facilitating the availability of and access to spatial data for all levels of government, the commercial sector, the non-profit sector, academia and citizens in general. 
Figure 8-9. Map of internet connectivity and Ebola treatment centres, Liberia

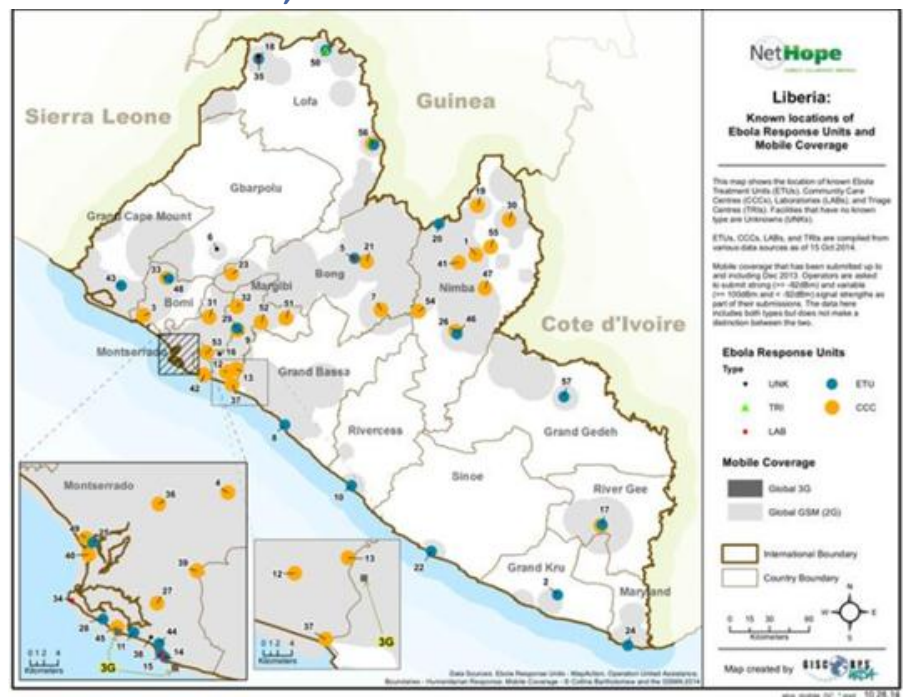

Source: NetHope, www.nethope.org

NGOs and research institutes working in Africa have increasingly been using geospatial information to enhance their programmes. A case in point is Nethope's mapping of Ebola treatment centres and internet connectivity to determine the location of future installation of emergency equipment providing internet access, which was crucial to report Ebola related data (Figure 8-9). The International Research Institute for Climate and Society (Columbia University) has also used satellite imagery to produce maps of the presence of desert aerosols (dust) in the air covering several countries in the northern part of Africa. Since breathing those aerosols makes one more vulnerable to meningitis, these maps are being used as predictive indicators to epidemics of this disease. ${ }^{857}$

\subsubsection{Integrating climate information}

Almost all African countries have national meteorological services (NMS) providing climate services, but their capacity to produce climate data is variable and mostly limited. A number of institutions as well as important public-private partnerships (PPP) are exploring innovative approaches for climate services.

One of the most recent innovative approaches in climate data generation is a PPP involving ACPC, IRI of Columbia University and hydro-meteorological instrument providers. This initiative "rescues" existing historical data through digitization of historical data and calibrates it with satellite data to generate nationwide gridded data by converting the point data to spatial coverage. This covers key parameters like rainfall and temperature (Box 8-10). Online map-rooms showing the climate data are already established for Ethiopia, ${ }^{858}$ Madagascar, ${ }^{859}$ Rwanda ${ }^{860}$ and Tanzania. ${ }^{861}$
Box 8-9. Using Earth Engine to assess socio-physical vulnerability to disasters in Senegal

A tool predicting socio-physical flood vulnerability in Senegal at high, sub-national resolution in near-time and in future scenarios has been developed. It relies on publicly available satellite imagery in Earth Engine862 and demographics data to refine a surface of risk inside any area of interest (e.g. country, watershed or storm prediction zone). The satellite imagery is used to determine the physical vulnerability while the demographic data is used to determine the social vulnerability. The tools final product is an online map of the results (see Figure 8-10). Given that the data for this model are publicly available and that the Earth Engine platform is cloud based (i.e. no local high computational power is needed), this type of tool can be easily applied in under resourced countries as a quick and cheap hotspot, diagnostic tool.

Figure 8-10. Combined socio-physical vulnerability to flooding in Senegal.

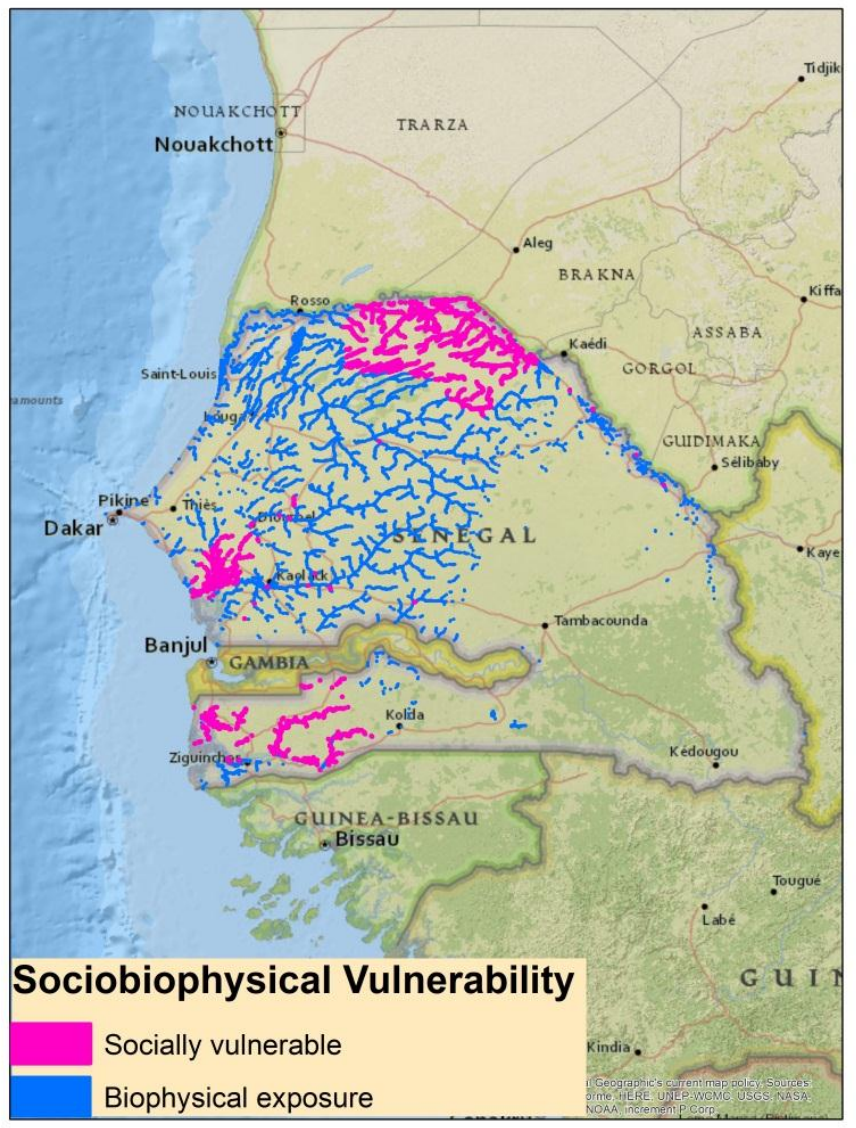

Source: Schwarz B., Tellman B., and Adams C. (2015). Unlocking the Big Data for Resilience with Google Earth Engine: Spotlight on Flood Vulnerability Predictions for Senegal. 
Box 8-10. Mixing different data sources to improve the availability of climate data in Africa

Past and present climate information is critical to inform climate resilient development, but climate data in Africa is often not available. Weather station coverage on the continent is a fraction of what the World Meteorological Organization considers to be basic coverage. While improving station network density is vital to improving the availability of climate information, investments in new observation stations made today will not resolve existing gaps in historical data. Besides, it is not financially feasible or practical to install weather stations everywhere.

The International Research Institute for Climate and Society at Columbia University, in collaboration with partners, has been leading an ambitious effort to simultaneously improve the availability, access and use of climate information at national levels: Enhancing National Climate Time Series (ENACTS). It focuses on the creation of reliable and actionable climate information that is suitable for national and local decision-making. To fill spatial and/or temporal data gaps, ENACTS combines quality-controlled station measurements with satellite rainfall estimates for rainfall and climate observations, model forecasts and/or satellite for temperature datasets (Figure 8-11). The final products cover 30 or more years of rainfall and temperature time series for every $4 \mathrm{Km}$ grid across a country.

Figure 8-11. Station observations (top left) are combined with satellite rainfall estimates (top right) to produce a more spatially complete and accurate estimates (bottom),

Tanzania
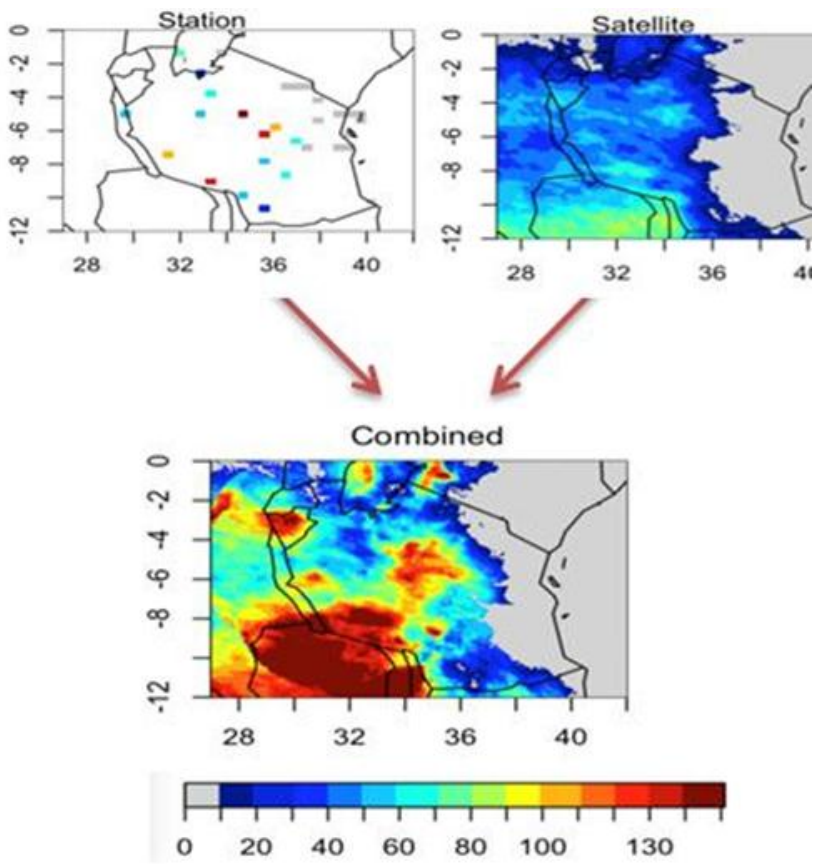

Source: Dinku (2015). ${ }^{863}$
Other tools are being developed in Africa to integrate climate data with other sources in order to assess the impact of climate change. The Demographic Explorer for Climate Adaptation (DECA) was established for Malawi. ${ }^{864}$ Developed by UNFPA, this tool integrates population infrastructure and climate data to illuminate the linkages between population dynamics and adaptation to global climate change. Climate data is also being combined with historical malaria prevalence data to predict peaks of malaria transmission. ${ }^{865}$

\subsubsection{Integrated environmental-economic accounts}

The System of Environmental-Economic Accounting $(\mathrm{SEEA})^{866}$ is a framework to integrate environmental and economic information. This system enables any data users to analyse environmental issues and their linkages to the economy, knowing that the comparisons are based on the same entities, for example, pollution levels caused by a producing industry can be linked to the specific economics of that industry. Environmental-Economic Accounting can be developed for specific resources - like water, energy and ecosystems - and for specific sectors - like agriculture or tourism. For instance, water accounts records the flows and stocks of water and stock of water and links them to economic information such as price of water, costs, charges, tariffs, etc. as a way of raising awareness of water use and the overall costs associated with water use. ${ }^{867}$

Although the use of environmental-economic accounts in Africa is still limited, some countries have made advances in certain areas. A Global Assessment on Environmental Economic Accounting, carried out between October 2014 to January 2015, received responses from eleven countries in the African Region: four countries currently have a programme on environmental-economic accounts; six countries have plans to begin a programme on environmental-economic accounting in the future. Among these ten countries, the accounts most commonly compiled and prioritized are energy and water accounts, as well as environmental taxes and subsidy accounts. Some countries have already a wide program of environmental-economic accounts. South Africa, for example, has already developed environmental-economic accounts in five areas, namely water, minerals, energy, fisheries and land. ${ }^{868}$

South Africa has taken a geographical approach to land accounts that can provide deeper insights into the areas that are undergoing greater rates of land use change. Further, the use of geographical information provides a clearer link to fundamental ecosystem services such as the provision of water, water filtration, and carbon sequestration, as well as highlighting those ecosystem types and associated species that are most threatened by loss of natural habitat (see Box 8-11). 
Box 8-11. A geographical approach to land accounts in South Africa

South Africa's National Development Plan 2030869 highlights the need for programmes to conserve and rehabilitate ecosystems and biodiversity assets. It calls for full cost accounting that internalises environmental costs in planning and investment decisions. In order to understand the changes in ecosystems and biodiversity assets and their ability to provide ecosystem services, pilot land cover and land use accounts were developed. Consistent land cover data at a fine spatial scale $(20 \mathrm{~m}$ resolution) were available from the provincial conservation authority, Ezemvelo KZN Wildlife, for the period 2005-11 (Figure 8-12). Analysis of KwaZulu-Natal's land cover data showed that between 2005 and 2011 there was outright loss of approximately 570,000 ha of natural vegetation, or about $7 \%$ of the province's area, much of which was converted from grassland or savanna to low density settlements or to cultivation. This habitat conversion can have cumulative impacts on ecosystem services like water and energy provision, which in turn can have an impact on economic and social goals and policies. Indeed, in KwaZulu-Natal, approximately 400,000 households (16\%) use wood as their main energy source for cooking, and approximately 350,000 households (13.5\%) have no formal water supply infrastructure.

Figure 8-12. Land cover data, KwaZulu-Natal, South Africa

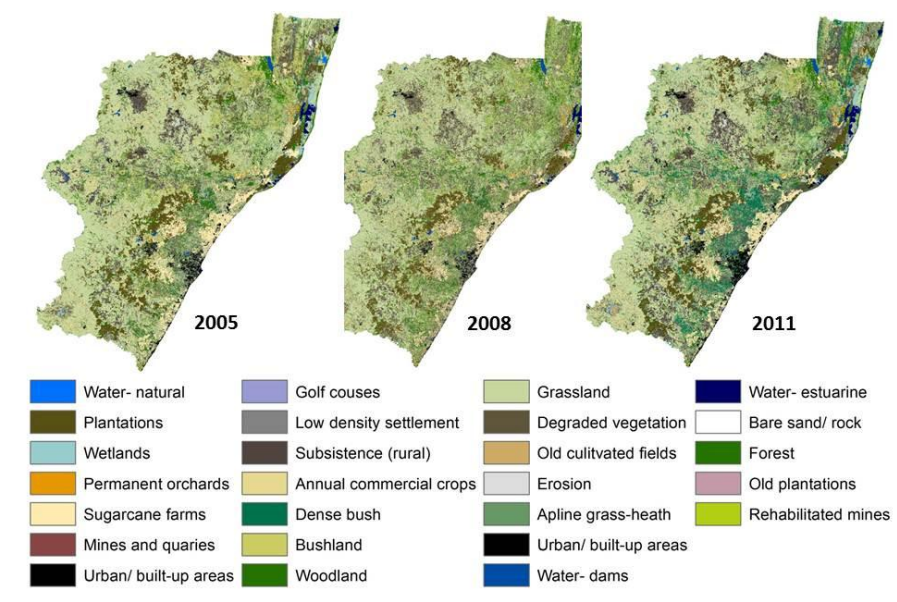

Source: Data courtesy of Ezemvelo KZN Wildlife.

\subsection{Innovative means of sharing data}

In many countries, users are often frustrated by limited access to data and the absence of tools to allow for analysis and visualisation. As elsewhere in the world, data access in Africa can bump into institutional, financial and technological obstacles. Some initiatives promoting free dissemination of data have been established, but to understand how innovative they are, it is worth analysing first how accessible data currently are across official institutions, big data providers, scientific institutions and NGOs.

Websites are considered the most practical mean to access data. Worldwide, national statistical offices from only five countries do not have a website, but three of these are in Africa. ${ }^{870}$ Another five African countries have a nonfunctional website. ${ }^{871}$ Even when a website exists, the official statistics are not always available online and even when they are, the format is not always easy to download and manipulate. A recent preliminary study evaluated nine countries worldwide on the openness of their official data three of them in sub-Saharan Africa. The evaluation criteria considered a country to be more open towards its official data if: data are available in machine-readable formats and can be read with free and non-commercial software; users can select the data of interest to them; metadata are present; the terms of use of the data are clear and allow for free use and reuse of the data. The three sub-Saharan African countries had comparatively lower scores than countries from other regions. ${ }^{872}$

Access to data other than official statistics is more difficult to evaluate, as there are no worldwide established practices. Providing access to cell phone records is often a decision of the cell phone carriers. Most application of cell phone records for development purposes are concentrated in a few countries in Africa, in part because those countries have more collaborative cell phone carriers. Raw social media data is also not readily accessible. Google has a basic online interface in which users can look for frequency of online searches of a given work or phrase since $2005 .^{873}$ Twitter and Facebook have developed free tools for users to search for specific data, but these tools have limitations in their accuracy and coverage. But the raw social media data, which would be needed for proper data analysis, is expensive. ${ }^{874}$

Low resolution satellite images tend to be free ${ }^{875}$ but higher resolution images, ${ }^{876}$ which are needed for instance for urban planning and management of land ownership, are commercial (though often free for research purposes). The prices of high resolution images vary with the vendor but, in general, are expensive. Although the cost is going down globally, high resolution images are still not affordable by many users in developing nations, including Africa. Due to these unaffordable costs, organizations in Africa often compromise the accuracy of the geo-information produced by using lower resolution satellite data.

As for scientific data, researchers and scientific institutions have their say on what to share but there have been strong 
calls for open scientific data worldwide, ${ }^{877}$ and the International Council of Science (ICSU) has established in 2009 the World Data System to facilitate data sharing among scientists - but these data are not necessarily available to the general public. In Africa, where researchers tend to suffer from insufficient resources, absence of data sharing can be due rather to lack of financial and technological resources to disseminate it. Nongovernmental organizations (NGO) are increasingly producing data to feed into the evaluations required by their donor agencies - depending on the agreement, these data may belong to the NGO or the donor who may or may not provide access to the data.

But more and more online platforms in or covering African countries are disseminating free data. The Open Data for Africa portal provides free online data to monitor development, at national and sub-national levels (Box 8-12). The Famine Early Warning System Network developed a dedicated African Data portal giving access to spatial data, satellite imagery, and other data as well as graphic products in support of famine monitoring. ${ }^{878}$ Open Data for the Horn facilitates access to geospatial information, data and knowledge sources, about the ongoing response to the drought in the Horn of Africa. ${ }^{879}$ Several websites are dedicated to disseminate free maps, GIS datasets and satellite images to assist the monitoring and management of natural resources and agriculture in Africa, including the African Platform for Knowledge and Data sharing on Earth Observation, ${ }^{880}$ ENDELEO $^{881}$ and the Global Monitoring for Food Security. ${ }^{882}$

\section{Box 8-12. Open Data for Africa}

A resolution of the African Heads of State on statistics at their summit of July 2012883 called for the development of an Africa database and support for countries to improve data management and dissemination systems to increase public access to data. The Africa Information Highway (AIH) initiative is a response to this directive. As a result, Africa is the first continent with an integrated data dissemination system. The Open Data for Africa portal, which was created by the African Development Bank under this initiative, provides free online data to monitor development, at national and sub-national levels. The 54 African countries and nine regional institutions contribute to this platform. The Open Data Portal can incorporate/disseminate data from national, international, unnamed or any other source. Any user can disseminate data on this platform and users can directly share data content with others through social media. In addition, a separate statistics data portal featuring official statistics from national statistical offices across Africa has also been established.
Data First is a free online data platform hosted by the University of Cape Town and dedicated to making African survey and administrative microdata available to researchers and policy analysts. ${ }^{884}$ USAID created a free online repository of the data from the agency's funded projects, which covers several African countries. ${ }^{885}$ AidData-Open Data for International Development provides free online information on development finance with visualization tools, which can retrieve data for African countries. In Senegal and Côte d'Ivoire, cell phone carriers in collaboration with government ministries, made anonymous data, extracted from the mobile network of these countries, available to international research laboratories. $^{886}$

Countries in Africa are also coming up with their own initiatives for data sharing. Under the Africa Information Highway initiative (Box 8-12), data portals with common IT platforms have been developed and installed in all 54 African countries and in 16 African regional and subregional organizations. As one impressive example, the Nigeria MDG Information System is an online interactive data platform with data on MDG indicators by province (Box 8-1). In addition, all government health and education facilities as well as water access points across Nigeria are mapped - for instance, internet users can use this data platform to know which water points are improved and functional. Rwanda and Kenya are making their census and survey microdata available through an online National Data Archive (Rwanda NADA ${ }^{887}$; Kenya NADA ${ }^{888,889}$ ).

All these innovative ways of data sharing use an online platform. But in order to be useful for populations at large, data and the findings from analysing that data should also reach those without internet access. Successful initiatives already exist. In Mozambique, a prizewinning initiative linked data from water level sensors to an alarm which alerts the local populations when the water reaches the flood alert level, giving the inhabitants in downstream vulnerable areas the time to move themselves and their possessions to a place of safety. To make the system sustainable, the sensors were developed using local materials. $^{890}$

\subsection{Improving the data-policy interface}

Data on its own is useless. Its real value comes from the evidence it can provide to inform decision-makers on which policies do and do not work -impact-evaluation studies provide this evidence. The aim of an impact evaluation is to have an impact, i.e. that as a result of the evaluation findings, policy makers decide to scale up, refine or discontinue. 
There are many well established methodologies to evaluate impacts of policy, but their use in Africa is limited. A review of methodologically sound impact evaluations studies, covering 120 developing countries, multiple sectors and conducted in the last three decades, found that impact evaluation evidence from sub-Saharan Africa is limited, particularly for studies that assess sanitation and hygiene programmes at scale. There is also a lack of studies on the impact of safety nets like conditional cash transfers and insurance. $^{891}$

Although many projects are still undertaken and many data are still collected without a planned evaluation of impact, there are also well-grounded examples of impact evaluation studies that have informed policy in African countries (see Box 8-13). The examples of Box 8-13 use innovative approaches to make them successful for policy intervention. They use of established methodology for determining impact evaluation (most use randomized control trials, but this is not the only valid methodology). In addition, they rely on the integration of evaluation into the programme and planning cycle; timely delivery and the involvement of stakeholders; creation of formal mechanisms to inform policy makers about these studies. Indeed, impact evaluation studies which are conducted within established processes involving policy makers tend to have higher chances to influence policy. ${ }^{892}$ Other initiatives have focused on choosing the right indicators for issue identification, policy formulation and policy assessment, like the UNEP supported pilot initiative in Ghana and Mauritius. ${ }^{893}$

Some impact evaluation studies are already using big data. For instance, satellite images have been used to evaluate the impact of large dams on agricultural productivity in Africa. $^{894}$

\section{Box 8-13. Impact evaluation in Africa - four studies which made an impact on policy making Early Childhood Development in Rural Mozambique ${ }^{895}$ \\ The study found that preschool had a clear impact on child development. Also, preschool children are more likely to have an older sibling at school because the pre-school frees up the older sibling who would have otherwise to take care of the younger sibling. As a consequence of this study, the government included early childhood education for the first time in the national education plan, set up a national early childhood commission and decided to expand preschool to 600 rural communities. \\ Evaluation of Youth Wage Subsidies in South Africa ${ }^{896}$ \\ In South Africa, unions were concerned that the youth wage subsidies would lead to the layoff of existing employees, as employers would replace them for the}

subsidized youth. This study was conducted to address this specific concern and found that the youth wage subsidies had no effect on existing workers. However, the youth wage subsidies had effects on the youth. Employers were more likely to employ youth who had wage subsidies than youth who had no wage subsidies. Also, youth who were subsidised tended to stay on the job once subsidies were over. This study was featured in the press and discussed in parliament; and was used to justify the 2014 budget allocation to youth wage subsidies.

Impact of cook stoves in rural Ghana ${ }^{897}$

This impact evaluation uses a randomised controlled trial to quantify the impact of an improved wood cookstove on changes in fuel use, exposure to smoke and self-reported health in the upper west region of Ghana. The findings showed that the programme did not result in expected reductions in wood fuel use or reduced exposure to fumes. Eight months after project implementation, only half of the improved stoves showed evidence of recent use. Given the low take up of cookstoves, Plan Ghana decided not to expand the programme in its current form. It is working instead on innovating the design to come up with a more appropriate stove.

Impact of "Mama Kits" programs on birth deliveries ${ }^{898}$

The Clinton Health Access Initiative's (CHAI) pilot programme funded by DFID is pioneering a new approach to support health ministries' decision making in Zambia, based on rigorous and demand-driven evidence. One of the evaluations looked at whether offering low cost "Mama Kits" (small packages containing cloth, nappies and baby blankets) upon birth deliveries increases the proportion of women in rural areas giving birth in healthcare facilities. This rigorous and rapid impact evaluation found that Mama Kits are a cost-effective intervention, with an average cost per death averted of $\$ 3,277$. In response, the Zambian Ministry of Community Development, Mother and Child Health scaled up the use of Mama Kits. In 2014 the Ministry drafted an operational plan and secured international funding for wider implementation of the programme.

8.6. Scaling up innovation in Africa: the way forward Innovative approaches are being applied in Africa to improve the timeliness, availability, and use of data for monitoring of progress towards sustainable development. Use of SMS and cell phones to collect data are expanding fast in the continent. But other data innovations are not so widespread. Most existing big data applications use cell phone data or satellite imagery because these are accessible and/or have better coverage. But the other big data is not yet that "big" in Africa as the proportion of people who have bank accounts, use credit cards, use social media etc. is still low. Some initiatives exist to integrate 
data sources and there is an increasing awareness of the need to share data more widely, though many data in Africa remain difficult to access.

Many data innovations in Africa are developed by research institutes and have not yet been used in channels influencing national policy-making. To empower African countries to produce quality frequent data with good coverage, upscaling data innovations is critical.

\section{Novel approaches to data can cover data gaps in areas covered by the SDGs}

For several topics covered by the SDGs, there are new data approaches in Africa, using new technologies, new methods and/or new data sources. The innovations discussed in this chapter and summarized in Figure 8-13 are relevant for poverty, education, water resources, terrestrial ecosystems, natural disasters, climate, and food security. In other countries in the world, novel Big data applications are being used - covering gender education, economic growth, peace and security, etc. - which may also be applicable in Africa (see table 7-5 on Big data in Chapter 7).

There is an increasing tendency to make use of multiple data sources: official statistics, geographic and satellite data, big data, scientific data, data produced by NGOs and research foundations, data from the media, from the crowd and from the business sector. To explore the full potential of these data sources, the data needs to be easily accessible and standardised - so that users are able to integrate difference sources and types of information. Data, and its metadata, needs to be open access (i.e. free and accessible). Most big data is currently owned by banks, mobile phone internet providers, social media providers, etc. Legislation must be put in place to provide secure access for those who need it to implement effective sustainable development policies [D Sanga].

In addition, data from unconventional sources should be provided together with confidence intervals or another uncertainty measure. As different innovative sources come into play, inclusion of uncertainty measures becomes even more important to compare the reliability of different data streams and for integrating them. Statistical models can also assist in exploring hidden information in raw data, in integrating different data sources and in providing information in the form of probabilities and scenarios to be used in decision making. More research will be needed to calculate uncertainty measures for unconventional data sources, identify techniques to correct for selection bias (e.g. data collected through mobile phones or online have a potential selection bias from the fact that generally certain segments of the population are not well covered) and to integrate different data sources.

\section{High mobile phone penetration in Africa offers new monitoring opportunities}

Vast parts of African societies have leap-frogged the age of analogue technology with the help of mobile phones. This gives a window of opportunity to monitoring sustainable development. Across the African continent, greater access to mobile phones has spurred new innovations in data collection and less so in cell phone data use. Access to the internet is still a challenge due to low internet connectivity, and data collection using internet platforms and usage of data produced in the internet - like from social media, online searches, online transactions, etc. - is rare.

The potential of big data depends on country context. In Africa cell phone has penetrated much more than internet. In African countries having very high penetration rates, cell phone data may be more valuable because it covers a larger proportion of the population. In these countries, cell phone records can be explored to increase either the availability or the frequency of data. For countries with low cell phone penetration rates, the usefulness of cell phone detailed records (CDR) is more limited.

Most of the big-data applications, but not all, need to be calibrated against official/traditional data. Therefore, strengthening traditional data sources must remain a priority, particularly in Africa where these sources are poor. Not having functional "small data" systems can be an obstacle for using big data, as there is no small data to validate the big data.

\section{The increasing use of geospatial information needs to continue}

Geospatial information is increasingly being used in Africa, but more capacity building will be needed to scale up existing initiatives and to bring innovative applications from other parts of the world to Africa. While the lack of consistent up-to-date base mapping - fundamental geographic datasets such as geodetic control, elevation, drainage, transport, land cover, geographic names, land tenure, etc. - across Africa remains a challenge, individual countries are making progress. Imagery derived from space-based earth observation platforms are already being used in Africa for improved weather forecasting, land use mapping, producing GHG inventories, and for disaster risk management. Satellite imagery has also been used to address health-environment interlinkages, such as for controlling water quality in lakes, and identifying environmental conditions prone to malaria and meningitis 
epidemics. Some African countries are collecting GIS information regularly in surveys and censuses and are using that geospatial information to map poverty as well as education and health needs and resources. These applications, which have already been successful in a few African countries, can also benefit other countries in the continent.

Other satellite imagery applications, like addressing vegetation fires, optimizing irrigation solutions and monitoring air pollution, monitoring biodiversity and illegal poaching, may also be useful in Africa.

\section{Share data more effectively}

Tools to share data online have been developed; what is needed now is to make them more widely available. In the short-run countries should be encouraged and supported to improve their national statistical and geospatial web sites, establishing data portals and using existing tools for improving access and use of data. Agreements with nonofficial data carriers - private sector, scientific institutions, data-producing NGOs and research institutes - will have to ensure sustainable data streams for monitoring.

\section{High-quality impact-evaluation approaches are being carried out in Africa but at a limited scale - policy-making would benefit from more studies of this kind}

As more and more data are available, more opportunities exist to properly evaluate the impact of policies. However, the emphasis on massive data collection can also draw away resources from impact-evaluation exercises, which have already been insufficient with traditional forms of data. Impact evaluation studies need to be planned from the start of new policies and programs so that proper monitoring mechanisms can be established. Impactevaluation remains expensive and takes time to produce results. More research will be needed to identify faster and cheaper procedures.

\section{Country ownership and capacity building will be key to implement data innovations}

Many African countries actively engage in piloting and implementing innovative approaches for improved data processes and evidence-based policy making. But research institutes and universities are still playing a leading role in using unconventional data approaches. Also, most innovations in the realm of big data are being done by researchers outside Africa. African researchers and national offices need the capacity to pursue data innovations in their own countries.
Further quick wins can be harnessed by starting campaigns, by calling for solutions to data challenges and by encouraging data-driven innovations to address countryspecific problems (like systematic releases of cell phone data to researchers). In the medium-term, mechanisms should be put in place to help countries identify their priorities for research and development. These priorities should then feed into the work programmes of regional and international agencies.

One should not lose sight of that fact that an important reason why these novel approaches are being explored is that many of the statistical systems in Africa are broken: out of necessity practitioners need to look elsewhere for data they need. Yet to inform decision-makers, and to monitor the SDGs, solid statistical systems will still be needed. From this perspective, it is not only important to stimulate innovation but also to incorporate innovations in existing statistical systems and modernizing them with tools like GIS, mobile data collection, open data portals, etc.

\section{Countries need access to independent advice on new technologies and tools and their relative strengths and drawbacks}

At present, too many research and development priorities are determined from the top down, rather than the bottom up. Further, where innovations, for example new software tools, are developed and disseminated by international agencies, countries find it difficult to evaluate and assess their suitability. Often the tools are promoted as part of an aid or technical assistance package and countries may feel obliged to take them up if they want the other parts of the package. Countries need access to independent advice on new technologies and tools and their relative strengths and drawbacks - a catalogue of innovations and a repository of users' reviews by theme/area of application may be useful to inform countries on different alternatives. Such a catalogue and users' reviews could also provide information on how well freely available innovations are an adequate substitute for commercial ones. Innovations that have been identified and documented also need a programme of training and technical assistance to accelerate adoption.

\section{Support data innovations with stable, regular and predictable funding}

A substantial number of developing countries have many calls on very limited resources. For some time they have been dependent on financial and technical aid to provide for investments in capacity as well as to meet the costs of some statistical activities. While it is desirable to increase 
funding, national statistical systems will further have to compete with other institutions for scarce resources. Increases in process efficiency e.g. through innovation can help producing better data and increasing the attractiveness for funding and recruiting. However, very few national statistical systems in low-income countries, especially in Africa, have either the technical or the financial strength to undertake research and development. Even when innovations are ready to be implemented, required initial investments of both money and human resources are often not available. Budget dependence on instable domestic funding and tied international support complicates medium term planning to account for positive future returns from these initial investments. Regular and predictable funding will be needed to implement and scale up data innovations. 


\section{Chapter 9. Conclusions}

Science is no stranger to international sustainable development policymaking. Agenda 21 contains an entire chapter on science for sustainable development. From a plethora of reports through to formalized scientific assessment processes - a prominent example being the Intergovernmental Panel on Climate Change - international sustainable development processes benefit from scientific advice and analysis. Within the United Nations, the Highlevel Political Forum (HLPF) has been given key functions in relation to sustainable development, including being tasked with strengthening the science-policy interface. This year's Global Sustainable Development Report sets out to support that function. It addresses the complex issue of the sciencepolicy interface at a number of levels, cognizant also of the emerging contours of the post-2015 development agenda, in particular the sustainable development goals. Much remains to be settled and decided. Many conclusions are, therefore, of necessity tentative.

\subsection{The science-policy interface and the High-level} Political Forum on sustainable development

A space has been created within the HLPF for strengthening the science-policy interface. Member States will determine more precisely how they wish to go about this. The Rio+20 outcome document refers, in this context, to "review of documentation, bringing together dispersed information and assessments, including in the form of a global sustainable development report, building on existing assessments ... " [para 85(k)]. The current Report concludes that the HLPF could strengthen the science-policy interface in three broad areas. The first concerns highlighting trends and providing policy relevant analysis, drawn from a broad range of sources. The analysis of interlinkages - examples of which are found in chapters three and four of the Report - falls under this broad heading. This function includes applying analysis and evidence of all relevant sciences natural and social - to the task of identifying and addressing obstacles and barriers to progress towards sustainable development. The second relates to actions that the HLPF could take to support enhanced dialogue between scientists and policy makers. In this regard, among the actions that the Report highlights are bringing the work of scientific advisory groups and initiatives to the intergovernmental arena, as well as providing a platform for two-way communication between international assessments and regional and national policy-making. A third cluster relates to the translation of the science-policy dialogue into policy-making. The Report concludes that actions here could include facilitating agreement on emerging issues that may call for an international response and providing guidance to the scientific community regarding research needs to inform sustainable development policy making.

The report highlights the challenges facing countries in special situations - LDCs, LLDCs and SIDS -in reaping the benefits from science and technology. It will be important for all three groups of countries to strengthen the sciencepolicy interface through establishing regular channels of communication and to encourage domestic science, technology and innovation, including through targeted capacity building for both the scientific and technological communities and policy makers. Translating research into briefs for policy makers that suit their timing and needs at different governance levels would be very important.

Concerted action can lead to an improved science-policy interface, as shown by developments in the area of disaster risk reduction. The Report concludes that, in recent years, partnerships between scientific organisations, on one side, and practitioners and policy makers, on the other, have significantly changed the uptake of evidence in DRR planning and policy. Use of scientific research, including risk assessments and probabilistic models, and consideration of the underlying drivers of risk in planning and monitoring should be further promoted. New methods and technological solutions for data gathering are being developed with increasing speed. In order to harness these as efficiently as possible, capacity development and technology transfer will be required to support developing countries.

Dynamic interaction between the policy community and the scientific community is important. The science-policy interface should not be entirely focused on what is currently policy-relevant; it should also be able to identify important emerging issues and challenges which have not yet caught the attention of policy makers. The Report concludes that a future exercise to identify science issues for the deliberations of the HLPF could be built on a broad set of inputs from across the diverse landscape of existing United Nations initiatives to identify "emerging 
issues" in respective areas of expertise, combined with crowd-sourcing to solicit scientific briefs from the "grass roots" scientific community. In this regard, consideration could be given to more systematic approaches for identifying emerging issues, developed in collaboration with United Nations system entities and interested partners from the scientific community.

\subsection{Interlinkages and implementation}

The Report explores, in several chapters, the question how in broad terms science can most usefully contribute to advancing the implementation of the post-2015 development agenda, with special reference to the SDGs. This question can be approached from many angles, but integration is the lodestar for the ideas presented in the Report, given the integrated nature of the SDGs and the post-2015 development agenda. The SDGs constitute a system in which the goals and targets strike a balance among and integrate the three dimensions of sustainable development. There are as well multiple across the goals and targets, which can be represented through network mapping.

Progress towards implementation of the SDGs and post2015 development agenda will need to be informed by sustainability science, that is, transdisciplinary analysis that examines sustainable development in its different dimensions - social, economic, environmental - as well as synergies and trade-offs across issues and sectors. In this context, the Report aims to provide a window into the wealth of assessments and analyses that can inform an integrated approach to policy making for the SDGs and post-2015 development agenda.

Policy makers could learn much from a systematic synthesis of diverse perspectives arising from assessments for particular SDGs and from fully integrated perspectives on the SDGs - across the three dimensions of sustainable development, across substantive areas, and across a wide range of geographic and time scales. In this context, implementation of the recent ICSU/ISSC recommendations on integrated SDG perspectives, contained in their "review of targets for the sustainable development goals: the science perspective", could be considered.

A SDG scenario modellers forum could also support the HLPF, providing and building capacity for integrated SDG modelling to inform both international follow-up and review and national planning and policy making. This could also be supported by an online and open database of international assessments on sustainable development.

The Report illustrates an integrative approach through the scientific coverage of the nexus among oceans, seas, marine resources and human well-being. It concludes that greater scientific attention is needed to socio-economic aspects of the nexus, in particular how human well-being is being and will be affected by degradation of marine and coastal ecosystems; also, how improvements in well-being could impact on the state of oceans and marine ecosystems. Projects and measures should ideally be designed and implemented in an integrated, cross-sectoral and cross-scale manner, in line with the ecosystem approach and involving all stakeholders.

Industrialisation remains a priority for most developing countries, whose productivity levels fall far below those of more advanced economies. Expansion of manufacturing and industrial diversification are proven methods of narrowing productivity and income gaps. The Report examines the role of industrial policies of different kinds in achieving this objective. It also looks at the linkages between industrialization and economic growth on the one hand and sustainable consumption and production on the other. In a globalized economy where much manufacturing is part of integrated global supply chains serving global markets, the preferences of consumers in those markets for products that meet certain whole-of-life-cycle sustainability criteria will have a growing influence on choice of production methods, wherever production occurs. Late industrializing developing countries will need to build capacities of their industries to respond to new and emerging customer preferences. Supplying these growing markets offers opportunities for producers able to meet sustainability criteria, and enhance cooperation trade capacity building could help developing country producers to seize such opportunities.

\subsection{Data for sustainable development}

Data, measurement and their role in the science-policy interface is a recurring theme in this report.

The report illustrates ongoing efforts to mobilize conventional and more innovative data sources to inform decision-making along the whole cycle of disaster risk reduction, from assessing risk, exposure and vulnerability, to supporting risk mitigation through better planning and early warning, to timely disaster response, to ex-post assessment of disaster impacts.

New methods and technological solutions for data gathering are being developed with increasing speed. The 
Report provides a glimpse of new and innovative approaches to making data work for sustainable development policy-making. Thus in Africa, due to the high penetration rates - well above $80 \%$ in some countries - cell phones are being increasingly used for data collection and cell phone data (call detail records and airtime credit) for monitoring development issues. These data have already been used in African countries to monitor poverty, food security, transmission of Ebola and malaria. Other innovative data approaches use satellite imagery to monitor poverty, crop productivity and water quality in lakes, predict meningitis, estimate GDP, detect flooding and map ecosystems. Most of these novel applications need to be regularly calibrated with robust statistics from other sources and thus will require further strengthening of national statistical systems' capacities.

To optimise resources to monitor sustainable development, countries will have to make an assessment of what their data needs are and identify which data innovations can best respond to those needs. The Report points to the potential usefulness of a catalogue of data innovations in all SDG areas, bolstered by users' reviews to inform countries on the effectiveness of different alternatives. Such a catalogue could also provide information on how far freely available innovations are an adequate substitute for commercial ones.

\subsection{Monitoring progress}

Drawing on the example of disaster risk reduction, the Report outlines how several questions related to definitions of terms and the target scope, accounting methods, baselines and data sources will need to be answered when setting up the monitoring framework for SDGs. The work on a post-Sendai DRR monitoring framework offers an opportunity for alignment with the work being done on measuring the DRR-related targets in the SDG. This alignment should help ensure that progress in disaster risk reduction can be reported as an integral part of progress on sustainable development.

In the case of countries in special situations, the monitoring and review of progress should aim to take advantage of synergies between the IPoA, VPoA and SAMOA Pathway, on the one hand, and the SDGs, on the other. The question of monitoring highlights a major challenge that has been recognized by these groups of countries: the lack of accurate and adequate data and statistics, and the need to strengthen national statistical capacities. In addition, another challenge in some cases is that the data does exist, having been collected by national and regional entities, but is not used for international assessments and analyses.

\subsection{The way forward}

This Report is being published a few months before the new post-2015 development agenda with its sustainable development goals is adopted. Thus, its future scope will need to evolve depending on how Member States wish to utilize the Report to support implementation of that agenda, and to assess progress towards the SDGs and the broad pursuit of sustainable development.

Innovative ways will no doubt continue to be explored for engaging the scientific community in the work of the highlevel political forum, in the interests of strengthening the science-policy interface, and for fostering a two-way dialogue between the scientific community and the community of policy-makers. Future editions of this Report will need to be shaped to ensure that it can be a useful tool for achieving these objectives.

Besides performing the "assessment of assessment" function specified in the Rio+20 outcome, if the Report is to inform effectively the work of the HLPF, it would also be important that it incorporate a systematic exercise that enables scientists to bring important emerging issues in sustainable development to the attention of policy-makers for their consideration. 
${ }^{1}$ United Nations, Prototype Global Sustainable Development Report (UN-DESA/DSD, 2014), https://sustainabledevelopment.un.org/globalsdreport/2014.

${ }^{2}$ UN General Assembly, The Future We Want: outcome document of the United Nations Conference on Sustainable Development, resolution 66/288, annex, paragraph 85.k; UN General Assembly, resolution 67/290, paragraph 20.

${ }^{3}$ Jeff Morris et al., Science policy considerations for responsible nanotechnology decisions (Nature Nanotechnology, 2011), 73-77.

${ }^{4}$ UNGA, Options for the scope and methodology for a global sustainable development report (Report of the Secretary-General, E/2014/87, June, 2014), http://www.un.org/ga/search/view_doc.asp?symbol=E/2014/87\&Lang=E

${ }^{5}$ Review of Targets for the Sustainable Development Goals - The Science Perspective, 2015, ICSU/ISSC report, 2015

${ }^{6}$ UN General Assembly, resolution 69/214, paragraph 15.

${ }^{7}$ UN-DESA, Prototype Global Sustainable Development Report, 2014, https://sustainabledevelopment.un.org/globalsdreport/2014.

${ }^{8}$ UNGA, Options for the scope and methodology for a global sustainable development report (Report of the Secretary-General, E/2014/87, June, 2014), http://www.un.org/ga/search/view doc.asp?symbol=E/2014/87\&Lang=E

${ }^{9}$ United Nations, Prototype Global Sustainable Development Report (UN-DESA/DSD, 2014), https://sustainabledevelopment.un.org/globalsdreport/2014.

${ }^{10}$ Scientific Advisory Board of the Secretary-General of the United Nations (2014), UN system priorities related to science for sustainable development, Background paper on items 4 and 5 of the SAB Terms of Reference, https://en.unesco.org/system/files/Background\%20Paper\%203.pdf

${ }^{11}$ Other functions of the HPF include: providing political leadership, guidance and recommendations for sustainable development; following up and reviewing progress in the implementation of sustainable development commitments, including means of implementation; enhancing integration of the three dimensions of sustainable development at all levels; promoting the sharing of best practices and experiences, enhance evidence-based decision-making at all levels; and contributing to strengthening ongoing capacity-building for data collection and analysis in developing countries. See UN General Assembly resolution A/67/290.

${ }^{12}$ United Nations, "Assessments for Sustainable Development," in Prototype Global Sustainable Development Report - (UN-DESA/DSD, 2014), https://sustainabledevelopment.un.org/globalsdreport/2014.

${ }_{13}$ United Nations, Prototype Global Sustainable Development Report (New York: UN-DESA, Division for Sustainable Development, 2014); R. Kates et al., (Sustainability science, Science, 2001), 292; R. Kates, What kind of a science is sustainability science? (PNAS, 2011), $108,49$.

${ }^{14}$ Paul Stock and Rob J.F. Burton. Defining terms for integrated (multi-inter-trans-disciplinary) sustainability research (Sustainability, 2011, vol. 3), $1090-1113$.

${ }^{15}$ United Nations. UN system priorities related to science for sustainable development - Background paper on items 4 and 5 of the SAB Terms of Reference (Scientific Advisory Board of the Secretary-General of the United Nations, 2014), 3.

${ }^{16}$ Paul Stock and Rob J.F. Burton, Defining terms for integrated (multi-inter-trans-disciplinary) sustainability research (Sustainability, 2011, vol. 3), 1090-1113.

${ }^{17}$ United Nations, UN system priorities related to science for sustainable development - Background paper on items 4 and 5 of the SAB Terms of Reference (Scientific Advisory Board of the Secretary-General of the United Nations, 2014), 4.

${ }^{18}$ J. D. Young, A.D. Watt, S. van den Hove, and the SPIRAL project team. Effective interfaces between science, policy and society: the SPIRAL project handbook (SPIRAL, 2013), http://www.spiral-project.eu/sites/default/files/The-SPIRAL-handbook-website.pdf.

${ }^{19} \mathrm{~K}$. Jacobs, Connecting Science, Policy, and Decision-making: A Handbook for Researchers and Science Agencies (NOAA Office of Global Programs, 2002).

${ }^{20}$ For example, the media played an important role in raising awareness of the acid rains problem in Europe. Please see: C. Barrier-Lynn. Scientifiques et acteurs environnementaux, in Sociétés contemporaines (June, 1991), 145-179.

${ }^{21}$ For example, scientific associations (as those identified in the context of science and diplomacy) can be, at least in part, considered as political actors.

${ }^{22}$ D. Cash et al, Knowledge systems for sustainable development (PNAS, 2003), vol. 14, 8086-8091.

2323 J. D. Young, A.D. Watt, S. van den Hove, and the SPIRAL project team. Effective interfaces between science, policy and society: the SPIRAL project handbook (SPIRAL, 2013), http://www.spiral-project.eu/sites/default/files/The-SPIRAL-handbook-website.pdf.

${ }^{24}$ For more information on factors of success for SPI, the reader is invited to consult: P. Gluckman, The art of science advice to government (Nature, 2014), vol. 507, 163-165; Existing guidelines on SPI, e.g. Swiss Academies of Arts and Sciences. Scientific policy advice: recommendations of the Swiss Academies of Arts and Sciences for researchers (Bern: 2011); European Academies Science Advisory Council (s.d.). EASAC guidelines: good practice in the dialogue between science academies and policy communities; as well as: Jones, N., H. Jones and C. Walsh, Political science? Strengthening science-policy dialogue in developing countries, (London: ODI Working Paper No. 294, Overseas Development Institute, 2008); Treyer, S., R. Billé, L. Chabason, and A. Magnan, Powerful international science-policy interfaces for sustainable development (IDDRI, 2012); European Commission, Assessing and strengthening the science and EU environment policy interface (Technical Report 2012-059, 2012); UNEP, Gap analysis for the purpose of facilitating the discussions on how to improve and strengthen the science-policy interface on biodiversity and ecosystem services (UNEP, 2009).

${ }^{25}$ D. Cash et al., Knowledge systems for sustainable development (PNAS, 2003), 14, 8086-8091; European Commission, Assessing and strengthening the science and EU environment policy interface (Technical Report, 2012). ; G. Glase and P. Bates, Enhancing science-policy links for global sustainability (International Council for Science (ICSU) for Stakeholder Forum, 2011); N. Jones, H. Jones and C. Walsh, Political science? Strengthening science-policy dialogue in developing countries (London: Overseas Development Institute, 2008); M. C. Nisbet and D. A. Scheufele, What's next for science communication? Promising directions and lingering distractions (American Journal of Botany, 2009), 96, 10; J. Weichselgartner and, R. Kasperson, Barriers in the science-policy-practice interface: Toward a knowledgeaction-system in global environmental change research (Global Environmental Change, 2010), 266-277.

${ }^{26}$ UNEP, Gap analysis for the purpose of facilitating the discussions on how to improve and strengthen the science-policy interface on biodiversity and ecosystem services, (UNEP, 2009); UNEP, Policy issues: Overview of international assessment landscape considering elements of best practice - Overview of environmental assessment landscape at global and regional levels (UNEP, 2009).

${ }^{27}$ Scientific Advisory Board of the Secretary-General of the United Nations, Embedding up-to-date and rigorous science in high-level policy discussions within the UN system, Background paper on item 2 of the SAB's Terms of Reference; UN system priorities related to science for sustainable development, Background paper on items 4 and 5 of the SAB Terms of Reference; Towards a strengthened science-policy interface, Background paper on item 1 of the Terms of Reference of the SAB; Report of the inaugural meeting, 30-31 January 2014, Berlin, Germany (2014).

${ }^{28}$ For example, a range of issues relating to how to convey uncertainty and complexity to policy makers and the public at large are not discussed in this chapter. See A. Engels. The science-policy interface (Integrated Assessment Journal: Bridging science and policy, 2005), 5, 1, 7-26; European Commission. Assessing and 
strengthening the science and EU environment policy interface (Technical Report, 2012).; K. Jacobs, Connecting Science, Policy, and Decision-making: A Handbook for Researchers and Science Agencies, (NOAA Office of Global Programs, 2002); D. Sarewitz, D., How science makes environmental controversies worse, (Environmental Science \& Policy, 2004), vol. 7, pp. 385-403; Scientific Advisory Board of the Secretary-General of the United Nations, Towards a strengthened science-policy interface (Background paper on item 1 of the Terms of Reference of the SAB, 2014).

${ }^{29}$ UNGA, Options for the scope and methodology for a global sustainable development report. Report of the Secretary-General, E/2014/87 (2014), http://www.un.org/ga/search/view doc.asp?symbol=E/2014/87\&Lang=E.

${ }^{30}$ All the submissions are available online at: http://sustainabledevelopment.un.org/gsdr2014.html.

${ }^{31}$ All the issues identified in this preliminary review are presented in more detail in a background paper prepared for this report, UN Division for Sustainable Development, 2015, Background paper 1 for chapter 1 of the Global sustainable Development Report, Department of Economic and Social Affairs, New York, March.

${ }^{32}$ Briefs and other inputs contributed for this chapter will be posted on the GSDR website.

${ }^{33}$ ICSU has recently created a network of national-level science advisors. A first conference of this network, entitled "Science advice to Governments: An emerging network for leading practitioners", was held in Auckland on 28-29 August 2014. A summary of the meeting and other documents can be found on the network's website, www.globalscienceadvice.org.

${ }^{34}$ United Nations, Prototype Global Sustainable Development Report (UN-DESA/DSD, 2014), https://sustainabledevelopment.un.org/globalsdreport/2014. See

chapter 3, Table 18 for the former, and chapter 6 for the latter.

${ }^{35}$ Including: collecting and synthesizing exiting evidence on the impacts of specific sectoral policies/actions on other sectors for the benefit of policy-makers.

${ }^{36}$ For example, its work contributed to the establishment of the United Nations Forum on Forests by ECOSOC in 2000. In addition, it was on the recommendation of the seventh session of the Commission that the General Assembly establish the United Nations Open-ended Informal Consultative Process on Oceans and the Law of the Sea to review developments in ocean affairs. The recommendation of the second session of the Commission also led to the processes establishing the Rotterdam Convention on the Prior Informed Consent Procedure for Certain Hazardous Chemicals and Pesticides in International Trade and the Stockholm Convention on Persistent Organic Pollutants.

United Nations General Assembly. Lessons learned from the Commission on Sustainable Development, Report of the Secretary-General, A/67/757, February, 2013, 10-11.

${ }^{37}$ Examples of non-UN reports mentioned by contributing experts included: The World's Water done by the Pacific Institute; annual reports of the Worldwatch Institute; annual Living Planet Reports; reports of the World Resource Institute; and the First Assessment Report of the Urban Climate Change Research Network: Climate Change and Cities.

${ }^{38}$ Another key question posed by contributing experts is how quantitative and able to detect change are existing assessments.

${ }^{39}$ Millennium Ecosystem Assessments. Ecosystems and Human Well-being: Health Synthesis. 2005.

http://www.millenniumassessment.org/documents/document.357.aspx.pdf.

${ }^{40}$ Examples of reports that have explored this approach are two reports prepared in 2012 for the project "Sustainable Development in the 21th century". The reports focused on agriculture and food systems (D. Giovannucci et al. Food and Agriculture: the future of sustainability: A strategic input to the "Sustainable Development in the 21st Century project". New York: UN-DESA, Division for Sustainable Development, 2012) and on energy systems (M. Howells and R. Roehrl. Perspectives on Sustainable Energy for the 21st Century. Sustainable Development in the 21st Century (SD21) project: New York, UN-DESA, Division for Sustainable Development, 2012).

${ }^{41}$ One practical approach suggested by experts was formalised 'intercomparison projects' where the research community, preferably in conjunction with decision makers, compares different approaches to understand why they may produce different results, and to clarify where there is confidence in findings and where (and why) there is still divergence, and whether it actually matters for decision making.

${ }^{42}$ D. Cash et al. Knowledge systems for sustainable development (PNAS, 2003), 100, 14, 8086-8091; Scientific Advisory Board of the Secretary-General of the United Nations. UN system priorities related to science for sustainable development. Background paper on items 4 and 5 of the SAB Terms of Reference. 2014.

${ }^{43}$ This could include documenting lessons from national and regional experiences related to scientific research related to sustainable development carried out by a broad range of actors, in terms of coordination practices and mechanisms, including for example common criteria, standards, methodologies and tools that could guide scientific research

${ }^{44}$ An expert suggested that the nature of scientific material underlying findings from assessments needed to be made clearer better explained to non - experts, politicians and civil society, in particular the difference between data and extrapolations obtained through models and projections. One expert suggested the establishment of working groups that could help translate new developments into understandable and context-relevant information, supporting the dissemination of new information and knowledge as well as helping officials to prepare adequately for international discussions, and finally translating such discussions into national action plans.

${ }^{45}$ D. Cash et al. Knowledge systems for sustainable development (PNAS, 2003), 100, 14, 8086-8091; UNEP. Gap analysis for the purpose of facilitating the discussions on how to improve and strengthen the science-policy interface on biodiversity and ecosystem services (UNEP/IPBES/2/INF/1, 2009); UN (2014b).

${ }^{46}$ For example, large programmes such as Future Earth, organizations such as ICSU, ISSC, the World Academy of Science (TWAS) are able to mobilize important research capabilities, have long-standing experience with inter- and trans-disciplinarity, and play an interface role between science and policy. At the sector level, myriad organizations play a key role in the science-policy interface.

${ }^{47}$ This would also be helpful inasmuch as it would encourage those scientists to find new ways to integrate a broader range of dimensions in their research.

${ }^{48}$ More than 170 briefs were received, in 6 different languages. The range of topics addressed is extremely wide and spans natural sciences, social sciences, science and diplomacy, and other topics. See the GSDR 2015 website, https://sustainabledevelopment.un.org/topics/science/crowdsourcedbriefs.

${ }^{49}$ D. Cash et al. Scale and cross-scale dynamics: governance and information in a multilevel world (Ecology and Society, 2006), 11, 2; Van den Hove and Chabason. The debate on an Intergovernmental Science-Policy Platform on Biodiversity and Ecosystem Services (IDDRI Discussion Papers N 01/2009 Governance, 2009); $\mathrm{T}$. Wilbanks and R. Kates, Global change in local places: How scale matters (Climatic change, 1999), 43,3, 601-628; UN Division for Sustainable Development, Report of the Expert Group Meeting for the Global Sustainable Development Report - A prototype report, future directions and network of scientific contributors (Croatia: Dubrovnik, 2013), 20-21. http://sustainabledevelopment.un.org/content/documents/2713ReportDubrovnikGSDR.pdf.

${ }^{50}$ Including: universities; research agencies; academies of science; national science councils; committees on development and technology; national climate change committees; advisory committees to line ministries; national planning commissions; department for planning, evaluation and monitoring; and ad hoc stakeholder groups. 


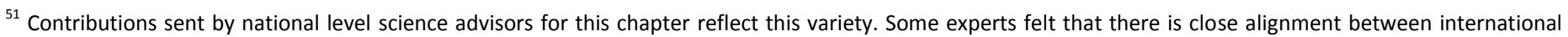

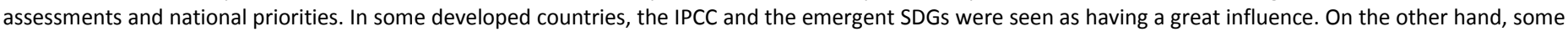

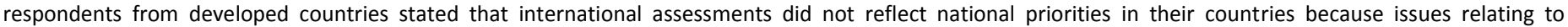

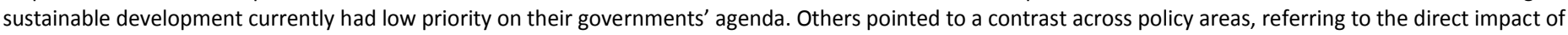

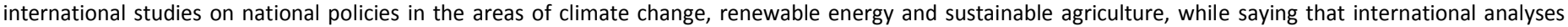

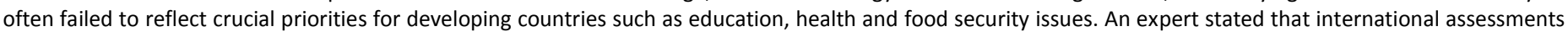

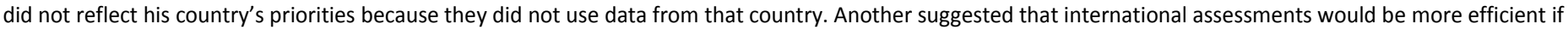

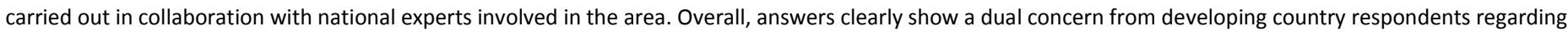

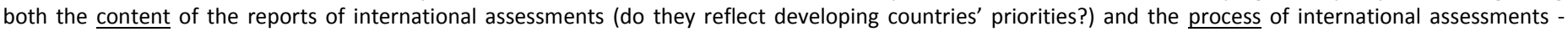
whether these draw on national data and embed bottom-up consideration of national priorities from the start.

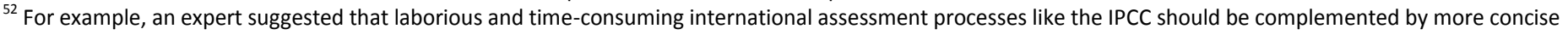
and timely analyses on more circumscribed topics.

${ }^{53}$ K. C. Urama et al., "Sub-Saharan Africa", In: UNESCO, Science Report 2010: The Current Status of Science around the World, United Nations Educational (Paris: Scientific and Cultural Organization, 2010)298-340, quoted in contribution from UNCTAD to the GSDR 2015.

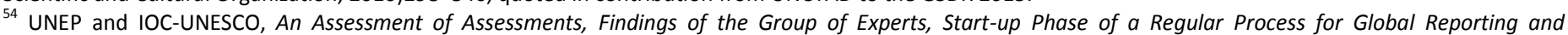

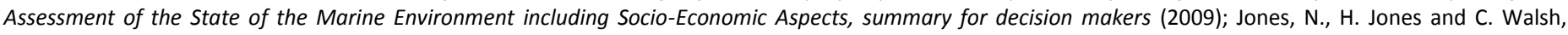

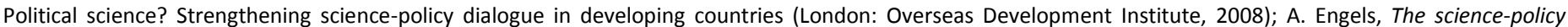

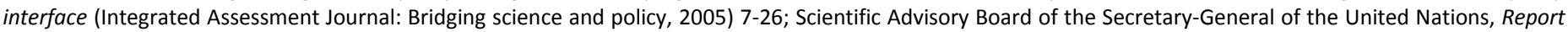

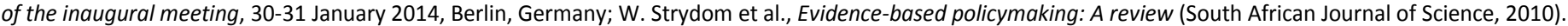

${ }^{55}$ TWAS, Building Scientific Capacity - A TWAS Perspective (Report of the Third World Academy of Sciences, 2004) No.2, TWAS.

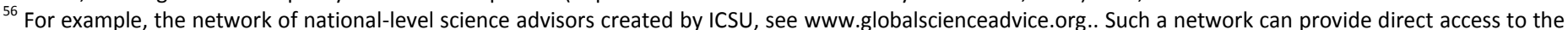
perspectives of the "supply-side" of the science-policy interface - that is, scientists or persons in a position to provide scientific advice to governments.

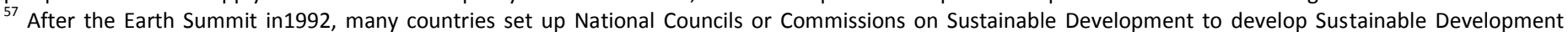

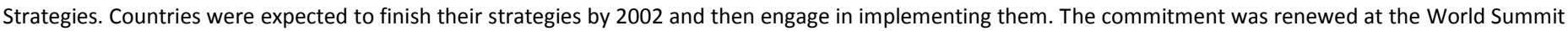
on Sustainable Development in 2002, with a target date pushed to 2005. There were over 100 councils or commissions created in the period from $1992-2002$.

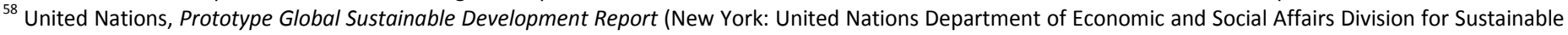

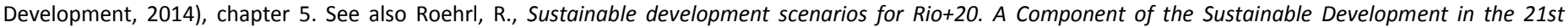
Century (SD21) project (New York: United Nations Department of Economic and Social Affairs, 2013).

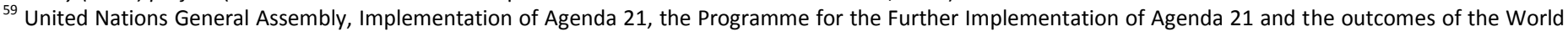

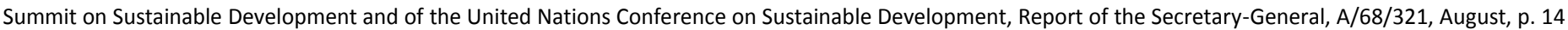
(2013).

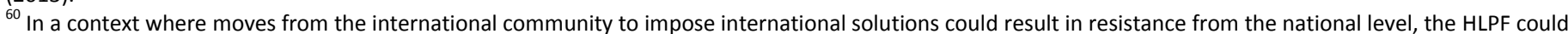
also play a role in highlighting the social and economic benefits of sustainable development.

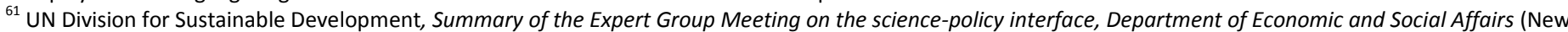

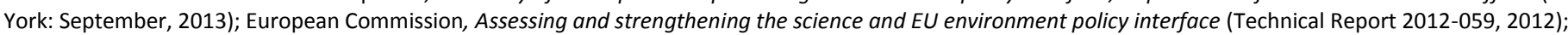

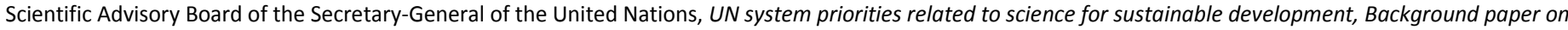
items 4 and 5 of the SAB Terms of Reference (2014).

${ }^{62}$ See InterAcademy Council, Inventing a Better Future: A Strategy for Building Worldwide Capacities in Science and Technology, (InterAcademy Council, IAC Reports, 2014); International Council for Science, Priority Area Assessment on Capacity Building in Science A report of the CSPR Assessment Panel (ICSU Reports, 2006).

63 UNCTAD, contribution to the GSDR 2015.

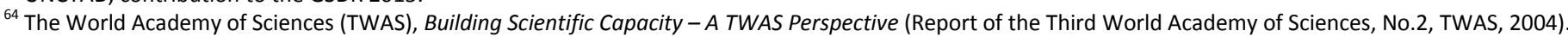

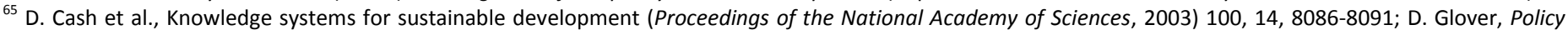

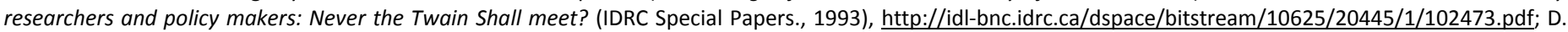

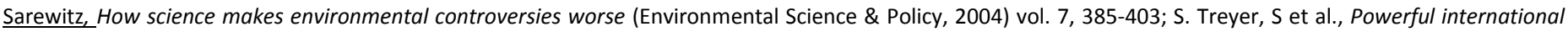
science-policy interfaces for sustainable development, (IDDRI Policy briefs no. 06/2012).

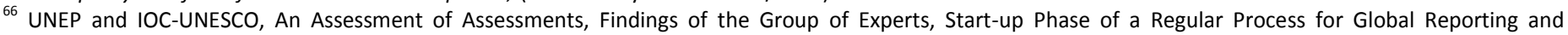

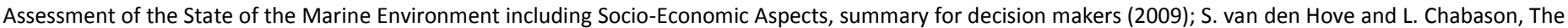

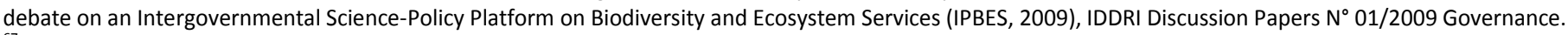

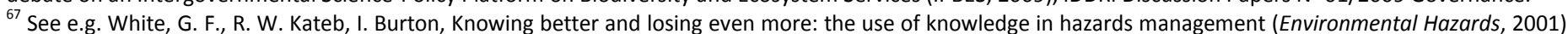

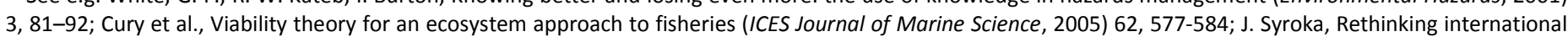

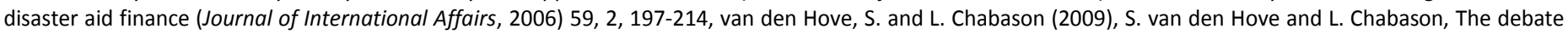
on an Intergovernmental Science-Policy Platform on Biodiversity and Ecosystem Services (IPBES, 2009), IDDRI Discussion Papers N 01/2009 Governance.

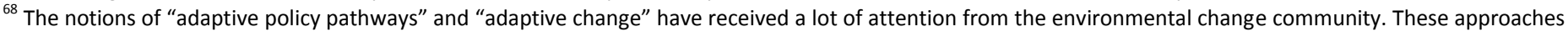

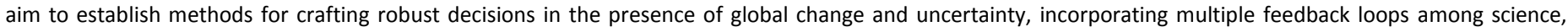

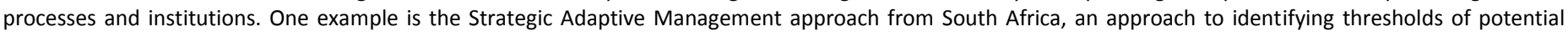

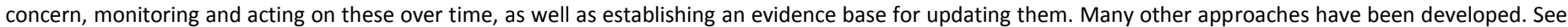

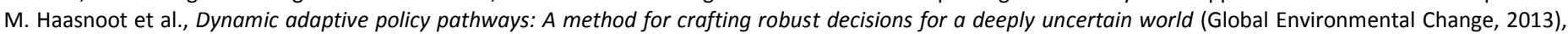

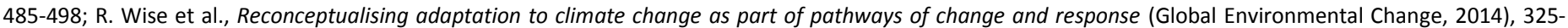

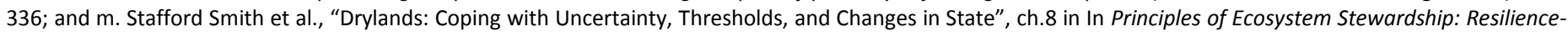
Based Natural Resource Management in a Changing World, F. Chapin, G. Kofinas and C. Folke, eds. (Springer, New York, 2009).

${ }^{69}$ United Nations, Prototype Sustainable Development Report (UNDESA, 2014), http://sustainabledevelopment.un.org/globalsdreport/

${ }^{70}$ For example, insufficient development progress can threaten peace and security and vice versa. Reduced freedom can threaten peace and vice versa. Development provides the capacity to sustain nature's life-support systems, but can also threaten them, in turn setting back development. 
${ }^{71}$ Please find the full document at: http://www.un-documents.net/our-common-future.pdf

${ }_{72}$ Please find the full document at: https://sustainabledevelopment.un.org/content/documents/Agenda21.pdf

${ }^{73}$ Please find the full document at: http://www.un.org/documents/ga/conf151/aconf15126-1annex1.htm

${ }^{74}$ General Assembly resolution A/RES/66/288 - The Future We Want, http://www.un.org/ga/search/view doc.asp?symbol=A/RES/66/288\&Lang=E , https://sustainabledevelopment.un.org/futurewewant.html

${ }^{75}$ Sustainable development as a concept after the Brundtland report brought together the great global issues of peace and security, development, and environment. In contrast to its forerunners, it did not emphasize freedom, even though it was recurring in statements by some member States in the UN

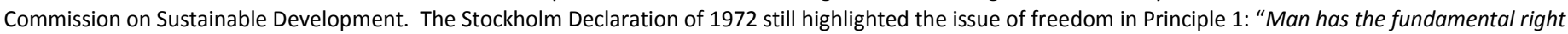
to freedom, equality and adequate conditions of life, in an environment of a quality that permits a life of dignity and well-being."

76 United States National Research Council, Policy Division, Board on Sustainable Development, Our Common Journey: A Transition Toward Sustainability

(Washington, D.C., National Academy Press, 1999), http://www.nap.edu/openbook.php?record id=9690

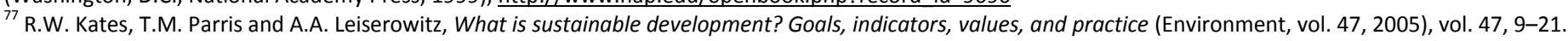
Available from http://www.environmentmagazine.org/Editorials/Kates-apr05-full.html

${ }^{78}$ OWG-SDG. Report of the Open Working Group on Sustainable Development Goals established pursuant to General Assembly resolution

66/288. A/68/L.61 (2014), http://www.un.org/ga/search/view doc.asp?symbol=A/68/L.61\&Lang=E

${ }^{79}$ OWG-SDG. Report of the Open Working Group on Sustainable Development Goals established pursuant to General Assembly resolution

66/288. A/68/L.61 (2014), http://www.un.org/ga/search/view doc.asp?symbol=A/68/L.61\&Lang=E

${ }^{80}$ For more information, please visit: https://sustainabledevelopment.un.org/sdgsproposal

${ }^{81}$ With the exception of community and freedom issues

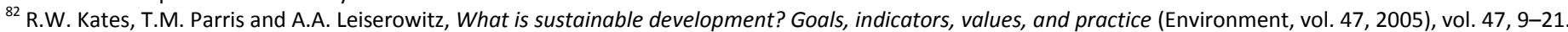
Available from http://www.environmentmagazine.org/Editorials/Kates-apr05-full.html

${ }^{83}$ ICSU and ISSC, Review of targets for the sustainable development goals: the science perspective (ICSU, 2015).

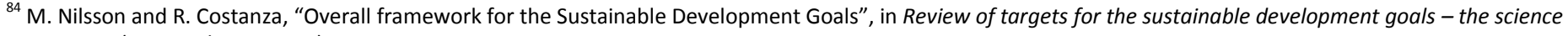
perspective (ICSU and ISSC, 2015).

${ }^{85}$ For more information, please visit: http://www.futureearth.org/

${ }^{86}$ For more information, please visit: www.post2015.jp

${ }^{87}$ For more information, please visit: www.irf2015.org

${ }^{88}$ A. Sen, Development as Freedom (Oxford University Press, 1999).

${ }^{89}$ R. Costanza et al., Time to leave GDP behind(Nature, 2014), 283-285.

${ }^{90}$ I. Kubiszewski et al., Beyond GDP: measuring and achieving global genuine progress (Ecological Economics, 2013), vol. 93, 57-68, http://www.sciencedirect.com/science/article/pii/S0921800913001584

${ }^{91}$ Kuznets, National Income, 1929-1932. $73^{\text {rd }}$ US Congress, $2^{\text {nd }}$ session, Senate document no. 124, page 7 (1934), http://library.bea.gov/u?/SOD,9888

${ }^{92}$ Griggs, D., M. Stafford Smith, J. Rockström, M. C. Öhman, O. Gaffney, G. Glaser, N. Kanie, I. Noble, W. Steffen, and P. Shyamsundar, 2014, An integrated

framework for sustainable development goals, Ecology and Society 19(4): 49. http://dx.doi.org/10.5751/ES-07082-190449.

${ }_{93}$ Table 18 of the Prototype Global Sustainable Development Report. http://sustainabledevelopment.un.org/globalsdreport/

${ }^{94}$ Costanza, R., and I. Kubiszewski (eds), Creating a sustainable and desirable future: insights from 45 global thought leaders (Singapore: World Scientific, 2014), http://www.worldscientific.com/worldscibooks/10.1142/8922

${ }^{95}$ For more information, please visit: http://data.myworld2015.org/

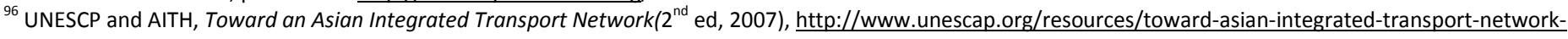
second-edition

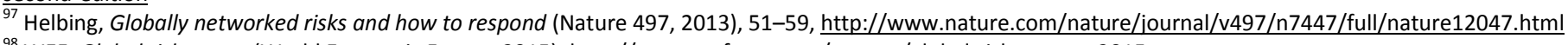

${ }_{98}$ WEF, Global risk report (World Economic Forum, 2015), http://www.weforum.org/reports/global-risks-report-2015

${ }_{99}$ Rockstroem, J., et al., (A safe operating space for humanity. Nature 461, 2009), http://www.nature.com/nature/journal/v461/n7263/full/461472a.html

${ }^{100}$ W. Steffen et al., Planetary boundaries: Guiding human development on a changing planet (Science 13, 2015).

http://www.sciencemag.org/content/347/6223/1259855

${ }_{101}^{1}$ ICSU and ISSC, Review of targets for the sustainable development goals: the science perspective (ICSU, 2015).

${ }^{102}$ D. Le Blanc, Towards integration at last? The sustainable development goals as a network of targets (DESA Working Paper Series no. 141. February 2015).

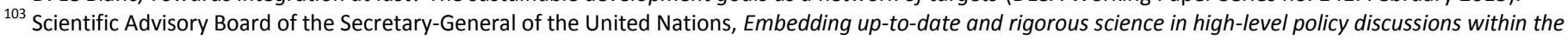

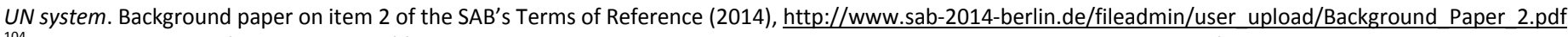

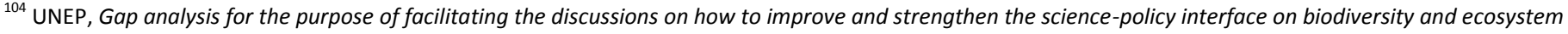
services (UNEP/IPBES/2/INF/1, 2009).

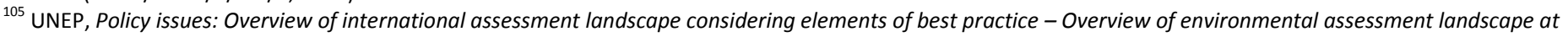
global and regional levels (UNEP/GC.25/INF/12, 2009)

${ }^{106}$ For more information, please see: http://www.unga-regular-process.org/

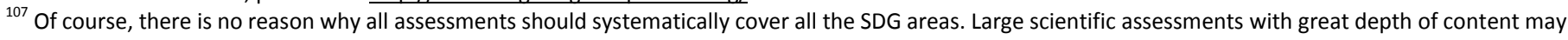

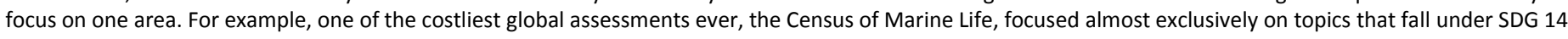
on oceans. For given resources, there is always a trade-off between integration and depth of treatment. Integration is only one dimension of interest.

${ }^{108}$ D. Giovannucci et al., Food and Agriculture: the future of sustainability: A strategic input to the Sustainable Development in the 21st Century (SD21) project, (New York: United Nations Department of Economic and Social Affairs, Division for Sustainable Development, 2012).

${ }^{109}$ M. Howells and R. Roehrl, Perspectives on Sustainable Energy for the 21st Century: Sustainable Development in the 21st Century (SD21) project (New York, United Nations, Department of Economic and Social Affairs, Division for Sustainable Development, 2012).

${ }^{110}$ D. Meadows et al., The Limits to Growth: A report for the Club of Rome's Project on the Predicament of Mankind (Universe Books, 1972).

${ }^{111}$ W. Haefele, Energy in a Finite World - Paths to a sustainable future. Report by the Energy Systems Program Group of the International Institute for Applied Systems Analysis (Ballinger Publishing Company, Massachusetts, 1981). 
${ }^{112}$ The 72 models are: AIM, ASF, ASTRA, CAPRI, CETAX, CLEWS/CLEWD, CLIMEX, CLUE, DEAN, DICE, E3ME, E3MG, ECOMOD, ECOSense, EFISCEN, ENTICE-BR, ETA, EU-CLUE Scanner, EUFASOM, EUROMOD, FAIR, FAMOUS, FUND, GAINS, GCAM, G-CUBED, GEM-CCGT, GEM-E3, GENIE, GINFORS, GTAP-E, GTEM, ICLIPS, IFS (International Futures), IGSM, IIASA/VID, IMACLIM, IMAGE, iTREN, LEITAP, LINK or WEFM, MAGICC, MAMS, MARKAL-TIMES, MERGE, MESSAGE, MIRAGE, NEAC, NEMESIS, NIEIR, OECD-GREEN, PACE, PAGE2002, PEEC, PHEONIX, POLES, PRIMES, QUEST, Rander's 2052, Rigobon and Rodrik, SGM (Second Generation Model), SENSOR, SEAMLESS, Threshold-21 (T21), TRANS-TOOLS, T-REMOVE, VACLAV, VLEEM, WaterGAP, WATSIM, WEM (World Energy Model), WorldScan.

${ }^{113}$ Please refer to: https://sustainabledevelopment.un.org/globalsdreport/2015/chapter2

${ }^{114}$ European Commission, A Scoping Study on the Macroeconomic View of Sustainability, final report for the European Commission, prepared by H. Pollitt et al from Cambridge Econometrics, and Elke Pirgmaier et al from Sustainable Europe Research Institute (2010).

${ }^{115}$ Hak et al., (2007).

${ }^{116}$ R. A. Roehrl, Sustainable development scenarios for Rio+20, a component of the sustainable development in the 21st Century (SD21) project (New York: United Nations Department of Economic and Social Affairs, Division for Sustainable Development, 2012).

${ }^{117}$ e.g. ECOMOD, GEM-E3, MARKAL-TIMES, OECD-GREEN, and PACE models

${ }^{118}$ Devarajan, S., M. J. Miller and E. V. Swanson, Goals for Development: History, Prospects, and Costs (Washington D. C.: World Bank, 2002)

${ }^{119}$ GEMCCGT, G-CUBED and GTAP

${ }^{120}$ e.g. DEAN, E3MG, GEM-E3, and WorldScan

${ }^{121}$ Daly, H.E. (1992), "Allocation, Distribution, and Scale: Towards an Economics that is Efficient, Just, and Sustainable", Ecological Economics 6, pp.185-193.

122 Jean-Charles Hourcade et al., Hybrid Modeling: New Answers to Old Challenges (The Energy Journal, 2006).

${ }^{123}$ Inter-linkage refers to "...a qualitative or quantitative relationship between two or more sustainable development indicators that can be based on statistical analysis or on the results of formal or applied methods or models of political, socio-economic and environmental interactions." Interlinkages exist if a change in one indicator causes changes in one or more other indicators, either directly or indirectly through third variables. Interlinkages also exist if two or more indicators are positively or negatively influenced by the same policy actions.

${ }^{124}$ Van Herwijnen, M. (ed.), Review report on methods, tools and models for assessment of SD in-terlinkages (Institute for Environmental Studies, University Amsterdam, 2007).

${ }^{125}$ e.g. AIM, CLEWD, DICE, IFs, and Rander's 2052

${ }^{126}$ In order to be in line with ongoing international discussions, the term "oceans, seas and marine resources" is used. It is nevertheless to be noted that the term "ocean" is oftentimes used in scientific literature as the various basins of the oceans are interconnected.

${ }^{127}$ For more information, please visit: http://www.worldoceanassessment.org/

${ }^{128}$ Annex II is available on the DESA-administered Sustainable Development Knowledge Platform under:

https://sustainabledevelopment.un.org/globalsdreport/2015.

${ }^{129}$ Source: Chapter lead's elaboration based on inputs received from contributing experts.

${ }^{130}$ Burkhard et al., Landscapes' capacities to provide ecosystem services-a concept for land-cover based assessments (2009).

${ }^{131}$ Secretariat of the Convention on Biological Diversity, Booklet: Biodiversity for Development and Poverty Alleviation (2012).

${ }^{132}$ FAO, The State of World Fisheries and Aquaculture (2012).

${ }^{133} \mathrm{IMO}$, International Shipping Facts and Figures: Information Resources on Trade, Safety, Security, Environment (2012).

${ }^{134}$ UNWTO, Secretariat of Ramsar Convention on Wetlands, Destination Wet Lands: Supporting Sustainable Tourism (2012).

${ }^{135} \mathrm{IOC} / \mathrm{UNESCO}$, IMO, FAO, UND, A Blueprint for Ocean and Coastal Sustainability.

${ }^{136}$ UNEP (2009): The Natural Fix?: The Role of Ecosystems in Climate Mitigation.

${ }^{137}$ United Nations General Assembly resolution A/66/298 (2011). Protection of coral reefs for sustainable livelihoods and development.

${ }^{138}$ IOC/UNESCO, IMO, FAO, UNDP, A Blueprint for Ocean and Coastal Sustainability (2011).

${ }^{139}$ Adaptation from United Nations Technical Support Team, TST Issues Brief: Oceans and Seas (2013).

${ }^{140}$ The United Nations Convention on the Law of the Sea (UNCLOS) sets out the legal framework within which all activities in the oceans and seas must be carried out. It enshrines the notion that all problems of ocean space are closely interrelated and need to be considered as a whole.

${ }^{141}$ Millennium Ecosystem Assessment, Ecosystems and Human Well-being: Synthesis (2015).

${ }^{142}$ United Nations General Assembly resolution A/68/970.

${ }^{143}$ See for example: Visbeck et al., Securing blue wealth: The need for a special sustainable development goal for the ocean and coasts (48 Marine Policy, 2014), 184-191.; Global Ocean Forum, Proposal for a Sustainable Development Goal on Oceans and Seas (2014).

${ }^{144}$ ICSU, ISSC, Review of the Sustainable Development Goals: The Science Perspective (2015).

${ }^{145}$ http://www.unga-regular-process.org/content/view/18/20/index.html

${ }^{146}$ For more information, please visit:: http://www.unep-wcmc-apps.org/gramed/.

${ }^{147}$ For more information, please visit: http://www.worldoceanassessment.org/

${ }^{148}$ The high seas are all parts of the sea that are not included in the exclusive economic zone, in the territorial sea or in the internal waters of a State, or in the archipelagic waters of an archipelagic State, according to the United Nations Convention on the Law of the Sea - "UNCLOS" (article 86).

${ }^{149}$ The Area is the seabed and ocean floor and subsoil thereof, beyond the limits of national jurisdiction (UNCLOS, article 1).

${ }^{150}$ Outcome of the Working Group, including recommendations and Co-Chairs' summary of discussions (issued as document A/69/780)

${ }^{151}$ e.g. United Nations World Ocean Assessment, European Commission's Mapping and Assessment of Ecosystem Services, Mapping Ocean Wealth , IOC-UNESCO's Ocean Biogeographic Information System.

${ }^{152}$ For more information, please visit: http://www.worldoceanassessment.org/

${ }^{153}$ For more information, please visit: http://www.coml.org/

${ }^{154}$ For more information, please visit: http://www.iobis.org/

${ }^{155}$ For more information, please visit: http://wwf.panda.org/

${ }^{156}$ e.g., wind and solar energy, hydropower, geothermal energy, and bio-energy

${ }^{157}$ For more information, please visit: http://www.worldoceanassessment.org/

${ }^{158}$ For more information, please visit:: http://oceanwealth.org/resources/

${ }^{159}$ For more information, please visit: http://www.worldoceanassessment.org/

${ }^{160}$ For more information, please visit: http://www.oceanhealthindex.org/ 
${ }^{161}$ This point is added with the clear understanding that negotiations are still ongoing at the global policy level. The last meeting of the Ad Hoc Open-ended

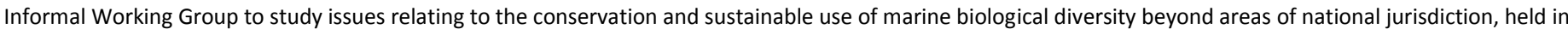

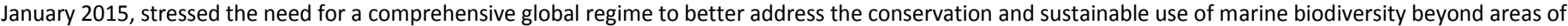

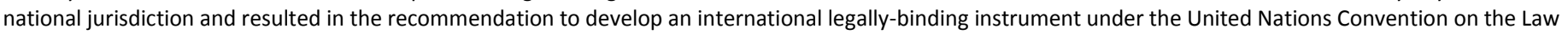

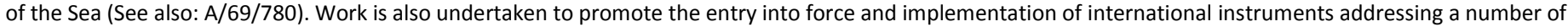
issues related, generally, to genetic resources (e.g. Nagoya Protocol on Access to Genetic Resources and the Fair and Equitable Sharing of Benefits Arising from their Utilization to the Convention on Biological Diversity). In addition, discussions are ongoing with regard to the development of an international instrument addressing the intellectual property rights aspects of genetic resources. (See also: Secretary-General report A/69/71/Add.1).

${ }^{162}$ For more information, please see: http://www.worldoceanassessment.org/

${ }^{163}$ Annex II is available on the DESA-administered Sustainable Development Knowledge Platform under:

https://sustainabledevelopment.un.org/globalsdreport/2015.

${ }_{164}$ e.g. UN System of Environmental Economic Accounting (SEEA); Economics of Ecosystems and Biodiversity (TEEB)

${ }^{165}$ Halpern et al. 2012, Elfes et al. 2013, Halpern et al. 2013

${ }^{166}$ For more information, please see: http://www.oceanhealthindex.org/

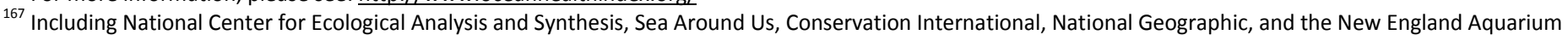

${ }^{168}$ See examples in Table 3-1 Important Inter-linkages between oceans, seas, marine resources and human well-being

${ }^{169}$ Halpern et al., A global map of human impact on marine ecosystems, 2008.

${ }^{170}$ Halpern et al., A global map of human impact on marine ecosystems, 2008.

${ }^{171}$ McCauley et al., Marine defaunation: Animal loss in the global ocean, 2015.

172 United Nations, TST Issues Brief: Oceans and Seas (United Nations Technical Support Team, 2013).

${ }^{173}$ Beck et al., Oyster Reefs at Risk and Recommendations for Conservation, Restoration and Management (Bioscience, 2011).

${ }^{174}$ IOC/UNESCO, IMO, FAO, UNDP, A Blueprint for Ocean and Coastal Sustainability, 2011.

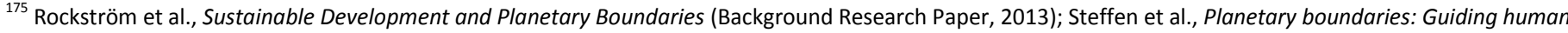
development on a changing planet, 2015

${ }^{176}$ United Nations. World Population Prospects: the 2012 Revision (UNDESA, 2012).

${ }^{177}$ Neumann et al., Future Coastal Population Growth and Exposure to Sea-Level Rise and Coastal Flooding - A Global Assessment (PLoS ONE, 2015).

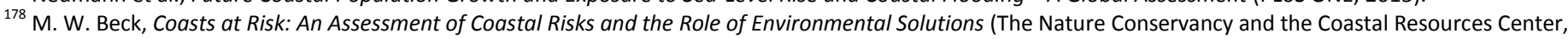
2014).

${ }^{179}$ Huq et al., Reducing risks to cities from climate change; an environmental or a development agenda? (2007).

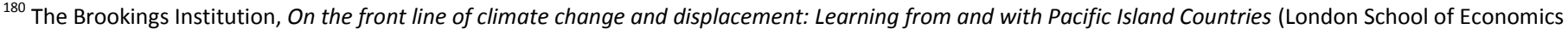
2011).

${ }^{181}$ For more information, please see: http://www.unga-regular-process.org/content/view/18/20/index.html

${ }^{182}$ For more information, please see: $\mathrm{http}$ ://www.worldoceanassessment.org/

${ }^{183}$ For more information, please see: $\mathrm{http}: / /$ www.worldoceanassessment.org/

${ }^{184}$ For more information, please see: $\mathrm{http://www.worldoceanassessment.org/}$

${ }^{185}$ For more information, please see: http://www.worldoceanassessment.org/

${ }^{186}$ For more information, please see: http://www.worldoceanassessment.org/

${ }^{187}$ Annex II is available on the DESA-administered Sustainable Development Knowledge Platform under:

https://sustainabledevelopment.un.org/globalsdreport/2015.

${ }^{188}$ For more information, please see: http://www.unga-regular-process.org/content/view/18/20/index.html

189 UNDESA, UN-DOALOS/OLA, IAEA, IMO, IOC-UNESCO, UNDP, UNEP, UNWTO, How oceans- and seas-related measures contribute to the economic, social and environmental dimensions of sustainable development: Local and regional experiences. Online publication, 2014.

${ }^{190}$ UNDESA, UN-DOALOS/OLA, IAEA, IMO, IOC-UNESCO, UNDP, UNEP, UNWTO, How oceans-and seas-related measures contribute to the economic, social and environmental dimensions of sustainable development: Local and regional experiences. Online publication, 2014.

${ }^{191}$ UNDESA, UN-DOALOS/OLA, IAEA, IMO, IOC-UNESCO, UNDP, UNEP, UNWTO, How oceans- and seas-related measures contribute to the economic, social and environmental dimensions of sustainable development: Local and regional experiences. Online publication, 2014.

192 UNDP,Catalysing Ocean Finance (Volume II), 2013.

193 UNDESA, UN-DOALOS/OLA, IAEA, IMO, IOC-UNESCO, UNDP, UNEP, UNWTO, How oceans- and seas-related measures contribute to the economic, social and environmental dimensions of sustainable development: Local and regional experiences. Online publication, 2014.

${ }^{194}$ Freed and Granek. Case study: Community-based Green Sea Turtle conservation in the Comoros, 2015.

195 UNDESA, UN-DOALOS/OLA, IAEA, IMO, IOC-UNESCO, UNDP, UNEP, UNWTO, How oceans- and seas-related measures contribute to the economic, social and environmental dimensions of sustainable development: Local and regional experiences. Online publication, 2014.

${ }^{196}$ UNDESA, UN-DOALOS/OLA, IAEA, IMO, IOC-UNESCO, UNDP, UNEP, UNWTO, How oceans- and seas-related measures contribute to the economic, social and environmental dimensions of sustainable development: Local and regional experiences. Online publication, 2014.

${ }^{197}$ UNDP/GEF, Linking Conservation and Livelihoods in the Oracabessa Bay Fish Sanctuary, Jamaica (Project description, 2011).

${ }^{198}$ Annex II is available on the DESA-administered Sustainable Development Knowledge Platform under:

https://sustainabledevelopment.un.org/globalsdreport/2015.

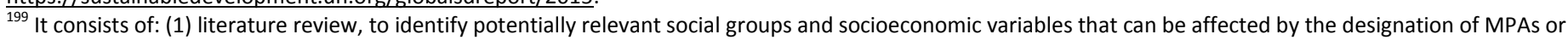

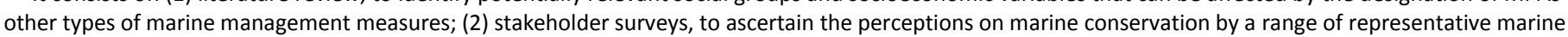

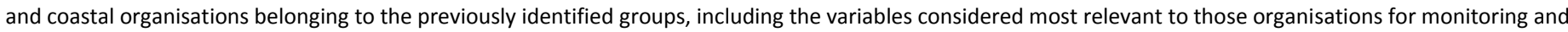
assessing the socioeconomic effects of marine management measures; and (3) GIS-based geo-statistical analysis using a Multiple-Paired-Before-After-ControlImpact design (MPBACl), to assess the effects of an MPA or set of MPAs on the set of variables considered most important for the stakeholders. See for more

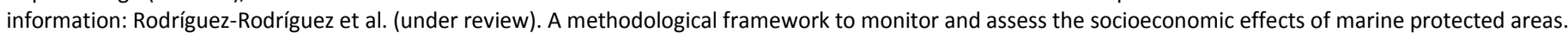
An English Channel case study. Environmental Science \& Policy".

${ }^{200}$ See for example: A/RES/68/70, paragraph 184. 
${ }^{201}$ For more information, please visit GRAMED: http://www.unep-wcmc-apps.org/gramed/.

${ }^{202}$ United Nations, A/68/82, Annex 2, http://www.un.org/depts/los/global_reporting/guidance for_contributors.pdf

${ }^{203}$ For more information, please visit: http://www.coml.org/

${ }^{204}$ For more information, please visit: http://www.iobis.org/

${ }^{205}$ The GOOS Biology and Ecosystems Panel, the GOOS Biogeochemistry Panel (IOCCP) and the GOOS Physics Panel (OOPC)

${ }^{206}$ For more information, please visit: http://www.ioc-goos.org

${ }^{207}$ See for example: http://www.pewtrusts.org/en/multimedia/video/2015/project-eyes-on-the-seas

${ }^{208}$ For more information, please visit GRAMED: http://www.unep-wcmc-apps.org/gramed/.

${ }^{209}$ More information on UN System Task Team on post-2015 Development Agenda - Disaster risk and resilience, Thematic Think Piece, UNISDR, WMO is available at: http://www.preventionweb.net/files/27462 20120607unttpostmdgthinkpieceondrra.pdf

${ }^{210}$ Estimates vary according to the source and timeframe used. Global database EM-DAT data indicates over 3 billion people affected on 2000-2014 and over 1.24 million deaths. Statistics can be found from EM-DAT website, available at: http://www.emdat.be/advanced search/index.html

${ }^{211}$ United Nations Office for Disaster Risk Reduction, Making Development Sustainable: The Future of Disaster Risk Management. Global Assessment Report on Disaster Risk Reduction (Geneva: UNISDR, 2015).

${ }^{212}$ United Nations Office for Disaster Risk Reduction, Making Development Sustainable: The Future of Disaster Risk Management. Global Assessment Report on Disaster Risk Reduction (Geneva: UNISDR, 2015).

${ }^{213}$ Estimates vary according to the source and timeframe used. Global database EM-DAT data shows 171 billion USD average losses per year for the last 5 years (2010 - 2014). Statistics can be found from EM-DAT website, available at: http://www.emdat.be/advanced_search/index.html

${ }^{214}$ United Nations General Assembly, Report of the Open Working Group of the General Assembly on Sustainable Development Goals (United Nations, 2014), http://www.un.org/ga/search/view_doc.asp?symbol=A/68/970\&Lang=E

215 United Nations General Assembly, Sendai Framework for Disaster Risk Reduction 2015-2030 (United Nations, 2015),

http://www.wcdrr.org/uploads/Sendai_Framework_for_Disaster_Risk_Reduction_2015-2030.pdf

${ }^{216}$ R. Pulwarty and M. Sivakumar, Information systems in a changing climate: Early warnings and drought risk management (Weather and Climate Extremes 3 , 2014), 14-21.

${ }^{217}$ Andrew Shepherd et al., The geography of poverty, disasters and climate extremes in 2030 (London: Overseas Development Institute, 2013).

${ }^{218}$ United Nations Office for Disaster Risk Reduction, Global Assessment Report on Disaster Risk Reduction, Risk and poverty in a changing climate, Invest today for a safer tomorrow (Geneva: UNISDR, 2009).

${ }^{219}$ Andrew Shepherd et al., The geography of poverty, disasters and climate extremes in 2030 (London: Overseas Development Institute, 2013).

${ }^{220}$ Hsiang Anttila-Hughes, Hsiang, Destruction, disinvestment, and Death: Economic and Human Losses Following Environmental Disaster' Working Paper (San Francisco, 2012)

${ }^{221} \mathrm{AAL}$ is the average expected loss annualized over a long time frame as derived from probabilistic scenario models.

${ }^{222}$ United Nations Office for Disaster Risk Reduction, Making Development Sustainable: The Future of Disaster Risk Management. Global Assessment Report on Disaster Risk Reduction (Geneva: UNISDR, 2015).

${ }^{223} \mathrm{FAO}$, Agriculture and Disaster Risk: A contribution by the United Nations to the consultation leading to the Third UN World Conference on DRR (2014).

${ }^{224} \mathrm{FAO}$, The impact of natural hazards on agriculture - a call to action on resilient livelihoods (to be published in 2015).

${ }^{225}$ World Bank, Convenient Solutions to an Inconvenient Truth : Ecosystem-based Approaches to Climate Change (World Bank, 2010), https://openknowledge.worldbank.org/handle/10986/2686

${ }^{226}$ FAO, Resilient Livelihoods - Disaster Risk Reduction for Food and Nutrition Security Framework Programme (2013), http://www.fao.org/docrep/015/i2540e/i2540e00.pdf

${ }^{227}$ The World Bank, Adapting to Climate Change in Europe and Central Asia (2009), http://www.worldbank.org/eca/climate/ECA_CCA_Full_Report.pdf

${ }^{228} \mathrm{FAO}$. The impact of natural hazards on agriculture - a call to action on resilient livelihoods (working title), to be published in 2015

${ }^{229}$ Statistics on injured can be found from EM-DAT database, available at: http://www.emdat.be/advanced_search/index.html

${ }^{230}$ Watson JT, Gayer M, Connolly MA. (2007) Epidemics after natural disasters. Emerging Infectious Diseases, serial on the Internet. Vol. 13, 1. Available at:

http://wwwnc.cdc.gov/eid/article/13/1/06-0779

${ }^{231}$ Use knowledge, innovation and education to build a culture of safety and resilience at all levels" is one of the priorities of the Hyogo Framework for Action 20052015.

${ }^{232}$ UNDP, Human Development Report 2007/2008 - Fighting climate change: human solidarity in a divided world (The Human Development Report Office, 20072008).

${ }^{233}$ United Nations Office for Disaster Risk Reduction, Assessing School Safety from Disasters - A Global Baseline Report (Geneva: UNISDR, 2013).

${ }^{234}$ United Nations Office for Disaster Risk Reduction, Making Development Sustainable: The Future of Disaster Risk Management. Global Assessment Report on

Disaster Risk Reduction (Geneva: UNISDR, 2015).

${ }^{235}$ A Contribution by the United Nations to the consultation leading to the Third UN World Conference on Disaster Risk Reduction (2014) Available at:

http://www.preventionweb.net/files/38763_water.pdf

${ }^{236}$ World Bank, Dar es Salaam Case Study Overview: Climate Change, Disaster Risk and the Urban Poor: Cities Building Resilience for a Changing World (Washington D. C.: The World Bank, 2011).

${ }^{237}$ Matthew E. Kahn, Sustainable and Smart Cities, Policy Research Working Paper 6878 (Washington, D.C: the World Bank, 2014).

${ }^{238}$ Extensive risk refers to the risk layer of high-frequency, low-severity losses. The issue is addressed more in detail in section 3.

${ }^{239}$ United Nations Office for Disaster Risk Reduction, Making Development Sustainable: The Future of Disaster Risk Management. Global Assessment Report on Disaster Risk Reduction (Geneva: UNISDR, 2015).

${ }^{240}$ Gender Responsive Disaster Risk Reduction; A contribution by the United Nations to the consultation leading to the Third UN World Conference on Disaster Risk Reduction, Available at: http://www.preventionweb.net/files/40425_gender.pdf

${ }^{241}$ Elaine Enarson, Women Confronting Natural Disaster - From Vulnerability to Resilience (Lyenne Rienner Publishers, Boulder, 2012).

${ }^{242}$ World Bank, Operationalizing the World Development Report 2012 on Gender Equality, Making Women's voice count; Integrating Gender Issues in Disaster Risk Management; Overview \& Resources for Guidance Notes (Washington D.C.: World Bank, 2012), http://www- 
wds.worldbank.org/external/default/WDSContentServer/WDSP/IB/2012/10/25/000386194_20121025020000/Rendered/PDF/658410REVISED00view0FinalOfor0e mail.pdf

${ }^{243}$ United Nations, Gender Responsive Disaster Risk Reduction: A Contribution by the United Nations to the consultation leading to the Third UN World Conference on Disaster Risk Reduction (2014), http://www.preventionweb.net/files/40425_gender.pdf

${ }^{244}$ United Nations Office for Disaster Risk Reduction, Making Development Sustainable: The Future of Disaster Risk Management. Global Assessment Report on

Disaster Risk Reduction (Geneva: UNISDR, 2015).

${ }^{245}$ D. Guha-Sapir et al., Risk factors for mortality and injury: post-tsunami epidemiological findings from Tamil Nadu (Centre for Research on the Epidemiology of Disasters, 2006).

${ }^{246} \mathrm{~K}$. Fuji, The great east Japan earthquake and disable persons: their high mortality rate, factors that hindered the support and the current challenges (Disability information Resources, 2012), http://www.dinf.ne.jp/doc/english/twg/escap_121031/fujii.html

${ }^{247}$ Secretariat of the Convention on Biological Diversity (2012) Cities and Biodiversity Outlook. Montreal. Available at: http://www.cbd.int/doc/health/cbo-actionpolicy-en.pdf

${ }^{248}$ United Nations Office for Disaster Risk Reduction, Making Development Sustainable: The Future of Disaster Risk Management. Global Assessment Report on Disaster Risk Reduction (Geneva: UNISDR, 2015).

${ }^{249}$ United Nations Office for Disaster Risk Reduction, Making Development Sustainable: The Future of Disaster Risk Management. Global Assessment Report on Disaster Risk Reduction (Geneva: UNISDR, 2015).

${ }^{250}$ World Bank, Climate change, Disaster Risk and the Urban poor: Cities Building Resilience for a Changing World. The International Bank for Reconstruction and Development, Sumary (Washington D.C.:World Bank, 2011), http://siteresources.worldbank.org/INTURBANDEVELOPMENT/Resources/336387-

1306291319853/Summary.pdf

${ }^{251}$ Sultana Naznin Nahar et al., Migration pattern and everyday life of slum people: A study on Chittagong city (International Journal of Physical and Social Sciences, 2014), 272-88.

${ }^{252}$ M. Jahan, Impact of rural urban migration on physical and social environment: the case of Dhaka city (International Journal of Development and Sustainability, 2012), 186-94, http://isdsnet.com/ijds-v1n2-10.pdf

${ }^{253}$ World Bank, Climate change, Disaster Risk and the Urban poor: Cities Building Resilience for a Changing World. The International Bank for Reconstruction and Development, Sumary. (Washington D.C.: World Bank, 2011), http://siteresources.worldbank.org/INTURBANDEVELOPMENT/Resources/336387-

1306291319853/Summary.pdf

${ }^{254}$ F. Ghesquiere, L. Jamin and O. Mahul, Earthquake Vulnerability Reduction Program in Colombia: A Probabilistic Cost-benefit Analysis (World Bank Policy Research Working Paper, 2006).

${ }^{255} \mathrm{C}$. Kenny, Disaster risk reduction in developing countries: costs, benefits and institutions (Disasters, 2012), 559-588.

${ }^{256}$ IPCC, "Summary for Policymakers". In: Managing the Risks of Extreme Events and Disasters to Advance Climate Change Adaptation. A Special Report of Working

Groups I and II of the Intergovernmental Panel on Climate Change (Cambridge University Press, Cambridge, UK, and New York, NY, USA, 2012), 1-19.

${ }^{257}$ Andrew Shepherd et al., The geography of poverty, disasters and climate extremes in 2030 (London: Overseas Development Institute, 2013).

${ }^{258}$ CRED, Annual Disaster Statistical Review 2013 (2014), http://cred.be/download/download.php?file=sites/default/files/ADSR_2013.pdf

${ }^{259}$ United Nations Office for Disaster Risk Reduction, Making Development Sustainable: The Future of Disaster Risk Management. Global Assessment Report on Disaster Risk Reduction (Geneva: UNISDR, 2015).

$260 \mathrm{~J}$. A. Church and N. J. White, A 20th century acceleration in global sea-level rise (Geophysical Research Lett letters, 2006), Vol 33, http://onlinelibrary.wiley.com/doi/10.1029/2005GL024826/abstract

${ }^{261}$ Andrew Shepherd et al., The geography of poverty, disasters and climate extremes in 2030 (London: Overseas Development Institute, 2013).

${ }^{262}$ United Nations International Strategy for Disaster Reduction, Global Assessment Report on Disaster Risk Reduction, Risk and poverty in a changing climate, Invest today for a safer tomorrow (UNISDR, 2009).

${ }^{263}$ United Nations General Assembly, Sendai Framework for Disaster Risk Reduction 2015-2030 (United Nations, 2015), http://www.wcdrr.org/uploads/Sendai_Framework_for_Disaster_Risk_Reduction_2015-2030.pdf

${ }^{264} \mathrm{GEF}$, Role of Ecosystem-based Adaptation in Reducing Disaster Risk, Global Environment Facility contribution to the report (2015), https://sustainabledevelopment.un.org/globalsdreport/2015

${ }^{265}$ World Bank, Convenient Solutions to an Inconvenient Truth : Ecosystem-based Approaches to Climate Change (World Bank, 2010), https://openknowledge.worldbank.org/handle/10986/2686

${ }^{266}$ World Bank, Convenient Solutions to an Inconvenient Truth : Ecosystem-based Approaches to Climate Change (World Bank, 2010), https://openknowledge.worldbank.org/handle/10986/2686

${ }^{267}$ Erian et al., Effects of Drought and Land Degradation on Crop Losses in Africa and the Arab Region with Special Case Study on: drought and conflict in Syria, Background Paper prepared for the 2015 Global Assessment Report on Disaster Risk Reduction (Geneva: UNISDR, 2014).

${ }^{268}$ United Nations Office for Disaster Risk Reduction, Making Development Sustainable: The Future of Disaster Risk Management. Global Assessment Report on Disaster Risk Reduction (Geneva: UNISDR, 2015).

${ }^{269}$ UNDP, Yasemin Aysan and Allan Lavell, Disaster risk governance during the HFA implementation period. Background Paper. Prepared for the Global Assessment Report on Disaster Risk Reduction 2015 (2014), http://www.preventionweb.net/english/hyogo/gar/2015/en/bgdocs/UNDP,\%202014a.pdf

${ }^{270}$ Katie Harris, David Keen and Tom Mitchell, When disasters and conflicts collide: Improving links between disaster resilience and conflict prevention (London: Overseas Development Institute, 2013).

${ }^{271}$ Angelika Planitz, "Disaster Risk Governance and the Principles of Good Governance", in: Davis, Georgieva, Yanagisawa (eds.), Disaster Risk Reduction for Economic Growth and Livelihood: Investing in Resilience and Development (UNDP Bureau for Crisis Prevention \& Recovery)

${ }^{272} \mathrm{P}$. Colin et al., Climate change in the Fertile Crescent and implications of the recent Syrian drought (Proceedings of the National Academy of Sciences of the United States of America, 2015).

${ }^{273}$ Jan Kellet and Alice Caravani, Financing Disaster Risk Reduction: A 20 year story of international aid (London: Overseas Development Institute, 2013).

${ }^{274}$ IPCC, "Managing the Risks of Extreme Events and Disasters to Advance Climate Change Adaptation", in A Special Report of Working Groups I and II of the

Intergovernmental Panel on Climate Change, eds. C. B. Field et. Al. (Cambridge University Press, Cambridge, UK, and New York, NY, USA, 2012).

${ }^{275}$ Jan Kellet and Alice Caravani, Financing Disaster Risk Reduction: A 20 year story of international aid (London: Overseas Development Institute, 2013). 


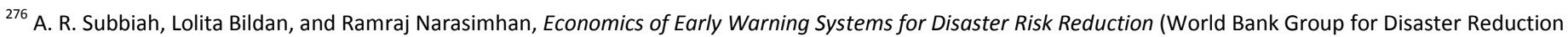
and Recovery, 2008), http://risk.earthmind.net/files/World-Bank-2008-Economics-Early-Warning-Systems.pdf

${ }^{277}$ Dan Sparks, Global Humanitarian Assistance. Aid investments in disaster risk reduction - rhetoric to action (2012),

http://www.globalhumanitarianassistance.org/wp-content/uploads/2012/10/Aid-investments-in-disaster-risk-reduction-rhetoric-to-action-Dan-Sparks1.pdf

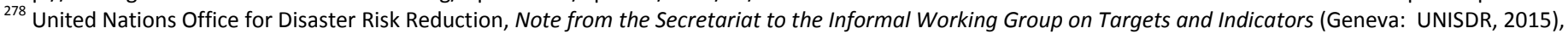

http://www.wcdrr.org/uploads/Note-from-the-Secretariat-on-Targets-with-senarios-120115.pdf

${ }^{279}$ United Nations Office for Disaster Risk Reduction, Making Development Sustainable: The Future of Disaster Risk Management. Global Assessment Report on Disaster Risk Reduction (Geneva: UNISDR, 2015).

${ }^{280}$ United Nations Office for Disaster Risk Reduction, Making Development Sustainable: The Future of Disaster Risk Management. Global Assessment Report on Disaster Risk Reduction (Geneva: UNISDR, 2015).

${ }^{281}$ United Nations Office for Disaster Risk Reduction, Making Development Sustainable: The Future of Disaster Risk Management. Global Assessment Report on Disaster Risk Reduction (Geneva: UNISDR, 2015).

${ }^{282}$ Source: UNISDR with data from the EM-DAT database and the World Bank

283 United Nations Office for Disaster Risk Reduction, Making Development Sustainable: The Future of Disaster Risk Management. Global Assessment Report on Disaster Risk Reduction (Geneva: UNISDR, 2015).

${ }^{284}$ R. Below, E. Grover-Kopec and M. Dilley, Documenting Drought-Related Disasters (The Journal of Environment \& Development, 2007), 328-344,

http://jed.sagepub.com/content/16/3/328.full.pdf+html

${ }^{285}$ R. Pulwarty and M. Sivakumar, Information systems in a changing climate: Early warnings and drought risk management (Weather and Climate Extremes 3 , 2014), 14-21

${ }^{286}$ D. Guha-Sapir, Monitoring sustainable development goals: note on baselines for DRR targets and indicators (Belgium: CRED, University of Louvain, 2012) Contribution to the chapter, available at GSDR website: https://sustainabledevelopment.un.org/globalsdreport/2015

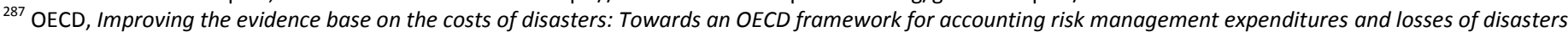
(Paris, 2014).

${ }^{288}$ Volker Meyer et al., Costs of Natural Hazards - A Synthesis (2012), http://conhaz.org/project/wp9-synthesis-recommendations/final-synthesisreport/CONHAZ_WP09_1_Synthesis_Report_final.pdf/view

${ }^{289}$ Preparatory Committee of the Third UN Conference on Disaster Risk Reduction (January 2015) Informal Working Group on Targets and Indicators, Seventh

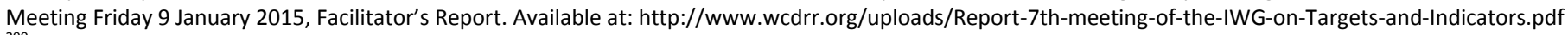

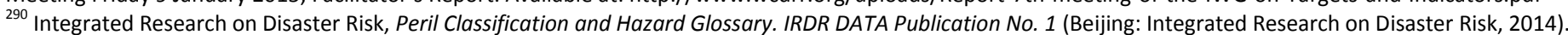

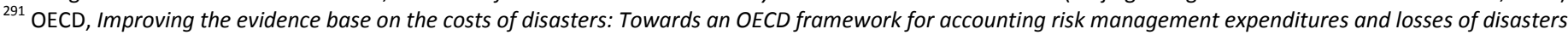
(Paris, 2014).

292 More information available at: http://www.globalquakemodel.org/what/seismic-hazard/instrumental-catalogue/

${ }^{293}$ More information available at: http://earthquake.usgs.gov/monitoring/gsn/

${ }^{294}$ More information available at: http://perils.org/web.html

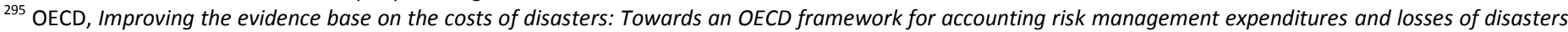
(Paris, 2014).

${ }^{296}$ More information available at: www.desinventar.org

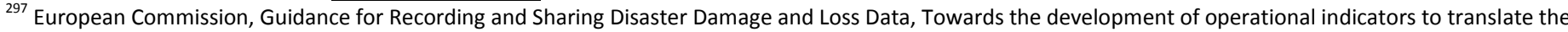
Sendai Framework into action (European Commission Joint Research Centre, Institute for the Protection and Security of the Citizen, 2015).

${ }^{298}$ European Commission, Recording Disaster Losses. Recommendations for a European Approach, (Italy: European Commission Joint Research Centre, 2014).

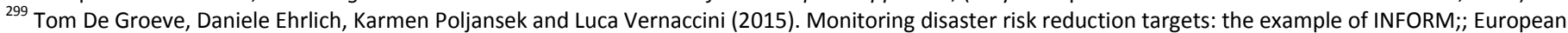

Commission, Joint Research Centre, Contribution to the chapter, available at GSDR website: https://sustainabledevelopment.un.org/globalsdreport/2015

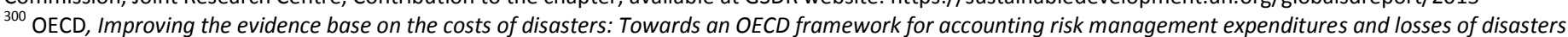

(Paris, 2014).

${ }^{301}$ Integrated Research on Disaster Risk (IRDR), Peril Classification and Hazard Glossary: DATA Project Report No. 1 (Beijing, 2014$)$.

302 More information available in the ESCAP Commission Resolution 70/2.

${ }^{303}$ Available at: http://www.irdrinternational.org/wp-content/uploads/2014/04/IRDR_DATA-Project-Report-No.-1.pdf

${ }^{304}$ Integrated Research on Disaster Risk (IRDR), Peril Classification and Hazard Glossary: DATA Project Report No. 1 (Beijing, 2014),

http://www.oecd.org/gov/risk/issues-paper.pdf.

${ }^{305}$ More information available in the ESCAP Commission Resolution 70/2.

${ }^{306}$ UNISDR. 2009 UNISDR terminology on disaster risk reduction (2009), http://www.unisdr.org/we/inform/publications/7817

${ }^{307}$ United Nations. Sendai Framework for Disaster Risk Reduction 2015-2030 (Sendai, 2015),

http://www.wcdrr.org/uploads/Sendai_Framework_for_Disaster_Risk_Reduction_2015-2030.pdf

${ }^{308}$ UNISDR, Making Development Sustainable: The Future of Disaster Risk Management - Global Assessment Report on Disaster Risk Reduction (Geneva, Switzerland: United Nations Office for Disaster Risk Reduction, 2015)

${ }^{309}$ UNISDR, Making Development Sustainable: The Future of Disaster Risk Management - Global Assessment Report on Disaster Risk Reduction (Geneva, Switzerland: United Nations Office for Disaster Risk Reduction, 2015)

${ }^{310}$ UNISDR, Making Development Sustainable: The Future of Disaster Risk Management - Global Assessment Report on Disaster Risk Reduction (Geneva, Switzerland: United Nations Office for Disaster Risk Reduction, 2015)

${ }^{311}$ Source: UNISDR with data from national loss databases.

${ }^{312} 3$ states are Tamil Nadu and Odisha in India, and Zanzibar in Tanzania. Countries that have published data sets in the last two years, including: Comoros,

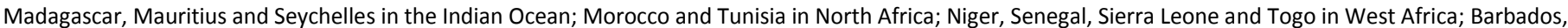
Grenada, Saint Lucia, Saint Kitts and Nevis, Saint Vincent, and Trinidad and Tobago in the Caribbean; Cambodia, Pakistan and the State of Palestine in Asia; and Albania, Serbia, Spain and Turkey in Europe

${ }^{313}$ Tom De Groeve et al., Monitoring disaster risk reduction targets (2015), in GSDR website: https://sustainabledevelopment.un.org/globalsdreport/2015. 


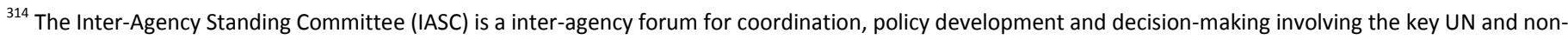
UN humanitarian partners.

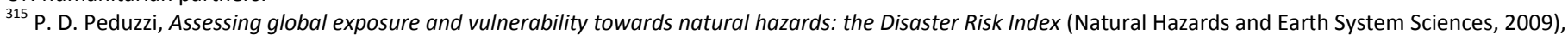
1149-1159, http://www.nat-hazards-earth-syst-sci.net/9/1149/2009/nhess-9-1149-2009.html

${ }^{316}$ UNU-EHS and Alliance Development Works, World Risk Report. Berlin, Germany: UNU-EHS and Alliance Development Works, 2014).

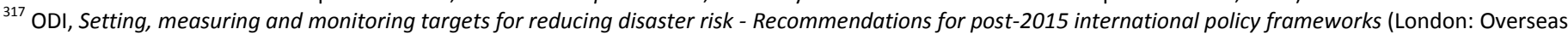
Development Institute, 2014), http://www.odi.org/sites/odi.org.uk/files/odi-assets/publications-opinion-files/9215.pdf

${ }^{318}$ UNISDR, Making Development Sustainable: The Future of Disaster Risk Management. Global Assessment Report on Disaster Risk Reduction (Geneva,

Switzerland: United Nations Office for Disaster Risk Reduction, 2015)

${ }^{319}$ UNISDR, Note from the Secretariat to the Informal Working Group on Targets and Indicators (Geneva, 2015), http://www.wcdrr.org/uploads/Note-from-the-

Secretariat-on-Targets-with-senarios-120115.pdf

${ }^{320}$ Source: UNISDR with data from the EM-DAT database

${ }^{321}$ UNISDR, Living with Risk: A global review of disaster reduction initiatives (New York and Geneva, 2004), http://www.unisdr.org/files/657 Iwr1.pdf

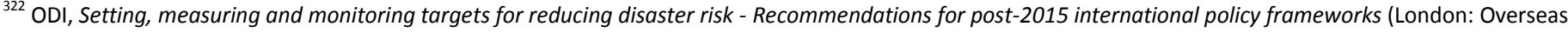

Development Institute, 2014), http://www.odi.org/sites/odi.org.uk/files/odi-assets/publications-opinion-files/9215.pdf

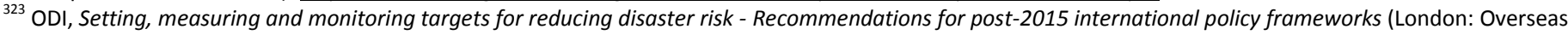
Development Institute, 2014), http://www.odi.org/sites/odi.org.uk/files/odi-assets/publications-opinion-files/9215.pdf

${ }^{324}$ Information available at: http://www.ecapra.org/

${ }^{325}$ Information available at: http://www.iiasa.ac.at/web/home/research/researchPrograms/EcosystemsServicesandManagement/CRIM-Model.en.html

${ }^{326}$ UNISDR, Making Development Sustainable: The Future of Disaster Risk Management - Global Assessment Report on Disaster Risk Reduction (Geneva,

Switzerland: United Nations Office for Disaster Risk Reduction, 2015)

${ }^{327}$ UNISDR, Making Development Sustainable: The Future of Disaster Risk Management - Global Assessment Report on Disaster Risk Reduction (Geneva, Switzerland: United Nations Office for Disaster Risk Reduction, 2015)

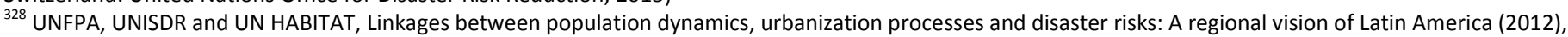
http://www.unisdr.org/files/31104_linkagesbetweenpopulationdynamicsur.pdf

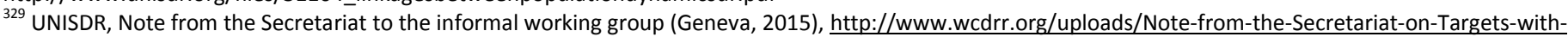
senarios-120115.pdf

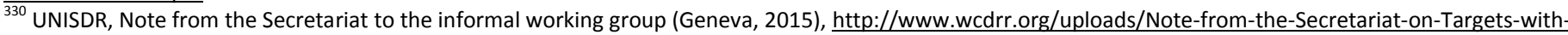
senarios-120115.pdf

${ }^{331}$ EMDAT, a widely used multi sourced standardized global disaster database (www.emdat.be) that systematically collects and validates data from 1900 to the

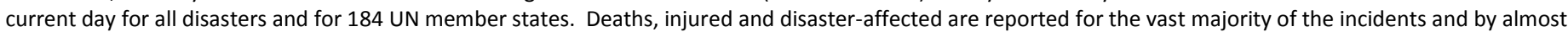
all the participating sources.

${ }^{332}$ D. Guha-Sapir and R. Below, Collecting Data on disasters: Easier said than done (Asian Disaster Management News, 2006 ), 9-10.

${ }^{333}$ The Brookings, IASC Operational Guidelines on the Protection of Persons in Situations of Natural Disasters (Bern Project on Internal Displacement, 2011), http://www.ohchr.org/Documents/Issues/IDPersons/OperationalGuidelines.pdf

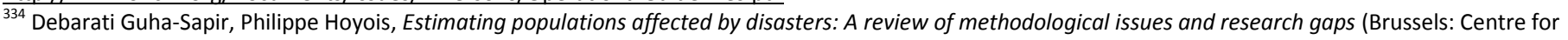
Research on the Epidemiology of Disasters, Institute of Health and Society, Université catholique de Louvain, 2015).

${ }^{335}$ United Nations. Guiding Principles on Internal Displacement (OCHA, 2004), http://www.brookings.edu/ /media/Projects/idp/GPEnglish.pdf

${ }^{336}$ E/CN.3/2015/9 - Report of Statistics Norway and the Office of the United Nations High Commissioner for Refugees on statistics on refugees and internally displaced persons.

${ }^{337}$ UNISDR, Making Development Sustainable: The Future of Disaster Risk Management. Global Assessment Report on Disaster Risk Reduction (Geneva: United Nations Office for Disaster Risk Reduction, 2015).

${ }^{338}$ UNISDR, Post-2015 Framework for Disaster Risk Reduction: a proposal for monitoring progress (2014), http://www.wcdrr.org/documents/wcdrr/prepcom1/Indicator\%20system\%20for\%20Post\%202015\%20Framework\%20June\%202015 v2.pdf

${ }^{339}$ UNISDR, A. Compilation of proposed post-2015 goals and targets on disaster resilience; Available at:

http://www.unisdr.org/2013/docs/newyork/climateDRRcompilation.pdf.

${ }^{340}$ Edited by Tom Mitchell, Lindsey Jones, Emma Lovell and Eva Comba, Disaster Risk Management in Post-2015 Development Goals, Potential targets and indicators (Overseas Development Institute, 2013).

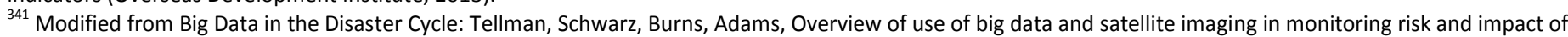
disasters;

${ }^{342}$ M. Borga et al., Flash flood forecasting, warning and risk management: the HYDRATE project (Environmental Science \& Policy, 2011), 834-844

${ }^{343}$ Sujay V. Kumar et al., Assimilation of Remotely Sensed Soil Moisture and Snow Depth Retrievals for Drought Estimation. J. Hydrometeor (2014), $2446-2469$.

${ }^{344}$ J. Verbesselt et al., Evaluating Satellite and Climate Data-Derived Indices as Fire Risk Indicators in Savanna Ecosystems (2006), $1622-1632$.

${ }^{345}$ M. J. McPhaden. et al., The Tropical Ocean-Global Atmosphere observing system: A decade of progress (Journal of Geophysical Research, 2008).

${ }^{346}$ Anyamba, A. et al., Prediction of a Rift Valley fever outbreak (2009), 955-959

${ }^{347}$ L. R. Beck, B. M. Lobitz and B. L. Wood, New Sensors and New Opportunities (2000), 217-227.

${ }^{348}$ D. Arribas-Bel, Accidental, open and everywhere: Emerging data sources for the understanding of cities (Applied Geography, 2014), 45-53

${ }^{349}$ Aulov, O., and M. Halem, Human Sensor Networks for Improved Modeling of Natural Disasters (2012),2812-2823.

${ }^{350}$ UN Global Pulse. Mining Indonesian Tweets to Understand Food Price Crises (2014), http://www.unglobalpulse.org/sites/default/files/Global-Pulse-MiningIndonesian-Tweets-Food-Price-Crises\%20copy.pdf

${ }^{351} \mathrm{~J}$. Ginsberg et al., Detecting influenza epidemics using search engine query data (Nature, 2009), $1012-4$.

${ }^{352}$ FLOODIS, a collaborative European Community project, is funded under the Seventh Framework Programme, and is testing this concept, with the support of

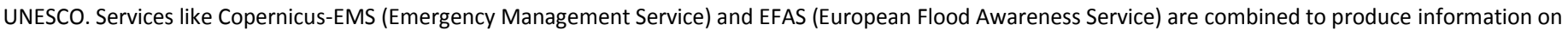
incoming and occurring floods events. More information available at: http://www.floodis.eu/).

${ }^{353}$ Information available at: https://www.disasterscharter.org/web/guest/home 
354 Information available at: http://www.aprsaf.org/initiatives/sentinel asia/

${ }^{355}$ G. Schumann, High-Resolution 3-D Flood Information From Radar Imagery for Flood Hazard Management (2007), $1715-1725$.

${ }^{356} \mathrm{~J}$. Verbesselt, Evaluating Satellite and Climate Data-Derived Indices as Fire Risk Indicators in Savanna Ecosystems (2006), $1622-1632$.

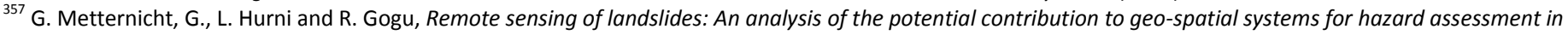
mountainous environments (Remote Sensing of Environment, 2005), 284-303.

${ }^{358}$ C. J. Tucker and B. J.Choudhury, Satellite Remote Sensing of Drought Conditions (Remote Sensing of the Environment, 1987 ), $243-251$.

${ }^{359}$ Tellman, Schwarz, Burns, Adams, Big Data in the Disaster Cycle: Overview of use of big data and satellite imaging in monitoring risk and impact of disasters

(2015). Contribution to the report. Available at GSDR website: https://sustainabledevelopment.un.org/globalsdreport/2015

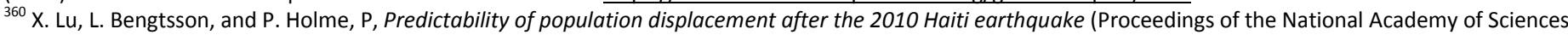
of the United States of America, 2012), 11576-81.

${ }^{361}$ D. Pastor-Escuredo et al., Flooding Through the lens of mobile phone activity (IEEE Global Humanitarian Technology Conference, 2014), 279-286, http://www2.die.upm.es/im/papers/GHTC 2014.pdf

${ }^{362}$ E. Lue, J. P. Wilson and A. Curtis, Conducting disaster damage assessments with Spatial Video, experts, and citizens (Applied Geography, 2014$), 46-54$.

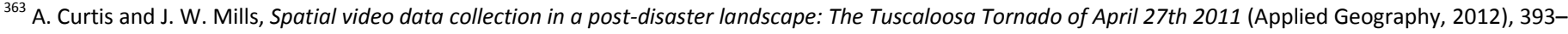
400.

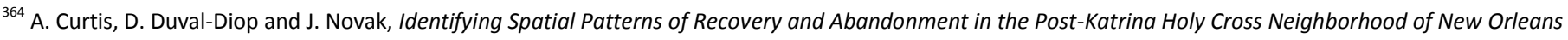
(Cartography and Geographic Information Science, 2010), 45-56.

${ }^{365}$ Patrick Meier, Digital Humanitarians: How Big Data is Changing the Face of Humanitarian Response (Taylor \& Francis Press, 2015).

${ }^{366}$ L. Barrington et al., Crowdsourcing earthquake damage assessment using remote sensing imagery (Annals of geophysics. 2011), 680-687,

http://www.annalsofgeophysics.eu/index.php/annals/article/view/5324

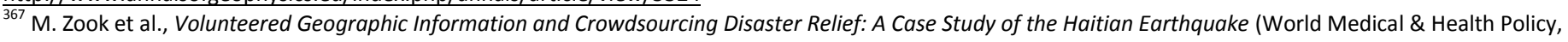
2011) 6-32.

${ }^{368}$ Available at: http://www.ushahidi.com/

${ }^{369}$ J. Heinzelman and C. Waters, Crowdsourcing crisis information in disaster-affected Haiti (United States Institute of Peace, 2010).

http://www.usip.org/sites/default/files/SR252\%20-\%20Crowdsourcing\%20Crisis\%20Information\%20in\%20Disaster-Affected\%20Haiti.pdf

${ }^{370}$ Gorokhovich Y. and Doocy S. (2012) Rapid Estimation of Areas and Populations affected by Typhoon Ketsana in the Philippines. Department of International Health, Johns Hopkins Bloomberg School of Public Health, Baltimore

${ }^{371}$ E. K. Noji, Estimating population size in emergencies (Bulletin of the World Health Organization, 2005$), 164$.

372 Information available at: www.climatewizard.org

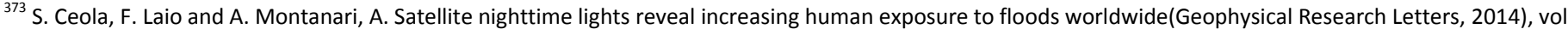
41:20, 7184-7190, http://onlinelibrary.wiley.com/doi/10.1002/2014GL061859/abstract

${ }^{374}$ E. Christenson et al., Climate-related hazards: a method for global assessment of urban and rural population exposure to cyclones, droughts, and floods. (International Journal of Environmental Research and Public Health, 2014), 2169-92, http://www.mdpi.com/1660-4601/11/2/2169

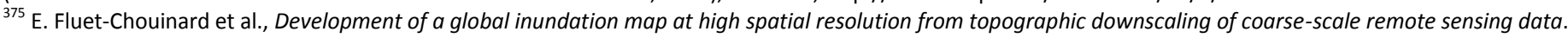
(Remote Sensing of Environment, 2014).

${ }^{376}$ J. K. Blackburn et al., Household-Level Spatiotemporal Patterns of Incidence of Cholera, Haiti, 2011 (Emerging Infectious Diseases, 2014 ), 1516-1520.

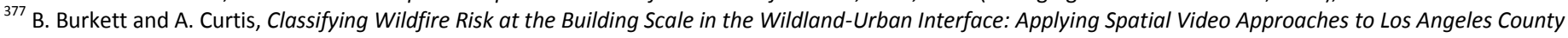
(Risk, Hazards \& Crisis in Public Policy, 2011) 1-20.

${ }^{378}$ Tellman et al., Big Data in the Disaster Cycle: Overview of use of big data and satellite imaging in monitoring risk and impact of disasters (2015), https://sustainabledevelopment.un.org/globalsdreport/2015

${ }^{379}$ Q. Wang and J. E. Taylor, Quantifying Human Mobility Perturbation and Resilience in Natural Disasters (2014), http://arxiv.org/ftp/arxiv/papers/1402/1402.1987.pdf

${ }^{380}$ Zaltz Austwick et al., The structure of spatial networks and communities in bicycle sharing systems (PloS One Research Article, 2013), http://journals.plos.org/plosone/article?id=10.1371/journal.pone.0074685

${ }^{381}$ See https://code.google.com/p/googletransitdatafeed/wiki/PublicFeeds for a complete list.

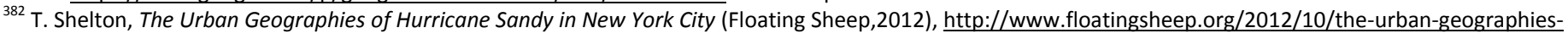
of-hurricane.htm

${ }^{383}$ Heinzelman and Waters, Crowdsourcing crisis information in disaster-affected Haiti, (United States Institute of Peace, 2010), http://www.usip.org/sites/default/files/SR252\%20-\%20Crowdsourcing\%20Crisis\%20Information\%20in\%20Disaster-Affected\%20Haiti.pdf

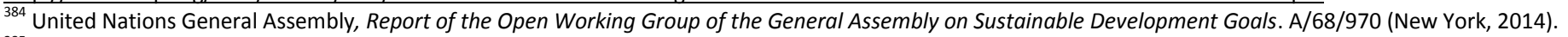

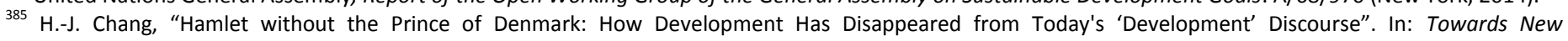
Developmentalism: Market as Means Rather Than Master, (eds.) S.R. Khan and J. Christiansen (Abingdon: Routledge, 2011); Economic Commission for Latin America and the Caribbean, Structural Change for Equality: An integrated approach to development (Santiago, 2012); UNIDO, Sustaining Employment Growth: The Role of Manufacturing and Structural Change (Vienna, 2013); ILO, Developing with Jobs, World of Work Report (Geneva, 2014); A. Andreoni, Production as Missing Dimension of Human Development. Background paper for the UNDP's Human Development Report 2015 (New York, 2015).

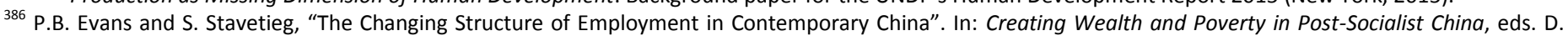
Davis and F. Wang (Stanford: Stanford University Press, 2009), 69-84.

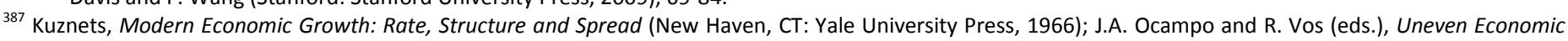
Development (London: Zed Books, 2008); M. McMillan and D. Rodrik, Globalization, Structural Change, and Productivity Growth (NBER Working Paper No. 17143., 2011); Economic Commission for Latin America and the Caribbean, Structural Change for Equality: An integrated approach to development (Santiago, 2012); UNIDO, Sustaining Employment Growth: The Role of Manufacturing and Structural Change (Vienna,. 2013); A. Andreoni, Production as missing dimension of human development, background paper for the Human Development Report 2015 (UNDP, 2015).

${ }^{388}$ D. Rodrik, Premature Deindustrialization (NBER Working Paper 20935, 2015).

${ }^{389}$ J. Felipe, A. Mehta, and C. Rhee, Manufacturing Matters ... but It's the Jobs that Count (ADB Economic Working Paper Series, 2014). 


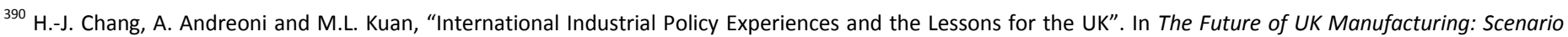
Analysis, Financial Markets and Industrial Policy, ed. A. Hughes (London: UK-IRC, 2014); J. Stiglitz and J.Y. Lin (eds.), The Industrial Policy Revolution I (Basingstoke: Palgrave, 2013); A. Noman, K. Botchwey, H. Stein and J. Stiglitz, Good Growth and Governance in Africa: Rethinking Development Strategies (Oxford: Oxford University Pres, 2011); M. Mazzucato, The Entrepreneurial State (London: Anthem Press, 2014); S. Berger, Making in America (Cambridge, MA: MIT Press, 2013).

${ }^{391}$ R. Hausmann and D. Rodrik (2002), Economic Development as Self-Discovery, NBER Working Paper No. 8952, May.

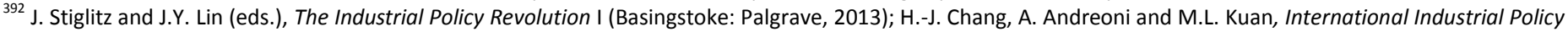
Experiences and the Lessons for the UK. Background paper for The Future of Manufacturing (London : Government Office for Science, 2014); E. O'Sullivan, A. Andreoni, G. Lopez-Gomez and M. Gregory, What is New in the New Industrial Policy? A Manufacturing System Perspective (Oxford Review of Economic Policy, 2013), 432-462; A. Andreoni, Varieties of Industrial Policy: Models, Packages and Transformation Cycles. IPD-JICA Task Force (Columbia University Press, 2014).

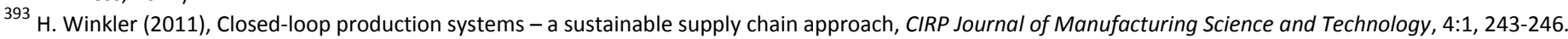

${ }^{394}$ D. Rodrik, Unconditional Convergence in Manufacturing (Quarterly Journal of Economics, 2013).

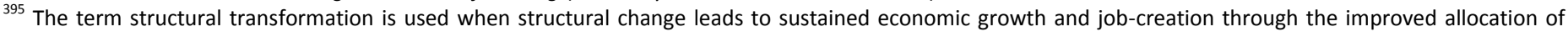
resources. See M.S. McMillan and D. Rodrik, Globalization, Structural Change and Productivity Growth. Working Paper 17143 (Cambridge, MA: National Bureau of Economic Research, 2011)..

${ }^{396}$ United Nations Technical Support Team ,Sustained and Inclusive Economic Growth, Infrastructure Development, and Industrialization, (2013).

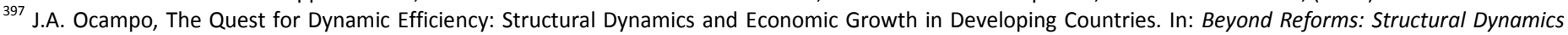
and Macroeconomic Vulnerability, ed. Ocampo, J.A., (Santiago: Economic Commission for Latin America and the Caribbean and Stanford University Press, 2005).

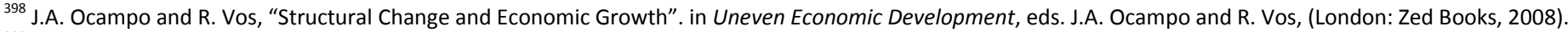

${ }^{399}$ UNDESA (2006). World Economic and Social Survey 2006: Diverging Growth and Development. New York, NY.

${ }^{400}$ M.S. McMillan and D. Rodrik, Globalization, Structural Change and Productivity Growth (Cambridge, MA: National Bureau of Economic Research, 2011).

${ }^{401}$ A. Lavopa and A. Szirmai, Industrialization, Employment and Poverty (Maastricht : UNU-MERIT Working Paper Series, No. 2012-081, 2012).

402 UNIDO estimation based on UNIDO INDSTAT2 .

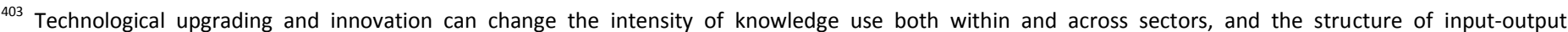
relationships. See: UNIDO, Industrial Development Report 2013: Sustaining Employment Growth - The Role of Manufacturing and Structural Change (Vienna, 2013).

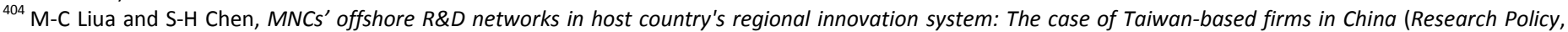
41:6, 2012).

${ }^{405}$ OECD, Perspectives on Global Development 2013 - Industrial Policies in a Changing World: Shifting Up a Gear (Paris, 2013).

${ }^{406}$ A.J.O. Silva and S. Mendonca, The Grand Green Challenge: Assessing Progress in Eco-Innovation through Y02 Patents (2015, forthcoming).

407 lbid.

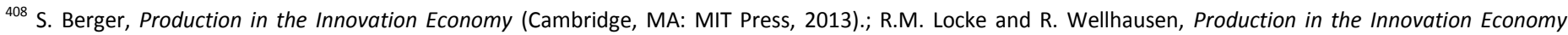
(Cambridge, MA: MIT Press, 2014).

${ }^{409}$ A.J.O. Silva and S. Mendoza, The Grand Green Challenge: Assessing Progress in Eco-Innovation through Y02 Patents (2015, forthcoming).

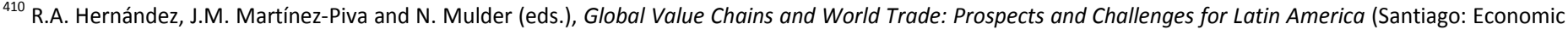
Commission for Latin America and the Caribbean, 2014).

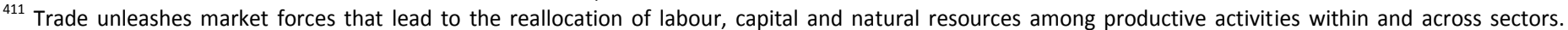
Imports of commodities, manufactures and services not efficiently produced domestically, can free up resources for use in more productive sectors. Access to large export markets helps producers realize economies of scale, enhancing production efficiencies for established exports and encouraging investment in new higher value added sectors. Production and export focuses on products for which a country has comparative advantage; both final products for end consumers and intermediate goods comprising GVCs. Further information on this topic is available in several UNCTAD publications, and most recently, "The Least Developed Countries Report: Growth with Structural Transformation: A post-2015 development agenda", UNCTAD, 2014, Geneva.

412 UNDESA, World Economic and Social Survey 2013: Sustainable Development Challenges (New York, NY: United Nations, 2013).

${ }^{413}$ UNIDO, Industrial Development Report 2013: Sustaining Employment Growth - The Role of Manufacturing and Structural Change (Vienna, 2013).

${ }^{414}$ P. Lai, China's Foreign Trade: Achievements, Determinants and Future Policy Challenges (China and World Economy, 2004), 38-50.

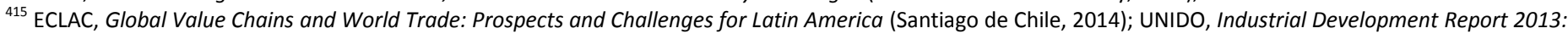
Sustaining Employment Growth - The Role of Manufacturing and Structural Change (Vienna, 2013); W. Milberg and D. Winkler, Outsourcing Economics: Global Value Chains in Capitalist Development (Cambridge: Cambridge University Press, 2013).

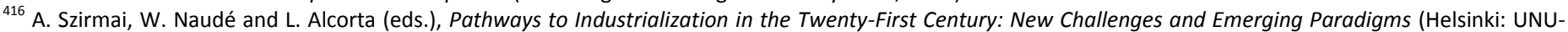
WIDER and Oxford University Press, 2013).

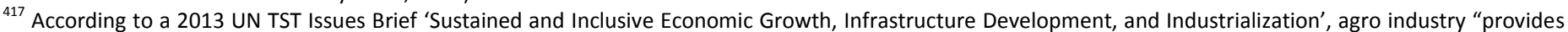
capital and services to farmers (e.g. seeds and equipment, training, production and market information), promotes entrepreneurship, raises demand for agricultural products and connects farmers with markets through the handling, processing, marketing and distribution of agricultural products. As a result, productivity and quality of agricultural production, farm returns, economic stability for rural households, food security and innovation throughout the value chain can be enhanced." Efficient agro-industry together with strong stakeholder linkages can stimulate agricultural growth, and increase farmers' incomes. UNIDO, FAD and FAO, The Importance of Agro-Industry for Socio-Economic Development and Poverty Reduction. Prepared for UN Commission on Sustainable Development $16^{\text {th }}$ Session (New York, 2008).

418 UNIDO, Industrial Development Report 2013: Sustaining Employment Growth - The Role of Manufacturing and Structural Change (Vienna, 2013).

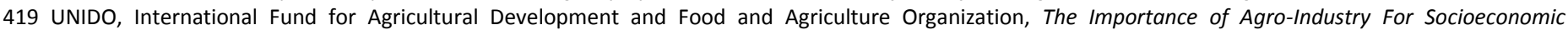
Development And Poverty Reduction. Discussion Paper: UN Commission on Sustainable Development - 16th Session. Prepared For Side-Event On: “How Agro-Industry Can Help Eradicate Poverty" (New York, 2008).

${ }^{420}$ Alliance for a Green Revolution in Africa, Africa Agriculture Status Report: Focus on Stable Crops (Nairobi: African Economic Outlook, 2014). 
African Economic Outlook, Structural Transformation \& Natural Resources - The Primary Sector in Africa Past and Present (Nairobi, 2013), www.africaneconomicoutlook.org/theme/structural-transformation-and-natural-resources/the-primary-sector-in-africa-past-and-present.

${ }^{421}$ UN ECA and African Union, Economic Report on Africa 2013: Making the Most of Africa's Commodities Industrializing for Growth, Jobs and Economic Transformation (Addis Ababa, 2013).

${ }^{422}$ Ibid.

${ }^{423}$ UN ECA, Economic Report on Africa 2015: Industrializing through trade (Addis Ababa, 2015 - forthcoming).

${ }^{424}$ S. Straub, Infrastructure and Growth in Developing Countries: Recent Advances and Research Challenges. Policy Research Working Paper 4460 (Washington, DC: World Bank, 2008).

${ }^{425}$ World Bank, World Development Report 1994: Infrastructure for Development (Washington, DC: World Bank, 1994).

${ }^{426}$ Economic infrastructure is comprised of energy and piped gas, telecommunications, piped water supply, sanitation and sewerage, and solid waste collection and disposal; roads and major dam and canal works for irrigation and drainage; and other transport sectors-urban and interurban railways, urban transport, ports and waterways, and airports. (Ibid.)

${ }^{427}$ A. Andreoni, Varieties of Industrial Policy: Models, Packages and Transformation Cycles. IPD-JICA Task Force (Columbia University Press,2014).

${ }^{428}$ E. O'Sullivan et al., What Is New in the New Industrial Policy? A Manufacturing System Perspective (Oxford Review of Economic Policy, 2013 ), $432-462$.

${ }^{429}$ A. Andreoni, Production as Missing Dimension of Human Development. Background paper for the UNDP's Human Development Report 2015 (New York, 2015 ); S. Barrientos, G. Gereffi and A. Rossi, Economic and Social Upgrading in Global Production Networks: A New Paradigm for a Changing World (International Labour Review, 2011), 319-340.

${ }^{430}$ D. Rodrik, Industrial Policy for the Twenty-First Century (Cambridge: Harvard University, 2004); H.-J. Chang, A. Andreoni and M.L. Kuan (2014). International Industrial Policy Experiences and the Lessons for the UK. Background paper for The Future of Manufacturing (London: Government Office for Science, 2014).

${ }^{431}$ H.-J. Chang, A. Andreoni and M.L. Kuan, International Industrial Policy Experiences and the Lessons for the UK. Background paper for The Future of Manufacturing (London: Government Office for Science, 2014).

${ }^{432}$ J.Y. Lin and H.-J. Chang, Should Industrial Policy in Developing Countries Conform to Comparative Advantage or Defy it? A Debate between Justin Lin and Ha-Joon Chang (Development Policy Review, 2009), 483-502.

${ }^{433}$ UNIDO, Breaking In and Moving Up: New Industrial Challenges for the Bottom Billion and the Middle-Income Countries (Vienna, 2009); UNIDO, Industrial Development Report 2013: Sustaining Employment Growth - The Role of Manufacturing and Structural Change (Vienna, 2013).

${ }^{434}$ UNCTAD, The Least Developed Countries Report 2014 - Growth with Structural Transformation: A Post-2015 Development Agenda (Washington, DC: United Nations, 2014).

${ }^{435}$ See e.g., Hidalgo and Hausmann, The building blocks of economic complexity (PNAS, 2009) vol. 106, no. 26.

${ }^{436}$ UNIDO, Input to the Report of the Secretary-General for the 2013 Annual Ministerial Review of UN ECOSOC (SQA/DPR/OD, 2013).

${ }^{437}$ United States Department of Commerce (2012). The Competitiveness and Innovative Capacity of the United States. Washington, DC.

${ }^{438}$ European Commission, Communication from the Commission to the European Parliament, the Council, the European Economic and Social Committee and the Committee of the Regions: "A Stronger European Industry for Growth and Economic Recovery" (Brussels, 2012)

${ }^{439}$ European Commission, Green Paper: Long-term Financing of the European Economy (Brussels, 2013).

${ }^{440}$ UNIDO and Government of Costa Rica, Declaration following the High-level Conference of Middle-Income Countries on Challenges for Sustainable Development and International Cooperation in Middle-Income Countries: The Role of Networks for Prosperity, (San José, Costa Rica: 2013).

${ }^{441}$ The question has been famously asked how one city in Pakistan, Sialkot, came to produce $40 \%$ of the world supply of soccer balls. The origin of the industry dates back to a time when British colonials wanted a local supply of soccer balls.

${ }^{442}$ A. Mohammed, Outlook on the Global Agenda 2015: Deepening Income Inequality, (World Economic Forum, 2014), http://reports.weforum.org/outlook-globalagenda-2015/top-10-trends-of-2015/1-deepening-income-inequality.

${ }^{443}$ J. Weiss, "Industrial Policy in the Twenty-First Century: Challenges for the Future." In Pathways to Industrialization in the Twenty-First Century: New Challenges and Emerging Paradigms, eds. A. Szirmai, W., Naudé and L. Alcorta, (UNU-WIDER and Oxford University Press, 2013).

${ }^{444}$ UNIDO, Inclusive and Sustainable Industrial Development: Creating Shared Prosperity - Safeguarding the Environment (Vienna, 2014).

${ }^{445}$ UNIDO, Industrial Development Report 2013: Sustaining Employment Growth - The Role of Manufacturing and Structural Change (Vienna: 2013).

${ }^{446}$ UNDP, Human Development Report 2013: The Rise of the South: Human Progress in a Diverse World, 2013.

${ }^{447}$ Upadhyaya,Shyam and David Kepplinger, How industrial development matters to the well-being of the population: Some statistical evidence (UNIDO Working

Paper 04/2014).

${ }^{448}$ ECLAC. Structural Change for Equity: An Integrated Approach to Development (Santiago, 2012).

${ }^{449}$ Structural Change For Equality: An Integrated Approach To Development, Thirty-Fourth Session Of ECLAC, 27-31 August (San Salvador: ECLAC, 2012).

${ }^{450}$ R. Islam, The Nexus of Economic Growth, Employment and Poverty Reduction: An Empirical Analysis (Geneva: International Labor Organization, 2004).

${ }^{451}$ Looking At Trade Policy Through "Gender Lens", Summary Of Seven Country Studies Conducted By UNCTAD (UNCTAD, 2014).

${ }^{452}$ Ibid.

${ }^{453}$ Makhtar Diop, 'How Empowering Women Can Help End Poverty In Africa', Blog, 2015, http://blogs.worldbank.org/nasikiliza/how-empowering-women-can-helpend-poverty-africa.

${ }^{454}$ Ibid.

${ }^{455}$ Shyam Upadhyaya and David Kepplinger, How Industrial Development Matters To The Well-Being Of The Population: Some Statistical Evidence. (Vienna: UNIDO, 2014).

${ }^{456}$ A Szirmai and A Lavopa, Industrialization, Employment And Poverty, Working Paper Series, No. 2012-081 (Maastricht.: UNU-MERIT, 2012).

${ }^{457}$ The Role Of Manufacturing And Structural Change, Industrial Development Report 2013: Sustaining Employment Growth (Vienna, 2013).

${ }^{458}$ World Development Report: Poverty., Fighting Poverty. American Economic Review, 83(2), (New York, NY: World Bank, 1990)..

${ }^{459}$ M Mahmood, A Andreoni and HJ Chang, Developing With Jobs: Manufacturing Growth, Productive Employment And Policies In Developing Countries, ILO Series (Palgrave Macmillan, 2015).

${ }^{460}$ The Role Of Manufacturing And Structural Change., Industrial Development Report 2013: Sustaining Employment Growth (Vienna: UNIDO, 2013)

${ }^{461}$ Ibid.

${ }^{462}$ The Role Of Manufacturing And Structural Change., Industrial Development Report 2013: Sustaining Employment Growth (Vienna: UNIDO, 2013).

${ }^{463}$ Ibid. 


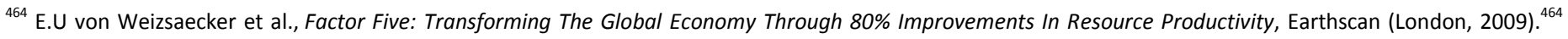
465 Ibid. Resource Revolution: Meeting The World'S Energy, Material, Food, And Water Needs (Washington D.C.: McKinsey Global Institute, 2011).

${ }^{466}$ Sustainable Consumption And Production - A Handbook For Policy Makers, Switch Asia Publication (Nairobi: UNEP, 2013).

${ }^{467}$ Growth With Structural Transformation: A Post-2015 Development Agenda, The Least Developed Countries Report (Washington D.C.: UNCTAD, 2014).

${ }^{468}$ Open Working Group, Sustainable Consumption And Production, Including Chemicals And Waste, TST Issues Brief: (New York: UNDESA DSD, 2013).

${ }^{469}$ Structural Change For Equity: An Integrated Approach To Development. (Santiago: ECLAC, 2012).

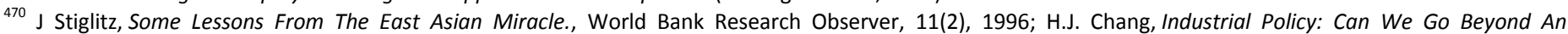
Unproductive Debate?, ABCDE, Annual World Bank Conference (Seoul, 2009); A. Andreoni, Varieties Of Industrial Policy: Models, Packages And Transformation Cycles, IPD-JICA Task Force (Columbia University Press, forthcoming, 2014).

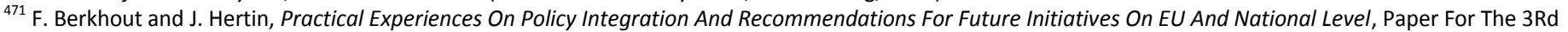
Blueprint Workshop Instruments For Integrating Environmental And Innovation Policy, (Brussels 26-27 September, 2002).

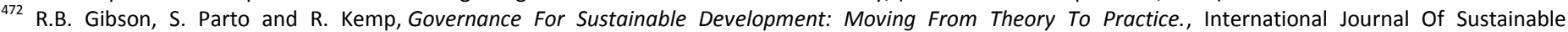
Development 8(1/2), Pp. 12-30, 2005.

${ }^{473}$ A. Primi, Production Transformation Policy Reviews: A New Policy Assessment And Guidance Tool For Policy Guidance And Knowledge Sharing, Background Document For The 3Rd Plenary Meeting Of The OECD Initiative For Policy Dialogue On Gvcs, Production Transformation And Development (Paris, 2015).

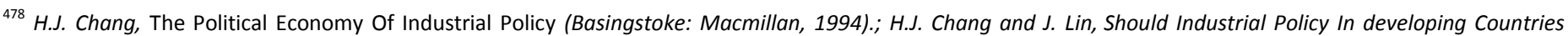
Conform To Comparative Advantage Or Defy It? A Debate Between Justin Lin And Ha-Joon Chang. Development Policy Review, 27(5), (Washington D.C.: New Structural Economics - A Framework for Rethinking Development and Policy - World Bank, 2009).

${ }^{479}$ A. Hirschman, The Strategy Of Economic Development. (New Haven, CT and London: Yale University Press., 1958).

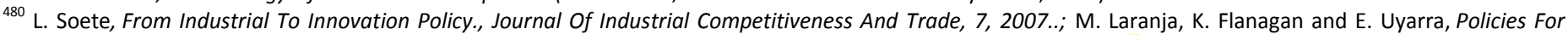
Science, Technology And Innovation: Translating Rationales Into Regional Policies In A Multi-Level Setting., Research Policy, 37, 2008.; E. O'Sullivan et al., What Is New In The New Industrial Policy? A Manufacturing System Perspective,, Oxford Review Of Economic Policy, 29(2), 2013.

${ }^{481}$ G. Tassey, The Technology Imperative, Cheltenham And Northampton: Edward Elgar, 2007.

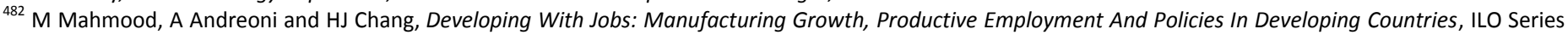
(Palgrave Macmillan, 2015).

${ }^{483}$ For more information see A/68/970 Report of the Open Working Group on Sustainable Development Goals.

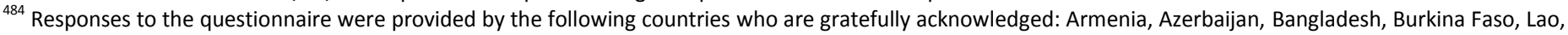
Mali, Mongolia, Nepal, Niger, Paraguay, Samoa, Solomon Islands, St. Vincent and the Grenadines, Sudan and Togo.

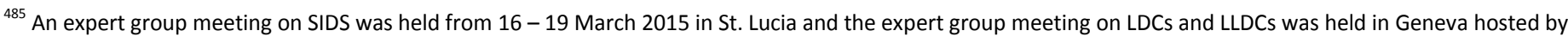
UNCTAD from 13 - 14 April 2014.

${ }^{486}$ For more information see Agenda 21, Chapter 17G, Paragraph 17.123

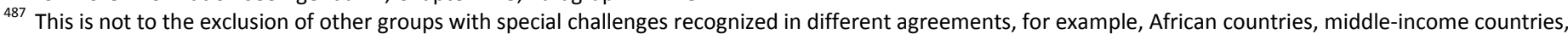
and countries in situations of conflict, all of whom are mentioned in The Future We Want.

${ }^{488}$ Report On The United Nations Conference On Environment And Development, Resolutions Adopted By The Conference Vol 1 (Rio de Janeiro: United Nations publication, Sales No. E.93.I.8 and corrigendum, 1992).

${ }^{489}$ For more information see Resolution A/66/288

${ }^{490}$ For more information see the report of the Open working group on SDGs $68 / 970$

${ }^{491}$ See the list of publications in Annex 3

${ }^{492}$ For more information see UNCTAD, 2015, contribution to the GSDR.

${ }^{493}$ Nicola Jones, Cora Walsh and Harry Jones, 'Political Science? Strengthening Science-Policy Dialogue In Developing Countries' Working Paper 294, Overseas Development Institute, 2008.

${ }^{494}$ For more information see UNCTAD, 2015, contribution to the GSDR.

${ }^{495}$ For more information see UNESCO, Institute for statistics database. April 2015

496 Ibid.

${ }^{497}$ For more information see OHRLLS 2015

${ }^{498}$ A file describing all the proposed indicators and a set of tables with available data for these indicators can be found at http://www.unohrlls.org/en/ldc/962/

${ }^{499}$ Strydom et al., 2010; Jones et al., 2008

${ }^{500}$ This was in essence the programme of the so-called Washington Consensus (Rodrik, 2006).

${ }^{501}$ For more information see UNCTAD, 2007: chap. 2

502 Gaillard et al., 2005

${ }^{503}$ For more information see UNCTAD 2015

${ }^{504}$ For more information see UNESCO, Institute for Statistics database, April 2015

505 Ibid.

${ }^{506}$ For more information see UN-OHRLLS contribution to GSDR2015

507 Ibid.

${ }^{508}$ For more information see A/68/970 Report of the Open Working Group on Sustainable Development Goals

${ }^{509}$ For more information see A/RES/68/224

${ }^{510}$ For more information see LDC proposal to the Co-Facilitators of the FfD Process, 28 February 2015

${ }^{511}$ For more information see A/RES/55/2 
${ }^{512}$ Report Of The International Ministerial Conference Of Landlocked And Transit Developing Countries And Donor Countries And International Financial And Development Institutions On Transit Transport Cooperation, (A/CONF.202/3) (Almaty, Kazakhstan, 2003).

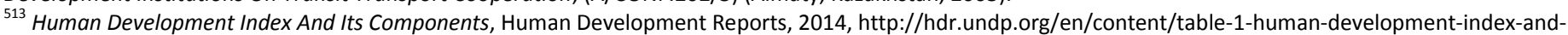
its-components.

${ }^{514}$ For more information see programme of work of Open Working Group sessions at https://sustainabledevelopment.un.org/owg1.html

${ }^{515}$ For more information see TST issue briefs at https://sustainabledevelopment.un.org/index.php?menu=1528

${ }^{516}$ For more information A/69/137, paragraph 61 and 64 (a)

${ }^{517}$ Ibid, paragraph 64 (a)

${ }^{518}$ For more information see complete information on ASYCUDA system on http://www.asycuda.org/

${ }^{519}$ For more information on updates of other landlocked countries using the ASYCUDA system: http://unctad.org/en/PublicationsLibrary/webdtlasycuda2014d1_en.pdf

${ }^{520}$ For more information see UNESCO, Institute for Statistics database, April 2015

521 Ibid.

522 UNEP, Emerging Issues For Small Island Developing States (Nairobi, Kenya: United Nations Environment Programme (UNEP), 2014).

523 Ibid.

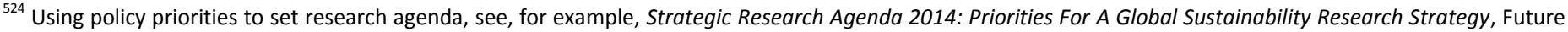
Earth: Research For Global Sustainability (Paris: International Council for Science (ICSU)., 2014). For discussion of modes of interaction between science and policy, see, for example, Simon Maxwell and Diane Stone, Global Knowledge Networks And International Development (London [u.a.]: Routledge, 2005).

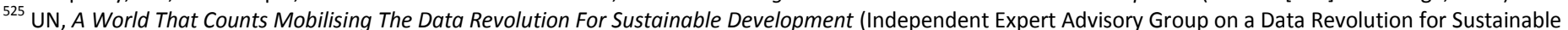
Development, 2014)

${ }^{526}$ For more information see UN Statistics Division records, at http://unstats.un.org

${ }^{527}$ Data provided by ILO to the GSDR 2015.

${ }^{528}$ Umar Serajuddin et.al , Data Deprivation : Another Deprivation To End, Policy Research Working Paper; No. WPS 7252. (Washington D.C.: World Bank Group, 2015), http://documents.worldbank.org/curated/en/2015/04/24426058/data-deprivation-another-deprivation-end.

529 'Environment And Urbanization', 2012, http://eau.sagepub.com/content/24/1.

${ }^{530}$ F. Brckschen, R. Schmid and T. Zbiransky, Cookbook For A Socio-Demographic Basket (Unpublished Paper, 2014).

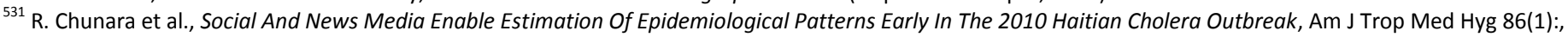
2012. For more information see http://www.google.org/denguetrends/intl/en_us/

${ }^{532}$ For more information see mdgs.un.org

${ }^{533}$ For more information see http://faostat3.fao.org/download/FB/FBS/E

${ }^{534}$ For more information see http://databank.worldbank.org/data/views/rep

${ }^{535}$ For more information see http://data.unicef.org/child-protection/birth-registration

536 List of indicators:

Extreme poverty - Proportion of population below $\$ 1.25 /$ day;

Hunger - Proportion of population below minimum level of dietary consumption;

Health access during birth - Births attended by skilled health personnel;

Secondary education enrolment - Net enrolment ratio in secondary education;

Gender equality in tertiary education - Ratio of girls to boys in tertiary education;

Water access - Proportion of the pop using an improved drinking water source;

Electricity access - \% population with access to electricity

Employment -Employment to population ratio;

Employment in industry - Share of employment in industry (\% of total employment);

Gini index - Gini Index;

Slum population - Proportion of urban population living in slums;

Food Waste - Food waste (in 1000 tonnes);

$\mathrm{CO}_{2}$ emissions $-\mathrm{CO}_{2}$ emission, Metric tons of $\mathrm{CO} 2$ per capita;

Marine protected areas - Marine protected areas;

Forest area - Forest area;

$\%$ registered births - Percentage of children less than five years old who are registered;

Free of duty exports - Proportion of total developed country imports (by value and excluding arms) from developing countries and least developed countries, admitted free of duty (by exporting country?); and ODA/DAC trade aid - Proportion of ODA provided to help build trade capacity (by recipient country?

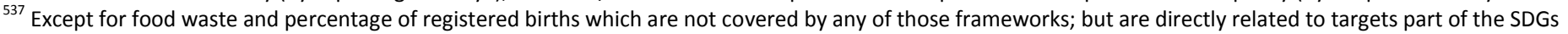
adopted by the Open Working Group on July 2014.

${ }^{538}$ David Le Blanc, Towards Integration At Last? The Sustainable Development Goals As A Network Of Targets, Working Paper No. 141 (UNDESA)

${ }^{539}$ For more information see UNCTAD, 2015, contribution to the GSDR.

${ }^{540}$ For more information see http://www.unep.org/science/chief-scientist/Activities/Cross-cuttinglssues/UNEPForesightProcess.aspx

${ }^{541}$ This corresponds to the first phase in bridging the science-policy gap.

${ }^{542}$ For more information see Chapter 1 , Box 4, for an elaboration of credibility, relevance and legitimacy in relation to the science-policy interface.

${ }^{543}$ Net primary productivity (NPP) is defined as the net flux of carbon from the atmosphere into green plants per unit time. NPP refers to a rate process, i.e. the

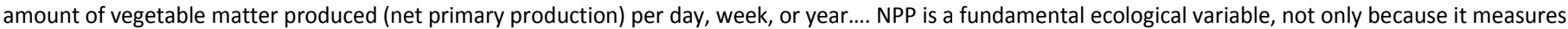

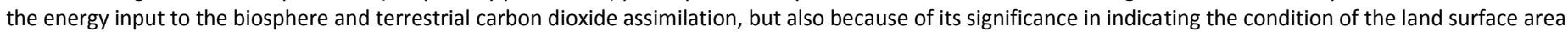
and status of a wide range of ecological processes." Available from http://daac.ornl.gov/NPP/html_docs/npp_est.html

${ }^{544}$ Global Risks 2014 Ninth Edition, Insight Report (World Economic Forum, 2014).

${ }^{545}$ G Gardner et al., State Of The World 2015, n.d. 
${ }^{546}$ Sustainabledevelopment.un.org, 'Crowdsourced Briefs ... Sustainable Development Knowledge Platform', 2015,

https://sustainabledevelopment.un.org/topics/science/crowdsourcedbriefs.

${ }^{547}$ Sustainabledevelopment.un.org, 'Crowdsourced Briefs ... Sustainable Development Knowledge Platform', 2015,

https://sustainabledevelopment.un.org/topics/science/crowdsourcedbriefs.

${ }^{548}$ State University of New York (SUNY) and Wageningen University.

${ }^{549}$ Submissions had to pass an internal review to ensure that they were in line with the criteria set out in the open call.

${ }^{550}$ Sustainabledevelopment.un.org, 'Global Sustainable Development Report ... Sustainable Development Knowledge Platform',

https://sustainabledevelopment.un.org/globalsdreport.

${ }^{551}$ Sustainabledevelopment.un.org, 'Crowdsourced Briefs .:. Sustainable Development Knowledge Platform', 2015, https://sustainabledevelopment.un.org/topics/science/crowdsourcedbriefs.

${ }_{552}$ Crowdsourced Science Briefs on Sustainable Development, 'Crowdsourced Science Briefs On Sustainable Development', https://gsdr2015.wordpress.com/.

${ }^{553}$ Technically, this is known as a Kamada-Kawai projection which minimizes the "energy" of a network of mechanical springs. It allows identification of the central SDG nodes and of clusters of the SDGs that are typically covered in an integrated in manner in some of the briefs.

${ }^{554}$ Helen Adams and Karen E. McNamara, Climate Change Responses: Mitigation And Adaptation For Whom?, Brief For GSDR, 2015.

${ }^{555}$ Keetie Roelen, Reducing child poverty: the importance of measurement for getting it right. Brief for GSDR, 2015

${ }^{556}$ Mohammed Yimer, Pastoral Development Pathways in Ethiopia; the Policy Environment and Critical Constraints. Brief for GSDR, 2015.

${ }^{557}$ Achim Dobermann, Transformative changes of agriculture and food systems. Brief for GSDR, 2015.

${ }^{558}$ Achim Dobermann, Planning and Implementing Action for Sustainable Agriculture. Brief for GSDR, 2015.

${ }^{559}$ Matteo Pedercini, Gunda Zullich and Kaveh Dianati, Fertilizer addiction: Implications for Sustainable Agriculture. Brief for GSDR, 2015.

${ }^{560}$ Otto Cars \& Dusan Jasovsky, Antibiotic resistance (ABR) - no sustainability without antibiotics. Brief for GSDR, 2015.

${ }^{561}$ Anita Shankar, Strategically engaging women in clean energy solutions for sustainable development and health. Brief for GSDR, 2015.

${ }^{562}$ Thematic Group on Early Childhood Development, Education, and Transition to Work Children as a Basis for Sustainable Development, Children as a Basis for Sustainable Development. Brief for GSDR, 2015.

${ }^{563}$ Clemens Mader \& Christian Rammel, Transforming Higher Education for Sustainable Development. Brief for GSDR, 2015.

${ }^{564}$ Nicoline de Haan \& Fraser Sugden, Including women and the poor in water management systems. Brief for GSDR, 2015.

${ }^{565}$ Anita Shankar, Strategically engaging women in clean energy solutions for sustainable development and health. Brief for 2015, GSDR.

${ }^{566}$ Ying Qin, Elizabeth Curmi, Zenaida Mourao, Dennis Konadu, and Keith S. Richard, Integrated resource policies for energy and water resources, with case studies of China and the UK. Brief for 2015, GSDR.

${ }^{567}$ Timothy O. Williams, Accessing and putting water to productive use in sub-Saharan Africa. Brief for 2015, GSDR.

568 Javier Mateo-Sagasta \& Pay Drechsel, Improving wate quality is an opportunity to avert a global crisis. Brief for GSDR 2015.

${ }^{569}$ 基于 TIMES-Water 模型的能源与水资源分析 TIMES-Water model for analysis of energy and water resources. Brief for GSDR 2015, submitted in Chinese through the Administrative Centre for China's Agenda 21 (ACCA21), Ministry of Science and Technology, China, and the Chinese Society for Sustainable Development (CSSD).

${ }^{570}$ Ilaria Lenzi, Jacopo Bonan and Ilaria Pais, Towards a Universal Energy Access: a multistakeholder path for a global change. Brief for GSDR 2015.

${ }^{571}$ Ilaria Lenzi, Jacopo Bonan and Ilaria Pais, Towards a Universal Energy Access: a multistakeholder path for a global change. Brief for GSDR 2015.

${ }^{572}$ Pamela Flattau, Design and diffusion of smart energy monitors for sustainable household consumption. Brief for GSDR 2015.

${ }^{573}$ Saahil Parekh and Siddharth Singh, Towards an Energy Efficient Oil \& Gas Sector. Brief for GSDR 2015.

${ }^{574}$ Julien Rochette \& Glen Wright, Strengthening the international regulation of offshore oil and gas activities. Brief for GSDR 2015.

575 David Acuña Mora \& Arvid de Rijck, Blue Energy: Salinity Gradient Power in Practice. Brief for GSDR 2015.

${ }^{576}$ Ivana Gadjanski, Fabrication laboratories - fab labs - tools for sustainable development. Brief for GSDR 2015.

${ }^{577}$ Henri Waisman, Carl Mas \& Emmanuel Guerin, Pathways to Deep Decarbonization, a Problem Solving Approach for a $2^{\circ} \mathrm{C}$ Society. Brief for GSDR 2015.

${ }^{578}$ Zeenat Niazi \& Anshul S. Bhamra, Decoupling Growth from Resource Generation. Brief for GSDR 2015.

${ }^{579}$ Alexandra Köves, György Pataki, Gábor Király \& Bálint Balázs, Sustainable employment in a non-growth oriented economy. Brief for GSDR 2015.

${ }^{580}$ Sigrid Kusch, Industrial symbiosis: powerful mechanisms for sustainable use of environmental resources. Brief for GSDR 2015.

${ }^{581}$ Karl Aiginger \& Michael Böheim, Fostering sustainable economic growth by redefining competitiveness and industrial policy: Towards a systemic policy approach aligned with beyond-GDP goals. Brief for GSDR 2015.

${ }^{582}$ Patrick Paul Walsh, Industrial Policy and Sustainable Development. Brief for GSDR 2015.

${ }^{583}$ Bojana Bajželj et al., Synergies between healthy and sustainable diets. Brief for GSDR, 2015.

${ }^{584}$ Daniele Giovannucci and Friedrich von Kirchbach, How New Metrics for Sustainable Agriculture Can Align the Roles of Government and Business. Brief for GSDR, 2015.

${ }^{585}$ Juana Isabel Vera López, Politicas publicas para la produccion social de vivienda como alternative para disminuir la irregularidad en America Latina. Brief for GSDR 2015.

${ }^{586}$ 特大城市应走的可持续之路：特大城市应走的可持续之路：以北京为例 Sustainable development in mega-cities: the case of Beijing. Brief for GSDR 2015.

${ }^{587}$ Kati Vierikko et al., Towards diverse and sustainable governance - Assessment of biocultural diversity (BCD) in European cities. Brief for GSDR, 2015.

${ }^{588}$ Frank Thomalla et al., Transforming disaster risk reduction for more inclusive, equitable and sustainable development. Brief for GSDR, 2015.

${ }^{589}$ Steven A. Moore, Reframing Social Housing as an Infrastructure of Production and Consumption. Brief for GSDR 2015

${ }^{590}$ Liette Vasseur and Mike Jones, Adaptation and resilience in the face of climate change: protecting the conditions of emergence through good governance. Brief for GSDR, 2015.

${ }^{591}$ Helen Adams \& Karen E. McNamara, Climate Change Responses: Mitigation and Adaptation for Whom? Brief for GSDR 2015.

${ }^{592}$ Muhammad Mehmood-UI-Hassan \& Jan De Leeuw, Enhancing the quality of African climate change science by investing in peer review capacity. Brief for GSDR, 2015.

${ }^{593}$ Hans A. Baer \& Thomas Reuter, Anthropological perspectives on climate change and sustainability: Implications for policy and action. Brief for GSDR, 2015.

${ }^{594}$ Fredrik Haag, Edward Kleverlaan \& Astrid Dispert, Estimations of the contribution of international shipping to greenhouse gas emissions. Brief for GSDR, 2015. 


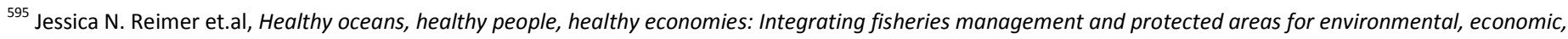
and social benefits. Brief for GSDR, 2015.

${ }^{596}$ LIU Hui and SU Jilan, Vulnerability of Nearshore Ecosystems from Rapid Intensive Coastal Development. Brief for GSDR, 2015.

${ }^{597}$ Kirsten Isensee \& Luis Valdes, Marine Litter: Microplastics. Brief for GSDR 2015.

${ }^{598}$ Kirsten Isensee \& Luis Valdes, Ocean Acidification. Brief for GSDR 2015.

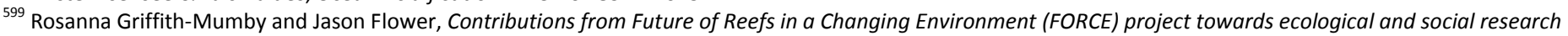
on coral reef ecosystems. Brief for GSDR, 2015.

${ }^{600}$ Kirsten Isensee \& Luis Valdes, The Ocean is Losing its Breath. Brief for GSDR 2015.

${ }^{601}$ Jérôme Pelenc, Jérôme Ballet and Tom Dedeurwaerdere, Weak Sustainability versus Strong Sustainability. Brief for GSDR, 2015.

${ }^{602}$ Stephen Tooth et.al, Wetlands in Drylands: 'Hotspots' of Ecosystem Services in Marginal Environments. Brief for GSDR, 2015.

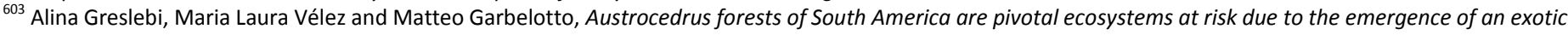
tree disease: can a joint effort of research and policy save them? Brief for GSDR, 2015.

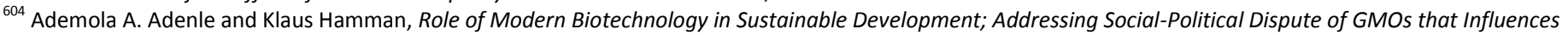
Decision-Making in Developing countries. Brief for GSDR, 2015.

${ }^{605}$ Norman Warthmann \& Claudio Chiarolla, Thinking a Global Open Genome Sequence Data Framework for Sustainable Development. Brief for GSDR, 2015.

${ }^{606}$ Friedrich Soltau, The promise of synthetic biology for sustainable development. Brief for GSDR 2015.

${ }^{607}$ Carol Warren et.al, Social Capital Formation in Community Development and Conservation Interventions: Comparative Research in Indonesia. Brief for GSDR, 2015.

${ }^{608}$ Carole-Anne Sénit, Strengthening democratic legitimacy in intergovernmental policy-making on sustainable development: the contribution of web-based civil society consultations. Brief for GSDR, 2015.

${ }^{609}$ Giovanny Daza, Aproximacion critica al desarrollo sostenible. Brief for GSDR 2015.

${ }^{610}$ Achim Doberman, Monitoring the Performance of Agriculture and Food Systems. Brief for GSDR, 2015.

${ }^{611}$ The Ministry of Science and Technology of China and the Chinese Society for Sustainable Development (CSSD) facilitated the solicitation of inputs from the Chinese scientific communities.

${ }^{612}$ Foresight-platform.eu, 'European Foresight Platform', http://www.foresight-platform.eu.

${ }^{613}$ This is, of course, due to the different selection criteria being used.

${ }^{614}$ Shengli Tao et al., 'Rapid Loss Of Lakes On The Mongolian Plateau', Proc Natl Acad Sci USA 112, no. 7 (2015): 2281-2286, doi:10.1073/pnas.1411748112.

${ }^{615}$ Thomas P. Van Boeckel et al., 'Global Trends In Antimicrobial Use In Food Animals', Proc Natl Acad Sci USA 112, no. 18 (2015): 5649-5654,

doi:10.1073/pnas.1503141112.

${ }^{616}$ A. D. I. Kramer, J. E. Guillory and J. T. Hancock, 'Experimental Evidence Of Massive-Scale Emotional Contagion Through Social Networks', Proceedings Of The National Academy Of Sciences 111, no. 24 (2014): 8788-8790, doi:10.1073/pnas.1320040111.

${ }^{617}$ A. Cozar et al., 'Plastic Debris In The Open Ocean', Proceedings Of The National Academy Of Sciences 111, no. 28 (2014): 10239-10244, doi:10.1073/pnas.1314705111.

${ }^{618}$ Lars O. Hedin, 'Biogeochemistry: Signs Of Saturation In The Tropical Carbon Sink', Nature 519, no. 7543 (2015): 295-296, doi:10.1038/519295a.

${ }^{619}$ IBM's TrueNorth chip.

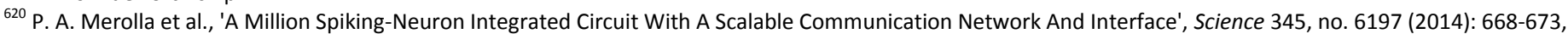
doi:10.1126/science.1254642.

${ }^{621}$ R. F. Service, 'Minds Of Their Own', Science 346, no. 6206 (2014): 182-183, doi:10.1126/science.346.6206.182.

${ }^{622}$ N. M. Haddad et al., 'Habitat Fragmentation And Its Lasting Impact On Earth's Ecosystems', Science Advances 1, no. 2 (2015): e1500052-e1500052, doi:10.1126/sciadv.1500052.

623 'Seven Days: 13-19 March 2015', Nature 519, no. 7543 (2015): 266-267, doi:10.1038/519266a.

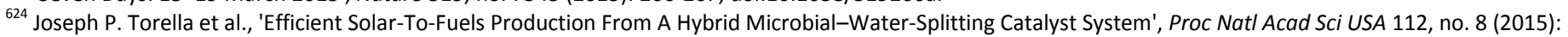
2337-2342, doi:10.1073/pnas.1424872112.

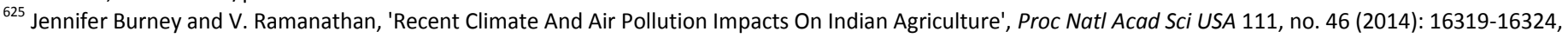
doi:10.1073/pnas.1317275111.

${ }^{626}$ The National Science Library, Chinese Academy of Sciences, Thomson Reuters IP \& Science, The Joint Research Center of Emerging Technology Analysis, RESEARCH FRONTS 2014: 100 TOP RANKED SPECIALTIES IN THE SCIENCES AND SOCIAL SCIENCES (The National Science Library, Chinese Academy of Sciences, Thomson Reuters, 2014), http://sciencewatch.com/sites/sw/files/sw-article/media/research-fronts-2014.pdf.

${ }^{627}$ R. Kitchin, 'Big Data And Human Geography: Opportunities, Challenges And Risks', Dialogues In Human Geography 3, no. 3 (2013): 262-267, doi:10.1177/2043820613513388.

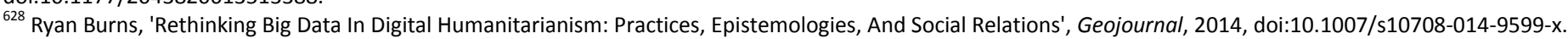

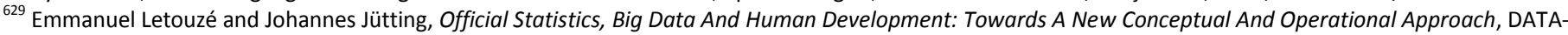
POP ALLIANCE WHITE PAPERS SERIES, pp7 2014.

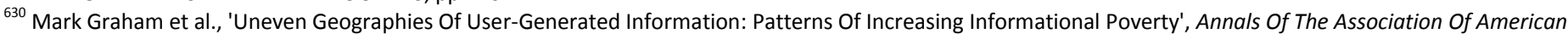
Geographers 104, no. 4 (2014): 746-764, doi:10.1080/00045608.2014.910087.

${ }^{631}$ Kwaw S. Andam et al., Protected Areas And Avoided Deforestation: A Statistical Evaluation, International Intiative For Impact Evaluation, 2007, http://people.duke.edu/ asp9/files/ParksImpacts-GEFreport-AndamEtal.pdf.

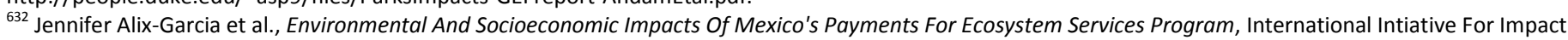

Evaluation, 2014, http://www.3ieimpact.org/media/filer/2014/03/21/ow_2013_pes_mexico_3ie.pdf.

${ }^{633}$ Eric Strobl and Robert O. Strobl, The Distributional Impact Of Large Dams: Evidence From Cropland Productivity In Africa, International Initiative For Impact Evaluation, 2011, http://www.3ieimpact.org/en/evidence/impact-evaluations/details/553/.

${ }^{634}$ The Economist, 'How To Catch The Overfishermen', 2015, http://www.economist.com/news/leaders/21640350-big-data-allow-fish-be-protected-nevergovernments-should-take-advantage.

${ }^{635}$ For example, in many countries wealthier people are more likely to have cell phones than poor people, however, this division has rapidly changed in many countries, including in Africa. 


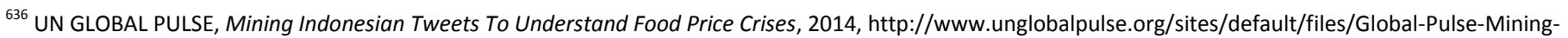
Indonesian-Tweets-Food-Price-Crises\%20copy.pdf.

${ }^{637}$ Paul Currion, '“If All You Have Is A Hammer" - How Useful Is Humanitarian Crowdsourcing?', Www.Crowdsourcing.Org, 2010,

http://www.crowdsourcing.org/document/if-all-you-have-is-a-hammer---how-useful-is-humanitarian-crowdsourcing/3533.

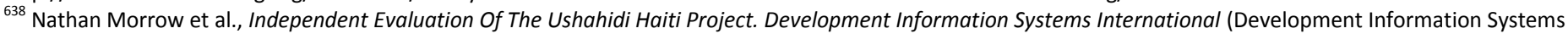
International, 2011), http://www.alnap.org/pool/files/1282.pdf.

${ }^{639}$ Christopher D. Elvidge et al., 'A Global Poverty Map Derived From Satellite Data', Computers \& Geosciences 35, no. 8 (2009): 1652-1660, doi:10.1016/j.cageo.2009.01.009.

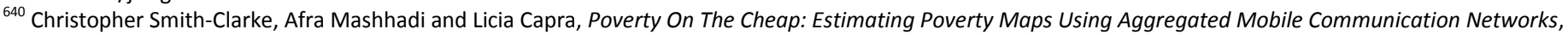

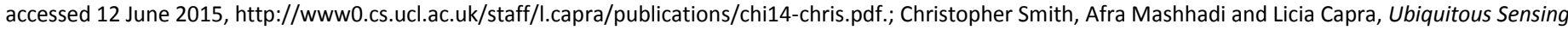
For Mapping Poverty In Developing Countries, accessed 12 June 2015, http://www.cities.io/wp-content/uploads/2012/12/d4d-chris-submitted.pdf.

${ }^{641}$ Alberto Cavallo, 'Online And Official Price Indexes: Measuring Argentina's Inflation', Journal Of Monetary Economics 60, no. 2 (2013): 152-165, doi:10.1016/j.jmoneco.2012.10.002

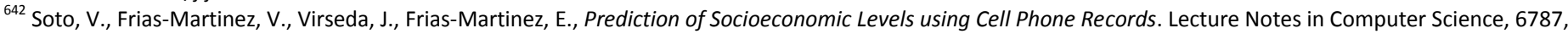
pp 377-388 2011.

${ }^{643}$ N. Eagle, M. Macy and R. Claxton, 'Network Diversity And Economic Development', Science 328, no. 5981 (2010): 1029-1031, doi:10.1126/science.1186605.

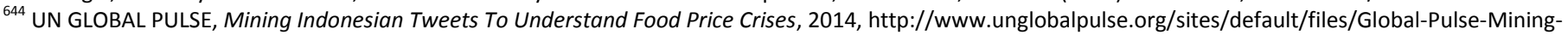

Indonesian-Tweets-Food-Price-Crises\%20copy.pdf.

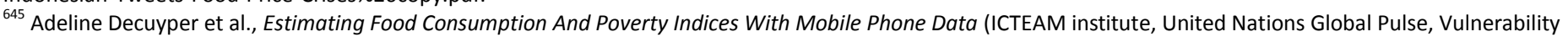
Analysis and Mapping, Real Impact Analytics, 2015), http://arxiv.org/pdf/1412.2595.pdf.

${ }^{646}$ UN Global Pulse, Using Mobile Phone Data And Airtime Credit Purchases To Estimate Food Security (New York: UN World Food Programme (WFP), Université

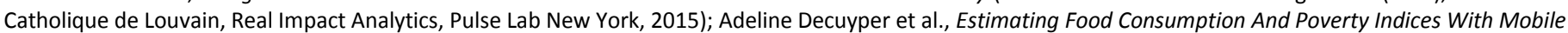

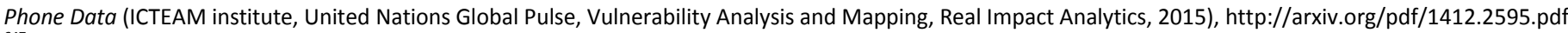

${ }^{647}$ Eric Strobl and Robert O. Strobl, The Distributional Impact Of Large Dams: Evidence From Cropland Productivity In Africa, International Initiative For Impact

Evaluation, 2011, http://www.3ieimpact.org/en/evidence/impact-evaluations/details/553/.

${ }^{648}$ UNECE Statistics, 'Australia (ABS) - Remote Sensing For Agricultural And Land Use Estimation - Big Data - UNECE Statistics Wikis', accessed 12 June 2015,

http://www1.unece.org/stat/platform/display/bigdata/Australia+\%28ABS\%29+-+Remote+Sensing+for+Agricultural+and+Land+Use+Estimation.

${ }^{649}$ P.S. Thenkabail, M.S.D.N. Gamage and V.U. Smakhtin, The Use Of Remote Sensing Data For Drought Assessment And Monitoring In Southwest Asia, Research Report 85 (International Water Management Institute, 2004), http://www.iwmi.cgiar.org/Publications/IWMI_Research_Reports/PDF/pub085/RR85.pdf.

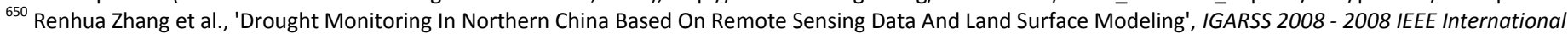
Geoscience And Remote Sensing Symposium, 2008, doi:10.1109/igarss.2008.4779485.

${ }^{651}$ Jeremy Ginsberg et al., 'Detecting Influenza Epidemics Using Search Engine Query Data', Nature 457, no. 7232 (2008): 1012-1014, doi:10.1038/nature07634.

${ }^{652}$ Qingyu Yuan et al., 'Monitoring Influenza Epidemics In China With Search Query From Baidu', Plos ONE 8, no. 5 (2013): e64323,

doi:10.1371/journal.pone.0064323.

${ }^{653}$ Eiji Aramaki, Sachiko Maskawa and Mizuki Morita, Twitter Catches The Flu: Detecting Influenza Epidemics Using Twitter, accessed 12 June 2015,

http://www.aclweb.org/anthology/D/D11/D11-1145.pdf.

${ }^{654}$ Lamb, A., et al. "Separating Fact from Fear: Tracking Flu Infections on Twitter." (North American Chapter of the Association for Computational Linguistics (NAACL), 2013.)

${ }^{655}$ For more information see www.influenzanet.eu

${ }^{656}$ For more information see www.flunearyou.org

${ }^{657}$ A. Wesolowski et al., 'Quantifying The Impact Of Human Mobility On Malaria', Science 338, no. 6104 (2012): 267-270, doi:10.1126/science.1223467.

${ }^{658}$ Amy Wesolowski et al., 'Commentary: Containing The Ebola Outbreak - The Potential And Challenge Of Mobile Network Data', Plos Curr, 2014,

doi:10.1371/currents.outbreaks.0177e7fcf52217b8b634376e2f3efc5e.

${ }^{659}$ R. Chunara, J. R. Andrews and J. S. Brownstein, 'Social And News Media Enable Estimation Of Epidemiological Patterns Early In The 2010 Haitian Cholera Outbreak', American Journal Of Tropical Medicine And Hygiene 86, no. 1 (2012): 39-45, doi:10.4269/ajtmh.2012.11-0597.

${ }^{660}$ Google.org, 'Google Dengue Trends', http://www.google.org/denguetrends/intl/en_us/.

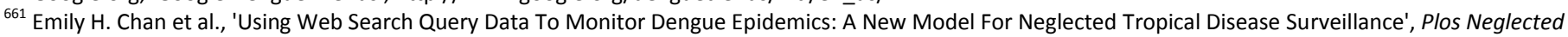
Tropical Diseases 5, no. 5 (2011): e1206, doi:10.1371/journal.pntd.0001206.

${ }^{662}$ Camille Pelat et al., 'More Diseases Tracked By Using Google Trends', Emerg. Infect. Dis. 15, no. 8 (2009): 1327-1328, doi:10.3201/eid1508.090299.

${ }^{663}$ Heidi J Larson et al., 'Measuring Vaccine Confidence: Analysis Of Data Obtained By A Media Surveillance System Used To Analyse Public Concerns About Vaccines', The Lancet Infectious Diseases 13, no. 7 (2013): 606-613, doi:10.1016/s1473-3099(13)70108-7.

${ }^{664}$ Michael J. Paul and Mark Dredze, You Are What You Tweet: Analyzing Twitter For Public Health, Proceedings Of The Fifth International AAAI Conference On Weblogs And Social Media, accessed 12 June 2015, http://www.aaai.org/ocs/index.php/ICWSM/ICWSM11/paper/viewFile/2880/3264.

${ }^{665}$ Marcel Salathé and Shashank Khandelwal, 'Assessing Vaccination Sentiments With Online Social Media: Implications For Infectious Disease Dynamics And

Control', Plos Computational Biology 7, no. 10 (2011): e1002199, doi:10.1371/journal.pcbi.1002199.

${ }^{666}$ UN Global Pulse. Understanding public perceptions of immunisation using social media. Brief. 2014

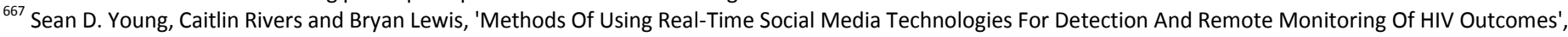
Preventive Medicine 63 (2014): 112-115, doi:10.1016/j.ypmed.2014.01.024.

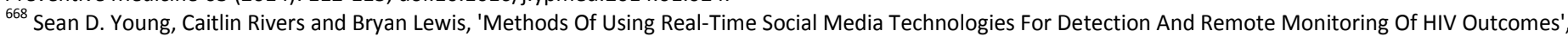
Preventive Medicine 63 (2014): 112-115, doi:10.1016/j.ypmed.2014.01.024.

${ }^{669}$ Emcdda.europa.eu, 'EMCDDA | Wastewater Analysis', http://www.emcdda.europa.eu/wastewater-analysis.

${ }^{670}$ Nih.gov, 'NIH System To Monitor Emerging Drug Trends', http://www.nih.gov/news/health/jul2014/nida-17.htm; Drugabuse.gov, 'Community Epidemiology

Work Group (CEWG) | National Institute On Drug Abuse (NIDA)', http://www.drugabuse.gov/about-nida/organization/workgroups-interest-groups-

consortia/community-epidemiology-work-group-cewg. 
${ }^{671}$ Pulselabkampala.ug, 'UNFPA Uganda Family Planning Perceptions', http://pulselabkampala.ug/dashboard/family_planning/; Unglobalpulse.org, 'Analyzing Attitudes Towards Contraception \& Teenage Pregancy Using Social Data (2014) | United Nations Global Pulse', http://www.unglobalpulse.org/UNFPA-socialdata.

${ }^{672}$ F. Brckschen, R. Schmid and T. Zbiransky. Cookbook for a socio-demographic basket. Unpublished paper. 2014

${ }^{673}$ Newsweek.com, http://www.newsweek.com/could-big-data-be-new-gender-equality-tool-292355.

${ }^{674}$ Unglobalpulse.org, 'Identifying Trends Around Workplace Discrimination Using Social Media | United Nations Global Pulse', 2014,

http://www.unglobalpulse.org/workplace-discrimination-indonesia.

${ }^{675}$ Rich Hume, 'The Netherlands' Digital Delta Project Takes Water Management To A New Level - A Smarter Planet Blog', A Smarter Planet Blog, 2013,

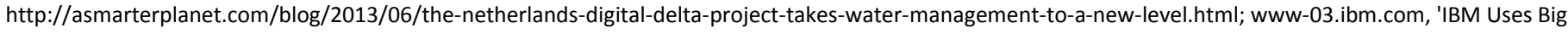
Data To Improve Dutch Flood Control System', 2013, https://www-03.ibm.com/press/us/en/pressrelease/41385.wss.

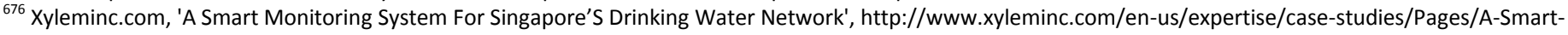
Monitoring-System-for-Singapore\%E2\%80\%99s-Drinking-Water-Network-.aspx.

${ }^{677}$ C. D. Elvidge et al., 'Relation Between Satellite Observed Visible-Near Infrared Emissions, Population, Economic Activity And Electric Power Consumption', International Journal Of Remote Sensing 18, no. 6 (1997): 1373-1379, doi:10.1080/014311697218485.

${ }^{678}$ UNECE Statistics, 'Experiment Report: Canadian Smart Meter Data - Big Data - UNECE Statistics Wikis', 2015,

http://www1.unece.org/stat/platform/display/bigdata/Experiment+report\%3A++Canadian+Smart+Meter+Data.

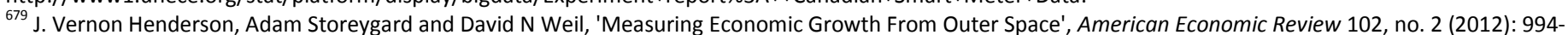
1028, doi:10.1257/aer.102.2.994.

${ }^{680}$ Sutton, P., Elvidge, C. \& Ghosh, T., Estimation of Gross Domestic Product at Sub-National Scales using Nighttime Satellite Imagery. International Journal of Ecological Economics \& Statistics 2007.

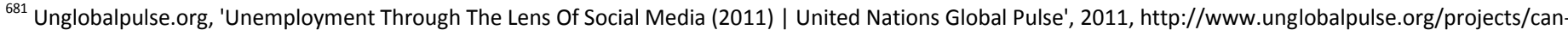
social-media-mining-add-depth-unemployment-statistics.

${ }^{682}$ HYUNYOUNG CHOI and HAL VARIAN, 'Predicting The Present With Google Trends', Economic Record 88 (2012): 2-9, doi:10.1111/j.1475-4932.2012.00809.x.

${ }^{683}$ Hyunyoung Choi and Hal Varian, Predicting Initial Claims For Unemployment Benefits, 2009,

http://static.googleusercontent.com/media/research.google.com/en/us/archive/papers/initialclaimsUS.pdf.

${ }^{684}$ Feasibility Study On The Use Of Mobile Positioning Data For Tourism Statistics (Eurostat, 2013),

http://ec.europa.eu/eurostat/web/tourism/methodology/projects-and-studies.

${ }^{685}$ Carna Botnet, 'Internet Census 2012', Internetcensus2012.Bitbucket.Org, 2012, http://internetcensus2012.bitbucket.org/paper.html.

${ }^{686}$ Thoralf Gutierrez, Gautier Krings and Vincent D. Blondel, Evaluating Socio-Economic State Of A Country Analyzing Airtime Credit And Mobile Phone Datasets, 2013, http://arxiv.org/pdf/1309.4496.pdf.

${ }^{687}$ Olivia De Backer, Big Data And International Migration, Harnessing Big Data For Development And Humanitarian Action (UN Global Pulse, 2014),

http://www.unglobalpulse.org/big-data-migration.

${ }^{688}$ UN Global Pulse and UNFPA. Estimating international UNFPA migration flows using online search data. Brief. 2014

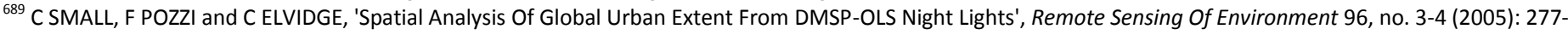
291, doi:10.1016/j.rse.2005.02.002

${ }^{690}$ Nirav N. Patel et al., 'Multitemporal Settlement And Population Mapping From Landsat Using Google Earth Engine', International Journal Of Applied Earth Observation And Geoinformation 35 (2015): 199-208, doi:10.1016/j.jag.2014.09.005.

${ }^{691}$ Mark Say, 'Transport For London Builds Customer Profiles Using RFID Data Analytics', Computerweekly, 2014, http://www.computerweekly.com/feature/Transport-for-London-builds-customer-profiles-using-RFID-data-analytics.

${ }^{692}$ Camille Roth et al., 'Structure Of Urban Movements: Polycentric Activity And Entangled Hierarchical Flows', Plos ONE 6, no. 1 (2011): e15923,

doi:10.1371/journal.pone.0015923.

${ }^{693}$ Nick Carney, 'Streamlining The London Tube With Data | Data-Smart City Solutions', Data-Smart City Solutions, 2013,

http://datasmart.ash.harvard.edu/news/article/oyster-cards-clarify-tube-congestion-202.

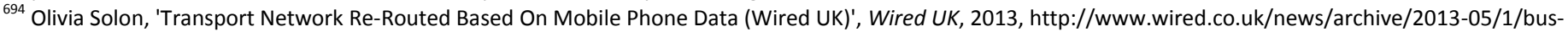
routes-mobile-data.;David Talbot, 'African Bus Routes Redrawn Using Cell-Phone Data | MIT Technology Review', MIT Technology Review, 2013,

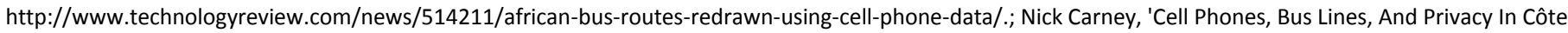

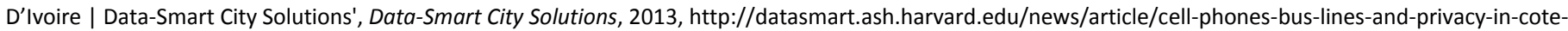

divoire-243.

${ }^{695}$ Commuting time between one's home and work are estimated as opposed to time use surveys which estimate time to 1 st stop vs time between home and

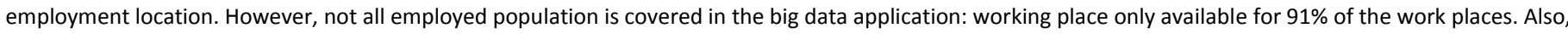
no way to distinguish remote working.

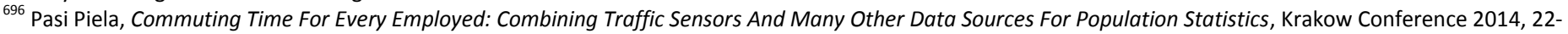
24 October, Krakow, Poland, 2014, http://geo.stat.gov.pl/documents/10179/130734/4_EFGS+2014+paper+Piela.doc/205f55af-34f8-45ee-b186-14b1db2ae264.

${ }^{697}$ Kevin S. Kung et al., 'Exploring Universal Patterns In Human Home-Work Commuting From Mobile Phone Data', Plos ONE 9, no. 6 (2014): e96180, doi:10.1371/journal.pone.0096180.

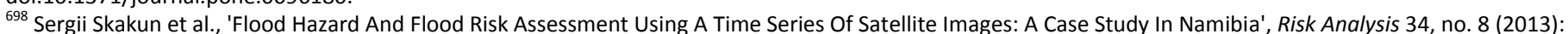
1521-1537, doi:10.1111/risa.12156.

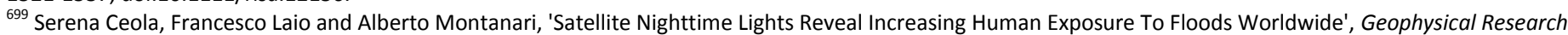
Letters 41, no. 20 (2014): 7184-7190, doi:10.1002/2014gl061859.

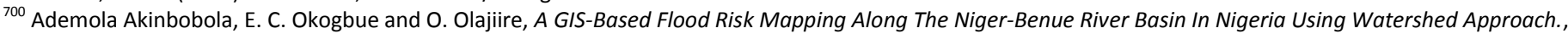

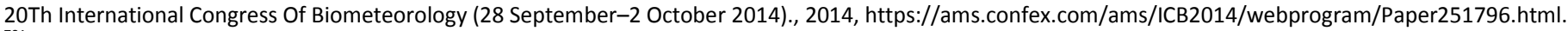

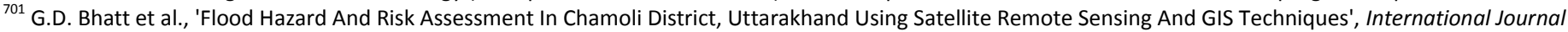
Of Innovative Research In Science, Engineering And Technology 03, no. 08 (2014): 15348-15356, doi:10.15680/ijirset.2014.0308039. 
${ }^{702}$ David Pastor-Escuredo et al., Flooding Through The Lens Of Mobile Phone Activity, 2014, http://arxiv.org/ftp/arxiv/papers/1411/1411.6574.pdf; Unglobalpulse.org, 'Using Mobile Phone Activity For Disaster Management During Floods (2014) | United Nations Global Pulse', 2014, http://www.unglobalpulse.org/tabasco-floods-CDRs.

${ }^{703}$ UN Global Pulse. Using twitter data to analyse public perception of a fuel subsidy reform in El Salvador. Brief. 2015

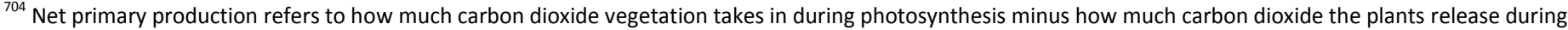
respiration

${ }^{705}$ M. Andersson, O. Hall and S. Keola, based on MODIS and GAUL data, from private communication.

${ }^{706}$ Christopher Elvidge et al., 'Satellite Inventory Of Human Settlements Using Nocturnal Radiation Emissions: A Contribution For The Global Toolchest', Global Change Biology 3, no. 5 (1997): 387-395, doi:10.1046/j.1365-2486.1997.00115.x.

${ }^{707}$ Eric A. Kort et al., 'Four Corners: The Largest US Methane Anomaly Viewed From Space', Geophysical Research Letters 41, no. 19 (2014): 6898-6903, doi:10.1002/2014gl061503.

${ }^{708}$ Oliver Schneising et al., 'Remote Sensing Of Fugitive Methane Emissions From Oil And Gas Production In North American Tight Geologic Formations', Earth's

Future 2, no. 10 (2014): 548-558, doi:10.1002/2014ef000265

${ }^{709}$ Global Pulse, USING TWITTER TO MEASURE GLOBAL ENGAGEMENT ON CLIMATE CHANGE, 2015

http://reliefweb.int/sites/reliefweb.int/files/resources/Climate\%20monitor_CCST_Final.pdf.

${ }^{710}$ Global Pulse, USING TWITTER TO MEASURE GLOBAL ENGAGEMENT ON CLIMATE CHANGE, 2015,

http://reliefweb.int/sites/reliefweb.int/files/resources/Climate\%20monitor_CCST_Final.pdf.

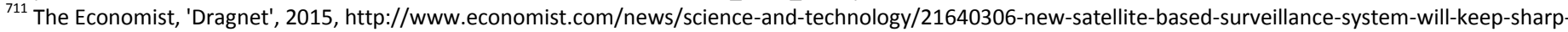

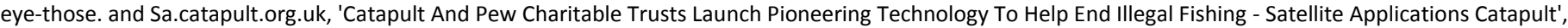
2015, https://sa.catapult.org.uk/-/catapult-and-pew-charitable-trusts-launch-pioneering-technology-to-help-end-illegal-fishing.

${ }^{712}$ Robert Vamosi, 'Big Data Is Stopping Maritime Pirates ... From Space', Forbes, 2014, http://www.forbes.com/sites/robertvamosi/2014/11/11/big-data-isstopping-maritime-pirates-from-space/.

${ }^{713}$ Eumetsat.int, 'Jason-2 — EUMETSAT', accessed 13 June 2015, http://www.eumetsat.int/website/home/Satellites/CurrentSatellites/Jason2/index.html.

714 Kwaw S. Andam et al., Protected Areas And Avoided Deforestation: A Statistical Evaluation (International Initiative for Impact Evaluation, 2007),

http://people.duke.edu/ asp9/files/ParksImpacts-GEFreport-AndamEtal.pdf

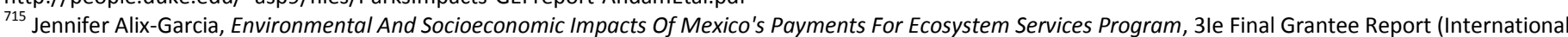
Initiative for Impact Education, 2014), http://www.3ieimpact.org/media/filer_public/2014/03/21/ow_2013_pes_mexico_3ie.pdf.

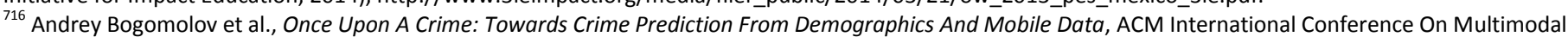
Interaction, 2014, http://arxiv.org/abs/1409.2983.

${ }^{717}$ Syria.newscientistapps.com, 'Syrian Conflict | New Scientist', accessed 13 June 2015, http://syria.newscientistapps.com/index.html; Dart-Throwing Chimp,

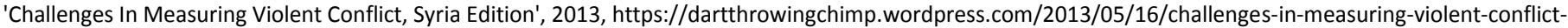
syria-edition/.

${ }^{718}$ For more information see www.ureport.ug

${ }^{719}$ For more information see http://www.devtrac.ug/

${ }^{720}$ Pierre Deville et al. Estimating population density with mobile phone data. (PNAS, vol. 111 no. 45, 2014) http://www.pnas.org/content/111/45/15888.full

${ }^{721}$ Catherine Linard et al., 'Population Distribution, Settlement Patterns And Accessibility Across Africa In 2010', Plos ONE 7, no. 2 (2012): e31743, doi:10.1371/journal.pone.0031743.

${ }^{722}$ Emre Kiciman, Nicole B. Ellison, Bernie Hogan, Paul Resnick, lan Soboroff:

Proceedings of the Seventh International Conference on Weblogs and Social Media, ICWSM 2013, Cambridge, Massachusetts, USA, July 8-11, 2013. The AAAI

Press 2013, ISBN 978-1-57735-610-3

723 e.g., Zillow, Trulia

724 e.g., Experian Real Estate data, ESRI business analysis

725 e.g., Landsat, MODIS, SRTM

${ }^{726}$ LiDar data, GeoEye, etc.

${ }^{727}$ United Nations. Report of the Global Working Group on Big Data for Official Statistics - Note by the Secretary-General. E/CN.3/2015/4, 2014, http://unstats.un.org/unsd/statcom/doc15/2015-4-BigData-E.pdf

${ }^{728}$ UNEP and Interpol, THE ENVIRONMENTAL CRIME CRISIS A RAPID RESPONSE ASSESSMENT: THREATS TO SUSTAINABLE DEVELOPMENT FROM ILLEGAL

EXPLOITATION AND TRADE IN WILDLIFE AND FOREST RESOURCES, 2015, http://www.unep.org/unea/docs/rracrimecrisis.pdf.

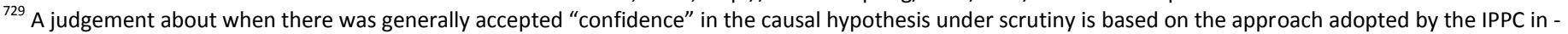

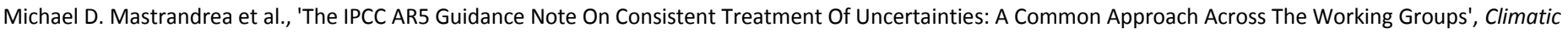
Change 108, no. 4 (2011): 675-691, doi:10.1007/s10584-011-0178-6.

${ }^{730}$ EEA. Late lessons from early warnings: science, precaution, innovation, European Environment Agency report EEA No $1 / 2013$; and Late lessons from early warnings: the precautionary principle 1896-2000 (Environmental issue report No 22, 2013).

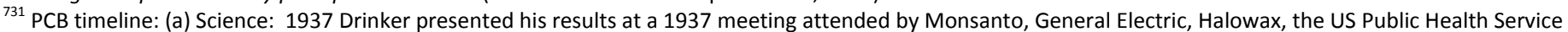
and state health officials from Massachusetts and Connecticut. The results were published but did not gain the wider attention of policy-makers (Drinker et al., 1937); 1969 Søren Jensen published his findings (Jensen et al., 1969) which showed remarkably high PCB concentrations in a large proportion of the Baltic Sea

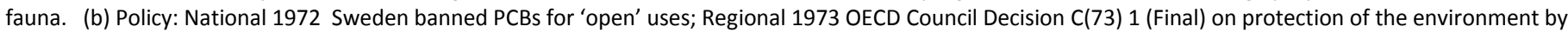

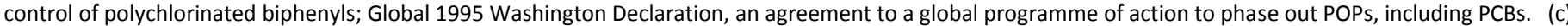

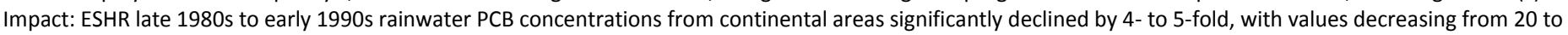

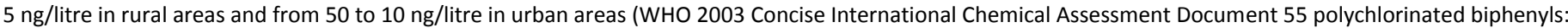

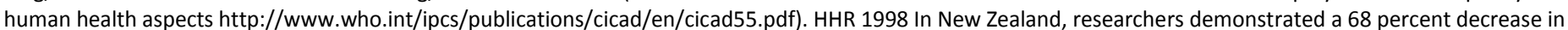

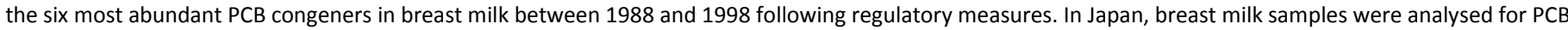
content to determine their yearly trend; the average PCB level increased from 1972 (1.302 $\mu \mathrm{g} / \mathrm{g}$ fat basis) to its highest in 1974 (1.514 $\mu \mathrm{g} / \mathrm{g}$ fat basis), and then decreased to about $13 \%$ of that level $(0.200 \mu \mathrm{g} / \mathrm{g}$ fat basis) in 1998 (WHO 2003). 


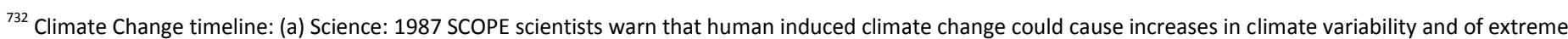

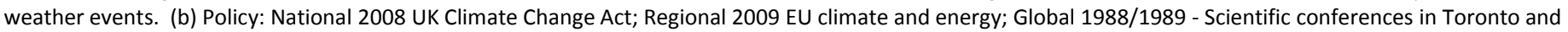

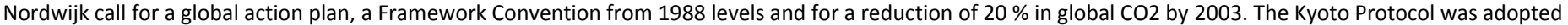
in Kyoto, Japan, on 11 December 1997 and entered into force on 16 February 2005. (c) Impact: CO2 concentrations continue to rise.

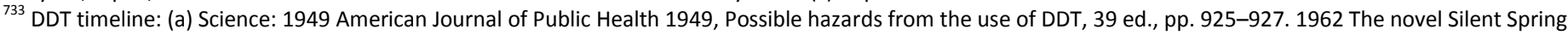

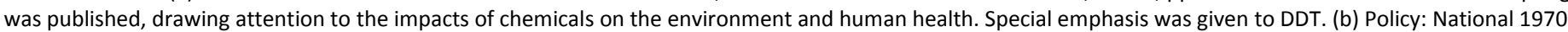

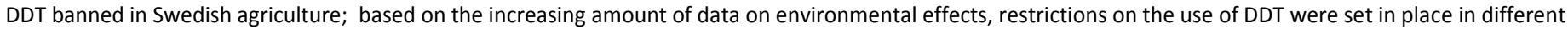

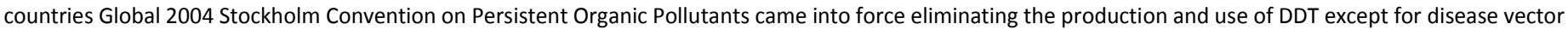

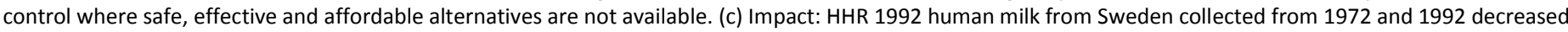
from 3081 to $483 \mathrm{pg} / \mathrm{g}$ lipid over this 20 year period (Lunden and Noren 1998).

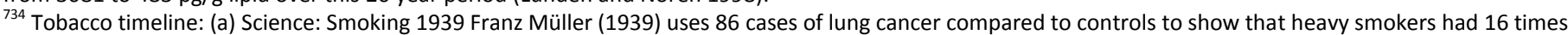

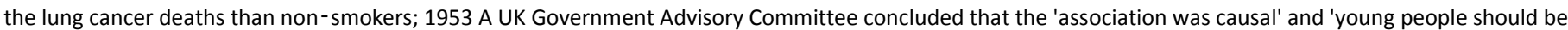
warned' (Ministry of Health, 1953a, 1953b and 1954). 2nd hand smoking 1981 Seminal epidemiological studies in 1981 demonstrated that second-hand smoke exposure was associated with lung cancer - General report in 1986 concluded that the link is causal (US DHHS, 1986). (b) Policy: National 1965 UK After

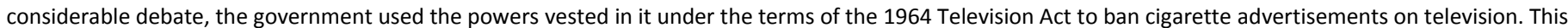

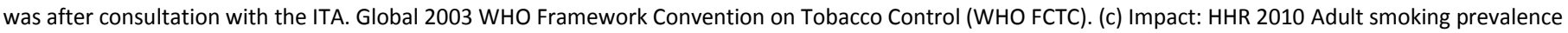
dropped from $27 \%$ in 2000 to $20 \%$ in 2010.

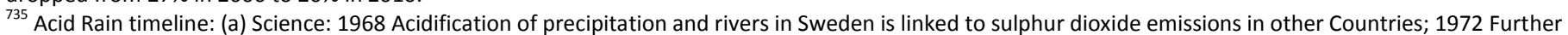

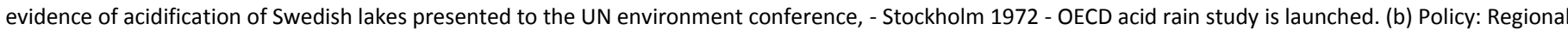

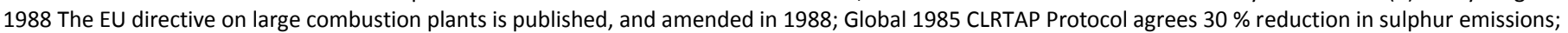
1999 Protocol to Abate Acidification, Eutrophication and Ground-level Ozone and its 2012 amended version (1999) United States and Canada are signatories to LRTAP. (c) Impact: ESHR 2050 In Europe and North America, full implementation of the LRTAP POPs Protocol, the Stockholm Convention, and other national

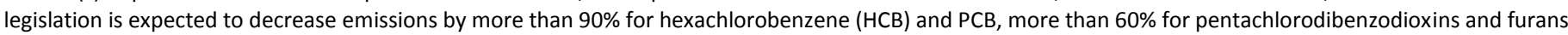
(PCDD/Fs), and 30-50\% for PAHs Over the next 40 years (11-22136-Part-D 2020-2050, 2010)

${ }^{736}$ Asbestos timeline: (a) Science: 1906 French factory report of 50 deaths in female asbestos textile workers and recommendation of controls; 1930 UK Merewether Report finds 66 \% of long-term workers in Rochdale factory with asbestosis. (b) Policy: National 1970 Asbestos was one of the first hazardous air

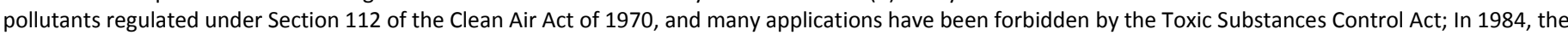

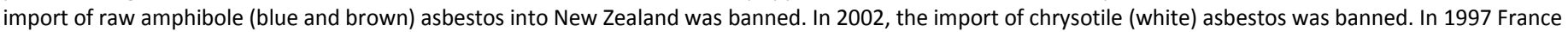
banned all forms of asbestos fibres and products in order to protect the health of workers and consumers; Regional 1998-99 EU and France ban all forms of asbestos; Global: 2004 Rotterdam Convention Asbestos is listed as a category of controlled waste under Annex I of the Basel Convention on the Control of Transboundary Movements of Hazardous Wastes and their Disposal [1992]. - 2000-01 WTO upholds EU/French bans against Canadian appeal - Rotterdam Convention: Annex III 2004- five forms of asbestos (actinolite, anthophyllite, amosite, crocidolite, and tremolite, representing 10\% of total asbestos). 2011:

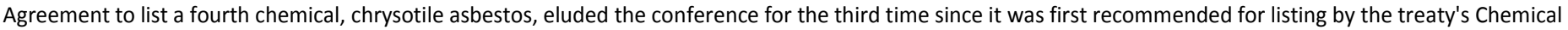

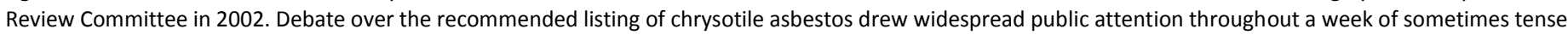
negotiations between the Convention's parties. (c) Impact: HHR 2006 (http://www.hse.gov.uk/Statistics/causdis/lungcancer/index.htm)

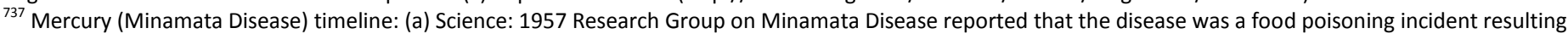

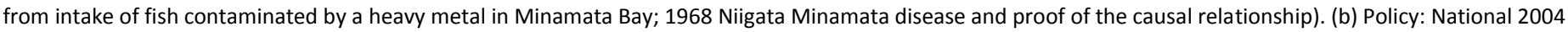

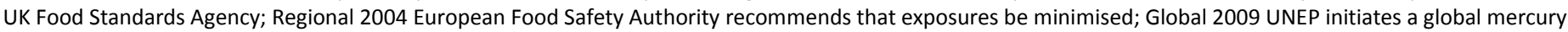

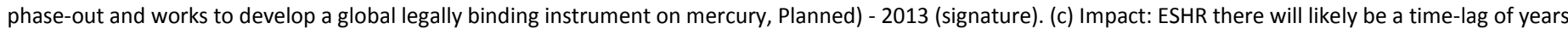

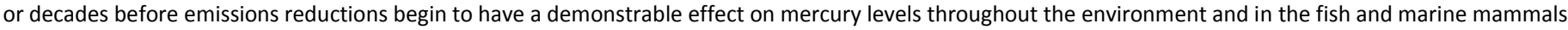
which are part of the human food-chain

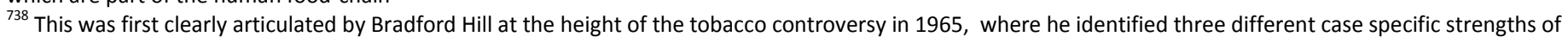

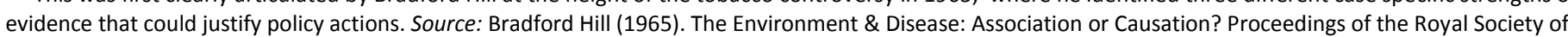
Medicine, 1965, 58, 295-300.

${ }^{739}$ Michael D. Mastrandrea et al., 'The IPCC AR5 Guidance Note On Consistent Treatment Of Uncertainties: A Common Approach Across The Working Groups', Climatic Change 108, no. 4 (2011): 675-691, doi:10.1007/s10584-011-0178-6.

${ }^{740}$ EEA. Late Lessons from Early Warnings, Climate Change chapter, pp. 331-335. (European Environment Agency, 2013).

${ }^{741}$ CEC. Communication on the Precautionary Principle. (European Union 2000).

742 Molina and Rowland, 1974; Cicerone et al., 1974

${ }^{743}$ similar to what Paul Crutzen had suggested about N20 emissions from fertilizer use in 1970

${ }^{744}$ Wikipedia, 'Ozone Depletion', accessed 13 June 2015, http://en.wikipedia.org/wiki/Ozone_depletion.

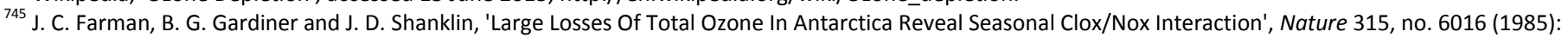
207-210, doi:10.1038/315207a0.

${ }^{746}$ Bert Metz et al., Safeguarding The Ozone Layer And The Global Climate System, n.d.

${ }^{747}$ Wikipedia, 'Ozone Depletion', accessed 13 June 2015, http://en.wikipedia.org/wiki/Ozone_depletion.

${ }^{748}$ PLINY (ca AD 77-79) Naturalis historiae, XXXIV, 48. "'For medicinal purposes lead is melted in earthen vessels, a layer of finely powdered sulphur being put underneath it; on this thin plates are laid and covered with sulphur and stirred with an iron rod. Whilst it is being melted, the breathing passages should be protected ... otherwise the noxious and deadly vapour of the lead furnace is inhaled; it is hurtful to dogs with special rapidity."

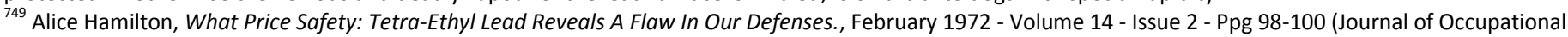
Medicine:, 1972), http://journals.Iww.com/joem/Citation/1972/02000/What_Price_Safety_Tetra_ethyl_Lead_Reveals_a_Flaw.2.aspx.

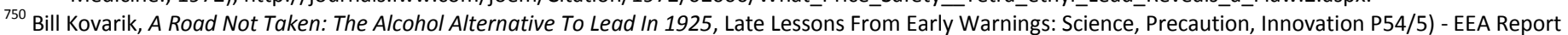
No 1/2013., 2013

751 Jamie Lincoln Kitman, THE SECRET HISTORY OF LEAD, 2000,

http://web4.uwindsor.ca/users/w/winter/Winters.nsf/0/b98c7c39d61ad93485257068006c4501/\$FILE/lead.Nation.pdf. 
${ }^{752}$ William Kovarik, 'Ethyl-Leaded Gasoline: How A Classic Occupational Disease Became An International Public Health Disaster', International Journal Of Occupational And Environmental Health 11, no. 4 (2005): 384-397, doi:10.1179/oeh.2005.11.4.384.

${ }_{753}$ M. Stasik et al. "Acute Tetraethyllead Poisoning". Arch. Toxikol. 24 (4): 283-291, 1969, doi:10.1007/BF00577576

${ }^{754}$ DeWitt \& Company Inc., 2000

755 J E Moore, 'Community Aspects Of Childhood Lead Poisoning.', Am J Public Health Nations Health 60, no. 8 (1970): 1430-1434, doi:10.2105/ajph.60.8.1430.

${ }^{756}$ Sven Hernberg, 'Lead Poisoning In A Historical Perspective', American Journal Of Industrial Medicine 38, no. 3 (2000): 244-254, doi:10.1002/1097-

0274(200009)38:3<244::aid-ajim3>3.0.co;2-f.

${ }^{757}$ Andersen and Clubb, Late lessons from early warnings: science, precaution, innovation p54/5) - EEA Report No 1 (2013). p568

${ }^{758}$ Who.int, 'WHO | Mortality And Burden Of Disease From Lead', accessed 13 June 2015, http://www.who.int/gho/phe/chemical_safety/lead_burden_text/en/.

759 IPCC Overview, 1990, p57

https://www.ipcc.ch/ipccreports/1992\%20IPCC\%20Supplement/IPCC_1990_and_1992_Assessments/English/ipcc_90_92_assessments_far_overview.pdf.

760 "The intemational negotiations on a framework convention should start as quickly as possible after presentation of this Report in line with

Resolution SS II/3 Climate.C. (August 1990) of the UNE P Governing Council and Resolution 8 (EC-XLII, June 1990) of the WMO Executive Council." IPCC

Overview, 1990, p60

https://www.ipcc.ch/ipccreports/1992\%20IPCC\%20Supplement/IPCC_1990_and_1992_Assessments/English/ipcc_90_92_assessments_far_overview.pdf.

${ }^{761}$ S. F. Hansen and D. Gee, 'Adequate And Anticipatory Research On The Potential Hazards Of Emerging Technologies: A Case Of Myopia And Inertia?', Journal Of Epidemiology \& Community Health 68, no. 9 (2014): 890-895, doi:10.1136/jech-2014-204019.

762 e.g. between food and food safety (BSE), or energy supply and its safety (Fukushima)

${ }^{763}$ EEA. Late lessons from early warnings: science, precaution, innovation, European Environment Agency report EEA No 1/2013; and Late lessons from early

warnings: the precautionary principle 1896-2000 (Environmental issue report No 22, 2013)

${ }^{764}$ For more information see ILO 2005 page 3.3-3.4

${ }^{765}$ For more information see EEA Issue Report 22, page 55

${ }^{766}$ For more information see EEA Report No 1/2013, page 17

${ }^{767}$ Examples include the Federal Trade Commission and the Federal Justice Department over leaded petrol in the USA in the 1930s, and between the Ministries of Agriculture and Health in the UK during the BSE crisis.

${ }^{768}$ Hoffman, 1918

769 P. Michel and B. Averty, 'Contamination Of French Coastal Waters By Organotin Compounds: 1997 Update', Marine Pollution Bulletin 38, no. 4 (1999): 268-275, doi:10.1016/s0025-326x(98)90144-8.

${ }_{770}$ Arthur L. Herbst, Howard Ulfelder and David C. Poskanzer, 'Adenocarcinoma Of The Vagina. Association Of Maternal Stilbestrol Therapy With Tumor Appearance In Young Women', American Journal Of Obstetrics And Gynecology 181, no. 6 (1999): 1574-1575, doi:10.1016/s0002-9378(99)70411-4.

${ }_{771}$ Arguably, if action had been taken much earlier on compelling animal evidence and on the ineffectiveness of DES, much harm could have been avoided.

${ }_{772}^{772}$ For more information see EEA Issue Report 22, page 66

${ }^{773}$ R. J. YOUNG et al., 'Benzene In Consumer Products', Science 199, no. 4326 (1978): 248-248, doi:10.1126/science.199.4326.248-a.

${ }^{774}$ Paul Knox Clarke and James Darcy, Insufficient Evidence? The Quality And Use Of Evidence In Humanitarian Action, ALNAP Study, 2014, http://www.alnap.org/resource/10441.

${ }^{775}$ Country considered to have data for an MDG indicator if it has at least one data point since 2000 available at the Official Database of MDG Indicators (mdgs.un.org). MDG indicators which are only meaningful at the global/regional level or for developed countries are not included in this analysis.

776 Based on data available for African countries on percentage of the population living under \$1.25/day, in the period 1990-2012, in the World Bank indicators database (http://data.worldbank.org/indicator/SI.POV.DDAY; accessed May 2015). For those countries with at least one data point, the frequency of data for each country was obtained by dividing the total number of years covered ( 23 years) by the number of data points available. This calculation excludes countries with no data at all from 1990 to 2012, for which the frequency of poverty data is more than 23 years. If these countries would be included, the estimated frequency would be more than ten years.

${ }^{777}$ Sustainable Development Solutions Network (2015). Indicators and a monitoring framework for the sustainable development goals - launching a data revolution for the SDGs (revised working draft, version 6). Available from http://unsdsn.org/resources/publications/indicators/

${ }^{778}$ Ramesh Krishnamurthy et al., Application Of Pre-Programmed PDA Devices Equipped With GPS To Conduct Paperless Household Surveys In Rural Mozambique, AMIA Annu Symp Proc. 2006; PMCID: PMC1839572 (American Medical Informatics Association, 2006), http://www.ncbi.nlm.nih.gov/pmc/articles/PMC1839572/.

${ }^{779} \mathrm{~N}$. Keita et al.Improving timeliness and accuracy of agricultural censuses and surveys data with the use of new technological tools: Lessons learned from the use of PDA/GPS (Brazil) and CAPI/GPS (Mozambique) in agricultural censuses. (Presented at the 22th Session of the African Commission on Agricultural Statistics, Addis-Ababa, Ethiopia, 30 Nov-3 Dec 2011)

${ }^{780}$ For more information see Paris 21. Informing a data revolution: country report on Cape Verde. 2014.

http://datarevolution.paris21.org/sites/default/files/Cape\%20Verde_IDR\%20in\%20depth\%20country\%20study\%20report_1.pdf

${ }^{781}$ Intervention of the head of the Central Statistics Office of Botswana, Ms. Anna Majelantle, at the Side Event 'Data Revolution: 2020 Round of Census in Africa', organized by IBGE during the $46^{\text {th }}$ Session of the UN Statistical Commission.

${ }^{782}$ Gouv.sn, 'Recensement Général De La Population Et De L'habitat, De L'agriculture Et De L'élevage - Gouvernement Du Sénégal', accessed 14 June 2015 , http://www.gouv.sn/Recensement-general-de-la.html.

${ }_{783}$ Mobenzi.com, 'Mobenzi', accessed 14 June 2015, http://www.mobenzi.com/.

${ }^{784}$ Intervention of the head of the Central Statistics Office of Botswana, Ms. Anna Majelantle, at the Side Event 'Data Revolution: 2020 Round of Census in Africa', organized by IBGE during the $46^{\text {th }}$ Session of the UN Statistical Commission.

${ }_{785}$ Paris21.org, 'Road Map', 2014, http://www.paris21.org/advocacy/informing-a-data-revolution/road-map.

${ }^{786}$ Nethope. Ebola Response Connectivity Initiative (ERCI), additional background information. 2015. (Unpublished).

${ }^{787}$ Nethope.org, 'The Vital Role Of Telecommunications In An Emergency » Blog » Nethope', 2014, http://nethope.org/blog/2014/12/the-vital-role-oftelecommunications-in-an-emergency/.

${ }^{788}$ Information shared at the Side Event 'Data Revolution: 2020 Round of Census in Africa', organized by IBGE during the $46^{\text {th }}$ Session of the UN Statistical Commission.

${ }_{789}^{7}$ J. G. M. (Hans) Hoogeveen et al., 'Collecting High Frequency Panel Data In Africa Using Mobile Phone Interviews', SSRN Journal, 2014, doi:10.2139/ssrn.2121496. 
${ }^{790}$ Oxfam. ICT in humanitarian practice. The DEWS/KoBo digital collection pilot. Brief, 2014.

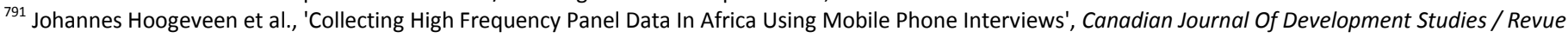
Canadienne D'études Du Développement 35, no. 1 (2014): 186-207, doi:10.1080/02255189.2014.876390.

${ }^{792}$ For more information see http://www.papor.org/files/2011/Presentations/Jana.pdf

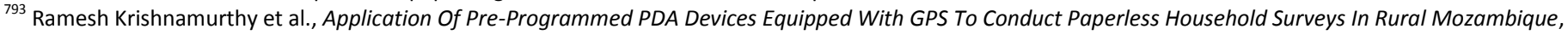

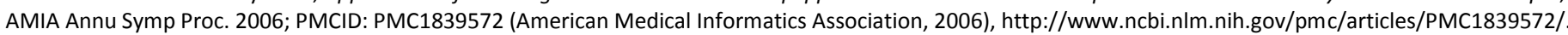
${ }^{794} \mathrm{~J}$. Lendorfer et al., Socio-economic impact of the crisis in north Mali on displaced people. (Unpublished paper, 2015).

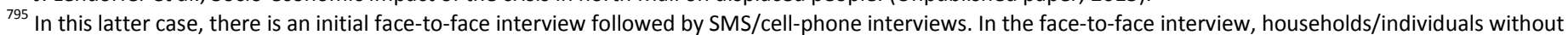
cell phones are provided with one for free, so that they can participate in the following surveys. This approach is being implemented in the project 'Listening to Africa' (http://www.worldbank.org/en/data/statistical-capacity-building/statistics-for-results-facility-catalytic-fund/L2A-statistics-for-results-project); the methodology is explained in the final report of the project 'Listening to LAC' (http://siteresources.worldbank.org/INTLACREGTOPPOVANA/Resources/8404421355332251652/8976232-1355959000860/L2L-Final-Report.pdf).

${ }^{796}$ For more information see http://www.papor.org/files/2011/Presentations/Jana.pdf

${ }^{797}$ For more information see www.ureport.ug

${ }^{798}$ For more information see http://www.frontlinesms.com

${ }^{799}$ For more information see http://ushahidi.com

${ }^{800}$ For more information see www.rapidsms.org

${ }^{801}$ Clark C. Freifeld et al., 'Participatory Epidemiology: Use Of Mobile Phones For Community-Based Health Reporting', Plos Med 7, no. 12 (2010): e1000376, doi:10.1371/journal.pmed.1000376.

${ }^{802}$ Anna Scott, 'Open Data: How Mobile Phones Saved Bananas From Bacterial Wilt In Uganda', The Guardian, 2015, http://www.theguardian.com/globaldevelopment-professionals-network/2015/feb/11/open-data-how-mobile-phones-saved-bananas-from-bacterial-wilt-in-uganda.

${ }^{803}$ Clark C. Freifeld et al., 'Participatory Epidemiology: Use Of Mobile Phones For Community-Based Health Reporting', Plos Med 7, no. 12 (2010): e1000376, doi:10.1371/journal.pmed.1000376.

${ }^{804}$ For more information see mdgs.un.org

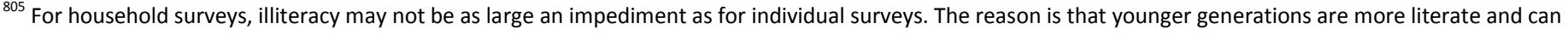
enter the responses provided by the head of household.

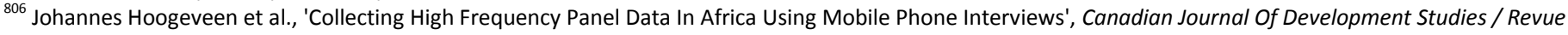
Canadienne D'études Du Développement 35, no. 1 (2014): 186-207, doi:10.1080/02255189.2014.876390.

${ }^{807}$ L. Chang and J. A. Krosnick, 'National Surveys Via Rdd Telephone Interviewing Versus The Internet: Comparing Sample Representativeness And Response Quality', Public Opinion Quarterly 73, no. 4 (2009): 641-678, doi:10.1093/poq/nfp075; Paul McDonald, Matt Mohebbi and Brett Slatkin, Comparing Google Consumer Surveys To Existing Probability And Non-Probability Based Internet Surveys (Google), accessed 15 June 2015 , http://www.google.com/insights/consumersurveys/static/consumer_surveys_whitepaper_v2.pdf.

${ }^{808}$ Ramesh Krishnamurthy et al. Application of pre-programmed PDA devices equipped with GPS to conduct paperless household surveys in rural Mozambique. (AMIA Annu Symp Proc.2006). http://www.ncbi.nlm.nih.gov/pmc/articles/PMC1839572/

${ }^{809}$ For more information see www.mtrac.ug

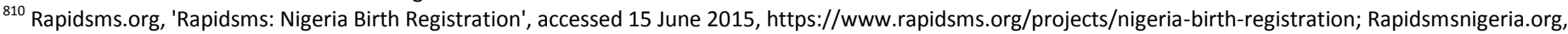
'Birth Registration Dashboard - Rapidsms', accessed 15 June 2015, http://rapidsmsnigeria.org/br.

${ }^{811}$ For more information see http://www.mobilevrs.co.ug

${ }^{812}$ For more information see https://www.rapidsms.org/projects/edutrac/

${ }^{813}$ For more information see http://akvo.org/

${ }^{814}$ For more information see http://mwater.co/

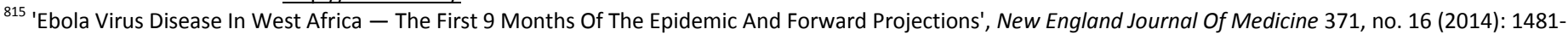
1495, doi:10.1056/nejmoa1411100.

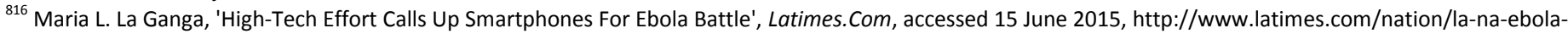
tech-20141118-story.html.

${ }^{817}$ Pgafamilyfoundation.org, 'Enhancing Communication To Fight Ebola - PGA Foundations', accessed 15 June 2015,

http://www.pgafamilyfoundation.org/news/news-articles/press-releases/enhancing-communication-to-fight-ebola.

${ }^{818}$ Data.hdx.rwlabs.org, 'Ebola Crisis Page - Humanitarian Data Exchange', accessed 15 June 2015, https://data.hdx.rwlabs.org/ebola.

${ }^{819}$ Jenny C Aker and Isaac M Mbiti, 'Mobile Phones And Economic Development In Africa', Journal Of Economic Perspectives 24, no. 3 (2010): 207-232,

doi:10.1257/jep.24.3.207.

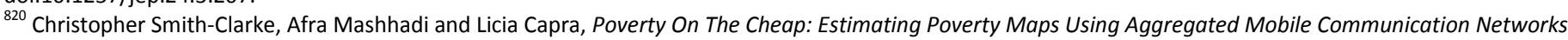
(ACM), accessed 15 June 2015, http://www0.cs.ucl.ac.uk/staff/l.capra/publications/chi14-chris.pdf; Christopher Smith, Afra Mashhadi and Licia Capra, Ubiquitous Sensing For Mapping Poverty In Developing Countries, accessed 12 June 2015, http://www.cities.io/wp-content/uploads/2012/12/d4d-chrissubmitted.pdf.

${ }^{821}$ F. Brckschen, R. Schmid and T. Zbiransky. Cookbook for a socio-demographic basket. Unpublished paper. 2014

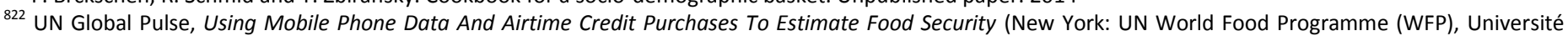

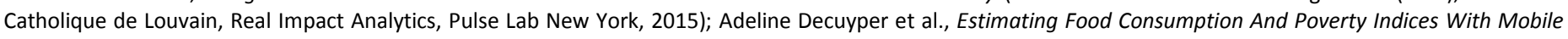

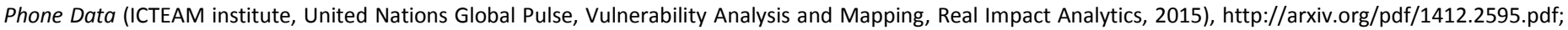

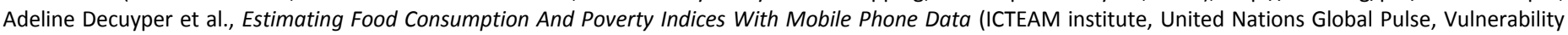
Analysis and Mapping, Real Impact Analytics, 2015), http://arxiv.org/pdf/1412.2595.pdf.

${ }^{823}$ David Talbot, 'African Bus Routes Redrawn Using Cell-Phone Data | MIT Technology Review', MIT Technology Review, 2013, http://www.technologyreview.com/news/514211/african-bus-routes-redrawn-using-cell-phone-data.

${ }^{824}$ Unglobalpulse.org, 'Mapping Mobile Phone-Based Data Collection Projects (2011) | United Nations Global Pulse', accessed 15 June 2015, http://www.unglobalpulse.org/projects/inventory-mobile-phone-based-data-collection-projects.

${ }^{825}$ A. Wesolowski et al., 'Quantifying The Impact Of Human Mobility On Malaria', Science 338, no. 6104 (2012): 267-270, doi:10.1126/science.1223467. 
${ }^{826}$ Amy Wesolowski et al., 'Commentary: Containing The Ebola Outbreak - The Potential And Challenge Of Mobile Network Data', Plos Curr, 2014, doi:10.1371/currents.outbreaks.0177e7fcf52217b8b634376e2f3efc5e.

${ }^{827}$ For more information see http://www.dhsprogram.com/

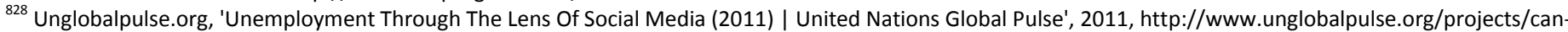
social-media-mining-add-depth-unemployment-statistics.

${ }^{829}$ Unglobalpulse.org, 'Analyzing Attitudes Towards Contraception \& Teenage Pregancy Using Social Data (2014) | United Nations Global Pulse', http://www.unglobalpulse.org/UNFPA-social-data.

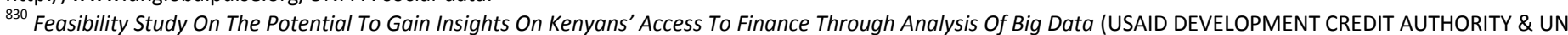
GLOBAL PULSE, 2013), https://usaidlearninglab.org/sites/default/files/resource/files/UNGlobalPulse-USAID-DCA-FeasStudyFinalReport-27Sept2013.pdf.

${ }^{831}$ For more information see mdgs.un.org

${ }^{832}$ Most of the low and medium resolution satellite data, such as MODIS, AVHRR, LandSat, ASTER, SPOT, and RapidEye, are freely available for users.

${ }^{833}$ Tom Bundervoet, 'Can Outer Space Tell Us Something Useful About Growth And Poverty In Africa?', Future Development, 2013,

http://blogs.worldbank.org/futuredevelopment/can-outer-space-tell-us-something-useful-about-growth-and-poverty-africa.

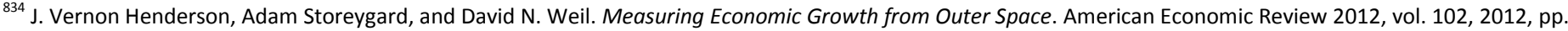
994-1028.

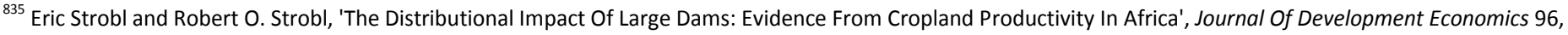
no. 2 (2011): 432-450, doi:10.1016/j.jdeveco.2010.08.005.

${ }^{836}$ Analyzing Environmental Trends Using Satellite Data: Selected Cases, Environment Change Analysis Series (UNEP), accessed 15 June 2015 , http://www.unep.org/dewa/Portals/67/pdf/Analyzing_Environment.pdf.

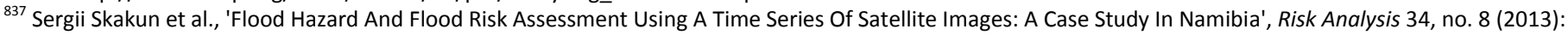
1521-1537, doi:10.1111/risa.12156.

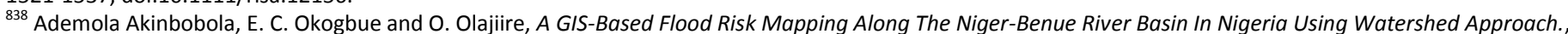

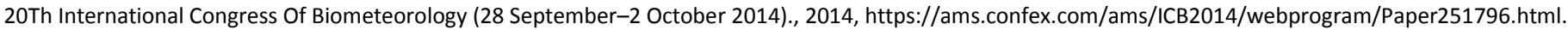

${ }^{839}$ Coordinated by DMC International Imaging Ltd (DMCii) , UK.

${ }^{840}$ South Africa launched its first satellite, SUNSAT, in 1999, built by post-graduate engineering students at the University of Stellenbosch. A second micro earth

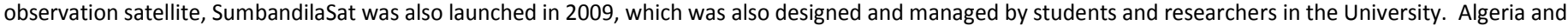
Nigeria also has their own space agency. Algeria launched its satellite AlSat-1, in 2002 and AlSat-2A, in 2010. Nigeria launched its first satellite, NigeriaSat-1, in

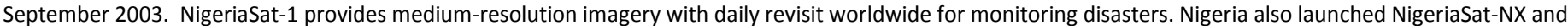

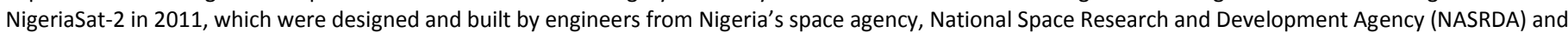
Surrey Satellite Technology Ltd. (UK).

${ }^{841}$ One of the flagship projects in the NEPAD Science and Technology Ministerial Programme areas.

${ }^{842}$ For more information see www.worldpop.org.uk

${ }^{843}$ Elbers, Chris, Jean O. Lanjouw, and Peter Lanjouw “Micro-Level Estimation of Welfare”, Policy Research Working Paper No. 2911, (The World Bank 2002).

${ }^{844}$ Elbers, Chris, Jean O. Lanjouw, and Peter Lanjouw. "Micro-level Estimation of Poverty and Inequality." Econometrica 71:1, 2003, pp. 355-364.

${ }^{845}$ For examples in Morocco, Guinea and Madagascar, see www.omdh.hcp.ma/file/87126/and https://ggim.un.org/docs/meetings/.../04_Morocco_GIS.pdf (Morocco); https://openknowledge.worldbank.org/bitstream/handle/10986/6943/WPS4743.pdf?sequence=1 (Guinea);

http://siteresources.worldbank.org/INTPOVRES/Resources/PovertyAlleviation_Through_Geographic_Targeting_JDEfinal_060116.pdf (Madagascar)

${ }^{846}$ Chris Elbers et al., 'Poverty Alleviation Through Geographic Targeting: How Much Does Disaggregation Help?', Journal Of Development Economics 83, no. 1 (2007): 198-213, doi:10.1016/j.jdeveco.2006.02.001.

${ }^{847}$ For more information see http://www.globalforestwatch.org

${ }^{848}$ Harold Coulombe and Quentin Wodon, 'Assessing The Geographic Impact Of Higher Food Prices In Guinea', Policy Research Working Papers, 2008, doi:10.1596/1813-9450-4743.

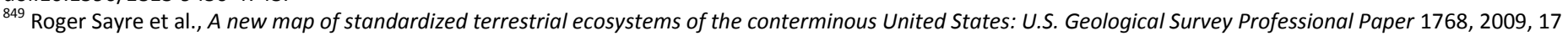
p. (Also available online at http://pubs.usgs.gov/pp/1768.).

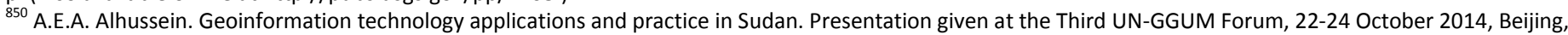
China. Available from http://ggim.un.org/docs/meetings/3rd\%20HLF/5\%2020141022\%20HLF3\%20Session1\%20Sudan\%20Alhussein.pdf

${ }^{851}$ Executed by the Economic Commission for Africa in collaboration with the African Union Commission. The project aims at developing a unified geodetic reference frame for Africa using data from a network of permanent Global Navigation Satellite System (GNSS) stations. GNSS includes the United States Global Positioning System (GPS), Russian GLONASS, the European Galileo, and Chinese Compass/Beidou Systems.

852 United Nations Economic Commission for Africa (ECA), African Science, Technology and Innovation Review 2013, 2014, Addis Ababa, Ethiopia

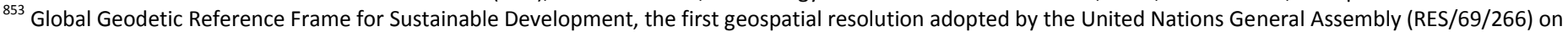
26 February 2015. This mandate will allow increased global sharing of geodetic information and data, improving the accuracy of global, regional and national geodetic information.

${ }^{854}$ For more information see http://rcmrd.org/

${ }^{855}$ See presentation at http://ggim.un.org/docs/meetings/3rd\%20HLF/5\%2020141023\%20HLF3\%20Session3\%20Uganda\%20Lwasa.pdf

${ }^{856}$ See presentation at http://ggim.un.org/docs/meetings/Chengdu\%20Forum/Present_ANG_Chebgdu-Forum.pdf

${ }^{857}$ Iridl.Ideo.columbia.edu, 'MISR Aerosol Monitoring For Meningitis', accessed 15 June 2015, http://iridl.Ideo.columbia.edu/maproom/Health/Regional/Africa/Meningitis/MISR/index.html?T=21-

30\%20Apr\%202009\&region=irids\%3ASOURCES\%3AFeatures\%3APolitical\%3AAfrica\%3AProvinces\%3Afeature_id\%40158001\%3Ads.

${ }^{858}$ http://www.ethiometmaprooms.gov.et:8082/maproom/

${ }_{859}$ Map.meteomadagascar.mg, 'Climate Analyses And Applications Map Room', accessed 15 June 2015, http://map.meteomadagascar.mg/maproom/.

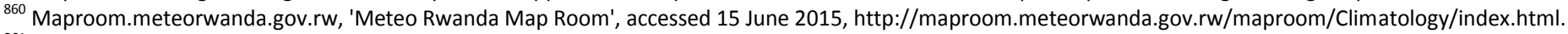

${ }^{861}$ Maproom.meteo.go.tz, 'Malaria Historical Analysis', accessed 15 June 2015, http://maproom.meteo.go.tz/maproom/Health/index.html.

${ }^{862}$ For more information see https://earthengine.google.org/\#index 


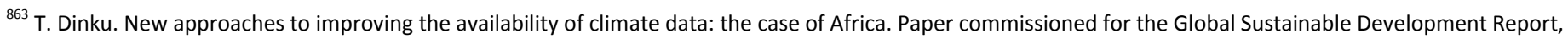
2015. Available from http://sustainabledevelopment.un.org/globalsdreport.html

864 http://www.popclimate.net/deca/deca-malawi

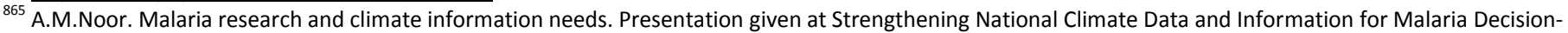
Making in Africa, 4-5 August 2014, Dar es Salaam, Tanzania. Available from http://www.rbm.who.int/docs/2014/climate-malaria-meeting-

2014/2_MalariaResearchClimatelnformation_Noor.pdf

${ }^{866}$ Unstats.un.org, 'Environmental-Economic Accounting', accessed 15 June 2015, http://unstats.un.org/unsd/envaccounting/seearev/.

${ }^{867}$ Unstats.un.org, 'Environmental-Economic Accounting', accessed 15 June 2015, http://unstats.un.org/unsd/envaccounting/seeaw/.

${ }^{868}$ United Nations Statistics Division.The system of environmental-economic Accounts (SEEA). Brochure. 2012, Available from: https://unstats.un.org/unsd/envaccounting/Brochure.pdf

${ }^{869}$ Produced by the National Planning Commission, which is convened by the Presidency.

${ }^{870}$ Open Data Watch. National Statistical Offices online, 2015. Available from http://www.opendatawatch.com/Pages/NSO-List.aspx

$871 \mathrm{~J}$. Hoogeveen. Statistics reform in African limited access orders: aligning incentives with results. Unpublished paper, 2015.

${ }^{872}$ Opendatawatch.com, 'The Open Data Inventory', accessed 15 June 2015, http://www.opendatawatch.com/Pages/Open-Data-Inventory.aspx.

${ }^{873}$ For more information see http://www.google.com/trends/

${ }^{874}$ Christina Warren, 'Measuring Social Media: Who Has Access To The Firehose?', Mashable, 2011, http://mashable.com/2011/03/13/sxsw-smaroi/.

${ }^{875}$ Free low and medium resolution satellite images are provided for instance by MODIS, AVHRR, LandSat, ASTER, SPOT and RapidEye.

${ }^{876}$ High resolution satellite images are provided for example by GeoEye1, WorldView1, WorldView2, QuickBird, IKONOS and SPOT-6.

${ }^{877}$ John D'Ignazio et al., 'Access To Scientific Data: The Social And Technical Challenges And Strategies', Proc. Am. Soc. Info. Sci. Tech. 43, no. 1 (2006): 1-4,

doi:10.1002/meet.14504301154.

${ }^{878}$ For more information see www.fews.net

${ }^{879}$ For more information see http://horn.rcmrd.org/

${ }^{880}$ For more information see https://rs.vito.be/africa/en/home/Pages/home.aspx

${ }^{881}$ For more information see http://endeleo.vgt.vito.be/index.html

${ }^{882}$ For more information see http://gmfsgeonetwork.eftas.eu/geonetwork/srv/en/main.home

${ }^{883}$ African Union. Decision on the implementation of the African Charter on statistics and the strategy for the harmonization of statistics in Africa (SHASA), Assembly/AU/Dec.9 (XIV), 2012.

${ }^{884}$ For more information see https://www.datafirst.uct.ac.za/

${ }^{885}$ For more information see http://www.usaid.gov/data

${ }^{886}$ For more information see http://www.d4d.orange.com/en/home

${ }^{887}$ For more information see http://www.statistics.gov.rw/; http://microdata.statistics.gov.rw/index.php/catalog

${ }^{888}$ For more information see $\mathrm{http}$ ://statistics.knbs.or.ke/nada/index.php/catalog

889 J. Hoogeveen. Statistics reform in African limited access orders: aligning incentives with results. Unpublished paper, 2015.

${ }^{890}$ Munichre-foundation.org, 'RISK Award - 2012 RISK Award Presentation', 2012, http://www.munichre-foundation.org/risk-award/Projects-and-Reports/RISKAward-2012/2012-RISK-Award-Presentation.html; Christian Barthelt and Thomas Loster, Making The City Of Beira Resilient To Floods And Cyclones (Munich Re Foundation, 2012), http://www.munichre-foundation.org/dms/MRS/Documents/RISK-Award/2013_IntoAction04_Beira_Final.pdf.

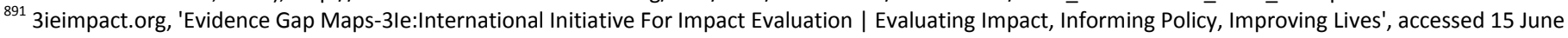
2015, http://www.3ieimpact.org/en/evidence/gap-maps/.

892 Interview with Howard White, Executive Director of 3ie.

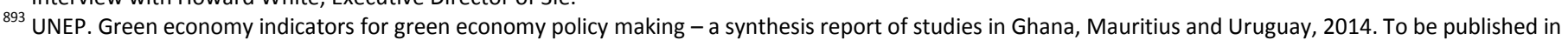
2015.

${ }^{894}$ Eric Strobl and Robert O. Strobl, The Distributional Impact Of Large Dams: Evidence From Cropland Productivity In Africa, International Initiative For Impact

Evaluation, 2011, http://www.3ieimpact.org/en/evidence/impact-evaluations/details/553/.

${ }^{895}$ Sebastian Martinez et al., The Promise Of Preschool In Africa: A Randomized Impact Evaluation Of Early Childhood Development In Rural Mozambique (3ie Impact, 2012), http://www.3ieimpact.org/publications/3ie-impact-evaluation-reports/3ie-impact-evaluations/impact-evaluation-1/.

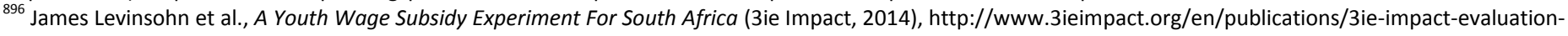
reports/3ie-impact-evaluations/3ie-impact-evaluation-report-15/.

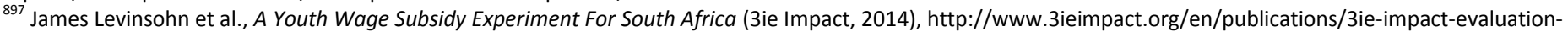
reports/3ie-impact-evaluations/3ie-impact-evaluation-report-15/.

${ }^{898}$ DFID Evaluation Annual Report 2013-14, Department For International Development (UK AID, 2015), https://www.gov.uk/government/uploads/system/uploads/attachment_data/file/406593/DFID-Evaluation-Annual-Report-2013-14.pdf.

${ }^{900}$ For more information see http://www.worldpop.org.uk/data/summary/?contselect=Africa\&countselect=United+Republic+of+Tanzania\&typeselect=Poverty www.omdh.hcp.ma/file/87126/

https://ggim.un.org/docs/meetings/.../04_Morocco_GIS.pdf

http://arxiv.org/pdf/1412.2595.pdf

http://www.limpoporak.com/en/management/value+of+water/water+stock+accounts/botswana.aspx

http://currents.plos.org/outbreaks/article/containing-the-ebola-outbreak-the-potential-and-challenge-of-mobile-network-data/

A. Wesolowski et al., "Quantifying the impact of human mobility on malaria”, Science, vol. 338, No. 6104 (2012), pp. 267-270.

UN Global Pulse Brief on attitudes towards contraception in Uganda

F. Brckschen, R. Schmid and T. Zbiransky, Cookbook For A Socio-Demographic Basket (Unpublished Paper, 2014).

http://rmgsc.cr.usgs.gov/ecosystems/docs/Africa_Ecosystems_Booklet_final.pdf (figure 8) http://www.speakupforblue.com/ocean-solutions/illegal-fishingreduced-due-to-use-of-technology https://sa.catapult.org.uk/-/catapult-and-pew-charitable-trusts-launch-pioneering-technology-to-help-end-illegal-fishing http://maproom.meteo.go.tz/maproom/Health/index.html

http://iridl.Ideo.columbia.edu/maproom/Health/Regional/Africa/Meningitis/MISR/index.html?T=21-30\%20Apr\%202009

http://iridl.Ideo.columbia.edu/maproom/Health/Regional/Africa/Meningitis/MISR/index.html?region=irids\%3ASOURCES\%3AFeatures\%3APolitical\%3AAfrica 
\%3AProvinces\%3Afeature id\%40158001\%3Ads\&T=21-30\%20Apr\%202009 ; 1) Poverty: Tatem et al., Pilot high resolution poverty maps (University of Southampton/ Oxford), http://www.worldpop.org.uk/data/summary/?contselect=Africa\&countselect=United+Republic+of+Tanzania\&typeselect=Poverty; Royaume du Maroc, Carte de paubreté 2007 (2010), www.omdh.hcp.ma/file/87126/. 2) Food security: Adeline Decuyper et al., Estimating food consumption and poverty indices with mobile phone data (Belgium: ICTEAM institute, Université catholique de Louvain, 2014), http://arxiv.org/pdf/1412.2595.pdf. 3) Water: LIMPOPO, SADC Virtual Water Trade and Water Footprints: CROPS Virtual Water Trade, available at: http://www.limpoporak.com/en/management/value+of+water/water+stock+accounts/botswana.aspx; 4) Health: Amy Wesolowski et al., Commentary: containing the Ebola outbreak - the potential and challenge of mobile network data (PLOS, 2014), http://currents.plos.org/outbreaks/article/containing-theebola-outbreak-the-potential-and-challenge-of-mobile-network-data/; Amy Wesolowski et al., Quantifying the impact of human mobility on malaria (Science, vol. 338, No. 6104, 2012), 267-270; UN Global Pulse Brief on attitudes towards contraception in Uganda. 5) Education: F. Brckschen, R. Schmid, T. Zbiransky, Cookbook for a socio-demographic basket (2014). 6) Terrestrial ecosystems: Image available at: http://rmgsc.cr.usgs.gov/ecosystems/docs/Africa Ecosystems Booklet final.pdf. 7) Oceans: Sonia Doblado, Illegal Fishing Reduced Due To Use of Technology (Speak Up for Blue, 2013), http://www.speakupforblue.com/ocean-solutions/illegal-fishing-reduced-due-to-use-of-technology; https://sa.catapult.org.uk/-/catapult-and-pew-charitable-trusts-launch-pioneering-technology-to-help-end-illegal-fishing. 8) Climate change: See contribution of Seleshi and Tufa. 9) Health and Climate Change: International Research Institute for Climate and Society, Seasonal Climatic Suitability for Malaria Transmission (Earth Institute, Columbia University), available at: http://maproom.meteo.go.tz/maproom/Health/index.html; International Research Institute for Climate and Society, MISR Aerosol Monitoring for Meningitis. NASA, 2000-2009 (Earth Institute, Columbia University), available at:

http://iridl.ldeo.columbia.edu/maproom/Health/Regional/Africa/Meningitis/MISR/index.html?region=irids\%3ASOURCES\%3AFeatures\%3APolitical\%3AAfr ica\%3AProvinces\%3Afeature id\%40158001\%3Ads\&T=21-30\%20Apr\%202009 and

http://iridl.ldeo.columbia.edu/maproom/Health/Regional/Africa/Meningitis/MISR/index.html?T=21-30\%20Apr\%202009 